

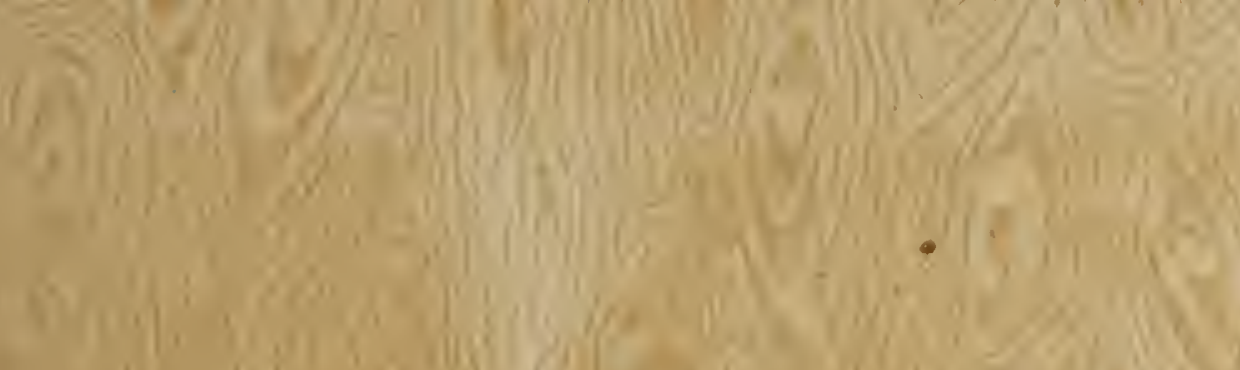

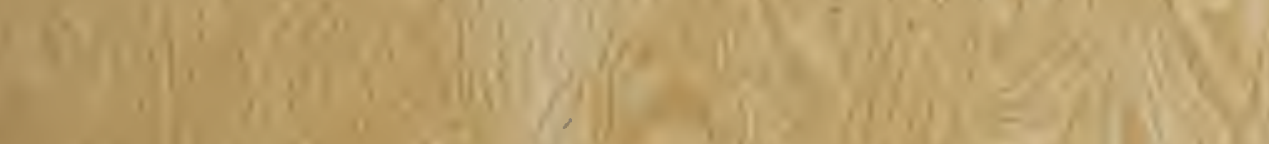

Wan il

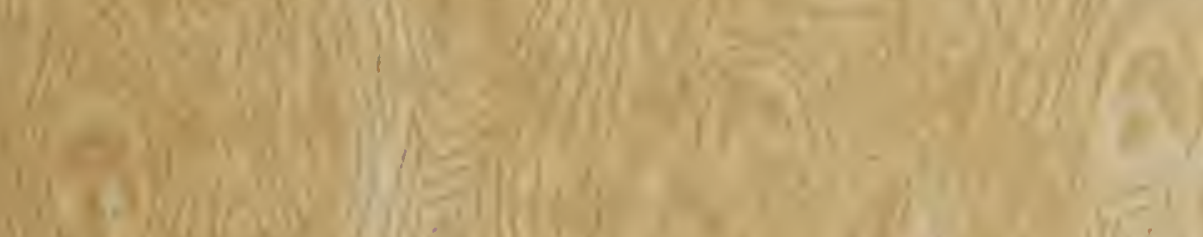

9.

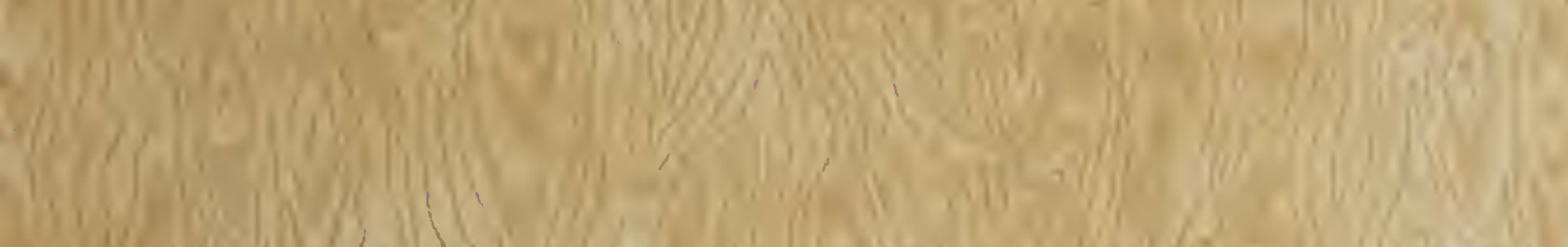

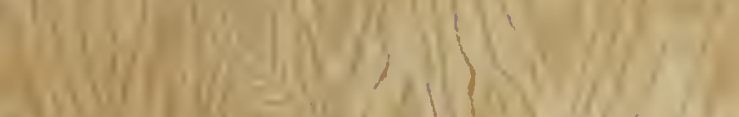

ming

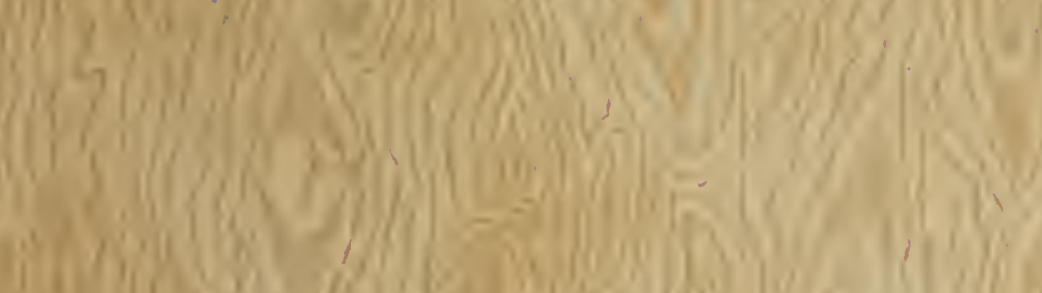

40

(3)

if $00 \times 1)(6-1)$

sol:

Sinction

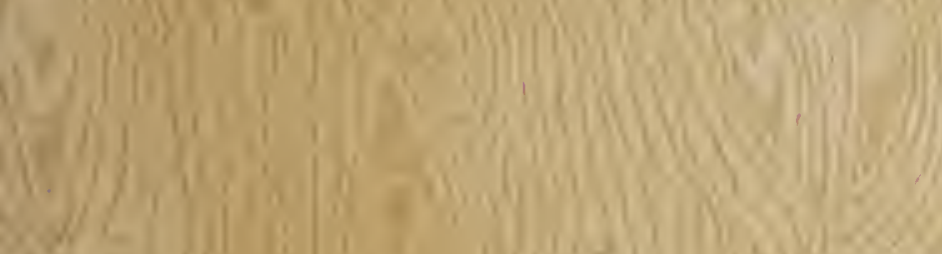

$\frac{-1}{3}$ 



\section{NAT URE}

VERSUS

Natural Selection:

AN ESSAY ON

ORGANic Evolution.

BY

CHARLES CLEMENT COE.

"To the solid ground

Of Nature trusts the mind that builds for aye;

Convinced that there, there only, she can lay

Secure foundations."

WORDSWORTH.

\section{LONDON :}

Swan Sonnenschein \& Co., Paternoster Square, E.C. 



\section{PREFA C E.}

T T may be well at the outset clearly to define the posi1 tion taken in the following work. The author believes that the process of Organic Evolution has taken place, but he does not believe that Natural Selection has been the means by which that result has been brought about. If any reader is of opinion that Organic Evolution and Natural Selection are synonymous terms, he is recommended at the outset to turn to the first chapter of the Third Book, in which it is attempted to show that Natural Selection is not identical with Organic Evolution.

In the second place, the reader is warned against the idea that any selection in nature can properly be called Natural Selection. Natural Selection is a very complex term. It is based on the analogy supposed to exist between the process of artificial selection and a process which is supposed to take place in nature. In Natural Selection the struggle for existence is supposed to be the selecting power, and it works by life and death; it secures the survival of the fittest, and hence it is based upon the principle of utility. It selects from those variations which are necessarily associated with sexual reproduction. It asks only for small variations, and it undertakes that the slight favourable variations shall survive. In this way it now produces the transmutation of species, and in a far-off past it was the only or 
principal agent of Organic Evolution. The object of this work is to show that Natural Selection, thus defined, has no place in the world of nature; that if it did exist, other factors of evolution would anticipate its action in the transmutation of species now going on; and last, but not least, that we have no definite proof of its action in the early stages of Organic Evolution.

In the third place it may be remarked that this discussion is simply confined to the endeavour to discover what the actual order of nature is. That should be the object of every one who seeks to discover the truth, whether he be a scientific man or a theologian. Whatever order is proved to exist, must be accepted by the scientific man as the system of nature, and beyond that point physical science cannot go. But the theologian is left at liberty to give his reasons for believing that this order of nature is the method of God. Hence it is most desirable, in a work like this, to avoid as far as possible all argument based on theological considerations. The stage at which the discussion of this question has now arrived, justifies us in doing so; although, even now, we have to deal sometimes with objections which arose when the debate was largely dominated by theological considerations.

It is often said, or implied, that a man who is not a scientific expert has no right to venture into the regions of biological controversy, and he is sometimes characterised as "a more or less acute paper philosopher." I venture to think that such a man, if he be only acute enough, may still have his rôle in the world of science. With the exception of a few universal geniuses who are ready to discuss, and express authoritative opinions on, all possible topics, the necessity of a subdivision of labour has been felt in the scientific world no less than in the economical world. 
Sir W. J. Dawson, speaking as the President of the British Association, at Birmingham, said :-

"It is impossible for any man to keep pace with the progress of more than one limited branch of science, and it is equally impossible to find an audience of scientific men of whom anything more than a mere fraction can be expected to take an interest in any one subject."

And as in the region of experiment and observation each man may set himself to cultivate his own department, why may not some men devote themselves to the discussion of theories-to that branch of science which consists in putting the right interpretation on the phenomena which have been observed and chronicled? When Mr. Galton, in considering a certain problem, referred to a mathematician to work the result from certain elements that were supplied, he took for granted the ability of the mathematician within his own sphere, and did not depreciate his part of the work because he was not an expert in physical or biological science.

But perhaps it will be said that it is impossible that the man who is not an expert in a particular branch, should understand anything about it. Nevertheless, in the address just quoted, Sir W. J. Dawson goes on to express a hope that the specialist can make himself understood:-

"There is, however, some consolation in the knowledge that a speaker who is sufficiently simple for those who are advanced specialists in other departments will, of necessity, be also sufficiently simple to be understood by the general public who are specialists in nothing."

And indeed it would be strange if the proof of principles or the statement of definite and special facts could not be made intelligible, and could not be submitted to the judgment of the general public. The command to every thinker, who is not a specialist-Go to a biological 
laboratory, read an elementary book on biology - is doubtless good advice; and yet a man might thus get the merest smattering of knowledge, or might easily become so absorbed in the comprehension of the details as to lose the grasp of the general idea. Who would think of demanding that the judge and the barristers and the jury should undergo an elementary course of chemistry before they took part in the trial of a reputed poisoner? They have only to weigh the testimony of professional witnesses, and to give, as far as possible, a verdict in accordance with that judgment which is a common attribute of mankind.

In conclusion, it might be said that Natural Selection has passed beyond the range of discussion, in that it has met with universal acceptance on the part of all persons competent to pass a judgment in the matter. But even in that case, discussion might still do good. Mr. John Stuart Mill says, in his Essay On Liberty.-

"However true an opinion may be, if it is not fully, frequently, and fearlessly discussed, it will be held as a dead dogma, not a living truth. . . This is not the way in which truth ought to be held by a rational being. This is not knowing the truth. Truth thus held is but one superstition the more, accidentally clinging to the words that enunciate truth."--(People's Edition. p. 20.)

The same writer goes on to say that heretical opinions are generally useful as a corrective of popular opinions.

"Popular opinions on subjects not palpable to sense are often true, but seldom or never the whole truth. They are a part of the truth; sometimes a greater, sometimes a smaller part; but exaggerated, distorted and disjoined from the truths with which they ought to be accompanied and limited. Heretical opinions, on the other hand, are generally some of these suppressed and neglected truths, bursting the bonds which kept them down, and either seeking reconciliation with the truth contained in the common opinion, or fronting it as enemies and setting themselves up with similar 
exclusiveness as the whole truth. . . Hence, even in revolutions of opinion, one part of the truth usually sets while another rises. . . Such being the partial character of prevailing opinions, even when resting on a true foundation, every opinion which embodies somewhat of the portion of truth which the common opinion omits, ought to be considered precious, with whatever amount of error and confusion that truth may be blended."-(Ibid. pp. 26, 27.)

When I reflect upon the fact that opposition to popular theories of the day is apt to be met with no sympathy and sometimes with slight courtesy, I feel sorely tempted to represent myself as a mere Devil's Advocate. In certain ecclesiastical circles that functionary plays, as is well known, a striking part. A great and good man is thought worthy of canonisation. But it is importantvitally important - that such distinction should not be conferred on the unworthy. And hence some one assumes the part of detractor. He tries to find out all that can be said against the individual singled out for the highest distinction. Of course he does not succeed in his attempt. Unless he is an envious cynic, who does not believe in any human goodness at all, he does not wish to succeed. It has occurred to me that I might play this part with respect to the theory of Natural Selection and its eminent supporters, and show that there is something to be said on the other side, in order that I might be refuted and that the popular theory might be duly glorified. If, in such case, the argument were weak, the failure would be forgiven, seeing there was so little to be said against the truth. If the reasons adduced seemed to be of some force it would only be understood that I was doing the system the compliment of applying to it the severest test which I was able to produce. I suppose such an effort would be described as well-meaning or as clever, according to the amount of ability which it displayed; but I should at least escape the charge of scientific heresy. 
viii.

And this method is approved in scientific as well as ecclesiastical circles. The supporters of scientific theory desire that it should be doubted and discussed in order that it may be fully believed and realised. But if the discussion does not produce this result, then he who is seriously defending unpopular heresy against an accepted belief, and putting his opinion in opposition to the popular view, does not always fare well at the hands of opponents, and would sometimes do well to remember the kindly humorous warning of Oliver Wendell Holmes, when discoursing on The Stability of Science:-

"The feeble sea-birds, blinded in the storms, On some tall lighthouse dash their little forms, And the rude granite scatters for their pains Those small deposits that were meant for brains. Yet the proud fabric in the morning's sun Stands all unconscious of the mischief done; Still the red beacon pours its evening rays For the lost pilot with as full a blaze, Nay, shines, all radiance, o'er the scattered fleet Of gulls and boobies brainless at its feet. I tell their fate, though courtesy disclaims To call our kind by such ungentle names; Yet, if your rashness bid you vainly dare, Think of their doom, ye simple, and beware!"

-(Poems. p. 109.)

And, indeed, when a man finds himself in an overwhelming minority on some important topic which has long exercised the thought of the wisest of his day and generation, it might be supposed that common modesty would compel him to mistrust his own judgment; and seeing that he is doubtless making some foolish mistake, common prudence might well suggest that he should keep his folly to himself as much as possible; and if he is a fool, at any rate, not to proclaim that fact from the house-tops. But if such a man should come to feel, not 
that he has adopted an heretical opinion, but that the heretical opinion has adopted him; if such a man should come to feel that it is a small thing to be called a fool, if at that cost he enforces a truth which he thinks will ultimately prevail,- - then the case is altered. He has his message to deliver, and delivered it must be, at any risk ; for he can have no peace till he has fulfilled the task imposed upon him,--till he can say, Liberavi animum meum. 


\section{ERRATA.}

Page 29, line 11. For "bey" read "bet."

" 89, " 4. For "nut-catchers" read "nut-hatches."

" I 55, " I 4. For "Artificial" read "Natural."

" 206, " 4. For " a museum" read "in a museum."

"278, "28. For "human" read "animal."

" 28r, " 5, from bottom. For "Colton" read "Cotton."

"283, "2 1 . For "away from " read "in the direction of."

" 308, „, I9. For "negative gravity" read "negative selection." 



\title{
CONTENTS.
}

\author{
$\mathrm{BOOK} I$.
}

The Transmutation of Species by means of Natural Selection:-Is it possible?

CHAPTER I. PAGE

THE THEORY DEFINED AND TESTS PROPOSED - - I

CHAPTER II.

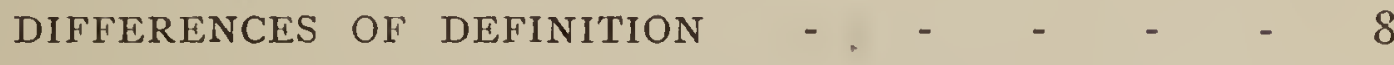

CHAPTER III.

DIFFICULTIES INHERENT IN THE THEORY - - - 25

CHAPTER IV.

THE THEORY COMPARED With THE REALITy - - 42

(a) Is the tendency to increase in a geometrical ratio followed by discriminative destruction? - 43

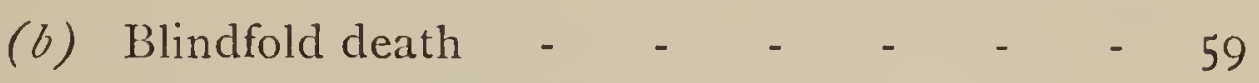

(c) "On the whole" and "In the long run" - 7 I

CHAPTER V.

THE THEORY COMPARED WITH THE REALITY (continued) 76

(d) Competition modified by co-operation - - 76

CHAPTER VI.

THE THREE STRONGEST ARGUMENTS - - - - IO3

(a) The conflict between race and race - - I03

(b) No organ or instinct exists for the sole benefit of another species - - - - - - II9

(c) The analogy between Natural and Artificial Selection - - - - - - $\quad$ I 30 
xii. CONTENTS-BOOK I. (CONTINUED).

CHAPTER VII.

PAGE

THE TWO BEST ILLUSTRATIONS - - - - - I57

(a) Defensive colouring - - - $\quad$ - $\quad$ - 159

I.-Colours which conceal - - - - - I82

2.-Mimetic colours - - - - - $\quad$ - $\quad$ I94

3.-Warning colours - $\quad$ - $\quad$ - $\quad$ - $\quad-203$

(b) Instinct - - - - - - - $\quad-220$

\section{$\mathrm{BOOK}$ I I.}

Natural Selection in relation to other methods of Transmutation of Species:-Can it compete?

CHAPTER I.

PAGE

THE STABility OF SPECIES - $\quad$ - $\quad$ - $\quad$ - $\quad$ - $\quad-293$

CHAPTER II.

THE EXTINCTION OF SPECIES - - - - $\quad$ - 314

CHAPTER III.

THE TRANSMUTATION OF SPECIES - - - - 329

CHAPTER IV.

THE CO-ORDINATED PARTS AND THE CORRELATED VARIATIONS OF ORGANIC STRUCTURES - - - 333

CHAPTER V.

PURE DARWINISM - $\quad$ - $\quad$ - $\quad$ - $\quad$ - $\quad$ - $\quad$ - 349

(a) Variations sometimes associated with sexual reproduction - $\quad$ - $\quad$ - $\quad$ - $\quad$ - $\quad$ - $\quad$ - 349

CHAPTER VI.

PURE DARWINISM (continued) - $\quad$ - $\quad$ - $\quad 373$

(b) More methods of selection than one - - 373 
CONTENTS-BOOK II. (CONTINUED). xiii.

CHAPTER VII.

PAGE

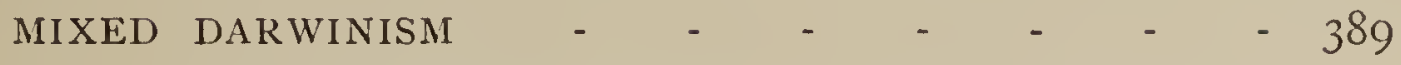

The transforming and the selecting influence of

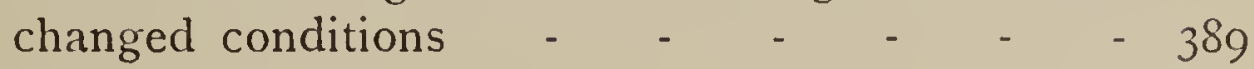

\section{BOOK II I.}

Organic Evolution by means of Natural Selection:What proof has been offered?

CHAPTER I.

PAGE

ORGANIC EVOLUTION NOT IDENTICAL WITH NATURAL SELECTION

CHAPTER II.

ORGANIC EVOLUTION NOT PROVED BY NATURAL SELECTION

CHAPTER III.

ORGANIC EVOLUTION NOT AIDED BY NATURAL SELECTION - $\quad$ - $\quad$ - $\quad$ - $\quad$ - $\quad$ - $\quad$ - $\quad$ - 490

CHAPTER IV.

NATURAL SELECTION NOT MANIFESTED IN ORGANIC EVOLUTION - $\quad$ - $\quad$ - $\quad$ - $\quad$ - $\quad$ - 524

(a) Geographical distribution - - - $\quad 524$

(b) Geological changes - - _ - $\quad 535$

CHAPTER V.

NATURAL SELECTION NOT MANIFESTED IN ORGANIC EVOLUTION (continued) - - - - - - $54 \mathrm{I}$

(c) Embryology - - - - - $\quad$ - 54 I

(d) Palæontology - $\quad$ - $\quad-\quad$ - $\quad$ - $\quad$ - 549

CHAPTER VI.

NATURAL SELECTION NOT MANIFESTED IN ORGANIC EVOLUTION (continued) - - - - - $\quad$ - 554

(e) Classification - $\quad$ - $\quad$ - $\quad$ - $\quad$ - 554

CHAPTER VII.

ORGANIC EVOLUTION WITHOUT NATURAL SELECTION - 584 



\title{
BOOK I.
}

The Transmutation of Species BY means of Natural Selection.

\author{
IS IT POSSIBLE?
}





\section{CHAPTER I.}

THE THEORY DEFINED AND TESTS PROPOSED.

"Old things need not be therefore true,

O brother men! nor yet the new.

Ah! still awhile the old thought retain, And yet consider it again."-A. Clough.

BY what process have all the different kinds of animal and vegetable organisms become what we now see them to be? This is the problem which has from time to time excited the interest of solitary thinkers, and which, within the last thirty or forty years, has profoundly agitated the scientific world. Two answers have been given to this question. On the one hand, it used to be asserted (it is still asserted by some) that the different kinds of animals and plants are the lineal descendants of organisms similar to themselves, and that those remote ancestors suddenly appeared upon the earth, some six thousand years ago, endowed with the power of reproducing their like from generation to generation. On the other hand, it is contended that all existing kinds of organisms, however complex, have been produced by successive changes from the simplest and least complex forms of life. The latter is the opinion of the majority of scientific men at the present day. This process is designated by the term Organic Evolution : and evolution is defined by Mr. Herbert Spencer as the result of the joint action of growth or increase in size, and of development or increase in [the complexity of] structure.*

* The Principles of Biology. i., p. 133, note. 
As there have been only two theories in the field, to disprove the one was to establish at least the strong probability for the other.

There is, however, another kind of argument which has been brought to bear:-Looking upon the organic world as a product of the past, studying as best we can the history of the changes on the earth's surface, we arrive at the conclusion that the organic world is just what we should expect it to be, if it were the result of the principle of evolution.

So far as the first line of argument is concerned, we may venture to say that the strong reasons which men supposed they had for believing in the fixity of species have been overcome by the still stronger evidence in favour of the transmutation of species. But that is not all. It is the opinion of the overwhelming majority of scientific men that the main, if not sole, agent in this transmutation is the principle of Natural Selection. We have now to consider how far this assertion can be sustained.

At the outset, it is of the greatest importance that we should clearly understand what we mean by Natural Selection, and realise that the phrase implies a very complex idea. But in order to understand what Natural Selection is we must first get a clear idea of what we mean by "Selection." Why is this principle invoked, and what is it able to accomplish? The answer is, that, in order that a race should undergo a permanent change equivalent to the transmutation of one species into another, it is necessary that variations should arise, that these variations should be inherited by the offspring, and that they should be continuously inherited until they become fixed in the race. Now the nature of this process will very much depend upon the nature of the variations acted on. The principle of selection is indispensable only in 
connection with those variations which are necessarily and inevitably associated with sexual reproduction. These provide materials for a considerable amount of modification, and it is easy to see why this should of necessity be the case. At the outset it is safe to say of all things animate and inanimate that-

"No compound of this earthly ball Is like another, all in all."

Hence the two parents are not alike to begin with. And it seldom happens that the offspring resemble father and mother in exactly equal degree: one "favours" the father, another the mother. In these circumstances we need not be surprised to find that the strongest family likeness does not prevent the occurrence of individual differences.

"Facies non omnibus una

Nec diversa tamen ; qualem decet esse sororum."

Between those who most closely resemble one another there is at least, as Mr. Wallace points out, an "absence of identity." Nor is this all. The offspring are not only compounds in ever-varying proportions of father and mother: they also tend to resemble, more or less, the grandfather or the grandmother, or some more remote ancestor, by the principle known as atavism or reversion to an ancestral type. As Oliver Wendell Holmes says, in his witty fashion :-

"At one moment we detect the look, at another the tone of voice, at another some characteristic movement of this or that ancestor, in our relations or others. There are times when our friends do not act like themselves, but apparently in obedience to some other law than that of their own proper nature. We all do things both awake and asleep which surprise us. Perhaps we have co-tenants in this house we live in. No less than eight distinct personalities are said to have co existed in a single female mentioned by an ancient physician of unimpeachable authority. In this 
light we may perhaps see the meaning of a sentence from a work which will be repeatedly referred to in this narrative, viz. :"This body in which we journey across the isthmus between the two oceans is not a private carriage, but an omnibus." "--(The Guardian Angel.)

This union of different elements is well expressed by Matthew Arnold in the following lines:-

"Born into life!-man grows

Forth from his parents' stem, And blends their bloods, as those

Of theirs are blent in them-

So each new man strikes root into a far fore time." -(Empedocles on Etna.)

In the second place, it should be observed that this "individuality of the individual" may co-exist with the most absolute fixity of the type. "Nature," says Milne Edwards, "is prodigal in variety but niggard in innovation."

There is only one way of dealing with this particular kind of variation in order to produce a transmutation of species, namely, that those variations which are similar to one another should be "selected," i.e., that they should be isolated for breeding purposes from the other variants which have not their peculiar characteristics. "Man," says Mr. Belt, "isolates varieties and breeds from them; and continuing to separate those that vary in the direction he wishes to follow, a very great difference is in a comparatively short time produced." *

But in order that this process should be successful, the isolation must be strictly and persistently carried out for many generations until the variation is fixed in the race. Mr. Darwin assures us that-

"A species may be highly variable; but distinct races will not be formed, if, from any cause, selection be not applied. The carp is highly variable: but it would be extremely difficult to select slight

* The Naturalist in Nicarasza. p. 207. 
variations in fishes, whilst living in their natural state, and distinct races have not been formed; on the other hand, a closely allied species-the gold-fish-from being reared in glass or open vessels, and from having been carefully attended to by the Chinese, has yielded many races."-(The Variation of Animals and Plants under Domestication. vol. ii., p. 236.)

Without selection individual differences will be swallowed up in the average of the race, through the principle which Mr. Francis Galton calls the regression to mediocrity. This principle differs from the ordinary action of atavism: which, as I have pointed out, will sometimes cause an individual to resemble a remote ancestor, and which produces an influence not to be easily calculated. The regression to mediocrity, on the other hand, represents the effect of the ancestry as a whole; and Mr. Galton seems to have succeeded in ascertaining the exact amount of this influence. This principle, I venture to believe, only applies to those variations which are inevitably and necessarily associated with sexual reproduction. Thus understood, it involves the absolute necessity for the strictest isolation of similar variants, but at the same time, it cannot be understood to mean that this regression to mediocrity will take place when similar variants are isolated for breeding purposes, for such an assertion would be diametrically opposed to the experiences of the cattle breeder and the pigeon fancier.

"It will be seen" (says Mr. Galton) "from the large values of the ratios of regression, how speedily all peculiarities that are possessed? by any single individual to an exceptional extent, and which blend freely together with those of his or her spouse, tend to disappear. A breed of exceptional animals, rigorously selected and carefully isolated from admixture with others of the same race, would become shattered by even a brief period of opportunity to marry freely." (Nature. vol. xxxiii., p. 297.)

But Mr. Galton emphatically states that the law of regression does not invalidate the principle of selection :- 
"It must be clearly understood that there is nothing in these statements to invalidate the general doctrine that the children of a gifted pair are much more likely to be gifted than the children of a mediocre pair. They merely express the fact that the ablest of all the children of a few gifted pairs is not likely to be as gifted as the ablest of all the children of a very great many mediocre pairs."-(Natural Inheritance. p. Io6.)

The isolation of similar variants from among those variations which are necessarily and inevitably associated with sexual reproduction is supposed to take place in nature by the survival of those which are fittest to live, and by the destruction of the rest. Hence Natural Selection "acts by Life and Death"*; and if it works with efficient strictness it must isolate "the fittest" by the destruction of all the rest.

The process is thus described. There is a tendency in all organisms to increase in a geometrical ratio, so that if this tendency were not checked, all the available space on the earth would soon be filled with one species. But this tendency is checked. Each species strives to maintain itself or to aggrandise itself, and it is this struggle for existence which gives the advantage to those variants which are fittest to live and secures their preservation; while others not so fortunately endowed are doomed to perish. So similar favourable variations are preserved in each generation until a transmutation of species has been effected.

Now, there are certain tests which I propose to apply to this theory of the transmutation of species by means of Natural Selection. In the first place, it would be reasonable to require that the statement of a scientific theory should be expressed in a self-consistent manner. In the second place, the theory should not, on the threshold of

* Darwin. The Origin of Species by means of Natural Selection: or the Preservation of Favoured Races in the Struggle for Existence. p. 156. 
the subject, present any great and a priori difficulties. In the third place, the principles of the theory should accord with the universally admitted phenomena of nature. In the fourth place, the arguments by which it is supported-the best and most powerful which the greatest experts can adduce-should be valid and convincing. In the fifth place, the particular instances, which are selected as the most favourable specimens of the action of Natural Selection, should be those in which the difficulties are minimised, and the efficiency of the process is most apparent. Let us see how far the theory will meet the requirements of these reasonable demands. 


\section{CHAPTER II.}

DIFFERENCES OF DEFINITION.

"We must speak by the card or equivocation will undo us:"

- Hemlet, Act 5, sc. I.

As the overwhelming majority of scientific men believe that Natural Selection occupies, to say the least, a most important position in relation to the transmutation of species, it might be expected that they would be quite agreed as to what Natural Selection is: that they would have a very clear and definite notion as to what is meant by this term. It is, therefore, with a good deal of surprise that we find that "several scientific men have thought the term 'Natural Selection' good, because its meaning is not obvious." * Surely it is difficult to conceive of any legitimate advantage which can arise from a vague definition and a consequently hazy comprehension of the essential and fundamental principles of a scientific theory. This is surely not characteristic of the truly scientific man, who would scorn by such uncertainty to justify the rebuke of the poet-

"The Gods laugh in their sleeve

To watch man doubt and fear, Who knows not what to believe

Since he sees nothing clear,

And dares stamp nothing false where he finds nothing sure."

--(Matthew Arnold. Empcdocles on Etna.)

That there has been considerable misapprehension on this subject is obvious from the fact that Mr. Romanes

* The Life and Letters of Charles Darivin. ii., 278. 
occupies several pages of his Darwin and After-Darwin with correcting what he regards as the mistakes and fallacies concerning Natural Selection of which its advocates no less than its opponents are guilty. Certainly, it must be admitted that some very shrewd and clever persons have engaged in this interesting enquiry, and it is therefore startling to find that it is so easy to fall into error as to what the theory means or implies.

This liability to misapprehension, however, is not altogether the fault of the critic or of the student; for putting on one side those points in which one expert differs from another, such as whether Natural Selection is the sole method of the transmutation of species, or only one among many, we have to take note of the fact that one writer sometimes contradicts himself on questions of very great importance:- such as the nature of the variations from which selection is made; the strictness or laxity of the selection; the result of the selection; whether it be the survival of the fittest, or only the elimination of the least fit; the constancy or occasional occurrence of Natural Selection; and the severity or mildness which characterises the struggle for existence.

The materials on which Natural Selection works are the variations which occur necessarily and inevitably in connection with the phenomenon of sexual reproduction; and obviously the nature attributed to them will largely influence the a priori credibility of the theory. If the variations are very slight, if they diverge in all directions, and if, therefore, only a few favourable variations occur, it is obvious that a stricter selection will be required than if the variations are considerable in quantity and if many favourable variations occur.

Mr. Darwin says that variations are slight. And yet he says that monstrosities graduate so insensibly into 
mere variations [in which mere individual differences are included] that it is impossible to separate them.

Mr. Wallace says that variation is generally very small in amount; that variation is merely the absence of identity: and yet he also says few persons consider how largely and universally all animals are varying.

A similar difference of opinion is found as to whether the same variation will occur in one or a few, or in many individuals.

Mr. Darwin says: "These individual differences afford materials for Natural Selection to act on."-(Origin of Species, p. 34.)

Professor Huxley says: "The variations from their specific type which individuals present 'are the objects of' the selective action of external conditions."

Mr. Romanes says :-

"The theory of Natural Selection, as such, furnishes no warrant for supposing that the same beneficial variety should arise in a number of individuals spontaneously. On the contrary, the theory of Natural Selection trusts to the chapter of accidents in the matter of variation; and in this chapter we read of no reasons why the same beneficial variation should arise simultaneously in a sufficient number of individual cases to prevent its being swamped by intercrossing with the parent species."

\section{Hence it is contended that-}

"A very large assumption is made, when it is said that the same variation occurs simultaneously in a number of individuals inhabiting the same area."-(The Journal of the Limnean Society. vol. xix., Zoology, p. 343.)

To this, Mr. Wallace, speaking from actual observation of nature, makes the following reply:-

"But that which Mr. Romanes regards as 'a very large assumption,' is, I maintain, a very general fact, and at the present time, one of the best established facts in natural history. A brief summary of these facts is given in my 'Island Life' (p. 57), and I possess in manuscript a considerable collection of additional facts, showing that simultaneous 
variation is a general phenomenon among the best known species of animals and plants. Unfortunately very few naturalists pay attention to individual variations."-(Fortnightly Review. rol. $x \%$, p. 307.)

If we represent the differences which occur among the inevitable variations associated with sexual reproduction from the point of view of direction, we shall find a similar difference of opinion.

They are represented as divergent, as varying in all directions.

"Natural Selection, or survival of the fittest, among divergent varieties of offspring, is the distinctive Darwinian factor." - (Le Conte. Evolution and its Relation to Religious Thought. p. 74.)

"The theory requires-variations of all parts in all directions.-(Mivart. The Genesis of Species. p. 6o.)

"All that this theory has to do, is to take the principle of promiscuous variation in all directions, as a datum supplied by observation." -(Romanes. Nature. vol.xxxiv., p. 360 , note.)

"The Darwinist can point to the results of 'artificial selection" unquestionably to demonstrate that, in our domesticated plants, and animals, variation is so far omniferous as to lend itself to all the morphological changes in divergent lines which have been produced by the continuous, or cumulative, selection of the horticulturist and the breeder."-(Romanes. Contemporary Review. vol. liii., p. 850.)

In the second place it is asserted that the variations cluster around a central line, from which a few variants diverge on either side.

\section{Professor George H. Darwin says :-}

"One may assume, with some confidence, that under normal conditions, the variation of any organ in the same species-may be symmetrically grouped about a centre of greatest density."(Nature. vol. viii., p. 505.)

"If one were to draw a vertical line on a wall, and were to measure the heights of several thousand men of the same race against this line, recording the height of each by driving in a pin, the pins would be densely clustered about a certain height, and the density of their distribution would diminish above and below. Quetelet experimentally verified that the density of the pins at any distance 
above the centre of the cluster was equal to that at a little distance below; he also found that the law of diminution of density on receding from the cluster was given by a certain mathematical expression, to which, however, I need here make no further reference. A similar law obtains with reference to the circumference of the chest; and one may assume, with some confidence, that, under normal conditions, the variation of any organ in the same species may be symmetrically grouped about a centre of greatest density, as above explained."-(Noture. vol. viii., p. 505.)

Mr. Wallace enunciates the same principle in the following passage :-

"If now we consider the population of a species with regard to any particular character or combination of characters, we may divide it into three groups-a central group in which the mean or average development prevails with little variation, one in which the character is excessively, and one in which it is little developed. These groups would not be of equal extent, the central portion-that in which the mean characteristics prevailed-being in accordance with the law of averages, much more numerous than the extremes; perhaps twice or even three times as great as either of them, and forming such a series as the following:-Maximum development Io, mean 30, minimum Io. These figures, whatever their exact proportions, would probably be pretty constant, for we have no reason to believe that the mean characters, or the amount of variation of a species, change materially from year to year or from century to century; and we may therefore look upon the central and most numerous group as presenting the typical form of the species, being that which is best adapted to the conditions in which it has actually to exist, while the extremes, being less perfectly adapted, are continually weeded out by natural selection."-(Nineteenth Century. vol. vii., pp. IOO-I.)

And yet Mr. Wallace elsewhere arrives at a different result. He says :-

"Mr. Allen also grives full details as to the variation of colour and marking, showing that these are not less striking than those of size and proportions; but the most important thing for us in regard to the question we are discussing is the amount of simultaneous variation of the same kind that is constantly occurring. To determine this I formed diagrams, in which each individual was represented by a spot placed on a horizontal line at a point determined by its actual dimensions. It would have been antecedently expected that the great bulk of the spots would be crowded together about a point 
representing the mean dimensions of the species, but this was by no means the case. Often the central point was not all crowded with dots, but they were grouped with rough uniformity for a considerable distance on each side of the centre, with a few isolated at greater distances representing the extremes of variation. Hence a species could usually be divided into two portions, with a considerable number of specimens in each showing divergence from the mean condition---the very 'simultaneous variation' which Mr. Romanes regards as 'a very large assumption." "--(The Fortnightly Reviezw. vol. xl., N.S., h. 309.)

Variations are thus represented as divergent, i.e., radiating in all directions; as forming a cluster around a central line ; and as forming two clusters at some little distance from the central line.

We find a similar discrepancy in the statements as to the strictness or the laxity of the selection which takes place in nature.

Mr. Wallace says:-

"Selection is constantly .... eliminating all that fall below the best working standard, and preserving only those that are fully up to it."-(Darwinism. p. 4I3.)

But elsewhere he speaks of-

"A struggle for existence, in which the weakest and least perfectly organised must always succumb."--(Contributions to the theory of Natural Selection. p. 33.)

- He also says :-

"Nature does not so much select special varieties as exterminate the most unfavourable ones." - (Wallace's Letter in Darwin's Life. iii., p. 46, note.)

\section{Mr. Darwin says :-}

"We must suppose each new state of the instrument (the human eye) to be multiplied by the million : each to be preserved until a better one is produced, and then the old ones to be all destroyed." --(Origin of Species. p. I46.)

On the other hand, the principle of a lax selection is asserted in the following passages by Mr. Darwin. 
"Unconscious selection by man which depends on the preservation of all the more or less valuable individuals, and on the destruction of the worst."-(Origin of Species. p. 7I.)

"During this process (unconscious selection) the best or most valued individuals are not separated and prevented crossing with others of the same breed, but are simply preferred and preserved: but this inevitably leads during a long succession of generations to their increase in number and to their gradual improvement; so that, finally, they prevail to the exclusion of the old parent form. This form of selection has probably led to far more important results than methodical selection, and is likewise more important under a theoretical point of view from closely resembling natural selection." -(The Variation. ii., Ist ed., p. 424.)

\section{Mr. Darwin further asserts that:-}

"Unconscious selection graduates into methodical and only extreme cases can be distinctly separated.-(The Variation. ii., p. I93.)

So that in point of fact natural and artificial selection are defined to mean the selection of the fittest only; the selection of the fittest in company with some not the fittest, and every possible step of gradation between these two; all which is pretty vague, to say the least.

The same uncertainty clings to the phrase "survival of the fittest." Mr. Cope declares that it is "an expression both comprehensive and exact."* But Mr. Wallace defines it thus:-

"Survival of the fittest, or natural selection, meaning simply that on the whole those die which are least fitted to maintain their existence."--(Contributions. p. 302.)

Mr. Herrbert Spencer, the author of the phrase, himself says :-

"Organisms which live thereby prove themselves fit to live in so for as they have been tried; while organisms which die thereby prove themselves in some respects unfitted for living.--(The Principles of Biology, i., p. 445.) 
Mr. Wallace even contends that the fittest cannot always survive :-

"Of the whole number of the increase produced annually, only a small per centage of the best adapted can be preserved."(Darwinism. p. 413.)

And yet elsewhere he says :-

"Whatever is really 'the fittest' can never be destroyed by Natural Selection, which is but another name for the survival of the fittest."-(Darrinism. p. 425.)

So that according to Mr. Wallace, Natural Selection means, the survival of the fittest only; the survival of the fittest in company with some not the fittest; the nonsurvival of all the fittest; and again the necessary survival of the fittest.

This difference sometimes escapes notice through the employment of the word preservation.

"This preservation during the battle for life of varieties which possess any advantage in structure, constitution, or instinct, I have called Natural Selection."-(The Variation. i., p. 6.)

Sometimes the word preserved is treated as identical with the word selected.

"The severe and often recurrent struggle for existence will determine that those variations, however slight, which are favourable, shall be preserved or selected, and those which are unfavourable shall be destroyed."

Mr. Darwin himself seems to have hesitated in his choice between these two terms.

"Talking of 'Natural Selection,' if I had to commence de noro, I would have used 'Natural Preservation.'-(Life and Letters. vol. ii., p. 346.)

"I suppose 'Natural Selection' was a bad term, but to change it now, I think, would make confusion worse confounded, nor can I think of a better. 'Natural Preservation' would not imply a preservation of particular varieties, and would seem a truism, and would not bring man's and nature's selection urder one point of view."-(Life and Letters. vol. ii., p. 3rS.) 
The term "preservation" is obviously ambiguous, for it may mean the preservation of the best and most useful, and of these alone; or it may mean the preservation of the best, and most useful, in company with those which are not the best. Now we are told that both these kinds of "preservation" take place alike in Art and in Nature.

It would facilitate the clear understanding of the subject if the two kinds of selection were to be distinguished by distinctive terms. We have to distinguish between preservation of the fittest alone, and preservation of the fittest and of some not the fittest. The latter is well expressed by the phrase "elimination of the worst."

In order that Natural Selection should take place, there must be a change of external conditions, otherwise there would be no advantage in a modification of organism. There must also be a struggle for existence, or there could be no Natural Selection. It therefore becomes a question of considerable interest to ask whether or not external circumstances frequently change; and whether or not the struggle for existence is always going on, seeing that on these questions depends the continuous or the intermittent action of Natural Selection.

Speaking of the change in external conditions, in his demonstration of the origin of species by Natural Selection, Mr. Wallace places on his list of proved facts: "Change of external conditions universal and unceasing." * In his Darwinism he mentions: "Changes of climate which are continually occurring, owing either to cosmical or geographical causes," $\dagger$ "under the ever-changing conditions both of the inorganic and organic universe." + But elsewhere he says: "Under conditions which do not perceptibly vary from year to year and from century to century." $\$$

* Contributions. p. zoz.

†p. 22. +f. 122. \$ t. 103. 
With respect to the struggle for existence, Mr. Wallace says :-

"There is a continual competition and struggle and war going on in nature. . . The fundamental cause of this struggle . . is ever acting over the whole field of nature, and no single species of animal or plant can possibly escape from it. This results from the fact of the rapid increase, in a geometrical ratio, of all the species of animals and plants."-(Dorwinism. p.25.)

But he also says :-

"The struggle for existence, under which all animals and plants have been developed, is intermittent and exceedingly irregular in its incidence and severity."-(Darwinism. p. 139, note.)

Mr. Darwin says :-

"In a state of nature, animals and plants have to struggle from the hour of their birth to that of their death for existence."-(The Variation. ii., p. 233, Ist ed.)

\section{But he also says :-}

"When we reflect on this struggle, we may console ourselves with the full belief that the war of nature is not incessant.-(Origin of Species. p. 6r.)

Naturally we have the same conflicting statements as to the constancy of the action of Natural Selection. Mr. Darwin says :-

"We must suppose that there is a power, represented by Natural Selection or the survival of the fittest, always intently watching each slight alteration . . . and carefully preserving each, which, under varied circumstances, in any way or in any degree, tends to produce a distincter image."-(Origin of Species. p. 146.)

"It may metaphorically be said that Natural Selection is daily and hourly scrutinising throughout the world the slightest variations, rejecting those that are bad, preserving and adding up all that are good, silently and insensibly working whenever and wherever opportunity offers at the improvement of each organic being, in relation to its organic and inorganic conditions of life."-(Origin of Species. p. 65-6.) 
But Mr. Darwin also says:-

"I do believe that Natural Selection will generally act very slowly, only at long intervals of time, and only on a few of the inhabitants of the same region." -(Origin of Species. p. 85.)

"The doctrine of Natural Selection or the survival of the fittest - . implies that when variations or individual differences of a beneficial nature happen to arise, these will be preserved; but this will be effected only under certain favourable circumstances." (Origin of Species. p. I69.)

\section{Mr. Wallace says :-}

"They (most people) do not see the constant and daily search after food, the failure to obtain which means weakness or death: the constant effort to escape enemies : the ever recurring struggle against the forces of nature. This daily and hourly struggle, this incessant warfare is nevertheless the very means by which much of the beauty and harmony and enjoyment of nature is produced, and also affords one of the most important elements in bringing about the origin of species."-(Darrvinism. p. I4.)

But he also says :-

"Survival of the fittest or Natural Selection meaning simply that on the whole those die who are least fitted to maintain their existence."-(Contributions. p.302).

Not only is there a difference of opinion as to whether the struggle for existence is continually going on, or intermittent in its action, but there is also a great difference of opinion as to its severity and hardship. To some it seems as if we always stood face to face with

With ravine;"

"Nature, red in tooth and claw,

while to others it seems as though life were on the whole well worth living even in the animal world.

Mr. Wallace says :-

"To most persons, nature appears calm, orderly, and peaceful. They see the birds singing on the trees, and insects hovering over 
the flowers, the squirrel climbing among the tree tops, and all living things in the possession of health and vigour, and in the enjoyment of a sunny existence. They do not see the constant and daily search after food, the failure to obtain which means weakness and death; the constant effort to escape enemies; the ever-recurring struggle against the forces of nature."-(Darwinism. p. I4.)

But elsewhere he says :-

"Now that the war of nature is better known, it has been dwelt upon by many writers as presenting so vast an amount of cruelty and pain as to be revolting to our instincts of humanity.

Now there is, I think, good reason to believe that all this is greatly exaggerated; that the supposed "torments" and "miseries" of animals have little real existence, but are the reflection of the imagined sensations of cultivated men and women in similar circumstances; and that the amount of actual suffering caused by the struggle for existence among animals is altogether insignificant." (Darwinism. p. 36-7).

Last, but not least, we come to the differences of opinion as to whether Natural Selection is, or is not, a necessary factor in the transmutation of species and in the production of organic evolution. Pure Darwinism asserts that Natural Selection is the only method. This view is stated with great explicitness by Professor E. Ray Lankester :-

"I do not hesitate to say that what may be called 'pure' Darwinism -the doctrine of the origin of species by the Natural Selection in the struggle for existence of non-significant congenital variations-is everywhere being more completely demonstrated by reasoning and observation as the single and sufficient theory of that origin; to the exclusion of Lamarckism, and still more certainly to the exclusion of any vestage of the doctrine of design."-(Nature. vol. xxxvizi., p. 364.)

Mr. Darwin, on the other hand, says :-

"There can be little doubt that the tendency to vary in the same manner has often been so strong that all the individuals of the same species have been similarly modified without the aid of any form of selection."-(Origin of Species. p. 72.) 
After the statements which have just been made, it can scarcely be said that the theory of Natural Selection is quite so definite or self-consistent as it is generally supposed to be. It is not quite certain that he who reads it as he runs will be sure to read aright, or that the wayfaring man will not be liable to err therein.

Now, in the first place, let me say that it is quite natural that there should be differences of opinion among different persons, and the first thing one has to remember is that Natural Selection may be held with various modifications. Some may believe that it is the one only method of the transmutation of species, others may hold that possibly there are many methods, among which Natural Selection is one. Some may follow Ray Lankester and Weismann, others may follow Darwin and Romanes. On this and other points we have modifications of the theory which almost amount to rival theories, and the attempt to reconcile the two would be a mere waste of time.

In the second place, a discrepancy, if it exists, may arise from the fact that even an eminent specialist sometimes writes from the point of view of the logical exponent of a theory, and sometimes in the character of a careful observer of nature. Both statements may be correct in their own field. Assuming certain data as the axioms of a theory, a man may reason as to what the result must be: looking out on nature, he may honestly record what the fact actually is: and he may not be quite aware of the discrepancy which exists between the two sets of statements. This may explain Mr. Darwin's treatment of the question whether variations are small or large.

Mr. Darwin asserts that Natural Selection deals only with slight variations; that on the theory of Natural Selection the variations must be slight; and in nature 
accordingly he finds that the variations are slight. This he speaks as the exponent of the theory of Natural Selection, but this does not prevent him from recording observations, which he makes as a student of nature, and which do not accord with the theory.

It seems to me to be quite conceivable that the same man may be an acute logician and a careful observer of nature. In one capacity he will expound the inevitable results of a principle which he supposes to be a law of nature. He may say: on my theory this or that will happen-this or that will be found to exist. And the same man may go forth to observe nature and simply report with conscientious exactness the phenomena that he observes. And perhaps it is because many men are in this way most honestly double-minded, that the dictum of George Eliot is fulfilled when she says in the proem to Romola: "The human soul is hospitable, and will entertain conflicting sentiments and contradictory opinions with much impartiality."

But sometimes it would seem that this discrepancy is observed. Perhaps it was this feeling which led $\mathrm{Mr}$. Darwin to omit a very remarkable passage in The Variation* $^{*}$ from the second edition of that work.

So far as the different views of the cruelty of the strife in nature are concerned, the judgment on this question will largely depend upon the subjective view of the spectator. To some the greatness and the cruelty of the carnage are most apparent. Others will dwell on the joy of life which does exist in spite of mortal woes and dangers. Sir Samuel Baker, having told us how to kill with great certainty and efficiency every wild creature in nature, moralises on the bitter struggle for existence which is everywhere apparent to him.

*Vol. ii., p. 424-already' quoted. 
"In every direction we see a struggle for existence; the empty stomach must be filled, therefore one species devours the other. It is a system of terrorism from the beginning to the end. The fowl destroys the worm, the hawk destroys the fowl, the cat destroys the hawk, the dog kills the cat, the leopard kills the dog, the lion kills the leopard, and the lion is slain by man. Man appears upon the scene of general destruction as the greatest of all destroyers, as he alone in creation, wars against his own species. We hear of love, and pity, and Christian charity; we see torpedoes and hellish inventions of incredible power to destroy our fellow-creatures. The inventors of these horrible engines of destruction receive titles and the highest honours, while those who have worked in progressive science for the welfare of mankind are forgotten in the obscure laboratory, although the saving light which they invented is gleaming above the hidden rock, for the benefit of all, to expose the danger of the sea. Thus with one hand we save, with the other we destroy."-(Wild beasts and their ways. vol. ii., p. 376.)

Compare with this the genial observation of the accomplished naturalist, Mr. Belt.

"Hawks of various kinds are very abundant in the tropics, and if the small birds had to personify death they would certainly represent him as one, for this is the form in which he must generally appear to them. Towards evening the hawk glides noiselessly along and alights on a bough, near where he hears the small birds twittering amongst the bushes. Perhaps they see him, and are quiet for a little, but he sits motionless as the sphinx, and they soon get over their fear and resume their play or feeding. Then suddenly a dark mass swoops down and rises again. It is the hawk, with a small bird, grasped in his strong talons, gasping out its last breath. Its comrades are terror-struck for a moment, and dash madly into the thickets, but soon forget their fear. They chirp to each other, the scattered birds reunite; there is a fluttering and a twittering; a rearranging of mates, then ayain songs, feeding, love, jealousy, and bickerings." (The Naturalist in Nicaragua. pp. 257-8.)

One reason of the discrepancy may arise from a certain indistinctness of appreciation either on the part of writer or reader, and sometimes, perhaps, on the part of both. Thus, in speaking of the nature of the variations which arise in nature, it is possible that the difference arises from the failure to distinguish the variations which are inevitably 
and necessarily associated with sexual reproduction from other variations that sometimes occur in connection with reproduction. We shall see presently how difficult it has been to realise what is meant by "accidental" variations in connection with the theory of Natural Selection, and how often the language of Natural Selection is unnatural and peculiar. If these explanations are true, it follows that there may be, and are, really more than one theory of Natural Selection; that the logical inferences of the theory may not always agree with the facts of nature; that we must allow for the personal equation; that we must take the greatest care that we understand a writer in the sense in which he wishes us to understand him.

These are not unnecessary warnings, as I can testify from personal experience, and may be helpful in explaining seeming contradictions. But there is one thing we are bound to protest against: and that is that a man shall use two phrases, two modes of representation--in fact, two contradictory theories-as though they were one and identical, just as it suits the exigencies of his present argument. It seems almost incredible that a great writer should have rejected the more accurate in favour of the sometimes more convenient phrase. But so it is! Mr. Darwin says :-

"I have called this principle by which each slight variation, if useful, is preserved, by the term Natural Selection, in order to mark its relation to man's power of selection. But the expression often used by Mr. Herbert Spencer of the 'survival of the fittest' is more accurate, and is sometimes equally convenient."-(Origin of Species. p. 49.)

\section{On which point Mr. Herbert Spencer says :-}

"Though Mr. Darwin approved of this expression, and occasionally employed it, he did not adopt it for general use, contending, very truly, that the expression Natural Selection is in some cases more convenient." - Ninetcenth Century. vol. xix., p. 750.) 
We would naturally follow the advice of such high authorities on the use of words connected with the theory of which they are such eminent exponents; but one pauses reluctantly to ask, why should the term Natural Selection be more convenient or equally convenient if the phrase "survival of the fittest" be more accurate? In what can the convenience of the less accurate consist, and to whom is it more convenient to be less accurate?

If we were dealing with ordinary men, and not with the greatest scientist and the greatest philosopher of the nineteenth century, it would be possible to find an answer to this question. We should say that having two inaccurate, rhetorical, unscientific phrases, it was eminently convenient to have a choice; so that when a doubt was raised as to the "survival of the fittest," we might talk about "Natural Selection," and when we were in difficulty as to "Natural Selection," we might use the phrase "survival of the fittest." 


\section{CHAPTER III.}

DIFFICULTIES INHERENT IN THE THEORY.

"Lest men suspect your tale untrue, Keep probability in view."-GAY.

THERE are certain difficulties in connection with this theory which meet us on the very threshold of the enquiry; inasmuch as they are inherent in the theory itself. This is certainly not what we should expect to find.

In the first place, it strikes one as rather startling that the transmutation of species by means of Natural Selection can only come into action in the face of adverse changes. For this process of transmutation starts from the point where a species has become adapted to its external conditions. Now if the conditions, though changing in detail, are nevertheless equally favourable to the race, it is obvious that no modification can be wrought by Natural Selection, for no change would then be useful to the race. If altered conditions were still more favourable than the old ones, there would be still less need for any responsive adaptation. It is, therefore, only in the face of adverse circumstances which make modification a necessity-a matter of life and death-that Natural Selection can come upon the scene. Disastrous change is the overture to the opera: the prologue to the play.

These changes must not be too rapid or the organisms would perish : they must not be too mild or they would not involve a question of life and death, i.e., they would not bring Natural Selection into action. The theory 
demands just the right amount of adverse circumstances which shall not exterminate, on the one hand, and which shall not fall short of a life-and-death severity on the other hand. This is surely a large demand to make on natural phenomena to start with.

But, in the second place, in this time of danger, in this critical period in the history of the race, it is most important that Natural Selection should act with promptitude. But here another difficulty occurs. Like Mr. Micawber it has to wait for favourable variations "to turn up;" and with respect to the emergence of these favourable variations Natural Selection is precisely analogous to a game of pure chance. In this sense it is perfectly true to say-

"The origin of mimetic coloration, like many other things, is yet unknown. An orthodox Darwinian attributes it to Natural Selection, which turns out on analysis to be hazard. The survival of useful coloration is no doubt the result of Natural Selection."(Cope. The Origin of the Fittest. p. 4 IIO.)

"On the Darwinian hypothesis, man is the child of Chance; as from the Evolution hypothesis, in its full generality, all life is the result of Chance."-(Graham. The Creed of Science. p. 27.)

If this be so, it is obvious that Natural Selection is heavily handicapped. We are not surprised, therefore, to find that the advocates of Natural Selection have repudiated with scorn the idea that Natural Selection has anything to do with chance.

\section{Professor Huxley says :-}

"But there are two or three objections of a more general character, based, or supposed to be based, upon philosophical and theological foundations, which were loudly expressed in the early days of the Darwinian controversy, and which, though they have been answered over and over again, crop up now and then at the present day.

"The most singular of these, perhaps immortal, fallacies, which live on, Tithonus-like, when sense and force have long deserted them, is 
that which charges Mr. Darwin with having attempted to reinstate the old pagan goddess, Clance. It is said that he supposes variations to come about 'by chance,' and that the fittest survive the 'chances' of the struggle for existence, and thus 'chance' is substituted for providential design."-(Life and Letters of Darwin. vol. ii., p. I99.)

It must be confessed that this subject is beset with no little difficulty; for if it is contended-as Pfaffer Kneipp* does contend-that chance is in reality "a vague and nonsensical word, because there is no such thing as chance," we ask in perplexity-Is there no such thing as a "game of chance?" There must be some sense in which that phenomenon, which has ruined so many, is a reality.

Some definitions throw very little light upon the subject. Dr. Johnson, for example, defines chance as the cause of fortuitous events, which leaves me, at any rate, about as wise as I was before, because I am still anxious to know what "fortuitous" means! It seems to me very much like defining an archdeacon as a clergyman who performs archidiaconal functions.

But Mr. Huxley asserts that Mr. Darwin has defined the sense in which he wishes the word chance to be understood.

"It is not a little wonderful that such an accusation as this should be brought against a writer who has, over and over again, warned his readers that when he uses the word 'spontaneous,' he merely means that he is ignorant of the cause of that which is so termed, and whose whole theory crumbles to pieces if the uniformity and regularity of natural causation for illimitable past ages is denied."-(Life and Letters. ii., p. I99.)

But when the opponent of Natural Selection is charged with forgetting that Mr. Darwin has defined a spontaneous phenomenon as one which occurs in connection with a law 
of whose action we are ignorant, the accuser should remember that Mr. Darwin himself uses chance in three different senses. He says :-

"I was so convinced that not even a stripe of colour appears from what is commonly called chance, that I was led ... . . to ask Colonel Poole whether such face stripes ever occurred in the eminently striped Kattywar breed of horses, and was answered in the affirmative."-(Origin of Species. p. I29.)

Here he understands by chance "what happens without necessary cause."

Again, when he explains that in using the word spontaneous he only means to assert his ignorance of the nature of the cause, in whose existence he firmly believes, he adopts another definition of cause, viz. : "what happens through a definite law, concerning the action of which we are ignorant."

But there is a third sense in which Mr. Darwin uses the word chance.

"In all the foregoing cases, the insects, in their original state, no doubt presented some rude and accidental resemblance to an object commonly found in the stations frequented by them."-(Origin of Species. p. I82.)

Here he adopts the definition of chance, which regards it as the coincidence of two sets of phenomena which have been produced by the definite action of the laws of nature.

"Chance is the combination of several systems of causes which are developed each in its own series independently of the others."

"All the phenomena of nature are linked in the bond of cause and effect; but all these phenomena do not form a single indefinite chain in which each phenomenon would come to occupy a place in its turn, and where there would only be room for a single phenomenon at a time. No! at one and the same moment there is an infinite number of phenomenal series which take place at all points of the globe and of the universe. These simultaneous phenomenal series are sometimes parallel and sometimes oblique. Representing these phenomenal series by lines, the points where they meet are points of coincidence. 
Sometimes this meeting of serial lines is determined beforehand by the nature of things : it sometimes occurs that they happen to meet together.

"This kind of coincidence is what is called chance. Chance is not a cause, but it is the coincidence of causes."-(Cournot. "Dict: des sciences philosophiques-Art: Hazard.")

"It sometimes occurs-often even-that two series of phenomena happen to meet together, yet without our being able to say that they have any action upon each other; and it is even a pleasure to our mind to find out what will happen in this case. For instance, if, in the game of rouge-et-noir, I beg that the black will win, and it wins accordingly, it is clear that my desire and my word could not have had any influence on the winning of one colour or the other, and likewise that the arrangement of the cards, which I did not know, could not have had any influence on the choice I have made. In this case two series of facts, absolutely independent of each other, have happened to coincide with each other, and to harmonize without any mutual influence. This kind of coincidence is what is called Chance ; and it is upon the very uncertainty of this coincidence that the pleasure and, at the same time, the terrible temptation of games of hazard rests."-(Paul Janet. Final Causes. pp. I8-I9.)

Now with regard to these three definitions, all are ready to admit there is no such thing as chance in the sense that there is any one event which has no cause, or that a single phenomenon can be produced without a cause. The reign of law is universal; so far all are perfectly agreed with what Mr. Huxley says on that subject.

"But probably the best answer to those who talk of Darwinism meaning the reign of chance, is to ask them what they themselves understand by chance. Do they believe that anything in this universe happens without reason or without a cause? Do they really conceive that any event has no cause, and could not have been predicted by anyone who had a sufficient insight into the order of nature? If they do, it is they who are the inheritors of antique superstition and ignorance, and whose minds have never been illumined by a ray of scientific thought. The one act of faith in the convert to science, is the confession of the universality of order and of the absolute validity, in all times and under all circumstances, of the law of causation.

"This confession is an act of faith, because, by the nature of the case, the truth of such propositions is not susceptible of proof. But 
such faith is not blind, but reasonable; because it is invariably confirmed by experience, and constitutes the sole trustworthy foundation for all action.

If one of these people, in whom the 'chance-worship' of our remoter ancestors thus strangely survives, should be within reach of the sea when a heavy gale is blowing, let him betake himself to the shore and watch the scene. Let him note the infinite variety of form and size of the tossing waves out at sea; or of the curves of their foamcrested breakers, as they dash against the rocks; let him listen to the roar and scream of the shingle as it is cast up and torn down the beach; or look at the flakes of foam as they drive hither and thither before the wind; or note the play of colours, which answers a gleam of sunshine as it falls upon their myriad bubbles. Surely here, if anywhere, he will say that chance is supreme, and bend the knee as one who has entered the very penetralia of his divinity. But the man of science knows that here, as everywhere, perfect order is manifested; that there is not a curve of the waves, not a note in the howling chorus, not a rainbow-glint on a bubble, which is other than a necessary consequence of the ascertained laws of nature; and that with a sufficient knowledge of the conditions, competent physicomathematical skill could account for, and indeed predict, every one of these 'chance' events."-(Life and Letters, vol. ii., pp. I99-20I.)

To the same effect Mr. Mackay wrote long ago :-

- "Wildest wind that shakes the blossoms,

Or on ocean chafes and swells,

Blows not uncontrolled and wanton,

But as Law compels.

Streams that wander and meander,

Loitering in the meads to play,

Or that burst in roaring torrents

Into foam and spray;

Avalanches, forest-crushing,

Fires that rage in Etna's breast,

Lava floods and tides of ocean,

All obey the same behest.

Law releases, Law restrains them."

-(Freedom and Law.)

And no variation of the organic frame any more than any other physical phenomenon, can be the result of chance, in the sense of being without an adequate cause. If we could know all, we should be able to see at once how 
every variation came to be exactly what it was. We should find out what the law or the condition was which brought about each particular modification.

It should also be remembered that when an opponent of Natural Selection talks of chance in this sense, he is not necessarily asserting his own belief that the transmutation of species does take place in this way: but that according to his interpretation of the language of its advocates, the supposed transmutation of species by Natural Selection must take place in this way.

With regard to the second definition, we may remark that it does not alter the essential character of the phenomenon: it only expresses our present relation towards it. Moreover it is misleading to use the word chance in this way, unless we are very explicit in stating what we mean. Surely it would be clearer to say that this phenomenon takes place through a law at present unknown to us, than to say that it takes place by chance. In this sense, the scientific man cannot say that there is no such thing as chance, unless he means to say that there is no law of nature, of whose action he is ignorant. And there is always a danger in making a mystery of an unknown cause, of being understood to mean, either that the event has no physical cause or that the physical cause is inscrutable, and must always remain so.

We come now to the third definition of chance-the accidental emergence of the favourable variation. Let us be careful to note what these words exactly mean. They do not signify that the colour of the objects in a given district is accidental; they do not mean that the colour exhibited by some few insects of a given group is accidental, because there is little doubt that, if we knew all, we should be able to explain the exact causes which brought about these phenomena. But the emphasis must 
be placed on the accident of the resemblance, for it is only by a happy coincidence that any variations necessarily associated with reproduction could resemble the colour of any given objects in a given locality. It is not the variations which are accidental in the sense of occuring without cause: it is the resemblance between the colour of certain objects and the colour of the variants necessary for the safety of the animal which is accidental or fortuitous.

And now why do these favourable variations arise by the principle of a game of chance? The answer is that the variations which are necessarily associated with reproduction are assumed to be indefinite in direction, diverging to all the points of the compass, and that the favourable variations must therefore occur through a happy coincidence.

These explanations afford, it is to be hoped, a complete answer to those who say that there is no such thing as chance and that it is superstitious to believe in such a thing. However much we may argue as to the existence or nonexistence of chance, it is certain that games of chance exist; and it is equally certain that the theory of Natural Selection is fittingly described as no other than a game of chance. But if this is so, how little likely it is that the transmutation of species should be effected by Natural Selection.

It might be said, however, that Natural Selection is not only a law of nature but a method of the Divine Providence. But that fact would not influence the result so long as the method was not tampered with. The omniscient God might be conceived as knowing every detail of a game of chance, but that fore-knowledge would not affect the issue. The Divine Being could not overrule the principle of creation by the accidental occur- 
rence of favourable variations except by acting contrary to the rule of the game, and this no scientific man or enlightened theist would believe to be possible, for this would be to substitute miracle for law, as the method of progressive development.

Another difficulty which presents itself at the first glimpse is the enormous cost of the process.' The fact that favourable variations are supposed to arise-and as limited by the theory probably can only arise-in a few individuals, demands that there should be an enormous output of life, which is provided for by the tendency of all organisms to increase in a geometrical ratio. The great output of life must be met with a great discriminative slaughter, or the strict isolation of the few favourably endowed variants would be impossible. And this process must go on for millions of years. Lest it should be thought that this representation is greatly exaggerated, let us hear the sort of mandate which the theory makes upon the resources of nature. Mr. Darwin, speaking of the evolution of the human eye, says :-

"We must suppose each new state of the instrument to be multiplied by the million; each to be preserved until a better one is produced, and then the old ones to be all destroyed. In living bodies variation will cause the slight alterations, generation will multiply them almost infinitely, and Natural Selection will pick out with unerring skill each improvement. Let this process go on for millions of years ; and during each year on millions of individuals of many kinds; and may we not believe that a living optical instrument might thus be formed as superior to one of glass, as the works of the Creator are to those of man?"-(Origin of Species. p. 146.)

The kind of slaughter which would take place in one generation by anything approaching to a real survival of the fittest, may be seen from the following illustration :-

"On the night of May 24th, 1864, there was a severe frost in Kent, and two rows of scarlet rumners ( $P$. multiflorus) in my garden, containing 390 plants of the same age and equally exposed, were C 
all blackened and killed except about a dozen plants. A still more severe frost occurred four days afterwards, and of the dozen plants which had previously escaped only three survived."-(Darwin. The Variation. and $e d$., ii., p. 300.)

There is one point which I have never seen referred to, but which seems to me most important. Why do the favoured few survive? Not simply because they are better than their fellows, but because they are good enough to survive while their fellows are not. But if this is so, surely that might sometimes happen which happens in the case of some competitive examinations. For though one competitor may be better than others, and though you arrange the candidates in a finely graduated scale, there may still not be one who is fit to take the scholarship, or to be put into the first class, or whatever the distinction coveted may be. Well, if this is so in the struggle between students, why should it not be so in nature? And then, sometimes, there might be a generation, no one of the individuals of which varied in a favourable way, and then what would happen to the race, if there were no one which was fit to live?

This difficulty may be met by assuming that the variations are not individual in occurrence, and not slight in quantity. But in proportion as you seek to remove this difficulty by contending that the variations are not slight, and are not individual, you lessen the causative influence of Natural Selection. This is clearly stated by Mr. Romanes, when he says :-

"It must be obvious that, in whatever measure there may be such a tendency to produce varieties of a limited number and kind, in that measure is the causative influence of Natural Selection limited; it is in this measure supplemented by some cause or causes of another kind. Here then we are in the presence of a most important question, in fact, the most important question with reference to the amount of causative action that is to be assigned to the principle of Natural Selection."-(Contemporary Reriew. vol. liii., p. 849.) 
Mr. Huxley, however, contends that Natural Selection would still act to some extent.

"If variability is definite, and is determined in certain directions rather than in others by conditions inherent in that which varies, even then Natural Selection would still continue to operate; for 'it is quite conceivable that every species tends to produce varieties of a limited number and kind, and that the effect of Natural Selection is to favour the development of some of these, while it opposes the development of others." -(Ency. Brit.-Art: Ezolution.)

This argument moreover assumes that the variations, considerable in amount and occurring in many individuals, are variations favourable to the welfare of the race, and hence tend to promote the transmutation of species through Natural Selection. As Mr. Meldola says:-

"The whole number of individuals composing any species may at any period of its existence be divided into two portions, presenting variations above and below a line of mean variability. Of these portions one must possess characters more or less advantagcous so far as concerns the external conditions, and the other portion must possess characters more or less disadvantageous with respect to those same conditions. On the first portion-which may be considered above the mean line-Natural Selection will act as a preserving agent; on the second portion-below the mean line-Natural Selection will act as a destructive agent."-(Nature. vol. wliii., p. 410.$)$

But do these variations represent the useful and the injurious? Do they not rather represent variations, which from the point of view of Natural Selection are absolutely indifferent? Probably they do not affect the physical wellbeing or the efficiency of operation in each individual.

Let us turn now to the other version of the theory, which suggests the idea of a lax selection, according to which some favourable variants survive in company with those who are not so privileged. In that case, unless they intermarried with one another, the favourable variation would be soon swallowed up in the average of the race. 
Sometimes, no doubt, similar variants have intermarried, and have segregated themselves from the rest of their companions, but the improbability of this marriage taking place generally in the interests of Natural Selection is forced upon our consideration, when we come to investigate the phenomena which are grouped together under the term Sexual Selection. There is, I believe, an impression that Natural Selection and Sexual Selection are allies, and work together for the erolution of the race-the former supplying the useful, and the other the beautiful.

On the contrary, I believe that the theory of Natural Selection has no greater difficulty to face than that presented by the various phenomena connected with the love, courtship, and marriage of animals. We have tolerably good evidence to show that similar variants do not necessarily intermarry among animals any more than they do among mankind. That principle is certainly true with regard to human marriages. In calculating the inheritance of human stature, Mr. Galton regards the union of tall and short individuals as accidental. And Will Carleton in his Farm Ballads makes an amusing protest to a similar effect:-

"'Like takes to like' is a proverb that's nothin' more than trash, And many a time I've seen it all pulverised to smash:

For folks in no way sim'lar, I've noticed agin and agin, Will often take to each other and stick together like sin."

The same principle is true of the animal world-

"Mr. Mayhew, who attended chiefly to the smaller breeds, is convinced that the females are strongly attracted by males of a large size. The well-known veterinary, Blaine, states that his own female pug became so attached to a spaniel, and a female setter to a cur, that in neither case would they pair with a dog of their own breed until several weeks had elapsed. Two similar and trustworthy accounts have been given me in regard to a female retriever and a spaniel, both of which became enamoured with tarrier dogs."-(Darwin. The Descent of Man. pt. 523-4.) 
We may examine this question from a two-fold point of view, the different nature of the sexual passion, and the different forms of married life. In all those cases, in which the union of the sexes is promoted by the blind influence of mere passion, there is no room for any kind of selection. The female of the Emperor Moth emits an aroma, which attracts the males from afar. She remains stationary, and awaits the arrival of her spouse. The first which arrives is the successful wooer. The female which can emit the strongest aroma will possibly attract the greatest number of attendants; and if all the males were at an equal distance from her, the one which first reached her would probably be the one which possessed the keenest scent or the swiftest power of flight, or both. But even here the chance of accidental position may interfere, so that a male who is not specially gifted may be the first to arrive. But grant that the male of strongest sense of smell and power of flight is the first to arrive, and that he is worthily mated to a female exceptionally gifted in her sexual way, yet the result would only be the development of this very useful and obvious method of perpetuating the species. But who can believe that in this connection, it is inevitable that sexual selection, acting on this principle, should secure the marriage of two individuals which happen to vary in that favourable manner, which is essential to the transmutation of a species.

If there is any truth in the choice which goes by the technical name of "Sexual Selection," then it would seem that selection is sometimes made on the basis of an xsthetic taste. The male chooses the most beautiful female: the female chooses the siveetest singer. There may be sometimes a definite attraction for all without our being able to specify what it is. "It is improbable," says Mr. Darwin, "that the union of quadrupeds in a state of 
nature should be left to mere chance. It is much more probable that the females are allured or excited by particular males who possess certain characters in a higher degree than other males, but what these characters are we can seldom or never discover with certainty." * But it is not at all certain that a selection made on the basis of resthetic taste would necessarily unite those favourable variants which, according to Natural Selection, had best be joined together.

Once more, there is the emotion of what we may venture to call "romantic love": which may be described as the attraction which one particular individual has for another individual of the opposite sex, and which is strikingly described in the following passage:-

"It is so strange! We see a million faces, we hear a million voices, we meet a million women with flowers in their breasts and light in their fair eyes, and they do not touch us. Then we see one, and she holds for us life or death. . . . She is not nobler, better or more beautiful than were all those we passed, and yet the world is empty to us without her."-(Ouida. A Branch of Lilac. p. S4.)

Shakespeare speaks to the same purpose:-

"Love looks not with the eyes, but with the mind;

And therefore is wing'd Cupid painted blind:

Nor hath Love's mind of any judgment taste:

Wings, and no eyes, figure unheedy haste;

And therefore is Love said to be a child,

Because in choice he is so oft beguiled."

-(Midsummer Night's Dream. Act i., sc. I.)

Is there anything corresponding to this tender sentiment in the animal world? Speaking of domestic dogs, Mr. Mayhew says :-

"The females are able to bestow their affections; and tender recollections are as potent over them as they are known to be in other cases, where higher animals are concerned. Bitches are not

*Darwin. Descent of Man. p. 525 . 
always prudent in their loves, but are apt to fling themselves away on curs of low degree. If reared with a companion of vulgar appearance, there often springs up between the pair a devotion which no time can afterwards subdue. The passion, for such it really is, becomes of a more than romantic endurance."-(Darwin. Descent of Man. p. 523.)

We may look at this matter from another point of view, by raising the question whether the different forms of married life adopted by animals are favourable to the isolation of similar variants; and the inheritance of their special endowments by their offspring.

Now if the general rule were a life-long monogamy, and if the pair lived to the same age, and if they united on the basis of the common possession of favourable variations, then we should have the precise conditions which we require. But it does not follow that these conditions will always be fulfilled. For probably the animals which are monogamists will unite on the basis of romantic love, and not on that of favourable variation. And in the case of the death of one there may be, and probably will be, a second marriage. There is also the case of a monogamous union which lasts only for one season, so that one female may have in a life-time several husbands, in which case we have ample evidence that the offspring by the second husband often bears a marked resemblance to the first.

We have a good illustration of that form of marriage known as polygamy, in which one husband has many wives, in the case of the seals. The following curious details on the courtship of one of the eared seals (Callorhinus ursinus) are given on the authority of Capt. Bryant, who had ample opportunities for observation. He says:-

"Many of the females on their arrival at the island where they breed appear desirous of returning to some particular male, and frequently climb the outlying rocks to overlook the rookeries, calling out and 
listening as if for a familiar voice. Then changing to another place they do the same again. . . As soon as a female reaches the shore, the nearest male goes down to meet her, making meanwhile a noise like the clucking of a hen to her chickens. He bows to her and coaxes her until he gets between her and the water so that she cannot escape him. Then his manner changes, and with a harsh growl he drives her to a place in his harem. This continues until the lower row of harems is nearly full. Then the males higher up select the time when their more fortunate neighbours are off their guard to steal their wives. This they do by taking them in their mouths and lifting them over the heads of the other females, and carefully placing them in their own harem, carrying them as cats do their kittens. Those still higher up pursue the same method until the whole space is occupied. Frequently a struggle ensues between two males for the possession of the same female, and both seizing her at once pull her in two, or terribly lacerate her with their teeth. When the space is all filled, the old male walks around complacently reviewing his family, scolding those who crowd or disturb the others, and fiercely driving off all intruders. This surveillance always keeps him actively occupied."-(Darwin. Descent of Man. p.523.)

It is quite clear that the female is not allowed to exercise any choice. She might well say with Portia, in The Merchant of Venice:-

"In terms of choice I am not solely led

By nice direction of a maiden's eyes;

Besides, the lottery of my destiny

Bars me the right of voluntary choosing."

$-($ Act ii., sc. I. $)$

It is the chief object of a polygamous male to get as large a harem as possible. And with this object he contends with any male who seeks to rob him of his wives.

The victory of the strongest males, and the consequent formation of large harems, necessarily result in many males leading a celibate life: which males may in all other respects, be fitter to live than their stronger and more fortunate brethren.

In connection with polygamy, the wife of one year might have another husband in the second year; and in that case, as already observed, the offspring by the second marriage 
would tend to resemble the husband of a former year; and thus the object sought to be attained by strict selection would be frustrated.

The form of marriage known as polyandry, in which one female has several husbands, would probably be fatal to the very preservation of a species. One method of exterminating rabbits, which is said to be found highly successful, is to trap as many as possible, kill off all the does that are caught, and let the bucks loose. "The results of this mode of operation are that the male rabbits as soon as they begin to predominate in numbers, persecute the females with their attentions and prevent them from breeding. They also kill the young rabbits that happen to be born; and even as Mr. Rodier asserts, when they largely predominate in numbers, worry the remaining does to death." * These considerations serve to convince us that Sexual Selection cannot possibly supplement the deficiencies which may arise through any laxity in the action of Natural Selection.

The theory then, contains in itself some striking difficulties. Natural Selection can only act in adverse circumstances: it has to await the "accidental" emergence of favourable variations. If the isolation is strict, it is tremendously costly; if it is not strict it is useless. Where Natural Selection is not strict, we have no right to assume that Sexual Selection will necessarily assist Natural Selection, and that the fittest variants will necessarily marry one another in preference to other less worthy survivors.

* Nature. vol. xxxix., p. 493 . 


\title{
CHAPTER IV.
}

\author{
THE THEORY COMPARED WITH THE REALITY.
}

"'Things ough' to ha' took most an oppersite turn, But The'ry is jes' like a train on the rail, Thet, weather or no, puts her thru without fail, While Fac's the ole stage thet gits sloughed in the ruts, An' hez to allow for your darned efs an' buts, An' so, nut intendin' no pers'nal reflections, They don't--don't nut allus, thet is,-make connections." -Lowell. The Biglow Papers.

"On parlait un jour de son Histoire Naturelle devant Voltaire. Oh ! pas si naturelle, dit celui ci d'une façon mordante."--Said of Buffor's Natural History.

". . . in vain, Opinions, those or these, Unaltered to retain The obstinate mind decrees; Experience, like a sea, soaks all-effacing in."

-MATTHEW ARNOLD.

WE have now to consider how far the facts of nature correspond with the requirements of the theory of Natural Selection, so far as its distinctive feature is concerned; namely, the power of Natural Selection to select. It is assumed that the tendency to increase in a geometrical ratio leads to an enormous output of life, which is succeeded by the discriminative destruction known as Natural Selection. It is assumed that the ordinary output of life, apart from enormous fertility, is succeeded by discriminative destruction. It is assumed that there is always a competition going on in nature between members of the same species and individuals of different species. These 
assumptions are essential to the theory; are they consonant with the facts of nature?

(a) IS THE TENDENCY TO INCREASE IN A GEOMETRICAL RATIO FOLLOWED BY DISCRIMINATIVE DESTRUCTION ?

"Multitudes - multitudes in the Valley of Decision."-(Joel. iii., I4.)

"Thy crowned are as the locusts, and thy captains as the great grasshoppers, which camp in the hedges in the cold day, but when the sun ariseth they flee away, and their place is not known where they are."-(Nahum. iii., 17 .)

It is contended that the tendency to increase in a geometrical ratio necessarily produces a struggle for existence, and that the struggle for existence necessarily leads to the survival of the fittest.

"A struggle for existence inevitably follows from the high rate at which all organic beings tend to increase."-(Origin of Species. p. 50.)

"The power of selection brought into play through the struggle for existence and the consequent survival of the fittest." - (The Variation. ii., A. I92.)

From the proved fact of the rapid increase of organisms, Mr. Wallace infers the struggle for existence as a necessary consequence. Then taking the struggle for existence as a proved fact, he infers the survival of the fittest as a necessary consequence. And then, from the survival of the fittest as a proved fact, he infers the changes in organic forms; and thus presents a demonstration of the transmutation of species by means of Natural Selection.*

Mr. Romanes says :-

"If, on independent grounds, we believe in the theory of evolution at all, it becomes obvious that Natural Selection must have had

* Contributions. p. 103 . 
some part in the process. For no one can deny the potent facts of heredity, variability, the struggle for existence and survival of the fittest. But to admit these facts is to admit Natural Selection as a principle which must be, at any rate, one of the factors of organic evolution, supposing such evolution to have taken place."(Darain and After-Daravin. part i., ph. 314-5.)

We have now to consider how far the actual facts of nature confirm these assumptions. First of all, it will be necessary to ascertain what the output of life actually is in nature. We must make a very definite distinction between the tendency towards a geometrical increase and the fact itself. This is not always borne in mind. Sometimes writers speak of the fact:-

"The fundamental cause of the struggle for existence which is ever acting over the whole field of nature results from the fact of the rapid increase in a geometrical ratio of all the species of animals and plants." -(Wallace. Darroinism. p. 25.)

Mr. Romanes mentions, among other facts, the fact of geometrical ratio of increase. ${ }^{*}$ It is true that such 'statements are generally qualified by the context; but I venture to think, if I may speak from my own experience, that they are apt to leave upon the mind of the ordinary reader an impression that the tendency to increase in a geometrical ratio is very often realised. And the ordinary reader seems to me so far justified by the consideration, that the theory of Natural Selection requires that he should assume that this does take place in nature, not only as a tendency, but as a realised tendency. Take, as an illustration of the effect of this representation, Mr. Croll's definition of Natural Selection.

"The theory of Natural Selection rests on two main classes of facts, which, from their generality, may be regarded as fundamental principles. The first (fact) is the enormous increase in geometrical progression possessed by all organisms. . . " --(The Basis of Evolution. D. IIO.)

* Contemporary lieview. vol. liii., p. S43-note. 
Let us consider what is implied by the fact of increase in a geometrical ratio. The result of increase in a geometrical ratio is "one of the greatest marvels of arithmetic." By its aid, if we are to believe the illustrations given and the stories told, the cunning of knowledge delights to circumvent the innocence of ignorance. That very remarkable abstraction, "every school boy," has heard of the gentleman who took a great fancy for a horse and rashly asked the horse-dealer to name his own price. Accordingly it was arranged that he should be paid for the nails in the horse's shoes-a farthing for the first and a halfpenny for the second, and so on to the twenty-fourth nail; by which means the stipulated price of the horse amounted to $£ 17,4765 \mathrm{~s} .33 / 4 \mathrm{~d}$.

In spite of the notoriety of the horse-shoe calculation, two persons accepted the offer of a well-known farmer of the Brechin district, who proposed to pay the expense of a picnic to thirty farmers, provided one of them would bring to him in the market on Tuesday one grain of oats, doubling the number of grains every Tuesday for twelve months. One of the persons accepting the offer undertook to carry all the oats on his back at the end of the year; but upon calculation it was found that the quantity of oats at the end of twelve months would amount to $1,034,834,468$ quarters 2 bushels, and the value, at 30 s. a quarter, was found to be $£ \mathrm{I}, 552,25 \mathrm{I}, 702$ 7s. $6 \mathrm{~d}$.!

To those who have any experience of calculations like these, it is obvious that the phrase "increase in a geometrical ratio" suggests the output of enormous numbers, and the expression is none the less significant when applied to living beings. In that connection it constitutes one of the marvels of the organic world. Writers on Natural Selection exhibit elaborate calcu- 
lations of what would happen if the principle were carried out without any let or hindrance:

"A single cod-fish has been known to lay six million eggs within a year. If these eggs were all to become adult cod-fishes, and the multiplication were to continue at this rate for three or four years, the ocean would not afford room for the species."--(Fiske. Outlines of Cosmic Philosophy. vol. ii., pp. IT-T2.)

With respect to the aphis - the "green blight" of the gardeners, with which most of us are more or less familiar, Mr. Theodore Wood says that a second generation may enter into the world within two or three days of the first, and that the fifteenth generation, if no destruction took place, would amount to-

$68,122.3$ I 8, 582.95 I ,682.30 I,000.000,000.000,000.

"Even slow-breeding man has doubled in twenty-five years, and at this rate, in less than a thousand years, there would literally not be standing-room for his progeny. . . . The elephant is reckoned the slowest breeder of all known animals, and I have taken some pains to estimate its probable minimum rate of natural increase. It will be safest to assume that it begins breeding when thirty years old, and goes on breeding till ninety years old, bringing forth six young in the interval, and surviving till one hundreci years old. If this be so, after a period of from 740 to 750 years, there would be nearly nineteen million elephants alive descended from the first pair."-(Origin of Species. p. 51.)

These illustrations will enable us to understand what the fact of increase in a geometrical ratio would be, if it were realised in the organic world. But we must remember that this tendency is never, or very rarely, realised. The law of geometrical increase is arrested more or less by other principles which keep it in check; so that what we have to reckon with is a potential, rather than an actual, increase in a geometrical ratio. If we consider the conditions which would be necessary to secure the actual increase, we shall see at once how very improbable it is that it will be often realised. 
"There is no exception to the rule that every organic being naturally increases at so high a rate that if not destroyed the earth would soon be covered by the progeny of a single pair." (Origin of Species. p. 5I.)

But there is great virtue in that "if": nor is this the only condition necessary. Professor Huxley has calculated that a single plant would occupy every available spot of the globe before the end of the ninth year: but of course this must take place under peculiarly favourable and well-nigh impossible conditions. We must suppose that there are no rivals, and that the dry land of the globe consists of the same kind of soil and has the same kind of climate, and that the conditions are everywhere the same and exactly suited to the plant. If no organisms were prematurely destroyed, if a species had no rivals, if external conditions were uniformly favourable, if all available spheres of life on this globe were accessible, then indeed we might see an increase in a geometrical ratio-until the earth could hold no more. There is surely great virtue in an "if"! but as a whole "litany of ifs" would not avail to realise the dream of unchecked fertility, it is rather a work of supererogation to enter upon elaborate calculations of a strictly hypothetical increase, which can never possibly take place on this earth of ours.

Mr. Wallace has a curious way of speaking of organic increase in a geometrical order. He seems to consider that it is possible that it should take place in connection with a fixed population:-

"As all wild animals increase in a geometrical ratio while their actual numbers remain on the average stationary, it follows that as many die annually as are born."-(Contributions. p. 309.)

"We must never for an instant lose sight of the fact of the enormously rapid increase of all organisms, which has been illustrated by actual cases, given in our second chapter, no less than 
by calculations of the results of unchecked increase for a few years. Then, never forgetting that the animal and plant population of any country is, on the whole, stationary, we must be always trying to realise the ever-recurring destruction of the enormous annual increase."-(Wallace. Darwinism. p. I22.)

But if the animal population remains the same from year to year it is quite impossible that there should be any such a thing as increase in a geometrical ratio at all. A geometrical progression is a series of numbers, which is increased or decreased by a constant factor, i.e., is always multiplied or divided by the same number. Thus, if we start with 4 for the first number of a series and take 2 as the constant factor we have the following series-

$4(4 \times 2=) \delta(8 \times 2=)$ I6 $(16 \times 2=) 32 \quad(32 \times 2=) 64 \quad(64 \times 2=)$ 12S.

Hence $4,8,16,32,64,128$ constitute a geometrical progression, a series of numbers increased by the constant factor 2. But if in every generation as many die as are born, there can be no such thing as a geometrical progression, i.e., a series of numbers increased by a constant factor generation after generation and year after year. Let us, for a momerit, consider the enormous difference which exists between increase in a geometrical ratio and a stationary population. The difference may be shown thus-

$$
\begin{array}{llllll}
4 & (4 \times 2=) & 8 & (8 \times 2=) & \text { I6 } & (16 \times 2=) \\
4 & (4 \times 2-4=) 4 & (4 \times 2-4=) & 4 & (4 \times 2-4=) & 32
\end{array}
$$

And of course the difference will be greater the greater the constant factor employed. In the case given above the difference in the output of life in six terms will be

$$
\begin{aligned}
& 4+8+16+32+64+128=252 \\
& 4+8+8+8+8+8=\frac{44}{208}
\end{aligned}
$$

In this case we are supposing 252 chances of favourable variations arising, in a case where only 44 in reality occur. 
But this is not all: we are invited to bear in mind the fact of the enormous increase in a geometrical ratio, which is both actual and potential, in order that we may understand "the ever-recurring destruction of the enormous annual increase" which accompanies, a fixed population.

Mr. Fiske adopts the same method of treating the subject in the following passage:-

"Let us take the case of a plant which yields one hundred seeds yearly, and suppose each of these seeds to reach maturity so as to yield its hundred offspring in the following year: in the tenth year the product would be one hundred thousand trillions. . . . We may now begin dimly to realise how prodigious is the slaughter which unceasingly goes on throughout the organic world. For obviously when a plant, like the one just cited, maintains year by year a tolerable uniformity in its numbers, it does so only because on the average ninety-nine seeds perish prematurely for one that survives long enough to produce other seeds."-(Outlines of Cosmic Philosophy. vo!. ii., p. IT.)

Here we have an output of life amounting to one hundred thousand trillions suggested; and at the same time it is admitted that the actual output only amounts to one thousand-that is, one hundred per annum for ten years.

The principle of a tendency to increase in a geometrical ratio cannot have the power which resides in heat when it is latent. In that case, whether latent or not, heat represents so much force in a particular condition. But a tendency which remains a tendency occupies a different category. We must not venture to build on the calculations of a potential increase which cannot possibly become actual, any more than we ought to treat as actual history the story of a world that might have been. There is about as much common sense in such rhetorical science as there is in such imaginative history. And nobody D 
consciously sets himself to write serious history after the fashion of the ditty of Guy Fawkes :-

"I'll sing you a doleful tragedy, Guy Fawkes the prince of sinisters,

Who once blew up the House of Lords, the King, and all his minister's;

That is, he would have blown 'em up, and they'd have all been cindered,

Or seriously scorched at least-if he had not been hindered."

It is obvious, then, that the output of life has been unduly appreciated and overvalued. This treatment is derived from Malthus, who, in his Essay on Population, laid down the proposition that the human race tended to increase in a geometrical ratio, while the vegetable world only increased in an arithmetical ratio. In adopting this doctrine as the basis of the theory of Natural Selection, Mr. Darwin and his followers seem to have enlarged the teaching of Malthus by extending the increase in a geometrical ratio to the vegetable world; while at the same time they seem to have lost sight of the fact, that the greater portion of the essay of Malthus is taken up with discussing the checks to this enormous increase of population in the case of man.

The tendency to increase in a geometrical ratio is ahways a potential attribute of every species: but the realisation of that tendency depends upon the conditions in which it is placed. In some cases there is an enormous increase, if not literally an increase in a geometrical ratio ; in some cases there is a fixed population from year to year; in some cases a species maintains its existence with the greatest difficulty, so that its numbers decrease in each generation. We have now to consider what is the relation between this actual output of life and that 
discriminative death which the theory of Natural Selection presupposes.

We cannot doubt for one moment that in certain cases the increase of animals and plants is sometimes enormous. This phenomenon is most obvious in connection with animals or plants which have immigrated into a country where the conditions are favourable to their well-being. The wild bees which now exist in millions in New Zealand are the offspring of two or three hives, which were once kept in the rooms of Cotton, of Christ Church, Oxford, and were taken over by him when he went to New Zealand with Bishop Selwyn. Some years ago fifty sparrows were sent to the same colony in the hope that they would increase and multiply and keep in check the insects which were so troublesome to the agriculturist. They have increased to an enormous extent, but they have changed their food; and the farmer has found in them foes even more terrible than blight or caterpillar. The sweet-briar, taken by a missionary to his Australian home, has flourished in a surprising manner, turning a cleared farm into an impenetrable thicket, and has to be torn out with cartropes and teams of horses. A Scotch emigrant took with him to Australia a thistle in a flower-pot. It was carefully transferred to the soil, and its growth was affectionately watched by the exiles from Caledonia. But soon the land was covered with monstrous thistles, which defied attempts at extermination.

"Columbus, in his second voyage, left a few black cattle at St. Domingo, and these ran wild and increased so much, that twenty-seven years afterwards herds of from 4000 to 8000 head were not uncommon. Cattle were afterwards taken from this island to Mexico, and to other parts of America, and in 1587 , sixty-five years after the conquest of Mexico, the Spaniards exported 64,350 hides from that country and 35,444 from St. Domingo. . . . In the pampas of Buenos Ayres there were, at the end of the last century, about twelve million cows and three million horses, besides 
great numbers in all other parts of America where open pastures afforded suitable conditions. Asses, about fifty years after their introduction, ran wild and multiplied so amazingly in Quito, that the Spanish traveller Ulloa describes them as being a nuisance. They grazed together in great herds. . . Hogs were turned out in St. Domingo by Columbus in 1493, and the Spaniards took them to other places where they settled, the result being that in about half a century these animals were found in great numbers over a large part of America, from $25^{\circ}$ north to $40^{\circ}$ south latitude. More recently, in New Zealand, pigs have multiplied so greatly in a wild state as to be a serious nuisance and injury to agriculture. To give some idea of their numbers, it is stated that in the province of Nelson there were killed in twenty months 25,000 wild pigs." (Wallace. Darrvinism. pp. 27-28.)

"Several of the plants, such as the cardoon and a tall thistle, which are now the commonest over the wide plains of La Plata, clothing square leagues of surface almost to the exclusion of every other plant, have been introduced from Europe."-(Origin of Species. p. 5r.)

In the cases which have just been cited the principal reasons for the increase, no doubt, are-a not too largelystocked country, plenty of food, a suitable climate, and absence of enemies. It is obvious in these cases that external conditions are favourable to the race, and that it could gain no advantage by being modified, and that therefore the transformation of species by Natural Selection cannot take place in this connection.

But sometimes, without any transportation to another country, there comes a great "wave of life." Circumstances suddenly become favourable to some quickly breeding species, and even in the course of one season the earth seems to teem with them. In this case also it is obvious that so long as there is a realised tendency to increase in a geometrical ratio, nothing like Natural Selection can take place. But the period during which this "wave of life" continues to flow in is generally limited, and we might almost suppose that there were laws of nature at work to arrest the abnormal fertility. 
Sooner or later a great destruction comes upon this flourishing race-a destruction which is certainly not discriminative, but which often threatens the species with extermination. Mr. Hudson lays down the principle that this great output of life may seem to favour the race for a time, but that it is unfavourable in the long run; since the short-lived undue predominence of a species is invariably followed by a long period of depression.*

This general principle may be illustrated by several examples. One cause is the alternation of frost and warm weather. Dr. B. Altum, speaking of mice, remarks that a warm winter, or a winter which steps in gradually, makes them multiply in menacing proportions, notwithstanding all their enemies, of which he gives a long list. But alternations of frost and warm weather destroy them in numberless quantities. "One single, sudden change can reduce thousands of mice to the number of a few individuals." +

"The contagious diseases which continually visit most animal species destroy them in such numbers that the losses often cannot be repaired for many years, even with the most rapidly multiplying animals. Thus, some sixty years ago, the soustiks suddenly disappeared in the neighbourhood of Sarepta, in South-eastern Russia, in consequence of some epidemics; and for years no sousliks were seen in that neighbourhood. It took many years before they became as numerous as they formerly were."-(A. Becker. Bulletin de lin Société des Naturalistes de Moscou, 1889. p. 625.)

"Large bags (of grouse). can only be made during prolific years, and, unfortunately for sportsmen, such fecundity is invariably followed by disease. According to the tracts of heather on any given moor, or, in other words, to the food supply, so will the number of grouse it carries be regulated. Thus, one moor may have one bird to the acre, whilst another has four. The balance of nature would seem to be preserved so long as local capacity is not exceeded, but, so soon as this occurs, disease, as the inevitable result, sets in.

* The Naturalist in La I'lata. p. 60 .

+ Ninetecuth Century. wol. wxirii., p. 717. 
And it may be taken as an axiom of sport that excessive preservation always means ultimate loss. . . . When the 'vermin' are exterminated by trapping, there is a greater abundance of every species of game. But at what cost? At ever-recurring but certain years of disease, and the almost total extinction of the moor game. At these times dead and dying birds may be picked up everywherebirds with lustreless plumage, and completely emaciated. When in the last stages of disease the birds come far down the moorlands, below the heather belts, and where sound, hearty grouse are never seen."-(J.W. Graphic. vol.xxxiv., p. 4IO.)

Another result of a great output of life is that, where enemies are at hand, they hasten to the slaughter, and threaten the unusually prolific species with extinction. Mr. Hudson tells us how an enormous development of life among the mice was succeeded by an enormous influx of enemies, of every kind and from every quarter.

"In the summer of $1872-3$, in La Plata, there was plenty of sunshine with frequent showers: so that the hot months brought no dearth of wild flowers as in most years. The abundance of flowers resulted in a wonderful increase of humble-bees. It was an ideal condition for the mice, which increased enormously. . . . But with the increase, their slaughter also commenced. The dogs subsisted almost exclusively on them ; the fowls also, from incessantly pursuing and killing them, became quite rapacious in their manner; whilst the Sulphur-tyrant birds and Guira cuckoos preyed on nothing but mice. The domestic cats grew wild in order that they might join the feast. Foxes, weasels and opossums fared sumptuously. Even the common armadillo brought the weight of its armoured body to bear upon them. In the autumn of the year countless numbers of storks and of short-eared owls made their appearance to join in the slaughter. . . The winter had been one of continued drought, and with the disappearance of their food and cover the mice had ceased to be."-(The Naturalist in La Plata. pp. 50-66.)

Prince Kropotkin points out how great are the disabilities even of survivors in such connection :-

"Those who survive a famine, or a severe epidemic of cholera, or small-pox, or diphtheria, such as we see them in uncivilised countries, are neither the strongest, nor the healthiest, nor the most intelligent. No progress could be based on those survivals-the 
less so, as all survivors usually come out of the ordeal with an impaired health, like the Transbaikalian horses just mentioned, or the Arctic crews, or the garrison of a fortress which has been compelled to live for a few months on half rations, and comes out of its experience with a broken health, and subsequently shows a quite abnormal mortality. All that Natural Selection can do in times of calamities is to spare the individuals endowed with the greatest endurance for privations of all kinds. So it does among the Siberian horses and cattle. They are enduring; they can feed upon the Polar birch in case of need; they resist cold and hunger. But no Siberian horse is capable of carrying half the weight which a European horse carries with ease; no Siberian cow gives half the amount of milk given by a Jersey cow, and no natives of uncivilised countries can bear a comparison with Europeans. They may better endure hunger and cold, but their physical force is very far below that of a well-fed European, and their intellectual progress is despairingly slow. 'Evil cannot be productive of good,' as Tchernyshevsky wrote of late in a remarkable essay upon "Darwinism." "-(Nineteenth Century. vol. xxviii., pp. $717-8$.)

It cannot be supposed that animals so debilitated will have even a normal strength to resist other disabilities, but apart from this consideration we must further bear in mind how very improbable it is that animals in this condition would possess their usual fecundity. Can we suppose for one moment that under conditions like these the mandate of Natural Selection can be fulfilled?

In the next place, we have to consider the case in which, owing to the balance of life between different races, the population remains stationary, or at any rate tolerably uniform from generation to generation. This is not increase in a geometrical ratio, although, as we have seen, Mr. Wallace speaks of a stationary population and a progressive increase as if they were not incompatible. But with respect to a uniform population, it may be observed that there is a great difference in different species in the output of life and the consequent destruction which occurs in each generation. Shall we, then, be justificd in supposing that the selective power of the destruction is 
in direct ratio to the output of life? Mr. Fiske evidently supposes that it is so, for he says:-

"A single cod-fish has been known to lay six million eggs within a year. . . With the cod-fish, as with animal species in general, the numbers during many successive generations oscillate about a point which is fixed, or move but slowly forward or backward. Instead of a geometrical increase with a ratio of six millions, there is practically no marked increase at all. Now this implies that out of the six million embryo cod-fish, a sufficient number will survive to replace their two parents, and to replace a certain small proportion of those contemporary cod-fishes who leave no progeny. Perhaps a dozen may suffice for this, perhaps a hundred. The rest of the six million must die. . . But in maintaining the characteristics of a race, only those individuals can be counted who produce offspring. It is obvious, then, that each species of organisms, as we know it, consists only of a few favoured individuals selected out of countless multitudes who have been tried and rejected as unworthy to live. No selection that is exercised by man compares in rigour to this. It is somewhat as if a breeder of racehorses were to choose, with infallible accuracy of judgment, the two or three fleetest out of each 100,000 , destroying all the rest, that the high standard of the breed might run no possible risk of deterioration. In such a rigorous competition as this, no individual peculiarity can be so slight that we are entitled to regard it as unimportant." (Darwinism and other Essays. pp. I2-I4.)

But it must not be taken for granted that a rigorous competition like this is realised in the case of the six million eggs of one cod-fish. For in the first place it can hardly be supposed that each of these six million eggs will be fertilised and become a fish at all. Moreover in the case of the fertilised egg and of the young fry "there must be much fortuitous destruction, which can have little or no influence on the course of Natural Selection."* But not only is it impossible to conceive of a strict selection, a discriminative destruction in the case of the six million eggs of a single cod-fish, we must further remember that there is a distinctly obvious correlation between the numbers born and the risk to life. Where there is a great 
liability to incur danger, there is a great output of life to meet the demand. This principle is fully recognised by Mr. Darwin :-

"The real importance of a large number of eggs or seeds is to make up for much destruction at some period of life; and this period in the great majority of cases is an early one. If an animal can in any way protect its own eggs or young, a small number may be produced, and yet the average stock be fully kept up; but if many eygs or young are destroyed, many must be produced, or the species will become extinct."-(Origin of Species. p. 52.)

The only chance of survival for the species at large is an output of life sufficient to meet the risk of death. "There shall the fire devour thee; the sword shall cut thee off, it shall eat thee up like the cankerworm: make thyself many as the cankerworm, make thyself many as the locusts."* That seems to be the principle on which nature has had to act, and in the presence of such necessity the elimination of the worst or the sole preservation of the best, taken in connection with much previous accidental destruction, would almost inevitably exterminate the race. At the least, it is obvious that the great output of life in each generation effects the preservation of a race rather than the transmutation of species.

Lastly, we have to consider the case in which it is impossible for a given species to maintain its position in relation to population. Mr. Darwin explains the phenomenon thus :-

"Rarity is the attribute of a vast number of species of all classes in all countries. If we ask ourselves why this or that species is rare, we answer that something is unfavourable in its conditions of life. . . If the conditions had gone on, however slowly, becoming less and less favourable, the species would certainly have become rarer and rarer, and finally extinct."-(Origin of Species. ph. 294-5.)

* Nahum. iii., 15. 
In such cases a rigid application of the principle of Natural Selection would either be impossible or fatalimpossible, because favourable variations would not be likely to occur among so few ; fatal, because the isolation of favourable variations by the destruction of the rest would lead to the extinction rather than the transmutation of the race.

The tendency of animals and plants to increase in a geometrical ratio is not accompanied with a discriminative destruction such as the theory of Natural Selection requires. Where the tendency of such increase is realised, no change can take place through Natural Selection, because it would not be of any advantage for such a prosperous race to be modified at all. In all those cases in which an enormous destruction follows upon a periodical enormous output of life-the destruction is not discriminative. In the case of a fixed population there will be as many deaths as births-there will not be any increase in a geometrical ratio at all. If there is an occasional "wave of life," it is met by specially heavy losses, through sudden change of temperature, through diseases, through a crowd of enemies which hasten to avail themselves of the unwonted feast. In those instances in which enormous fertility in each generation is the rule-as in the case of the cod-fish-the destruction is not discriminative, but the output of life is correlated with the loss of life. But if this is so, the enormous fertility of organic life lends no assistance to Natural Selection, taking that term in its strict and technical sense. Vain is the tendency which is seldom or never realised; vain is the output of numbers, if the destruction is not discriminative; vain is the hypothesis of discriminative destruction in all those cases in which it would be fatal to apply it. Are we not justified in saying, that while the tendency to increase in 
a geometrical ratio is sometimes realised under very favourable circumstances, it is a baseless assumption to suppose that it will be often realised; and that while a great output of life often occurs, it is a baseless assumption to assert that it must be followed by a discriminative destruction?

\section{(b) BLINDFOLD DEATH.}

"Gaunt: I thank my liege, that, in regard of me, He shortens four years of my son's exile: 13ut little vantage shall I reap thereby; For, ere the six years, that he hath to spend, Can change their moons, and bring their times about, My oil-dried lamp, and time-bewasted light, Shall be extinct with age, and endless night; My inch of taper will be burnt and done, And blindfold death not let me see my son." -(Richard II. Act i., sc. 3.)

After what has been said in the preceding section, we shall be justified in asserting that the enormous output of life which sometimes occurs in nature is not followed by that discriminative destruction which the theory of Natural Selection requires. Putting on one side the fact of the enormous fertility of organic life, we have now to consider how far the death which takes place in nature is discriminative: how far it is accidental, which in this connection means non-discriminative. Now, it is an axiom of the advocate of Natural Selection that there is and can be no such thing as accidental death. The logic of the theory demands for the animal world an-

". . . existence unexposed

To the blind walk of mortal accident."

-(Wordsworth. The Excursion. 
Mr. Wallace says:- "We must get rid of the idea that chance determines which shall live and which die."** This requirement is certainly not met by the actual phenomenon of destruction as it occurs in nature. There we find a large amount of accidental death in the sense of indiscriminative, non-selective death. This Mr. Darwin admits. "With all beings there is much fortuitous destruction which can have little or no influence on the course of Natural Selection." $†$

When John of Gaunt thanks the King because his son's exile has been shortened by four years, he foresees that he will not be the gainer thereby, because before the remaining six years can have run their course he will be dead, and a blindfold death will not let him see his son; which means, in plain English, that death will not act in accordance with his wishes, and save his life in order that he may see his son once more. In this sense, the death which takes place in nature is sometimes blindfold: it does not act in accordance with the principles of Natural Selection. There is a great deal of death which takes place quite irrespective of the question as to which is best or worst - the best fitted or the least fitted to live.

We find illustrations of the action of an indiscriminative death in the case of the young, the immature and the mature. With respect to the young especially does this remark apply. The issue of their struggle for life might be expressed in the language of Leontes concerning the infant found on the sea-shore:-

". . . commend it strangely to some place,

Where chance may nurse or end it."

- (Winter's Tale. Act ii., sc. 3).

* Darainism. p. 123.

+ Origin of Species. p. 68 . 
Dr. Weismann testifies to the enormous amount of destruction which takes place among the young:-

"The young of birds are greatly exposed to destructive agencies. . . In the majority of birds, the egg, as soon as it is laid, becomes exposed to the attacks of enemies; martins and weasels, cats and owls, buzzards and crows are all on the look out for it. At a later period the same enemies destroy numbers of the helpless young, and in winter many succumb in the struggle against cold and hunger, or to the numerous dangers which attend migration over land and sea, dangers which decimate the young birds."(Weismann. Essays upon Heredity. p. 12.)

"Even the eggs of our most powerful native bird of prey, the golden eagle, which all animals fear, and of which the eyrie, perched on a rocky height, is beyond the reach of any enemies, are frequently destroyed by late frosts or snow in spring, and at the end of the year in winter the young birds encounter the fiercest of foes, viz., hunger."-(Weismann. Essays. p. I2.)

We have the authority of Mr. Darwin for asserting that a great deal of this destruction is non-selective.

"A vast number of eggs or seeds are annually devoured. Yet many of these eggs or seeds would perhaps, if not destroyed, have yielded individuals better adapted to their conditions of life than any of those who happened to survive."-(Darwin. Origin of Species. p. 68.)

Mr. Henslow speaks to the same effect in his Floral Structures.

"The greatest difficulty I have always felt in the idea that a plant was selected because it had some floral structures more appropriate than others, lay first in the fact that the principal period of the struggle for life takes place in the seedling stage, before any varietal and specific characters have appeared; and unless there were a large number of the seedlings which would ultimately bear the improved flower, or else a superior constitutional vigour be guaranteed to be correlated with the particular varietal characters to be preserved, these alone could have nothing to do with the survival of the fittest."-(The Origin of Floral Structures through Insect and other Agencics. p.333.) 
Death often takes place among the individuals not yet mature, under conditions in which it cannot produce the result anticipated by the theory of Natural Selection.

"When the mango fruit is swelling in late April, but still unripe, it is dreadful to see the utter destruction entailed by a large troop of monkeys. It is not what they actually consume, but the immense quantity which they spoil by recklessly biting hundreds and thousands of unripe fruit and throwing them discarded upon the ground." -(Baker. Wild Beasts and their Ways. vol. ii., p. 359.)

The same fate of indiscriminative death also takes place in connection with the mature.

"A vast number of mature animals and plants, whether or not they be the best adapted to their conditions, must be annually destroyed by accidental causes, which would not be in the least degree mitigated by certain changes of structure or constitution, which would in other ways be beneficial to the species."-(Origin of Species. p. 68.)

The element of accident must enter largely into the struggle between animals of prey and their victims.

"The excessive voracity of the pike has long been proverbial. No animal substance which it can swallow, and which is capable of being digested, seems to be unpalatable to it. . . . A large pike often takes possession of a particular hole in the bank of a river, from which it issues to seize any creature that may pass."(Chambers' Encyclopicedia. Ist ed.)

Speaking of the Wari, or wild pigs (Dicoteles tajaçu), found in Nicaragua, Mr. Belt says :-

"These Wari go in herds of from fifty to one hundred. They are said to assist each other against the attacks of the jaguar, but that wary animal is too intelligent for them. He sits quietly upon a branch of a tree until the Wari come underneath; then jumping down, kills one by breaking its neck; leaps up into the tree again, and waits there until the herd depart, when he comes down and feeds on the slaughtered Wari in quietness."-(The Naturalist in Nicarrgua. p. 3o.)

It cannot be that in such circumstances the jaguar picks out the worst, or probably has any reason for selecting one more than another. 
"It is clear that in such animals as insects, we can only speak figuratively of normal death, if we mean by this an end which is not due to accident. In these animals an accidental end is the rule, and is therefore, strictly speaking, normal."-(Weismann. Essays. p. 22.)

In these cases we have no right to assume that death has produced results equivalent to those of a discriminating choice. The theory requires that there should be strict competition between all the members of a species; but in order that this strict competition should take place it is necessary that the trial should be made under exactly the same conditions. This point is brought out very distinctly by Mr. Fiske in the following passage:-

"Who can doubt that antelopes are so fleet, only because all but the fleetest individuals are sure to be overtaken and eaten by lions? Protected from the lions, a thousand generations might well make them as lazy and clumsy as sheep."-(Darvinism and other Essays. p. 15.)

But what are the facts of the case?

"The lion often springs upon his prey by a sudden bound, accompanied with a roar ; and it is said if he fails in seizing it, he does not usually pursue, but retires as if ashamed. It is certain, however, that the lion also often takes his prey by pursuing it, and with great perseverance. The animal singled out for pursuit may be swifter of foot than the lion, but great power of endurance enables the lion to make it his victim."-(Chambers' Ency.)

Here the lion does not catch the hindmost of a herd that is the slowest, but it singles out one individual and follows it so persistently that the victim is caught in spite of its speed.

Sometimes, the bird or beast of prey is so much swifter than its victim that it is sure to capture the animal which it selects for pursuit.

"In his work on Game Preservers and Bird Preservers, Mr. Morant tells us that the celerity of the falcon is so tremendously in excess of that of the fleetest grouse that all differences in speed among the 
latter birds utterly vanish. The strongest winged and most vigorous moorcock, if once espied in the air by the enemy, has practically no greater chance of escape than a feeble and sickly bird. On the contrary, the boldest and most energetic grouse-who may fairly be assumed to be, as a rule, the healthiest-will fall victims more frequently than their weaker brethren, from the mere fact that they are more active and venturesome, and hence more likely to be on the wing. The effects of the co-existence of falcons and grouse in any country will be, therefore, not the development of a form of the latter better adapted for rapid flight, and ultimately, in the course of many generations, endowed with longer and more pointed wings, but merely a thinning of numbers which will tell equally upon the strong and the weak, and which in some cases may even give an advantage to the latter. This argument of Mr. Morant's concerning the influence of the falcon upon the development of the grouse appears to us applicable not merely to this individual instance, but to every case where a bird or a beast has to struggle for existence against enemies greatly its superiors in speed, in strength, or in general resources. Slight increments of swiftness or force, trifling improvements in offensive or defensive arms, would be absolutely thrown away under such circumstances, however valuable they might be as against an enemy but slightly superior to the original form. Hence there are numbers of cases where it must become questionable how, on the principle of Natural Selection, advances in these important directions are to be effected."-(The Quarterly Journal of Science. vol. viii., p. 455).

Then it is very difficult to suppose that over a large area the test of any one disability would be applied so rigidly to every individual as to secure the survival of the best able to endure. It is said that those who live show themselves best fitted to live by the very fact of their survival. But it is difficult to believe that the test applied is as exact as when a race is run. For even in the case of the advent of extreme cold, there may be some, that were not the hardiest, which would survive because they happened to occupy a sheltered spot; while others, far more hardy, might be in the most exposed position. In any struggle, in which two members of a persecuted species were pitted against two enemies, if one of them escaped and the other was caught you could 
not say that the one that escaped was the fleetest, unless you knew the two enemies were exactly equal in their swiftness. In short, when any given test is applied we can be certain that the fittest will survive only on the condition that the trial takes place under exactly similar circumstances, and in many instances it would be very difficult to prove that this was the case. Accident, under whatever form it may assume, is evidently opposed to the principle of discriminative competition.

"If Hercules and Lichas play at dice Which is the better man, the greater throw May turn by fortune from the weaker hand:

So is Alcides beaten by his page;

And so may I, blind fortune leading me, Miss that, which one unworthier may attain, And die with grieving."

-(Merchant of Venice. Act ii., sc.. .)

And yet Mr. Wallace, after reviewing all the phenomena of death in the natural world, tells us that we must divest our minds of the idea of accidental death.

"We must think over all the causes of destruction to each organism,--to the seed, the young shoot, the growing plant, the full-grown tree, or shrub, or herb, and again the fruit and seed; and among animals, to the egg or new-born young, to the youthful, and to the adults. Then, we must always bear in mind that what goes on in the case of the individual or family group we may observe or think of, goes on also among the millions and scores of millions of individuals which are comprised in almost every species; and must get rid of the idea that chance determines which shall live and which die."-(Daravinism. pp. 122-3.)

There is a sense, no doubt, in which there is no such thing as accidental death. The theologian who realises the immanent presence of God in the universe may assert that "there is a special providence in the fall of a sparrow." But when Mr. Wallace says that there is no chance in the destruction which is in nature, the observation has no application to the present discussion-unless it means that all destruction is discriminative, which it certainly is not. 
We have seen that Natural Selection has been variously interpretated as the survival of the fittest only, or as the elimination of the least fit. But whichever interpretation you adopt is not justified by the results of the action of death in the natural world. The facts of the case do not justify us in contending that the struggle for existence brings about even the elimination of the least fit.

"Seedlings also," says Mr. Darwin, "are destroyed in vast numbers by various enemies. For instance, on a piece of ground, three feet long and two wide, dug and cleared, and where there could be no choking from other plants, I marked all the seedlings of our native weeds as they came up, and out of the 357 no less than 295 were destroyed chiefly by slugs and insects." Commenting on which passage, Mr. G. W. Bulman asks :- "Is there, then, anything to show that the 295 plants destroyed were less vigorous than the 62 survivors? There is no evidence or $\dot{\alpha}$ priori argument to prove that slugs and insects choose for food the less vigorous seedlings. Putting oneself in their place-the only method available in the absence of experimental knowledge of their tastes-we should say the more vigorous and better-grown would be chosen."*

But if we are not at liberty to assume that the elimination of the worst will take place, how much less can we be certain of the survival of the fittest! This, however, is not all. It sometimes happens that the struggle for existence produces the destruction of the best. The phrase, Aux bons meschet-il, embodies the conviction that sometimes, at any rate, the best men have the worst luck. There is safety sometimes in mediocrity." We are-

"Happy, in that we are not over-happy;

On fortune's cap we are not the very button." -(Hamlet, Act ii., si. 2.)

* The National Review. vol. xviii., pp. 6o-r. 
If this principle can be shown to be true in the natural world, it contradicts one of the axioms of the theory as laid down by Mr. Wallace :-

"Whatever is really the fittest can never be destroyed by Natural Selection, which is but another name for the survival of the fittest." -(Darwinism. p. 425.)

A few illustrations will serve to show that the struggle for existence sometimes leads to the destruction of the best and fittest. It is not credible, for example, that any animal feeding on nuts would carefully abstain from taking the best, or that it would conscientiously begin to eat the worst first, so that its posterity might reap the advantage in a finer growth of fruit. An evidently careful and genial student of nature tells us that the contrary took place with a red squirrel which he narrowly watched.

"One of these was the saucy red squirrel. He glided along the branches like a sunbeam, and constituted our dark-eyed miracle of the forest. He would watch our approach, then glicle up the high hazel and survey us from above. Then he perked his ears and chattered, and once let down a full-ripe filbert close to our feet. From examining this we found how he came at its contents, and often watched him in the process. He would sit upon his haunches, half-hidden in the foliage, holding a cluster of nuts. These he held in his forepaws, and would presently abstract one, allowing the rest to drop. After adroitly securing the nut, he would quickly rasp away the small end, and, having made a hole, would then insert his foreteeth and split the shell. He only ate the largest and soundest nuts, and was careful to pare off every particle of the brown skin of the kernel before beginning to eat." -(The Graphic. vol. xxxvi.,p.319.)

M. de Lanessan cites illustrations to the same effect.

"None of you will be ignorant of the terrible havoc which an unseasonable cold produces on fruit trees. The least hoar-frost occurring at the time when the shoots of the vine begin to expand is sufficient to destroy that year's vintage. An intense frost occurring at the same time would decree the death of the plant itself. Rains too prolonged would make the wheat to perish in the earth- 
too hot a sun would kill the young plant. IVhat will be the consequences of these accidents? Are we able to apply to this case the law of Darwin, and to admit that in the struggle for existence which the vegetable sustains against the acciclents of external conditions-that is to say, against winds, rains, cold, heat-the result will always be the preservation of the strongest and fittest? I do not think so. The intensity of the derangements produced by these agents varies indeed, it is true, in a certain measure with the constitutional vigour of the vegetables attacked; but as the result of different conditions, it may very well occur that the most vigorous plants will be killed, while the feeblest resist. In the case of the vine, for example, as the stems of the most vigorous are those whose buds open first, they are those also which the spring frosts will kill."(La Lutte pour l'Existence ct l'Association pour la Lutte. pp. I2-I3.)

"Can we affirm," he elsewhere says, "that the most robust and best armed plants are also those which have the most chance of escaping the attacks of the different animals just mentioned? By no means. It is the accident of circumstances which exercises on the fate of vegetables with respect to herbivorous and granivorous animals the preponderating influence. This vigorous plant will be devoured by the caterpillars, while another of the same sort, much more feeble, will escape this danger. The first will have no offspring; the second, on the contrary, will perpetuate its race." - $(p ., I 6$.

The same argument applies to animals no less than to plants. Whether Mr. Darwin's theory of Sexual Selection be sustained or not, there are certain broad facts which can scarcely be denied. Where there is a struggle between rivals, the strongest will win in the fight, barring accidents; and whether or not it be true that "none but the brave deserve the fair," the "brave" who wins the battle also wins a spouse. Hence it follows that among the expectant males which are looking forward to a new season of love and courtship, the most vigorous will win the day, and will carry off the more vigorous and better-nourished females who are ready to enter into courtship before their 
weaker or less healthy sisters.* Strength on the one hand, and precocity on the other, are wedded together. Now, it is supposed that by this means the most vigorous adults produce the most vigorous offspring of the year. The evidence quoted in support of this view goes to show that the first brood is stronger than the second, but it does not necessarily follow from this that the offspring of a less precocious female will not be as vigorous as the offspring of those who are the first to wake to the dream of love. But we will suppose, for the sake of argument, that it is so- that the earliest broods are the strongest and the best in every way. Then it may be well to take note that it is just these broods which are liable to be destroyed through the agency of a fickle and uncertain climate. The love-making of the North-American grouse commences habitually before the snow has completely disappeared. This affords no difficulty if there is no return of wintry weather; but a few days of exceptional warmth are sometimes followed by a return of cold northern blasts, accompanied by snow. The result is fatal to the already hatched chicks, and no less to the as yet unhatched eggs; so much so, that in one season there were three or four coveys of quail within a radius of sixty miles, where thousands had been the year before. Maternal solicitude avails nothing in such a catastrophe, as is brought home to us most pathetically by the story of the frozen bird found sitting on her frozen eggs. $\dagger$

Where the destruction is not so universal, where only the most precocious suffer, it is obvious that if there is any force in the argument for their superiority, a treacherous spring may bring about not the survival, but the destruction, of the best and fittest.

* Darwin. Descent of Man. p. 213.

† The Ninctenth Century. vol. xixiii., Hp. 60I-2. 
Gregariousness in cattle, combined with the struggle for existence, tends, according to $\mathrm{Mr}$. F. Galton, to check independence of character.

"We have seen that it is the cattle who graze apart, as well as those who lead the herd, who are recognised by the trainers of cattle as gifted with enough independence of character to become fore-oxen. They are even preferred to the actual leaders of the herd, because, as they dare to move alone, their independence is the more conspicuous. Now the leaders are safe enough from lions, because their flanks and rear are guarded by their followers; but each of those who graze apart, and who represent the superabundant supply of self-reliant animals, have one flank and the rear exposed, and it is precisely these whom the lions take. Looking at the matter in a broad way, we may justly assert that wild beasts trim and prune every herd into compactness, and tend to reduce it into a closely united body with a single well-protected leader. The development of independence of character in cattle is thus suppressed far below its healthy natural standard by the influence of wild beasts, as is shown by the greater display of self-reliance among cattle whose ancestry, for some generations, have not been exposed to such danger."-(Macmillan's Magazine. vol.xxiii.,p.356.)

But all this is perfectly irregular from the point of view of the survival of the fittest, and the advocate of the theory ought to be as much surprised at such a phenomenon as the Northern farmer was when he found that he had to die, while senseless old Jones and thriftless young Robins were permitted to live.

Do godamoighty knaw what a's doing a-taäkin' o' meä? I beänt wonn as saws 'ere a beän an' yonder a pëä ;

An' Squoire 'ull be sa mad an' all-a' dear a' dear!

And I'a managed for Squoire coom Michaelmas thutty year.

A mowt 'a taäen owd Joänes, as 'ant a aäpoth o' sense, Or a mowt 'a taäen young Robins--a niver mended a fence." -(Tennyson. The Northern Farmer. Old Style.)

The evidence cited above will surely afford some ground for supposing that it is not an absurd superstition to believe that there is such a thing as accidental death. Mr. Huxley-as we have seen in a passage quoted on page 27-is indignant that Mr. Darwin "should have been 
charged with having attempted to reinstate the old pagan goddess, Chance. It is said that he supposes that the fittest survive the chances of the struggle for existence." It is sufficient for the argument which has been urged, that death in nature should be to some extent blindfold and indiscriminative, so far as the survival of the fittest is concerned; but apart from all these considerations, the issue between death and life is often a matter of accident. In the one case the course of the victim happens to miss, and in the other case to encounter, the course of some destructive agency. That risk has been abundantly proved to exist with regard to the organic world. If it is superstitious not to shut our eyes to the most obvious facts of experience and not to argue as if they did not exist, there are many who would feel honoured by being designated by that opprobrious epithet.

Mr. Wallace, who pleads that we must get rid of the idea of accidental death, asserts that, if all animals were exactly alike, death would be accidental. But the facts show that a great deal of death is accidental, though organisms vary so greatly. Those who are fond of repeating the dictum that survivors, by the mere fact of their survival, prove themselves to be the "fittest," would do well to amend their statement, and to assert that such survivors are either the fittest or the most fortunatewhich is a different affair altogether.

(c) "ON the Whole" and "IN the LONG RUN."

"[Bi]ologists who chase

[A halting theory] through time and space." - COWPER (slightly altered).

If there is any force in the arguments which have been used in the preceding sections, it is obvious that there is 
not in nature that "power of selection" which is the very essence of the theory of Natural Selection. But it would be unjust to dismiss the consideration of this subject without giving a careful consideration to the remarkable contention, that what is not accomplished in a limited space or time may be confidently anticipated to take place on the whole and in the long run.

Mr. Darwin contends that on his hypothesis the variations which take place in nature must be slight, and that the validity of his theory depends on this assumption. At the same time he recognises that there is a great amount of variation displayed by the individuals of a species at the present day. But instead of accepting this result as a proof of the weakness of his theory, he appeals, from the narrow experience of the present, to the large results of all time.

"On the theory of Natural Selection we can clearly understand the full meaning of that old canon in Natural History, Natura non facit saltum. This canon, if we look to the present inhabitants of the world, is not strictly correct; but if we may include all those of past times, whether known or unknown, it must on this theory be strictly true."-(Origin of Species. p. I66.)

One can hardly trust oneself to make any remark on this passage, for fear of incurring the charge of misrepresentation, but the statement seems to amount to this. That which is false of a part of the organic world becomes true if you take in the whole. It is as though you were to say: A portion of the population has red hair, it is not true to say that they have all dark complexions; but if you include the whole nation from its earliest history to the present day, it will be found "strictly true" that they are all dark-complexioned.

Speaking of the lapse of time, Mr. Darwin says :-

"The mere lapse of time by itself does nothing either for or against Natural Selection. I say this because it has been erro- 
neously asserted that the element of time has been assumed by me to play an all-important part in modifying species."

But this denial only extends to the hypothesis that "all the forms of life are necessarily undergoing change through some innate law." For he goes on at once to assert :-

"Lapse of time is only so far important-and its importance in this respect is great-that it gives a better chance of beneficial variations arising, and of their being selected, accumulated and fixed."-(Origin of Species. p. 82.)

Now, if the process of the transmutation of species by Natural Selection were always slow but, at the same time, sure in each generation, it is obvious not only that time would be required, but also that time would be successful in bringing about the desired change. But if, as we have seen, the conditions of life do not secure the necessary power of selection in each generation, how can a repetition of failures make an ultimate success?

Mr. Wallace uses the same argument with respect to accidental death.

"Although in many individual cases death may be due to chance rather than to any inferiority in those which die first, yet we cannot possibly believe that this can be the case on the large scale on which nature works."-(Darwinism. p.I22.)

On what principle, we venture to ask, does Mr. Wallace assume the universality of a discriminative death-because nature works on so large a scale? Whence have the observers of nature obtained their evidence of accidental death if not from every sphere of organic life, from the rapidly-increasing aphis to the slow-breeding elephant and man? Is it because spheres of nature remain to be explored? But surely we can only anticipate in unexplored spheres the action of the principles with which we are already acquainted in spheres which 
have been investigated. I fail to discover any principle which will justify those who recognise accidental death as a phenomenon of nature-however limited in its action-in saying that they cannot possibly believe that it will be the case on a great scale. There is but one intelligent explanation. It is a desperate effort to retain unaltered a preconceived opinion in spite of the most damaging evidence to the contrary.

Mr. Wallace further says :-

"Though the survival in individual cases may sometimes be due rather to accident than to any real superiority, yet we cannot doubt that in the long run those survive which are the best fitted by their perfect organism to escape the dangers which surround them."

"The best organised, or the most healthy, or the most active, or the best protected, or the most intelligent, will inevitably, in the long run, gain an advantage over those which are inferior in these qualities; that is, the fittest will survive, the fittest being, in each particular case, those which are superior in the special qualities on which safety depends."-(Darroinism. p. IO3, p. I23.)

Mr. Wallace says, "though the survival in individual cases may be due to accident." But does this fairly represent the fact that the great majority of deaths in each generation takes place in early life before the power of selection can possibly come into play? He says that "the fittest will survive." We have already seen how his assumptions on this point are contradicted in detail by our actual experience. No mere repetition of our experience can "in the long run" produce an entirely different result. There must be a new heaven and a new earth, and an entirely different condition of organic life, if future destruction is to be altogether discriminative. But on what principle can we assume that this will be the case? Such statements simply amount to the reiteration of the logical requirements of the theory in opposition to all our experience. Mr. Wallace has no ground for eliminat- 
ing the element of accidental death; still less for laughing it to scorn as an idle chimera. In this connection he cannot be justified in-

\section{". . . taking change and chance \\ With laugh on laugh of triumph."}

-(Swinburne. The Sisters).

Even if the power of selection were sure in its action as far as it went, so that the fittest in each generation always survived, the process of transmutation might still, it is admitted, take a great time to accomplish. But the conditions may be such as to require a comparatively speedy transmutation. And this is possible without assuming any great cataclysmal change in external conditions. The power of attaining sufficient modification ultimately would avail little, if immediate modification was required by the necessity of the case. When Fred Vincy finds himself unable to pay the money for the bill to which Mr. Garth had put his name, and which was sorely needed for Alfred's premium, he said, "I shall certainly pay it all, Mrs. Garth-ultimately." "Yes, ultimately!" said Mrs. Garth, who, having a special dislike to fine words on ugly occasions, could not now repress an epigram:"But boys cannot well be apprenticed ultimately: they should be apprenticed at fifteen."* Equally vain would be the power of selection to modify an organism ultimately, if an immediate adaptation were necessary for the continuance of the species. 


\section{CHAPTER V.}

THE THEORY COMPARED WITH THE REALITY

(continued).

\section{(d) Conpetition Motheied by CO-Opekation.}

"None of us liveth to himself, and no man dieth to himself."

"As we have many members in one body, so we being many are one body.

"And whether one member suffer, all the members suffer with it; or one member be honoured, all the members rejoice with it."-PAUL.

THE theory of Natural Selection demands that there should be the strictest and the keenest competition between the individuals of the same species and the individuals of different species, and between species and species.

"There must in every case be a struggle for existence; either one individual with another of the same species, or with the individuals of distinct species."-(Darwin. Origin of Species. p. 50.)

"Every species is for itself, and for itself alone: an outcome of the always and everywhere fiercely-raging struggle for life."(Romanes. The Scientific Evidences of Organic Evolution. p. 76.)

"As the species of the same genus usually have--though by no means invariably--much similarity in habits and constitution, and always in structure, the struggle will generally be more severe between them, if they come into competition with each other, than between the species of distinct genera." -(Darwin. The Origin of Species. p. 59.)

"The struggle for life--this bellum omnium contro omnes-is an indisputable and undeniable fact which we here accept in its widest relations."--(Oscar Schmidt. The Doctrine of Descent and Darruinism. p. 140.) 
This struggle is due, according to $\mathrm{Mr}$. Wallace, to the absence of co-operation, to the self-dependence and isolation of each individual. It is a struggle not in some vague sense of all against all, but in a most definitely personal and terrible manner of one against all and of all against one.

"We must consider why it is that Natural Selection acts so powerfully upon animals; and we shall, I believe, find that its effect depends mainly upon their self-dependence and individual isolation. There is, as a general rule, no mutual assistance between adults, which enables them to tide over a period of sickness. Neither is there any division of labour; each must fulfil all the conditions of its existence."-(Wallace. Contributions to Natural Selection. ph. $3 I T-I 2$.

"As the individual existence of each animal depends upon itself, those that die must be the weakest, the very young, the aged, and the diseased; while those that prolong their existence can only be the most perfect in health and vigour--those who are best able to obtain food regularly and avoid their numerous enemies. It is, as we commenced by remarking, a 'struggle for existence,' in which the weakest and least perfectly-organised must always succumb."-(Wallace. Contributions to Natural Selection. pp.32-33.)

"The closer the kindred of the competitors, the more ardent is the struggle for the existence."-(Oscar Schmidt. The Doctrine of Descent. p. I43.)

Here, then, you have in the clearest possible statements the logical and consistent demands of the theory of Natural Selection. If the fittest is to survive, there must be a fair field and no favour. The theory would find all that it asks from nature if it could be shown that the bellum omnium contra omnes were indeed, as Dr. Oscar Schmidt affirms, "an indisputable and undeniable fact."

In testing this uncompromising statement, we may first of all ask:-What evidence has been adduced on this subject? The answer to this question is given by Prince Kropotkin, who points out that, while Mr. Darwin assumes that this competition is a fact in nature, he gives 
no illustration of its action between individuals of the same species-

"The idea which permeates Darwin's work is certainly one of real competition going on within each animal group for food, safety, and possibility of leaving an offspring. He often speaks of regions being stocked with animal life to their full capacity, and from that overstocking he infers the necessity of competition. But when we look in his work for real proofs of that competition we must confess that we do not find them sufficiently convincing. If we refer to the paragraph entitled 'Struggle for Life most severe between Individuals and Varieties of the same Species,' we find in it none of that wealth of proofs and illustrations which we are accustomed to find in whatever Darwin wrote. The struggle between individuals of the same species is not illustrated under that heading by even one single instance : it is taken as granted."

\section{The competition between closely allied animal species}

" . . . is illustrated by but five examples, out of which one at least (relating to the two species of thrushes) now proves to be doubtful. But when we look for more details in order to ascertain how far the decrease of one species was really occasioned by the increase of the other species, Darwin, with his usual fairness, tells us: 'We can dimly see why the competition should be most severe between allied forms which fill nearly the same place in nature; but probably in no case could we precisely say why one species has been victorious over another in the great battle of life." (Nineteenth Century. vol. xxviii., pp. 7I3-4.)

On the other hand, Prince Kropotkin has vividly described the effect upon his own mind and that of a fellow naturalist when the dictum of Natural Selection was brought to the test of actual experience.

"I recollect myself the impression produced upon me by the animal world of Siberia when I explored the Vitim regions in the company of so accomplished a zoologist as my friend Polyakoff was. We both were under the fresh impression of The Origin of Species, but we vainly looked for the keen competition between animals of the same species which the reading of Darwin's work had prepared us to expect, even after taking into account the remarks of the third chapter (p. 54 of the small edition). We saw plenty of adaptations for struggling, very often in common, against the adverse circumstances of climate, or against various enemies; and Polyakoff wrote many a good page upon the mutual dependency of carnivores, 
ruminants, and rodents in their geographical distribution. We witnessed numbers of facts of mutual support, especially during the migrations of birds and ruminants. But even in the Amur and Usuri regions, where animal life swarms in abundance, facts of real competition and struggle between higher animals of the same species came very seldom under our notice, though we eagerly searched for them. The same impression appears in the works of most Russian zoologists, and it probably explains why Kessler's ideas were so welcomed by the Russian Darwinists, whilst like ideas are not in vogue amidst the followers of Darwin in Western Europe."(Nineteenth Century. vol.xxviii., pp.341-2.)

The same writer warns us that we may sometimes be deluded by appearances as to the relative amount of competition within the limits of the same species, because the conditions in which animals are found in places thickly populated by men is no guide to their natural mode of life, when left to themselves.

"It is worthy of note that there are species living a quite isolated life in densely-inhabited regions, while the same species, or their nearest congeners, are gregarious in uninhabited countries. Wolves, foxes, and several birds of prey may be quoted as instances in point."-(Nineteenth Century. vol. xxviii., p. 348.)

"The wolf is said to be unsociable, yet he often hunts in packs; he has a cry which brings his brethren to join him in attacking large and powerful animals; and full-grown wolves, travelling together, go in single file, like Indians on the war-path, having been trained to this very practice when young by their mothers."-(Blackwood. vol. cliii., p. 263.)

No doubt there are cases in which it would seem that the individuals of the same species do compete with one another. But it should be borne in mind that among animals as well as among men there are very marked differences of disposition.

"Nature is variety itself, offering all possible varieties of characters, from the basest to the highest. Here you have the dominative swans; there the extremely sociable kittiwake gulls, among whom quarrels are rare and short; the prepossessing Polar guillemots, which continually caress each other; the egoist she-goose, who 
has repudiated the orphans of a killed comrade, and, by her side, another female who adopts anyone's orphans, and now paddles surrounded by fifty or sixty youngsters, whom she conducts and cares for as if they all were her own breed. Side by side with the penguins, which steal one another's eggs, you have the dotterels, whose family relations are so 'charming and touching' that even passionate hunters recoil from shooting a female surrounded by her young ones; or the eider-ducks, among which (like the velvetducks, or the coroyas of the Savannahs) several females hatch together in the same nest; or the lums, which sit in turn upon a common covey."-(Nineteent/ Century. vol. xxviii., p. 70o.)

Although the competition which is supposed to take place in nature is an important item in all its different manifestations in determining the stress of the struggle for existence, it is above all things important that the advocate of Natural Selection should establish the truth of his assertion that the individuals of the same species do compete and do not co-operate: for on that condition only could we be assured of the survival of the fittest. In considering the evidence for the fact of co-operation, as opposed to competition, among the members of the same species, we may remark that a great portion of the lives of many animals is spent either in the domestic circle or in the common life of the flock and of the herd: and a very little experience will enable us to come to the conclusion that mutual help, rather than supreme selfishness, is the law of their life.

First let us take some illustrations of parental care. A writer in Chambers' Journal says:-

"The assertion that 'self-preservation is the first law of nature,' is a cruel libel upon a large section of animal creation. To preserve and safeguard their offspring, many, if not most, creatures will risk and even sacrifice their lives. The more powerful animals might naturally be expected to do battle for their young; but it is surprising to find that the weakest and most timorous defy strength and forego fear on account of their progeny. That beings which flee from man and other despots, when the preservation of self only is concerned, should disregard personal danger, and fight till death 
when the safety of their helpless offspring is concerned, is indeed a marvel of nature. From the fragile bird to the mighty elephant, from the lowly snake to the highly organised chimpanzee, this devoted attachment of the mother for her young is seen to exist." -(Chambers' Journal. 5th series. vol. ii., p. 573).

In this respect the devotion to their young exhibited in the animal world may put to shame the conduct of some human fathers and mothers.

"Wisdom! to leave his wife, to leave his babes, His mansion, and his titles, in a place From whence himself does fly? He loves us not: He wants the natural touch: for the poor wren, The most diminutive of birds, will fight, Her young ones in her nest, against the owl. All is the fear, and nothing is the love: As little is the wisdom, where the flight So runs against all reason."-(Macbeth. Act iv., sc. 2.)

When we consider the devotion which the animal often shows to its offspring, there is a tinge of irony in the contention that there need not necessarily be antagonism between a starving mother and her children.

"If there is only a crust of bread in the house, and mother and children are starving, their interests are not the same. If the mother eats it, the children want it ; if the children eat it, the mother must go hungry to her work. Yet it does not necessarily follow that there will be antagonism between them, that they will fight for the crust, and that the mother, being strongest, will get it and eat it." (Ruskin. Unto this Last. p. 6.)

The following illustrations of parental love are interesting, not only because they display an heroic self-forgetfulness, but also because they show how a great affection has power to overcome a natural timidity :-

"The owner of a country station was sitting one evening on the balcony outside his house, when he was surprised to notice a kangaroo lingering about, alternately approaching and retiring from the house, as though half in doubt and fear what to do. At length she approached the water pails, and, taking a young one from her 
pouch, held it to the water to drink. While her baby was satisfying its thirst, the mother was quivering all over with excitement, for she was only a few feet from the balcony, on which one of her great foes was sitting, watching her. The little one having finished drinking, it was replaced in the pouch, and the old kangaroo started off at a rapid pace. When the natural timidity of the kangaroo is taken into account, it will be recognised what astonishing bravery this affectionate mother betrayed. It is a pleasing ending to the story that the eye-witness was so affected by the scene that from that time forward he could never shoot a kangaroo."

Mr. Francis Galton says:-

"There is no more cowardly and more helpless creature than a private nember of a herd. It falls a ready victim to the attack of foes, but a cow who has calved by the wayside and has been temporarily abandoned by the caravan, is never seized by lions. The incident frequently occurs, and as frequently are the cow and calf eventually brought safe to the camp; and yet there is usually evidence in footprints of her having sustained a regular siege from the wild beasts; but she is so restless and eager for the safety of her young, that no beast of prey can ever approach her unawares. This state of exaltation is of course exceptional."-(Macmillan's Magazine. vol. xxiii., p. 355.)

\section{Sir Samuel W. Baker narrates the following incident :-}

"A native cow had a calf; this being her first-born, the mother was exceedingly vicious, and it was unsafe for a stranger to approach her, especially as her horns were unusually long and pointed. The cattleshed was scarped out of the hillside, and was within a few feet of the blacksmith's house. The roof was thatched. During the night a leopard, which smelt the presence of the cow and calf, mounted the roof of the shed and proceeded to force an entrance by scratching through the thatch. The cow at the same time had detected the presence of the leopard, and ever-mindful of her calf, she stood ready to receive the intruder, with her sharp horns prepared for its appearance. It is supposed that upon the leopard's descent it was at once pinned to the ground before it had time to make its spring. The noise of a tremendous struggle aroused the blacksmith, who, with a lantern in his hand, opened the cattle-shed door and discovered the cow in a frantic state of rage, butting and tossing some large object to and fro, which evidently had lost all power of resistance. This was the leopard in the last gasp, having been run through the body by the ready horns of the courageous mother, whose little calf was nestled in a corner, unmindful of the maternal struggle."-(Wild Beasts and their Ways. vol.i., pp. 282-3.) 
Speaking of the Cerous campestris-the common deer of the pampas-Mr. Hudson says :-

"When the doe with fawn is approached by a horseman, even when accompanied with dogs, she stands perfectly motionless, gazing fixedly at the enemy, the fawn motionless at its side; and suddenly, as if at a preconcerted signal, the fawn rushes directly away from her at its utmost speed, and going to a distance of six hundred to a thousand yards, conceals itself in a hollow in the ground or among the long grass, lying down very close with neck stretched out horizontally, and will thus remain until sought by the dam.

After the fawn has run away, the doe still maintains her statuesque attitude, as if resolved to await the onset, and only when the dogs are close to her she also rushes away, but invariably in a direction as nearly opposite to that taken by the fawn as possible. At first she runs slowly with a limping gait, and frequently pausing as if to entice her enemies on, . . . but as they begin to press her more closely her speed increases."--(The Naturalist in La Plata. pp. $I I O-1 T$.)

I once lodged in a house at a famous sea-side resort, over the front door of which was carved a coat of arms with this motto, Homo homini lupus. There seemed to me a touch of irony in this, as indicating the probable character of lodging-house keepers in general, if not of this one in particular. Ever since, these words have occurred to me as somewhat justifying a cynical view both as to men and wolves, and especially the latter. It was only the other day that I learned to read an entirely new meaning into this apparently cynical motto, "A man is a wolf to his fellow man"! The head of a family which has been bereaved of its mother will do well to follow the example, in principle if not in detail, of the father wolf. Mr. T. R. D. Stebbing, in an article on "Wolves and Wild Boars in Modern France," says:-

"It is true that, when the cubs are quite young, the she-wolf dispenses with her husband's company, lest his vigorous appetite should too fondly embrace his offspring. But should the mother lose her life, the young do not for that reason die of hunger. The Comte de Canteleu, in I890, in his 'Manuel de Vénerie 
Française,' acknowledges that he was wrong in supposing this when he wrote his earlier 'Treatise on Wolf-hunting.' The older books knew better. The male wolf is by no means destitute of paternal love. The famous sportsman, Colonel Thornton, in the amusing account of his tour in France at the beginning of this century, is very explicit on this subject, borrowing, no doubt, from an older'French authority. The male wolf, he says, if his mate happens to die, 'feeds the young cubs, defends them against every enemy, and when they have acquired a little strength, he conducts them into large coinfields and other situations not far from the forest or thickets. He there places them in security while he prowls in quest of food. He carries to them all he can catch, such as sheep or other animals: but he first devours them himself, and on his return to his cubs he disgorges the half-digested food, which is swallowed by the cubs.' M. de Canteleu confirmed this ancient observation by repeated experiments, separating the shewolf from her cubs, leaving them alone with their father, 'and to my great astonishment,' he says, 'he fed them to perfection, disgorging the food for them as the mother does." "-(Blackwood's Edinburgh Magazine. rol. cliii., pp. 263-4.)

Innumerable illustrations might be given as to the co-operation between the members of the same species when associated in flocks or herds, and of the immense value of that co-operation to the individuals. Mr. Francis Galton says :-

"It is essential to the safety of oxen living in a country infested by" large carnivora that they should keep closely together in herds. - . Cattle have to take care of themselves against the wild beasts, and they would be infallibly destroyed by them if they had not safeguards of their own, which are not easily to be appreciated, at first sight, at their full value. We shall understand them better by considering the precise nature of the danger that an ox runs when he is alone. It is not simply that he is too defenceless, but that he is easily surprised. A crouching lion fears cattie who turn boldly upon him, and he does so with reason. The horns of an ox or antelope are calculated to make an ugly wound in the paw or chest of a springing beast, when he receives its thrust in the same way that an over eager pugilist meets his adversary's 'counter' hit. . . . Cattle are obliged in their ordinary course of life to spend a considerable part of the day with their heads buried in the grass, where they can neither see nor smell what is about them. A still larger part of therr time must be spent in placid rumination, during which they cannot possibly be on the alert. But a herd of such animals, when 
considered as a whole, is always on the alert; at almost every moment some eyes, ears, and noses will command all approaches, and the start or cry of alarm of a single beast is a signal to all his companions. To live gregariously is to become a fibre in a vast sentient web over-spreading many acres; it is to become the possessor of faculties always awake, of eyes that see in all directions, of ears and nostrils that explore a broad belt of air; it is also to become the occupier of every bit of vantage-ground whence the approach of a lurking enemy might be overlooked. The protective senses of each individual who chooses to live in companionship are multiplied by a large factor, and he thereby receives a maximum of security at the cost of a minimum of restlessness. When we isolate an animal who has been accustomed to a gregarious life, we take away his sense of protection, for he feels himself exposed to danger from every part of the circle around him, except the one point on which his attention is momentarily fixed, and he knows that disaster may easily creep up to him from behind; consequently his glance is restless and anxious and is turned in succession to different quarters; his movements are hurried and agitated, and he becomes a prey to the extremest terror:"--(Macmillan's Magazine. vol. xxiii., pp.355-6.)

\section{Prince Kropotkin says:-}

"The fishing associations of the pelicans are certainly worthy of notice for the remarkable order and intelligence displayed by these clumsy birds. They always go fishing in numerous bands, and after having chosen an appropriate bay, they form a wide half-circle in face of the shore, and narrow it by paddling towards the shore, catching all fish that happen to be enclosed in the circle. On narrow rivers and canals they even divide into two parties, each of which draws up on a half-circle, and both paddle to meet each other, just as if two parties of men dragging two long nets should advance to capture all fish taken between the nets when both parties come to meet. As the night comes they fly to their resting-places-always the same for each flock-and no one has ever seen them fighting for the possession of either the bay or the resting-place. In South America they gather in flocks of from forty thousand to fifty thousand individuals, part of which enjoy sleep while the others keep watch, and others again go fishing:"--(The Nineteenth Century. wol. xixizi., pp. 349-50.)

He also mentions the anxiety displayed by all individuals in a herd of chamois as long as all of them have not cleared a difficult passage over rocky cliffs.*

* Kropotkin. $p \cdot 707$. 
It is interesting to note that the cranes have realised the ideal of the modern socialist. They are extremely sociable and live on the most excellent and friendly terms, not only with their congeners but also with most aquatic birds, with this result:-

"The crane is in continual activity from early in the morning till late in the night; but it gives a few hours only in the morning to the task of searching for its food, chiefly vegetable. All the remainder of the day is given to society life. 'It picks up small pieces of wood or small stones, throws them in the air and tries to catch them; it bends its neck, opens its wings, dances, jumps, runs about, and tries to manifest by all means its good disposition of mind, and always it remains graceful and beautiful." "-(Kropotkin. p. 352.)

According to the same authority, animals which lead a more or less solitary life will assist one another when need arises.

"Some land crabs of the West Indies and North America combine in large swarms in order to travel to the sea and to deposit therein their spawn, and each such migration implies concert, co-operation, and mutual support. As to the big Molucca crab (Limulus), I was struck (in I882, at the Brighton Aquarium) with the extent of mutual assistance which these clumsy animals are capable of bestowing upon a comrade in case of need. One of them had fallen upon its back in a corner of the tank, and its heavy saucepan-like carapace prevented it from returning to its natural position, the more so, as there was in the corner an iron bar which rendered the task still more difficult. Its comrades came to the rescue, and for one hour's time I watched how they endeavoured to help their fellow-prisoner. They came two at once, pushed their friend from beneath, and, after strenuous efforts, succeeded in lifting it upright; but then the iron bar would prevent them from achieving the work of rescue, and the crab would again heavily fall upon its back. After many attempts one of the helpers would go in the depth of the tank and bring two other crabs, which would begin with fresh forces the same pushing and lifting of their helpless comrade. We stayed in the Aquarium for more than two hours, and when leaving we again came to cast a glance upon the tank: the work of rescue still continued! Since I saw that I cannot refuse credit to the observation quoted by Dr. Erasmus Darwin-viz., that 'the common crab, during the moulting season, stations as sentinel an unmoulted or hard-shelled individual to 
prevent marine enemies from injuring moulted individuals in their unprotected state." "-(Kropotkin. p.343.)

"As to the beetles, we have quite well observed facts of mutual help amidst the burying beetles (Necrophorus). They must have some decaying organic matter to lay their eggs in, and thus to provide their larvæ with food; but that matter must not decay very rapidly. So they are wont to bury in the ground the corpses of all kinds of small animals which they occasionally find in their rambles. As a rule, they live an isolated life, but when one of them has discovered the corpse of a mouse or of a bird, which it could hardly manage to bury itself, it calls four, six, or ten other beetles to perform the operation with united efforts; if necessary they transport the corpse to a suitable soft ground, and they bury it in a very considerate way, without quarrelling as to which of them will enjoy the privilege of laying its eggs in the buried corpse. And when Gleditsch attached a dead bird to a cross made out of two sticks, or suspended a toad to a stick planted in the soil, the little beetles would in the same friendly way combine their intelligences to overcome the artifice of man. The same combination of efforts has been noticed among the dung beetles."-(Kropotkin. p. 342.)

The following incident goes to show that the rights of the individual are in some cases respected in a most remarkable way:-

"A. Alcock has made some observations upon the habits of the red ocypode crab, a terrestrial species which is common in some parts of India. This crab lives in holes in the sand, and although gregarious in the sense that numbers frequent the same spot, it appears that only in one respect is there social combination between the various individuals of the community. It has long been known that the species of Ocypoda are furnished with a highly-developed stridulating organ upon one of the chelæ. Mr. Alcock has noticed that each crab has a burrow to itself, and that if one of them, as often happens in the case of a panic, attempts to enter by mistake the burrow of another, the rightful occupier stridulates to warn the intruder of its error, whereupon the latter immediately retreats in search of its own abode. So strong is this instinct against trespassing, that a crab will always undergo the risk of a fresh run for safety rather than persevere in seeking concealment in the burrow of another. It is suggested that the benefit of this instinct is the avoidance of all ills, such as suffocation and bloodshed, which might result from overcrowding in the burrows."-(Anmal Magazine of Natural History. No. 6, vol. x., p. 336.-Apud. The Year Book of Science: a Revieze of $1892 . \quad p \cdot 353$. 
Nor is the assertion that there is a necessary competition between the members of different species borne out by actual observation. Mr. Darwin tells us that-

"Animals of many kinds are social; we find even distinct species living together. For example, some American monkeys; and united flocks of rooks, jackdaws and starlings. Man shows the same feeling in his strong love for the dog, which the $\operatorname{dog}$ returns with interest. Everyone must have noticed how miserable horses, dogs, sheep, \&c., are, when separated from their companions, and what strong mutual affection-the two former kinds at least-show on their reunion."(Descent of Man. p. IOO.)

\section{Prince Kropotkin says :-}

"As soon as spring comes back . . . each of our hedges, each grove, each ocean cliff, and each of the lakes and ponds, with which Northern America, Northern Europe, and Northern Asia are dotted, tell us the tale of what mutual aid means for the birds; what force, energy, and protection it confers to every living being, however feeble and defenceless it otherwise might be. Take, for instance, one of the numberless lakes of the Russian and Siberian steppes. Its shores are peopled with myriads of aquatic birds, belonging to at least a score of different species, all living in perfect peace, all protecting one another. For several hundred yards from the shore the air is filled with gulls and terns, as with snowflakes on a winter day. Thousands of plovers and sand-coursers run over the beach, searching their food, whistling and simply enjoying life. Further on, on almost each wave, a duck is rocking, while higher up you notice the flocks of the Casarki ducks. Exuberant life swarms everywhere. And here are the robbers - the strongest, the cunningest ones, those 'ideally organised for robbery?' And you hear their hungry, angry, dismal cries, as for hours in succession they watch the opportunity of snatching from this mass of living beings one single unprotected individual. But as soon as they approach, their presence is signalled by dozens of voluntary sentries, and hundreds of gulls and terns set to chase the robber. Maddened by hunger, the robber soon abandons his usual precautions: he suddenly dashes into the living mass, but, attacked from all sides, he again is compelled to retreat. From sheer despair he falls upon the wild ducks, but the intelligent social birds rapidly gather in a flock and fly away if the robber is an ern; they plunge into the lake if it is a falcon; or they raise a cloud of water-dust and bewilder the assailant if it is a kite. And while life continues to swarm on the lake, the robber flies away with cries of anger, and looks out for carrion, or for a young bird or field-mouse not yet used to obey in time the warnings of its comrades. In 
the face of an exuberant life, the ideally-armed robber must be satisfied with the off-fall of that life."-( pp.699-700.)

"We see 11 our forests the societies formed by the young nutcatchers (Sittc casia), together with titmouses, chaffinches, wrens, tree-creepers, or some woodpeckers. In Spain the swallow is met with in company with kestrels, flycatchers, and even pigeons. In the far West the young horned larks live in large societies, together with another lark (Sprague's), the skylark, the Savannah sparrow, and several species of buntings and longspurs. In fact it would be much easier to describe the species which live isolated than to simply name those species which join the autumnal societies of young birds, not for hunting or nesting purposes, but simply to enjoy life in society and to spend their time in plays and sports, after having given a few hours every day to find their daily food." - $(p .7 O I$.

"The quagga zebra . . . lives on excellent terms not only with ostriches but also with gazelles, several species of antelopes, and snus-i.e., it lives together with ruminants feeding on the same grass as itself." - $(p .707$-note.)

As the result of this co-operation it will sometimes happen that the best and fittest to live will perish in the act of defending the flock or herd to which they belong. But however this may be, it is quite clear that co-operation will prevent the sole survival of the fittest.

The advocate of Natural Selection argues consistently with his theory that the improvement of the race is secured by the severity of the struggle between individuals of the same species. Weismann puts the case with admirable clearness.

"In order that any part of the body of an individual of any species may be kept at the maximum degree of development, it is necessary that all individuals possessing it in a less perfect form must be prevented from propagation-they must succumb in the struggle for existence. I will illustrate this by a special instance. In species which, like the birds of prey, depend for food upon the acuteness of their vision, all individuals with relatively weak eyesight must be exterminated, because they will fail in the competition for food. Such birds will perish before they have reproduced themselves, and their imperfect vision is not further transmitted. In this way the keen eyesight of birds of prey is kept up to its maximum." (Weismann. Lissays. p. 29I.) 
It is obvious from this passage that the theory demands the strictest competition; it excludes the least kind of co-operation. Dr. Weismann has taken an illustration, which will enable us to test the truth of the theory.

If birds and beasts of prey lived in flocks and herds, and yet acted on the principle of utter selfishness, each bird would do what the different vessels of a fleet engaged in the seal fishery are said to have done. The process is graphically described by Mr. Nansen in his work, Across Greenland.

"The first thing, of course, is to find the seal, and this is often a difficult task, for it must not be supposed that they are at all generally distributed over the ice. The sealers often have to search for weeks, skirting the edge of the ice-fields and examining every bay or inlet which admits of a passage in. The glasses are in constant use in the crow's-nest on the maintop. Then, if after long search signs of seal are at last discovered far away among the floes, and the ice does not lie too close to make a passage possible, the engines are at once put to their highest speed. The one object is now to push in and anticipate one's competitors. Just as at the card-table there is no fellowship, so among the sealers of the Arctic seas altruism is a virtue unknown. Every ship does its best to outwit its fellows, and nothing brings so much satisfaction as the success of an ingenious trick. So if there happen to be several vessels in one's neighbourhood when one discovers seal, and there is reason to believe that the others are still in ignorance of the find, the first thing is to entice the others away and set off in pursuit alone. To gain this object recourse is had to the most extraordinary stratagems. To steam off at full speed in quite a different direction, as if one already saw, or expected to see, seal in that quarter, so draw the others off, and then a while afterwards sneak back and start off to make one's capture alone, is an artifice in daily use at these times" - Vol. $i$, pp. I74-5.)

This, however, does not seem to be the way in which flocks and herds conduct themselves. The white-tailed eagle of the Russian steppes pursues a method in which the principle of co-operation is conspicuous, the quicker vision of one securing the advantage of all. 
"Whilst studying the fauna of the Russian steppes, he (Syevertsoff) once saw an eagle belonging to an altogether gregarious species (the white-tailed eagle, Haliaetos albicilla) rising high in the air ; for half an hour it was describing its wide circles in silence, when at once its piercing voice was heard. Its cry was soon answered by another eagle which approached it, and was followed by a third, a fourth, and so on, till nine or ten eagles came together and soon disappeared. In the afternoon Syevertsoff went to the place whereto he saw the eagles flying. Concealed by one of the undulations of the steppe, he approached them, and discovered that they had gathered around the corpse of a horse. The old ones, which as a rule begin the meal first - such are their rules of propriety-already were sitting upon the haystacks of the neighbourhood, and kept watch, while the younger ones were continuing the meal, surrounded by bands of crows. From this and like observations Syevertsoff concluded that the white-tailed eagles combine for hunting. When they all have risen to a great height they are enabled, if they are ten, to survey an area of at least twenty-five miles square; and as soon as any one has discovered something he warns the others. Of course it might be argued that a simple instinctive cry of the first eagle, or even its movements, would have had the same effect of bringing several eagles to the prey, but in this case there is strong evidence in favour of mutual warning, because the ten eagles came together before descending towards the prey, and Syevertsoff had, later on, several opportunities of ascertaining that the white-tailed eagles always assemble for devouring a corpse, and that some of them-the younger ones first-always keep watch while the others are eating. In fact the white-tailed eagleone of the bravest and best hunters-is a gregarious bird altogether, and Brehm says that when kept in captivity it very soon contracts an attachment to its keepers." - Kropotkin. pp.348-9.)

\section{Longfellow testifies to similar conduct on the part of} the vultures.

"Never stoops the soaring vulture

On his quarry in the desert, On the sick or wounded bison;

But another vulture watching From his high aërial look-out, Sees the downward plunge, and follows;

And a third pursues the second, Coming from the invisible etherFirst a speck and then a vulture, Till the air is dark with pinions." 
The following account, given by Sir Samuel W. Baker, shows clearly that those who are the first to catch sight of the prey are not the only ones to benefit by the discovery.

"When an animal is killed and skinned, before the operation is completed the first bird to appear is the wily and ommipresent crow ; the next is the ordinary buzzard. Both these birds are near the surface of the earth, seeking their food with untiring energy. But although they may have keen powers of scent, even they, in my opinion, are mainly guided by their acuteness of vision, as they are always on the alert, hunting in every direction, and in fact keeping a sharp look-out. The third arrival is the small red-necked vulture. This bird descends from a great height. It is now most interesting to watch the concentration from all quarters of the compass; this is easily arranged by lying beneath a bush, and shading the eyes while you gaze into the deep-blue sky. It will appear to be alive with the smallest flies, all moving, all hurrying, and descending. These become rapidly larger, and you are aware that they are vultures, collecting from such enormous altitudes that, were a mountain-top exposed, it would be capped with everlasting snow. While you are straining your eyes to peer into those blue vaults, you are startled by a tremendous rush like the roar of a rocket; this is the descent, with closed wings, of one of the large bare-necked vultures, which has plunged like a plummet for some thousand feet, to share in the feast below. All those birds flying at high altitudes have been soarnng upon endless wings, never fatigued by motion, as they seldom flap, but only adjust themselves to the currents of air upon which they float; and having with their extraordinary powers of sight observed the hurry of smaller birds to some attractive point, they have at once directed their course to fulfil the Biblical expression, "Where the carcase lies, there shall the eagles (vultures) be gathered together." -(Sir Samuel W. Baker. Wild Beasts and their Ways. vol. ii., pp. 102-3.)

In both of these cases the bird which can see the farthest or happens to be wide awake, not only benefits itself but all the colleagues with which it is associated. This surely contradicts the idea that keenness of vision is enhanced by Natural Selection, which gives life to those who catch sight of their prey; and leaves the others without food, nigh unto perishing. 
It should further be observed that co-operation prevents the elimination of the worst. The argument is sound which says that, "as the individual existence of each animal depends upon itself, those that die must be the weakest, the very young, the aged, and the diseased; while those that prolong their existence can only be the most perfect in health and vigour." But by the same reasoning, if the individual does not live unto himself, the opposite result may be anticipated, and does actually take place.

"Life in societies enables the feeblest insects, the feeblest birds, and the feeblest mammals to resist, or to protect themselves from, the most terrible birds and beasts of prey; it permits longevity; it enables the species to rear its progeny with the least waste of energy, and to maintain its numbers albeit a very slow birth-rate; it enables the gregarious animals to migrate in search of new abodes. . . . Those species which willingly or unwillingly abandon it are doomed to decay."-(Kropotkin. p. 7 II.)

The very young are not left to perish by their natural protectors, as the following instances will show:--

"In Abyssinia, Brehm encountered a great troop of baboons, who were crossing a valley. Some had already ascended the opposite mountain, and some were still in the valley. The latter were attacked by the dogs, but the old males immediately hurried down from the rocks, and with mouths widely opened, roared so fearfully that the dogs quickly drew back. They were again encouraged to the attack; but by this time all the baboons had reascended the heights, excepting a young one, about six months old, who, loudly calling for aid, climbed on a block of rock and was surrounded. Now one of the largest males, a true hero, came down again from the mountain, slowly went to the young one, coaxed him, and triumphantly led him away - the dogs being too much astonished to make an attack."--(Darwin. Descent of Man. p. IOI.)

"The gamekeeper here found a hawk's nest this year, with five young ones on it. He took four and killed them, but left one with its wings clipped as a decoy to destroy the old ones by. They were both shot next day in the act of feeding the young one, and the keeper thought it was done with. The next day he came again and found two other charitable hawks, who had come with an adopted feeling to succour the orphan. These two he killed, and 
then left the nest. On returning afterwards he found two more charitable individuals on the same errand of mercy. One of these he killed; the other he also shot, but could not find. No more came on the like fruitless errand."-(Rev. F. O. Morris, on the authority of the Hon. and Rev. O. W. Forester. Times, Aug. 6th. I868.-Descent of Man. pp. 409-IO-note.)

"The sagacity with which the bisons defend themselves against the attack of wolves is admirable. When they scent the approach of a drove of these ravenous creatures, the herd throws itself into the form of a circle, having the weakest and the calves in the middle, and the strongest ranged on the outside; thus presenting an impenetrable front of horns."-(Thompson. Passions of Animals. p. 305.)

"Wild swine associate in herds and defend themselves in common. Green relates that in the wilds of Vermont a person fell in with a large herd in a state of extraordinary restlessness; they had formed a circle with their heads outwards, and the young ones placed in the middle. A wolf was using every artifice to snap one, and on his return he found the herd scattered, but the wolf was dead and completely ripped up. Schmarda recounts an almost similar encounter between a herd of tame swine and a wolf, which he witnessed on the military frontiers of Croatia. He says that the swine, seeing two wolves, formed themselves into a wedge, and approached the wolves slowly, grunting and erecting their bristles. One wolf fled, but the other leaped on the trunk of a tree. As soon as the swine reached it they surrounded it with one accord, when, suddenly and instantaneously, as the wolf attempted to leap over them, they got him down and destroyed him in a moment."(Thompson. Passions of Animals. pp. 308-9.)

Mr. George Maw was informed, when he was in the Asturias in I855, that on an alarm of wolves the mares and foals congregate.

"The mares form themselves into a sort of cordon, heads outwards, surrounding a space enclosing the young foals, and are ready for attacking with their fore feet the wolves on their approach.

"My informant gave me a graphic account of such an attack, of which he was an eye-witness for nearly an hour, and described to me how the wolves circled round and round the defenders, first at some distance, then gradually approaching nearer and nearer, seeking an opening into the enclosure, till at last they came within striking distance, and he saw one wolf rolled over dead by a blow from the forefoot of one of the mares. The forefoot is not commonly used 
for defence by any equine species; but it is obvious the more powerful hind leg blow would be of little service against the spring of a wolf from behind, without the directing eye to guide the stroke."(Nature. vol. xxxv., p. 297.)

The old do not perish for the want of filial care. Witness the case of the rat who was seen to bring out a blind old patriarch, and then retire :-

"He soon returned, leading by the ear a second rat, who appeared to be blind. A third rat joined them soon afterwards, and assisted the original conductor in picking up fragments of biscuit and placing them before their infirm parent, as the blind old patriarch was supposed to be."-(Quarterly Review. vol. ci., p. 130.)

The diseased do not perish through neglect.

"An accurate observer, Mr. Lonsdale, informs me that he placed a pair of land snails (Helix pomatia), one of which was weakly, into a small and ill-provided garden. After a short time, the strong and healthy individual disappeared, and was traced by its track of slime over a wall into an adjoining and well-stocked garden. Mr. Lonsdale concluded that it had deserted its sickly mate, but after an absence of twenty-four hours it returned, and apparently communicated the result of its successful exploration, for both then started along the same track and disappeared over the wall."(Descent of Man. p. 263.)

"J. C. Wood's narrative of a weasel, which came to pick up and to carry away an injured comrade, enjoys a well-merited popularity." -(Man and Beast. p. 344.)

"So also the observation of Captain Stansbury, on his journey to Utah, which is quoted by Darwin. He saw a blind pelican which was fed, and well fed, by other pelicans upon fishes which had to be brought from a distance of thirty miles."-(T. H. Morgan. The American Beaver, 1868. p.272.-Descent of Man. ch.iv.)

"As to facts of compassion with wounded comrades, they are continually mentioned by all field zoologists. Such facts are quite natural. Compassion is a necessary outcome of social life."(Kropotkin. p. 7r2.)

No doubt there is a struggle sometimes between individuals of the same species, or of closely allied species, or constantly between species and their natural enemies. 
But what is the result of that struggle? Certainly not that discriminative choice of the best individuals of a species and destruction of all the rest, which Natural Selection demands. For a struggle between two races will cease either in the extermination of one of them, or a balance of life between the two. When one species exterminates the other, and the victorious species remains unmodified, there is obviously no possibility of Natural Selection coming into play. Where a certain balance of life obtains between the two, both the assailant and the assailed must co-operate with individuals of the same species, or perish; while, to quote Mr. Darwin's words, "those communities which included the greatest numbers of the most sympathetic members would flourish best, and rear the greatest number of offspring."*

Now in all these cases it should be observed that we have a struggle between conflicting races, which gives the victory to that side on which there is the greatest and most intelligent co-operation. The victory is gained by the esprit de corps shown by the whole herd or flock, by their loyalty to one another. In other words, they flourish in proportion as selfishness is eliminated from their midst, so far as bitter competition is absent from their ranks.

Experience shows that in relation to any given species competition between individuals is as dangerous to the welfare of the species as co-operation is beneficial.

"Speaking generally, I can say that all isolated individuals are fatally suppressed in the struggle for existence against external conditions, against vegetables and other animals, while those which live in society partially escape these same enemies and perpetuate their races. It follows from this, that all the animals-at least all those which have numerous enemies, all the herbivorous animalsought to live in societies more or less extended. This is, in effect, what we have already shown to be the case."--(De Lanessan. La Lutte pour PExistence. p. 49.) 
Syevertsoff mentions some of the species of falcons which have an almost ideal organisation for robbery, and nevertheless are in decay; while other species practising mutual aid do thrive. The absolute necessity for cooperation is explicitly stated in the following passage:-

" 'Don't compete!-competition is always injurious to the species and you have plenty of resources to avoid it'! That is the tendency of nature, not always realised in full, but always present. That is the watchword which comes to us from the bush, the forest, the river, the ocean. 'Therefore combine-practise mutual aid! That is the surest means for giving to each and to all the greatest safety, the best guarantee of existence and progress, bodily, intellectual, and moral.' That is what nature teaches us; and that is what all those animals which have attained the highest position in their respective classes have done." -(Kropotkin. ph. 7I8-9.)

It seems to me to be quite impossible to harmonise the demands of the theory of Natural Selection for a bitter competition between individuals of the same species, or of different species, with the co-operation which is constantly found in nature. Some attempt at such reconciliation seems to have been made by Mr. Darwin when he wrote :-

"I should premise that I use this term (struggle for existence) in a large and metaphorical sense, including dependence of one being on another."-(Origin of Species. p. 50.)

Now, so far as the individuals of the same species are concerned, the struggle between them for existence-the selfish competition which the theory of Natural Selection demands as a condition of the survival of the fittest-is surely the very antithesis of that kindly co-operation and sympathy of which so many illustrations have been given. In this connection it must be a mistaken use of terms to include mutual dependence in the idea of mutual competition, and such extension of the phrase, even if it be admitted "in a large and metaphorical sense," is destructive of the 
argument for Natural Selection. There is, however, one plain sense in which the struggle for existence may include "dependence of one being upon another." When race struggles against race the members of each race must learn to depend one upon another if they are to avoid destruction. But, here again, we must remember that it is competition between the individuals of the same species which the theory of Natural Selection demands and, as we have seen, calls for in vain.

Prince Kropotkin seems to think that this extension of the term by Mr. Darwin shows the large and enlightened view which he took of nature; and that his followers in insisting on competition have displayed a narrow-minded and a one-sided view. In point of fact they have been consistently loyal in demanding what the theory assuredly requires. In illustration of the larger view of Nature, Prince Kropotkin says: "In the great struggle for life-for the greatest possible fulness and intensity of life, with the least waste of energy-Natural Selection continually seeks out the ways precisely for avoiding competition as muçh as possible."

It is true that competition is sometimes avoided in nature, but it would be difficult to show how this is brought about by Natural Selection. Certainly migration and emigration, and other means by which competition is avoided, are not due to Natural Selection; that is to say, if we understand Natural Selection in its proper and technical sense. So far as the individuals of the same species are concerned, competition and co-operation are mutually exclusive, and that particular kind of improvement which is supposed to be due to competition is rendered impossible by the action of co-operation.

Before leaving this subject, I must not omit to consider two phenomena which occur in connection with the herds 
of oxen. Most persons will have been influenced by the moralising of the melancholy Jacques, as he lay where

$$
\text { “. . . a poor sequester'd stag, }
$$

That from the hunter's aim had ta'en a hurt,

Did come to languish ; . . . "

and will have sympathised with his invective against the selfishness of the herd-

"Sweep on, you fat and greasy citizens;

'Tis just the fashion; Wherefore do you look Upon that poor and broken bankrupt there?" -(As You Like It. Act ii., sc. I.)

But this is not all. For in some cases the members of a herd will not only leave a sick companion severely alone, but, seized with sudden rage, they will sometimes gore a wounded comrade to death. Mr. Hudson, in a striking essay on The Strange. Instincts of Cattle, attempts a solution of these difficulties. He distinguishes between flocks of birds and herds of oxen. The former are all equals: among the latter there is strife for preeminence.

"Among mammals equality and harmony are rare. The instinct of one and all is to lord it over the others, with the result that one more powerful or domineering gets the mastery, to keep it thereafter as long as he can. The lower animals are, in this respect, very much like us; and in all kinds that are at all fierce-tempered, the mastery of one over all, and of a few under him over the others, is most salutary; indeed it is inconceivable that they should be able to exist together under any other system." - (The Naturalist in La Platc. p. 336.)

"The hottest contests are always between dogs that are well matched; neither will give place to the other, and so they fight it out. But from the foremost in strength and power down to the weakest there is a gradation of authority; each one knows just how far he can go, which companion he can bully when he is in a bad temper or wishes to assert himself, and to which he must humbly yield in his turn. In such a state the weakest one must always 
yield to all the others, and cast himsclf down, seeming to call himself a slave and worshipper of any other member of the pack that chooses to snarl at him or command him to give up his bone with a good grace.

"This masterful or domineering temper, so common among social mammals, is the cause of the persecution of the sick and weakly. When an animal begins to ail he can no longer hold his own; he ceases to resent the occasional ill-natured attacks made on him, his non-combative condition is quickly discovered, and he at once drops down to a place below the lowest; it is common knowledge in the herd that he may be buffeted with impunity by all, even by those that have hitherto suffered buffets but have given none. But judging from my own observation, this persecution is not, as a rule, severe, and is seldom fatal. It is often the case that a sick or injured animal withdraws and hides himself from the herd; the instinct of the 'stricken deer' this might be called. But I do not think that we need assume that the ailing individual goes away to escape the danger of being ill-used by his companions; he is sick and drooping, and consequently unfit to be with the healthy and vigorous. That is the simplest and probably the true explanation of his action; although in some cases be might be driven from them by persistent rough usage. However peaceably gregarious mammals may live together, and however fond of each other's company they may be, they do not, as a rule, treat each other gently. Furthermore, their games are exceedingly rough and require that they shall be in a vigorous state of health to escape injury. Horned animals have no buttons to the sharp weapons they prod and strike each other with in a sportive spirit. I have often witnessed the games of wild and half-wild horses with astonishment, for it seemed that broken bones must result from the sounding kicks they freely bestowed on one another. This roughness itself would be a sufficient cause for the action of the individual, sick and out of tune and untouched by the glad contagion of the others, in escaping from them; and to leave them would be to its advantage (and to that of the race) since, if not fatally injured or sick unto death, its chances of recovery to perfect health would be thereby greatly increased."-(The Noturalist in La Plata. pp. 337-9.)

Speaking of the goring to death of a wounded comrade by the other members of the herd, Mr. Hudson explains that it is a delusion sometimes accompanying what he calls the rescuing instinct :-

"The first thing that strikes us is that, in these wild abnormal moments of social animals, they are acting in violent contradiction 
to the whole tenor of their lives; that in turning against a distressed fellow they oppose themselves to the law of their being, to the whole body of instincts, primary and secondary, and habits, whıch have made it possible for them to exist together in communities. It is, I think, by reflecting on the abnormal character of such an action that we are led to a true interpretation of this "dark saying of nature."-(The Naturalist in La Plata. p. 340.)

"It is precisely the animals, high or low in the organic scale, that are social and possess the instinct of helping each other, that will on occasions attack a fellow in misfortune--such an attack being no more than a blunder of the helping instinct."-( $p .343$.

"A noble courage, greatly surpassing that exhibited on all other occasions, is displayed by an infinite number of mammals and birds of gregarious habits, when repelling the attacks of some powerful and dangerous enemy, or when they rush to the rescue of one of their captive fellows. Concerning this rage and desperate courage of social animals in the face of an enemy, we see ( $\mathrm{I}$ ) that it is excited by the distressed cries, or by the sight of a member of the herd or family flying from, or struggling in, the clutches of an enemy; (2) that it affects animals when a number of individuals are together, and is eminently contagious, like fear, that communicates itself, quick as lightning, from one to another until all are in a panic, and like the joyous emotion that impels the members of a herd or flock to rush simultaneously into play."-( $p .34 I^{-2}$. $)$

"The effectiveness of the rescuing instinct depends altogether on the emotion of overmastering rage excited in the animal, rage against a tangible visible enemy, or invisible, and excited by the cries or struggles of a suffering companion. Clearly, then, it could not provide against the occasional rare accidents that animals meet with, which cause them to act precisely in the way they do when seized or struck down by an enemy."--(p. 342.)

He then goes on to explain how, under certain circumstances, the members of a herd mistake their stricken fellow for an enemy and treat him accordingly, and he rejoices in the relief which is afforded when we are able to look upon this phenomenon

"no longer as something ugly and hateful, a blot on nature, but as an illusion, a mistake, an unconscious crime, so to speak, that has for its motive the noblest passion that animals knowthat sublime courage and daring which they exhibit in defence of a distressed companion. This fiery spirit in animals, which makes 
them forget their own safety, moves our hearts by its close resemblance to one of the most highly-prized human virtues."-(The Naturalist in La Plata. pp.346-7.)

After full consideration of the facts which have been adduced, it is very difficult to resist the conclusion that the competition required by the logic of Natural Selection is very largely modified by the co-operation which obtains among the members of the animal world. There may be exceptions to the rule. We need not, however, be surprised to find selfishness among animals any more than we are to find selfishness among men; and it would be as rash to deny the existence of disinterestedness and co-operation in the one case as in the other. If $\mathrm{Mr}$. Hudson's explanations are admitted, and they appear to be most reasonable, we may regard "the strange instincts of cattle" as a curious but inevitable accompaniment of co-operation. It would not be too much to say that we find in nature scarcely a trace of that bellum ommizm contra ommes, which Oscar Schmidt declares to be an indisputable and undeniable fact, to be accepted in its widest relations; and which is generally pronounced to be an indispensable condition of the action of Natural Selection. 


\section{CHAPTER VI.}

THE THREE STRONGEST AKGUMENTS.

"In point of argument the truth is always far the strongest."

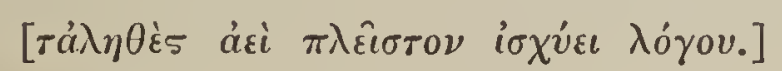

-SOPHOCLES.

Mr. ROMAnes, in his Darwin and After Darwin, adduces three main arguments in favour of the theory of Natural Selection. Now, when a writer of wide knowledge and great critical acumen, who is also one of the experts on a given subject, definitely sets himself the task of finding the strongest arguments for a particular theory, we are sure that the advocacy of the subject will not suffer in his hands. It is reasonable to suppose that he will make the best possible selection. On the other hand, the controversialist who deals with such arguments cannot be charged with selecting the weakest points for his attack.

(a) The Conflict Between Race and Race.

"When Greeks joined Greeks then was the tug of war."

- Nathaniel LeE.

"The one is taken and the other left."

The first argument in favour of the transmutation of species by means of Natural Selection is drawn from the conflict between one race and another, which results in 
the extermination of the less fit and the survival of the more fit of the two competitors. Mr. Romanes says:-

"First, it is a matter of observation that the struggle for existence in nature does lead to the extermination of forms less fitted for the struggle, and thus makes room for forms more fitted. This general fact may be best observed in cases where an exotic species proves itself better fitted to inhabit a new country than is some endemic species which it exterminates. In Great Britain, for example, the socalled common rat is a comparatively recent importation from Norway, and it has so completely supplanted the original British rat, that it is now extremely difficult to procure a single specimen of the latter: the native black rat has been all but exterminated by the foreign brown rat. The same thing is constantly found in the case of imported species of plants. I have seen the river at Cambridge so choked with the inordinate propagation of a species of water-weed which had been introduced from America, that considerable expense had to be incurred in order to clear the river for traffic. In New Zealand the same thing has happened with the European watercress, and in Australia with the common rabbit. So it is doubtless true, as one of the natives is said to have philosophically remarked, 'the white man's rat has driven away our rat, the European fly drives away our fly, his clover kills our grass, and so will the Maoris disappear before the white man himself.' Innumerable other cases to the same effect might be quoted, and they all go to establish the fact that forms less fitted to survive succumb in their competition with forms better fitted."-(Romanes. Darwin and After Darwin. ph. 285-6.)

In asserting that the victory of one race over another is a strong argument for the theory of Natural Selection, Mr. Romanes is merely maintaining the position taken by Mr. Darwin. The very title of Mr. Darwin's great work, The Origin of Species by means of Natural Selection, or the Preservation of Favoured Races in the Struggle for Life, implies that the victory of one race over another is Natural Selection. And the implication is emphasised in the body of the work, where he contends that "the theory of Natural Selection is grounded on the belief that each new variety, and ultimately each new species, is produced and maintained by having some advantage over 
those with which it comes into competition; and the consequent extinction of the less favoured forms almost inevitably follows."*

Mr. Wallace asserts that "this daily and hourly struggle, this incessant warfare . . affords one of the most important elements in bringing about the origin (? transmutation) of species." He then proceeds to illustrate this struggle by the displacement of one species by another; by the weeds which take the place of flowers in the neglected garden; by the disappearance of native weeds in the presence of imported ones; by the failure to naturalise suitable plants; by the victory of the beech over the birch; by the survival of one set of plants and the extinction of others in the Pampas; by the extermination of the English watercress in New Zealand by the willows which are planted on the banks of the streams; by the expulsion of the black rat by the brown rat; by the victory of the European horse-fly over a fly native to New Zealand; and by the survival of the small Asiatic cockroach and the extermination of a larger Russian species. He does not say that these phenomena prove the transmutation of species by Natural Selection; but one does not see the force of the argument in a work on Darwinism unless he meant us to infer this. It is true that he might have argued that this struggle between race and race is a proof of a struggle for existence, and that it prepares the mind for admitting the probability of the struggle for existence which produces a transmutation of species by means of Natural Selection. But he does not say this distinctly; and we may presume that he intended us to infer what Mr. Romanes and Mr. Darwin assert so emphatically. 
The displacement of one species by another may be due to a struggle between the two; but it may also arise from an independent effort of the two species to adapt themselves to new conditions in which one species fails and another succeeds; or again, it may arise from the fact that one species is already fitted for new conditions and another species is not. The first of these phenomena may be described literally as a struggle between two conflicting species. In the other instances the two species struggle with the difficulties of their new conditions without reference to one another, and only in a metaphorical sense can be said to struggle with each other.

We have now to consider how far these facts may be regarded as affording a proof of the transmutation of species by means of Natural Selection.

In the first place it should be observed that the displacement of one species by another does not necessarily imply that the victorious species is in any way more fit to live, or more adapted to its external conditions than the other. It simply shows that one species has the power to exterminate the other. Mr. Wallace contends that "the displacement of one species by another can be illustrated by innumerable cases, and that they all go to establish the fact that forms less fitted to survive succumb in their competition with forms better fitted." Now, if this means that the one has some advantage over the other, the assertion simply declares what is the most obvious of facts; but if it means that the surviving species is in any other way more fitted to live, more adapted to external conditions, this is to assert what in very many cases is not true. There is no reason for supposing that the black rat is any less fit to . live, any less adapted to the conditions by which it is surrounded, than the brown rat. For in their native country the two varieties live together; in some countries 
of Europe the black rat is even the more numerous; in England the black rat flourished for five centuries before the advent of the brown rat. The English watercress in New Zealand was certainly adapted most perfectly to the conditions in which it was placed, for it grows "so luxuriantly in that country as to completely choke up the rivers, sometimes leading to disastrous floods, and necessitating great outlay to keep the stream open; and yet it has been exterminated from the very localities in which it flourished."

In these cases there is no mystery in the victory of one species over the other. We may explain the extermination of the black rat by the brown rat, from England, by supposing that there were special circumstances which had not occurred elsewhere. It appears that, in the countries where both kinds of rats are to be found, their habits and their haunts are different, and hence they do not come into collision with one another. But if, in consequence of coming over in ships, the brown rat acquired the habit of picking up a living in places where man dwelt, it might then come into immediate contact with the native settlers. We may further suppose that prior to the arrival of the brown rat, the black rat occupied all the ground which could be occupied by rats of their habits of life, in consequence of the presence of enemies or through the limited supply of food. The invader comes into competition with this long naturalised cousin of his. Both species tend to increase at an enormous rate, but there is not room for both. And then begins the competition between race and race. Now the invader was the stronger and the larger of the two species; it had also the fiercer disposition, and there does not seem to be much mystery in the fact that it gained the ascendancy. There are many ways in which this might be brought about. The most obvious way would be for 
the stronger race to seize upon the supplies of food, to starve out the weaker species, and to kill them if they resisted. But there is another possibility. In the absence of other food, and perhaps sometimes on other occasions also, the rat is a cannibal; feeding upon other members of its orwn species, just as in the scarcity of their normal diet caterpillars have been observed to do. But if this were so another result would follow. The experiments of Yung show that among frogs the relative number of males and females depends upon the food which the parents eat. The proportion of females to males increases when an animal diet is substituted for a vegetable diet, and when a cannibal diet is adopted no less than ninety per cent. are females. Now, if this result follows in the case of other kinds of animals, and if we consider the enormous fertility of the rat, in ordinary cases, and bear in mind how this would be enhanced by such an excessive amount of females, the victory of the brown rat over the black rat is accounted for without any difficulty whatever.

The willow succeeds in displacing the English watercress from the rivers of New Zealand by a very simple and intelligible process. "The roots of these trees penetrate the bed of the stream in every direction, and the watercress, unable to obtain the requisite amount of nourishment, gradually disappears."*

In these cases there is no abstract survival of the fittest: both are equally fit apart from one another.

But if the argument of the advocates of Natural Selection were amended by the substitution of undoubted cases, in which the more fit drove out the less fit species, this would not constitute Natural Selection. You may call it a selection of a favoured species - and it undoubtedly 
takes place in nature-but it is not Natural Selection, for the obvious reason that Natural Selection means the transmutation of a species by the selection of favourable variations which arise in connection with sexual reproduction.

In those cases in which the displacement of species is due to a struggle between race and race, the struggle ends in the extermination and possibly the extinction of one species and in the survival of the other species, unmodified by the struggle through which it has passed. The black rat has been exterminated by the brown rat, which remains the same as it was before the conflict. The willow which exterminates the English watercress in New Zealand undergoes no modification. The same observation applies to the weeds which take the place of cultivated flowers in the abandoned garden. Goldsmith, who, in The Deserted Village, has drawn a picture familiar to many-

"Near yonder copse, where once the garden smiled,

And still where many a garden flower grows wild"-

described only the first stage of a strange metamorphosis. For not only do weeds soon usurp the ground and destroy a number of the flowers, but these weeds in their turn give place to other weeds-the very weeds associated with human culture giving place in time to weeds of nature's unaided growth. Mr. Wallace would seem to give two explanations of this displacement; for, on the one hand, he says that "all the plants concerned may be perfectly hardy -all may grow freely from seed." On the other hand, he says, "of the many hundreds of hardy plants which produce seed freely in our gardens, very few ever run wild, and hardly any have become common." But whichever explanation you take makes no difference to the argument. 
For in the first explanation, one species drires out the other, and neither is modified. In the second explanation, the withdrawal of the protection and stimulus of culture does not lead to reversion to a wild ancestral form, but to extinction.

No evidence is given, in connection with the struggle of one species with another, of any modification of the triumphant species. If there were such evidence, it is astonishing that it is not adduced in this connection. But one case is cited by Mr. Wallace, in which a distinct attempt is made by one of the combatants to adapt itself so as to be able to co-exist with its opponent. In the forests of Denmark, wherever the soil is suitable for the beech, it drives out the birch.

"The latter loses its branches at the touch of the beech, and devotes all its strength to the upper part, where it towers above the beech. It may live long in this way, but it succumbs ultimately in the fight-of old age if of nothing else, for the life of the birch in Denmark is shorter than that of the beech. . . . The tufted, bushy top of the beech preserves a deep shade at its base. Hardly any young plants can grow under the beech except its own shoots; and while the beech can flourish under the shade of the birch, which allows the rays of the sun to pass to the soil below, the latter dies immediately under the beech. The birch is only saved from total extinction by the fact that it can grow where the beech cannot; forests of birch are only found now in sterile sandy tracks." (Wallace. Darwinism. p. 2I.)

Here we have no case of a transmutation of species by adaptation to new and unfavourable conditions such as Natural Selection ought to achieve for the birch, if it were the powerful agent which the theory presupposes. But the attempt is made. The birch loses its branches at the touch of the beech and devotes all its strength to the upper part, where it towers above the beech. But the attempt, in spite of all its efforts, fails. Even if the attempt had succeeded, the transmutation would not have 
taken place by means of Natural Selection, or, in other words, by the survival of favourable variations which arise in connection with sexual reproduction.

The displacement of one species by another may be due to independent action on the part of each to adapt itself to new conditions in which it is placed. In that case, one fails and the other succeeds. Mr. Wallace refers to several cases in which the attempt to naturalise a new species has met with no success.

"Attempts to naturalise suitable plants usually fail, for A. de Candolle states that several botanists of Paris, Geneva, and especially of Montpellier, have sown the seeds of many hundreds of species of hardy exotic plants in what appeared to be the most favourable situations, but that, in hardly a single case, has any one of them become naturalised. Even a plant like the potato -so widely cultivated, so hardy, and so well adapted to spread by means of its manyeyed tubers--has not established itself in a wild state in any part of Europe. It would be thought that Australian plants would easily run wild in New Zealand; but Sir Joseph Hooker informs us that the late Mr. Bidwell habitually scattered Australian seeds during his extensive travels in New Zealand, yet only two or three Australian plants appear to have established themselves in that country, and these only in cultivated or newly moved soil."-(Wallace. Darwinism. pp. 15-6.)

All these instances illustrate the point that some plants are unable to adapt themselves to the new conditions in which they are placed, especially if they be suddenly transplanted to a new sphere. In other cases plants would seem to have a power of adaptation which enables them to overcome the disabilities of their new habitat. We may thus account for the survival of certain plants in the pampas of the southern part of South America. Mr. Edward Clark tells us that the country is characterised by the absence of rivers and water storage, by the periodical occurrence of droughts or siccos in the summer months; and that the open plain is overrun by numberless wild rodents, the original tenants of the pampas, 
and covered with droves of imported horses and cattle. In the seasons of drought the latter are starved by thousands, and in their effort to live destroy every vestige of vegetation. The existence of an unprotected tree is impossible; though the soil is naturally fertile and favourable to the growth of trees, and they grow luxuriantly when protected. The eucalyptus is covering large tracts wherever it is enclosed, and willows, poplars, and the fig trees surround every estancia when fenced in.*

Now, in a country like this, it is evident that those species which can resist the effects of drought and the attacks of rodents and cattle, or which can adapt themselves to these conditions, will be the only ones which can possibly survive; not because they struggle with the unprotected species, but because they alone can struggle with the difficulties presented by their conditions of life. The only plants which hold their own are the indestructible thistles, grasses and clover; the herbaceous oxalis producing viviparous buds of extraordinary vitality, a few poisonous species such as the hemlock, and a few tough thorny dwarf acacias and wiry rushes which even a starving rat refuses.

I shall endeavour to show in the Second Part of this Essay how the direct action of outward conditions, apart from Natural Selection, produces the very characteristics which aid these organisms in the struggle to overcome the disabilities of their position; when that has been done it will justify the assertion that in this case the one disability modifies the organism so as to resist the other disability. Drought produces that protection which the plants require against their animal foes.

* Wallace. Darwinism. f. 23 . 
The survival of one species in face of the extermination of another may be due in some cases to the fact that one species is already adapted to its new conditions while the other is not, and cannot be. The one is fit to live in the conditions, the other is not. In some instances it is difficult to understand why this is the case.

"Mr. W. T. Thiselton Dyer has communicated to Nature an interesting letter from Mr. Gammie, who has charge of the cinchona plantations of the Bengal Government at Darjeeling, which indicates how unobvious constitutional differences may exist between closely connected forms of plants scarcely distinguishable by palpable morphological differences, which may determine survival in the struggle for existence. Alluding to the attempts at ipecacuanha-growing under his care, Mr. Gammie says :- 'Our original stock of plants came from Kew and Edinburgh-the great majority from Edinburgh. The few plants from Kew differed a good deal in appearance from the Edinburgh lot, which, again, differed greatly from each other. All the Kew plants were of one sort, which we named, from the start, the Kew variety. It was rougher in the leaf than the Edinburgh sorts, and not so strong-growing while under glass. After we had satisfied ourselves that we could make nothing of ipecacuanha, from a commercial point of view, we put all the plants out in the open, under shade, and let them take their chance. By this time we had all the sorts mixed up together; and as we had originally at least ten Edinburgh plants for each one of the Kew sort, and the Edinburgh lot had, besides, been much the stronger growers under glass, the Kew plants formed less than 5 per cent. of the whole. But very soon the Edinburgh sorts began to disappear, until, in the course of a year or two, there was not a single plant of one of the Edinburgh varieties alive, whilst almost every plant of the Kew variety lived." "(Vol. xxxv., p. 227.)

We may further remark that sometimes the displacement of one species by another merely consists in their living apart. Cowslips are found in a meadow and primroses in an adjoining wood, each in abundance but not often intermingled. Numbers of closely-allied species are to be found in the same country but almost always in different stations; and so do not come into competition with one another.*

* Darivinism. $\quad$ th. 35-6. 
Closely-allied plants may inhabit the same districts, when one prefers meadows, the other woods; one a chalky soil, another sand; one a damp situation, another a dry one. We have already seen that the beech and the birch flourish apart even in the country where the two cannot live together. Prince Kropotkin accounts for the black rat and the brown rat existing in the same country-I presume in Russia-by the fact that they frequent different habitats.

"As to the brown rat, it is known that, owing to its amphibian habits, it usually stays in the lower parts of human dwellings-low cellars, sewers, \&c. - as also on the banks of canals and rivers; it also undertakes distant migrations in numberless bands. The black rat, on the contrary, prefers staying in our dwellings, under the floor, as well as in our stables and barns. It thus is much more exposed to be exterminated by man; and we cannot maintain, with any approach to certainty, that the black rat is being either exterminated or starved out by the brown rat and not by man." - (Nineteenth Century. vol. xxwiii., p. 713.)

Sometimes different species live together and flourish.

"In the equatorial virgin forests there is so great a variety of forms, and they are so thoroughly intermingled, that the traveller often finds it difficult to discover a second specimen of any particular species which he has noticed. Even the forests of the temperate zones, in all favourable situations, exhibit a considerable variety of trees of distinct genera and families, and it is only as we approach the outskirts of forest vegetation, where either drought or winds or the severity of the weather is adverse to the existence of most trees, that s we find extensive tracts monopolised by one or two specics." (Wallace. Darwinism. p. 35.)

There is also a vertical as well as a horizontal association of quite different forms. An anonymous writer, in an article entitled "A Malagasy Forest," says :-

"No one can be long in the forest without observing that the plants range themselves, roughly speaking, into three tiers. There are, first of all, the trees-long gaunt things-that have been obliged to stretch themselves upwards to get their leaves and flowers to the 
light. Viewed from some elevated point outside, it is these that seem to form the forest, but within they are merely the canopy of the forest proper. It is often difficult to know what these trees really are, for to get at the flowers and leaves they must be either climbed or cut down, neither of which proceeding is always practicable. Then come the shrubs, which have to be content with such light as they can get. Below these there is an entangled mass of herbs, ferns in profusion, grasses, mosses, prickly blackberries, and what not. . . . Try to make a way through them, and you will soon be convinced what a dense, prickly', complex entanglement it is."-(The Comhill Magczine. New series. vol. xxii., p. I94.)

What explanation are we to give of these facts? Mr. Wallace clearly shows that the great variety of trees in a tropical forest is due to the mutual protection which is afforded by their juxtaposition. So far from seeing in all this a struggle for existence between competing species or between individuals of the same species, M. de Lanessan pronounces that we have here an association of individuals and species which is useful to all concerned in the struggle which all have to undergo with the disabilities of their external conditions.

"Among certain plants of very different species there is a combination which enables them to resist the disabilities of external conditions. You all know, for example, that the violet can only live under the shade of other plants, either because it there finds the constant moisture which it needs, or because it is there protected from the rays of the sun. Let a grain of violet seed attempt to germinate far from this shade in an uncovered place. The plant which grows from it will be killed by the drought or by the rays of the sun. The violet, then, has need of the companionship of plants higher than itself. It places itself, so to speak, under their protection, and finds in this companionship the assistance which is necessary to it. I ought to add that the plants which protect the violets find an advantage to themselves in the shade which they furnish to the lastmentioned. The violets in effect form at their feet a sort of green carpet, which diminishes the evaporation of the water contained in the soil and so maintains a moisture favourable to the growth of the protected and the protector. Between these two orders of plants the aid is reciprocal; the feeblest render to the strongest similar services to those which they, the strongest, receive from the feeblest."-(De Lanessan. La Lutte pour l'Existence. pp. 20-I.) 
"Sow a single handful of grains of wheat in your garden, in the following summer your crop will be very small, if it is not absolutely nothing. The few grains which you have sown will be eaten by the birds or carried off by the ants before they have been able to germinate. If they escape this first danger, they might be devoured by the caterpillars. If some, more favoured, succeed in flowering and the grain ripens, you will do well to make haste to gather these last, for the sparrows will very easily anticipate you. Throw now some thousands of handfuls of grains of the same wheat on the sides of the large furrows which the ox has traced in the plain, and however numerous the enemies may be, the ears of corn, turned yellow by the sun, will wave in the summer under the breath of wind, and will give you an abundant harvest. The richer in individuals the crop of wheat which covers the plain, the greater will be the chance in the struggle for existence which each individual is destined to undergo."-(De Lanessan. La Lutte pour l. Existence. pp. 20-I.)

The writer in The Cornhill is tempted to interpret the phenomenon which he describes so vividly in the same manner. With respect to this scene, he says :-

"Outwardly, at least, concord and mutual helpfulness seem to prevail among the numerous vegetable forms in the forest. Plants of the most diverse character, and belonging to the most widely separated families, are found in harmonious company. Here a beautiful tree-fern finds shelter beneath a forest giant, the tree-fern in its turn spreading its green umbrella over a number of herbs, some of which have become so familiar as to twine themselves around its knotted stem. Beneath these, again, some soft tender moss, or a minute brilliant red fungus, or a pyramid-shaped Lycopodium, for all the world like a miniature Christmas-tree, with its fructification dangling from its branches as so many ornaments, finds its home. No space is lost. The germs of vegetable life are ever ready to seize upon unoccupied spots. There is scarcely a crevice or a cranny anywhere without an occupant."

He corrects himself, however, and rises superior to the delusion incidental to a superficial view of the subject.

"But alas! all this harmony and brotherly kindness is illusory. Every individual has secured its position by its own unaided energy, and the apparent harmony we see is but the complex result of individual enterprise. There is constant rivalry and competition going on, and as in the human, so in the plant world-certain 
families, or rather certain members of families, have, through some unknown powers of their own, or advantageous outward circumstances, been more successful than their rivals, and have gained the day. For instance, we may see in some parts of the forest that bamboos, or the cardamon plant, or small palms, have almost wholly monopolised the ground."-(The Cornhill Magazine. New series. vol. xizi., p. I94.)

And in another paragraph he spealss of various growths as "pushing and elbowing one another for dear life."

In these passages the writer infers that there is a struggle for existence among plants that live together by referring to plants that live apart, as though the isolation of the latter were the result of the competition of the former. But where only one kind of plant is found, it is probable that the immediate circumstances will be found specially favourable or less adverse to its development. It secures the sole possession of a particular sphere because it is more or less especially adapted to its needs. The fact that different species live apart in spheres different from each other would seem to indicate a cessation of internecine struggle. On the other hand, the fact that many species live together and assist one another in the struggle against the disabilities of their external conditions is an illustration of that principle of co-operation which, as we have seen, logically excludes the view of a ruthless competition between race and race.

We have seen that when one species displaces another it is not necessarily more fit to live than the other, but only that it possesses some advantage over the other which can sometimes be discerned and sometimes not. We have seen that the struggle ends in the extinction, or at least the extermination, of one species and the continued existence of the triumphant species in an unmodified form. Among all the instances cited by Mr. Wallace in his argument for Natural Selection based on 
the struggle for existence, only one example is given of the attempt of the threatened species to maintain its place by modification of its structure: and that attempt miserably fails. We have seen that the displacement of one species by another may be due to an independent effort of each species to overcome some external disability, which is successful in one case and fails in another; or to the fitness of one species and the unfitness of another for a new sphere. We have seen that sometimes different species live apart or live together, and all or most of them flourish equally well.

These phenomena seem to me utterly to militate against the idea that the transmutation of species by means of Natural Selection is proved by the survival of one species and the extermination of another species. The destruction of one perfectly adapted species by another perfectly adapted one; the conflict of race with race which leads to the extermination of the one and the preservation in an unmodified form of the other; the survival of one species which is modified by the direct action of the conditions and the destruction of others which are unable to adapt themselves to the same conditions; the fitness of one species to new conditions and the unfitness of another;-may be taken as vivid illustrations of the preservation of favoured species in the struggle for life and of a certain kind of selection which takes place in nature: but there is no trace whatever of the action of Natural Selection, either in the strictest or the most lax sense of that term. And yet, strange to say, the struggle for existence which does not necessarily produce the survival of the fittest, but only of the stronger of two competing species; which does produce extermination; which leaves organisms unmodified; which does not adapt the unfit to new conditions; which ceases in the 
mutual separation of allied species; which produces a co-operation of very distinct species, enabling them to resist the disabilities of their outward conditions; which, in no one of its different phases produces the transmutation of species by Natural Selection, is cited as the strongest argument to prove the efficient and all-embracing influence of that supposed law of nature.

(b) NO ORGAN OR INSTINCT EXISTS FOR THE SOLE BENEFIT OF ANOTHER SPECIES.

"Bear ye one another's burdens."

"Every man must bear his own burden." -PAUL.

The second argument urged by Mr. Romanes is based upon the fact that "among all the millions of structures and instincts which are so invariably and, for the most part, so wonderfully adapted to the needs of the species presenting them, we cannot find a single instance, either in the vegetable or animal kingdom, of a structure or an instinct which is developed for the exclusive benefit of another species." * This argument does not, however, apply to the cases in which "a structure or an instinct is of primary benefit to its possessor and then becomes of secondary benefit to some other species on account of the latter being able in some way or other to utilise its action." $\dagger$

"From the first Darwin invited criticism to adduce a single instance, either in the vegetable or animal kingdom, of a structure or an instinct which should unquestionably be proved to be of exclusive use to any species other than the one presenting it. $\mathrm{He}$

* Darcuin and After Darruin. p. 286.

+ Ibid. p. 288 . 
even went so far as to say that if any one such instance could be shown he would surrender his whole theory on the strength of it. - . Now, as this invitation has been before the world for so many years and has not yet been answered by any naturalist, we may by this time be pretty confident that it never will be answered. How tremendous, then, is the significance of this fact in its testimony to Darwin's theory. . . . Therefore I say that this immensely large and general fact speaks with literally immeasurable force in favour of Natural Selection as at all events one of the main causes of organic evolution."-(Darwin and After Darroin. ph. 286-7.)

It might seem a simple act of prudence to leave unnoticed so powerful an argument as this; and bearing in mind the warning that "fools rush in where angels fear to tread," it might be well to give up an attempt which no one has been rash enough to make. But if this unanswered challenge constitutes "a general consideration of the largest possible significance in the present connection," one would have supposed that the advocates of the theory would have frequently employed so powerful an argument. But curiously enough it is not so. Mr. Romanes says :-

"It is somewhat remarkable that the enormous importance of this argument in favour of Natural Selection as a prime factor of organic evolution has not received the attention which it deserves. Even Darwin himself, with his characteristic reserve, has not presented its incalculable significance, nor do I know any of his followers who have made any approach to an adequate use of it in their advocacy of his views."-(Darwin and After Darwin. ph. 29I-2.)

That the opponent should avoid and ignore an argument of so much importance-an argument which, it might be assumed, he could not answer satisfactorily-is intelligible enough; but that the advocate should hesitate to use such an argument is simply astonishing, when we consider the very great acumen, sometimes almost amounting to genius, which characterises those who have defended this theory. Let us see if there are any reasons why this strong argument has not been employed. 
I venture to say that the reason why no naturalist has responded to this challenge arises from the fact that he is invited to discover what cannot possibly exist in the actual world of nature. No one, however opposed he may be to the theory of Natural Selection, would think of denying that there is a struggle for existence, or that self-preservation is the first law of nature, though it is not, let us hope, the only one. In such a case the last thing that anyone could expect to find on a priori grounds is the existence of organs and instincts which are primarily of no use to their possessors, but which are employed for the benefit of another species. This phenomenon would handicap the assisting species so that it would run the risk of self-effacement.

The fact of the absence of the phenomenon under consideration is said to be "just precisely what we should expect if this theory (of Natural Selection) were true, while upon no other theory can its universality and invariability be rendered intelligible." But surely all theories of the transmutation of species, when brought out of the region of pure speculation, must assume as the axioms of their reasoning the struggle for existence and the need for modification in order that organisms should be adapted to new and different conditions. Whatever be the problem that a race has to solve-to preserve a present adaptation or to create a new one, to adapt itself to new conditions by one method or by another-it must be solved in such a way as to secure the preservation of the race.

It is contended that on the hypothesis of the beneficent design theory, "it is inexplicable that no species should ever be found to present a structure or an instinct having primary reference to the welfare of another species, when, ex hypothesi, such an endless amount of thought has been 
displayed in the creation of structures and instincts having primary reference to the species which present them." But if we take the ground that beneficent design works through the processes of evolution, in a world where the struggle for existence exercises a never-ceasing influence, the divine action will operate in accordance with the conditions laid down, and with the laws framed, by an infinite wisdom. The phenomenon which we are asked to discover could not be produced in nature: it could only be brought about by miraculous intervention-an hypothesis not to be entertained in scientific discussion. I have been proceeding on the supposition that this arrangement, if possible, would be beneficial. I cannot discuss that point here at length, but I venture to affirm that a self-sacrifice which paid no attention to self-preservation and self-development in the highest as well as the lowest sense of those terms, would be neither good for the devotee, for the object of his beneficence, or for society at large. And what I believe to be true of human society, I see no reason for thinking untrue when applied to the animal world.

Surely all that the theory of beneficent design can reasonably require under these circumstances is that certain structures and instincts which are primarily useful to one species, should have a secondary importance through the co-operation of one species with another. Hence the only question which remains to be answered is as to whether there is in nature this co-operation which beneficent design may reasonably be supposed to have foreseen and provided for. So far as I am able to understand Mr. Romanes, he gives two diametrically opposite answers to this question. On the one hand he says, "Every species is for itself and for itself alone-an outcome of the always and everywhere fiercely raging struggle for life." And yet in the next sentence he refers to 
"cases where a structure or an instinct is of primary benefit to its possessor and then becomes of secondary benefit to some other species, on account of the latter being able in some way or other to utilise its action."** The second of these statements considerably qualifies the first. And it can be shown to be true in many instances not only that a dominant race uses another for its own purposes, but that the co-operation is voluntary on both sides, and that great benefits are gained by its adoption.

This co-operation conferring advantage to both species seems to me exactly to answer Mr. Romanes' requirements. "How magnificent a display of divine beneficence would organic nature have afforded if all-or even some-species had been so interrelated as to have ministered to each other's wants!" But if this be so, all the demands which can fairly be made on behalf of the theory of beneficent design are amply satisfied by the co-operation which actually exists.

Mr. Romanes quotes the concluding sentence from the article on "Instinct," contained in the 8th edition of the Encyclopaedia Britannica, which runs thus:-

"It thus only remains for us to regard instinct as a mental faculty, sui generis, the gift of God to the lower animals, that man, in his own person, and by them, might be relieved from the meanest drudgery of nature."

In the course of his comments on this passage, Mr. Romanes says :-

"This example will serve to show not only the distance that we have travelled in our interpretation of organic nature between the two successive editions of the Encyclopaedia Britannica, but also the amount of verification which this fact furnishes to the theory of Natural Selection. For, inasmuch as it belongs to the very essence of this theory, that all adaptive characters (whether instinctive or structural) must have reference to their own possessors, we find over- 
powering verification furnished to the theory by the fact now before us-namely, that immediately prior to the enunciation of this theory, the truth that all adaptive characters have reference only to the species which present them was not perceived. In other words, it was the testing of this theory by the facts of nature that revealed to naturalists the general law which the theory, as it were, predicted-. the general law that all adaptive characters have primary reference to the species which present them. And when we remember that this is a kind of verification which is furnished by millions of separate cases, the whole mass of it taken together is, as I have before said, overwhelming."-(Darwin and After Darwin. p. 29r.)

I have quoted this statement in extenso, lest by compression I should have fallen into unintentional misrepresentation. We must bear in mind that while Mr. Romanes asserts that all adaptive characters have reference only to the species which presents them, he admits that the functions, organs and instincts which are of primary importance to a species may also be of secondary utility to other species. He therefore may be understood to contend that it is a general law of nature that all adaptive characters have primary reference to the animals which possess them; that immediately prior to the enunciation of the theory of Natural Selection this truth was not perceived; and that it was the testing of the theory of Natural Selection which revealed to naturalists the general law which this theory, as it were, predicted.

We must be very careful at the outset how we interpret statements to the effect that animals were endowed with instincts for the sole benefit of man. Take, for example, what Paul says with reference to the law:- "thou shalt not muzzle the ox that treadeth out the corn." He contends apparently that the precept was not given for the benefit of oxen, but is only to be regarded as an allegorical command to the effect that, as we should say in the present day, the workman should have "a living wage," that he should be able to live by his work. But 
the commentator warns us not to misunderstand this rhetorical exaggeration of allegorical teaching. "The Apostle," says Dean Stanley, "could scarcely have meant to use the expression 'that God does not care for oxen' as absolutely true, in the face of such passages as Psalms xxxvi. 6, cxlvii. 9."* In the same way, it is quite possible that a philosopher might contend that animals were made for the use of man without denying that their instincts were of primary use to themselves. Take, for example, the instance of William Somerville, the author of the poem called The Chase. No one could assert more emphatically than he does that the animals were made for the use of man. Witness the following passage:-

"The soul

Of man alone, that particle divine,

Escapes the wreck of worlds, when all things fail.

Hence great the distance 'twixt the beasts that perish

And God's bright image, man's immortal race.

The brute creation are his property

Subservient to his will, and for him made.

As hurtful, these he kills; as useful those

Preserves, their sole and arbitrary King."

-(Bookiv., lines 4-I2.)

And yet he instances an instinct which is certainly of primary use to the animal. Speaking of a pack of hounds, he says :-

"Others apart by native instinct led

Knowing instructor! 'mong the ranker grass

Cull each salubrious plant, with bitter juice

Concoctive stored, and potent to allay

Each vicious ferment. Thus the hand divine

Of Providence, beneficent and kind

To all his creatures, for the brutes prescribes

A ready remedy and is himself

Their great physician."

-(Book i., lines 208-2r6.)

* Stanley's Epistles of St. Paul to the Corinthians. vol. i., p. 172. 
This, it should be observed, is a "native" instinct, and is surely conceived as being of use to animals, even when they are not in the service of man. But however this may be, the criticism of $\mathrm{Mr}$. Romanes raises the question as to the universal opinion before the publication of The Origin of Species on two points. First, did all philosophers believe that instincts were of no primary use to the animals that possessed them? Secondly, did all philosophers believe that man was the final cause of creation, and that all things were made for his especial benefit?

As to the first point, it is hardly conceivable that any one who has studied the phenomena of instincts, however cursorily or under whatever mistaken ideas, could doubt for one moment that they must, in the first place, have been of primary importance to their own possessors. But if evidence is required to show that long ago this opinion was held, we have only to refer to the pages of Kirby's Bridgewater Treatise, in which he speaks of "the infinite variety of instincts, and their nice and striking adaptation to the circumstances, wants and station of the several animals that are endowed with them."* Dr. Roget, in his Bridgewater Treatise, bears testimony to the fact that the individual and the species are preserved not by "the slow and uncertain calculations of prudence," but by "innate faculties, prompting by an unerring impulse to the performance of the actions required for those ends." $\dagger$ "The doctrine of Instincts," says Archdeacon Paley, "is that of appetencies, superadded to the constitution of an animal for the effectuating of a purpose beneficial to its race." +

\footnotetext{
* Vol. ii., p. 164 .

+ Vol. ii., p. 514 .

¥ Natural Theology. chapter xviii.
} 
With respect to the second point, it is indeed true that philosophers have held the doctrine that man is the final cause of the creation, and that all things were made for his especial benefit. Bernardin de SaintPierre asserted that wherever fleas are, they jump on white colours, and that this instinct has been given them that we may more easily catch them. He informs us that the melon has been divided into sections by nature for family eating, and he adds that the pumpkin, being larger, can be eaten with one's neighbours.* But it is no less true that this view has been held up to ridicule by philosophers long, long before the promulgation of the theory of Natural Selection.

Cicero, in his De Naturî Deormm, puts the following argument into the mouth of Velleius:- "Or were these things made, as you almost assert, by God, for the sake of men? Was it for the wise? If so, then this great design was adopted for the sake of a very small number. Or for the sake of fools? First of all there was no reason why God should consult the advantage of the wicked; and, further, what could be His object in doing so, since all fools are, without doubt, the most miserable of men, chiefly because they are fools?"-(Book i., § 9.)

"Although it be," says Descartes, "a pious and good thought as regards morals, to believe that God has made all things for us, to the end that that may stir us up the more to love and thank Him for so many benefits, although it be also true in some sense, because ther is nothing created from which we cannot derive some use, . . . it is not at all probable that all things have been made for us, in such a way that God has had no other end in creating them; and it would be, as I think, impertinent to seek to use this opinion in support of reasonings in physics, for we cannot doubt that there are an infinity of things now in the world, or that there formerly were, though they may have entirely ceased to be, without any man having seen or known them, and which have never served him for any purpose."-(Descartes. Principes de la Philosophie. vol. iii., p. 3.)

"Man," says Goethe, "is naturally disposed to consider himself as the centre and end of creation, and to regard all the beings that surround him as bound to subserve his personal profit. He takes

\section{* Etudes de la Nature. Etude xi.}


possession of the animal and vegetable kingdoms, devours them, and glorifies that God whose Fatherly bounty has prepared the festal board. He removes its milk from the cow, its honey from the bee, its wool from the sheep; and because he uses these animals for his profit, he imagines they have been created for his use. He cannot imagine that the least blade of grass is not there for him."-(Eckermann. Gespräche mit Goethe. t. ii., p. 282.)

"Why," says Montaigne, "should not a gosling say thus: "All the parts of the universe regard me; the earth serves me for walking, the sun to give me light, the stars to inspire me with their influences. I have this use of the winds, that of the waters; there is nothing which this vault so favourably regards as me; I am the darling of nature. Does not man look after, lodge, and serve me? It is for me he sows and grinds. If he eat me, so does he his fellow-man as well ; and so do I the worms that kill and eat him. . . . A crane could say as much, and still more magnificently, for the liberty of its flight, and for the possession of that high and beautiful region." (Essais. ii., xii. See P. Janet's Final Causes. pp. Ig2-4.)

Hence when Theodore Parker, on the I 7 th December, I 859, wrote his amusing satire, "A Bumble-bee's Thoughts on the Plan and Purpose of the Universe," which might have been, and possibly was, suggested by Mr. Darwin's account of the correlation between the humble-bee and the red clover, it is quite clear that he did not promulgate a new philosophy which was the result of the publication of The Origin of Species. He merely took the newest and the most striking illustration. The assumption that the world and all that it contains was made for man alone is satirised with cutting irony in the speech of the philosophical Bumble-bee, which he is represented as making on the 2 Ist of June, in the year One million six hundred and seventeen before our era, the burden of which is that the Bumble-bee is the purpose of the universe: "Yes, gentlemen, the plan of the universe intends the Bumble-bee as its End and Final Cause. Without him the world would have been as unmeaning as a flower with no honey in its breast." *

* The Collected Works of Theodore Parker. vol. xii., pp. 150.I64. 
If, then, what I have said can be sustained, Mr. Darwin challenged the scientific world to find a phenomenon which could not possibly exist, and Mr. Romanes considers it one of the strongest arguments to assert that this challenge has never been answered and that this phenomenon has not been found. Mr. Romanes demands of the advocates of the theory of beneficent design that this impossible phenomenon should have taken place; and in addition first denies and then affirms that mutual cooperation, followed by mutual advantage, which is all that the theory of beneficent design could reasonably demand. And not content with this, he quotes the conclusion of an article on "Instinct," which appeared before the publication of The Origin of Species, to show the change which Natural Selection has made in the universal opinion which prevailed previously, when in point of fact it had long ago been taught that there was a marvellous correlation between the instincts and the organisms and outward conditions of animals; and that it was absurd to suppose that the great globe and all its organic contents had been made solely for the benefit and advantage of man. Natural Selection could not have produced this total change of front, because no such total change of opinion took place at the crisis named. We should often be mistaken in the intelligence of an epoch or crisis in history if we were to judge it by the narrow and prejudiced views which even a writer in the last edition of the Encyclopaedia Britannica may happen to express, for apparently it is possible for such an author to write on such a subject as a partisan of a particular view, rather than as a compiler of existing opinions. And even if all this had taken place, just as Mr. Romanes supposes, proof would still be required to show that this change of opinion had taken place as the result of the propagation of the special doctrines of Natural Selection; 
for the theory of organic evolution, the evidences for which Mr. Romanes has so lucidly stated, would have caused men to see the folly of supposing that organs and still more, instincts should be given to animals not for their own use, but solely for the use of man, long before man himself came upon the scene.

There need be no great wonder in our minds when we find that this argument has been so little used, when we consider how little support it renders to the theory of Natural Selection.

It is with great reluctance that I have entered on a discussion, so purely theological, in this, connection; but it seemed to me necessary, if possible, to remove the impression that the argument for Natural Selection is especially strong in its refutation of the principles of a rational theology.

(c) THE ANALOGY BETWEEN NATURAL AND ARTIFICIAL SELECTION.

"The chief objection to historical parallels is, that the diligent narrator may lack space, or (what is often the same thing) may not be able to think of them with any degree of particularity, though he may have a philosophical confidence, that, if known, they would be illustrative."-(Middlemarch. vol. ii., p. 2J3.)

"Like-but oh ! how different."

-WORDSWORTH.

The third argument is based upon the close analogy between Natural and Artificial Selection. Dr. Romanes puts the case thus:-

"The third general class of facts which tell so immensely in favour of Natural Selection as an important cause of organic evolution, 
are those of domestication. The art of the horticulturist, the fancier, the cattle breeder, \&c., consists in producing greater and greater deviations from a given wild type of plant or animal, in any particular direction that may be desired for purposes either of use or of beauty. . . We know as a matter of fact that all these differences have been produced by a process of Artificial Selection or pairing. . . . Now it is immediately obvious that in these cases the process of Artificial Selection is precisely analogous to that of Natural Selection -and of sexual selection-in all respects save one : the utility or the beauty which it is the aim of Artificial Selection continually to enhance, is utility or beauty in relation to the requirements or to the tastes of man; whereas the utility or the beauty which is produced by Natural Selection and sexual selection, has reference only to the requirements or the tastes of the organisms themselves. But with the exception of this one point of difference, the processes and the products are identical in kind. . . . It becomes impossible to doubt that selection by nature is able to do at least as much as Artificial Selection in the way of thus creating new types out of old ones. Artificial Selection, indeed, notwithstanding the many and marvellous results which it has accomplished, can only be regarded as but a feeble imitation of Natural Selection which must act with so much greater vigilance, and through such immensely greater periods of time. In a word, the proved capabilities of Artificial Selection furnish, in its best conceivable form, what is called an argument a fortiori in favour of Natural Selection."-(Darwin and After Darwin. pp. 205-6.)

This is the position which is taken by Mr. Darwin and his expositors.

"Man may be said to have been trying an experiment on a gigantic scale, and it is an experiment which nature during the long lapse of time has incessantly tried. Hence it follows that the principles of domestication are important for us."-(Darwin. The Variation. Ist.ed. vol. i., p.3.)

"The experimental argument which lies at the very base of Mr. Darwin's theory is that man's process in forming new breeds of pigeons is the analogue of nature's process in evolving new forms from old-the one is Artificial Selection, the other Natural Selection." -(St. Clair. Darwinism and Design. p. Io8.)

Shakespeare is supposed to speak somewhat to the same effect in The Vinter's Tale:- 
"Perdita:

I have heard it said,

There is an art, which, in their piedness, shares

With great creating nature."

"Polixenes: Say there be;

Yet nature is made better by no mean,

But nature makes that mean : so, o'er that art,

Which, you say, adds to nature, is an art

That nature makes. You see, sweet maid, we marry

A gentler scion to the wildest stock;

And make conceive a bark of baser kind

By bud of nobler race: this is an art

Which does mend nature,-change it rather; but

The art itself is nature."

$$
\text { -(Acti\%., sc. 3.) }
$$

In considering this argument, it may be well to note at the outset how very complex is the idea implied by the phrase "the facts of domestication." In the first place, there is a domestication which takes place altogether apart from Artificial Selection. Man introduces animals into new conditions, teaches them new habits, or developes old habits, and the inevitable consequence is, that a considerable change takes place which transmutes species quite apart from any selective infuences. The man who first tamed an animal and used it as his servant never thought of modifying the structure of the creature, and was probably unconscious of any influence which he was exercising in that direction. His chief thought was to preserve a race which had become useful to him; and often domesticated animals have been produced solely with this view. In some cases anything like Artificial Selection is impossible, or so difficult that it is never or rarely attempted.

Here, then, we have simple domestication, or domestication without selection. But after a time, we can well understand that it would occur even to savages that it would be well for them not only to preserve the race, but to improve the breed. With this object in view, they would select the best specimens to become the parents of the 
next generation. The principle of utility would be the measure of that which was best. The sportsman would naturally breed from the swiftest greyhounds with the best "staying power," and from the staunchest pointer who best understood his business. But in this breedimproving selection, we may discern, if I mistake not, three gradations:-(I) There would be those who are content to select with a view to utility alone, on the principle of the adage, "Handsome is as handsome does." (2) Every useful purpose which an animal fulfils tends to alter its form. There is, for example, a form which is best adapted for swift motion, as seen in the greyhound and the race horse, just as there is a form of vessel most adapted for fast sailing. Hence it would be natural to aim at the perfection of this form as an outward symbol of practical utility. And it is quite conceivable that the form which was perfect from the point of view of utility, might also come to be regarded as beautiful from an rsthetic point of view. Without contending that the sense of the beautiful has its origin in utilitarian notions, it is obvious that an object may be beautiful or not in our eyes according as it is associated with ideas of utility; as when we admire the colour on the cheek of beauty, because it is the accompaniment of physical health, and look with disgust upon the same colour on the nose of the inebriate, because it is associated in our mind with excess and disease. This would tend to a still more definite selection, the principle of utility and the principle of taste co-operating to produce one common result. (3) But sometimes we find that in the production of useful animals, the useful and the beautiful have both to be introduced, even when the ornamental has no necessary association with utility, or the breeder will not find purchasers. This is especially true with regard to riding-horses. 
Mr. Waiter Gilbey points out that the breeder of horses has to look chiefly to his sales to repay him for his trouble, and draws the inference that a horse, to be valuable, must be good looking. "This," says Mr. James Long, "is very true. There are plenty of useful slaves-horses which owners would hardly part with at any price, and which have no appearance to recommend them. But the buyer is only guided by what he sees, and, especially in horses, he will seldom take any word of recommendation from a stranger. Good looks are absolutely essential." But it must not be supposed that the principle of utility can therefore be ignored. No sensible man would buy a good-looking horse that was good for nothing else but to be admiredunless it were to sell again. How the principle of utility and taste co-operate is seen from what Mr. Gilbey further says :- "There are thousands of moneyed men who demand safety as a sine quâ non. Give them good temper and safe legs, and you may ask your own price for a goodlooking animal." *

There is, however, another kind of selection practised by man, in which the principle of utility altogether disappears, and the object which the experimenter proposes to himself is to produce an animal which shall realise the idea which he has formed in his own mind, which shall correspond to his conception of what is beautiful, or which shall in some way or other gratify his fancy. Hence, while we speak of the cattle-breeder, we talk of the pigeon-fancier. The process is as follows. First, the fancier pictures to himself an ideal form-an image which exists only in his own mind. Then he sets to work to modify a given organism till it resembles his ideal. If necessary, his first step is to produce the greatest quantity

* Mr. James Long. Farm Notis, Manchester Guardian, Dec. 29th, I887. 
of variation in all directions; to breed as many individuals, and as often as is possible. Then he watches the offspring and sets apart those which have any of the features of, or who show any inclination to vary in the direction of, the type which he has in his mind. Those which he selects he isolates most strictly for breeding purposes; the process is continued through successive generations, and the result is that in a very short time-considering the magnitude of the change produced-the type which he had pictured in the chambers of his imagery has taken flesh and become incarnate in a new variety. Selection here results in the creation of a new type and may be called type-producing, as distinguished from breed-improving.

We have now to consider what justification Mr. Romanes has for saying that "the process of Artificial Selection is precisely analogous to that of Natural Selection in all respects but one." We will defer for a moment or two the consideration of the one exception while we draw attention to some points of very considerable differences between the two processes.

In the first place it is obvious that Artificial Selection is the result of personal choice and of frequent interposition on the part of man. He follows a definite method, but with a certain amount of freedom of action in the face of any difficulty which may arise. In Natural Selection, on the other hand, selection is supposed to be due to the automatic action of the conditions of life, apart from any personal interposition.

In discussing this point it may be well to observe that the distinction which I wish to emphasise need not involve us in any theological disquisition. The question is not raised as to what is behind the system of nature. We are indebted to $\mathrm{Mr}$. Romanes for the clear enunciation of this principle in the following passages:- 
"All that is done by the theory of Natural Selection, or by any other possible theory of a scientific kind, is to suggest, with more or less probability, a modus opercudi; but who, or what, it may be that is ultimately concerned in the energising of the process, is a question which natural science can never be in a position to answer. . . . There the question must be left by science, to be taken up by philosophy."-(Romanes. Contemporary Reviere. vol. liii., p. 854.)

"In itself, science has no necessary relation to any such (i.e., theistic) belief. It is neither theistic nor atheistic, it is simply extra theistic." -Romanes. Nerture. vol. xxiv., p. 420.)

"Whether or not there is an ultimate design pervading all naturea causa causarum, which is the final raison d'etre of the cosmos, this is another question, and one which I take to have no point of legitimate contact with natural science."-(Romanes. Fortnightly Reviere. vol. xxx., p. 739-note.)

These statements accord with the position taken up by theologians as represented by Dr. Martineau.

"Science discloses the method of the world, but not its cause; religion its cause but not its method; and there is no conflict between them, except when either forgets its ignorance of what the other alone can know."-(Martineau. The National Review. vol. x.., p. 398. I862.)

On the basis of this eirenicon between religion and science, all that we have to deal with here is the order of nature. Taking this view, the obvious distinction occurs to us that Natural Selection works according to system, automatically; and that Artificial Selection works through the constant exercise of human intelligence and the constant interposition of a personal interference. This is a most important distinction, because it is clear that Natural Selection must be more difficult to achieve than Artificial Selection. It is therefore much to be regretted that this distinction has been obscured by the nomenclature employed by Mr. Darwin. He distinguishes two different kinds of Artificial Selection; he calls one methodical and the other unconscious selection. 
"Methodical selection is that which guides a man who systematically endeavours to modify a breed according to some predetermined standard."-(The Voriation. vol. ii., p. I93.)

"Unconscious selection is that which follows from men naturally preserving the most valued individuals without any thought of altering the breed."-(The Voriation. vol. ii., p. 193.)

"Unconscious selection graduates into methodical, and only extreme cases can be distinctly separated."-(The Variation. vol. ii., p. 193.)

Now the phrase, unconscious selection, seems to me to be especially unfortunate. It might indeed be said that savages who have tamed wild animals, so as to make them their servants, have modified these animal organisms without being conscious of what they were doing. But any kind of definite selection (whatever be its object, whether to improve a breed or to create a new type; whatever be its strictness, whether it selects the very best or only kills off the worst), is pursued according to a method, and cannot be pursued without consciousness on the part of the human operator. There is no real ground, then, for attributing a quasi-unconsciousness to one of the methods of selection practised by man. On the other hand, a quasiconsciousness is attributed to the processes of nature. Mr. Darwin justifies this mode of speech on the following grounds :-

"No one objects to chemists speaking of elective affinity, and certainly an acid has no more choice in combining with a base, than the conditions of life have in determining whether or not a new form be selected or preserved."-(The Variation. vol.i., p. 6.)

But surely the reason why no one objects to this mode of speech in chemistry is because the language is at once recognised as purely figurative, whereas in the present case, the effect is to lessen one important distinction between Natural and Artificial Selection, by attributing a quasiconscious choice to the automatic action of nature. 
Again Mr. Darwin says :-

"The term unconscious selection has been objected to as a contradiction, but see some excellent observations on this head by Professor Huxley (Natural History Revicer, October, I864, p. 578), who remarks that when the wind heaps up sand-dunes it sifts and unconsciously selects from the gravel on the beach grains of sand of equal size."-(The Variation. vol. ii., p. I97-note.)

Now what takes place in connection with the phrase "the wind unconsciously selects" is this: First we use a figure of speech which nobody will misunderstand, a1id personifying the wind we say that it selects. And then, to be sure that no mistake shall be made, we say that it unconsciously selects. But it is obvious that such use of language has the effect of disguising, or, at least, of lessening, the difference between Natural and Artificial Selection. Now I venture to assert that there is a sufficient difference here to make it worth while for the exponent of the theory to take note of it, even if he did not think that it made any practical difference. But surely in practice selection by the automatic action of the order of nature is more difficult to accomplish than selection by the personal interposition of man.

There is arother very important distinction between Natural and Artificial Selection. In both cases the object to be attained is the isolation for breeding purposes of individuals which vary in the same manner; but the method by which this end is attained in the two cases is very different. Natural Selection isolates by death, Artificial Selection by physical separation.

"Natural Selection acts by life and death."-(Origin of Specics. p. 156.$)$

"The exclusive breeding of similar variants is secured in nature by killing off all the other individuals."-(Romanes. The Contemporary Revicav. vol. lizi., p. 846.) 


\section{In Artificial Selection,-}

"He (man) does not rigidly destroy all inferior animals."--(Origin of Specics. p. 65.)

"Artificial selection is secured by fencings all the other individuals out of the field."-(Romanes. The Contemporary Review. vol. liii., p. 846.$)$

It follows from this difference of method that, in the strictest Artificial Selection, there is nerer any danger of extirpating a species, because those which are rejected by the cattle-breeder or pigeon-fancier are not killed off, and are allowed to reproduce their kind more or less. But in Natural Selection the isolation is by death, and the results may well be fatal in some cases if the strict isolation of favourable variations be carried out. The one process is more dangerous to the survival of the race than the other, to say the very least. This is seen at once by referring to the following illustrations of Artificial Selection on the one hand and of Natural Selection on the other:-

"The best flock-masters (in Germany) do not trust to their own judgment or to that of their shepherds, but employ persons called sheep-classifiers. . . In Saxony, when the lambs are weaned, each in his turn is placed upon a table that his wool and form may be minutely observed. The finest are selected for breeding and receive a first mark. When they are one year old, and prior to shearing them, another close examination of those previously marked takes place; those in which no defect can be found receive a second mark, and the rest are condemned. A few months afterwards a third and last scrutiny is made; the prime rams and ewes receive a third and final mark, but the slightest blemish is sufficient to cause the rejection of the animal."-(The Variation. iol. ii., pp. rg6-\%. Ist ed.)

Contrast with this the passage already quoted, but which is so important that it will bear repetition:-

"On the night of May 24th, I864, there was a severe frost in Kent, and two rows of scarlet rumers ( $P$. multifloms) in my garden, 
containing 390 plants of the same age, and equally exposed, were all blackened and killed, except about a dozen plants. In an adjoining row of Fulmer's dwarf-bean ( $P$. vulgaris) one single plant escaped. A still more severe frost occurred four days afterwards, and of the dozen plants which had previously escaped, only three survived."(The Variation. vol. ii., p. 309.)

A still severer frost, applying a third test and so assisting to discover those who were literally the fittest to resist the effects of cold, would probably have carried off the remaining three, or left, it may be, only one survivor, as in the case of the dwarf-bean. In the case of the Saxon lambs, it is obvious that there was no danger of extermination.

In connection with this contrast, it is interesting to observe that Mr. Romanes recognises its existence, but argues that it makes no difference which method is pursued.

"All that the causation of the case requires is that there should be cxclusine breding botreen the similarly-modified individuals. Whether this exclusive breeding is secured by killing off all other individuals, or by fencing them all out of a field, is plainly immaterial."-(Contemporary Review. vol. liii., p. 846.)

Again, I say, it is curious to find the advocate of Natural Selection ignoring this striking difference as Mr. Romanes does in his Darwin and After Darwin, although he recognises it elsewhere. Moreover, in a world dominated by "the struggle for existence," the cost at which the isolation is made must be a matter of supreme importance. For though the effect of a single selection would be the same in any one generation, the cost of it would be greater ; and that would tell in the course of successive generations.

It might be said that the isolation by separation might take place, and does take place, in nature. If, on enquiry further on, we find that this is so, it will not affect my present argument, for this is not the isolation brought 
about by the struggle for existence and the death of all but the fittest. In other words, this is not the isolation which the theory of Natural Selection presupposes.

But not only does Artificial Selection act by physical separation and not by death, but, as Mr. Darwin points out, man "protects, during each varying season, as far as lies in his power, all his productions." * Man protects the young, from which, when fully developed, he makes his choice, from all the indiscriminative death which occurs among the eggs and seeds and young in nature. He protects his domestic animals, as far as possible, from the effects of climate; he defends them or helps them to defend themselves from their enemies. If need be, he protects them from themselves. He feeds them well, and he does the same for all. In Natural Selection, all such protection is conspicuous by its absence. This surely is another difference that counts for something; so at least it appears in the judgment of practical men.

"A French gardener, M. Duval, regards it as a national calamity that such a number of pear trees are periodically cut down for firewood before they have borne fruit."-(The Variation. vol. ii., p. 260.)

The reason for this is that in France a considerable number of the best pears have been discovered in woods; and this has occurred so frequently that Poiteau asserts that improved varieties of our cultivated fruits rarely originate with nurserymen. By cutting down trees before they have borne fruit, the chance of obtaining better varieties is therefore diminished. Now in nature there is, as we have seen, an immense amount of indiscriminative death, especially among the young and the immature, which must militate against the survival of the fittest.

* Origin of Spcries. t. 65. 
We may regard the protection of Artificial Selection and the absence of such protection from Natural Selection from another point of view. The different disabilitics of nature constitute so many different kinds of selection, each one of which tends to secure the survival of the fittest - the fittest being in each case different; that is to say, the death which takes place in nature (if we suppose it to be selective), would cause the survival of the fittest, first of one type and then of another. Now this is the very opposite of what takes place in Artificial Selection. In that connection men form a very definite idea of the kind of animal which they wish to produce, and then select rigorously and continuously in accordance with one unchanging test of fitness. Lord Spencer writes :-

"It is therefore very desirable, before any man commences to breed either cattle or sheep, that he should make up his mind to the shape and qualities he wishes to attain, and steadily pursue this object." (The Variation. vol. ii., p. T95.)

The experience thus gained assures us that if Natural Selection is to act with the same efficiency as Artificial Selection, it is essential that only one test should be applied in each generation; in other words, that a race should be subjected to only one disability in each generation, and that the race should be subjected to the same disability generation after generation. But it is not probable that one disability will present the one constant selectire influence for so long a period. In nature, organisms are liable to suffer from many kinds of difficulty. There are the liabilities connected with climate; with birds or beasts of prey; and with parasites; with the limited amount of food available for the individuals of a given species.

It is quite conceivable that during one season there should be a day of extreme cold or a week of unwonted heat, a sudden invasion of encmies in increased numbers, 
or a short supply of food. Now, if Natural Selection is strict in its selection at every point, those which are most fit to endure cold would survive in the one case; those which are most fit to endure enormous heat would survive in the second case; those which were most fit to cope with enemies in the third case; and those which were most able to endure famine in the fourth case.

It is further obvious that these different tests will be applied with different degrees of rigour in successive years. In some there will be an exceptionally high or low temperature, which will kill off all those who are not especially fitted by constitution to bear sudden changes or to endure a given temperature. In some years there will be an unusual multiplication of the birds or beasts which prey upon a particular species. In some years there will be an extraordinary fertility or a quite abnormal scarcity in connection with the food required for a particular race, or an especial fertility of a given race will produce the same effect as a limited supply of sustenance. These different kinds of paramount disability will imply a different test, applied generation after generation and year after year, which must be equivalent in effect to what would follow if in Artificial Selection breeders were to alter their ideal every year. We shall be able to realise what effect all this will have upon the transmutation of species by supposing that the same method were followed in Artificial Selection.

Let us assume, for the sake of argument, that horseflesh had come into general use as human food, so that horses were bred with the special view of providing butchers'meat like bullocks or pigs. In that case there would be three principal types of horses, which the breeder would aim at producing: the type of the race horse, which would be bred with a view of producing horses who could run with the greatest speed; the type of the cart horse, which 
would be bred with a view of producing horses of the greatest strength; and the type of the edible horse, which would be bred with a view of obtaining an animal with as little bone and as much flesh as possible-an animal which matures as soon as possible and grows fat as easily as possible. Now, from actual expericnce of existing race horses, cart horses, and prize cattle and pigs, we know that these different types could be produced artificially. But they are produced artificially by rigid selection of the best according to a given type, and this selection goes on generation after generation. And it is quite clear that this is a most essential part of the process; for if the best race horse were to interbreed with the best cart horse, and the offspring were to breed with the horses of least bone and most flesh, we should producc probably an average horse, doing away with the effect of previous selection. We should most certainly not produce supreme excellence in any one type. Of course this difficulty would be easily overcome if we conceived of a given number of each generation which were in every respect, and from cvery point of view, the fittest to live. Thus Mr. Wallace says :-

"At one period of life, or to escape one kind of danger, concealment may be necessary; at another time, to escape another danger, swiftness; at another, intelligence or cunning; at another, the power to endure rain or cold or hunger ; and those which possess all these faculties in the fullest perfection will generally survive."-(Daruinism. p. I23.)

This argument ignores the fact of accidental or indiscriminative death. But putting this consideration on one side, we venture to ask where are these Admirable Crichtons to be found which excel at once in all these qualities; which are, at once, least visible and swiftest in the hour of danger, and most intelligent or cunning in the time of difficulty, and best able to bear rain or hunger? It is not 
that we question for a moment that an animal like the hare might have all these gifts-able to conceal itself when sitting on its form; swift of foot when pursued by enemies; intelligent enough to increase its chance of escape by stratagem, and also able to bear the inclemency of a rigorous climate. What we do venture to doubt is that certain individuals would excel in all these respects beyond the rest of their generation and secure their survival by virtue of this manifold excellence.

It might be argued that in some cases, at any rate, those which survived a very severe test thereby gave evidence of at least a general vigour of constitution, which would enable them to endure other tests to which they might be subjected equally well. Thus Mr. Darwin says :-

"Even when climate-for instance, extreme cold-acts directly, it will be the least vigorous individuals, or those which have got least food through the advancing winter, which will suffer most."--(Origin of Species. $p .54$.

But this hardly agrees with what Mr. Darwin himself elsewhere says of the Forelle pear.

"The Forelle pear flowers early, and when the flowers have just set-and this is the critical period-they have been observed, both in France and England, to withstand with complete impunity a frost of $18^{\circ}$ and even $14^{\circ}$ Fahr., which killed the flowers, whether fully expanded or in bud, of all other kinds of pears. This power in the flower of resisting cold, and afterwards producing fruit, does not invariably depend, as we know on good authority, on general constitutional vigour."-(The Variation. vol. ii., p. 306.)

But if we admit the principle that individuals of a given generation are so variously endowed that some would be the fittest to endure one test and the least fit to endure another, then it would necessarily follow that the elimination of the worst from one point of view might imply the destruction of the best from another point of view ; or, to say the least, the selection of the best from one point of view might mean the blindfold destruction of the race 
so far as another kind of fitness is concerned. Thus, in any one given generation, if a species were subjected to four different tests, it might follow that the most favourable variation with respect to one disability might be destroyed by the action of one of the other tests. It is conceivable that all the most favourable variations might in turn disappear. The effect would be similar to what would take place in Artificial Selection if first the fleetest, and then the fattest, and then the strongest horse were saved and the others destroyed. Again, if during an exceptional season one particular disability prevailed, it would prevent the action of Natural Selection with respect to other advantageous variations which might arise. Mr. Darwin puts this case very clearly:-

"Even if the fitting variations did arise, it does not follow that Natural Selection would be able to act on them and produce a structure which apparently would be beneficial to the species. For instance, if the number of individuals existing in a country is cletermined chiefly through destruction by beasts of prey, by external or internal parasites - as seems often to be the case-then Natural Selection will be able to do little or will be greatly retarded in modifying any particular structure for obtaining food."-(Origin of Species. p. I80.)

This principle is orerlooked by Mr. Wallace in the following passage :-

"Now let us suppose a change going on which renders it bencficial for a species to obtain longer wings in order to escape from sone enemy, and a stronger bill to enable it to capture some fresh insect, both of which (the enemy and the insect) are gradually increasing in the country. Variations of both these kinds occur in abundance every year, to an amount measured by ten or twenty per cent. of the average dimensions. Either of the variations would be useful and would be preserved separately, while the combined variation would be doubly useful and would also be preserved whenever it appeared." -(Wallace. Nineteenth Century. vol. vii., p. IO4.)

Now, in this passage, Mr. Darwin's principle, that prorision against one danger does not necessarily secure safety 
from another, is overlooked. But on the supposition that a crisis has arrived in which it is necessary for a bird to have a longer or a stronger beak for one purpose, and a longer and stronger wing for another, then it is clear that the long wings will not enable him to eat the insect, though they might enable him to go where it is to be found, nor will the longer bill enable him. to escape his enemy. It is only the combined variation which would be sure to survive.

Professor Milnes Marshall compares the action of Natural Selection to the process of purchasing an umbrella.

"If you go into a shop to purchase an umbrella, the one you select is by no means necessarily that which most nearly approaches ideal perfection, but the one which best hits off the mean between your idea of what an umbrella should be and the amount of money you are prepared to give for it--the one, in fact, that is on the whole best suited to the circumstances of the case, or the environment, for the time being. It might well happen that you had a violent antipathy to a crooked handle, or else were determined to have a catch of a particular kind to secure the ribs, and this might lead to the selection, i.e., the survival, of an article, that in other and even in more important respects was manifestly inferior to the average. So it is also with animals."-(Nature. vol. xlii., p. 475.)

Illustrations are generally powerful arguments, because they present a subject in an interesting, concrete way: they are convincing, because it seems to us that great principles are thus brought to a practical test: and they are more likely to be remembered. But the value of the illustration depends upon its exact correspondence with the principle to be explained. No doubt Professor Marshall would choose out an umbrella as he describes: taking one which cost not more than a certain sum, avoiding a crooked handle, determining to have a catch of a particular kind. If he were fortunate enough to find an umbrella endowed with all these characteristics, he would select it for purchase. 
But if the shape of the handle and the nature of the catch occurred in an accidental sort of way among umbrellas of all prices, and if he took care to mention his different requirements one at a time-then first he might say that he would not have an umbrella with a crooked handle, so all the umbrellas with crooked handles would be put out of his way. Then suppose that among the straightest handled umbrellas he asked for a catch of a particular kind-which might be old-fashioned or a new fashion hardly yet come in, and so not to be found in any great number-then all the other umbrellas with all other kinds of catches would be put aside; and then it is quite conceivable that he might not like the look or the price of the remaining umbrellas. Of course when this was discovered, the obliging shopman would begin de novo. But selection by death as it is supposed to occur in nature knows nothing of $d a$ capo operations; and hence, as it seems to me, the difficulty presented by successive tests of fitness is not overcome by the parable of the umbrella. It does not prove that "animals will, in each generation, have the best chance of survival which are most in harmony with their environment." Hence we have a fourth most important difference between Natural and Artificial Selection which has been overlooked by Mr. Romanes.

We have seen that Natural Selection is handicapped by co-operation among animals which often prevents that rigid and pitiless competition which the theory presupposes. Now, it is quite clear that domestic animals cannot combine in a similar way to resist the will of the breeder.

Mr. Romanes incidentally and parenthetically remarks that the facts of domestication illustrate not only the action of Natural Selection, but also of Sexual Selection. But I venture to think nothing can be more different than 
the love, courtship and marriage of animals as it occurs in the freedom of nature and as it is modified by the art of man. For surely Artificial Selection is nothing more than the control exercised by the will of man over the sexual passions of animals. The breeder of dogs has not the slightest regard for the romantic love which may bind the well-bred dog to a mongrel, and he vetoes the union of the two as emphatically as any fashionable mother in May Fair frowns upon the "detrimental" who aspires to her daughter's hand. He takes care that the blind impulse of passion shall be directed aright. He cares nothing whether the tastes of the animals are satisfied in their marriage. It is his taste which has to be gratified.

The breeder does not respect the sanctities of the monogamic union; nor does he allow the males of certain species to fight with one another for the possession of their large harems; he does not permit polyandry of a promiscuous sort. In short, he puts upon animal love, courtship and marriage a restriction which is, of course, conspicuous by its absence in nature. There is an immense difference between the two propositions, when we contend that Artificial Selection controls Sexual Selection, and when we assert that Natural Selection, unless of the strictest kind, is rendered abortive by Sexual Selection.

But if we put aside all these considerations, and assumed the unqualified truth of the principle laid down by Mr. Romanes, one great difficulty would remain to be considered. The advocate of the theory lays upon Natural Selection a burden from which Artificial Selection is perfectly free. Man can produce what variant he pleases, perfectly irrespective of the principle of utility. He can create whatever form his fancy paints. If in so doing he 
makes the animal helpless, he can protect it, even though it be one of what Mr. Tegetmeicr calls "the monstrosities of the fancier." * But the principle of utility dominates Natural Selection with an iron rule. And not only must the variation preserved be useful to the animal-it must be (if we are to be strict in our logical development of the theory) a matter of life and death. The favourable variation survives; the unfavourable variation perishes. It is not enough that we should recognise the fact that these two features of Artificial and Natural Selection are not perfectly analogous; they are stupendously different, and would be sufficient in itself to make us doubt whether what has been achieved by Artificial Selection is possible to Natural Selection.

We have now to consider the one exception which Mr. Romanes finds to the complete analogy between the processes of Artificial Selection and Natural Selection.

"The utility or the beauty which it is the aim of artificial selection continually to enhance, is utility or beauty in relation to the requirements or to the tastes of man; whereas the utility or the beauty which is produced by Natural Selection and sexual selection, has reference only to the requirements or the tastes of the organisms themselves." -(p. 296.)

But if we consider all "the facts of domestication," we shall find that Mr. Romanes is hardly justified in making this distinction between the two processes so absolute as he does. For in some cases, at any rate, what is useful to man is also useful to the animal. Its mere domestication is a blessing to both. The animal gains a powerful and intelligent protector, the man secures a faithful companion and a useful servant or a valuable possession. In all cases in which the animal is used for operations kindred with those which it pursues in a wild condition, the training and selection of man make it more capable, in whatever

* Nature. vol. xxxiii., p. 412 . 
condition it is placed. It is only in the case of mere fancy breeds that the animal is not benefited by the curious transmutation brought about by selection.

Mr. Romanes supplies us with some beautifully-executed plates representing the different kinds of dogs and other animals which have been the outcome of Artificial Selection. He presents these as an overwhelming proof of the efficacy of the selective principle in the modification of organic types ( $p .297)$, and adds: "It is surely unquestionable that in these typical proofs of the efficacy of Artificial Selection we have the strongest conceivable testimony to the power of Natural Selection in the same direction" (p. 3I3). That would be perfectly true if the operation was carried on in the same way in both cases; but the triumph of Artificial Selection does not imply the necessary triumph of Natural Selection if the process is different.

We want to have the identity of the two processes demonstrated to us. We know that domestic dogs differ from one another, but they have very little more to do with the proof which Mr. Romanes is attempting to establish, than the dogs of Lear and Edgar with any rational conversation, when the mad king, in the midst of arraigning his daughters, says :-

"Lear: The little dogs and all, Tray, Blanch, and Sweet-heart, see they bark at me."

And the sham madman takes up the running :-

"Edgar: Tom will throw his head at them :-Avaunt, you curs!

Be thy mouth or black or white,

Tooth that poisons, if it bite;

Mastiff, yreyhound, mongrel grim,

Hound, or spaniel, brach, or lym ;

Or bobtail tike, or trundle-tail ;

Tom will make them weep and wail :

For, with throwing thus my head,

Dogs leap the hatch, and all are fled."

-Act iii., sc. 6. 
The dogs and the pigeons and the cattle are admirably drawn, and prove quite conclusively the power of Artificial Selection. The perspective of the drawings is not, however, as Mr. Romanes says, exactly what it should be, and so some of the animals look larger than they actually are. The perspective of the animals is rather at fault, I am inclined to think, in the logical argument that they adorn. They are put in the foreground on the implication that they are the outcome of a process precisely analogous (barring one item) to that of Natural Selection. We admit that the drawings may rightfully be regarded "as an overwhelming proof of the efficacy of the selective principle in the modification of organic types." We deny the assertion that in these typical proofs of the efficacy of Artificial Selection we have the strongest conceivable testimony to the power of Natural Selection.

But not only does Mr. Romanes exhibit the products of Artificial Selection as the proofs of the power of Natural Selection, although the processes are so different, but he also affirms that the results of Natural Selection must be much greater than those of Artificial Selection. "Artificial Selection, notwithstanding the many and marvellous results which it has accomplished, can only be regarded as a feeble imitation of Natural Selection, which must act with so much greater vigilance and through much immensely greater periods of time." But in a very limited period of time Artificial Selection can work the most marvellous transformation, so that the cattle-breeder and the pigeon-fancier have been said to wield a magician's wand. If the process is marvellously successful in so short a time, one does not see what else there is to be gained by immensely greater periods of time-when the transmutation is once completed. As for the assertion that Natural Selection must act with so much greater 
vigilance, we answer that Artificial Selection acts with a vigilance which, if not impossible, is singularly improbable in nature. Not only does Artificial Selection bar out accidental death and control Sexual Selection in a manner impossible in nature, but it selects with a care which cannot be surpassed in nature or anywhere else. Let us hear what Mr. Darwin says upon this subject.

"In the great majority of cases a new character, or some superiority in an old character, is at first faintly pronounced and is not strongly inherited; and then the full difficulty of selection is experienced. Indomitable patience, the finest powers of discrimination and sound judgment, must be exercised during many years. A clearly predetermined object must be kept steadily in view. Few men are enciowed with all these qualities, especially with that of discriminating very slight differences; judgment can be acquired only by long experience; but if any of these qualities be wanting, the labour of a life may be thrown away. I have been astonished when celebrated breeders, whose skill and judgment have been proved by their success at exhibitions, have shown me their animals, which appeared all alike, and have assigned their reasons for matching this and that individual. The importance of the great principle of selection mainly lies in this power of selecting scarcely appreciable differences, which nevertheless are found to be transmissible, and which can be accumulated until the result is made manifest to the eyes of every beholder." -(The Variation. vol. ii., p. 193.)

I think it would be rather a rash assertion to make if we were to say with Mr. Romanes that the death which takes place in nature "must act with so much greater vigilance" than is exhibited by the cattle-breeder and the pigeon-fancier: for this death is often indiscriminativethe conditions under which the test is applied are often such that it would be rash to say whether the survivor were the fittest or the most fortunate. Above all, the animals of prey, which are often the agents of so-called selection in nature, are so much impressed with the importance of satisfying their hunger that they would not be likely to take note of differences which escaped the keen eyes of Mr. Darwin. 
The question as to whether the processes of nature and of art are closely analogous to one another, and whether the method of nature is not superior to that of art, is capable of a very practical solution. If the method of nature is almost precisely similar to that of art-if the method of nature is infinitely superior to that of artwhy should we not persuade the cattle-breeder and the pigeon-fancier to adopt the method of nature? And if they are too conservative to alter their methods, if they are naturally content with their brilliant success, why not offer a prize of $£ I, 000$ to the man who will most successfully reproduce in art the process which the theory of Natural Selection supposes to be always going on in nature?

Let us see what he would be required to do. In the first place he must invent some system of selection which will work automatically and not require his supervision or interference when it is once started. He must take care not to protect his eggs and seeds and undeveloped young, but let the fox and the weasel, and indeed any wild or tame creature that may be about, take what he can get. When it comes to selection he must kill off all those from which he does not intend to breed. And he must not act on one principle of selection throughout, but apply different tests in each generation and throughout many generations. Those which ultimately survive these various processes must not at the last be isolated for breeding purposes, but they are to marry as they please. In addition to all this, if you want to have exactly the same process as that of Natural Selection you must only select, when you do select, such variations as are of vital importance to the race; in short, the breeder or the fancier must surround his art with all the disabilities which we have seen to obtain in nature. What cattle-breeder, what pigeon-fancier, would undertake 
to exercise his magic skill under these restrictions? What language would be adequate to express his feelings when this proposition was made to him? What opinion would he have of the intelligence of the philosopher who suggested such an experiment? And yet these proposed restrictions do actually occur in nature; and, in spite of them, Natural Selection is supposed to resemble Artificial Selection, and to produce results almost infinitely greater than those of art. Natural Selection, which is supposed to dominate nature and largely to direct the transmutation of species, must act, if it acts at all, under disabilities which would make all the efforts of Artificial Selection futile, and yet the experiment of Artificial Selection is cited as the most convincing proof of the reality of Artificial Selection. The only way of getting over the difficulty presented by this discrepancy would be to deny that there is any analogy whatever between the two processes; but this denial, as the Rev. G. St. Cláir has shown, would constitute a rejection of the Darwinian hypothesis.

"Mr. Darwin says : 'Nothing at first can appear more difficult to believe than that the more complex organs and instincts should have been perfected not by means superior to, though analogous with, human reason, but by the accumulation of innumerable slight variations, each good for the individual possessor.' In this passage it is assumed that the accumulation of variations, till a species is formed, is a process not at all analogous to man's processes, but to be contrasted with the latter; yet the experimental argument which lies at the very base of Mr. Darwin's theory is that man's process of forming new breeds of pigeons is the analogue of nature's process in evolving new forms from old-the one is Artificial Selection, the other Natural Selection."-(St. Clair. Darruinism and Design. p. 107-8.)

So much, then, for Mr. Romanes' precise analogy between Artificial and Natural Selection, barring one exception. Artificial Selection works by personal interposition; Natural Selection works by automatic action. Artificial Selection isolates by separation; Natural Selection isolates by death. 
Artificial Selection protects from accidental death; Natural Selection is incapable of affording such protection. Artificial Selection aims with constant and cautious anxiety to select according to a preconceived type; Natural Selection, acting through the various disabilities of the conditions of animal life, selects (if it selects at all) first one type of excellence and then another. Artificial Selection does not permit animals to combine in their own defence; Natural Selection cannot prevent animals from co-operating to prevent a rigid selection of the best by death. Artificial Selection overrules the love, courtship, and marriage of animals; Natural Selection is powerless to interpose in the matter of Sexual Selection. Artificial Selection can produce almost any form it pleases, selecting any variations it may have a fancy for; Natural Selection is dominated and controlled by the principle of utility, and can secure the survival only of those variations which are of vital importance to the animals themselves.

Can we expect similar results from processes so different? Can we expect transcendently greater results from a process so full of disabilities when we find that the other process is free from those drawbacks? No practical man would think of adopting the method which is supposed to take place in nature, because he knows that it would be a complete failure. But if this is really so, the comparison between Natural and Artificial Selection can scarcely be called an argument a fortiori in favour of Natural Selection. The success of Artificial Selection under conditions impossible in nature would rather go to show that Natural Selection is powerless, save in the dream of the scientific theorist, and omnipotent only in the realm of a fantastic imagination. 


\section{CHAPTER VII.}

THE TWO BEST ILLUSTRATIONS.

"More particulars

Must justify my knowledge."

-Cymbeline. Act ii., sc. 4 .

WHEN a particular department of nature is selected for the exposition of some general principle, the object may be to illustrate the action of what is believed to be a universally acknowledged law of nature, or else to test the correctness of a tentative theory. There can be no doubt whatever as to the advantage, so far as explanation is concerned, of a concrete illustration of an abstract principle. "The philosopher," says Dugald Stewart, "whose mind has been familiarised by education and by his own reflections to the correct use of more comprehensive terms, is enabled . . . to arrive at general theorems; which, when illustrated to the lower classes of men in their particular applications, seem to indicate a fertility of invention little short of supernatural."*- This principle is duly recognised by Mr. Romanes, when he says that "perhaps the proof of Natural Selection as an agency of the first importance in the transmutation of species may be best brought home to us by considering a few of its applications in detail." $\dagger$

Now it is perfectly legitimate for those who approach the consideration of a particular group of phenomena, to

* Elements of The Philosophy of the Human Mind. Part i., chapter iv. + Darwin and After Darwin. p. 316. 
assume the truth of the given law which they believe to have been already proved. Thus Mr. H. F. Osborn says that "the law of Natural Selection is well established, and no more under discussion." Those who believe this may confidently enter on a new field of enquiry, expecting to find illustrations of the action of Natural Selection there as elsewhere. That is the spirit in which Mr. Poulton entered on his most valuable investigations. He says :-

"Any scientific work which I have had the opportunity of doing has been inspired by one firm purpose-the desire to support, in however small a degree, and to illustrate by new examples those great principles which we owe to the life and writings of Charles Darwin, and especially the pre-eminent principle of Natural Selection."-(Preface. p. xiii.)

That is the spirit which inspired Mr. Darwin when he penned the following passage :-

"When both sexes of birds are so obscurely coloured that it would be rash to assume the agency of sexual selection, and when no direct evidence can be advanced showing that such colours serve as a protection, it is best to own complete ignorance of the cause, or, which comes nearly to the same thing, to attribute the result to the direct action of the conditions of life."-(Descent of Man. p. 49I.)

What is this but a predetermination to know nothing but Selection, Natural or Sexual? Apart from one of these explanations, we can know nothing! In the same way, Mr. Romanes takes for granted the action of Natural Selection in his attempt to solve the problem presented by instinct. Moreover, it was necessary, as a mere matter of historical sequence, that the proof of the transmutation of species as against the fixity of species, of evolution as against sudden creation, of transmutation of species and organic evolution by means of Natural Selection rather than by other means, should have been first established. Mr. Henry Walter Bates promulgated the theory of mimicry, having been first convinced of the truth of 
Natural Selection; and no one would have thought of instinct being developed by Natural Selection who had not first been convinced that it was an all-embracing law of nature.

Such a treatment of the subject is perfectly legitimate for those who are certain that Natural Selection is a great law of nature. Still it may be very much questioned whether such a conviction tends to produce a perfectly unprejudiced treatment of the subject. But the enquirer into the truth of Natural Selection regards a new sphere of nature as simply offering a new test of the theory. He can take nothing for granted but what can be proved; he will try to enter on the new enquiry with an open mind and with a perfect absence of all bias. This attitude of mind is well expressed in the following statement, made by Professor Eimer, in concluding his work on Organic Evolution:-

"Our duty is work; our right is free investigation; our satisfaction the establishment of a grain of truth for the benefit of mankind; our hope, knowledge."-( $p .435$.

Animated, if possible, by this spirit, we have now to consider how far it is true to say that defensive colouring and instinct afford either the best illustrations of the supposed law of nature, or the best proofs of that wellknown theory.

\section{(a) DEFENSIVE COLOURING.}

"You shall play it in a mask."

-Midsummer Night's Dream. Act i., sc. 2.

Mr. Romanes selects defensive colouring as affording the best illustration of the action of Natural Selection.

"Among all the possible fields from which evidences of this kind (the application of the theory in detail) may be drawn, the best 
is that which may be generically termed defensive colouring."(Darwin and After Darwin. p. 3I6.)

Mr. Henry Walter Bates was the first to apply the theory of Natural Selection to the phenomena of animal colouring. In his classical paper entitled "Contributions to an Insect Fauna of the Amazon Valley, Lepidoptera: Heliconidae,"* he described the manner in which one species of butterfly, protected by a nauseous taste, was imitated or mimicked by another insect not so protected, and he attributed this strange resemblance to the action of Natural Selection. This interpretation was afterwards extended to those species which mimic the colour and form of some of the objects by which they are ordinarily surrounded. The existence of certain very conspicuously coloured insects presented an unexpected difficulty; but Mr. Wallace met this objection with an explanation which has been generally accepted as a remarkable confirmation of the theory.

Such is the historical order of the application of Natural Selection to the problem of defensive colours. But we shall perhaps understand the question better if we realise the logical explanation which binds together these different phenomena; for, as Mr. Poulton says: "in this, as in so many other cases, the steps by which the subject is best approached are almost exactly opposite to the historical steps by which it was gradually understood." $\dagger$

The logical nexus, which binds together all the phenomena of defensive colouring, may be stated thus. At the outset, the advocate of Natural Selection, already convinced, as we have seen, that his theory is a great law of nature, has no hesitation in assuming that defensive colouring is an illustration of the action of this great principle.

* The Transactions of the Linnean Society. vol. xxiii., part the third, $p p .495 .566$.

+ The Colour of Animals. p. 220. 
But if this is so, a difficulty at once occurs in connection with those animals which are conspicuously coloured, and yet enjoy immunity from attack. This difficulty is removed by the discovery that these creatures have certain disabilities attached to them : are hard to catch, difficult to swallow, or not good to eat; and that it is therefore of advantage, both to themselves and their enemies, that they should have some distinct "advertisement of inedibility." This advantage being once admitted, it is obviously beneficial to a species which is not thus protected and which is good to eat, that it should mimic those which are difficult to catch or unpleasant to eat. I venture to affirm that we cannot find in connection with any scientific investigation a more splendid illustration of the extension of a theory so as to afford an all-embracing explanation of varied phenomena. It only remains for us to ask whether the actual facts agree with this great and striking generalisation.

It is interesting to observe that the facts were known long before the time of Mr. Bates. Boisduval, in 1836 , drew attention to the resemblance between butterflies of different genera and species; * and in I8I5 Kirby and Spence speak of insects "imitating the colour of the plants, or parts of them, which they inhabit"; and refer to "the spectre tribe (Phasma) as going still further in this mimicry." + Therefore Mr. Bates cannot be credited with the invention of the term "mimicry," except in so far as it is understood to mean that mimicry is produced by the action of Natural Selection.

Before dealing with the different classes of phenomena embraced under the generic term of defensive colouring, it may be well to consider certain features of this method of

\footnotetext{
* Species Général des Lépidoptives. pp.372-373.

+ Introduction to Entomology. p. 405. 
transmutation by means of Natural Selection which belong alike to colours which conceal, to colours which act as warnings, and to insects which mimic the coloration of insects of different genera and species.

In the first place, after what has been said, it becomes a mere truism to assert that the efficacy of Natural Selection will be in inverse ratio to the amount of accidental death. We have seen that it is a logical demand of the theory, when dealt with from an abstract point of view, that we must get rid of the idea of accidental death. Here, then, is a good test to apply. The theory of defensive colouring, if it be so admirable an illustration of the action of Natural Selection, ought to introduce us to a sphere where accidental death is reduced to a minimum; or, at the very least, is not so common as in other spheres.

We shall be justified in applying this test especially to the insect world, for Mr. Wallace gives several conclusive reasons for the fact that the phenomena of mimicry abound among insects more than in other departments of the animal kingdom.* What evidence, then, can be adduced from the observation of naturalists to show that the insect world is less free than other spheres of nature from accidental death? I have not been able to find any such evidence adduced by the scientific theorist, but a very different testimony is given by the practical naturalist. Mr. Samuel H. Scudder says :-

"The great sources of destruction here, as in all groups of animals, are in early life. How large a proportion of the eggs that are laid by butterflies ever finally produce imagines? Let those answer who have attempted to follow their history in their native haunts. My experience leads me to believe that, at the very least, nine-tenths - perhaps ninety-nine hundredths-never reach maturity. Hymenopterous and dipterous parasites beset them at every step; the eggs, although so small and often heavily ridged, cannor escape the

* Contributions. pp. 99-10o. 
ovipositors of the tiny Pteromali; while in attempting to breed caterpillars taken in the field, the chance is so greatly against the evolution of a butterfly that hymenopterists actually choose this method of supplying their cabinets. 'Of two hundred larve of Pieris Brassicae,' Mr. Drewson, of Denmark, writes to me, 'I obtained only twenty pupæ; all the rest were attacked by Microgaster glomeratus, and my own attempts with the larvæ of Pyrameis Atalcnta, both in America and Europe, have been even more unavailing. These caterpillars seem to be peripatetic banquetting halls of Microgasters and Tachina."-(Nature. vol. iii., p. I47.)

\section{Weismann says :-}

"It is clear that in such animals as insects we can only speak figuratively of normal death, if we mean by this an end which is not due to accident. In these animals an accidental death is the rule; and is therefore, strictly speaking, normal."-(Essays upon Heredity. p. 22.)

A sphere in which accidental death is normal can scarcely be regarded as the most favourable for the illustration of the action of Natural Selection, for two reasons : in the first place, because there will be little certainty as to the survival of favourable variations; and secondly, because in some cases there might be a danger of exterminating a group by selection applied after so great an amount of accidental death. On this latter point Mr. J. Jenner Weir says :-

"It appears to me rather that as so few specimens become imagines in proportion to the eggs produced, the more need is there that these few should survive."-(Nrature. r'ol. iii., p. I66.)

We may regard the difficulty of "accidental" death from another point of view. The analogy of transmutation by Artificial Selection, or, in other words, by the isolation of similar variants from among the variations necessarily connected with reproduction, teaches us that there must be one object to be attained, and one process of selection strictly dominated by that object. Therefore, if Natural Selection is to work in nature, there must be one risk, one 
means of escaping that risk, and, as a consequence, one definite transmutation of a group. We have, then, to ask whether the insect world is liable to only one great risk, the risk of being seen and therefore captured by their enemies; only one mode of defence, the adoption of certain colours, whether the object be to conceal, to warn, or to mimic.

It may be questioned whether we could find in any sphere of nature a single illustration of the principle, "one risk, one remedy"; certainly it is not so in the insect world, with which we are at present more especially concerned. We know that insects are liable to various dangers besides those which arise from being visible to the enemies which prey upon them in their perfectly developed forms. In the earliest stage, they are liable, as we have just heard, to suffer from the attacks of parasites, which lay eggs in their eggs. The larvæ which are hatched from eggs which have been thus treated simply afford temporary board and lodging for the parasite, and perish miserably. In the case just cited only twenty survive out of two hundred. Nine-tenths of the individuals had succumbed before they were subjected to the selective process which the theory supposes to account for defensive colouring.

But, apart, from parasites, insects have other difficulties to encounter before they reach their last stage of development. It is true that the birds which prey upon the imago disappear with the approach of wirter.

"Many of our migrant singers, like the swallows, eat only such things as they can catch in their swift flight, open-mouthed, through the air; these are few and far between in the raw and cold atmosphere of winter here. Swift and swallow, nightingale and cuckoo, warbler, wheatear, whinchat, blackcap, wryneck, flycatcher,-all the merry troupe of strolling singers must follow the sun and the creatures that dance in the sunbeams to lands that are sunny in winter."-(The Cornhill Magazine. New series. vol. xxii., ph. $167-165$. 
But when these disappear, other insect-eaters come upon the scene.

"The tree-creepers and the tits, insectivorous in their propensities, are content to seek food in the crevices of bark up and down the branches of old trees, in the cracks of walls, in and out among the stones and bricks of old buildings, peering, probing, pecking at the creatures that have thought to get safely through the cold weather by hiding." -(Ibid. p. I64.)

\section{Our winter migrants find in our}

“ . . . river estuaries, oozy mudbanks and golden sands, among other things larvæe and all manner of marine insects. . . . Inland too, we have stores of bird-food in winter. Very seldom indeed is the ground so hard frozen that the rooks and the thrushes cannot probe it with their long bills and find here a worm and there a grub, and there the larva of some bright butterfly."-(Ibid. p. I63:)

Even in the season when insects fully developed are on the wing, they are not saved merely by the colours which they assume.

"It seems probable, that in some cases, that which would appear at first to be a source of danger to its possessor may really be a means of protection. Many showy and weak-flying butterflies have a very broad expanse of wing. . . . They are often captured with pierced and broken wings as if they had been seized by birds from which they had escaped. But if the wings had been smaller in proportion to the body, it seems probable that the insect would be more frequently struck or pierced in a vital part."--(Wallace. Contributions. p. 73.)

Thus the increased expanse of wing has been a source of safety which has hindered the action of Natural Selection in its attempt to weed out some of the variants.

So far as the modification of colour is concerned, it may further be observed that the coloration of the wings assists in enhancing this immunity from destruction.

"The brilliant colour is so placed as to serve for protection ; as, for example, the eye-spots on the hind wings of moths which are pierced by birds, and so save the vital parts of the insect; while the bright 
patch on the orange-tip butterflies (which, Mr. Darwin denies, are protective), may serve the same purpose. It is, in fact, somewhat remarkable how very generally the black spots, ocelli, or bright patches of colour are on the tips, margins, or discs of the wings; and as the insects are necessarily visible while flying, and this is the time when they are most subject to attacks by insectivorous birds, the position of the more conspicuous parts at some distance from the body may be a real protection to them."-(Wallace. Tropical Nature. p.202.)

"Other species of aphides (Eviosoma), and many of the coccida, secrete a white, flocculent, waxy cotton, under which they lie concealed. In many of the Homoptera, this secretion only amounts to a white powder, covering the body, as in some of the Fulgoridae. In others it is more abundant, and it reaches its extreme limit in a species of Phenax that I found at Santo Domingo. The insect is about an inch in length, but the waxy secretion forms a long thick tail of cotton-like fibres, two inches in length, that gives the insect a most curious appearance when flying. This flocculent mass is so loosely connected with the body that it is difficult to catch the insect without breaking the greater part of it off. Mr. Bates has suggested that the large brittle wings of the metallic Morphos may often save them from being caught by birds, who are likely to seize some portion of the wide expanse of wing, and this breaking off, frees the butterfly. Probably the long cumbersome tail of the Phenax has a similar use. When flying, it is the only portion of the insect seen; and birds trying to capture it on the wing are likely to get only a mouthful of the flocculent wax."--(Belt. Nicaragua. pp. 229-230.)

Even when the insect has been captured by the enemy, and subsequently rejected, this will not be so dangerous as it otherwise might be, owing to the elasticity of the entire structure of some insects.

"Most of the species of Danais and Acraca . . possess (a) means of defence, which, as far as I am aware, has not hitherto been recorded, viz., the remarkable elasticity of their entire structure. No pressure of the thorax, short of absolute crushing of the tissues, suffices to kill or even paralyse these butterflies; and the collector who treats them as he would species of other families, soon finds his collecting-box alive with its struggling occupants. So flexible are the wings, that the insect generally succeeds in withdrawing them from crossed fences of pins which form a complete barrier to any motion on the part of ordinary butterflies; and, however bent 
and distorted the wings may become in such exertions, I have never known a fracture of nervures or membrane to result, the organs resuming their natural position even after having been bent double for some hours. While entomologising in Natal, my Kafir collector used often to bring me numerous examples of the commonest species in his box, and when engaged in the necessary work of rejection, I constantly found the limp-winged Danaidx and Acraeidx, as soon as they were released from the transfixing pin, fly off with perfect ease and apparent nonchalance. . . . This elasticity of structure is not confined to the butterflies in question, being a character of many moths, and markedly of some belonging to the families Agaristidxe and Zygaenidx. It is remarkable that the three SouthAfrican moths in which I have found this peculiarity most developed, viz., Pais decora, Eusemia euphemia, and Glaucopis formosa-all have a strong and offensive odour, emit drops of white or yellow fluid, and are slow-flying, brightly coloured, and abundant species."(R. Trimen. On "Mimetic Analogies among African Butterfies." Trans. Limnean Soc. vol. xxvi., pp. 498-499.)

In the second place the action of Natural Selection must be in inverse ratio to the amount of the direct action of changed conditions by virtue of which similar organisms are influenced by similar conditions in a similar manner. In this case there is either no need for Natural Selection at all; or it plays at most a comparatively insignificant part in the transformation.

Now, it is worthy of observation that it was in this particular connection that $\mathrm{Mr}$. Darwin makes a very notable admission, in a letter dated October I 3 th, I 876 :-

"In my opinion, the greatest error I have committed has been not allowing sufficient weight to the direct action of the environment, i.e., food, climate, etc., independently of Natural Selection. . . When I wrote my 'Origin', and for some years afterwards, I could find little good evidence of the direct action of the environment; now there is a large body of evidence, and your case of the Saturnia is one of the most remarkable of which I have heard."-(Life and Letters. vol. iii., p. 158.)

But not only is this a sphere in which the direct transforming influence of the environment is made obvious,it is clear that there are many cases in which the process 
of selecting favourable birth variations could not possibly have been pursued. If the organism were only able to adapt itself to external conditions through the action of Natural Selection, differences of colour sufficiently great to constitute a specific difference would require some little time to be produced. But in the following case an individual assumes one or other of three differently coloured garbs, according to the colour of the flower it frequents. Now, whatever you may call this process, and by whatever means it may be achieved, it is certain that it is not Natural Selection, and that sexual reproduction and struggle for existence do not account for the transmutation.

"M. E. Heckel, of Marseilles, has recently described an interesting case, which may be frequently seen in the South of France. 'The spider, Thomisus onustus, is often found in the flowers of Convolunlus arvensis, where it hides itself for the purpose of snaring two Diptera, Nomioides minutissimus and Melithreptus origani, on which it feeds. Convolvulus is abundant, and three principal colourvariations are met with: there is a white form, a pink one with deep pink spots, and a light pink form with a slight greenishness on the external wall of the corolla. Each of these forms is particularly visited by one of three varieties of Thomisus. The variety which visits the greenish form has a green hue, and keeps on the greener part of the corolla; that which lives in the white form is white with a faint blue cross on the abdomen and some blue at the end of the legs; the variety which lives in the pink form is pink itself on the prominent parts of the abdomen and legs. If the animal happens to live on Dahlia versicolor, the pink turns to red, and if it lives in a yellow flower-Antirrhinum majus, for instanceit becomes yellow. At first, Professor Heckel supposed the three varieties of Thomisus to be permanent, but he discovered accidentally that any one of these peculiarly coloured spiders, when transferred to a differently coloured flower, assumes the hue of the latter in the course of a few days; and when the pink, white, green, and yellow varieties are confined together in a box, they all become nearly white."-(Nature. vol. xliv., p. 45r.)

Prince Kropotkin, in reviewing the result of recent investigations, asserts that they go to show that the variations are not accidental; meaning thereby, it is to be 
presumed, that they are not due to the seiection of those favourable variations which occur in connection with sexual reproduction. He says :-

"The meaning of these researches is self-evident. No naturalist will probably attempt to explain the animal colours and markings without the aid of Natural Selection. But it becomes less and less probable to admit that animal colours are a result of a selection of accidental variations only."--(Ninetcenth Century. vol.xxxiii.,p.689.)

But he goes on to say:-

"As to the relative parts which must be attributed in the origin of each separate variation to Natural Selection on the one side, and to the direct action of environment on the other side, it would simply be unscientific to trench upon such questions in a broadcast way, so long as we are only making our first steps in discriminating the action of the latter agency."

But if the direct action of environment is already proved to be very great, that in itself is enough to show that the theory of defensive colouring is not an especially favourable illustration of the action of Natural Selection. If already it can be shown that the variations are not accidental, that, according to our view, is enough to prove that the Natural Selection of birth variations does not come into play. It is surely not unscientific to note how facts either lessen the possible action of a law or even call in question the truth of a theory. We may not yet have solved the problem: but we know enough to declare that the requirements of the theory are not realised when the phenomena are closely observed. The change is produced without Natural Selection : it is not produced by the selection of favourable birth variations. If this be so, we shall not be justified in holding the judgment any longer in suspense. The logical demands of the theory must remain the same, unless the theory itself is to be largely modified. If the facts already contradict the theory, what is there 
to wait for? The fact that the variations which arise are not accidental, is another reason for affirming that this is not a sphere in which the action of Natural Selection is seen to the best advantage.

This result of the study of defensive colouring has done more, as it seems to me, than any other branch of scientific enquiry to remove the idea of the mystery which surrounds the origin of variation. So long as it was believed that there was a realm which was beyond the investigation of man, and which contained problems that he could not hope to solve, it served to discourage enquiry, and it enabled the adrocate to say that Natural Selection was the only explanation. On this subject, Mr. Fiske says :-

"Until after the publication of Mr. Darwin's speculations, the colours of plants and animals had never been made the subject of careful and philosophical study. So far as any hypothesis was held concerning these phenomena, it was the vaguely conceived hypothesis that they are due to the direct action of such physical conditions as climate, soil, or food. But there are fatal objections to such an explanation. . . But even supposing that the most general features of animal colouring could be explained on this hypothesis, which they cannot be, there would still remain the more remarkable cases of tree-frogs . . . and of the so-called leafbutterflies; . . . and the existence of such cases is a stumblingblock in the way of all theories save the theory of Natural Selection." -(Cosmic Philosophy. vol. ii., p. 20-I.)

The investigations which scientific men have recently made have surely withdrawn the reil of mystery from the process by which defensive colouring is produced.

In the third place the favourable action of Natural Selection is in inverse ratio to the exercise of the intelligence of the animal. This principle is maintained by $\mathrm{Mr}$. Wallace, who contends that the intelligence of man arrests the effect of Natural Selection upon his physical frame; and it is only an extension of this principle to assert that 
the influence of Natural Selection will be in inverse ratio to the development of intelligence on the part of any animal. This argument becomes the stronger when we bear in mind that colour is often the result of the direct action of the transforming influence of surrounding conditions. If such effects follow from new conditions and the animal intelligence avails itself of the protection thus produced, there does not seem to be any opening left for the introduction of the principle of Natural Selection. The less the organism remains passive under the operation the smaller will be the opportunity for the action of Natural Selection. It is this fact which gives such significancy to the reiterated assertion on the part of the advocates of Natural Selection, that the word mimicry is to be understood in a strictly figurative and rhetorical sense. But in point of fact there is an enormous amount of evidence, which shows that animals are conscious of the protection afforded by colour, and that they assist the "disguises" which arise from their likeness to inanimate objects by their own intelligence and contrivance. Sometimes an animal will cover itself with an altogether artificial protection.

"Certain crabs (Stenorhynchus, Inachus, Pisa, Maia) fasten pieces of seaweed, \&c., on their bodies and limbs. Bateson has watched the process in Stenorhynchus and Inachus. "The crab takes a piece of weed in his two chelæ, and, neither snatching nor biting it, deliberately tears it across, as a man tears paper with his hands. $\mathrm{He}$ then puts one end of it into his mouth, and after chewing it up, presumably to soften it, takes it out in the chelæ and rubs it firmly on his head or legs until it is caught by the peculiar curved hairs which cover them. If the piece of weed is not caught by the hairs, the crab puts it back in his mouth and chews it up again. The whole proceeding is most human and purposeful. Many substances, as hydroids, sponges, polyzoa, and weeds of many kinds and colours, are thus used, but these various substances are nearly always symetrically placed on corresponding parts of the body, and particularly long, plume-like pieces are fixed on the head sticking up from it. 
Not only are all these complicated rocesses gone through at night as well as by day, but a Stenorhynchus, if cleaned and deprived of sight, will immediately begin to clothe itself again with the same care and precision as before.' Bateson states that Stenorhynchus does not betray any disposition to remain in an environment which harmonises with its dress."---(Poulton. The Colour of Animals. pp. 78-9.)

I have quoted the remarks of Mr. Poulton and $\mathrm{Mr}$. Bateson, but they do not seem to militate against my argument. For if the crab covers itself with seaweed, it carries its own protection about with it, and there is no need that it should remain among seaweed. The fact that it continues to perform this action when blind does not lessen its usefulness; and, if it did, it would only afford an illustration of an action become instinctive and performed when no longer useful; but, in its first inception, it must have been an intelligent operation.

Another remarkable illustration of the co-operation of the animal to secure its own concealment is found in the fact that some caterpillars make their immediate surroundings to resemble themselves.

"In all the examples hitherto described, and countless others, the insect is defended by resembling its surroundings; the very interesting caterpillar of a South American butterfly (Anaea sp. ?) described by Wilhelm Muller, acts differently, and makes its surroundings resemble itself. It gnaws the leaf in such a manner as to leave a number of rough models of itself attached to the mid-rib, and then sits down beside them. The caterpillar is green above and dark beneath, although the former colour interrupts the latter at certain points, and comes into contact with the mid-rib on which the insect is resting. The dark colour is not distinguishable from the deep shadow behind the leaf, and therefore the appearance is that of an elongated patch of green, connected with the mid-rib by two narrow stalks. The larva, in eating, leaves several pieces of leaf, attached to the mid-rib by one or two stalks, which, therefore, present a very similar appearance to that of the larva itself."-(Poulton. The Colour of Animals. pp.36-7.)

After this evidence it will not seem wonderful to us to find that insects seem to be quite conscious of the protec- 
tion afforded by a correspondence between their bodies and their usual sphere. Of this intelligence many instances may be given.

"My brother, Georg Semper, has communicated to me," says Karl Semper, "the following case, lately observed by him, of the adaptation of an old species to the colour of new surroundings- or rather of its availing itself of it for protection. During the last ten years (1870-1880) the well-known white-leaved variety of Acer negundo has been largely planted in gardens in Hamburg, and since this the common white cabbage butterfly has accustomed itself to settle by preference on this shrub. It is, then, extremely difficult, as my brother informs me, to distinguish the butterflies as they sit on the leaves, their yellowish colour being lost in that of the leaves."-(The Natural Conditions of Existence as they affect Animal Life. p. 466.)

"Certain dragon-flies apparently are attracted," says Mr. Darwin, "by particular colours. Mr. Patterson observed that the Agrionidae, of which the males are blue, settled in numbers on the blue float of a fishing-line; whilst two other species were attracted by shining white colours."-(Descent of Man. p. 29o, 2nd ed.)

"There can be no doubt that birds have a very keen sense of the protectiveness of colour: if you staitle a blue tit it will seek a high branch against the sky-blue, and brown, and green; a robin flits away to the brown shadow of a bush; I have even known a young robin, threatened by an elder (they are great disciplinarians), take refuge near a reddish-brown dress.

"A thrush is wonderfully clever, almost as soon as it is fledged, in finding its own tints on some wall or tree-trunk, and making believe to be a piece of it to such an extent that one may approach quite close to it and it will remain absolutely motionless as long as one's eye is upon it ; but if the eye is removed, even for a 'twinkling,' the bird will have hopped down noiselessly behind something before one can look again."-(Nature. vo!. xxxvi., p. 244.)

"I was much more surprised with the behaviour of a green, leaflike locust. This green, leaf-like locust stood immovably amongst a host of ants, many of which ran over its legs, without ever discovering there was food within their reach. So fixed was its instinctive knowledge that its safety depended on its immovability, that it allowed me to pick it up and replace it amongst the ants without making a single effort to escape. This species closely resembles a green leaf, and the other senses, which in the Ecitons appear to be more acute than that of sight, must have been completely deceived. It might easily have escaped from the ants by using its wings, but it would only have 
fallen into as great a danger, for the numerous birds that accompany the army ants are ever on the outlook for any insect that may fly up, and the heavy flying locusts, grasshoppers, and cockroaches have no chance of escape."-(Belt. Nicaragua. p. rq.)

"About three years ago I was visiting a house well covered with ivy of a variety with rather large leaves. One recently-grown branch had developed a few whitish or cream-coloured leaves, as a 'sport' amongst the ordinary green leaves. This branch being near the dining-room window, was convenient for observation. Every evening for several days, about sunset, a large cabbage-white butterfly (Pieris brassicae) used to search out one of these half-dozen white ivy leaves, and roost upon it for the night. The protective value of the creamywhite leaf for the creamy-white underside of the butterfly was perfect. The butterfly seemed to be the same individual on each evening."-(John T. Carrington. Science Gossip. Neze series. vol. i., p. ro.)

Of all the cases in which inanimate objects are mimicked, there is none which impresses us with more wonder than the resemblance of some animals to the droppings of birds. Professor Henry Drummond, in his "Tropical Africa," tells us that as he lay upon a boulder in the dried-up bed of a stream at a post where a canopy of leaves arched overhead the home of many birds, the granite boulders of the dry stream-bed and all along the banks were marked with their white droppings. One day he was startled to see one of these droppings move, and as he watched, it was a bird dropping suddenly become alive and moving over a rock, and then it was a bird-dropping again. "Now, should any sceptic persist that this was a bird dropping, I leave him to account for a birddropping with six legs, a head, and a segmented body." This deception, it should be observed, is rendered possible ( I) by the structure, and (2) by the intelligent co-operation of the insect. "It is as white as a snowflake. This whiteness is due to a number of little tufts of delicate down growing out from minute protuberances all orer the back. 
It is a fringe of similar tufts round the side that gives the irregular margin so suggestive of a splash." But the intelligence of the animal is necessary to complete the deception. "When at rest it lay motionless on the stoneno legs, no head, no feelers, nothing to be seen but a flat patch of white." The motion of the insect is slow and monotonous, with frequent pauses to impress surrounding nature with its moribund condition.*

"The excreta of birds are also very commonly resembled by moths as well as by caterpillars. This is the case with the little Chinese Character (Cilix spinula) and with many grey and white Geometers which rest on the upper sides of leaves with their wings extended as if 'set.' In this position they forcibly suggest the appearance of birds' excrement, which has fallen on to a leaf from a great height, and has therefore become flattened into a wide patch."-(Poulton. The Colours of Animuls. p. 57.)

The wonder of all this is surpassed in the following case :-

"The caterpillar of Selenia illunaria has a very similar structure and colouring at the times when it resembles such very different objects as a twig and the excrement of a bird, the whole difference being made by a modification of attitude alone."-(Poulton. The Colours of Animals. p. 33.)

After these illustrations of the intelligent co-operation of animals, in order to produce the mimicry of inanimate objects, it is difficult to withhold the same explanation from the mimicry of one organism by another, of which many illustrations may be given.

"The movements as well as the shape and colour of the insect imitated are mimicked. I one day observed what appeared to be a hornet, with brown semi-transparent wings and yellow antennx. It ran along the ground, vibrating its wings and antennæ exactly like a hornet, and I caught it in my net, believing it to be one. On examining it, however, I found it to belong to a widely different order." -(Belt. Nicaragua. p. 3I9.) 
"A large caterpillar startled Mr. Bates, by its close resemblance to a small snake. The first three segments were dilatable at the will of the insect, and had on each side a large black pupillated spot which resembled the eye of the reptile. Moreover, it resembled a poisonous viper."-(Wallace. Contributions. p. g9.)

"It was a small spider that closely resembled an ant, and so perfect was the imitation that it was not until I killed it that I determined that it was a spider and that I had needlessly feared its sting. What added greatly to the resemblance was that, unlike other spiders, it held up its two fore legs like antennx and moved them about just like an ant."-(Belt. Nicaragua. t. 314.)

"Many of the small tree-frogs are no doubt also mimickers. When seen in their natural attitudes, I have been often unable to distinguish them from beetles or other insects sitting upon leaves.-(Wallace. Contributions. p. I03.)

"The walking-stick insects hang loosely about shrubs in the forest, and have the extraordinary habit of stretching out their legs unsymmetrically, so as to render the deception more complete."

"A large old thrush has been trying to make itself look like a serpent, and succeeded remarkably well. The object appears to be to frighten away a smaller and more active thrush, no doubt younger and with sharper ears, which seems to be getting all the worms. It appears afraid to attack its young rival, but runs towards it as if it meant to do so; and when the young one turns round and faces it, the old one crouches down so that nothing of it is seen but a crest-like back, two glaring eyes, the spotted throat, and a dark line formed by the front view of the beak and the lines at the corners of the mouth, which look very much like a serpent's mouth. The young bird looks alarmed and retreats. The crouching is not followed by a spring." -(J. M. H. "Protective Imitation." Nature. wol. xxiv., p. 3.)

In the case of certain butterflies the protective colourings are on the under side of the wings. If these butterflies sat on plants with their wings spread out and the upper part exposed, they would be very conspicuous; but the opposite is the fact, and after reading the cases already quoted, it would be difficult to suppose that their intelligence did not aid in the result. If, then, it be true to assert that the action of Natural Selection will be in inverse ratio to the extent to which an animal is not the 
merely passive victim of external conditions of selection, we have here another reason for believing that protective colouring does not present the most favourable illustration of the action of that supposed law of nature.

Before leaving this subject, we may further enquire whether a certain sphere of nature presents a favourable illustration of the action of a given law in proportion to the amount of influence which that law is supposed to exercise in the production of a given phenomenon. One would be tempted to say at the outset that the action of Natural Selection will be in inverse ratio to the amount of assistance which is rendered by other factors, that it will be most favourably observed where it has most to do. It would seem absurd to say that it is most effective when it has least to do. We should surely be disappointed if we had gone to see the popular actor of the season in the character of Hamlet, and if we found that he had chosen to be cast for the part of Fortinbras, who walks across the stage towards the end of the fourth act and comes to clear it up at the end of the fifth. This illustration may also serve to remind us that the character which plays an insignificant part in a drama is apt to be left out altogether, as in the play of Hamlet, when the curtain falls upon the stage strewn with dead. And is it not possible that if Natural Selection is required to do so little it can be dispensed with altogether? There are cases in which close resemblance is brought about without Natural Selection, and if this case of mimicry-i.e., close resemblance-is nearly accomplished apart from Natural Selection, what need is there for it at all?

"If, then, we must admit that the first beginning of change takes place without the operation of this principle, why should we claim for it the main, almost the exclusive, agency in the changes which follow? Some other principle, at present unknown to us, originates these variations; what right have we to say that this principle, whatever it

L 
may be, then ceases to act, instead of being the main agent in all the other subsequent changes?"-(Alfred W. Bennett. Nature. vol. iii., p. 32.)

Now, so far as the amount of co-operation required by Natural Selection is concerned, we have diametrically opposite opinions. Mr. Bates, whose paper is in effect an illustration of the Darwinism of Darwin, contends that Natural Selection is necessary, but that it plays a comparatively small part in the process of transmutation. Mr. Wallace, to whom we are indebted for supplying the logical nexus which binds together the theory of mimicry, in the largest sense of that term, declares that the process is very difficult and very protracted. Mr. Bates says:-

"I think the facts of similar variation in two already nearly allied forms do sometimes show that they have been affected in a similar way by physical conditions. A great number of insects are modified in one direction by a seaside habitat. I found, also, the general colours of many widely different species affected in a uniform way in the interior of the South American continent. But this does not produce the specific imitation of one species by another; it only prepares the way for it." $-(\not .508$.

"I do not forget that at each step of selection the forms of Leptalis must have had sufficient resemblance to an Ithomia to lead to their preservation, or at least to prevent their complete extinction; as, however, the two analogues so much resemble each other at the commencement of the process, these steps would not be numerous." (p. 5I2.)

Mr. Wallace, to account for the small number of mimics in comparison with the models, gives a very different account of the action of Natural Selection.

"In most of them, favourable variations both of colour, form, structure, and instinct or habit, must have occurred to produce the perfect adaptation we now behold. All these are known to vary, and favourable variations, when not accompanied by others that were unfavourable, would certainly survive. At one time a little step might be made in this direction, at another time in that. A change of conditions might sometimes render useless that which it had taken 
ages to produce-great and sudden physical modifications might often produce the extinction of a race just as it was approaching perfection, and a hundred checks, of which we can know nothing, may have retarded the progress towards perfect adaptation; so that we can hardly wonder at there being so few cases in which a completely successful result has been attained, as shown by the abundance and wide diffusion of the creatures so protected."--(Contributions. $p$. 68-60.)

Whichever of these two authorities we follow, defensive colouring cannot be said to afford the most favourable illustration of the action of Natural Selection. If $\mathrm{Mr}$. Bates' view is adopted, the part played is very slight, and one does not see the necessity for the introduction of Natural Selection for which he contends. If Mr. Wallace's view be correct, then this department does not offer a very favourable illustration of the action of Natural Selection, seeing that the process is so difficult and so protracted and so often accompanied by failure.

But in this particular case, we are not at liberty to leave the actual amount of difference an open question and to argue from either hypothesis as to the possible result. For in the case of defensive colouring the initial change must be considerable before Natural Selection can come into action. There must be enough likeness to deceive before the individual so favoured can be saved.

But, for the sake of argument, let us take the two hypotheses of slight changes and of considerable changes in each generation, and let us see what would be the effect upon the supposed action of Natural Selection. The agent in this case is the bird or beast of prey which acts efficiently by virtue of its keenness of vision, and it is one of the commonplaces of the theory that the vision of the enemy is quickened by the protracted process. Let us see what the result must be, first, in the case of considerable variations. If the process of Natural Selection begins at that point where certain insects pass into invisibility, or are 
sufficiently disguised so as not to be observed, how is it that the enemy can acquire the greater keenness of vision? All that the theory requires is that it should not observe those variants which are concealed by their colour or by their form. This oversight is absolutely necessary to the theory, but how can the repetition of such oversight-howsoever often it may be repeated-produce the necessary increase of discernment, which the theory absolutely demands.

If, on the other hand, it be maintained that the change takes place gradually, then the slight differences in colour would not make the animal unobserved, and it would continue to be caught; even if the whole race became gradually more accommodated to the colour of their surrounding, or to the resemblance to some other object, this would only quicken the vision of the enemy, and it would be quite educated up to the point of seeing what was invisible to those less interested by the time the great change was consummated. But how in such circumstances could the insect-eater become the agent of Natural Selection?

So that in this sphere of nature, either Natural Selection comes very late upon the scene and acts through the blindness of the enemy, or the enemy, educated by the observation of slight rariations, continues to devour the species indiscriminately, and thus does not fulfil the office assigned to it by the theory. But this choice is not permitted to us. The first step taken before Natural Selection comes into play, leads to the favoured individuals escaping observation. How can a repetition of this process increase the discernment of the enemy?

In connection with protective colouring in that sphere in which it is most usually manifested, we find a realm of nature in which accidental death is normal; in which animals owe their survival to escape from many different 
kinds of risk; in which the occurrence of variations which are not accidental, in the sense of being simply variations due to sexual reproduction, is constant; in which intelligence plays no unimportant part in securing the necessary advantages in the struggle for existence; in which the stages of the process are variously described as very easy and very difficult; in which the enemy must be unobservant, and thereby becomes wonderfully quick-sighted; or in which the victim continues "to be observed and destroyed, so that no selection can take place. On the face of it, this can scarcely be the most favourable illustration that can be found of the effective action of Natural Selection.

It is true that it is the all but universal opinion that all these phenomena have been brought about by Natural Selection. A great deal of careful observation has been brought to bear upon the subject, and most interesting experiments have been made; but, so far as I can gather, no proof has been offered that the selection of favourable birth variations has brought about these results. Have we any evidence of a group of individual insects which have gone into a new habitat, and have remained altogether unmodified during the life of the first generation, which have exhibited slight variations in the direction of protective colouring in a few individuals of the next generation? Have we the direct evidence of actual observers that these variations, in a favourable direction, have been preserved, while the others have been destroyed. We have no such evidence that I am aware of. On the latter point Mr. Poulton speaks out very plainly when he reminds us that "very little of the destruction of life, which we know takes place, is actually witnessed by us.” * The 
process has often been described. It has been pictured over and over again by the imagination of scientific theorists, but in the general terms of faith rather than with convincing details of demonstration derived from the observed modification of a given group of individuals. Yet such a successful experiment ought to be possible if the theory were in accordance with the facts of nature.

I.-COLOURS WHICH CONCEAL.

"The shadow cloaked from head to foot."

-TENNYSON.

We are told that there are some organisms so concealed by their colour that they are only to be recognised by the shadows which they cast. It is the extreme illustration of a very frequent phenomenon which is supposed to secure the safety of the individual and the survival of the species. We have now to ask whether this phenomenon has been brought about by Natural Selection, and whether it has been produced in such a manner that it affords the most favourable illustration of the action of that reputed law of nature.

On the threshold of the subject, we must pause to consider whether concealment by colour affords that perfect immunity from attack which is generally attributed to it. Whether a given animal is visible or invisible is very much a question of experience or inexperience on the part of the spectator. "We must get out of the way," says Mr. Beddard, "of judging instances of this kind from the human standpoint. The most acute observers among us are dull compared with uncivilised man and many animals."* He makes this remark apropos of the

\footnotetext{
* Animal Coloration. p. IIo.
} 
circumstance that a native who accompanied Mr. Henry Drummond perceived that an apparent wisp of hay was a living creature, although the Professor was quite unconscious of the fact. But in point of fact it is not a question of civilisation or barbarism, or of habits of ordinary observation or indifference. The facility of observing such phenomena and seeing through their disguises is dependent upon the degree of actual experience in the observation of individual cases. If the civilised man, the barbarian, or the quick-sighted animal had only a motive for exercising keen observation, there is no reason, whatever to doubt that the most complete disguise would avail nothing. We will take the familiar example of the hare, concerning which Mr. Poulton says:-

"Among the mammalia it would be hardly possible to meet with a better example of protective colouring and attitude than that of the hare as it sits motionless, exactly resembling a lump of brown earth, for which indeed it is frequently mistaken."-(The Colours of Animals. p. 67.)

And yet the hare is not concealed, even when seen from afar, from the eye of the experienced sportsman, although it be quite invisible to the eye of a novice. Naturalists and sportsmen tell us that sometimes it is the eye only which reveals the presence of the animal and makes its concealment a vain thing. Somerville (though Dr. Johnson spoke slightingly of his poetry, saying that "he wrote well enough for a gentleman"), was a keen sportsman, and may be trusted to write from experience when he says :-

"Ah, there she lies! how close! she pants, she doubts

If now she lives; she trembles as she sits,

With horror seized. The withered grass that clings

Around her head, of the same russet hue, Almost deceived my sight, had not her eyes, With life full-beaming, her vain wiles betrayed." 
This catching the eye of the hare upon its form may be fatal when practised by a beast of prey, if it exercises upon the victim the same fascination as it did in the case of the human eye, in an incident related by $\mathrm{Mr}$. Charles St. John :-

"I found a hare sitting the other day within five feet of where I was standing, and in a very open place. I wanted to show her to one of my children who was riding four hundred or five hundred yards from the spot; so I stood still and sent a man to call the boy. In the meantime I had to call loudly at, and rate my dogs, four of which were hunting about the place, seeing with their quick and peculiar instinct that I saw something. The dogs became very eager, and it required a great deal of calling to keep them quiet and make them lie down for five minutes. When the child came I had to point the hare out to him. The poor little animal, notwithstanding all this noise, did not move as much as one of her ears, but remained perfectly motionless, with her eye fixed on mine. The moment I took my eye off her (which I had not done all this time) she clarted off, and springing through the only spot free from her numerous enemies, she was over the brow of the hill in two strides."-(Natural History and Sport in Moray. p. 275-note.)

We are assured by Somerville that the hare itself seems to be well aware that the safety gained by colour-concealment is very precarious.

"As wandering shepherds on th' Arabian plains

No settled residence observe, but shift

Their moving camp, . . .

So the wise hares

Oft quit their seats, lest some more curious eye Should mark their haunts, and by dark treacherous wiles Plot their destruction."-(The Chase. Book ii., lines 19-28.)

The conjecture that animals are quick-sighted enough to see their victims which are supposed to be concealed by colour is borne out by actual experience. Mr. Bateson in his notes on the protective habits of shrimps and prawns, "states that the wrasse will find a shrimp if the least bit be exposed, in spite of its protective coloration. 
If, however, the sand be fine, a shrimp will bury itself absolutely."**

But if for the sake of argument we were to grant that the concealment was complete, so long as the protectively coloured organism remained at rest-the hare upon its form, the green insect on the green leaf, the white insect on the white flower-the animal cannot save its life by remaining constantly motionless. The statuesque immobility on which its safety so much depends cannot be permanent. It must move; and, by moving, it will become more or less visible, and therefore more or less open to attack. It need scarcely be said that the merest novice sees the hare the moment it starts from its form. "Insects," says Mr. Wallace, "are necessarily visible while flying, and this is the time when they are most subject to attacks by insectivorous birds." $\dagger$ The Duke of Argyll says :-

"The young of all birds which breed upon the ground are provided with a garment in such perfect harmony with surrounding effects of light as to render this manœuvre easy. It depends, however, wholly for its success upon absolute stillness. The slightest motion at once attracts the eye of any enemy which is searching for the young."-(The Contemporary Reviezs. vol. xxxviii., p. 7o6.)

It seems to me to be very probable that an insect-eater, or any other foe of a species concealed by colour, might easily be educated so as to be able to discern the animal at rest as well as in motion. The first stage in such a process seems to have taken place in one of Mr. Poulton's experiments.

"I have found that the insect-eating, wood-haunting green lizard (Lacerta viridis) will generally fail to detect a stick caterpillar in its position of rest, although it is seized and greedily devoured directly it

* Poulton. The Colours of Animals. p.204.

+ Tropical Nature p. 202. 
moves. The marvellous resemblance of Cleora lichenaria even deceived one of these lizards after the larva had moved more than once. The instant the caterpillar became rigid, the lizard was puzzled and seemed unable to realise that the apparent piece of lichen was good to eat. After a few moments, however, the lizard was satisfied, and ate the caterpillar with the keenest relish." - (The Colours of Animals. $p p .40-I$.

But if it could be shown that the hare was concealed by its colour, so as to make it absolutely invisible when motionless; if it could be shown that the animal only moved under conditions in which it was perfectly safe to do so, it would still be in danger, for it carries with it and leaves behind it an aroma which is as delightful to the nostrils of the enemy as it is fatal to the concealment of the victim. It is conjectured that in classical times one kind of dog was employed to find the hare upon its form, and others to chase it. It was found by scent and chased by sight. The modern huntsman follows as

Hang on the scent unwearied."

"the patient pack

And Somerville is so enamoured of this sport that he denounces those who hunt the hare by sight in language worthy of an ecclesiastical anathema. It may further be observed that the hare is as aware of its danger from this source as from the quick eyes of those who can see through its concealment. So much, then, for the colour of the hare, so often quoted as a result of the action of Natural Selection, because it is saved by its invisibility. But that implication can scarcely be sustained. It is seen by the experienced sportsman, while it is quite invisible to the novice. It is seen by the merest novice the moment that it begins to move. It is found and followed by scent as well as by sight.

In the same way, it can be shown that the protection of winter white, which some animals assume, does not confer 
that immunity from attack with which it is generally credited. "The arctic fox, the ermine, and the alpine hare," says Mr. Wallace, "change to white in winter only, because in summer white would be more conspicuous than any other colour, and therefore a danger rather than a protection." * This is the assumption necessary in order to establish the proposition that winter white has been brought about by Natural Selection. But in order that winter white should be a protection to animals, it is essential that snow should remain upon the ground during the winter months, and that winter white should only be assumed by animals during the season when the landscape is covered with snow. But neither of these conditions are present in the actual world of nature. The winter white of animals is not confined to countries in which the snow is on the ground constantly during a given period. There is no such definite period in some countries, and yet the animal is white through the winter months. "The stoat always becomes white in the alpine districts of Scotland, frequently in the North of England, occasionally in the Midlands, and Mr. Couch has seen two white stoats in Cornwall." $\dagger$ It may be said that this is a characteristic which has become fixed in the race. That might account for the present condition of the species. But if the species arose through the elimination of the conspicuous colours, and if that is a constant law of nature, then it ought to have been exterminated by the same principle, if it persists in maintaining a conspicuous white in a country which is only occasionally covered with snow. In $N^{\top}$ ew Brunswick the winter lasts from the middle of December till the middle of March, + but in New Brunswick the American hare

* Contributions. p. 50 .

† Poulton. pp. IOI-2.

$\ddagger$ Chambers' Encyclopacitia. 
(Lepus Americanus) "keeps his winter coat till May, when it is gradually shed, the change being complete in June. The winter coat gradually develops in October and November, and is retained from December till the end of April."* "The snow-bunting is whiter at one season of the year than at the other, but curiously enough the change is precisely the reverse of what one would expect. It is whiter in summer instead of in winter." $\dagger$ Moreover the habits of animals are not such as the theory requires.

"The alpine, mountain, or northern hare Lepus alpinus (variabilis) takes the place of the common hare in the Alps and the Arctic regions. Its winter coat is perfectly white, except the tips of the ears, which are black. This animal confines itself principally to the zone between the trees and the limit of perpetual snow; but in winter it betakes itself to the woods."-(Vogt and Specht. The Natural History of Animals. Mammatia. vol. ii., p. I74.)

In other words, it does not occupy that position in which its colour would afford the best protection. There is, furthermore, as Karl Semper has pointed out, the difficulty of understanding how this change could have been brought about gradually through the means of Natural Selection.

"It is difficult to understand how a race of brown animals can be gradually transformed by selection into a variety which always turns snow-white in winter. Granting that a brown weasel could, by any external or internal cause, be changed during the winter into a brown and white spotted one, this weasel would not have the smallest advantage over the brown one in consequence of the white mixture in its fur, for it would be quite as conspicuous as a plain brown one in the pure white of the snow, perhaps even more so. That a white variety should arise from a gradual increase of the white patches in the piebald fur is not to be thought of. It might indeed be possible that a selection should be effected, if a pure white variety were at once and from the first produced from the animals which first exhibited this modification of their summer colouring, since these, like the nearly white ones, would in fact enjoy an essential advantage over the brown or spotted ones."-(Animal Life. p. II6.)

* Poulton. The Colours of Animals. p. 95.

+ Beddard. Animal Coloration. p. $7 I$. 
Now, we have on record a case in which the sudden change took place in consequence of sudden exposure to extreme cold; but the result was fatal, for the animal soon died.

"A classical experiment made by Sir J. Ross, considerably over fifty years ago, seems decisive on the above-mentioned point, as far as the species experimented upon is concerned. A Hudson's Bay lemming kept in the cabin, and thus shielded from the low temperature, retained its summer coat through the winter. It was accordingly placed on deck in a cage, on February Ist, and next morning, after having been exposed to a temperature of $30^{\circ}$ below zero, the fur on the cheeks and a patch on each shoulder had become perfectly white. On the following day the patches on each shoulder had extended considerably, and the posterior part of the body and flanks had turned to a dirty white; during the next four days the change continued but slowly, and at the end of a week it was entirely white, with the exception of a dark band across the shoulders, prolonged posteriorly down the middle of the back. No further change took place, and the lemming died of cold on February i8th ; the thermometer having been between $30^{\circ}$ and $40^{\circ}$ below zero every night." (Poulton. The Colours of Animals. p. 94.)

This experiment shows how fatal it would be to a race to be subjected to changes of temperature sufficiently great to produce a transformation of colour in one week. And yet this is what is required if the race is preserved by the colour which conceals it.

Another instance which is supposed to be peculiarly illustrative of the action of Natural Selection is to be found in the arctic white of animals inhabiting regions covered with perennial snow. "The white appearance of arctic birds and mammals," says Mr. Poulton, "must be advantageous for concealment in a region so largely covered with snow." * Mr. Grant Allen says :-

"Among the arctic snows a brown or black animal would immediately be perceived, and, if defenceless, at once devoured; while, if a carnivore, it would seldom or never approach unperceived near

* The Colours of Animals. p. ro. 
enough to its prey to effect a capture. Hence all such variations are at once repressed, and almost all arctic animals, like the American polar hare, are pure white. Elsewhere bears are black or brown; in the polar region the native species is nearly indistinguishable from the snow in which it lives."-(Encyclopaedia Britamica. vol. xvi., p.343.)

The process is thus described by Mr. Wallace:-

"If an animal spreads from a temperate into an arctic district, the conditions are changed. During a large portion of the year, and just when the struggle for existence is most severe, white is the prevailing tint of nature, and dark colours will be the most conspicuous. The white varieties will now have an advantage: they will escape from their enemies or will secure food, while their brown companions will be devoured or will starve, and as 'like pro. duces like' is the established rule in nature, the white race will become permanently established, and dark varieties, when they occasionally appear, will soon die out from their want of adaptation to their environment. In each case the fittest will survive, and a race will be eventually produced adapted to the conditions in which it lives."--(Contributions. pp. 66-67.)

In considering the change which produces permanent arctic white, we may suppose that the favourable variations must arise in one of three ways. All the organisms of a given group may be modified by cold in the same way; some of the organisms may exhibit slight variations in direction of white, in connection with differences of birthvariation, such as we see in other cases; or certain individuals may possess a greater congenital susceptibility to cold than others. In the first case, if there were a steady progress in all the individuals in the direction of a white colour, Natural Selection would not be required. If the change was gradual, in the case of some, these individuals would still be visible, and consequently they would not be protected from their enemies, and Natural Selection could not come into operation. It is true that the assumption that some individuals are more sensitive to the influence of temperature than others seems to be borne out by 
observation. Mr. F. E. Beddard directed Mr. Poulton's attention "to three arctic foxes (Canis lagopus) from Iceland, which have been in the Zoological Gardens since I887. One of these turns perfectly white every winter, while the other two remain dark."* But it might be said that this is no proof of what would take place if the animals had remained in Iceland. Yet it would seem that the arctic fox exhibits the same individual differences in nature. "It has been said that the arctic fox is white in winter and in summer of various colours; but Payne says this is inaccurate, and that Canis lagopus may be found white, blue, or grey at all seasons of the year." $\dagger$

But while these cases prove that difference of individual susceptibility, which the theory of Natural Selection requires, they can scarcely be quoted as a proof of the action of Natural Selection; for the persistence in three different individuals of one of three different colours, through all seasons, contradicts the assumption of Natural Selection, that the conspicuous will be destroyed and the inconspicuous will be saved.

As Mr. Grant Allen has taken the case of the polar bear to illustrate the permanent white of arctic animals, it may be interesting to enquire how far the facts of the case justify the assumptions of those who maintain that the phenomenon has been brought about by Natural Selection. "Among the arctic snows a brown or black animal would immediately be perceived, and, if defenceless, would be at once devoured; while, if a carnivore, it would seldom or never approach near enough to its prey to effect a capture." But is the polar bear so white as to be invisible? Mr. Beddard tells us that "although the hairs are largely depigmented, they are not entirely so; at any rate, the

\footnotetext{
* Poulton. The Colours of Animals. p. IOI.

† Semper. Animal Life. p. 427, note 39.
} 
colour, except in very young bears, is of a creamy tint rather than white. So pronounced is this sometimes, that the Scotch whalers know the animal by the name of Brownie."**

Mr. Arnold Pike says of the polar bear that, "seen first at a long distance, he commonly requires but little stalking." + If this be so, the polar bear does not seem to afford a very good illustration of "protective" or "aggressive" colouring; for he is not invisible either by his natural foes, if he has any, nor by his victims.

On the other hand, we can scarcely explain the arctic white of his victims on the hypothesis that they escape his notice. That is not probable, for several reasons. In the first place he is very quick of vision, presumably as quick of vision as his prey; he is swift of foot, and "the soles of his feet are covered with close set hairs, which enable him to go on slippery ice as securely as upon terra firma"; he is as keen of scent as he is of sight, and against this the protective white of his victims would avail nothing. But this is not quite the whole of the story.

"The polar bear inhabits only the realms of ice on the shores of the arctic sea. The ice girdle which surrounds the north pole is in fact its true home. It advances and retires with this girdle, which man has in vain attempted to break through, and if it sometimes penetrates into less inhospitable shores it is because it has allowed itself to be carried away by an ice-floe."-(Vogt and Specht. wol.i., p. 205.)

It would seem that in the summer-time it preys chiefly upon seals. Mr. Clive Phillips informs us that

"The seals bask on the ice with their heads always close to, if not actually over, the water. If the bear approached them from behind, the seal would flop into the water (where it would be safe from the attacks of its foe. Accordingly the bear) drops into the

* Animal Coloration. p. $7 \delta$.

† Badminton Library. Big Game Shooting. vol. ii., p. 16. 
water some way to leeward and swims noiselessly along the ice edge. Even if the seal perceives the white head, the only visible portion of the swimming bear, it probably takes it for a drifting splinter of ice, and pays no more attention to it, until a blow from the heavy forepaw of the bear ends sleep and life together. The walrus is also attacked, of course, on the ice only; for in the water both walrus and seal can sport around their enemy with impunity."(Big Game Shooting. vol. ii., pp. I6-17.)

"During the winter, it does not retire from the battle of life, like its less hardy congeners, but wanders on through the storm and lasting darkness. Only the females which are about to cast their young in the spring lie dormant in the winter. Why the rest are roaming in the darkness or what they find to eat in that land of death, I cannot tell (says Mr. Arnold Pike), for the seals do not lie on the ice in the dark-time."--(Vogt and Specht. vol. ii., pp. I7-I8.)

It must find something to eat, or it could not survive, but, endowed with keen scent and means of rapid locomotion, it could easily secure its prey when it is to be found.

The general effect of these statements concerning the provess and the habits of the polar bear certainly does not afford any great amount of elucidation as to the method by which its constant white colour has been produced.

The same arguments will apply to the phenomenon of the uniform colour of desert animals. If two widely-different races of animals live together in the same desert, the one as a beast of prey and the other as its victim, it is obvious that the victim cannot alvays escape through the protection of its coat; and that the race of victims still continues may be taken as suggestive that the enemy is not always able to steal upon his victim unawares because unseen. How little protective concealment can avail, as against aggressive concealment, is secn in the following instance. It might be thought that a large white butterfly, with its body half buried among the white M 
blossoms of the wild carrot, would be safe. But in one particular case, at any rate, it was not so. The Rev. B. G. Johns says :-

"I touched him with my fingers and shook the flowers sharply, but he never moved. On looking closely, I found that a snowy-white spider, hidden among the blossom, had seized on him from below, killed him with one fatal bite, and was then sucking his blood. . . With his long thin legs he held his prey so tightly that I drew him out of his lurking place still holding on to the dead body of the poor butterfly. On that same cluster of flowers there were three other white spiders of the same kind, and of so venomous a nature that, on afterwards dropping two of them into a bottle of spirits of wine, one instantly seized the other and bit his legs off." -(The Ninetecnth Contury. vol. xxxii., p. 459.)

\section{2.-MIMETIC COLOURS.}

"This is good mummicking-this is!"

"Captain Zachariasen said that mummicking was apt to spread in a family like measles."-BESANT. The Captain's Room.

In considering how far the phenomena connected with mimetic colours present a specially favourable illustration of the action of Natural Selection, it may be remarked that the objects of this particular kind of modification are very few. Mr. Wallace says that "the third law (of mimicry) is that the species which resemble these dominant groups are comparatively less abundant in individuals and are often very rare."* Mr. Bates estimates their numbers at about one in a thousand in the group they resemble. It is true that $\mathrm{Mr}$. Bates also says that "a mimetic species need not always be a rare one, although this is very generally the case; it may be highly prolific, or its persecution may be intermitted when the

* Contributions. pp 76-77. 
disguise is complete."* But it is enough for our argument to know what actually takes place without discussing the abstract problem of what might take place. This chosen illustration of the action of Natural Selection exhibits its influence as extending over a small area, or at any rate affecting, comparatively speaking, only a few individuals.

In the second place, the theory is based upon the assumption that the models always possess some disability which gives them immunity, and that the otherwise unprotected mimics thus gain an advantage by growing into their likeness.

"It is to be remarked that the forms imitated have alurys some kind of defence against insectivorous birds or mammals. They are provided with stings or unpleasant odours or flavours, or are exceedingly swift in flight, excepting where inanimate nature is initated for concealment."-(Belt. The Naturalist in Nicaragua. p. 3I6.)

This is certainly what the theory requires, because the resemblance of one species to another cannot have been developed by Natural Selection unless the modified species profits by the arrangement. And yet, as a matter of fact, the resemblance between species and species is not always useful. Mr. Wallace gives an illustration from Professor Westwood's Oriental Entomology:-

"There are many species in India (like those figured by Professor" Westwood in his Oriental Entomology) which have the hind legs very broad and densely hairy, so as exactly to imitate the brush-legged bees which abound in the same country. In this case we have more than mere resemblance of colour, for that which is an important functional structure in the one group is imitated in another whose habits render it perfectly useless."-(Contributions. $\quad$ p. gr.)

In the case of butterflies there is mimicry and mimicry. There is what is termed true mimicry-i.e., the mimicry which seems to agree with the requirements of the theory; 
and there is a so-called false mimicry, in which no useful end is answered, by the resemblance which one species bears to another. In the first place, it happens sometimes that two unprotected species mimic one another.

"In tropical Africa we find two unrelated groups of butterflies, belonging to two very distinct families (Nymphalidæ and Papilionidx) characterised by a prevailing blue-green colour not found in any other continent. Again we have a group of African Pierida, and in the same country one of the Lycaenidæ (Leptena erastus) is coloured so exactly like these that it was at first described as a species of Pieris. None of these four groups are known to be in any way specially protected, so that the resemblance cannot be due to protective mimicry."-(Wallace. Tropical Nature. pp. 255-6.)

"In another series of genera (Catagramma, Callithea, and Agrias), all belonging to the Nymphalidx, we have the most vivid blue ground, with broad bands of orange, crimson, or a different tint of blue or purple exactly reproduced in corresponding, yet unrelated, species, occurring in the same locality; yet, as none of these groups are known to be specially protected, this can hardly be true mimicry."

"A few species of two other genera in the same country (Eunica and Siderone) also reproduce the same colours, but with only a general resemblance in the markings. Yet again, in tropical America, we have species of Apatura which, sometimes in both sexes, sometimes in the female only, exactly imitate the peculiar markings of another genus (Heterochroa) confined to America. Here, again, neither genus is protected, and the similarity must be due to unknown local causes."-(Ibid. p. 257.)

In the second place, there are cases in which two protected species mimic one another.

"In South America, in the three sub-families Danaina, Acraeina, and Heliconiina, all of which are specially protected, we find identical tints and patterns reproduced, often in the greatest detail, each peculiar type of coloration being characteristic of separate geographical sub-divisions of the continent. . . . Other changes of a like nature. . occur in species of the same groups inhabiting these same localities, as well as Central America and the Antilles. The resemblance thus produced between widely different insects is sometimes general, but often so close and minute, that only a critical cxamination of structure can detect the difference between them. 
Yet this can hardly be true mimicry, because all are alike protected by the nauseous secretion which renders them unpalatable to birds." -(Wallace. Tropical Nature. pp. 256-7.)

The imitation of a protected species by another species also protected was thus explained by Dr. Fritz Muiller, in I879. He assumed that insect-eating birds only learn from experience to distinguish the edible from the inedible butterflies, and in doing so necessarily sacrifice a certain number of the latter. The quantity of insectivorous birds in tropical America is enormous, and the number of young birds which every year have to learn wisdom by experience as regards the species of butterflies to be caught or avoided is so great that the sacrifice of life of the inedible species must be considerable, and, to a comparatively weak or scarce species, of vital importance. "If two species are so much alike as to be mistaken for one another, the fixed number annually sacrificed by inexperienced birds will be divided between them, and both will benefit. But if the two species are very unequal in numbers the benefit will be comparatively slight for the more abundant species, but very great for the rare one. To the latter it may make all the difference between safety and destruction."*

We may observe, in passing, that if this were a satisfactory explanation of the fact that protected species mimic protected species, it would leave quite unexplained the phenomenon of unprotected species mimicking unprotected species; and we should still have resemblance of coloration brought about apart from Natural Selection. But the explanation of the resemblance between protected species is not altogether convincing. We question whether young birds are left to learn what to eat and avoid from

* Wallace. Daruinism. pp. 252-3. 
strictly personal experience. Is there no instinctive avoidance here, as elsewhere, in consequence of the inheritance of ancestral tendencies? Is there no parental instruction, as in many cases there undoubtedly is? If so, disagreeable insects would not be attacked at all. Moreover, in many cases insects would not necessarily suffer if they were attacked, because they.would be saved, as Mr. Wallace has shown, by the eye-spots upon their wings, or, as Mr. Trimen testifies, by the extreme elasticity of their whole structure.

But if we assume, for the sake of argument, that the resemblance as it now exists is useful to both species, this fact is far from proving that it has been produced by Natural Selection. For the idea is, that the fewer signs of inedibility, the better it will be for the foolish, inexperienced young birds, and still more for their victims. But if this is so, how confused these same young birds must have been when these two protected species were in the process of growing like one another. Two modes of arriving at this result are conceivable. One species may adopt the livery of the other. In that case, you will have the models of one pattern, and the unmodified members of the mimicking species of another pattern, and between the two, one, two or several gradations not like either of them, and yet all of them nasty to eat. If both species undergo changes in the same direction, the confusion will be greater rather than less. How is Natural Selection to aid in a case like this?

But whether these objections have any weight in them or not, the fact remains that unprotected species mimic unprotected species. In this case of false (!) mimicry it is admitted that Natural Selection is necessarily excluded. Some other explanation must be found; and I see no reason for doubting that in this, as in other cases, the 
solution of the problem is to be found in the fact that these species inhabit the same localities, are exposed to the same special conditions of climate, feed on the same plants, live the same life, and so are transformed into the same outward semblance by the same external conditions. Bearing this fact in mind, it is interesting to observe what the first condition of the theory of mimicry is.

"The first law is that in an overwhelming majority of cases of mimicry, the animals, or the groups which resemble each other, inhabit the same country, the same district, and, in most cases, are to be found together on the very same spot."-(Wallace. Contributions. pp. 76-7.)

In other words, the two species are placed under those conditions in which the transformation in other cases takes place apart from Natural Selection. If the transformation is the same in both cases, all the similar organisms will be modified by similar conditions in the same way, and there will be no room for the slow process of the selection of birth-variations. The first law of the production of mimicry by Natural Selection would thus at once prevent the development of mimicry by Natural Selection. The idea that true mimicry has the same source as false mimicry is confirmed by the fact that when the locality is changed the models undergo a change, and the mimics follow suit, if indeed they do not change simultaneously. The theory accounts for the mimicry of the imitators; but it does not account for the change in the models. This is not due to Natural Selection. It must be due to other causes. But if the models are changed by other influences, why not the so-called mimics?

We have already dwelt upon the fact that the process of producing resemblance between different species by Natural Selection is represented as very easy on the one hand and very difficult on the other. In this connection I 
will only dwell upon one point. If Natural Selection acts by the survival of a few favourable variants and the destruction of the rest, and if the favourable change in each generation is slight, what, it might be asked, is to prevent a slightly modified favourable variant from being destroyed? Mr. Wallace suggests a solution to this problem.

"Tropical insectivorous birds very frequently sit on dead branches of a lofty tree, or on those which overhang forest paths, gazing intently around and darting off at intervals to seize an insect at a considerable distance, which they generally return to their station to devour. . . At long distances those who slightly resembled the Heliconidæ might be mistaken for one of the uneatable group, and so be passed by and gain another day's life, which might in many cases be sufficient for it to lay a quantity of eggs and leave a numerous progeny."-(Wallace. Contributions to Natural Selection. pp. So-2.)

But the chance of escape from birds watching from afar does not meet the difficulty presented by large flocks of different insectivorous birds hunting together. According to Mr. Belt,-

"Trogons, fly-catchers, tanagers, creepers, woodpeckers, \&c., hunt together, traversing the forest in flocks of hundreds together, belonging to more than a score different species; so that whilst they are passing over, the trees seem alive with them. Mr. Bates has mentioned similar gregarious flocks, met with by him in Brazil ; and I never went any distance in to the woods around Santo Domingo without seeing them. The reason of their association together may be partly for protection, but the principal reason appears to be that they play into each other's hands in their search for food. The creepers and woodpeckers and others drive the insects out of their hiding-places, under bark, amongst moss, and in withered leaves. The fly-catchers and trogons sit on branches and fly after the larger insects, the fly-catchers taking them on the wing, the trogons from off the leaves on which they have settled."-(The Naturalist in Nicaragua. pp. I22-3.)

Mr. Belt also reminds us that the numerous birds which accompany the army ants are ever on the outlook for any insect that may fly up.* These facts militate against 
the idea that slightly-modified insects will be saved by the distance from which they are watched by their enemies. If the production of similar colours depends upon the "accidental" emergency of a slight resemblance, those who are anxious to be informed of the odds for or against any coming event will be glad to hear what Mr. Bennett has to say upon the subject.

"Suppose there are twenty different ways in which a Leptalis may vary, one only of these being in the direction ultimately required. The chance of any individual producing a descendant which will take its place in the succeeding generation, varying in the required direction, is $\frac{1}{20}$ : the chance of this operation being repeated in the same direction in the second generation $\frac{1}{20^{2}}=\frac{1}{400}$. The chance of this occurring for ten successive generations is $\frac{1}{20^{10}}$, or about one in ten billions. Now another factor comes into the calculation, and that is, the number of individuals among which this chance is distributed. Mr. Bates and Mr. Wallace agree in stating that, hoth in South America and in the Malay archipelago, the imitative species are always confined to a limited area, and are always very scarce compared with the imitated species. We will assume that the number of individuals of the imitative Leptalis existing at any one time is one million. The chance of there being among these million a single individual approaching the Ithomia to the extent of one-hundredth is $\frac{1000000}{1000000000000}$; or, the chance against it is ten millions to one."*

"Against these odds the primitive variety would long ago have been worn out; the individual deviation being lost amid the renewals of the original type through multitudes practically exhaustless." (Martineau. A Study of Religion. vol. i., p. 282.)

Speaking of the opinions on the subject of the strange external resemblance between insects of distinct generafamilies and orders-as well as species, held by naturalists before the promulgation of Natural Selection, Mr. Wallace says :-

"In only one case does it appear that the resemblance was thought to be useful and to have been designed as a means to a definite and

* Nature, vol. iii., p. $3 I$. 
intelligible purpose. The flies of the genus Volucella enter the nests of bees to deposit their egrs, so that their larva may feed upon the larva of the bees, and these flies are each wonderfully like the bee on which it is parasitic. Kirby and Spence believed that this resemblance or mimicry was for the express purpose of protecting the flies from the attacks of the bees, and the connection is so evident that it was hardly possible to avoid this conclusion."--(Contributions. pp. 75-6.)

It is a very remarkable fact that this particular instance of aggressive mimicry, which was the first instance of mimicry which attracted the attention of scientific men, has recently been shown not to be quite so simple and convincing as it has hitherto been assumed to be.

The hypothesis of aggressive mimicry implies that each variety of Volucellæ preys upon the species of bee which it most resembles, the red-tailed variety on the red-tailed bee, and the yellow variety on the yellow-banded bee. But both varieties have been reared from the nests of each type of bee, both from the red-tailed and the yellow-banded.

"It is still possible that both varieties are born of one mother; and it is possible, too, that each female does her best to choose the nest of a bee like herself, but in support of this hypothesis, I know no evidence, and indeed Künckel, after considering this possibility, gives it as his opinion that probably the varieties of $V$. bombylans lay indifferently in the nests of all Bombi. . . . In my rooms at this moment are several nests of B. muscorum, each containing many larvæ of $V$. bombylans. There is, then, evidence, that the two varieties, though they may breed together, yet remain substantially distinct; and that though they respectively resemble different species of bees, they are both found together, not only in nests of bees which they resemble, but also, and in my own experience, more abundantly in the nests of another bee which they do not resemble. $V$. pellucens, though in no wise resembling the common wasp, yet lives in its nests, together with $V$. inanis, which does resemble a wasp, and with V. zonaria, which is like a hornet."-(Mr. William Bateson. Nature. vol. xlvi., p. 586.)

We have thus seen that the resemblance of one species to another is sometimes brought about apart from Natural 
Selection; that the first law of mimicry by Natural Selection is that two species shall occupy the same habitat -i.e., live under conditions analogous to those which produce mimicry without Natural Selection; that the process of slight variation in successive generations would not afford the protection which the theory requires; and, last but not least, that the mimicry of one species by another takes place under conditions other than those which the theory assumes.

\section{3.-WARNING COLOURS.}

. . " "hic niger est ; hunc, tu, Romane, caveto."

-HORACE.

Mr. Wallace thus explains the line of argument by which he was led to adopt the theory of warning colours.

"I reasoned that since some caterpillars were evidently protected by their imitative colouring, and others by their spiny or hairy bodies, the bright colours of the rest must also be in some way useful to them. I further thought that as some butterflies and moths were greedily eaten by birds, while others were distasteful to them, and these latter were mostly of conspicuous colours, so probably these brilliantly coloured caterpillars were distasteful and therefore never eaten by birds. Distastefulness alone would, however, be of little service to caterpillars, because their soft and juicy bodies are so delicate, that if seized and afterwards rejected by a bird, they would almost certainly be killed. Some constant and easily-perceived signal was therefore necessary to serve as a warning to birds never to touch these uneatable kinds, and a very gaudy and conspicuous colouring, with the habit of fully exposing themselves to view, becomes such a signal, being in strong contrast with the green or brown tints and retiring habits of the eatable kinds." "We may fairly claim this as a case in which the power of prevision has been successfully exerted, and therefore as furnishing a very powerful argument in favour of the truth of the theory of Natural Selection." (Contributions. pp. 118, I20.) 
Speaking of the development of the electric organ in certain fish as a yet unanswerable difficulty from the point of view of Natural Selection, Mr. Romanes expresses the opinion that further investigation will bring this phenomenon under the influence of Natural Selection, and he gives two reasons for this faith; (I) because Natural Selection obtains so generally that it is probable that it will be found active in this case also ; and (2) because the difficulty will be explained on the principles of Natural Selection, just as the difficulty of gaudily-coloured and therefore conspicuous organisms have been.*

The value of a theory depends upon the correspondence between the assumptions on which it is based and the facts of nature which it is framed to explain. Let us, then, consider the grounds on which $\mathrm{Mr}$ Wallace argues when he infers that the correlation between conspicuous colour and nauseous taste, or some other disability, has been brought about by Natural Selection.

The theory of warning colours was framed to explain an apparent inconsistency. The colours which conceal animals and the colours of one species which mimic the appearance of another species, were supposed to owe their origin to their usefulness. It was accordingly assumed that conspicuous colours were useful in some other way. The probability of the usefulness of organic colours is here assumed. It is interesting, therefore, to observe that Mr. Darwin contends that it is not reasonable to suppose that all colours will be found useful.

"Bearing in mind how many substances closely analogous to natural organic compounds have been recently formed by chemists, and which exhibit the most splendid colours, it would have been a strange fact if substances similarly coloured had not often originated, independently of any useful end being thus gained, in the complex laboratory of living organisms."

* Daravin and After Daruin. D. 373 . 
In point of fact, he asserts that some organic colours are not useful.

"The most probable view in regard to the splendid tints of many of the lowest animals seems to be that their colours are the direct result either of the chemical nature or the minute structure of their tissues, independently of any benefit thus derived. Hardly any colour is finer than that of arterial blood; but there is no reason to suppose that the colour of the blood is in itself of any advantage. - . The tints of the decaying leaves in an American forest are described by everyone as gorgeous; yet no one supposes that these tints are of the least advantage to the trees."-(Descent of Mon. vol. i., p. 323.)

It is asserted by Mr. Beddard that where there is a varied environment, the utility of protective coloration, when it occurs, will be accidental. "With a varied environment," he says, "such as a wood, for instance, we may easily get a large number of examples of coloration among its insect inhabitants that are purely accidental."** If an animal exactly resembled the immediate environment, it would always have to remain in that particular environment, or the protection it enjoys would avail nothing. Professor Drummond cites the puff-adder, one of the most beautiful and ornate of all the tropical reptiles, as an illustration of defensive colouring, because its true habitat is among fallen leaves, in the deep shade of the trees, by the banks of streams, and in such a position at a distance of a foot or two its appearance so exactly resembles the forest-bed as to be almost indistinguishable from it. $\dagger$

But Mr. Beddard reminds us that "the colours cannot be exactly protective because the reptile does not always conceal itself in such situations as Mr. Drummond describes. It often lies half-buried in the sand." $\ddagger$ But it

\footnotetext{
* Animal Coloration. p. is 8 .

+ Tropical Africa. pp. I65-6.

* Animal Coloration. p. 121 .
} 
seems to me that he is hardly justified in adding that "it would not probably be very conspicuous then." For if it be true that the whole body is ornamented with strange devices in green, yellow, and black, so that, lying a museum, its glittering coils certainly form a most striking object, it seems difficult to believe that half its body, with a background of sand, would go altogether unobserved. The robin is supposed to be protectively coloured, because amid the red herries and brown leaves of autumn its colour tends to concealment. But it cannot carry this environment about with it. In any other position its red breast will make it a conspicuous object, especially when the snow is on the ground, as our Christmas cards testify. But if it depends for safety on its protective colouring, a new and most pathetic meaning is given to the nursery rhyme-

"The north wind doth blow,

And we shall have snow, And what will poor robin do then?

Poor thing!"

Clearly he and his race would perish miserably if the only condition of their survival were a power of adapting themselves to the colour of their surroundings. These remarks tend to prove that all organic colours are not useful; and therefore the assumption that all brilliant and conspicuous colours are probably useful, which is the first axiom of the theory of warning colours, must not be accepted as a sure basis of reasoning.

When the theory is stated in an abstract form it seems to be assumed that there is a constant correlation between conspicuous colours, and nauseous taste or some other disability. Referring to the contrast presented by conspicuous and inconspicuous insects, Mr. Poulton says:-

"These two groups form perhaps the sharpest contrast in nature. We assume almost as a matter of course that the latter are pro- 
tected in some other way; that if captured they would prove to be of little value, or even positively nauseous or dangerous." - (The Colours of Animals. pp. I59-60.)

Again, he asserts that-

"All well-concealed forms are good for food, and are eagerly chased and devoured by insectivorous animals, while unpalatable forms are conspicuously coloured." - $(p .4 I$.

\section{It was in full belief in this principle that Mr. Belt wrote} his account of a Nicaraguan frog.

"In contrast with these obscurely coloured species, another little frog hops about in the daytime dressed in a bright livery of red and blue. He cannot be mistaken for any other, and his flaming vest and blue stockings show that he does not court concealment. He is very abundant in the damp woods, and I was convinced that he was uneatable so soon as I made his acquaintance and saw the happy sense of security with which he hopped about. I took a few specimens home with me and tried my fowls and ducks with them, but none would touch them. At last, by throwing down pieces of meat, for which there was a great competition amongst them, I managed to entice a young duck into snatching up one of the little frogs. Instead of swallowing it, however, it instantly threw it out of its mouth and went about jerking its head as if trying to throw off some unpleasant taste."-( The Naturaiist in Nicaragua. p.32I.)

And yet this correlation is by no manner of means universal. Conspicuously coloured insects arc not always uneatable.

"The highly conspicuous larre of one of our rarer hawk moths (Deilcphila galii) must fall an easy prey to creatures that feed upon them, for it has been proved experimentally that they are not, as yaudily-coloured insects often are, clistasteful to insect-cating animals; their colours cannot therefore have been acquired as an advertisement of their inedibility."-(Beddard. p. g.)

"The tiger moth and the leopard moth are particularly referred to by Mr. Poulton as being inedible forms. They are both highly conspicuous and easily captured, particularly the second insect, which is frequently met with on the ground, under trees, where the larva has no doubt fed up. Nevertheless both these moths were greedily eaten by Lacerta ocellata, the large South European 'eyed lizard'; this 
lizard, it may be observed, would be quite likely, under natura conditions, to meet with the two moths. They live where the lizard lives, and they are constantly met with on the ground."-(Beddard. pp. $157^{-8 .)}$

On the other hand, nauseous properties are not always associated with conspicuous coloration. Mr. Poulton, who, as we have just seen, assumes this correlation as a matter of course, and boldly asserts that it actually exists, also declares that there is no necessary correlation in this respect.

"It must not be supposed that nauseous properties are necessarily attended by warning colours; there are very many instances in which they are accompanied by protective resemblances and habits."(Poulton. p. $I 6 r_{\text {. }}$ )

It is quite clear, then, that a nauseous taste or other disability does not always accompany "a conspicuous colour; and that a conspicuous colour does not always accompany a nauseous taste or other disability. This is one of those cases in which it is not safe to judge from appearances. Sometimes, at any rate,-

"Opinion's but a fool, that makes us scan The outward habit by the inward man." -(Pericles. Act ii., sc. 2.)

Another assumption of the theory is that there is not only a correlation between gaudy colours and some disagreeable property, but that there is also an instinctive comprehension of this correlation in the minds of the animals which results in their not attempting to attack a gaudily-coloured insect. Such, at least, is the assertion of Mr. Beddard.

"The theory of warning coloration is not based upon particular cases of recognition. The broad principle, which is believed in by the supporters of this theory, is that a gaudy and striking coloration is associated with a nasty taste and with a corresponding impression in the minds of animals that these two facts go together." - (Animal Coloration. p. 15s.) 
This idea of an instinctive aversion to conspicuous colours is based upon the hypothesis that they are always associated with some disability, which, in point of fact, is not the case. Now this universal instinctive aversion could only have come about in one of two ways-either through the direct gift of God or through inherited experience. But it is obvious that if the correlation does not always exist, the instinct which assumes that it does cannot arise from divine inspiration or from an. inherited experience; and, if it does exist, it is as likely to be delusive as not.

In the next place it is assumed that a nauseous insect would not be protected sufficiently without conspicuous colours, because "there would be nothing about it to impress the memory of an enemy." *

We venture to doubt whether the conspicuous colours which often accompany some disagreeable quality are at all necessary for the safety of the animal so distinguished. I will take the mephitic skunk as an illustration. It is conspicuously marked, being one of nature's studies in black and white, and I suppose that it would be generally accepted as a striking example of the principle of warning colours. Its well-known protection consists in the fact that "it emits a fiery, burning liquid, which, on a mucous membrane, burns like sulphuric acid; having an effluvium after which crushed garlic is lavender; and which appears to pervade the whole system like a pestilent ether; nauseating one until sea-sickness seems almost a pleasing sensation in comparison." Now one would think that any living being which had once been syringed with this delightful concoction would be likely to give the source of it a very wide berth. It would be careful to note the form and the contour of the creature, however modestly it might 
be arrayed. The enemy would understand the meaning of its apparent tameness when in repose, and would abstain from stirring it up. In motion the skunk is easily to be distinguished by its gait ; for "when undisturbed it shuffles along in an erratic way usual to this odoriferous animal"; that is to say, its gait is sufficiently peculiar to be observed by one who has any interest in the matter. But if we suppose that the attacking animal has not observed the general contour of the body, and has not taken note of its shuffling gait, it could hardly have failed to observe the conduct of the animal when the attempt is made to seize it. For "when attacked it generally puts its foes to flight without resorting to malodorous measures; stamping its little feet in rage, jumping up, spitting and hissing, and flourishing its brush like a warlike banner above its head." It is impossible to doubt that these signs would be sufficiently significant without the addition of its conspicuous black and white. If we allow any intelligence to the animal of prey, we cannot doubt that it will take note of these signs, and remember what happened the last time it attempted to seize this irritable and very demonstrative creature.

Few will deny to animals the power of warning the members of their own species of particular dangers; and some such communication would doubtless be made on this subject by one of the individual animals which had had experience on the subject. Mr. Hudson tells us how he always made it a point to convey this warning to settlers new to the country. "In talking to strangers from abroad I have never thought it necessary to speak of sunstrokes, jaguars, or the assassin's knife; but have never omitted to warn them of the skunk, minutely describing its habits and personal appearance." But if no such warning were given, one experiment would 
suffice for the inexperienced. The skunk carries its large white tail slung over its back, and whether it intentionally invites attack on that organ or not, the foe that attacks it will almost inevitably seize the tail. We have striking evidence as to the result.

"An eagle-vulture was seen to seize a skunk's tail with its claw, but immediately after began staggering about, with dishevelled plumage, tearful eyes, and a profoundly woe-begone expression on its vulture face. The skunk, after turning and regarding its victim with an 'I-told-you-so' look for a few moments, trotted unconcernedly off."

Apparently the human assailant fares no better.

"An Indian chief once recommended an Argentine officer to seize a skunk by the tail, and all would be right. The officer said that on quitting the Indian camp he started a skunk, and, glad of an opportunity to test the truth of what he had heard, dismounted and proceeded to put the Indian plan in practise. Here the story ended abruptly; and when I eagerly demanded to hear the sequel, the amateur hunter of furs lit a cigarette and vacantly watched the ascending smoke."

There is no need, as it seems to me, for the conspicuous warning of the colour of the skunk. But it would seem that this protection fails just where it is most needed. So at least it was found to be in the experience of Mr. Hudson, who gives a graphic account of the effect upon one of riding over a skunk in the dark.

"There is to be a dance at a neighbouring house a few miles away; he has been looking forward to it, and, dressing himself with due care, mounts his horse and sets out, full of joyous anticipations. It is a dark, windy evening. Unhappily, the path is already occupied by a skunk, invisible in the darkness, and it refuses to get out of it, until the flying hoofs hit it and send it, like a well-kicked football, into the thistles. The forefoot of the horse has been sprinkled. The rider, after coming out into the open, dismounts and walks away twenty yards from his animal, and literally smells himself all over, and with a feeling of profound relief, 
pronounces himself clean." But he has deceived himself, as he finds out on his arrival at the house, and nothing remains for him but to slip out and ride home.-(The Naturalist in La Plata. p. 1I7.)

It is obvious that under all other circumstances the skunk, even if it were arrayed in the least conspicuous garb, would be safe from attack. One taste would be enough for the enemy. Its nonchalant indifference when lying at rest, its shuffling gait when in motion, its irritable action when attacked, would be amply sufficient for purposes of recognition; and there is, so far as I can see, no reason for believing that the colour of its fur has been developed as a warning colour by the action of Natural Selection.

The general argument, of which the skunk has been taken as an illustration, may be confirmed by reference to the quotation placed at the head of this section. It means the very opposite of what it might seem to do when the words are taken apart from their context. The poet does not warn us to have nothing to do with a man of dark complexion, because it is the outward and visible sign of atrabiliousness; but rather to beware of him whose actions sufficiently reveal his character. "This man is black of heart; shun him, thou that hast the spirit of a Roman."

It might be said that this is no argument so far as inconspicuous insects are concerned. But surely it is paying a very small compliment to the insect-eater to believe that it would not be able to recognise an inconspicuously coloured insect that was nasty to eat. It is contended that a nauseous insect, if attacked and immediately rejected, would be sure to die.

"Distastefulness alone would, however, be of little service to the caterpillars, because their soft and juicy bodies are so delicate that, if seized and afterwards rejected by a bird, they would almost 
certainly be killed. Some constant and easily perceived signal was therefore necessary to serve as a warning for birds never to touch these uneatable kinds."-(Wallace. Contributions. p. II 8 .)

But if it be true, as Mr. Trimen has shown, that certain butterflies are of so elastic a structure as to be injured very little or not at all by very rough treatment, the insect which is seized and then rejected on account of its evil taste, might escape with little or no injury.

Another assumption of the theory of warning colours is that the disabilities would be in themselves sufficient to ward off the attack of foes, if the enemy were only aware of the fact that the victim were possessed of those disabilities. Now a great many experiments have been made on this subject, and it is necessary to bear in mind that it will be dangerous to draw large inferences from an isolated fact or two. An animal may be fasting on one occasion and may have just dined on a second occasion; and it is quite possible that it will eat with avidity when hungry what it will not touch when its appetite is satisfied. Moreover, in this case, as in so many others, it is possible that tastes may differ; and that what one animal will eat with a relish, another will reject with disgust. Moreover, the conditions under which the experiments are made may sometimes be more or less perplexing, in so far as they do not resemble the conditions in nature.

The explanation of the problem presented by very different and apparently conflicting results may be found in the growth of varied experiences due to varied conditions of ancestral development. We may start with the probability that, in a state of nature, no insect-eater would adopt a new species of diet so long as the supplies of its familiar victims were numerous enough. An unknown insect presented to a sufficiently-fed insect-eater would not be noticed. But if it were very hungry, and especially if 
the ordinary diet ran short for any reason, it is probable that it would experiment upon any new species which might come in its way. There is no reason to suppose that in that case it would be deterred by glaring colour or otherwise. If the experiment proved that the new animal had some great disability, and other food were forthcoming, it would be let severely alone, as in the following case :-

"The chameleon had just been imported into this country when I received it, and it had probably never seen a common hive bee in its life. I put a living bee in the cage and the lizard immediately began to watch it, and as soon as it had settled, captured it with a dexterous shot of its long tongue. As the tongue was being withdrawn with the bee adhering to the sticky pad at its extremity, the chameleon was stung and immediately showed signs of discomfort, throwing its head from side to side and thus jerking the bee of. For many months after this I put bees into the cage at irregular intervals; but the chameleon's education in this direction was complete, the single experience was sufficient, and no other bee was touched."-(Poulton. p. 199.)

But if the supply of food fell short, we can well suppose that a fresh effort would be made to overcome the difficulty, whatever it might be. Take, for example, the treatment of an insect covered with hairs. In one case we read that "a lizard appeared to intimate that it would eat the caterpillar if it were not for its hairy covering." But "no such hesitation was exhibited by another lizard (Uraniscodon plica), which captured and ate one with the greatest rapidity." * "A magpie ate two caterpillars after it had carefully rubbed off the hairs." $\dagger$ Other methods of overcoming other difficulties have been recorded. Mr. Beddard tells us that a Cebus monkey sucked a magpie caterpillar and threw away the skin, as a boy sucks an orange and disposes of the peel. $\neq$ The explanation of this fact is that

* Beddard. pp. 159.60. † I6id. p. 155. $\quad$ t 173 . 
the disagreeable taste is sometimes due to the pigment cells contained in the skin, and thus the intelligence of the monkey rendered the protection of the caterpillar of no avail.

Some animals pinch their victims before they swallow them.

"A drone-fly (Eristalis tena $x^{\text {) }}$, which presents so remarkable a likeness to a bee, was offered to an Australian crow, which took it and carefully pinched it with the tip of the bill before eating." (Beddard. p. I53.)

"These caterpillars (the larvæ of our common Nocture, Mamestra persicariae) were eaten after being well pinched by a Glossy Starling, and by the Greater Spotted Woodpecker."-(

"The Australian plover pinched the larva carefully before swallowing it."-(p. 156.)

The explanation in this case is doubtless to be found in the source of the disagreeable element, viz., the osmateria or "stench-throwers," which secrete an offensive-smelling substance, and eject it when the animal is attacked. By voiding the contents of this organ, the insect would become more eatable, and this is probably the cause of the tactics of the bird.

In the case in which a disagreeable flavour pervaded the whole system of the victim, and no other food was at hand, the insect-eater would have to choose between eating what was distasteful at first or perishing from want of food. In the majority of cases the animal would prefer the former alternative. At first, no doubt, it would eat its victim without any great relish. It would feel very much as the backwoodsman did when he said, "I kin eat crow; O yes, I kin eat crow; but, blame me, if I hanker arter it." But habit will do much, and doubtless after a time the sense of anything disagreeable would pass away. The flavour would become actually agreeable, and food 
without the somewhat of bitter in it would seem insipid and worthless; of which developed taste the lovers of high game may be taken as a familiar illustration. Mr. Poulton remarks that,-

"The acquisition of an unpleasant taste or smell, together with a conspicuous appearance, is so simple a mode of protection, and yet apparently so absolutely complete, that it seems remarkable that more species have not availed themselves of it."

He accounts for this by the assertion that the antagonistic principle is to be found in--

"The too complete success of the method; for if a very common insect forming the chief food of some animal gained protection in this way, the latter might be forced to devour the unpalatable food in order to avoid starvation; (and if compelled to persevere through the want of other food,) would gradually come to devour it with relish."

He supports this argument by a very interesting fact:-

"There is an entire disappearance of all insects with warning colours during the seasons when insect life is scarce and when insecteating animals are hard pressed for food. And yet, if tt were safe to rely on such a mode of defence, the warning colours would be especially conspicuous at these times, when all the tints of nature are sombre." But these creatures disappear-they hide themselves-and in the absence of other food they are eaten.-(The Colours of Animals. pp. $178-80$.

The inference to be drawn from the above consideration is surely not favourable to the idea that an animal which has a certain disability will not be eaten on that account, and that a warning colour is a sufficient protection from attack.

We have endeavoured to show that the assumptions on which the theory is based are not to be relied on. Organic colour is not necessarily useful in all cases. There is not a constant correlation between conspicuous colour and some disability from the insect-eater's point of 
view. Consequently there is no universal instinctive shrinking from conspicuous colour on the part of the enemy. It is false to say that certain disabilities will not deter from attack apart from warning colours. It is not certain that if an insect were attacked and rejected that it would therefore perish. It is not true that certain disabilities associated with conspicuous colours deter from attack. How far the animals so endowed are liable to attack depends upon the pressure of necessity due to hunger or to skill in overcoming disabilities on the part of the insect-eater.

Nor is the explanation of the way in which warning colours have been produced by Natural Selection more satisfactory. Starting with an edible species which has not a particularly conspicuous colouring, it is assumed that there is first an evolution of a nauseous taste or other disability, and secondly an evolution of warning colours. Mr. Wallace gives two different explanations of the way in which a nauseous taste was developed. In his Tropical Nature, he speaks of the time when "the Danaidæ first began to acquire those nauseous secretions, which are their protection in the early stages of their development"; and then of another time when they became decidedly unpalatable.* In his Darwinism, he says, "The Heliconidæ first arose from some ancestral species or group which, owing to the food of the larve or some other cause, possessed disagreeable juices that caused them to be disliked by the usual enemies of their kind." +

If the nauseous taste were the result of the direct action of the adoption of some new food-plant, one of two results would follow. Either the enemy would leave the insect severely alone, having plenty of other food to resort to; and then, in the absence of any interposition on the part

$$
\text { * p. 190. } \quad+\text { p. } 243 \text {. }
$$


of the agent of selection, Natural Selection would not come into play at all. Or, on the other hand, a species of insect-eater, which lived on one particular species of victim, might prefer to eat the slightly nauseous victim instead of attempting the radical change of seeking a new source of food altogether. It is natural to suppose that it would attempt the former course, seeing that it must have studied the habits of its victims and could catch them more easily than others. It has been ascertained that certain species do restrict themselves to one particular victim. Thus Mr. Bates tells us :-

"We have proof, in the case of sand-wasps, which provision their nests with insects, that a single species is very generally selected out of numbers, even of the same genus, existing in the same locality. I was quite convinced in the case of Cerceris binodis of South America, which destroys numbers of a Megalostomis (family Clythrida), that the great rarity of the beetle was owing to its serving as prey to the Cerceris."-(Transactions of the Linnean Society. vol. xxiii., part 3, p. 5 II.)

In this case all would be alike eaten, and there. would be no Natural Selection.

Let us now take the alternative explanation; that an edible form first began to develop a slightly nauseous taste in some individuals which still remained unchanged in outward form. In that case, they could not be distinguished from their unmodified companions. Two very opposite results have been conjectured as ensuing from this fact. Mr. Wallace asserts that the modified insects would be attacked just as much as ever.

"If any particular butterfly of an eatable group acquired the disagreeable taste of the Heliconias, while it retained the characteristic form and colouring of its own group, this would really be of no use to it whatever; for the birds would go on catching it among its eatable allies (compared with which it would rarely occur), it would be wounded and disabled even if rejected, and its increase would thus be as effectually checked as if it were devoured."(Contributions. p. $8 I$. ) 
But in answer to this view, we have already shown that a butterfly may be attacked and rejected without being necessarily destroyed. On the other hand, Mr. Beddard cites the authority of Dr. Seitz for the assertion that "in the Heliconius beskiz, a species with a particularly evil odour, it was found that only a very few individuals were odoriferous"; and then he goes on to say, "If the odour is as objectionable to birds and lizards as it is to us, it looks as if the majority traded on the unpleasant reputation of the few." ${ }^{*}$ In other words, the whole group would be avoided because some individuals were disagreeable, and in this case no Natural Selection would take place.

I have already argued that the addition of a gaudy colour to an offensive taste is not needed for the preservation of a species-cannot be a matter of life and death, i.e., cannot be brought about by Natural Selection. If that is so, still more difficult is it to believe that the gradual steps between the inconspicuous and the gaudy colour can have been brought about by that agency. It only remains to say that gaudy colour and disagreeable taste are sometimes conferred at the same time and by the same agency.

Dr. Eisig points out that pigment in the skin has been actually proved in some cases to be excreted matter, and it may be so in other cases where no direct evidence is forthcoming. $\mathrm{He}$ is of opinion that this pigment is itself largely the cause of the distastefulness. "I may remark," says Mr. Beddard, "that a Cebus monkey sucked a magpie caterpillar and threw away the skin, as a boy sucks an orange and disposes of the peel." This is, so far, evidence that the pigmented skin is the distasteful part. If so, we 
arrive at an interesting conclusion that the brilliant colours (i.e., the abundant secretion of pigment) have caused the inedibility of the species, rather than that the inedibility has necessitated the production of bright colour as an advertisement.* Mr. Darwin informs us that "the extreme beauty of the Eolidæ (naked sea-slugs) is chiefly due to the biliary glands being seen through the translucent integuments." $\dagger$ Bile and beauty seem to us a queer combination; and it would sound very strangely in our ears, if we could hear the lovers among the sea-slugs apostrophising one another and declaring one another to be as beautiful as they are bilious. Such facts are no less fatal to the theory of Darwinism, for we see clearly that a phenomenon which at once produced a nasty taste and a gaudy colour would make short work of the protracted process which Mr. Wallace has conjectured to take place, and the discovery of which is supposed to be the crowning triumph of the advocate of Natural Selection.

\section{(b) INSTINCT.}

"Les gens de qualité savent tout sans avoir rien appris."

-Molière.

It has been asserted that the problem of instinct affords the best test of the doctrine of evolution, and that the theory of Natural Selection is most successful in its explanation of the phenomena of instinct.

"Among the many sagacious sayings of the patient and profound thinkers of Germany, not the least noteworthy was Schelling's affirmation that the phenomena of instinct are some of the most important

* Beddard. p. r73.

+ Descent of Man. pp. $26 r \cdot 2$. 
of all phenomena, and capable of serving as a very touchstone whereby the value of competing theories of the universe may be effectually tested. His prescience has been justified by our experience. The greatest scientific event of the present time is the wide acceptance of the theory of evolution and its use as a weapon of offence and defence. . . . Now it would be difficult to find a more searching test of that theory's truth than is supplied by a careful study of instinct."-(St. George Mivart. The Fortnightly Rervere. vo!.xxxvii., p. 321.)

\section{Mr. Romanes says :-}

"Perhaps in no one department of his work has Mr. Darwin been more successful in displaying the probable causation of biological facts than he has been in the province of instinct. If we accept the theory of Natural Selection as of any validity at all in explaining the evolution of structures, it must also be of some validity in explaining the evolution of instincts. . . . If the theory of evolution is of any validity in any case as a scientific interpretation of natural phenomena, nowhere is it more successful in this respect than in the domain of instinct."-(The Fortnightly Review. vol. xxxviii, p. 94.)

It may be remarked in passing that Mr. Darwin does not seem to anticipate that the study of the phenomena of instinct will prove especially favourable to the theory of Natural Selection.

"Many instincts are so wonderful that their development will probably appear to the reader a difficulty sufficient to overcome my whole theory."-(Origin of Species. p. 205.)

"I do not pretend that the facts given in this chapter strengthen in any great degree my theory, but none of them annihilate it."(Ibid. p. 233.)

This modified statement may be due to the modesty of genius, but it is in remarkable contrast to the opinion expressed by Mr. Romanes.

In order to understand the part which Natural Selection is supposed to play in connection with instinct, it will be necessary to understand clearly what instinct is. In order to do this we will begin by availing ourselves of the Duke 
of Argyll's graphic description of the conduct of a nestling of the water-ouzel, which had never been in the water until it stumbled into a pool which lay in its way, as it was trying to escape being caught.

"The effect was most curious. When the young bird touched the water, there was a moment of pause, as if the creature were surprised. Then instantly-down it dived with all the facility of its parents; and the action of its wings under the water was a beautiful exhibition of the double adaptation to progression in two very different elements which is peculiar to the wings of most of the diving birds. The young dipper was immediately lost to sight among some weeds, and so long did it remain under water that I feared it must be drowned; but in due time it appeared all right."-(Contemporary Reviere. vol. xxxviii., p. 70o.)

This act of diving will enable us to realise some of those features which belong to all the first actions prompted by a perfect instinct. In the first place, there was the pool, which afforded an external sphere, fitted for this particular kind of activity. In the second place, there was an elaborately constructed organism, capable of making the necessary movements of a very complicated nature. In the third place, there was a nervous sensibility, which responded to the external stimulus of the water, and prompted to the appropriate movements necessary to accomplish the act. On this account, Paley places instincts next to relations.

"Instincts are a species of relation. They contribute, along with the animal organisation, to a joint effort, in which view they are related to that organisation."-(Natural Theology. chapter xviii.)

This wonderful capacity was inherited; the act "being performed under circumstances which had been frequently experienced during the life-history of the species." It was an innate gift; born in the very organism of the little creature. It was not the result of personal observation. The little fledgling had never seen other birds dive. It 
was not the result of personal training; for, after a moment of surprise, the bird performed the operation of diving at once. It was not the result of parental instruction, for the old birds had not had any opportunity of teaching their young brood. The act was perfect from the very first. "Then instantly down it dived with all the facility of its parents." Perfect from the first, it left no room for improvement. Its parents dived no more perfectly after the experience of a life-time. The instinctive capacity is neither increased nor lessened by experience. This instinctive act was blind-unconscious of ends or of the means of attaining them. Stimulated by contact with the water, the wonderful mechanism responded by the necessity of the case, and the plunge was a leap in the dark. These are the characteristics of the first action prompted by a perfect instinct. No one can doubt the existence of such a phenomenon; and in spite of the assertion of one able writer, we shall always require the word "instinct" to indicate actions like that of the little water-ouzel-even if they fell short of its absolute perfection.

In dealing with the phenomena of instinct, it has been customary with many to assume that actions like that of the water-ouzel were typical of all animal action. Animals were supposed to be always and everywhere guided by instinct, and instinct was supposed to be perfect from the first and unchangeable to the last. Those who held this view supposed either that animals were mere automata or else that they were conscious automata-in other words, that they were mere living machines, having no consciousness of the actions which they performed; or that they were conscious of the actions which they performed, but that they were not conscious of the utility of those actions. It is the opinion of others that some animals are intelligent 
beings. But again opinions differ; for some suppose that the instinct and intelligence act apart from one another; while others believe that the intelligence interposes whenever it is needed to modify instinct. Some believe that the animal world was produced by a special act of creation, and was endowed from the first with instincts and organisms adapted to the conditions in which they were placed; while others believe that instincts have been developed by a process analogous to that of the evolution of organic structures.

It will suffice for the purposes of the present argument to affirm three principles. In the first place, if the principle of organic evolution be assumed, it is obvious that instincts, no less than structures, must have been developed. The probability of this assumption becomes very great when we attempt to interpret the facts by the theory of special creation on the one hand and that of evolution on the other hand. The conception of instinct which is based upon the idea of a special creation is fraught with the utmost difficulty. On this hypothesis we cannot account for the fact that some animals are born with instincts which are imperfectly developed; it leaves no room for the growth of new instincts, unless we suppose that animals are the subjects of new accessions of divine inspiration; it makes no provision for adaptation to new conditions which render old instincts useless or injurious. Moreover this view necessarily loses all its claim upon our belief as soon as the doctrine of special creation, with which it has been associated, is admitted to be untenable. On the other hand it has been one of the greatest triumphs of the theory of organic evolution to remove much confusion of thought. This principle will account for all the anomalies associated with the subject. If the principle of evolution be admitted, we can understand at once how it has come to pass 
that some animals are born with instincts perfect for the work they have to do ; and other animals with imperfectly developed instincts or mere instinctive tendencies. It accounts for the failure of instinct when the animal is placed in a sphere of which its race has had no experience. It justifies us in expecting a new development of instinct, no less than new modifications of structure, to meet the exigencies of new conditions.

In the second place we venture to assume that some animals are intelligent and that their actions are sometimes under the surveillance of their intelligence. It might be difficult to prove that this was the case in some instances; as when, for example, animals are born with perfect instincts which never require to be modified in the face of unchanged conditions. But it is obvious that different animals are born in different stages of development, both of organism and of instinct. The bird which is hatched in a nest built in a tree is at first utterly helpless and completely dependent upon its parents. The bird that is hatched in a nest on the ground could not escape destruction unless it were endowed with fully-developed powers of locomotion and an instinctive knowledge of its parents' cries of warning or of invitation.

The power of the animal to correct its innate tendencies of itself and to receive instruction from others, no less than the power to impart instruction, implies a certain amount of intelligence, and should serve to convince us, without any elaborate argument, that animal experience is made up of instinct and of intelligence. It is unnecessary for my present purpose to enter at large into any proof that all the actions of all animals are purely instinctive and non-intelligent. In face of the simplest act of animal intelligence, I refuse to bow to the dictum of utter scepticism expressed by Bonnet, when he asserts that "philosophers 
will in vain torment themselves to define instinct until they have spent some time in the head of an animal without being that animal." If a human being argues in that way he might almost as well say that he cannot know whether the apparently intelligent actions of another man arise from intelligence, unless he could spend some time in the head of that man, without being that man. But however good an opinion an individual may have of himself, and however broadly he may assume that for the most part all other human beings are a pack of fools, he would hardly go the length of asserting that, so far as he knows, he is the only intelligent being upon earth.

"Can we divest ourselves of the persuasion that the movements of animals, directed, like our own, to obvious ends, proceed from voluntary acts and imply the operation of an intellect not wholly dissimilar in its spiritual essence from our own? . . . No artificial logic or scholastic jargon will long prevail over the natural sentiment which must ever guide our judgment that animals possess powers of feeling, and of spontaneous action, and faculties appertaining to those of intellect."

\section{Menault says :-}

"What!-creatures that have faculties, that feel, remember and compare their feelings, that express themselves in a more or less direct fashion, but ever in sympathy with their emotions of joy, grief, anger, passion-such creatures have no intelligence? By God! I should like to know what intelligence is!"-(Buichner. Mind in Animals. p. 20.)

In execrable verse the poet Prior enunciated a sound philosophy, at any rate so far as the following lines are concerned:-

"Then vainly the philosopher avers

That reason guides our deeds and instinct theirs.

How can we justly different causes frame,

When the effects entirely are the same?" 
In the third place, we venture to affirm that it is most improbable that animals would in all cases be conscious of the acts which they perform, but not conscious of the utility of those actions. It cannot, however, be denied that instinct is blind in some connections. The instinct of aversion, which leads a young animal to avoid a particular action, is very strong and constant; and this will be necessarily blind, because it does not allow the animal to have any personal experience on the subject. A good illustration of an inherited aversion will be found in the case of the Himalayan rabbit, which Mr. Romanes made the object of a most interesting experiment, and from whose conduct he drew the probable inference that its ancestry had learned long ago to avoid the nettles that were indigenous in the country in which they lived; and that this aversion had been inherited. It may also be admitted that the first action inspired by a perfect instinct is performed blindly-first, because the response of the organism takes place at once, so as to leave no time for reflection; and, secondly, because it would be very difficult to prove that the animal knows beforehand the purpose of the instinctive action.

But when we attempt to extend this principle to all instinctive action, we are at once beset with difficulty. For if the action is successfully performed, it is reasonable to suppose that the animal which is conscious of the action which it performs will also appreciate the utility of that action. A young chicken may be supposed to scratch by a blind instinct, and in equal ignorance of the result to peck at a certain object which it sees; but when it discovers that this object is good and pleasant to eat, it is difficult to suppose that the blindness which accompanied the first instinctive action is not taken arvay at once and for ever afterwards. On the other hand, when 
the blind instinct makes a mistake and the young chicken pecks at its own excrement, we see by its action that it is perfectly aware of the mistake that it has made and the necessity of exercising a certain amount of self-control. Professor C. Lloyd Morgan, after making many experiments on instinct in chicks and ducklings, comes to the conclusion that-

"The inherited activities on their first performance are not guided by consciousness, though they are probably accompanied by consciousness. The rôle of consciousness is that of control and guidance. Only on the first performance of an inherited activity is the chick a conscious automaton. In so far as the activity is subsequently modified and perfected by intelligence, the agent exercises conscious control."-(Natural Science. vol.iv., p. 213.)

The most prominent writers on the evolution of instinct by Natural Selection are necessarily convinced believers in the principle of evolution. Darwin and Romanes also hold that some animals are intelligent, and that their instinctive action is often modified by what Pierre Huber calls "a little dose of judgment or reason." Hence the problem which we have now therefore to discuss narrows itself to this point. The principle of organic evolution is assumed to be true. It is admitted that some animals are intelligent beings. Under these conditions we have to enquire what proof can be adduced in favour of the assertion that instincts have arisen, or have been developed, through the agency of Natural Selection. In answering this enquiry, the fact of animal intelligence is most important, for two reasons. In the first place the intelligent animal is necessarily conscious of the significance of the instinctive actions which it performs. Dr. Martineau, who does not believe that animals are intelligent, clearly sees what would follow if they were. .

"The difference between man and his companion creatures on this earth is not that his instinctive life is less than theirs; but 
that in him it acts in the presence and under the eye of other powers which transform it, and by giving to it vision as well as light, take its blindness away."-(Old and New. vol. vi., p. 40z.)

But if this is so, it is quite clear that in a matter of life and death, which Natural Selection presupposes, the intelligent animal will not yield itself the blind, unconscious, and unquestioning subject of Natural Selection in the matter of instinctive action.

In the second place it is admitted that the intelligence of animals will anticipate the action of Natural Selection. Mr. Romanes says :-

"We find abundant proof of the intelligence of animals guiding the course of variation; so that, unlike the case of structures, instincts do not require to wait for Natural Selection to seize upon fortuitous variations, but themselves supply variations, which, in relation to any change of environment, are from the first adaptive." -(The Formightly Review. vol. xxxviii., p. 94.)

If this principle be admitted, then it follows that, if instincts are to be developed by Natural Selection, it must be in the absence of intelligence. How, then, can this absence of intelligence occur in connection with the experience of animals credited with intelligence? (I) It is conceivable that some of the actions of an animal are guided by instinct and others by intelligence; and that the processes have no connection with one another. (2) The evolution of instinct, apart from intelligence, may occur before intelligence comes upon the scene; or (3) after intelligence has "lapsed"; or (4) in cases in which the intelligence takes no cognizance of non-intelligent and non-purposive actions, which yet become habitual and are inherited; or (5) in cases in which the animal cannot possibly know the utility of the action which it performs; or (6) in cases in which certain intelligent actions have become instinctive, which could not possibly have been inherited. 
(I) It is contended by some that instinct and intelligence act apart from one another, in so far as intelligent animals are altogether the creatures of impulse, of blind instincts in what may be called their professional action. Mr. Spalding says :-

"I have no doubt that observation will bear out the popular belief, that what may be called the professional knowledge of various species, those special manifestations of practical skill, dexterity and cunning that mark them off from each other, no less clearly than do the physical differences whereon naturalists base their classifications, is instinctive and not acquired."--(Macmillan's Magazine. vol. xxvii., p. 288.)

Mr. Reid says :-

"The more sagacious animals may be taught to do many things which they do not by instinct... But in their own arts they need no teaching." - Essays on the Active Powers of the Human Mind. Essay iii., chapter ii.)

And Wordsworth speaks of-

"The constitutions, powers and faculties Which they inherit, cannot step beyond And cannot fall beneath-that do assign To every class its station and its office."

-(Excursion. $)$

But, on the contrary, Mr. Kirby, in his Bridgewater Treatise, says :-

"It should be borne in mind, however, that though the intellect is not the great principle, yet it must be admitted that all animals, gifted with the ordinary organs of sensation, more or less employ their intellect in the whole routine of their instinctive operations." (Bohn's Edition. vol. ii., p. 776 .)

I may here remark that we must be careful not to draw too large an inference from a few experiments. We must remember that there is a considerable difference in the degree of intelligence in different individuals of the same species; and that, while one may not be able to solve 
the problem suggested by new conditions, there may be here and there one who can. A good illustration of this point is to be found in an incident described by Mr. Hudson. During a plague of mice which occurred in a region of La Plata, every long hollow stalk of the giant thistle had a mouse in it. Some children found that some excitement and fun were to be got by placing one of the stalks with a mouse in it before a cat.

"Smelling her prey, she would spring at one end of the stalk, the end towards which the mouse would be moving at the same time, but would catch nothing; for the mouse, instead of running out, would turn back to run to the other end; whereupon the cat, all excitement, would jump there to seize it; and so the contest would continue for a long time, an exhibition of the cleverness and stupidity of instinct both of the pursuer and the pursued. There were several cats at the house, and all acted in the same way except one. When a stalk was placed before this cat, instead of becoming excited like the others, it went quickly to one end and smelt at the opening, then, satisfied that its prey was inside, it deliberately bit a long piece out of the stalk with its teeth, then another strip, and so on progressively, until the entire stick had been opened up to within six or eight inches of the further end, when the mouse came out and was caught. Every stalk placed before this cat was demolished in the same business-like way; but the other cats, though they were made to look on while the stick was being demolished by their fellow, could never learn the trick."-(The Naturalist in La Plata. pp. 6I-2.)

Clearly the inference from this story is that many cats are sometimes stupid, but not that all cats are always unintelligent.

Some of the experiments which are made on the subject of animal intelligence seem to me to be particularly unfair; because the conditions are such as could scarcely have taken place in nature, and must have had the effect of confusing the mind of the animal. If that interpretation of the phenomenon is true, the trial is not so much a scientific experiment as a practical joke, intended to 
confuse and probably followed with results similar to those foreseen by the poet.

"The centipede was happy, till

One day the toad, in fun,

Said, 'Pray which leg goes after which?'

This strained his mind to such a pitch,

He lay distracted in a ditch,

Considering how to run."

In these and kindred cases, it would be well for us to bear in mind the suggestive remark of Sir John Lubbock, characterised by equal modesty and justice, who says, in the introduction to his Ants, Bees and Wasps, "I am fully conscious that experiments conducted as mine have been leave much to be desired, and are scarcely fair upon the ants." * Both these sources of possible error are illustrated in the following case :-

"There is a caterpillar that makes a very complicated hammock, the construction of which may be divided into six stages. One of these caterpillars, which had completed its own hammock, having been transferred to another carried only to its third stage, completed this also by re-performing the fourth, fifth and sixth stages. But another caterpillar, taken out of a hammock which had been only carried to its third stage and put into one already completed, appeared much embarrassed and seemed forced to go back to the point at which it had itself left off, executing anew the fourth, fifth and sixth stages which had been already wrought out."(Dr. Carpenter. Mental Physiology. p. 6I.)

The explanation of the above case no doubt is, that one caterpillar was more intelligent than another, but that the possibly less intelligent was "much embarrassed" by a condition of things which could not possibly have occurred in nature.

(2) In the next place, it is supposed by some that the evolution of instincts may take place before intelligence makes its appearance, either in the race before it has 
been developed to the stage of intelligence, or in the individual before it has grown to be an intelligent being. Mr. Romanes contends that some animals are too low in the zoological scale to be intelligent. He says:-

"Many instincts are displayed by animals too low in the zoological scale to admit of our supposing that they can ever have been due to intelligence. To give only one illustration. The larva of the caddice-fly lives in water and constructs for itself a tubular case made of various particles glued together. If, during its construction, this case is found to be getting too heavy-i.e., its specific gravity greater than that of the water-a piece of leaf or straw is selected from the bottom of the stream to be added to the structure; and conversely if the latter is found to be getting too light, so as to show a tendency to float, a small stone is morticed in to serve as ballast. In such a case as this it seems impossible that an animal so low in the zoological scale can ever have consciously reasonedeven in the most concrete way-that some particles have a higher specific gravity than others, and that by adding a particle of this or that substance, the specific gravity of the whole structure may be adjusted to that of the water. Yet the actions involved are no less clearly something more than reflex; they are instinctive, and can only have been evolved by Natural Selection."-(Mental Evolution in Animals. p. IOI.)

Now, in reply to this argument, we admit that it is a perfectly legitimate assumption, from the point of organic evolution, to take for granted that intelligence must have been developed, and that there must have been a stage at which the non-intelligent became the intelligent. But before we draw a definite line, and say with confidence that intelligence is only found above a certain grade of organic development, we must be sure that the facts of actual experience justify the assumption. Mr. Romanes says that the caddice-fly is too low in the zoological scale to be intelligent. What, then, is the position of this animal in the zoological scale? It belongs to the class of insects. Are we to understand Mr. Romanes to assert that insects are too low in the upward path of development to be intelligent? 
"We cannot reasonably suppose insects to be gifted with instincts adapted for occasions that are never likely to happen. If, therefore, we find them in these extraordinary and improbable emergencies still availing themselves of the means apparently best calculated for ensuring their object, and if, in addition, they seem in some cases to gain knowledge by experience, if they can communicate information to each other, and if they are endowed with memory, it appears impossible to deny that they are possessed of reason." (Spence. pp. 559-560.)

The caddice-fly belongs to the order Neuroptera. Does Mr. Romanes maintain that this order is unintelligent though other orders are intelligent? If so, dragon-flies, may-flies, scorpion-flies, ant-lions and termites are unintelligent. Let us take as a test the case of the larva of the ant-lion.

"It feeds upon the juices of insects, particularly of ants, in order to obtain which it excavates with the greatest ingenuity a funnelshaped hole in sandy ground, and lies in wait at the bottom, all but its mandibles buried in the sand. Insects which approach too near to the edge of the hole then become its prey, by the loose sand giving way, so that they fall down the steep slope. If they do not fall quite to the bottom, but begin to scramble up again, the ant-lion throws sand upon them by jerking its head, and so brings them back. It employs its head in the same way to eject their bodies from its pit, after their juices have been sucked, and casts them to a considerable distance; and by the same means throws away the sand in excavating its hole, first ploughing it up with its body and then placing it upon its head by means of one of its forelegs. It always begins by working round the circular circumference of its future hole, and gradually narrows and deepens it, turning quite round after each time that it works round the hole, so as to employ next time the foreleg of the other side. When it meets with a stone which it cannot remove, it deserts the excavation and begins another."-(Chambers' Encyclopedia-Art: Ant-lion.)

Or shall we interpret Mr. Romanes to assert that the caddice-fly is alone unintelligent among insects of the order to which it belongs? The particular action which Mr. Romanes selects as an illustration of his argument appears to me to exhibit all the signs of intelligence. 
If we went up in a balloon and saw an aeronaut throw out ballast when he wanted to ascend and let out gas when he wanted to descend, we should never doubt that he was an intelligent being and that he knew perfectly well what he was about. Moreover it would be difficult to conceive of any action which more required the constant supervision of the intelligence. We constantly meet with similar statements made by other writers. Thus Professor Henry Calderwood says :-

"No one will propose to assign intelligence to the jelly-fish, starfish, snail, and centipede, though no one denies to them sensibility and motor activity." -(The Relations of Mind and Brain. p. I98.)

So far as the first-mentioned animal is concerned, $\mathrm{Mr}$. Romanes says :-

"This jelly-fish carries its larvæ on the inner sides of its bell-like body. The mouth and stomach of the jelly-fish hang down like the tongue of a bell, and contain the nutrient fluids. Now, McCready observed this depending organ to be moved first to one side and then to the other side of the bell, in order to give suck to the larvæ on the sides of the bell-the larvæ dipping their long noses into the nutrient fluids which that organ of the parent's body contained. I cite this case because, if it occurred in one of the higher animals, it would properly be called a case of instinct; but as it occurs in so low an animal as a jelly-fish, it is quite impossible that intelligence can ever have played any part in originating the action. Therefore we may set it down as the uncompounded result of Natural Selection." -(Science Lectures.)

And yet the same author says :-

"I observed jelly-fish crowding into the path of a sunbeam shining through a darkened tank, and saw that they did so in order to follow the crustaceans on which they feed, and which always seek the light." -(Mental Evolution in Animals. p. 258.)

This has certainly the appearance of an intelligent action. With respect to the star-fish, "it is believed that the mother star-fish exercises a degree of watchfulness altogether unusual among marine animals of so low a grade." 
"Mrs. Elizabeth Agassiz relates that a gentleman of her acquaintance removed the attached bunch of eggs from a star-fish in his aquarium, for examination, and afterwards put them back again. To his surprise, the star-fish at once crawled toward them and gathered them again into a cluster under her. Curious to test how far this apparently maternal solicitude was a reality, he again took away the eggs and put them in a distant part of the aquarium. A second time the animal spread herself over them. Once more removing the eggs to the opposite end of the tank, he set a piece of stone in front of them. The distressed mother immediately began to search for her lost treasures, and when, after circling the obstacle, she seemed to catch sight of them, she made straight for the eggs and a third time enwrapped them in her embrace. This incident is remarkable not only for the strong maternal attachment displayed, but also for the sharpness of eyesight it implies."-(Scribner's Magazine. vol.xixi., p. 652.)

The intelligence of the snail seems to be duly indicated in the following experiment :-

"Mr. W. White fixed a land-shell, mouth uppermost, in a chink of rock. In a short time the snail protruded itself to its utmost length, and attaching its foot vertically above, tried to pull the shell out in a straight line. Not succeeding, it rested for a few minutes, and then stretched out its body on the right side and pulled its utmost, but failed. Resting again, it protruded its foot on the left side, pulled with its full force, and freed the shell. This exertion of force in three directions, which seems so geometrically suitable, must have been intentional."-(Romanes. Animal Intelligence. p. 26.)

The centipede is armed with eight eyes and seventeenjointed antennæ; it is the quick and ruthless hunter of insects, pursuing them to their lurking-places and giving them no quarter. On what ground should we deny the possession of intelligence to this insect of prey which we should readily allow to a beast of prey, if he conducted himself in a similar manner?

Again, the line is drawn between intelligent and nonintelligent animals, because it is taken for granted that intelligence cannot exist before a particular stage of organic development has been reached. I will take an 
extreme illustration to test the truth of this principle. The simplest type of an animal is an amœba. It consists of a minute mass of protoplasm or living jelly, every part of which has the same endowments and takes an equal share in every action which the creature performs.* The amœba is sensible to impressions; moves more or less quickly and voluntarily; selects the food which it likes, and assimilates organic matter; it breathes in as much as it expires carbonic acid formed in the process. $\dagger$ Of one of these "jelly-specks," the gromia, Dr. Carpenter says :-

"Suppose a human mason to be put down by the side of a pile of stones of various shapes and sizes, and to be told to build a dome of these, smooth on both surfaces, without using more than the least possible quantity of a very tenacious but very costly cement in holding the stones together. If he accomplished this well, he would receive credit for great intelligence and skill. Yet this is exactly what these little 'jelly-specks' do on a most minute scale; the 'tests' they construct, when highly magnified, bearing comparison with the most skiful masonry of man. From the same sandy bottom one species picks up the coarser quartz-grains, cements them together with phosphate of iron secreted rom its own substance, and thus constructs a flask-shaped 'test' having a short neck and a single large orifice. Another picks up the finest grains and puts them together with the same cement into perfectly spherical 'tests' of the most extraordinary finish, perforated with numerous small pores, disposed at pretty regular intervals. Another selects the mimutest sand-grains and the terminal portions of sponge-spicules, and works there up together-apparently with no cement at all; by the mere 'laying' of the spicules-into perfect white spheres, like homocopathic globules, each havingr a single fissured orifice. And another which makes a straight, many-chambered test that resembles in form the chambered shell of an orthoceratite, the conical mouth of each chamber projecting into the cavity of the next, while forming the walls of its chambers of ordinary sand-grains rather loosely held together, shapes the conical mouths of the successive chambers by firmly cementing together grains of ferruginous quartz, which it must have picked out from the general mass."-(Principles of Mental Physiology. pp. 42-43.)

* Carpenter, + Semper. 
But in spite of all this, he says :-

"We can scarcely conceive that a creature of such simplicity should possess any distinct consciousness of its needs, or that its action should be directed by any intention of its own."-( $\not p .4 I-42$.)

What shall we say in a case like this? We must either assert somewhat dogmatically that the simplest organisms cannot be the seat of animal intelligence, or we must admit the possibility of intelligence apart from the particular differentiation with which we are acquainted in the case of man. And surely that is possible. Dr. Carus says :-

"When we find that there can be respiration without lungs, that nutrition, growth, and secretion may exist without a circulation of fluids, and that generation may take place without distinct sexes, why should we doubt that sensitive life may exist without nerves, or motion without muscular fibres?"-(Kirby. Bridgewater Treatise. vol. i., p. 2II.)

"I adopt," says Mr. H. F. Finch, "Haeckel's cellular psychology which attributes the elements of intellectual sensation and volition to infusoria and organic cells in general, in opposition to the older neural psychology, according to which psychical action begins with the nervous system in the scale of animal life. This latter view has given a longer lease of life to the old theory of instinct regarded as a mysterious power of nature."--(Nature. vol. xix., p. 340.)

"It is anthropomorphic," says Mr. H. M. Stanley, "to suppose that all intelligence must be fitted with the same organs that we possess."-(Mind. vol. x., p. 424.)

There seems some reason, to my mind, in these contentions; but if there is force in them, it will be difficult to find a sphere of life from which intelligence is necessarily excluded.

It is contended that the actions of the higher animals, which are performed at an age before they have become intelligent beings, are necessarily instinctive and nonintelligent, and therefore that they offer material for 
the evolution of instinct by means of Natural Selection. In this argument there is no question of the actual intelligence of the race or of the potential intelligence of the individual, should life be spared. It only asserts that there is a period in early life when the young animal has not yet become intelligent. In reply to this contention, we may remark that the emergence of intelligence in any individual does not depend altogether on the grade in the zoological scale, so much as it does on the stage of development which an animal has attained at birth. The birds which are hatched in a tree are in a less advanced stage than the birds which are hatched in a nest situated on the ground. But the less developed animals are reared under the care of intelligent and devoted parents, who supplement instinctive tendency with training and instruction; and it would be rash to assume that there was any considerable period when the lives so cared for remained unintelligent.

"Easy the lesson of the youthful train,

When instinct prompts and when example guides."

-(The Chase. Book iv., lines 128-9.)

But it is obvious that this explanation does not account for some instinctive actions. The existing organism of the mammalia being what it is, it would be impossible for the young mammal to learn the art of sucking. It would perish if it could not perform that most complicated operation at once. The explanation is that it repeats in a perfect manner the operation which its remote ancestry gradually acquired.

"The ancestors of all the mammalia are said by evolutionists to have been marsupials or pouched animals. When we investigate the early life of these creatures we find that the young marsupial is born in a very imperfect state of development, so that special arrangements have to be made to secure its existence. The mother apparently employs her mouth in placing the young at the nipple, where it remains suspended. The mammary glands of the mother 
are furnished with special muscles, which force the milk into the mouths of the young. At first the young are able to use the muscles of the mouth only to adhere firmly, but do not possess the strength or skill to obtain the milk by sucking. In order to prevent the young from being choked, the air passage is entirely separated from the throat, and the milk passes on each side of the larynx into the æsophagus. After two months have elapsed, the young suck spontaneously."-(See Hacckel. vol. i., p. 39r.-Nicholson. Zoology. First edition. p. 627.-Chambers' Encyclopaedia-Marsupialia.)

I had worked out the problem for myself some years ago ; it was therefore very gratifying to find Mr. Romanes, when answering Mr. Mivart, giving the same explanation of the origin of an instinct which takes effect before the intelligence is developed in the higher animals.

"He (Mr. Mivart) says, "it is impossible to believe that any of the progenitors of an infant of to-day first acquired, during his or her lifetime, the habit of sucking.' This, no doubt, appears at first sight a most conclusive case; for as the instinct in all mammals only lasts during the earliest babyhood of the individual, its inception can never have been due to intelligence; while, if its development had depended on the slow process of natural selection, all the young mammals ought to have been starved before the instinct of sucking had been begun. While writing my own book, this case occurred to me as a possible difficulty; but afterwards I passed it over in view of a consideration which must have escaped Mr. Mivart. 'The progenitors of an infant of to-day' were the marsupials, and in the marsupials the young animal does not suck, or only does so in part ; it is forcibly fed by the mother, who squirts the milk into its mouth. From such a beginning as this, it is easy to understand how the instinct of sucking originated, and subsequently became perfected in successive generations."-(Fortinghtly Review. vol. xxxviui, pp. 97-8.)

The case of such instincts does not, therefore, exclude intelligence in such a way as to allow for the action of Natural Selection to secure the survival of favourable variations arising among those variations which are incidental to birth. For, in the first instance, parental intelligence guides the imperfectly developed instincts; in the second case, the instinct is perfect from the first, or very nearly so; and the survival of the individual depends upon the 
prompt and unmodified reproduction of an art learned by a long line of remote ancestors.

(3) In the third place we have to consider the proposition that instincts may be developed or modified by Natural Selection in the absence of intelligence on account of what is known as the "lapsing" of the intelligence. We are indebted to Mr. George Henry Lewes for this theory, and it may be interesting to note, first, what Mr. Lewes teaches on this point; and, secondly, how the theory has been modified by Mr. Romanes in order to make room for the action of Natural Selection.

The process by which an intelligent action is developed into an instinct is as follows:-First of all, we have the intelligent action which solves some new problem presented by some new condition. This act, which is prompted by intelligence, is often required to meet daily difficulties, and quickly becomes a habit. The habitual action soon becomes easy to perform, so that it requires less and less attention on the part of the agent, until at last it becomes automatic-i.e., the agent performs the action unconsciously. This perfectly developed habit is inherited by offspring actually or potentially. In those animals which have to be most self-reliant in their earliest days this perfect habit will be inherited in complete or almost complete perfection. And thus an intelligent action becomes an instinctive one by processes which we can illustrate from the experiences of men and animals. We have abundant evidence of the fact that the intelligence of some animals is sufficient to solve the problem suggested by changed conditions. Mr. Arthur Nichols gives a most graphic description of a new method adopted by his retriever :-

"Towards the evening of a long day's snipe-shooting on Dartmoor, my retriever flushed a widgeon which fell to my gun in the river 
Dart, and of course instantly dived. I said no word to the dog. $\mathrm{He}$ did not plunge in after the widgeon there, but galloped down stream about 50 or 60 yards, and then entered the water and dashed from side to side-it was about 20 or 30 feet wide-working up stream and making a great commotion in the water, until he came to the place where we stood. Then he landed and shook himself, and carefully hunted the near bank a considerable distance down, crossed to the opposite side, and diligently explored that bank. Two or three minutes had elapsed, and the party was for moving on, when I called their attention to a sudden change in the dog's demeanour. His 'flag' was now up and going from side to side in that energetic manner which, as every sportsman knows, betokens a hot scent. I then knew that the bird was as safe as if it was already in my bag. Away through the heather went the waving tail, until 20 or 30 yards from the bank opposite to that on which we were standing, there was a momentary scuffle, the bird just rose from the ground above the heather, the dog sprang into the air, caught it, came away at full gallop, dashed across the stream, and delivered it into my hand. The dog had learned from long experience in Australia and the narrow cañadas in the La Plata that a wounded duck goes down stream; if winged, his maimed wing sticks out and renders it impossible for him to go up, and will invariably land and try to hide away from the bank. But if the dog enters at the place where the bird fell, the latter will go on with the stream for an indefinite distance, rising now and then for breath, and give infinite trouble. My dog had found out all this long since, and had proved the correctness of his knowledge times out of number, and by his actions had taught me the whole art and mystery of retrieving duck. His object was to flurry the bird, and force it to land by cutting it off lower down the stream. Then assuming, as his experience justified him, that the bird had landed, he hunted each bank in succession for the trail which he knew must betray the fugitive." (Nature. vol. xix., p. 496.)

The new method of action once discovered quickly becomes a habit of the life, sometimes at once. The bees that were observed trying to make their way into the blossom of a passion-flower are a case in point.

"Mr. Wailes observed that all the bees, on their first visit to the blossoms of a passion-flower on the wall of his house, were for a considerable time puzzled by the numerous overwrapping rays of the nectary; and only after many trials, sometimes lasting two or three minutes, succeeded in finding the shortest way to the honey at the 
bottom of the calyx. But experience having taught them this knowledge they afterwards constantly proceeded at once to the most direct mode of obtaining the honey; so that he could always distinguish bees that had been old visitors of the flowers from new ones, the last being invariably at first long at a loss, while the former flew at once to their object."-(Kirby and Spence. Entomology. p. 563.)

What is done habitually soon comes to be done without special attention; the mechanism set going works of itself-automatically, as it is called.

"Mr. Herbert Spencer tells of an old soldier who was one day carefully carrying a choice pie home to his dinner. Some cruellydisposed individual came behind him, and suddenly cried in a commanding voice, 'Attention!' Immediately the old soldier stood bolt upright, with his hands to his sides, while the pie came to grief upon the pavement. This response to the word 'Attention!' had become to him instinctive." -(Romanes. Science Lectures. p. 163. )

The intelligent action which becomes a habit so perfect that it works automatically is inherited by the offspring.

"Among the descendants of the dogs originally introduced into South America by the Spaniards, there are breeds which have learned by their own experience, without any human training, the best modes of attacking the wild animals they pursue; and since young dogs have been observed to practise these methods the very first time they engage in the chase, with as much address as old dogs, it can scarcely be questioned that the tendency to the performance of them has been embodied in the organisation of the race, and is thus transmitted hereditarily."-(Carpenter. Mental Physiology. p. 104.)

Such is Mr. Lewes' explanation of the origin of instinct, which certainly does not require the interposition of Natural Selection for its complete realisation. Mr. Romanes supposes that the process is carried two steps further. He conceives that in certain cases where modification becomes necessary, intelligence interposes to adapt the instinct to new conditions; and that the action so modified becomes a habit, is often automatically performed, 
and at last is inherited as an instinct. But he is not content with making this perfectly consistent addition to Mr. Lewes' explanation. He proceeds to say that the time comes when intelligence has altogether lapsed; the instinctive action then becomes liable to fortuitous variations, and Natural Selection secures the survival of those that are favourable.

The first point to remark in this theory as modified by Mr. Romanes is that the intelligence of the animal is represented as interposing in one case and not in another. And this view seems to have arisen from the use of the word "lapsing." For what can lapsing mean except that that which is lapsing will ultimately become "lapsed"?-just as the "going, going" of the auctioneer leads to the "gone!" which accompanies the fall of the hammer. But if we grant that there comes a time when intelligence has lapsed, that cannot mean that it has ceased to be present in the experience of the intelligent animal, but only that a certain action has become automatic, and that the intelligent element has passed away from it. If the intelligent animal still remains intelligent, why, it may be asked, should not its intelligence come into action in one crisis as well as in another? If a change of instinct is necessary in changed conditions for the welfare of the animal (and only on that condition can Natural Selection intervene), what is to prevent the intelligence of the animal from discerning the necessity and striving to meet it. We cannot doubt that it would try its very best to discover some new modus operandi as a necessary condition of a new modus vivendi. And instances could be quoted to show that the issue was between some new mode of action or death. In either case the evolution of instinct by Natural Selection would be out of the question 
We may assume, for the sake of argument, that sometimes an important and useful modification of an instinctive action takes place unintelligently. The animal happens by accident to do what is useful to it. In that case, such a fortunate fluke could not be developed by the agency of Natural Selection in the presence of an intelligent race. For the advantage would be at once perceived, and the new method would be at once adopted. It would be taught to others or imitated by others and inherited. In the following case, it may very well be believed that the escape of some of the birds arose from a happy accident; but the experience thus gained was evidently reproduced in the race.

"About tivelve years ago, I was residing on the coast of Co. Antrim, at the time the telegraph wires were set up along that charming road which skirts the sea for twenty-five miles between Larne and Cushendall. During the winter months large flocks of starlings always migrated over from Scotland, arriving in the early morning. The first winter after the wires were stretched along the coast I frequently found numbers of starlings lying dead or wounded on the roadside, they having evidently in their flight in the dusky morn struck against the telegraph wires--not blown against them, as these accidents often occurred when there was but little wind. Strange to say, that throughout the following and succeeding winters hardly a death occurred among the starlings on their arrival."-(Nature. vol. xx., p. 267.)

There is no such thing as the lapsing of intelligence, so far as the general intelligence of an intelligent animal is concerned. Intelligence lapses, if at all, from the action which has become automatic; and it is natural to assume that what is in a lapsing condition will ultimately become altogether lapsed. But, as it seems to me, it would be more in accordance with the facts of the case to speak of the intelligence having become latent rather than lapsed. Let us take the case of the old soldier. If the order to stand at attention had been followed by the command, 
Quick march! it may be questioned whether the old habit of obedience would have prevailed. The loss of the pie would have broken the charm. In the same way, every instinct which was once an intelligent action may be accompanied by a sub-consciousness which could not be altogether unobservant of advantage or disadvantage in connection with some useful modification or with some change of the external conditions.

Mr. Romanes adduces the following illustration of the fact that intelligence acts up to a certain point; and that Natural Selection then comes in to perfect the instinctive action.

"The grouse of North America display the curious instinct of burrowing a tunnel just below the surface of the snow. In the end of this tunnel they sleep securely; for when any four-footed enemy approaches the mouth of the tunnel, the bird, in order to escape, has only to fly up through the thin covering of snow. Now in this case the grouse probably began to burrow for the sake of protection or concealment, or both; and, if so, thus far the burrowing was probably an act of intelligence. But the longer the tunnel, the better would it have served the purposes of escape, and therefore Natural Selection would almost certainly have tended to preserve the birds which made the longest tunnels, until the utmost benefit that length of tunnel could give had been attained."-(Mental Evolution in Animals. p. 202.)

The theoretical explanation given in the above passage implies-first, that safety was due to the length of the "burrow," and, secondly, that the precise length of it was determined not by the continued action of the intelligence of the bird, but by the survival of those individuals which, by a happy accident, chanced to make a "burrow" of the right length. Now, let us consider the circumstances under which the length of the tunnel would prove a source of safety. In order that the grouse should escape it must be able to fly up easily from under the superincumbent snow. It would be fatal for it to be buried in 
a burrow beneath snow the surface of which was frozen into ice. In the next place, the enemy must approach the grouse through the burrow as a ferret does in the case of a rabbit's burrow; and, in the third place, the burrow must be long enough to give the animal a sufficient warning and opportunity for escape. Now, it would appear that, in Russia, the grouse do not burrow in the snow, until it is at least an inch and a half deep, nor towards the end of winter when crusts of ice form on the top of the snow. The birds burrow in the snow that lies lightly and through which it is easy to fly. Thus the first condition of safety is secured. As to whether the beast of prey would approach the grouse through the tunnel, that does not seem to me to be so absolutely certain. We are told that the bird, when it has reached the end of the burrow, "pokes a hole through the top with its head for air." Now, if we may credit the attacking animal with an ordinary amount of intelligence, we may suppose that it will understand that the grouse lies under this air-hole; in which case it is quite possible that it might approach it from above.

In Russia, I am told that the fox will scratch the snow away to get at the field-mice beneath; and if the fox can smell the mice beneath the snow, it is reasonable to suppose that it would still more be able to find the grouse, and the sleeping animal, being attacked from above, would not be able to fly away. In this case, it is obvious that the length of the burrow would make no difference to the safety of the animal. But let us assume, for the sake of argument, that the attack is made through the burrow. We are instructed to picture a state of things in which the precise length of the burrow will make the difference between the life and death of the individual, between the extinction or preservation of the race. In this safe 
position the grouse sleeps securely. But it is difficult to understand how it comes to wear this charmed life. Surely it is not altogether free from danger. It cannot burrow in loose snow without leaving some trace of its operations, of which the intelligent beast of prey would soon learn the meaning. It can be found by scent if not by sight. As it seems to me, the only way of sleeping securely in such a case would be to sleep with one eye open, ever on the alert against danger. If not, the difference in the length of the burrow of a few inches, more or less, would not present the issue of life or death.

One does not see, therefore, what safety would come from a burrow of a definite length, supposing always that the bird were sufficiently covered to be protected from the cold and concealed from enemies. But there is a farther consideration which leads us to suppose that the exact length of the burrow is not determined by the calculations of intelligence nor by the good fortune of those who unconsciously hit on the right length, and are so preserved while others less fortunate are destroyed. Probably the length of the burrow is determined by the manner in which it is made, for the grouse plunges down from the branch of a tree into the snow, and the length of the burrow is determined by the strength and the weight of the animal ; for we can well believe it exerts all the energy of which it is capable.

In all such cases there is no doubt a competition between caution in attack, on the one hand, and vigilance in avoiding danger on the other, in which sometimes one side and sometimes another will win the day; but it is difficult to suppose that an exact length of burrow can secure perfect safety, while a shorter burrow will involve destruction; and yet that is what Mr. Romanes' theoretical explanation of the phenomenon suggests. 
Mr. Nansen, in his interesting work Across Greenland, offers us a good illustration of the way in which the theory of Natural Selection is often invoked when the circumstances of the case scarcely require its introduction. He speaks as a convinced believer in animal intelligence :-

"Many people seem to think that animals cannot develop their own faculties, and have no power of making observations, or of drawing conclusions from their own experience. I am not one of these people, and I believe that animals, wild as well as tame, have eyes to see with, ears to hear with, and understanding of the same kind as we men, if not in so high a degree."-(Vol. i., p. 185.)

He applies this principle to the shyness of the bladdernose seal which resulted from the attacks made upon them by Norwegian sealing vessels.

"Experience soon taught him, and it was not long before he grew shyer. He would no longer let the boats come close in before he took to the water. The rifle had now to be used, often at long ranges, and even so, it was not easy to fill one's boats. The most remarkable thing was that it was not only the old seal that grew shy, but the youngest animals were now astonishingly wary. The parents must have imparted their experience to the offspring or the same result must have been brought about by heredity, though this seems scarcely likely to have happened in so short a time. . . . They have learned this lesson in the short space of a decade."-(Vol. i., p. 187.)

But this reasonable hypothesis becomes a matter of doubt in the mind of Mr. Nansen. He says that "perhaps this bladdernose seal affords a good illustration of animal intelligence." He declares that, "plausible as this theory seems, it must be admitted that there are other ways of explaining this change of habit. It may arise from the action of Natural Selection alone, or from the action of animal intelligence supplemented by Natural Selection."

The theory that the shyness of the bladdernose seal is due to the intelligent perception and avoidance of danger is something more than plausible. It does not 
take a period of ten years to teach some animals the caution which is necessary for the preservation of their lives. It happened that I lived in the country at a time when the farmers of a certain parish vacillated in their policy towards sparrows. At one time they were assured that the sparrows were their best friends; at other times they yielded to the popular prejudice in the opposite direction. The sparrows knew as well as the farmers what was going on. In the Reign of Terror they were always on the qui vive, and flew away at the slightest noise; while at other times they were as bold as brass and as tame as barn-door forwls.

The ease with which the seals were captured at first arose from the fact of the novelty of the attack; and it seems reasonable to suppose that as soon as the animals understood their danger, they were intelligent enough to avoid it. If we once grant this, we can well believe that in the case of the seals, as well as other animals, the young would inherit shyness in face of danger as an instinctive tendency.

On the other hand, the explanation that this shyness may have been due to Natural Selection is beset with difficulties. If Natural Selection be the sole cause, then we must assume that intelligence played no part in the matter. There were degrees of congenital shyness in the case of the seals, just as there are degrees of boldness or shyness in human beings. Now this shyness must have been either altogether unintelligent-a mere matter of nerves-or it must have been intelligent. In either case it could not fail to be influenced by the intelligence of the race. The conditions of the family are such that discipline prevails, and no mere congenital shyness would be allowed to develop itself. On the other hand, grant that the shyness was permitted to develop itself, and was 
intelligent and also successful, it would become the object of imitation by others.

Nor is it possible that Natural Selection should be required to complete what intelligence had begun. For Natural Selection works by life and death, and it is difficult to understand how the intelligent animal which had faced previous crises with success should yield itself, the passive victim of fate, at any subsequent period of its history.

(4) The fourth way of explaining how Natural Selection can act in the development of instincts so as to escape the interference of intelligence, is to assume that the intelligent animal may be unobservant of certain actions which are not intelligently performed, and are not of an adaptive character, but which are nevertheless inherited and fixed in the race. Mr. Romanes says that one mode of the origin of instincts

"consists in Natural Selection, or survival of the fittest, continuously preserving actions which, although never intelligent, yet happen to have been of benefit to the animals which first chanced to perform them."-(Mental Evolution in Animals. p. I77.)

The proof which he gives of this assertion is:-

"I. That non-intelligent habits of a non-adaptive character occur in individuals. 2. That such habits may be inherited. 3. That such habits may vary. 4. That when they vary the variations may be inherited. 5. That if such variations are inherited we are justified in assuming, in view of all that we know concerning the analogous case of structures, that they may be fixed and intensified in beneficial lines by Natural Selection."-(Ibid. p. I80.)

It should be observed that the selection of non-intelligent habits of a non-adaptive character is cited as a proof of the selection of actions which, although never intelligent, yet happen to have been of benefit to the animals that first used them! The two expressions are not identical, unless we interpret habits of a non-adaptive character 
to mean really useful habits, the usefulness of which the animals did not observe. But we cannot accept this interpretation of the phrase, because from the illustrations given of the non-intelligent habits of a non-adaptive character, we see that they are for the most part assumed to be useless, foolish, unintelligent.

It will conduce to a clearer understanding of the question if we regard these two passages as suggesting two entirely different methods by which instincts might be developed by Natural Selection. Now, with respect to the first statement, we have to deal with variations which are from the first useful to the race; and our contention is that the intelligent animal will observe this utility, and so anticipate the action of Natural Selection, especially when such utility is a matter of life and death, as it must be the very moment that Natural Selection comes into action.

The second mode of stating the case assumes that certain habits, which display no intelligence on the part of the animal, and are not adapted in any way to the conditions in which it lives, may have arisen in connection with intelligent animals, so that when a change of conditions makes them of use, they may come under the influence of Natural Selection.

Now, in order to justify this argument, we must first be sure that such habits are unintelligent. We must next be well assured that these actions could have arisen de novo and are not the result of some habit which was once more adaptive than it is now; we must be sure that such actions, supposing that they could have been developed in the way supposed, would become subject to the influence of Natural Selection when, through change of circumstances, they become useful. Now the first point to be observed is that some of the instances cited are not non-intelligent and non-adaptive habits. The Abyssinian pigeon when fired 
at plunges down so as almost to touch the sportsman, and then mounts to an immoderate height. It is a bold line to take, but surely a safe one. It is not the act of a fool. The purpose of it is to elude the sportsman's shot by taking him by surprise and by flying up in such a way that it is very difficult for him to fire, however prepared by previous experience.

The guanacoes have the habit of returning, like flies, to the same spot to drop their excrement. This is pronounced to be a senseless and a useless act. And yet it has a certain resemblance to the act of civilised man, who, perhaps, if put upon his defence, would call the custom decent, respectable, and not altogether unintelligent. The rationale of such a proceeding may be seen from the fact that large poultry farms are not a success; because,

" in all cases where a large number of fowls are congregated together, the ground becomes contaminated by the excrement of the birds; the food is eaten off the soiled surface; disease breaks out among the adults, and rearing chickens successfully is out of the question." (Encyclopaedia Britannica. vol. xix., p. 646.)

If the biscache almost invariably collects all sorts of rubbish about its burrow, we ought to be quite sure that it has no purpose to gain by that custom before we condemn the action as a "foolish and useless habit." Those who will take the trouble to read Mr. Hudson's chapter on The Biography of the Vizcacha will not remain in doubt on this subject. The biscaches or vizcachas on the pampas of Buenos Ayres live in societies, usually numbering twenty or thirty members. The village, which is called a vizcachera, is composed of a dozen or fifteen burrows or mouths; for one entrance often serves for two or more distinct holes. A vast amount of loose earth is brought up and forms a very irregular mound, fifteen or thirty inches from the surrounding level. These entrances are 
constructed in a particular way-the result being that the opening is a very considerable one; often four to six feet across the mouth, and sometimes deep enough for a tall man to stand up waist-deep in.

The next point to be observed is that the vizcachera is the centre of a clear space, often of half an acre in extent, on which there is an even, closely-shaven turf. This clearing is surrounded by the usual rough growth of herbs and giant grasses. And now we come to the senseless, useless act, of which Mr. Hudson says :"Another remarkable habit of the vizcacha-that of dragging to and heaping about the mouth of his burrow every stalk he cuts down and every portable object that by dint of great strength he can carry-has been mentioned by Azara, Darwin and others."

All these arrangements are of the highest utility, and we are justified in supposing that even if they are sometimes instinctively performed now, they had their origin in intelligent purpose.

In the first place, the manner of burrowing is of great advantage, because, on the perfectly level and shelterless pampas, the durability of the burrow-a circumstance favourable to the animal's preservation-is owing altogether to its being made in a certain way, and to several burrows being made together. The two outer trenches diverge so widely from the mouth that half the earth brought out is cast behind instead of before it, thus creating a mound of equal height about the entrance, by which it is secured from water during great rainfalls, while the cattle avoid treading over the great pit-like entrances. But the burrows of the dolichotis, the armadillo, and other species, when made on perfectly level ground, are soon trodden on and broken in by cattle; in summer they are choked up with dust and rubbish; and the loose earth 
having all been thrown up together in a heap on one side, there is no barrier to the water which, in every great rainfall, flows in and obliterates the kennel, drowning or driving out the tenant.

In the second place, the vizcachas have many enemies and it must therefore be of great advantage that there should be a perfectly clear space all around their dwelling, so that no cover should be afforded for any animal attempting to take them by surprise, but that they should be able to see the enemy from afar. The space also affords a comparatively safe place to feed in; and if the vizcachas are attacked, the cleared space offers no impediment to their speedy retreat.

In the third place, the space having to be cleared, the choice lay between taking the débris to the outer circle of the clearing or placing it around the mound, and especially round the large burrows. If the former course were adopted it would afford a cover in which the enemy might conceal itself, and from which it would rush to the attack. By adopting the latter course, the mound is raised, and this answers a double purpose. It gives added security to the burrows, which are liable to be inundated; and perhaps the material which is brought to the mound serves to bind together the loose earth and to make it more able to resist the action of the water. The higher the mound, the greater will be the advantage it confers as an outlook against danger; an advantage which seems to be demonstrated by the habits of the animals, which are often seen sitting on their haunches endeavouring to get as wide a view as possible.*

Dogs, we are told, display the meaningless habit of barking round a carriage. But is there no meaning and

* Hudson, The Naturalist in La Plata. pp. 28q-313. 
no purpose in that bark? It is a significant thing to begin with that only dogs which have been domesticated can bark at all. "The habit is almost universal with domesticated dogs, but does not characterise a single natural species of the family." * But if this is so, does not this look as if it were the language which it adopts in its intercourse with man? Mr. Romanes admits that the barking may be significant in certain cases.

"It is not, I think, improbable that what appears to be the acquired instinct of barking is, as it were, an offshoot from this acquired instinct of property, and of protecting self as property by drawing the attention of a master to the approach of strangers or enemies." (Romanes. Mental Evolution in Animals. p. 235.)

Are not the various tones of that bark suggestive of many shades of meaning? And is not the act of running round a carriage and barking an expression of exuberant joy and delight, of humble sympathy and affection? Can it therefore be altogether meaningless? Even in those cases in which the dog barks round the carriage which does not belong to its master, and it may be supposed to be inspired by a love of mischief or a feeling of hostility, we can scarcely call it a senseless act from its point of view, whatever it may be from ours.

We are told that "one animal conceives a strong though senseless attachment to another animal of a different species." + This is one of the illustrations given of non-intelligent habits of a non-adaptive character; and yet it is difficult to understand how it can be regarded either as an act void of intelligence or wanting in adaptation. The relation between man and domesticated animals is one which has its obvious uses, whether we have regard to the sentimental tie of friendship or the mutual

* Darwin. The V'ariation. vol. i., pt. 26-7. t Romanes. p. $r 83$. 
assistance which is often rendered. Different species of animals, as we have already seen, often live together, rendering mutual assistance and reaping a common advantage; and there seems no reason why individual members of different species should not do the same. The difference which distinguishes them may only serve to enhance the attraction of the mutual affection or the value of the mutual service.

There are certain actions which may be described as tricks of manner. "Scarcely any two sporting dogs point in exactly the same manner, although every dog adheres to his particular attitude through life."* But this is only to say that as no two individuals are exactly alike, so also their actions are not exactly alike. Such differences may therefore be regarded as the inevitable result of differences of organisation. So long as such differences do not affect the usefulness of the action, they are of no practical value. The mannerism of the sporting dog need not lessen its efficiency. If the pointer moves stealthily and without noise in the direction of the game; if it stops at that point where it would be fatal to its purpose to go further; if it stands like a statue with uplifted foot and outstretched tail, it fulfils all the necessary functions of its art; and it is immaterial to the sportsman so long as it does all this, whether or no it does it with a gait and manner of its own. Moreover, it is quite possible that individual differences may be useful for purposes of recognition. We can tell one man from another by the tread of his footstep, by the tone of his voice, by a characteristic cough, even if we do not see him. If we see him, we can tell by his gait who he is, even when he is at a considerable distance. How inconvenient it would be not to recognise one 
individual from another, we may see at once from considering the difficulty which is felt in the case of twins who are sometimes almost if not altogether indistinguishable.

If tricks of manner impaired the utility of an hereditary action, they would scarcely go unnoticed and unrebuked. In the animal world the instruction of parents supplements the deficiency of instinctive action, just as the trainer's supervision does in the case of domesticated animals. The attention of Mr. Romanes was first drawn to this point by observing how such tricks were suppressed by those who had the care of children. In none of these cases could tricks of manner present material for the evolution of new instincts by means of Natural Selection.

The difference of disposition and of habit is quoted in confirmation of this argument. If such differences arose without any cause, in a perfectly casual way, without any act of intelligence, without any attempt to adaptation,then they might become the material for unintelligent and non-adaptive habits which, being inherited, would become a blind foolish instinct. But is this so? "One ant will let itself be killed rather than let go the pupa which it carries; another will let it fall, and run away." One is a hero and a martyr; the other is a coward and a poltroon. But both acts have an end to fulfil; both acts are performed with a very definite purpose. In the one case, the ant tries to save the pupa; in the other case, the ant tries to save itself; and while both are intelligent enough to have a purpose, unfortunately it is only the coward who accomplishes the end that it has in view. It would surely be bitter irony to say that the ant which relinquishes a pupa acts on blind instinct. Shakespeare intends to be thus ironical when he makes Falstaff say,

"Instinct is a great matter; I was a coward on instinct." --(King Henry IV. Part i., act ii., sc. 4.) 
Some cats take to mousing, and others can never be taught. The difficulty here is only with the animal which neglects the common practice of the race. But there is no mystery in this case. Petted and overfed, the parent cats may have communicated to their offspring that lazy dependence upon others, which is the natural result of their own position. Nor is there any mystery in the fact that some members of a species retain the ancestral habits of their race with their accompanying instincts; and that others adopt new modes of life and lose the old ancestral aptitude in consequence.

In the cases which have been just cited, we venture to say that the actions are not non-intelligent and not nonadaptive. We have now to consider actions which were once intelligent and adaptive, but which have been modified by circumstances. But these cases do not afford any illustration of the origin of new, unintelligent and unadaptive instincts, but rather the survival of old instincts which have lost some of their usefulness through the change of conditions, which is a very different thing. Mr. Romanes quotes a letter from Mr. Thwaits to Mr. Darwin, in which Mr. Thwaits says that in Ceylon,-

"His domestic ducks quite lost their natural instincts with regard to water, which they never enter unless driven. The young birds, when forcibly placed in a tub of water, are quite alarmed and have to be quickly taken out again or they would drown in their struggling." This peculiarity is confined to one particular breed or strain. Mr. Romanes characterises this as the commencement of a racial and useless deviation from a strong ancestral instinct.-(Mental Evolution in Animals. p. I88.)

Now, if all the tame ducks had exhibited a change of instinct, there would have been no wonder in this matter, for, living under different conditions, it is very easy to suppose that new habits may have arisen and become 
confirmed. But we are told that this peculiarity only applies to one particular breed or strain. In order to understand the precise significancy of the difference, it would be necessary to know what the peculiar breed was, and what had been the antecedents of its immediate ancestry; and the problem would then no doubt be solved.

The implication is that the young duck takes instinctively to the water; and that the natural instinct is lost in the case under consideration. But do the facts of the case bear out this hypothesis? According to Dr. Stiebeling, of New York, "if young ducks are brought to a pond they will go and drink, but they will not go in." It is asserted by Mr. Thwaits that when forcibly placed in a tub of water they are quite alarmed, and have to be taken quickly out, or they would drown in their struggling. But Dr. Stiebeling says : "If they are placed in deep water they try to get out of it as quickly as possible, and therefore make active movements with their legs which necessarily propel them; and as an animal cannot sink, look like the movements of swimming." "If the ducklings be hatched under a hen they take much longer before they become used to the water than if hatched under a duck; for the latter, like all water birds, takes her young on her back and swimming out she shakes them off into the water. When the ducklings reach dry land again they shake themselves and try to clean the water off." $\dagger$ So that in point of fact the hurrying out of the water is the first stage in learning the art of swimming.

Even if there were an instinctive tendency, under ordinary conditions, which led the recently hatched ducklings to seek the water, it is conceivable that it might be

† Apud Buichner. Mind in Animals. pp.25-6. 
lost if circumstances prevented the performance of the instinctive act at a given period of growth and development; just as the instinctive capacity of sucking is lost if it be not practised at a very early period. Nor is it difficult to conceive of the occurrence of such circumstances, for the nest of the wild duck is not always near the water, and hence we find that, -

"When all the fertile eggs are hatched, her next care is to get the brood safely to the water. This when the distance is great necessarily demands great caution, and so cunningly is it done that but few persons have encountered the mother and offspring as they make the dangerous journey. . . . Once arrived at the water, they are comparatively free from harm, though other perils present themselves from its inmates in the form of pike and other voracious fishes, which seize the ducklings as they disport in quest of insects on the surface, or dive beneath it. Throughout the summer the duck continues her care unremittingly, until the young are full grown and feathered." (Encyclopaedia Britannica. vol. vii., p. 506.)

It is clear, then, that the facility with which a young duck takes to water has been greatly overrated; and it is easy to understand how, in the absence of parental assistance, encouragement, and instruction, the aquatic bird might become a terrestrial one. This is a case in which there is not a senseless departure from a perfectly developed ancestral instinct-it is rather a case of an instinctive tendency which fails through want of the conditions necessary for its development-a possibility always liable to occur in the case of all animals born with imperfectly developed instincts.

It is said that rabbits, in the island of Sor, have ceased to make burrows, but perhaps there is no mystery in this case if it resembles the one which Reclam has in view.

"When rabbits for several generations have lived where they could not burrow, the descendants of these non-digging rabbits have lost the love or desire, formerly so strong in them, of digging holes." - (Apud Büchner. Mind in Animals. p. I8.) 
As a proof that "non-intelligent habits of a non-adaptive character occur in individuals," Mr. Romanes sàys :"Almost innumerable instances might be given of individual variations in the instincts of nest-building." But if this be admitted, it would only show that the instinct of nest-building is far from being perfect, and that it requires to be supplemented as so many imperfect instincts do. We can scarcely doubt that this is so, when we are assured that young birds brought up alone in cages either build very bad nests or none at all; that old birds build better nests than young ones, and that birds-like the rooks, for example-have their work inspected and are not allowed to go on with a nest which is badly begun. Sometimes, no doubt what seems like want of skill and a palpable decline from parental excellence, may be due to want of material or to a perception that a much simpler nest will suffice under new conditions.

It only remains to say that some modifications of nestbuilding are obviously acts of a high intelligence, of which the following may be taken as an illustration :-

"A pair of jackdaws endeavoured to construct their nest in one of the small windows that lighted the spiral staircase of an old church tower. As is usual, however, in such windows, the sill sloped inwards with a considerable inclination, and consequently, there being no level base for the nest as soon as a few sticks had been laid and it was beginning to acquire weight, it slid down. This seems to have happened two or three times. Nevertheless the birds clung with great pertinacity to the site they had selected, and at last devised a most ingenious method of overcoming the difficulty. Collecting a great number of sticks, they built up a sort of cone upon the staircase, the summit of which rose to the level of the window-sill and afforded the requisite support to the nest. This cone was not less than six feet high, and so large at its base as quite to obstruct the passage up the staircase. Yet, notwithstanding the large amount of material which it contained, it was known to have been constructed within four or five days." - (Jesse. Apud Carpenter. Mental Physiology. p. 86.) 
It seems to me that the cases which have been investigated do not go to show that unintelligent habits of a non-adaptive character have arisen de novo. Either they are intelligent and adaptive, or they have lost those characteristics through change of circumstances. If, then, we cannot find illustrations of such instincts, we need not exercise our imagination in picturing how Natural Selection would act if change of circumstances made these variations useful.

(5) In the fifth place, it is contended that certain instincts must have been developed apart from intelligence, because animals sometimes perform actions the prospective utility of which they cannot possibly understand. But it may be doubted whether this blindness always exists, or, at any rate, is so absolute as is sometimes supposed. Take as an illustration the case of the butterfly which lays its eggs on the cabbage-leaf. Dr. Duncan, in his lecture on Insect Metamorphosis, says :-

"Does the butterfly remember its existence as a gormandising caterpillar and therefore retain some notion of the propriety of laying eggs over cabbages? Does the Odynerus fly remember its underground life and obey some impulse to provide the unseen offspring with food different to that which she loves? It is possible; and, as nothing is too wonderful for psychologists, there may be something in the suggestion."-(Nature. vol. vii., p. 53.)

Very wonderful it would be if the butterfly had never had any personal experience of cabbage. But in point of fact, what have been its antecedents? Before the brief career of its imago condition it has spent its time in gorging and in sleeping. Again and again it has burst the buttons of its jacket and a new jacket has been provided -eating meanwhile nothing but cabbage. As the sense of smell is strong in insects, and particularly useful with us in exciting old memories, I can see no reason why this two 
weeks' old butterfly should not remember its larval condition with its huge feasts of cabbage, and provide for its offspring the food of its early days. For this beautiful butterfly is, after all, metamorphosed cabbage!

Speaking with reference to this subject, Professor Ludwig Buichner says:-

"It is certainly not very marvellous that young animals (like turtles) should follow the scent of an element (the sea) in which their parents and ancestors have lived for unknown ages. This is yet more plainly seen in the far-famed instinct of metamorphosed insects, which always lay their eggs on places suitable for the nourishment of the escaping caterpillars. . . . Here, without doubt, they are guided in their action by the sense of smell so highly developed in insects, and perhaps also by some kind of memory from their caterpillar or maggot condition. 'The Sphinx Euphorbiae,' says Noll ( $p$. I5 $_{5}$ ), 'knows the milkwort by its shape more than by its smell.' And why should it not? Is it not the particular flower with which it is thoroughly acquainted? Has it not itself, in its growth, in its caterpillar stage, lived always on this plant, imitated its colour, and nourished itself on this alone? Has it not built up its body out of its tissue, taken into itself its volatile oils and its alkaloids? The dancing butterfly, seeking honey as its food, certainly knows what it enjoyed in its youth, and where it lived; for, even though its form be changed, though its intestines with their peripheral nerves have disappeared with its transformation, yet the chief part of its central nervous system remains, as has been proved in the transformation of caged insects, and may therefore have well preserved the youthful impressions which in man are indeed the most lasting." -(Mind in Animals. p. 27.)

We may take as another illustration the incubating instinct, of which Mr. Romanes says :-

"It is quite impossible that any animal can ever have kept its eggs warm with the intelligent purpose of hatching out their contents, so we can only suppose that the incubating began by warm-blooded animals showing that kind of attention to their eggs which we find to be frequently shown by cold-blooded animals. Thus crabs and spiders carry about their eggs for the purpose of protecting them ; and if, as animals gradually became warm-blooded, some species, for this or for any other purpose, adopted a similar habit, the imparting of heat would have become incidental to the carrying about of the eggs. 
Consequently, as the imparting of heat promoted the process of hatching, those individuals which most constantly cuddled or brooded over their eggs would, other things being equal, have been most successful in rearing progeny; and so the incubating instinct would be developed without there having been any intelligence in the matter."-(Art: Instinct. In Encyclopaedia Britannica. ed., r888.)

We are told that the incubating process began by warmblooded animals showing that kind of attention to their eggs which we find is frequently shown by cold-blooded animals, who are only anxious to protect the eggs from destruction by enemies, and without any thought of hatching them out.

But in reply to this it is not quite certain that coldblooded animals are content with simply protecting their eggs, for we are told that "the pythons (at all events when in captivity) coil themselves round their eggs and keep up a temperature very considerably above that of the surrounding medium." * But if the python is thus careful about maintaining the temperature of the eggs, under circumstances which render it necessary, what ground have we for supposing that the warm-blooded animals will not do the same?

In this passage I understand that it is implied that all incubation is the result of a blind instinct. But certainly this is not so, for, as Buichner says :-

"What has instinct to do with it when the ostrich, like many other birds, leaves the business of hatching its eggs to the sun during the day, and only covers them with its body during the cool of the night? Or when the same bird, acting in this way in Senegal never leaves its eggs day or night at the Cape of Good Hope, where the warmth of the air is less? Or when geese and ducks in our moderate climate leave their eggs for awhile without any care, while the same birds in the polar regions in such a case cover their nests with feathers as a protection against the cold?"-(Mind in Animals. p. rg.) 
It is contended that "it is quite inconceivable that any animal can have kept its eggs warm with the intelligent purpose of developing their contents." That would be a conclusive argument if it were applied to the case of birds which had been created birds, and consequently could not be expected to know anything about the future of the eggs which they laid. But the actual bird, which is the product of a long process of development, inherits ancestral experiences, and, as some assert, has even an inherited memory. Then we must also make some allowance for the experience which each individual has gained during the process of incubation by which it has itself been developed into life. I once heard a middleaged man arguing with a youth, and asserting that he knew nothing at all as to the point in dispute because he had never been a father. "No," said the youth, "but I have been a son." And there was reason in the retort. The son, out of his own experience, knew something not only of the duties of a son, but also of a father. In the same way the bird which has had no experience of hatching eggs may have some distinct recollection of having been itself hatched.

When we remember how fully equipped some young birds are when they emerge from the egg; we can well believe that in the later stages of their development within the egg they were not altogether unconscious of what was passing around them. The emergence from the egg must have been a startling experience. It is true that Dr. George Macdonald says :-

"No wisest chicken, I presume, can recall the first moment when the chalk-oval surrounding it gave way, and instead of the cavern of limestone which its experiences might have led it to expect it found a world of air and movement and freedom and blue sky-with kites in it."-(Wiifred Cumbermede. chapter i.) 
But surely such an event would be remembered, and the life before and after the breaking of the shell would represent so strong a contrast that the marvellous experience would not be undergone in vain. It would understand the mystery of the egg when in due time it became a parent. In the case of birds which are hatched at an earlier stage of development, we have evidence to show that they are keenly observant of what is going on around them shortly after their emergence from the egg.

"Birds taken from the nest at two or three weeks old have already learned the call note of their species . . . A goldfinch taken from the nest at two or three days old acquired the notes of a wren. . . This shows that very young birds can both hear and remember."-(Wallace. Contributions. pp. 220-2.)

These considerations justify us in asserting that it is not quite inconceivable-that it is not quite impossible, that any animal can have kept its eggs warm with the intelligent purpose of developing their contents.

(6) In the next place, we have to consider the cases in which instincts acquired by individuals cannot be inherited; because the individuals in which these instincts are developed are incapable of sexual reproduction. The social insects are either male, female or neuter; and in some cases there are two or even three kinds of neuters. The difficulty is stated thus by Mr. Darwin:-

"If a working ant or other neuter insect had been an ordinary animal, I should have unhesitatingly assumed that all its characters had been slowly acquired through Natural Selection, namely, by individuals having been born with slight profitable modifications, which were inherited by the offspring; and that these again varied and again were selected and so onwards. But with the working ant we have an insect differing greatly from its parents yet absolutely sterile; so that it could never have transmitted successively acquired modifications of structure or instinct to its progeny."-(Origin of Species. p. 229). 
In attempting to solve the problem thus presented, Mr. Darwin makes three assumptions as to the present condition of these neuter insects; he indicates the only way in which he thinks it possible that Natural Selection could act in such a case. And he adduces arguments in support of his hypothesis.

He asserts that the neuter insect is "annually born, capable of work, but incapable of reproduction." His assertion contains two assumptions. It implies-(Ist) That the neuter insect is born a neuter, or, in other words, that the egg once laid must develop into a neuter insect. (2nd) That the neuter insect can never become fertile.

Now, as to the first of these propositions, the facts are these. If the queen bee lays an unfertilised egg, it hatches into a male; if it lays a fertilised egg, it contains a potential female, which may become a fertile female or a neuter according to the food on which it is fed and the conditions in which it is placed, and especially upon the size of the cell in which it is deposited.

This well-ascertained fact suggests the a priori probability that what occurs in connection with bees will also occur in connection with ants. Arguing against the opinion of Mr. Dewitz, that the queens and workers of ants are produced from different kinds of eggs, Sir John Lubbock says :-

"However great the difficulty may be to understand how the ants can have learnt to produce queens and workers from one kind of egg, the same difficulty exists almost to the same extent in bees, which, as Mr. Dewitz admits, do possess the power. Moreover it seems to me very unlikely that the result is produced in one way in the case of bees and another in that of ants. . . . On the whole, then, I cannot but think that ants, like bees, possess the power of develoing a given egg into either a queen or a worker."-(Ants, Bees and Wasps. $p$. 40-I.) 
Mr. Cunningham had formed a similar conjecture, and he claims that this conjecture has now been confirmed by actual investigation.

"At last I find that, according to Emery, Grassi, an Italian biologist, has satisfied himself and published direct evidence that the termites have the power of regulating the number of workers and soldiers by rearing them at will by appropriate feeding and treatment. - . Emery concludes that the workers of all social insects are reared in a similar way from germs which are capable of producing normal sexual individuals."-(Natural Science. vol. iv., p. 287.)

If this evidence be accepted-and I am not aware that it has been called in question-it follows that the first assumption of the theory that the neuter is born a neuter, or, in other words, that the queen lays different kinds of eggs which are necessarily developed into males, females or neuters, can no longer be accepted as true.

Again, it is assumed that the neuter insect is incapable of sexual reproduction. Once a neuter, always a neuter; "capable of work, but incapable of procreation." But the experiments of Sir John Lubbock go to show that in nests which have no queens all the eggs were laid by neuters and all of them hatched out into males; and he thinks that in most nests there are a few fertile workers.* The third assumption is as follows :-

". Ants work by inherited instincts and by inherited organs or tools, whilst man works by acquired knowledge and manufactured instruments."-(Origin of Species. p. 233.)

One does not exactly understand in what sense Mr. Darwin asserts that "ants work by inherited instincts"; for he asserts that the acquired faculties of the worker cannot be inherited. It is to be supposed that he means to say that these instincts arise through those variations which 
are necessarily associated with reproduction. If this is what he means, he seems to claim for sexual reproduction a remarkable power of modification. But apart from this difficulty, we must assume that in this passage he wishes to exclude the idea that they work with intelligence and acquired knowledge; for he contrasts their instincts with man's acquired knowledge. But this assumption is not in accordance with facts. Ants, bees and wasps are intelligent creatures, adapting themselves to new conditions as they occur, and teaching others what they have themselves learned. It is obvious that the whole difficulty of the problem we are now discussing is not as to whether neuter insects are intelligent, but whether the habits suggested by their intelligence can be inherited.

But even if these assumptions were not proved to be based in error, it would be difficult to understand how this phenomenon had been brought about by Natural Selection. We have to account for the origin of the neuters, not only as sterile females, but also possessed of special organisms with which special functions are correlated. We have to account for the development of two and even three different kinds of neuter insects, and we have to picture to ourselves the process by which this complex result has been brought about. The explanation given is that the selection which takes place is not the survival of the best individuals and the destruction of the rest, but the selection of those families which reap the greatest advantage through this subdivision of labour and the destruction of the rest; which results in the survival of those queens which possess or inherit the faculty for breeding the most workers.

This suggests two points to be considered. How does one family gain this victory over another? and, secondly, what chance is there that the surviving queens of the surviving families will themselves be able to survive? 
Mr. Darwin and Professor Weismann differ in the way in which they state the first point. Mr. Darwin says:-

"It can be shown that some insects and other articulate animals in a state of nature occasionally become sterile; and if such insects had been social, and it had been profitable to the community that a number should have been annually born capable of work but incapable of procreation, I can see no special difficulty in this having been effected through Natural Selection."-(Origin of Species. p. 229.)

"We may conclude from the analogy of ordinary variations that the successive slight profitable modifications did not first arise in all the neuters in the same nest, but in some few alone; and that by the survival of the communities with females which produced most neuters having the advantageous modification, all the neuters ultimately came to be thus characterised."-(Origin of Species. p. 23I.)

Dr. Weismann, professing to interpret Mr. Darwin, represents him as saying something very different from what he actually asserted.

"Darwin discussed the existence of neuters in the insect states. He accounted for their origin by supposing that a selection of the fruitful females must have taken place, inasmuch as females which produced sterile offspring, in addition to fruitful issue, were of special value to the state; for the existence of members that were workers only was a gain to it and strengthened it, and assured it a superiority over other colonies that had no workers. So in course of time the states with workers conquered those with none, and in the end caused them to disappear. In the same way all the variations among the workers arose to make them more fit to be of service to the state."(The Contemporary Review. vol. lxiv., p. 3r4.)

Professor Weismann's way of stating the case renders it more easy to understand how one nest should survive in the struggle for existence, while another should succumb. But I am not aware that there is any evidence to show that there are families which have a certain number of neuters and others which have none; and, indeed, one would not expect to find them, for the association of social insects seems to be based upon the production of these workers. 
In the two passages which I quoted from Mr. Darwin, two processes seem to be suggested. (Ist) The immediate production by the variation of sexual reproduction of a neuter class. (2nd) The slight and gradual modification of the characteristics which distinguish the neuters. As to the first point, it assumes that the neuter is born a neuter, which it seems is not true to the facts of the case, and may therefore be dismissed. The second suggestion assumes a very slight and gradual modification in a few individuals; and it is difficult to understand how such a modification, carried on to a little greater extent in one nest than in another, could ensure the survival of the one and the elimination of the other.

If the survival of one family and the destruction of another family cannot be proved to take place as the result of a few neuters, more or less, in each nest, still more difficult is it to believe that the females which possess the power of laying more neuter eggs would be sure to survive, after their family had prevailed in the struggle for existence. Take, for example, the simplest and probably the earliest form of the social life of insects -the case of the wasps. Mr. Grant Allen has given us a graphic description of the way in which the race is preserved from extinction.

"With the first frosts the mass of what was once a flourishing community of worker wasps is cut off wholesale and perishes miserably of cold and inanition. . . . Lest the whole race should thus die off without issue or representative, every autumn there is born in each nest a special brood of perfect male and female insects, whose task it is to provide for the continuance of their kind across the intervening gulf of northern winter. There are several hundred females in the nest, of equal rank, and the question which or how many among them are finally to become the foundresses of new nests is decided in nature's usual rough-and-ready fashion-by the chances of survival. For the immediate future they betake themselves to the snuggest and warmest holes they can find in moss or banks and there 
endeavour to sleep away the winter in a drowsy condition. At the first breath of spring they emerge-'but not the six hundred.' Frost and hunger have killed most of them off; only one or two queens out of all the pioneers which went forth from the old nest have lived through the hard times to become the foundresses of new colonies and future dynasties."-(Grant Allen. Longman's Magazine. vol.xxiii., p. 522.)

Here we are told that the survival of one queen rather than another "is decided in nature's rough-andready fashion by the chances of survival." That is the way in which this well-informed and charming writer describes a struggle which we should have expected to have resulted in the strictest survival of the fittest.

The case of the termites is no more favourable to any process of selection such as the theory requires.

"In the evening, soon after the first tornado, which proclaims the approach of the ensuing rains, the males and females emerge from their clay-built citadels by myriads and myriads to seek their fortune. Borne on ample wings and carried by the wind, they fill the air. The next morning they are discovered covering the surface of the earth and waters, deprived of the wings which before cnabled them to avoid their numerous enemies, and looking like large maggots. They are the prey of innumerable enemies, to the smallest of which they make not the least resistance. Insects, especially ants, which are always on the hunt for them, leaving no place unexplored; birds, reptiles, beasts, and even man himself, look upon this event as their harvest and make them their food; so that scarcely a single pair in many miilions get into a place of safety and lay the foundation of a new community."-(Kirby and Spence. Entomology. p. 308.)

The only arguments adduced by Mr. Darwin in favour of his hypothesis-the existence of gradations of structure -are (Ist) the fact of correlation, and (2nd) the fact of gradations in the forms of neuter insects. But neither of these facts can be accepted as a proof of the action of Natural Selection. They are indicative, it may be, of the way in which the transmutation of certain specific forms has been brought about, but they do not in $\mathrm{R}$ 
themselves convey any necessary hint as to the agent by which the transmutation has been brought about.

It has sometimes been asserted that it is impossible to conceive of the evolution of neuter insects by any other means than that of Natural Selection. But I venture to think that it is not so. Looking at this phenomenon by the light of organic evolution, let us see if we can do anything to solve the problem. The complex communities of social insects have been derived from some simpler method of life. At the outset the solitary female builds a nest, lays her eggs, and dies; and the eggs in due season are hatched, and a new generation begins to run the annual course of insect existence. The next stage would perhaps be when, in addition to the mere laying of the eggs, some provision was stored up for the future larva as well. The next stage might be reached when the mother builds the nest, lays her eggs, and then attends to them until they are hatched. In the next stage, we may suppose that the female founder of the nest would become so fertile as to have more than one brood in the year, and would then instruct the first brood in the art of building the nest and of caring for the young of the second brood. By this process the sexual development of the first brood would be delayed, but when the work required of them was done they might then resume the normal development. In those cases in which the undeveloped female becomes developed, there is no need for a marriage flight in order that she should lay fertile eggs. But the eggs which she lays would only produce males. The normally fertile female possesses a receptaculum seminis, and the eggs which she lays are either unfertilised or fertilised. Unfertilised eggs produce males; fertilised eggs produce potential females, which may be developed into fertile females or 
not, according to the treatment which they receive. By this means it is obvious that, through their male offspring, the gifts acquired by females whose sexual development has been arrested, may be communicated to the next generation. On the other hand, when both sexes exist in an undeveloped condition for a time, their full development would lead to a supply of both male and female; and the opportunities of inherited faculty would be increased. In this way it is quite conceivable that certain acquired faculties would be inherited. The arts practised by the first parents-of building a nest, of feeding the young, of defending their family-would be inherited by all their offspring; the newly-acquired gifts which arise from the work done by undeveloped females, would be inherited for a time at least.

We have thus pictured a possible way in which the arts acquired by neuters may have been inherited, and now it only remains for us to say that there are certain secondary sexual organs which are correlated with male and female; that these differ in structure in order to adapt them to the different habits of the two sexes; and that it is in accordance with this fact that we find special modifications correlated with the neuter insect.

"The male and the female scarabæus differ considerably. The male is furnished with horns, and his duty is to carry balls of wet Nile mud on his head to his mate to deposit her eggs in. Besides the horns, there are three other projections from his shoulders, forming so many prongs, to hold his burden safe during his flight from the river inland. . . . The female has no horns, and could not by any possibility carry the pellet which is necessary for the hatching of her eggs."-(Villiers Stuart. The Funeral Tent of an Egyptian Queen. pp. I2, I3.)

Now, if variations so considerable as these occur in connection with the secondary sexual differences of male and female, it seems reasonable to suppose that similar 
differences may be developed in connection with the subdivision of labour which occurs in connection with neuter insects. And inasmuch as different food and treatment result in the different issues of female and neuter insects, so it is not unreasonable to suppose that it may be with different kinds of neuters. The marvel of the whole theory is not lessened by such explanations, but they serve to establish an analogy between these and the more familiar phenomena of insect life.

For the reasons which have just been assigned, I do not believe that instincts can have arisen or been modified by the action of Natural Selection in the case of those animals which are endowed with intelligence. Let us once more note what Mr. Romanes says upon this subject, quoting him a little more fully than heretofore.

"If we accept the theory of Natural Selection as of any validity at all in explaining the evolution of structures, it becomes simply impossible to dispute that it must also be of some validity in explaining the evolution of instincts. For instincts, no less than structures, are of use to the animals possessing them ; like structures, they vary and are inherited; like structures, therefore, and no less than structures, they are amenable to all those influences which are comprised in the term, 'survival of the fittest.' And when, in addition to this, we find abundant proof of the intelligence of animals guiding the course of variation-so that, unlike the case of structures, instincts do not require to wait for INatural Selection to seize upon fortuitous variations, but themselves supply variations which in relation to any change of environment are from the first adaptive-when we find this, we cannot fail to perceive that in no department of organic nature is Natural Selection operating at so much advantage. Lastly, when over and above all this we find abundant evidence of the principle of 'lapsing intelligence' cooperating with that of Natural Selection, we must upon the whole conclude that, if the theory of evolution is of any validity in any case as a scientific interpretation of natural phenomena, nowhere is it more successful in this respect than it is in the domain of instinct." -(Fortnightly Review. vol. xxxviii., pp. 93-4.)

It should be observed that Mr. Romanes starts with the assertion that the influence of Natural Selection in 
the modification of structures justifies us in anticipating that it will be equally effective in the modification of instincts, and then immediately proceeds to assert that, in the case of instincts, intelligence anticipates the slower processes of Natural Selection.

In the second place, he asserts that in this anticipation of the process of Natural Selection by intelligence, Natural Selection is operating at a greater advantage than in any other department of organic nature. If he had said this of the principle of evolution, it would have been perfectly true. But what he says amounts to this,- - that a supposed law of nature acts at the greatest advantage when it is anticipated by another law. That seems to me very much like saying that the race-horse never shows to so much advantage as when it is left far behind by its competitor; that the strategist never shows to so much advantage as when he marches a small force to seize an undefended town, and finds that the enemy has anticipated his ruse and has fortified the place, so that attack is hopeless; or that the suitor is never so successful as when his rival has anticipated his action and won the hand of his ladylove. If this is the best illustration of the action of Natural Selection, it must be regarded as no better than the most pronounced failure. Nor can it be a much better illustration of the action of Natural Selection to represent it as supplementing the influence of lapsing intelligence, since we believe that it is improbable-and indeed, impossible - that it should so intervene.

Elsewhere, Mr. Romanes compares the evolution of instinct by lapsing intelligence with evolution by Natural Selection. He quotes the following passage from Sir John Lubbock:-

"I suppose that the sand-wasps originally merely killed their prey by stinging them in many places, and that to sting a certain segment 


\section{8}

was found by far the most successful method, and was inherited like the tendency of a bull-dog to pin the nose of a bull, or of a ferret to bite the cerebellum (of a rabbit?). It would not be a very great step in advance to prick the ganglion of its prey only slightly, and thus to give its larvæ fresh meat instead of only dried meat."

\section{Commenting on this, Mr. Romanes says :-}

"Here, by the way, we have an excellent instance of the difficulty which we so often encounter in the domain of instinct, when we relinquish the so-called Lamarckian principle of the inheritance of acquired characters. The hypothesis in question goes upon the supposition that some of the ancestors of the sphex were intelligent enough to notice the peculiar effects which followed upon stinging insects or caterpillars in the particular regions occupied by nervecentres, and that, in consequence of being habitually guided by their intelligence to sting in these particular regions, their action became hereditary-i.e., instinctive. But if, in accordance with post-Darwinian theory, we relinquish this possible guidance by intelligence, and suppose that the whole of this wonderful instinct was built up by Natural Selection waiting for congenital-i.e., fortuitous-variations in the direction of a propensity to sting, say, the nine nerve-centres of a caterpillar-then it surely becomes inconceivable that such an instinct should ever have been developed at all."-(Nature. vol. xxxix, p. 77.)

And yet this is the same advocate who regards the realm of instinct as the favourite sphere for the exhibition of the action of Natural Selection.

It only remains for me to show that the evolution of instinct, apart from the interposition of human intelligence, as it is depicted by $\mathrm{Mr}$. Darwin, is not possible. It is worthy of notice, at the outset, that Mr. Darwin does not define the term instinct. "I will not attempt any definition of instinct." * Having given a definition of what is usually said to be instinctive, he adds: "but I could show that none of these characteristics is universal." It is, however, important to observe that he adopts the dictum of Pierre Huber, to the effect that a little dose of judgment or reason often comes into play even with animals low in the

* Origin of Species. p. 205. 
scale of existence. Nor does he discuss the origin of instinct, but only the development of higher instincts from lower ones.

"I may premise that I have nothing to do with the origin of the mental powers, any more than I have with that of life itself. We are concerned only with the diversities of instinct and of the other mental faculties in animals of the same class." $-(p .205$.

The problem being thus limited, its solution is attempted on the lines of demonstration already employed in the transmutation of species. In order that instincts should be modified by Natural Selection, the first necessity is that instincts should vary. "If it can be shown that instincts vary," * is therefore the first postulate. In the second place instincts must vary "spontaneously." "I believe that the effects of habit are in many cases of subordinate importance to the effects of the Natural Selection of what may be called spontaneous variations of instincts; - that is, of variations produced by the same unknown causes which produce slight deviation of bodily structure." $\dagger$ We may assume that these spontaneous variations are variations which arise in connection with sexual reproduction. It is only by a happy coincidence that favourable variations can arise, and only by a deadly struggle that favourable variations can be isolated for breeding purposes by Natural Selection. In the case of a perfect instinct adapted to existing circumstances, no variations can be favourable so long as the conditions remain unaltered. This is implied by Mr. Darwin when he says: "Under changed conditions of life it is at least possible that slight modifications of instinct might be profitable to a species." +

In the next place instincts must vary slightly. "Natura non facit saltum is applicable to instincts as well as to

* p. 206. + p. 206-7.

\# Origin of Species. p. 206. 
corporeal structures." * How important Mr. Darwin esteems this principle to be may be seen from the following statement: "If it could be demonstrated that any complex organism existed which could not possibly have been formed by numerous successive slight modifications, my theory would absolutely break down." The process will be a more or less protracted one- "No complex instinct can possibly be produced through Natural Selection except by the slow and gradual accumulation of numerous slight yet profitable variations." $\dagger$

Now in considering this theory, the first thing to be borne in mind is that in those cases in which we have an instinct correlated to a particular structure and to certain outward conditions, no change can be profitable and, therefore, if any change takes place it will take place apart from Natural Selection. But this is not all. For if it be true that Natural Selection is actively engaged in preserving the stability of species in connection with unchanged conditions, then it is surely equally reasonable to suppose that it would tend to promote the constancy of instinct where change was useless at the least, and. might so easily prove prejudicial. If Natural Selection is to be invoked to alter old established instincts, it must be in the face of changed conditions and new problems. Mr. Darwin insists that the variations of instinct shall be slight, that they shall be the result of variations of instinct due to sexual reproduction, and that favourable variations shall be selected.

Now if circumstances altered very gradually we could then believe that the slow process of the Natural Selection: of slight favourable variations might suffice to secure the wèll-being of the race. But very often new circumstances. 
demand the adoption of a new habit as a condition of safety. It is a case of ending or mending, and of doing this not in the course of generations but at once, in the course of days and it may be of hours.

A writer in Nature gives us an illustration of the sudden change of instinctive action on the part of the toad, of which the following is a summary:-

"It should be premised that when a toad is disturbed and jumps into the water, he makes a shallow dive, rises immediately to the surface, swims upon it by a sweeping curve at once to the bank again and there it rests awhile before coming to the land. On the other hand, the frog when similarly disturbed makes a strong dive directly to the bottom upon which they lie prone, with the legs flexed against the body and into the mud of which they settle themselves a little. There they remain and exhaust the patience of one who may attempt to wait for them to rise. Some years ago the country immediately adjacent to the eastern base of the Rocky Mountains was changed by irrigation from a comparative desert into a veritable garden of Eden. Vegetation brought insects and the insects frogs and toads. The action of the settlers in regulating their irrigating ditches (especially if they had to keep them-free from weeds) would have been fatal to the toad if he had maintained his customary mode of action, or even if he had slightly modified it; but in order to escape the new danger, he adopted a new method, and like the frog made a strong dive directly to the bottom."-(C. A. White. Nature. vol. xvii., p. 248.)

Thus it is obvious that the canon Natura non facit saltum cannot be applied to this toad-he made a sudden leap from one method to another, and it was a leap for life.

The following account of a modification in the art of nest-building may be cited as another proof of the occurrence of crises in which it was necessary that the intelligence should at once interpose to save the threatened life. Mr. W. Colton Oswell says :-

"The ornithological name of the bird I don't know, but he's something between a toucan and a hornbill-neither one nor the otherabout the size of a large pigeon, though, if I remember right, more like a woodpecker in build. After marriage the birds select a hole in 
a tree, and gather a few sticks for a nest; the hen takes some feathers off her breast to line it, and lays her eggs. When this is done, and incubation begins, the male bird goes to the nearest pond, and brings wet clay, with which he stops up the hole at which his wife went in, leaving one narrow opening in the centre, and through this the excellent fellow feeds mamma and little ones, until the latter are fledged and ready to leave the nest; then he and she, from outside and in, jointly peck away the clay, which has by this time, under the dry heat, become as hard as a brick, and madame and her family make their début. The poor monsieur is a rickle of bones, madame as round as a ball; the Kafirs knowing this always dig her out as a tit-bit whenever they find the nest. And what's it done for? An African wood is filled with all sorts of cats, and without a protection the toucan (that's not right, but let it stand) family would soon be improved off the earth, for a hole in a tree comes handy to a cat; but the clay very soon gets too hard for his claws, and the bird hatches in security. Now come with me towards a Kafir kraal, such as those of the Ba-Quaina or Ba-Wangketsi, permanent tribes. We walk through the outskirts; there's our friend the toucan again, but there's his wife, too, and they keep alternately flying to and from that hole in the tree out of which many gaping mouths are protruded at each visit. They are the same birds, but the house-door is open. Within a radius of five to six miles of every large kraal no cat exists. The Kafirs kill everything that runs upon four legs for food or clothing; the best carosses are made of cat-skins - I have one with thirty-six pussies in it ; and the birds have found this out."-(Big Game Shooting. vol. i., pp. 134-5.)

At other times, no doubt, the inability of a species to adapt itself to new conditions proves fatal. Mr. Hudson gives an account of the pampa or creolla sheep, which illustrates this point. He tells us that this pampa or creolla, living in a country subject to sudden great changes of temperature, to drought and failure of grass, is hardy enough to exist without any shelter and requiring from their master (man) only protection from the larger carnivores. "I have often seen a lamb dropped on the frosty ground in bitterly cold windy weather in midwinter, and in less than five seconds struggle to its feet and seem as vigorous as any day old lamb of other breeds. The dam, impatient at the short delay, and not waiting to give it 
suck, has then started off at a brisk trot after the flock, scattered and galloping before the wind like huanacos rather than sheep, with the lamb, scarcely a minute in the world, running freely at her side."* Now here we have an endowment of a very wonderful kind which must have arisen in 300 years, for the pampa is a descendant of a European sheep which was introduced at that date. It is clearly adapted to the wild conditions of the life and to the necessity of living in a flock in order to escape destruction.

And doubtless it is a result of this necessity to the wild sheep-that the new-born lamb, after having, with some difficulty, found the teats of its mother, is impelled in the next place to follow after any object receding from it, and, on the other hand, to run from anything approaching it, even from its own dam. This "blinding" instinct, as $\mathrm{Mr}$. Hudson calls it, is quickly laid aside when the lamb has learned to distinguish its dam from other objects, and its dam's voice from other sounds. When four or five days old it will start from sleep, but instead of rushing wildly away from any receding object, it first looks about it and will then recognise and run to its dam. With perfectly satisfactory results, so long as the sheep are domesticated or semi-domesticated-i.e., protected from carnivores at the least. But now comes another act in this drama which constitutes it a tragedy. There came a time when, in La Plata, cattle-breeding was profitable while wool was not worth the trouble of shearing; so many flocks of sheep were a distance out and lost in the wilds. Out of the many thousands thus turned loose to shift for themselves, not one pair survived to propagate a new race of feral sheep. In a short time pumas, wild dogs, and other beasts 
of prey had destroyed them all. But would it not have been different if the young had not unlearned the "blinding" instinct which gave safety to the young of the ancestral race? *

When it is contended that slight variations might be profitable, and therefore become the objects of the action of Natural Selection, we should bear in mind that this involves the severest stress in the struggle for existence. It implies that the few individuals (if any) in each generation which happen to vary in their instinctive action in a way favourable to the well-being of the race, should be preserved while all the rest are destroyed; and that this process should be continued generation after generation. No species could survive a treatment like this, even if a very small change were favourable.

It might, however, be contended that it was a mistake to insist on the variations of instinct being slight. They might be very considerable. But if so, they would be proportionately prejudicial so long as circumstances did not change; and would be suppressed by Natural Selection accordingly, if there is any force in the argument that the stability of species is preserved by Natural Selection. These considerable variations might be an advantage so far as they happened to accord with change of external conditions. But even in that case the few who possessed these advantages would alone survive; they would at once become a rare species. If a second disability were met in the same way, they might easily become an extinct species.

When I consider all these difficulties, I come to the conclusion that it was a true insight, and not mere modesty, which led Mr. Darwin to suppose that the 
application of his theory to the realm of instinct would not present it in the most favourable light.

The argument which has hitherto been urged has been conducted with special reference to the reasoning of Mr. Darwin and Mr. Romanes. Mr. Darwin believed in the intelligence of the higher animals, and in the development of a simple into a more complex instinct by Natural Selection in spite of that intelligence. Mr. Romanes showed how in intelligent animals a new instinct might be developed by the principle of "lapsing" intelligence, supplemented by Natural Selection; and by the Natural Selection of non-intelligent action of a nonadaptive character, independently of the intelligence of the animal. I have endeavoured to show that these positions cannot be maintained in accordance with the facts of the case. If we had only animals to deal with, and if we believed that all animals were endowed with intelligence, nothing more need to be said upon the subject of the development of instinct by means of Natural Selection.

It may, however, be that the lowest animals are unintelligent; are mere living automata, whose organisms respond to certain stimuli in consequence of acquired physical habits, which have in them no mental element whatever. And whether this is so or not, what are we to say with respect to the members of the vegetable world? Shall we endow them with consciousness of internal change; with conscious sensitiveness to external conditions; with intelligence which assists in adapting their organisms to external conditions? Or shall we say that their organisms have acquired physical habits which have no mental element whatever?

Now, it would seem that some writers believe that the element of intelligence is present in vegetable organisms. 
Mr. David Syme says :-

"If we admit that animals possess intelligence, we cannot logically deny the same attribute to vegetative organisms, as many of the higher orders of plants exhibit greater intelligence than many of the lower animals."--(The Modification of Organisms. p. 132.)

Mr. Darwin, speaking of the sensitiveness of the root-tips of plants, says :-

"It is hardly an exaggeration to say that the tip of the radicle thus endowed, and having the power of directing the movements of the adjoining parts, acts like the brain of one of the lower animals; the brain, being seated within the anterior end of the body, receiving impression from the sense-organs and directing the several movements."

Dr. J. E. Taylor appears to identify these habits of motion with the instinctive actions of animals. He says:-

"Instinct is now generally regarded as the experience of the race, as distinguished from that of the individual. The registration of experience may be in itself an intelligent rather than an automatic act. To speak of the 'tendencies' on the part of plants to assume a certain habit is merely to coin a word to disguise our ignorance of the process. A tendency for the plant to behave in a certain manner is merely a habit based upon the past experience of its ancestors, as to what has proved best for them as a species."The Sagacity and Morality of Plants. p.4.)

This view may be illustrated by instituting a comparison between animal instincts and vegetable habits.

"The principal instincts of animals have been grouped by naturalists under three heads:-(I) Those dependent, immediately or remotely, upon incitations from the alimentary canal-e.g., mode of seeking, capture, seizing, storing or swallowing of food. (2) Those dependent upon incitations from the generative organs-e.g., pairing, nidification, oviposition, care of young. (3) Those dependent upon more general impressions, perhaps partly internal and partly external in origin (hybernation and migration)."-(Bastian. The Brain as an Organ of Mind. p.227.)

As a case of a vegetable movement akin to the instinctive catching of food on the part of the animal, we may take the well-known case of the Drosera or Sun-dew. 
The tiny plant grows in peaty soil, inconspicuous but for the frequent glisten of the sunlight upon its drop-studded leaves. As you watch the little plant, lo! the food comes. A fluttering insect touches the glistening spots with vibrating wing or dependent feet. The gland that has caught the victim secretes more and more fluid. And now the other tentacles begin slowly to bend towards the place where the captive still struggles faintly. After a time the fluid alters in quality ; it becomes acid, and in a short time the insect has been digested by the plant and the tentacles move back, the leaf is as it was before, and after a while will be ready for another victim. "That a tentacle, whose own gland is touched should bend is strange enough. That tentacles, remote from those actually touched, should have transmitted to them, through the tissues of the leaf, some influence which causes them to bend and the glands on their summits to secrete more fluid and more acid fluid, is still more strange. The fact, to those who remember how in the animal kingdom nerves will transmit an influence to glands and modify the nature of their secretions, is of deepest significance."--(Dr. Aveling. The Student's Darwin. pp. 88-9o.)

In illustration of the movement of vegetable life, similar to the instinctive actions of animals associated with reproduction, we may instance the strange motions of stamens and pistils. Mr. David Syme says:-

"As soon as the pollen is mature, the stamens move towards the pistils or the pistils towards the stamens, or both towards each other. These movements never commence till the pollen is mature, and cease the moment fertilisation has been accomplished; and what is still more extraordinary, if it should happen that fertilisation has already been brought about by artificial means or by the visits of insects, these movements, being then unnecessary, never take place. Fertilisation is impossible if the pollen should by any means become wet; hence plants take the greatest care possible to prevent this occurring. Many plants close their corolla when it is about to rain, or when the air is moist with dew; others hide their flowers under their leaves at night. Even aquatic plants have to keep their pollen dry-almost an impossible thing for them, one would imagine, yet they contrive to accomplish it."-(On the Modification of Organisms. p. I33.)

In the same way the ovipositor of the insect finds its analogue in the action of the peduncle of the Ivy Linaria, which grows on an old wall-its flowers and the flowerstalks stand out for the sun and insects to visit the little 
snap-dragon.. But no sooner does the corolla fall than the peduncle begins to curve inwards to the wall and usually contrives to tuck its seed vessels well into the brick-work again.

As an illustration of migration, we may take the Selaginelia convoluta, which is found in the arid deserts of Central America. "In the dry season, when every particle of moisture is extracted from the soil, it is detached from its growing place, rolled up into a ball, and carried away by the violent equinoctial gales which prevail at the time in those regions-often to very great distances. It remains coiled up in this form for a considerable time, but if carried to a marsh or the margin of a stream, or any other moist place, it begins slowly to unfold itself and spread itself out flatly on the soil, assumes its former vigour and freshness, takes fresh root, developes its fructification and casts abroad its seed upon the air. When this new situation is dried up it resumes its old unsettled habits and, like an adventurous pilgrim, takes advantage of the wind to emigrate to a more favourable locality."

Now if these actions are the outcome of intelligence as much as the actions of animals, then the arguments already adduced will suffice to exclude the action of Natural Selection, seeing that intelligent adaptation will anticipate the slower process of Natural Selection. But if they are physical habits, without any mental element in them whatever, the problem of instinct does not arise, for by universal consent it does involve the presence of a mental element.

To revert once more to the lowest form of animal life. We may suppose, for the sake of argument, that the actions of the simplest organisms are illustrations of reflex action, which have had their origin in the mutual interaction of the organism and its conditions. If there is any 
truth in the doctrine of evolution, and if the earliest experience of animal life was devoid of any mental element, then there must have been a time when the unconscious became conscious, and the unintelligent became intelligent. In that case the animal, when it first becomes intelligent, will find itself already in possession of an organism adapted to its conditions; responding to certain stimuli with appropriate action. But from the moment that intelligence comes upon the scene the animal will be conscious of some of these reflex actions-at least, it will control their subsequent development; and if there is any force in the argument which I have urged, the action of Natural Selection will be excluded. It only remains to ask whether the reflex actions of a living automaton, such as a vegetable organism possibly is, can be produced by other influences than those of Natural Selection. Speaking as a believer in Darwinism, Prince Kropotkin sums up the results of certain experiments upon vegetable organisms in the following remarkable words :-

"The above-mentioned researches, and many more which could be mentioned besides, already prove that it lies to a great extent in man's hands to modify the shape, the structure, and the general aspect of plants, not only on the long and circuitous way of selection of casual variations, but also by the direct method of appealing to environment to produce the desired variations, and to make a start with them. This is what nature does every day and everywhere on a gigantic scale."-(Nineteenth Century. vol. xix\%., p. 69I.)

I have now applied to the theory of Natural Selection the tests which were suggested in the first chapter. Looking for a clear and distinct statement of the theory, we have found conflicting assertions; assuming that there would be no a priori difficulties, we have found that the theory, as a theory, presented very great demands on our faith; expecting to find the facts of nature 
corresponding with the demands of the theory, we have discovered the very opposite to be the case; hoping that the specially-selected arguments would add great force to the general statement of the theory, we have found ourselves unconvinced; anticipating some special conviction in connection with departments of nature chosen as the most favourable spheres for the illustration of the theory, we have found that they do not afford the most obvious manifestations of the action of the principle, but that, on the other hand, they are beset with difficulties of their own. If there is any force in the argument which has been urged, it follows that the transmutation of species by means of Natural Selection is not possible, either in the realm of abstract thought, which is dominated by a consistent logic, or in the actual world of nature, which lies open to the investigation of science. 


\section{BOOK I I.}

Natural SElection in Relation to OTHER METHODS OF TRANSMUTATION OF SPECIES :-

$C A N$ IT COMPETE? 

CHAPTER I.

THE STABILITY OF SPECIES.

"We lift our heads-a race of other days."

-Sprague. Centennial Ode.

" . . where the generous hills

Lift a green isle betwixt the sky and plain,

To keep some Old World things aloof from change."

-George Eliot. Agatha.

I HAVE hitherto endeavoured to show that it is not probable that there can have been a transmutation of species through the agency of Natural Selection. I now propose to follow an entirely different line of argument. I will assume that Natural Selection is a great law of nature, or that we know of no reason why it should not be so. Even in that case, I venture to believe that it can be proved that there are many other methods by which the transmutation of species can be effected; and that Natural Selection will not be able to hinder their emergence, or to compete with them when they come upon the scene. But before we pass on to consider the rival methods of transmutation, we should remember that it would be a great mistake to suppose that a transmutation of species must necessarily take place. We have abundant evidence to show not only that species are transmuted, but also that species either remain unaltered or die out and become extinct. We must first of all, then, consider the stability of species and the extinction 
of species in order to understand what bearing these phenomena have on the theory of Natural Selection; and, in dealing with these subjects, I shall be compelled to refer to the difficulties which we have seen to stand in the way of the theory of Natural Selection.

Ample evidence has been adduced to show that some species have remained practically unaltered through centuries of historical ages and through æons of geological time. Cuvier compared the mummied remains of certain animals in Egypt with organisms of the same species still living in that country, and came to the conclusion that no appreciable change had taken place for 3000 or 4000 years. Shells are found in the superficial deposits which cover the rocky subsoil of Goat Island, near the Falls of Niagara, belonging to exactly the same species as those which now inhabit the still waters of Lake Erie; and it has been thence inferred that the species has remained unaltered for 30,000 years. As we work our way through the great series of the tertiary formations, we find species identical with those which live in the present day. The lamp shells (Terebratula) of the cretaceous epoch exist unchanged or with insignificant variations to the present day. The very substance of our English chalk consists of skeletons of Globigerince which are identical with the Globigerince of to-day.

"Among the higher animals, some types have had a marvellous duration. In the chalk, for example, there is found a fish belonging to the highest and the most differentiated group of osseous fishes, which goes by the name of Beryx. The remains of that fish are among the most beautiful and well-preserved of the fossils found in our English chalk. It can be studied anatomically, so far as the hard parts are concerned, almost as well as if it were a recent fish. But the genus Beryx is represented, at the present day, by very closely-allied species which are living in the Pacific and Atlantic Oceans. . . The carboniferous formations, in Europe and in America, contain the remains of scorpions in an admirable state 
of preservation, and those scorpions are hardly distinguishable from such as now live. . . Close scrutiny is needed in order to distinguish them from living scorpions."

These instances, culled from Mr. Huxley's New York Lectures on Evolution, amply suffice to illustrate the principle that some species remain unaltered from age to age.

We may, then, accept the long-continued stability of species as an undoubted fact, and proceed at once to consider what explanation can be given of this phenomenon. In the first place, it may be surmised that species sometimes remain unchanged because the external conditions remain essentially unmodified. We must remember that the transmutation of a species implies that that species is already in existence; that it has been adapted to the conditions of life by which it has been surrounded; and that a change of external conditions to which it is necessary that the species should be adapted is, in many cases, though not in all, the occasion, if not the cause, of the transmutation. If this view be correct, the fixity of some species implies that the outward conditions of life have remained unaltered or so little altered as not to affect the correlation between the organism and the conditions among which it lives and moves and has its being. If the flora and fauna of Egypt have remained unaltered during the last six thousand years, so also, we have every reason to believe, has the climate.

It should, however, be observed that, in order to account for the stability of species, it is not absolutely necessary to assume that the climate of any one spot on earth has remained unchanged during the geological ages. We have only to suppose that certain species have migrated from a sphere which has become unsuitable to them, and have found another to which they are already adapted. During successive glacial periods it is certain that many species 
must have migrated forwards and backwards, changing their locality but not their climate, and remaining always "unchanged by changing place." If, then, a given species could manage through the geological ages to find a sphere similar to the one to which it had been long ago adapted, there seems no reason why it should undergo modification, at any rate through the influence of external conditions.

In the second place we learn from the experience of artificial selection that, while conditions remain unchanged, those variations which necessarily arise in connection with sexual reproduction do not lead to the establishment of new varieties, races, or species, apart from the principle of selection. Mr. Darwin illustrates this law by comparing the gold-fish and the carp. The former are kept in glass vessels and have been made the subjects of artificial selection and have therefore yielded many races. The carp have remained unmodified, because artificial selection could not be brought to bear upon them. These facts illustrate the general principle that, without the isolation of similar variants for breeding purposes, the variations which are necessarily associated with sexual reproduction will be swallowed up in the average of the race by virtue of the principle of regression to mediocrity, and thus the characteristic type of a species will be maintained.

It is further very important to observe in this connection that a very great amount of individual variety is consistent with the continued stability of species. Nor does the idea of the stability of species exclude the idea of a severe struggle for existence ; for it is almost impossible to conceive that the species which have undergone little or no change through all the xons of geological time can have been altogether free from the strife. And this probability becomes a certainty when we consider what actually takes place at the present time. When circum- 
stances favour some races, they begin to increase in numbers to an enormous extent; they are as prosperous as it is possible for them to be, but their prosperity is fatal to many of them as individuals, and sometimes threatens their existerıce as a race. Enemies of all kinds are attracted to the unwonted feast, and the happy creatures which a short time ago rejoiced in their numbers, are threatened with extinction. This is surely a struggle for existence, but a struggle which may leave, and actually has left, the race altogether unmodified in structure, as in the case of the mice in La Plata, described by Mr. Hudson-already quoted on page 54 .

In considering the bearing of stability of species upon the theory of Natural Selection, it is first of all obvious that it limits the power of Natural Selection considered as an agent in the transmutation of species. Enormous numbers of living beings have existed generation after generation through the æons of the geological ages, and their specific types have remained unaltered. Such stability has prevented the transmutation of species by whatever means it might otherwise have been effected. But this is not all. It is quite conceivable that, owing to causes which will be referred to shortly, some individuals of an otherwise unchanged species might become modified so as to be transmuted into a new species. But so long as circumstances remained unaltered, no such change could be wrought by Natural Selection; for so long as the conditions remained unchanged, the organisms which had once been adapted to those conditions would not gain any advantage from any such modification, and therefore no such change could be brought about by Natural Selection.

One might have supposed that the facts which have just been cited would have led the advocates of the theory 
to admit that Natural Selection could have had no part whatever in relation to a species whose typical form remained the same throughout long periods of time. But it is not so. It is confidently asserted that the stability of species itself is largely due to the action of Natural Selection, for it is contended that it not only produces the adaptation of the organism to the conditions, but maintains it after it has been produced. Mr. Fiske says :-

"We see that Natural Selection, like a power that slumbers not nor sleeps, is ever preserving the stability of species, by seizing all individual peculiarities that oscillate within narrow limits on either side of the mean that is most advantageous to the species, while cutting off all such peculiarities as transgress these limits." (Darwinism and other Essays. p. 15.)

Mr. Herbert Spencer recognises

"Natural Selection as a means of preserving an already established balance between the powers of a species and the forces to which it is subject."-(Principles of Biology. vol. i., p. 445.)

Now the first objection to this view is that the interposition of Natural Selection is not required to maintain the stability of a species which has become adapted to new conditions. We have seen that variations necessarily associated with sexual reproduction are swallowed up in the average of the race; so that, in spite of constantly emerging variety, the specific type is preserved essentially unchanged. Now by the law of parsimony we are forbidden to assume the existence of another cause, when one which is sufficient to produce all the phenomena is already in the field. The principle of regression to mediocrity, about whose action there is no doubt, will account for the stability of species, and we need not therefore look for another cause; and we must not, if the law of parsimony is to be obeyed. 
The idea that, in face of unchanged conditions, Natural Selection is necessary to produce the stability of species, is not only unnecessary, it is also contrary to experience. The carp remains unmodified, or, in other words, the stability of the species is maintained in the absence of selection; and yet we are asked to believe that in nature the presence of Natural Selection produces the stability of species. Thus the same result is supposed to take place from diametrically opposite causes. This apparent inconsistency can only be removed by distinguishing between two very different results: the mere maintenance of the stability of species, which we have seen does not exclude a great amount of individual variety, and the preservation of a species at the highest conceivable point of a typical excellence. Let us see what proof there is that Natural Selection has produced either of these results.

The arguments already adduced serve to show that the stability of species can be maintained apart from Natural Selection, and that therefore we need not in this case invoke the principle of selection to do what the regression to mediocrity is perfectly competent to accomplish unaided.

The principle of regression to mediocrity is clearly antagonistic to any permanent modification of structure; and when an organism is already adapted to new conditions, it is sufficient to maintain the correlation. Other principles which might be required to transmute a species will not be required to preserve its stability. The cessation of Natural Selection, supposing that principle had been on the field previously, would simply leave the law of variation and the law of regression to mediocrity to balance one another.

We now come to the hypothesis that Natural Selection has been at work to maintain the species at the highest realisation of its perfect adaptation. What evidence can 
be adduced that Natural Selection has acted in this way? Now we can apply two tests-I. The character of the selection which takes place in nature; 2 . The product of that selection as evidenced by the varieties which are actually to be found in any species, the stability of which has been long established. The analogy of artificial selection will be found useful in settling the first point. So far as type-producing selection is concerned, artificial selection results in an artificial product-" the monstrosity of the fancier"; and it is obvious that this can be maintained only by the strictest selection. But the selection which is supposed to take place in nature results in an adaptation to the new circumstances which arise in nature, and, as we have said, when that adaptation is once accomplished, it will be maintained by the principle of regression to mediocrity. Even in those cases in which the transmutation effected is less abnormal, the highest possible excellence is only maintained by the strictest selection, as, for example, in the case of the Saxon flock-masterswhere the lambs are thrice subjected to the most searching examination, and the best are put aside on each occasion. But we have no such selection as this in nature; for during the very period which elapses between birth and the adult condition, a great deal of the destruction is accidentali.e., has no relation whatever to relative excellence. Then again, in artificial selection one type of excellence is preserved; but in the destruction which occurs in nature the selection is first in favour of one variation and then in another, the effect of which must be to produce an average animal, and not one of especial endowments in one or more directions. Hence either in nature there is no selection, or a selection which produces general stability of species rather than an ideal perfection. Then again, if we apply the other test, and ask what is the product of this 
supposed selection, all investigation goes to prove that there is a great deal of variation in all species, however fixed. This fact is generally urged to show the possibility of transmutation of species by means of Natural Selection, in so far as it offers material for selection to act on. But there is another way of looking at this matter. If, in those cases in which the species has remained stable, we take a given number of adults who have passed through the period when destruction has been most at work-we must look upon the relative differences as the result of the action of Natural Selection. We do not find what we should expect if Natural Selection were preserving the species at its highest possible excellence; but we do find that enormous difference between individuals, which is consistent with the stability of a species.

Now it follows, necessarily, that if Natural Selection has not maintained the highest efficiency of a species, the cessation of Natural Selection will not.lead to that deterioration which might otherwise have been anticipated, but rather to that stability of species which the principle of regression can of itself maintain.

It is interesting to note the reasons which are assigned for the supposed deteriorating results of the cessation of Natural Selection. It was taken for granted that there will be plus and minus variations on either side of the average. Mr. Herbert Spencer thereupon assumed that in the absence of Natural Selection these plus and minus variations would neutralise one another, and so the stability of the species would be maintained. But Mr. Romanes replied that in the absence of Natural Selection there would be an excess of minus variations. Whereupon Mr. Spencer asked for proofs, and Mr. Romanes adduced two.

"(1). When selection is withdrawn there will be no excessive plus variations, because so long as selection was present the efficiency 
of the organ was maintained at its highest level; it was only the minzus elements which were then eliminated. (2). As soon as selection is withdrawn and heredity is simply left to itself, any failures either in the force or in the precision of heredity will be allowed to survive and perpetuate themselves."-(Contemporary Review. vol. lxiv., pp. $6 I I-2$.

In considering the first proof, we must remember that the variations which are necessarily connected with reproduction are represented by different writers as taking place in three different ways; (I) as diverging in all directions from a common centre; (2) as clustering round a central line, with a few variants on either side of a central column; (3) as constituting two columns on either side of a central line. The first view of the subject is the one generally advanced, and it is urged as the strongest of all possible arguments for the necessity of selection. The second view has been urged theoretically by Mr. Wallace; while the same writer has shown that in one instance which he investigated, the third view was the one which actually corresponded to the facts of the case. To make ourselves perfectly safe, we will assume the possibility of all these variations occurring in connection with a species whose stability has been long maintained. What part could Natural Selection play in these different circumstances?

If we suppose that the variations are in all directions, then it seems probable that only a few variations will represent an ideal perfection; and if Natural Selection is to maintain the highest efficiency of the species, all the rest must be destroyed. But Mr. Romanes does not take this view. He contends that there will be a large output of the unuseful.

"According to the Darwinian theory, it is only those variations which happen to have been useful that have been preserved; yet, even as thus limited, the principle of variability is held to have been sufficient to furnish material out of which to construct the 
whole adaptive morphology of nature. How immense, therefore, must be the number of unuseful variations. These are probably many hundred of times more numerous than the useful variations, although they are all, as it were, stillborn or allowed to die out immediately by intercrossing."-(Joumal of Linnean Society. Zoology. vol. xix., p. 348.)

If this view is the correct one, Natural Selection secures the survival of a few favourable variations and the destruction of a few unfavourable ones, but does not prevent a large number of unuseful variations from surviving; but it is assumed that these will be stillborn or die out immediately by intercrossing. Here, then, the principle of regression to mediocrity does more than Natural Selection to maintain the efficient stability of species.

But it is not at all so clear that these unuseful variations will be stillborn and will be immediately absorbed in the average of the race; and, if not, there is no reason why they should not intermarry with the more typically perfect; and in this way the average-not the ideal perfection-of the race would be maintained.

If, now, we take the hypothesis that the variants range themselves in a central column, on either side of which there are struggling variants, then the principle of regression to mediocrity will do all that is required; the phus and the minus will neutralise one another, and Natural Selection is not required.

Next, let us suppose that the variants range themselves in two columns on either side of a central line. In the first place, we must be well assured that these variants are real sheep and goats-all useful on the one side and all prejudicial on the other side. Only on this hypothesis could Natural Selection act in the way supposed; for if there were a large output of unuseful variations, Natural Selection could not touch them. But if Natural Selection did choose all the column to the right because it 
contained favourable variations, and rejected all the column to the left because it contained prejudicial variations, such selection would be apt to promote the transmutation of species rather than the stability, as Mr. Meldona suggests.

"It is obvious that many individuals are similarly and simultaneously modified, and since the action of selection in the conservative sense is exerted upon individuals above the mean, while the loss by destruction falls upon those which are below the mean, it follows that in the next generation the line of mean variability will be raisedi.e., the species will have come into closer harmony with the external conditions, and so on in successive generations till equilibrium is reached."-(Nature. vol. xliii., p. 4TO.)

Clearly the writer is here picturing this selection of one column and rejection of another as a means of producing a modification of species by raising the line of mean variability. But if this is the effect of such selection, how can the perfect adaptation of species to existing conditions be maintained by the same process?

There is also one other consideration which must not be lost sight of in this connection. I am not aware that it has been ever proved that the one column is composed of useful and the other of injurious variations. Many differently correlated organisms may be equally efficient in fighting the battle of life. Moreover, we must not suppose that they will be rigorously selected in the face of accidental death; or that survivors will not intermarry promiscuously, simply because they are represented as occupying different sides of a straight line drawn on a diagram to illustrate the classification of variants, which is justified by the researches of scientific men.

If, then, in the face of unchanged conditions the principle of regression to mediocrity has produced the stability of species, and Natural Selection has not been active in maintaining the ideal excellence of a species, the idea 
that the cessation of Natural Selection produces a deterioration of species cannot be maintained. Yet this is an assertion which Mr. Romanes maintains in this second proof.

"As soon as selection is withdrawn and heredity is simply left to itself, any failures either in the force or in the precision of heredity will be allowed to survive and perpetuate themselves. In the course of many generations these failures will become more and more cumulative. The useless organ will, therefore, more and more degenerate in size or in structure, as the case may be-and this through the mere cessation of the previously sustaining influence of selection." -(Contemporary Revicu. vol. laiv., p. 6I2.)

The argument of Mr. Romanes seems hardly to agree with his assertion that unuseful variations will be stillborn or die out at once in consequence of intercrossing, for the unuseful is surely a kind of failure, either in the force or precision of heredity.

If the unuseful are stillborn or absorbed in the average of the race when Natural Selection is at work, why should not this process continue after the cessation of Natural Selection? Moreover, if we were to grant that Natural Selection had been active in securing the ideal perfection of a species, and had then ceased to act, the special ideal perfection would disappear, no doubt, but the principle of regression to mediocrity would still remain to secure the ordinary stability of the species.

What Mr. Romanes calls the cessation of Natural Selection, Weismann also calls panmixia, or the unimpeded interbreeding of all variants in the absence of Natural Selection. Now, of the power of this panmixia, Weismann speaks confidently, writing with all the emphasis of italics.

"I will only call to mind the fact that, according to the principle of panmixia, every faculty must disappear as soon as it ceases to be necessary." - Essays upon Heredity. vol. ii., p. 209.)

"But they degenerate because and in so far as they are superfuous for the full performance of the tasks of a worker; so in this way 
again we are led to panmixia."--(Contcmporary Revicw. vol. Ixiv., p. 317.$)$

"I believe that I have shown that organs which have ceased to be useful become rudimentary and ultimately disappear, owing to the principle of panmixia alone."-(Essays upon Horcdity. vol. ii., p. 76.$)$

Now this seems to me a very remarkable statement. For, in the first place, as we shall have to show hereafter, there is a curious survival of the useless, which is very startling, considering the many reasons for its total removal which different scientific men have suggested.

Mr. Darwin declares that-

"Variations neither useful nor injurious would not be affected by Natural Selection, and would be left either a fluctuating element, or would ultimately become fixed, owing to the nature of the organism and the nature of the conditions."-(Origin of Spccics. p. 63.)

\section{Dr. Weismann asserts that-}

"The process by which the degeneration of superfluous organs takes place may fittingly be called 'universal crossing' (Panmixia), because it implies that not those individuals only in which any particular organ is best developed survive and propagate their species, but that survival is quite independent of the efficiency or non-efficiency of the organ."--(Essays on Hcredity. vol. $i i ., p .2 I$.

But the statement is still more remarkable, because it attributes to panmixia, or the cessation of Natural Selection, a power of adapting organisms to new conditions similar to that which Mr. Darwin and Dr. Weismann attribute to Natural Selection itself.

"Natural Selection is continually trying to economise every part of the organisation. If, under changed conditions of life, a structure -before useful-becomes less useful, its diminution will be favoured, for it will profit the individual not to have its nutriment wasted in building up an useless structure."-(Origin of Specics. pp.II7-II8.)

Dr. Weismann says :-

"The complete disappearance of a rudimentary organ can only take place by the operation of Natural Selection; this principle will 
lead to its elimination, inasmuch as the disappearing structure takes the place and the nutriment of other useful and important organs."-(Essays on Heredity. Isted. vol. i., p. 88.)

Thus, according to one representation, the useless structure is removed by Natural Selection, while according to another it is removed by the cessation of Natural Selection. Surely common sense should lead the advocate of Natural Selection to take the former view of this subject, for the theory of Natural Selection is consistently represented as bringing about the removal of the useless-consistently, i.e., with the logical requirements of the theory; for if a race survives by virtue of its strength, it is obvious that it would be prejudicial for it to waste its nourishment on an organ which was not a source of strength. If a species has to win the race of life, every extra weight that did not make for speed and endurance would be prejudicial; and if the theory of Natural Selection were true, it is impossible to conceive how slight a weight might make the difference between success and failure. We may see a good illustration of this principle in the case of the race-horse. The experts were almost unanimous in the opinion that the superiority of Ladas over Match-box was represented by six pounds; which I suppose means that a dead weight of six pounds placed on the back of Ladas would have lost him the race. But even in spite of this supposed competition, a useless organ is sometimes left untouched, sometimes takes a long time in becoming aborted.

Dr. Weismann also speaks of panmixia as negative selection. He refers to certain results as being brought about by-

"Selection-either negative selection alone (panmixia) or with the aid of positive selection, which prefers and gives the victory to the less injurious."-(Contemporary Review. vol. Lxiv., p. 335.) 
This is certainly a very remarkable statement; for, since panmixia means the cessation of selection, Dr. Weismann in effect says that selection may be efficacious by acting and by not acting-just as if we were to describe two motions of a machine as its action and its inaction, and speak of its two kinds of efficient work, when in motion and when at rest.

What can be done by Natural Selection during the cessation of Natural Selection except to stand aside and leave other laws of nature to do their work? In unchanged conditions and without selection we shall have that output of varicty which is ever going on in connection with sexual reproduction and that principle of regression to mediocrity which is always maintaining the specific type, the average of the race. To misrepresent this process by assuming that the principle of regression will not act, and that in the absence of selection failures will flourish or monstrosities will arise or degeneration will set in, and to call all this "panmixia" and "negative" gravity, seems to me an exercise of the imagination of a scientific man, though I do not think that it would be correct to characterise it as the exercise of a scientific imagination. But if Dr. Weismann's excursion into Alice's Wonderland only dates from the publication of the article from which I quote, he has been anticipated in the use of the word "negative"; for long ago Mr. Stockton told his exquisite story of "Negative Gravity," the secret of which he did not reveal, but the painful consequences of which he narrated so vividly. But Mr. Stockton was at any rate consistent. His negative gravity produced different results from his positive gravity. But the parable of negative gravity conveys a warning against a too ready acceptance of the doctrine of negative selection. For negative selection is no more suitable to the actual world than 
negative gravity. If Dr. Weismann had the power of immediately causing an organ to disappear which was not useful at the time, and were to exercise that power, he would be the most execrated of mortals. The goose remains unchanged in structure in spite of its luxurious condition as a domesticated animal, which makes it that strange anomaly-a bird with fully developed wings which cannot fly. Dr. Weismann, wielding the power of negative selection, would say, "Off with her wings!" which would spoil the look of the bird to begin with, and deprive some authors of the goose-quill which they still use. But it would do more. The muscles which control the motions of the wing would also disappear, and the epicure would have to sit down to his Christmas goose with little more than skin where he looked to find a succulent breast. Negative selection is no more fit for this world than negative gravity has so cleverly been shown to be.

For myself, I believe no more in negative selection than I do in negative gravity. I believe that it is only in its most artificial productions that the type will degenerate the moment that the principle of selection is withdrawn. I believe that variation and regression to mediocrity will co-operate to bring about the stability of a species, so long as the surrounding circumstances remain the same.

If, then, I am right in assuming that there has been a stability of species under conditions which exclude the action of Natural Selection, it may be well for us to consider some of the inferences which may be drawn from that fact.

In the first place it militates against the idea that the transmutation of species has been the necessary result of some inherent principle of development. According to Professor Owen, the doctrine of "derivation holds that 
every species changes in time by virtue of inherent tendencies thereto."**

Mr. Darwin and Mr. Mivart contend that the nature of the conditions are of comparatively little importance as compared with the nature of the organism.

"We clearly see that the nature of the conditions is of subordinate importance in comparison with the nature of the organism in determining each particular form of variation;-perhaps of not more importance than the nature of the spark, by which a mass of combustible matter is ignited, has in determining the nature of the flames."-(Origin of Species. p. 8.)

"If the mere presence of these incident forces produces so ready a response in animals and plants, it must be that there are in their case conditions disposing and enabling them so to respond according to the old maxim-Quicquid recipitur, recipitur ad modum recipientis; as the same rays of light which bleach a piece of silk blacken nitrate of silver. If, therefore, we attribute the forms of organisms to the action of external conditions-i.e., of incident forces on their modifiable structure, we give but a partial account of the matter, removing a step back, as it were, the action of the internal condition, power, or force, which must be conceived as occasioning such ready modifiability."-(On the Genesis of Species. pp. $166-7$.

There are cases in which this is true; but we must guard ourselves from assuming as a necessary inference that this nature of the organism refers to any necessary principle of development put into the simplest form of life; but we must rather explain the phenomenon as arising from a complicated constitution which has been acquired by a race as the result of manifold impressions made upon it by external conditions. Dr. Martineau, speaking of evolution, says :-

"It means to unfold from within; and it is taken from the history of the seed or embryo of living natures. And what is the seed but a casket of pre-arranged futurities, with its whole contents prospective, settled to be what they are by reference to ends still in the distance?"-(Essays, Reviezes and Addresses. vol. iv., p. 606.)

* Anatomy of Vertebrates. vol. iii., p. Sos. 
To this Mr. Herbert Spencer replies :-

"Now this criticism would have been very much to the point, did the word Evolution truly express the process it names. If this process, as scientifically defined, really involved that conception which the word Evolution was originally designed to convey, the implications would be those Mr. Martineau alleges. But, unfortunately for him, the word, having been in possession of the field before the process was understood, has been adopted merely because displacing it by another word seemed impracticable. And this adoption of it has been joined with a caution against misunderstandings arising from its unfitness. Here is a part of the caution. 'Evolution has other meanings, some of which are incongruous with, and some even directly opposed to, the meaning here given of it. . . The antithetical word Involution would much more truly express the nature of the process; and would, indeed, describe better the secondary characters of the process which we shall have to deal with presently.' (First Principles. Second edition, \$ 97.) So that the meanings which the word involves, and which Mr. Martineau regards as fatal to the hypothesis, are already repudiated as not belonging to the hypothesis."-(Essays. vol. iii., p. 243.)

But Dr. Martineau in the same essay has remarked: "Surely nothing can be evolved which has not been first involved."* He therefore recognises the very principle for which Mr. Herbert Spencer contends. The difference, of course, lies in the different opinion as to how the involution took place.

In the second place, the stability of species should prepare us for the fact that the transmutation of species cannot be brought about without overcoming a certain immobility; and we must not be surprised if the transmutation of species does not take place as quickly and as generally in some cases as it does in others. On the other hand, we must be very careful not to be misled by a hasty impression. In some cases considerable modification has taken place without exciting attention. Take, for example

* Essays, Addresses and Revienus. vol. iv., p. 607 . 
the assertion which Mr. Darwin makes with respect to the water-ouzel :-

"In the case of the water-ouzel, the acutest observer by examining its dead body would never have suspected its sub-aquatic habits; yet this bird, which is allied to the thrush family, subsists by cliving, using its wings under water, and grasping stones with its feet."-(Origin of Species. p. I42.)

If we accepted Mr. Darwin's assertion as correct, it would be easy to reply that no change has taken place because the organs were perfectly capable of performing the new functions which the new conditions required. The wings need not be adapted in order to enable the bird to dive, and the feet could clasp the stones as well as the twigs of trees. But are the facts just what Mr. Darwin represents them to be? On the contrary, Mr. Wallace says :-

". . . their dense and somewhat fibrous plumage retains so much air that the water is prevented from touching their bodies or even from wetting their feathers to any great extent."--(Darwinism. p. $I I 6$.

This seems to indicate a change to adapt the race to its newly-acquired aquatic habits. Professor Rolleston indicates another modification :-

"The modifications in the tibia of the birds commonly known as Divers (Colymbinae), and the large intra-hepatic venous sinuses which they, in common with the mammals just spoken of possessed, were beautiful adaptations to the special habits of these animals, but nothing at all reminding us of these structures would be found in such a bird as the water-ouzel (Cinclus aquaticus). Indeed, the soft parts of this bird presented very few points of difference from those of a Redwing (Turdus iliacus), dissected at the same time with it, except in a much greater development of the second pectoral muscle. The large size of this muscle was permanently recorded on the keel of the ouzel's sternum; and this point might perhaps have enabled us a priori to predict that the bird possessed the peculiar habits which have given it its trivial name. This ridge extends the whole length of the keel in the water-ouzel, and in 
this point-as well as in the lesser relative depth of that process, and in the greater relative breadth of the lateral portions of the sternum, and in its more nearly circumscribed posterior emarginations - the bird in question differed from allied species of dissimilar habits."-(Scientific Papers and Addresses: vol.i., pp. 63-4.)

The first limitation of the action of Natural Selection is therefore to be found in the stability of species. Vast hordes of living creatures have endured without specific change for æons of geological time. It is as though Nature had drawn a magic ring around some of her products, "to keep some Old World things aloof from change," and within this charmed circle, in spite of occasional struggle for existence, Natural Selection has played no part, either by acting or by refraining from action. 


\section{CHAPTER II.}

THE EXTINCTION OF SIECIES.

". . Nature lends such evil dreams,

So careful of the type she seems,

So careless of the single life.

So careful of the type? but no.

From scarped cliff and quarried stone

She cries, 'A thousand types are gone:

I care for nothing, all shall go.'"

$$
\text { -Tennyson. In Memoriam. lv., lvi. }
$$

A CEnTURY ago it was held to be impossible that any species should ever become extinct. When the hairy elephant known as the mammoth was first discovered, it required the arguments of acute reasoners to persuade an unbelieving world that this species of elephant differed in any essentiai degree from the elephants which still survive.

"It was in 1796 that Cuvier announced that the teeth and bones of the European fossil elephants were distinct in species from both the African and the Indian elephant, the only two living species. This fundamental fact opened out to him new views about the creation of the world and its inhabitants, and a rapid glance over other fossil bones in his collection showed him the truth and the value of this great idea (namely, the existence of extinct types), to which he consecrated the rest of his life."-(H. N. Hutchinson. Extinct Monsters. Second edition, p. I94.)

Since that day science has achieved one of her greatest successes in making us acquainted with these extinct species. Disjecta membra have been collected, skeletons 
have been reconstructed; these skeletons have been clothed with flesh, in a way which is justified by actual discovery or by fair inference based on the definite knowledge of comparative anatomy and physiology; and we have been instructed to picture to ourselves the external conditions amid which these animals lived. By careful investigation, by acute reasoning, and by the legitimate exercise of the imagination, the spirit of science has breathed upon the remains in the valley of dry bones, and bid them live again in the world of the imagination; so that we have pictures of the past which every new discovery makes more complete and reliable.

It would be beside the object of the present work to dwell on results which are now so generally acknowledged to be true; or to describe the fauna and the flora which have now passed away. It is a palpable fact that age after age and æon after æon have seen the extinction of types which once largely dominated the world.

Nor is this phenomenon confined to the eras of a remote past. When we compare the accounts of the present fauna and flora of a particular district with those which obtained in a not remote past, we are often struck with the fact that extermination, if not extinction, of species has recently taken place. The lover of nature is ever bewailing the fate of beautiful creatures, exterminated from their favourite haunts or altogether lost to the world through the extinction of species. Kingsley, in one of his Prose Idylls, laments the effect produced by the draining of Whittlesea Mere.

"They are all gone now. No longer the ruffs trample the sedge into a hard floor in their fighting rings; while the sober reeves stand round admiring the tournament of their lovers, gay with ears and tippets, no two of them alike;-gone are the ruffs and the reeves, spoonbill, bittern, avosets; the very snipe disdain to breed; 
-gone, too, not only from Whittlesea, but from the whole world, is that most exquisite of English butterfles, Lycoena dispar, the Great Copper, and many an insect more!"-( $\not p .90,9 I$.

The extinction of species is moreover foreshadowed in the case of those animals and plants which are becoming rarer and fewer from year to year. They are evidently doomed to disappear at no distant date, unless indeed the circumstances should alter and more favourable conditions should be introduced.

In considering the causes which have led to this extinction, we may first of all remark that there is a sense in which a species may be said to have become extinct, even when the race has continued to flourish. When all the members of a species undergo considerable modification, the result may be denominated a new species, and the ancestral forms may be regarded as extinct species.

The extinction of species in the more usual acceptation of that term may arise from various causes. In the first place, sudden and considerable change of external condition, food, climate, will often prove fatal to a race.

"The pre-existing structure of an organism prevents it from living under any new conditions except such as are congruous with the fundamental characters of its organisation-such as subject its essential organs to actions substantially the same as before. Great changes must kill it."-(Herbert Spencer. The Principles of Biology. vol. i., p. 427.)

"It is an everyday experience that changes in environment occur without any preparation for them on the part of living things. If the changes are very great, death is the result."-(E. D. Cope. The Origin of the Fittest. p. 227.)

"By the breaking of an isthmus, and the consequent irruption of a multitude of new inhabitants into an adjoining sea, or by the final subsidence of an island, the process of extinction may have been rapid. . . In some cases the extermination of whole groups, as of ammonites towards the close of the secondary period, has been wonderfully sudden."-(Origin of Species. p. 294.) 
Another cause of extinction is to be found in the sudden invasion of a particular area by an animal which is the foe of a particular species. An interesting case of this kind occurred in the island of Jamaica; and what happened in this instance by the intervention of man might easily occur in connection with changes going on in nature.

"Twelve years ago rats multiplied enormously in the sugar-cane plantations of Jamaica, where they gnawed the sweet stalk, leaving the cane which they had attacked, as soon as they had made an incision in it, which determined its destruction, and then began upon another. This mode of operation entailed a very observable loss upon the planters, and they resolved to act energetically. The Reque des Sciences Naturelles appliquécs tells us how in the meanwhile a proprietor in the isle, M. Bancroft Erpent, having brought over from India six ichneumons, a species which has constituted itself the hereditary foe of rats and serpents; these animals having rapidly multiplied, had soon chased the rodents from the plantations. The rat's then invaded the farms and villages, the ichneumons pursued them thither, and above all destroyed their numerous young in their nests. Driven to a new retreat, the rats found another place of protection in the summit of various cocoa-nut trees which had just been planted in the island; the ichneumons could not follow them thither. After that time the rats lived at peace at the top of the cocoa-nut trees, but the planters preferring to hinder them from establishing themselves there, set themselves to provide the bottom of the trees with a covering of sheet iron, two metres high, nailed round the trunk. The suppression of this last refuge made them diminish in numbers more and more. As to the ichneumons, so useful on their arrival, having no more rats to devour, they have turned their attention to the hen-roosts, where they destroy the eggs and chickens. They have thoroughly, totally destroyed the quails and the partridges of the island, whose eggs, laid on the earth, offer an easy prey. They empty them by making a small hole in them, and the ignorant mother continues to sit on the sterilised eggs. The inhabitants of Jamaica, saved from the rats by the ichneumons, are now looking for a new animal which will relieve them of their saviours."-(La Science Pour Tous. Dec.6th, I89o. p.392.)

Another reason of the extinction of species is to be found in great complexity of structure. For this complexity of structure not only involves a complex correlation of the different organs of the individual body, but also 
a very close and definite correlation between the whole organism and its surrounding conditions; and hence considerable changes-and, indeed, even slight modificationsin the conditions may be fatal to the species in proportion to its adaptation.

A species may become extinct in certain cases, not because it is not eminently adapted to the position in which it is placed, in a great many respects, but because some very slight disability may prevent it from flourishing or may cause it to become altogether extinct. In his Origin of Species, Mr. Darwin propounds the problem how the horse came to be exterminated in South America. He says :-

"Seeing that the horse, since its introduction by the Spaniards into South America, has run wild over the whole country, and has increased in numbers at an unparalleled rate, I asked myself what could so recently have exterminated the former horse under conditions of life apparently so favourable."-(Origin of Species. p. 294.)

The solution of this problem may perhaps be found in a passage in the same work, where it is asserted that, in Paraguay,-

"Neither cattle nor horses nor dogs have ever run wild, though they swarm southward and northward in a feral state; and Azara and Rengger have shown that this is caused by the greater number in Paraguay of a certain fly, which lays its eggs in the navels of these animals when first born."-(Origin of Species. p. 56.)

In this case extinction follows, because among many favourable conditions there is one which is fatal to the welfare of the species.

Sometimes two species are found which could flourish equally well apart from one another, and yet one species seems to have the power to exterminate the other when brought into juxtaposition. 
"The exact causes of this displacement (of one set of species by another) are by no means of such a simple nature. All the plants concerned may be perfectly hardy, all may grow freely from seed, yet when left alone for a number of years each set is in turn driven out by a succeeding set, till at the end of a considerable period-a century or a few centuries, perhaps-hardly one of the plants which first monopolised the ground would be found there."-(Wallace. Darwinism. p. I5.)

It is possible that a group of variants which arise in connection with any species will compete with the parent form; and that form which is best adapted to the conditions will survive.

Speaking of the reasons which lead especially to the extinction of large animals, Mr. Wallace says :-

"There is, however, another cause for the extinction of large rather than small animals whenever an important change of conditions occurs, which has been suggested to me by a correspondent, but which has not, I believe, been adduced by Mr. Darwin nor by any other writer on this subject. It is dependent on the fact that large animals, as compared with small ones, are almost invariably slow breeders, and as they also necessarily exist in much smaller numbers in a given area, they offer far less materials for favourable variations than do smaller animals. In such an extreme case as that of the rabbit and elephant, the young born each year in the world are probably as some millions to one; and it is very easily conceivable that in a thousand years the former might, under pressure of rapidly changing conditions, become modified into a distinct species, while the latter, not offering enough favourable variations to effect a suitable adaptation, would become extinct."--(Wallace. The Geographical Distribution of Animals. vol.i., pp. 158-9.)

Two other somewhat exceptional causes remain to be indicated. Mr. Wallace says :-

"It is clear that we are now in an altogether exceptional period of the earth's history. We live in a zoologically impoverished world, from which all the hugest and fiercest and strangest forms have recently disappeared; and it is no doubt a much better world for us now they have gone. . . . We cannot but believe that there must have been some physical cause for this great change; and it must have been a cause capable of acting almost simultaneously over large portions of the earth's surface, and one which as far as the 
tertiary period at least is concerned, was of an exceptional character. Such a cause exists in the great and recent physical change known as 'The Glacial Epoch.'"-(The Geographical Distribution of Animals. vol.i., pp. 150-I.)

And now man, for whom this world has been made a pleasanter place to live in by the extinction of some old world monsters, does his very best to complete the work of extinction. The slaughter of wild animals has become a science, and big game shooting will go on until there is no big game left to kill.

We have now to consider the bearing of these facts upon the theory of the transmutation of species by Natural Selection. In the title of his great work, Mr. Darwin seems to imply that "the origin of species by means of Natural Selection" is assured by "the preservation of favoured races in the struggle for existence." In the body of that work he says:- "On the theory of Natural Selection, the extinction of old forms and the production of new and improved forms are intimately connected together." *

If Natural Selection be a real law of nature, there is no doubt that it will contribute to produce the survival of favoured races, and the extinction of those which have failed in the struggle for existence. But those who are in doubt on this subject would like to have some assurance that the extinction of species can be cited as a proof of the transmutation of species by means of Natural Selection. We will consider the phenomenon from three points of view; (I) when the whole species is transmuted and ancestral forms become virtually extinct species; (2) when all the members of a species are destroyed and their transmutation is rendered impossible; (3) when a species bifurcates or ramifies, and there is possibly a 
struggle between the parent species and more or less nascent varieties.

When a whole species undergoes considerable variation, it becomes a new species. This seems to be assumed by Mr. Wallace. He describes the process by which he conceives that the adaptation of a species to new conditions may have been brought about. "But," he adds, "it will now be a different creature." " And it would seem to follow from this, that the ancestral form has become an extinct species; so that, in this case, the extinction of species is the necessary prelude of the transformation of species. A different creature would naturally be classified in a different species to that from which it had arisen, if we knew nothing of its origin. But will this knowledge make any difference? It certainly does with some persons, who have provided us with very different definitions of the word species. The old fashioned idea of species is that God made so many different kinds of animals to be fruitful inter se, to multiply and to reproduce offspring after their own typical likeness. The test of likeness is not, however, held very rigidly. It is assumed that a species may be variable but yet immutable, as indeed is the fact in some cases. But when, in spite of this latitude of interpretation, it is found that considerable changes take place in a given race, quite sufficient to constitute the offspring a new species-if we judge only by the comparative likeness or unlikeness-then the definition is modified altogether; the test of a true species is not to be found, we are told, in similarity or dissimilarity, but in the continuous fertility of the offspring.

Now, it is quite clear that these definitions exclude one another ; they are not capable of being harmonised. Exact 
likeness does not admit of considerable difference, and vice vers $\hat{a}$; and any definition of the fixity of species which makes species to depend upon continuous fertility of the offspring, and not on likeness, is really only a statement of the transmutation of species, in other and somewhat perplexing terms.

It seems to me to be a far more reasonable definition of species to declare that it is a distinction introduced by man in his attempt to classify the different kinds of living creatures which may be, and often has been, a merely provisional classification. In this case there can be no doubt that the transmutation of a whole species involves the extinction of ancestral forms and the substitution of what is, in effect, a new species. In this sense, the poet salutes aspiring man as "the herald of a higher race," and bids him to-

. "move upward, working out the beast, And let the ape and tiger die."

Moreover, this fact in itself only testifies to a quasi extinction of species as the precursor and accompaniment of transmutation of species. It does not necessarily suggest any proof as to the manner in which transmutation has been brought about. It would be a mere begging of the question to assert that, because transmutation has been accompanied by extinction, such extinction may be cited as a proof of the action of Natural Selection.

In the second place, the extinction of a whole species in the ordinary sense of that word, by whatever cause it may be brought about, prevents the transmutation of that species.

"He that fights and runs away

May turn and fight another day;

But he that is in battle slain

Will never rise to fight again."-(Ray.) 
And if a living $\operatorname{dog}$ is better than a dead lion, we may rest assured that, for purposes of organic evolution, a surviving race of dogs is better than an extinct race of lions. Moreover, the extinction of a species shows the incapacity of that species to adapt itself to certain conditions. In the forests of Denmark, as we have already pointed out, the birch in vain struggles to survive in company with the beech. In such a case, it might have been expected that Natural Selection would have found out some modus vivendi for this threatened species. For by the theory, in adverse circumstances, variations of every kind arise, favourable variations are selected, and thus the organism is adapted to its conditions. But it has failed to do this. Extinction is not, in this case, the accompaniment of Natural Selection, properly so called. On the contrary, it testifies to the inefficiency of that supposed law of nature where its aid is most required.

We have already shown that the extinction of one species by another species is not a proof of the transmutation of species by means of Natural Selection; because in all the cases cited, one species is exterminated and the other species remains unmodified.

One of the reasons given by Mr. Wallace for the extinction of large animals is based upon the principles of Natural Selection. Large animals have few offspring, and therefore do not afford that opportunity for the output of great numbers which the accidental emergence of favourable variations requires. But it is quite clear that large animals have survived when the conditions have been favourable. If so, the slowest breeding animals will increase their numbers immensely. Nor is it necessary for a race to bring forth a large number at one birth in order to survive the struggle for existence. "The Fulmar petrel lays but one egg, yet it is believed to be the most numerous 
bird in the world."* Thus the one reason given for the extinction of large animals, which is based on the theory of Natural Selection, carnot be sustained.

We have considered the case of the transformation of a whole species and of the destruction of a whole species. But there is another possibility to be considered. Some members of a species may remain unmodified, while others may undergo transmutation in one or more directions. In this way, it is conceivable that there should be a bifurcation and even a ramification of species. If these can co-exist amicably, they will lead to a manifold transmutation of species; but if they compete with one another, this will lead either to the extermination of the unmodified parent form or of the nascent varieties. Let us, then, see what probability there is that the bifurcation or ramification of species has been brought about by Natural Selection; or what probability there is that the victory of species over variety, or variety over species, has been brought about by Natural Selection.

We are indebted to Mr. Fiske for an elaborate picture of the process by which the bifurcation of a species may be brought about by Natural Selection. This method of argument is infinitely superior, in my opinion, to the plan which is sometimes adopted, when the action of a principle is dogmatically asserted but no hint is given as to how it might be accomplished, to say nothing of any evidence that it has actually been accomplished. Mr. Fiske says :-

"We may form a rough notion of the way in which a single species
bifurcates into two well defined species. Suppose a race of ruminants
to have been living in Africa before the introduction of carnivora, and
suppose that for sundry reasons, the vitality of the race was but little
affected by moderate variations in the sizes of its individuals, so that

* Origin of Species. p. 52. 
while some were comparatively light and nimble, others were comparatively large and clumsy. Now, introducing upon the scene the common ancestor of the lion and the leopard-by immigration either from Asia or from some other adjacent territory now submerged-let us note some probable features of the complex result. First as regards the attacked ruminants, it is likely that in course of time the lightest and swiftest individuals, habitually taking refuge in flight, would have greatly increased both in fleetness and in timidity; the largest and most clumsy of the species, unable to save themselves by fleeing, would often be forced to stand and fight for their lives, and would thus ultimately have gained in size, strength and courage; while those who were neither nimble enough to get out of the way nor strong enough to fight successfully, would have all been killed off. And thus after a while, by perpetual destruction of the means and preservation of the extremes, we should get two kinds of ruminant, as different from one another as the antelope, which escapes by his fleetness and cautious timidity, and the buffalo, which boldly withstands the lion and not unfrequently conquers or repulses him."-(Cosmic Philosophy. vol.ii., p. I8.)

Mr. Fiske here makes three assumptions. (I) He presupposes the pre-existence of two nascent varieties in a given species-some being comparatively light and nimble, others comparatively large and clumsy. (2) He assumes that the light variety would seek safety in flight, and that the heavy variety would try to escape destruction by standing still and fighting for their lives. (3) He takes for granted that the fleetest and most timid of the one section and the strongest and most brave of the other section would be saved, and so a bifurcation of species would take place. But how, I would ask, could the initial difference have arisen in a species which had the same habits? There would be no light and nimble specimens of a race which was never pursued; there would be no heavy and clumsy specimens in a species which had constantly to run for its life. Why should a herd of deer which act for the common good and stick together take to two modes of saving themselves? And there is the second difficulty, already dwelt upon, that the co-operation 
of the herd prevents that survival of the swiftest only, which the theory requires.

But we will assume that from some cause or other one or more groups of variants have arisen in connection with a given species. It does not follow that Natural Selection will necessarily interfere. For it is quite conceivable that variant groups may arise which do not differ in any vital point from the parent species. One may have as good a chance of living as the other, and Natural Selection would then not come upon the scene. On the other hand, unfavourable variations, even in their incipient stages, would be suppressed by Natural Selection, if it were a law of nature, so that the co-existence of variants with parental forms cannot be accounted for by the action of Natural Selection.

Again, it is quite possible, when there is sufficient room, that variants might segregate themselves, or adopt different habits, or migrate to a distance, so as not to compete with the parent form. Mr. Darwin admits that, "If both have become fitted for slightly different habits of life or conditions, they might live together."* A good illustration of this point is to be found in the Uria lacrymans:-

"In various parts of the Northern seas a remarkable variety of the common Guillemot (Uria troile) is found, and in Faroe one out of every five birds, according to Graba's estimation, presents this variation. It is characterised by a pure white ring round the eye, with a curved narrow white line, an inch and a half in length, extending back from the ring. This conspicuous character has caused the bird to be ranked by several ornithologists as a distinct species under the name of $U$. lacrymans, but it is now known to be merely a variety. . . . We thus see that two distinct forms of the same species may co-exist in the same district."-(Descent of Man. p. 424.)

But, for the sake of argument, we will assume that there is a struggle for existence between a group of variants and

* Origin of Species. p. 169. 
the parent species. It is obvious at the outset that if the variants have less advantage than the parent stock, they will, according to the theory, be destroyed, and then the stability of species, rather than its transmutation, will ensue. If, on the other hand, the variants, which presumably will be in the minority, have the advantage, and if that advantage is gained by the survival of the best among themselves and the destruction of all the rest, the process may be too costly to secure their preservation as a race. It is possible that they might supplant the parent species and yet not permanently establish themselves. The process would always be liable to produce that rarity which is the precursor of extinction ; or, if rarity already existed, to convert that rarity into extinction. Other methods of transmutation, on the other hand, which are not dependent upon the accidental emergence of favourable variations, and which do not work by life and death, are not so obnoxious to this danger.

The connection between the extinction of species and Natural Selection appears to be this. A quasi extinction of species is the prelude of transmutation, when all the members of a species undergo modification; but this fact does not necessarily imply that Natural Selection has been at work. The extinction of a whole species obviously prevents the transmutation of that species, whether by Natural Selection or any other cause. There is no reason to suppose that the bifurcation or ramification of species has been produced by Natural Selection; nor does it follow that species and variants will necessarily compete with one another. This conflict can be, and often is, avoided. If conflict did arise, it would either lead to the stability of species, if the parent species survived, or threaten the few surviving favourable variants with extinction. Finally the extinction of species reminds 
us of the immense risk which would accompany the action of Natural Selection, if it were indeed a law of nature, while it is obvious that no such risk attends other possible modes of modification. Shall we, then, still say that the extinction is the work of Natural Selection? Shall we say that the extinct species has been "eliminated by Natural Selection?" There is no doubt, in a certain sense, a selection; "one is taken and the other is left." But surely this is not Natural Selection in the proper and definite and technical meaning of the term which implies not the survival of one species at the expense of another; but the modification of a given species by the selection of variations which are useful to the species in the struggle for existence. If a cattle breeder were to kill off all of a particular breed for which there was no longer any demand, you would hardly call that artificial selection.

From what has been said in the two previous chapters, it is certain that the transmutation of species, by whatever means it be brought about, has to compete with the two very different tendencies-the fixity of species and the extinction of spocies. The stability of species shows us how difficult it is in some cases to bring about any transmutation of species; the extinction of species warns us of the danger which may accompany this attempt. For the reasons which have already been assigned, the competition must be exceptionally bitter in those cases in which the reputed law of Natural Selection is brought into action. Hence it is probable that at the threshold of our enquiry Natural Selection may be excluded where other methods of transmutation are possible. 


\section{CHAPTER III.}

THE TRANSMUTATION OF SPECIES.

"Corpora vertuntur nec quod fuimusve sumusve

Cras erimus."

-Ovin.

WE now propose to ask what part the théory of Natural Selection plays in connection with other possible methods of the transmutation of species.

It may be well, for the sake of clearness, to look at this matter (first) from the point of view of those who believe that Natural Selection is the sole method by which the transmutation of species is brought about, and (secondly) from the point of view of those who believe that transmutation can take place apart from Natural Selection as well as through its agency. In the former case, the principle is laid down that no modification acquired by "the body" of the individual during life can be inherited; that only those variations with which an individual is born can be inherited by the offspring; and that the favourable variations can only survive through the action of Natural Selection-i.e., through selection by life and death.

We must continually bear in mind the reason why the principle of selection is esteemed so important in this connection. Those variations which are necessarily and inevitably associated with sexual reproduction would be swallowed up in the average of the race by the principle of regression to mediocrity, unless similar variants were compelled to breed together. But this principle of selection is only required in the case of those variations which 
are necessarily and inevitably associated with reproduction. There are some birth variations which are reproduced and fixed in the race altogether apart from any principle of selection.

In the first place, if individuals of different species can produce offspring which are fertile inter se, and whose offspring continues to be so from generation to generation, a new species, or at least a new variety, is at once brought into existence,-apart from the principle of selection, natural or artificial-through the principle of the continuous fertility of the offspring of hybrids. In the second place, if an individual exhibits at birth a considerable variation from the normal type, and if this individual has the power of impressing its peculiar variation upon its offspring; if the offspring breeds true, and if these similar variants by preference interbreed with one another; and if, failing this, these new forms impress their likeness upon their offspring, then there will be a transmutation of species without Natural Selection through the principle of the prepotency of the great variant. If some similar cause affects all the members of a species, previous to their birth, in a similar manner-whether the influence act on both the sexual elements before impregnation has been effected,* or on the fotus after impregnation, or after impregnation and before birth-then it is reasonable to suppose that these variations would be inherited, on the principle that birth variations of all kinds are heritable, and that if similar variants breed together their offspring will resemble their parents.

With respect to the variations necessarily associated with reproduction which do require the principle of selection, it does not follow as a matter of course that the

* Darwin. The Variation. vol. ii., t. 270. 
selection which takes place in nature must be what is technically known as Natural Selection, namely a selection by life and death. For in artificial selection isolation is brought about by physical separation, and in nature it is conceivable that similar variants may be prevented from interbreeding with the normal members of the species by a physical barrier. Again, it is the experience of breeders that different breeds will keep together; and it is quite probable that similar variants would tend to associate with themselves as much, as possible. Here isolation would be caused by social segregation. It is found also that similar variants are sometimes fertile with themselves, and not fertile with the normal members of the species, or that they come to maturity later or earlier than the rest of the species. In which case isolation would be brought about by physiological differentiation. From what has been said, it is clear that there are two distinct kinds of birth variations; first, those which are necessarily and inevitably associated with sexual reproduction; and, secondly, those which occasionally take place. We are prepared to show, in accordance with the statements just made, that there are occasional variations connected with sexual reproduction which do not require the principle of selection in order to secure their becoming fixed in the species; and also that when the principle of selection is needed, there are in nature other modes of isolating for breeding purposes besides that known technically as Natural Selection. Thus the charmed circle which is drawn around pure Darwinism has certain breaks in it. The very principles on which pure Darwinism is based are such as to imply the possibility of other modes of transmutation. There is nothing in the principles of Natural Selection to prevent the emergence of these other methods. 
If, now, we turn to mixed Darwinism, i.e., to the theory which admits that species may be transmuted by Natural Selection, and also by the direct action of changed conditions, this admission, to say the least, lessens the action of Natural Selection; but we may go further, and we venture to assert that if the direct action of circumstances modifies the organism which is susceptible to their influences, this process will prove the more rapid and the more successful method, and Natural Selection will be powerless to compete with it. And in a world which is dominated by the struggle for existence, a principle which cannot compete, whether it be a theory of man or a law of nature, is to that extent powerless. 
CHAPTER IV.

THE CO-ORDinAted PARTS AND THE CORRELATED

VARIATIONS OF ORGANIC STRUCTURES.

"The whole body fitly joined together and compacted by that which every joint supplieth, according to the effectual working in the measure of every part, maketh increase of the body unto the edifying (building up) of itself."

"For let our finger ache, and it endues Our other healthful members ev'n to that sense Of pain."--Othello. Act iii., sc. 4 .

"When one part is modified . . . other parts of the organisasation will be unavoidably modified." -DARWIN.

BEFORE we proceed to compare the effect of Natural Selection with that of other influences in bringing about a transmutation of a specific type, we have first to enquire whether there is anything in the very nature of the organism itself which will co-operate in producing such a result. There can be little doubt that there is such a principle at work. In every organism the different parts are co-ordinated to one another. The symmetry of the whole is secured by the proportionate relation which exists between the parts. The efficiency of the whole as an apparatus to perform a given work is the result of the functional activity of the parts and their co-operation 
for the benefit of the whole structure. These phenomena are characteristic of all specific types, and consequently the transmutation of species involves the change of a structure of co-ordinated parts into another type of organism whose parts are co-ordinated in some other way. But this is not all. It would seem that there is a tendency inherent in these organisms which assists in this transmutation. It is expressed by saying that "when one part is modified . . other parts of the organisation will be unavoidably modified." * This principle is best described as the law of correlated variation. The various manifestations of this principle are due to three causessymmetry, function, and development. It is clear that if one symmetrical organism is to be changed into another, the change of one part will necessitate the change of others also. It is equally evident that if the new organism is to be an efficient apparatus, the change in one part must be accompanied by others also. This a priori necessity is realised in the actual world. Structures which have obviously undergone modification are still characterised by symmetry of form and the efficient co-operation of parts.

As an illustration of the influence of symmetry, we may take the case of the ancon ram, in which we have a birth variation amounting to a new variety, if not to a new species. It is reasonable to suppose that in such a case pressure on one part may have modified other parts, so as to substitute one proportion of parts for another; for, as Mr. Darwin says :-

"A modification which arises during an early stage of growth tends to influence the subsequent development of the same part, as well as of other and intimately connected parts."-(The Variation. vol. ii., p. 320.)

* Darwin. The Variation. vol. ii., p. 320. 
We see an illustration of the effect of function when a new habit is adopted and a new correlation of the parts is the necessary result. Speaking of the American trotters, Mr. Lupton says :-

"Their tibire, or long bones from their stifle joints to their hocks, are unusually long as compared with an English horse, and this gives them their magnificent hind action that causes them to be such fast trotters. . . . This powerful hind gait, always present in the American trotter, is seldom manifested in English horses. . . . The incentive to their propagation in the United States has been the trotting-track, similarly as the race-course has caused the creation of the English thoroughbred."-(The Nineteenth Century. vol. xx.r., pp. 936-7.)

There is here evidently a correlated variation corresponding to the different kinds of action to which the horses arc habituated; and surely when we take the influence of the trotting track into consideration, we shall be ready to believe not simply that the American horse can trot because it has specially modified hind legs, but also because the practice of trotting has modified the organism so as to make it most efficient for that purpose.

It also follows from the idea of a structure of coordinated parts that greater use in one direction, followed by an enlargement of the parts used, will bring about a decrease of other parts which are no longer used, or not used so much as heretofore. As the amount of food which an animal can take is limited, and the consequent amount of support derived from it is limited, a great demand made by one organ or set of organs must be met at the expense of others. This law is known as the principle of "compensation of growth" and "balancement."

"As Goethe expressed it, 'In order to spend on one side, nature is forced to economise on the other side.' . . . If nourishment flows to one part or organ in excess, it rarely flows, at least in excess, to another part. Thus it is difficult to get a cow to give much milk 
and to fatten readily. The same varieties of the cabbage do not yield abundant and nutritious foliage and a copious supply of oilbearing seeds." - (Origin of Species. p. II7.)

On the other hand, when one portion of a limb is removed, the remaining portion is strengthened so as to do the additional work thrown upon it.

"According to the interesting observations of M. Sedillot, when a portion of one bone of the leg or fore-arm of an animal is removed, and is not replaced by growth, the associated bone enlarges till it attains a bulk equal to that of the two bones, of which it has to perform the functions. This is best exhibited in dogs in which the tibia has been removed; the companion bone, which is naturally almost filiform and not one-fifth the size of the other, soon acquires a size equal to, or greater than, the tibia."-(The Variation. vol. ii., p. 296.)

Thus correlated variation is the agent whereby one structure of co-ordinated parts is transformed into another structure with parts more or less otherwise co-ordinated. But there is another cause which probably is quite as efficient and far-reaching. I refer to the fact that the co-ordinated parts of the structure are the result of a process of development; and in consequence of this fact there is a close sympathy between certain associated parts, the result being that when one part is modified, other parts are unavoidably modified.

Those parts which are developed from corresponding embryonic parts-as the arm, fore-leg, and wing of different animals, or the fore and hind limbs of the same animal, parts which are at one period identical in their structure, and necessarily exposed to the same conditions - tend to vary in the same way. These parts are called homologous, and the principle which expresses the relation of one to the other is known as homology. We have three kinds of homology-serial, represented by the centipede; lateral, represented by the two corres- 
ponding sides of the human body; vertical, represented by the vertebræ of the axolotl.

"Parts which are homologous tend to vary in the same manner; and this is what might have been expected, for such parts are identical in form and structure during an early period of embryonic development, and are exposed in the egg or womb to similar conditions." -(The Variation. vol. ii., p. 322.)

That such sympathetic modifications take place by reason of an inherent principle, will be seen from the following passage, in which Sir James Paget, speaking of symmetrical disease, says :-

"A certain morbid change of structure on one side of the body is repeated in the exactly corresponding part of the other side."

He then quotes and figures a diseased lion's pelvis, from the College of Surgeons' Museum, and says of it:-

"Multiform as the pattern is in which the new bone, the product of some disease comparable with human rheumatism, is depositeda pattern more complex and irregular than the spots upon a mapthere is not one spot or line on one side which is not represented as exactly as it would be in a mirror on the other. The likeness is more than daguerreotype exactness."-(Lectures on Surgical Pathology. I853. vol.i., pp. I8-22.)

It is obvious that this principle of correlated variation is a most important factor of modification, because it extends the influence of modification beyond the part which is immediately affected; and as the different parts are associated on different principles of correlation, a very considerable change may be made in different directions throughout the whole structure.

We have now to consider in what relation this tendency to modification inherent in an organism composed of COordinated parts and produced by a process of development, stands to any causes of modification which may act upon it from without; and especially what is the relation 
between this principle and the theory of Natural Selection. We may first observe that Mr. Darwin admits that the phenomenon of correlated variation can take place apart from Natural Selection.

"We thus see that with plants many morphological changes may be attributed to the laws of growth and the interaction of parts independently of Natural Selection."-(Origin of Species. p. 175.)

Mr. Darwin also asserts that those correlated variations which are useless cannot have been produced by Natural Selection.

"I know of no case better adapted to show the importance of the laws of correlation and variation independently of utility, and therefore of Natural Selection, than that of the difference between the outer and inner flowers in some Compositous and Umbelliferous plants."--(Origin of Species. pp. I15-6.)

If this be so, it is clear that there is no department of organic life in which it is more necessary to examine the phenomena and to make ourselves quite sure as to the causes which initiate and carry out this change. If in some cases Natural Selection may have nothing to do with the phenomenon, and in other cases it cannot, we must not be too ready to identify the effect with this particular cause.

But Mr. Darwin is not content to leave the matter thus. He says much in depreciation of the principle of correlated variation. It is very curious to observe that in his work on The Variation of Animals and Plants he begins the discussion of the subject by mentioning exceptions to the principle, or at any rate cases in which the principle seems to be in abeyance.

"All the parts of the organisation are to a certain extent connected or correlated together; but the connection may be so slight that it hardly exists, as with compound animals or the buds on the same tree. Even in the higher animals various parts are not at all 
closely related, for one part may be wholly suppressed or rendered monstrous without any other part of the body being affected."- (The Variation. vol. ii., p. 3Ig.)

This looks like putting the cart before the horse. The general principle should surely be first announced, and then the exceptions or apparent exceptions should be stated. Mr. Darwin also urges the plea of ignorance in this case :-

"In cases of true correlated variation, we are sometimes able to see the nature of the connexion; but in most cases the bond is hidden from us, and certainly differs in different cases. We can seldom say which of two correlated parts first varies and induces a change in the other, or whether the two are simultaneously produced by some distinct cause." -(The Variation. vol. ii., p. 320.)

Remarks like these would in some connections require no comment. They are simply an honest expression of a present ignorance or of a very partial knowledge, and they produce the pleasing effect of suggesting the keen insight and perfect candour of the writer. But we must beware of giving such statements a different significance. Either correlated variation is a law of nature or not. If it is not, let us say so at once, and have no more to do with it. But if it is a law of nature, it will be as efficient as all other laws are; and if we do not find the results which we anticipate, we may depend upon it that the reason is either because we are looking for results which we have no right to expect, or because some other law of nature is modifying the effect of this. So, far as we are ignorant we are bound to remove that ignorance, if possible; but if not, we have no right to question the existence of a law whose action is in other connections manifest to all.

The doubts thrown upon the efficacy of the principle of correlated variation assume a new significancy when we find that Mr. Darwin introduces the principle of Natural Selection into his very definitions of correlated variation; 
as though Natural Selection were an essential factor in the process. In his Origin of Species he does this the very first time that he makes mention of correlated variation.

"I mean by this expression (correlated variation) that the whole organisation is so tied together during its growth and development, that when slight variations in any one part occur, and are accumulated through Natural Selection, other parts become modified."(Origin of Species. p. II4.)

He speaks to the same effect in The Variation of Animals and Plants:-

"Correlated variation is an important subject for us, for when one part is modified, through continued selection, either by man or under nature, other parts of the organisation will be unavoidably modified."(Vol. ii., p. 320.)

Mr. Fiske recognises the principle of correlated variation as the ally of Natural Selection. He says :-

"It is enough for the purposes of the Darwinian theory to know that they (the laws of correlated growth) exist. For, taken all together, they show that natural selection operating on even the most superficial variations is quite competent to work deep-seated changes of structure and function."-(Darwinism and other Essays. p. I7.)

And now, leaving loose definitions and curious modes of stating cases, let us ask what ground there is for attributing any influence to Natural Selection in this connection.

We are told that when one part is modified by selection, other parts of the organism will be unavoidably modified. This is true of artificial selection and may possibly be true of Natural Selection also. Assuming, for the sake of argument, that it is true, we must not be led away by this assertion to believe that correlated variation is necessarily dependent upon the initiative of the principle of selection. We have seen by Mr. Darwin's own showing that Natural Selection may not in some cases, and cannot in others, influence correlated variation. 
But if Natural Selection sometimes takes a part in this business and sometimes does not, it is obvious that it is not an essential factor; and, in short, that the modification of one part will lead to the correlated variation of other parts, whatever be the cause of the modification of the one part. Correlated variation is the ready ally of any transforming cause which may operate on a particular part; it is not, and it never ought to be represented as, the special coadjutor of Natural Selection. Even if Natural Selection did inaugurate such change, which there is some reason to doubt, it would only produce a result which is achieved by many other influences; and when it came into action it would play, after all, only a very small part in the totaiity of the effect produced.

Mr. Darwin further states that the results of correlated variation may be mastered by Natural Selection.

"These tendencies, I do not doubt, may be mastered more or less completely by Natural Selection. Thus a family of stags once existed with an antler only on one side; and if this had been of any great use to the breed, it might probably have been rendered permanent by selection."-(Origin of Species. p. II5.)

Now it is quite clear that Natural Selection did not produce this exception to the rule of correlated modification; and, as there is no reason to suppose that one antler is more useful than two, there is no kind of probability that Natural Selection should have had anything to do with rendering such a modification permanent in a race. Moreover the perpetuation or the non-perpetuation of a variation like this depends upon its being inherited by offspring. But it is probable that such an exceptional phenomenon will not be inherited, the co-ordinated structure of the race asserting itself over the non-correlated peculiarity of the individual; or, if inherited, it will tend to die out of itself, unless the variant should have the 
power of impressing its own likeness upon its offspring as some variants have. If this view can be sustained, then either the principle of correlated variation asserts itself in the first generation or after a few generations; or it is mastered by the power of the individual to impress its own likeness on offspring; but in neither of these cases has Natural Selection anything to do with the matter. In other cases Mr. Darwin asserts that, where there is an appearance of correlation, the true explanation is to be found in the sole action of Natural Selection.

"Some other correlations are apparently due to the manner in which Natural Selection can alone act. For instance, Alph. de Candolle has remarked that winged seeds are never found in fruits which do not open. I should explain this rule by the impossibility of seeds gradually becoming winged through Natural Selection, unless the capsules were open; for in this case alone could the seeds, which were a little better adapted to be wafted by the wind, gain an advantage over others less well-fitted for wide dispersal."(Origin of Species. p. II7.)

"We may often falsely attribute to correlated variation, structures which are common to whole groups of species, and which in truth are simply due to inheritance; for an ancient progenitor may have acquired through Natural Selection some one modification in structure, and, after thousands of generations, some other and independent modification; and these two modifications, having been transmitted to a whole group of descendants with diverse habits, would naturally be thought to be in some necessary manner correlated."-(Origin of Species. pp. II6-7.)

"Bronn also insists that distinct species never differ from each other in single characters, but in many parts, and he asks how it always comes that many parts of the organisation should have been modified at the same time through variation and Natural Selection. But there is no necessity for supposing that all the parts of any being have been simultaneously modified. The most striking modifications excellently adapted for some purpose might, as was formerly remarked, be acquired by successive variations, if slight, first in one part and then in another; and as they would be transmitted all together, they would appear to us as if they had been simultaneously developed."-(Origin of Species. ph. I69-170.) 
"It is not at all necessary that the several parts of the body should have simultaneously varied. Each stag presents individual differences, and in the same district those which had slightly heavier horns, or stronger necks, or stronger bodies, or were the most courageous, would secure the greater number of does, and consequently leave a greater number of offspring. The offspring would inherit, in a greater or less degree, these same qualities, would occasionally intercross with each other or with other individuals varying in some favourable manner; and of their offspring, those which were the best endowed in any respect would continue multiplying; and so onwards, always progressing, sometimes in one direction and sometimes in another, towards the present excellently co-ordinated structure of the male elk."-(The Variation. vol. ii., p. 334.)

Let us now consider what probability there is that Natural Selection, when left alone, will produce results similar to those of correlated variation. We must bear in mind that the materials on which Natural Selection acts are those variations which are necessarily associated with reproduction. Now it should be remembered that every individual variant whose individuality is the necessary result of sexual reproduction, is itself an illustration of the action of correlated variation, inasmuch as it is a structure all of whose parts are co-ordinated; so that a relative proportion is maintained between the parts, and they are able to co-operate in the production of a common work useful or necessary for the individual. Here, then, is a coordinated structure ready made, in the production of which it is fair to assume that any modification in one part has been accompanied with modifications in other associated parts. And as each organism which presents itself for selection is a co-ordinated structure, so also, if there be any truth in the principle under discussion, every transmutation must be made subject to the principle of correlated variation. And yet Mr. Darwin invites us to ignore altogether the principle of correlative variation. "It is not at all necessary that the several paits of the body should 
have simultaneously varied." But this is just what is necessary, if there is any truth in the law of correlated variation. It would be perfectly competent for any one who did not believe in the existence of this principle to argue that there is no such thing, and to maintain that it is Natural Selection and not correlated variation which produces co-ordinated structures. But to contend that the law of correlated variation can exist in nature, and to assume without proof that in certain cases it does not come into action, seems most unreasonable. The law of change in the organism is surely as permanent as the organism itself, while the modifying cause from without may vary. It is impossible to suppose that correlated variation will be suppressed for unnumbered generations in order that Natural Selection may have the field to itself. But if the principle of correlated variation is always at work, then every slight variation in one part will be accompanied by slight variations in other parts, and the choice will be between one co-ordinated structure and another. In this case, we may ask what is the precise selection-value of one of these co-ordinated structures over another? It is quite conceivable that the same swiftness in flight, the same strength in effort, the same capacity to overcome difficulty, may be manifested in a given number of individuals, no two of which have exactly the same co-ordination of parts.

But we will suppose, for the sake of argument, that individuals are born with one part which is not correlated with the rest of the structure; that one stag has a heavier head than is normal, and another a stronger neck, and another sturdier legs, it is difficult to see what the selection-value of such variants would be. Let us look at this matter from the point of view of Natural Selection and sexual selection; for the two methods are not synonymous, although 
Mr. Darwin tells us, on the same page, that "according to the doctrine that I maintain, the horns of the male elk were slowly gained by sexual selection"; and then, after describing the conflict for the females, adds that "Natural Selection would thus tend to give to the male elk its present structure."

In order to bring in the principle of Natural Selection, we must assume that the variants produced by sexual reproduction are not necessarily organisms composed of co-ordinated parts; that Natural Selection will choose out here a part in one individual and there a part in another individual; that these will survive and intermarry, and thus two elements necessary for the production of a co-ordinated structure, similar to that produced by correlated variation, will be secured. Thus, to take Mr. Darwin's own illustration, Natural Selection will choose out the larger antler of one individual and the stronger neck of another. This idea is full of difficulty. If there is anything in the principle of correlated variation, as applied to individuals, the animal with a larger antler will either have the stronger neck at birth or the neck, compelled to bear the larger weight of the head, will increase in strength through the greater demands made upon it, so that the correlation will be secured before the age of sexual maturity arrives.

If this were not so, it must be because the variation was so slight that any increase of strength in the neck was not required. But if so, Natural Selection could not select such an individual, because it is inconceivable that such a slight difference could make the difference between life and death. But, on the other hand, if the head were made much heavier and the neck were not strengthened, this would be a positive disadvantage to the animal, and it would be apt to succumb in the struggle for existence. 
On the other hand, the stronger neck by itself would supply a variation not wanted, and therefore useless.

Again, if we assume that the heavier head was the sole modification in one or in a few individuals, and that the stronger neck was the sole modification in another, then, in order that these two individuals-or, if you will, a small number of such individuals-should intermarry, it is necessary that they alone should survive, and that the others should be all destroyed. That is to say, the injurious variation of the one and the useless variation of the other must triumph over the other members of the group which were perfectly adapted to the conditions in which they lived. Such selection might be possible under the type-producing selection of man, but not through the action of Natural Selection.

But Mr. Darwin says that the antler of the Irish elk has been developed through Sexual Selection. The first stage is thus described:-

"Each stag presents individual differences, and in the same district those which had slightly heavier horns, or stronger necks, or stronger bodies, or were the most courageous, would secure the greatest number of does."

Now, first of all, these differences cannot be so very slight, since they are supposed to secure the victory to their fortunate possessors. In the second place, these variants have to compete with the most courageous; and nothing is said about the structure of that combatant. I should be inclined to say that courage would count for more than a slightly heavier head or stronger neck. In the third place, what conceivable advantage could come from a heavier head associated with a neck which had not proportionate strength to use that head as a batteringram? The stronger neck might be useful by itself, but it certainly would be more useful if associated with a 
heavier head. A stronger body would avail little to assist its owner, unless the head and neck were also specially developed, though it might cause its owner to protract its defence. Again, are we to suppose that all the heavy heads, and all the strong necks, and all the big bodies compete with those which vary like themselves, and then with those who differ from themselves, somewhat on the same principle as the members of different clubs are chosen to compete in a tennis tournament? And if they did, can you speak with confidence as to which shall prove to be the winner? Supposing that you were a sporting character; on which would you bet,- the slightly stronger head, or the slightly stronger neck, or the more slightly stalwart limbs, or the nondescript of whom we know nothing save his pluck? I venture to think that it would be a game of pure chance. "The offspring of the victor would inherit these same qualities." And yet we must remember that in the harem there are the mothers to be taken into account, and there is also the average of the race to be reckoned with; and it is by no manner of means clear that a slight, abnormal modification, such as we are considering now, will be inherited.

The next stage is the intercrossing. But how can that take place? Only in this way; that the heavier heads should triumph over the stronger necks in one generation, and the stronger necks triumph over the heavier heads in the next generation. But why should this be, except by the merest accident, on which no theory ought to count? And yet it is assumed that this sort of thing can go on till these scattered variations in many organisms can be gathered into a new co-ordinated structure,"always progressing, sometimes in one direction and sometimes in anothcr, towards the present excellently co-ordinated structure of the male elk"! 
It follows, then, from what has been said, that the principle of correlated variation obtains in nature; that it will act, whatever cause produces the initial modification in one part; that Natural Selection cannot act in connection with this principle; and that neither Natural Selection nor Sexual Selection can of itself evolve results similar to those produced by correlated variation. We have, then, in the principle we are considering, a very powerful agent in the transmutation of species; but one which affords no reason for supposing that the transmutation of one structure of correlated parts into another structure of parts differently correlated can be brought about through the action of Natural Selection. 


\section{CHAPTER V.}

\section{PURE DARWINISM.}

\section{(a) variations Sometimes ASSOCiAted With SEXUAi.}

\section{REPRODUCTION.}

"Out of the deep, my child, out of the deep,

Through all this changing world of changeless law And every phase of ever-heightening life, And nine long months of ante-natal gloom With this last moon, this crescent, her dark orb Touched with earth's light-thou comest, darling boy!"

-Tennyson. De Profundis.

THE argument for pure Darwinism, which asserts that Natural Selection is the sole cause of the transmutation of species, is based upon the belief that no modification of "the body" of an individual can be inherited; that congenital or birth variations can be inherited, and that Natural Selection will choose out the favourable variations which occur. Now in order that this argument should have any validity, it must be tacitly assumed that there are no birth variations, save those which are necessarily and inevitably associated with sexual reproduction; that these variations will not resemble one another through the action of a definite cause; and that there is in nature no other way of isolating similar variants for breeding purposes than by Natural Selection. In this and the following chapter I shall show that these tacit assumptions are not in accordance with the facts of the case. 
To prove that all birth variations are not those necessarily and inevitably associated with sexual reproduction, we may first adduce the fact that the members of different species unite to produce offspring which more or less partakes of the likeness of both parents. "If," says M. Flourens, "species could change, hybridisation would assuredly be the most direct and efficacious means of bringing about this change.* . . . If the hybrids could perpetuate themselves indefinitely, hybrids would form species, aś many new species as there were hybrids." $\dagger$ But he contends that "hybridisation is not in any case nor in any sense, neither for vegetables or animals, a source of new species." + Three arguments are adduced in favour of this assertion. (I) It is said that individuals of the same species and varieties of the same species, are perfectly fertile inter se. (2) It is contended that the offspring of different species have a limited fertility. (3) It is maintained that the offspring of hybrids are either infertile or lapse into one or other of the parental forms.

Now, we may grant the truth of these assertions, so far as to admit that these phenomena do sometimes take place. But it does not therefore follow that there is always this fertility between individuals of the same species and the varieties of the same species; that there is always a limited fertility between the offspring of different species; or that the continuous fertility of hybrids which maintain their hybrid organisation is always impossible in nature.

Neither individuals nor varieties of the same species are always fertile inter se.

"It is impossible to resist the evidence of the existence of a certain amount of sterility (in the varieties of the same species)

* Examen du Livre de M. Darwin sur l'Origine des Espèces. p. $9 I$. +1bid. p. g2. $\$ p . I 17$. 
in the few following cases, which I will briefly abstract. The evidence is at least as good as that from which we believe in the sterility of a multitude of species. The evidence is also derived from hostile witnesses, who in all other cases consider fertility and sterility as safe criterions of specific distinction."-(Origin of Species. p. 257.)

"The yellow and white varieties (of Verbascum), when crossed, produce less seed than the similarly coloured varieties of the same species. . . The blue and red varieties of the pimpernel are absolutely sterile together, while each is perfectly fertile within itself."-(Journal of Linnean Society. Zoology. vol. xix., p. 359).

"It is most instructive to compare . . . the evidence advanced by our best botanists on the question whether certain doubtful forms should be ranked as species or varieties with the evidence from fertility adduced by different hybridisers, or by the same observer from experiments made during different years. It can thus be shown that neither sterility nor fertility affords any certain distinction between species and varieties. The evidence from this source graduates away, and is doubtful in the same degree as is the evidence derived from other constitutional and structural differences."-(Origin of Species. p. 237.)

On the other hand, offspring of different species are sometimes fertile inter se.

"Some species have a remarkable power of crossing with other species." . . . "The degree of fertility both of first crosses and of hybrids graduates from zero to perfect fertility."-(Origin of Species. pp. 244, 24I.)

"Kölreuter makes the rule universal; but then he cuts the knot, for, in ten cases in which he found two forms, considered by most authors as distinct species, quite fertile together, he unhesitatingly ranks them as varieties." . . "If two forms, hitherto reputed to be varieties, be found in any degree sterile together, they are at once ranked by most naturalists as species. For instance, the red and blue pimpernel, which are considered by most botanists as varieties, are said by Gärtner to be quite sterile when crossed, and he consequently ranks them as undoubted species. If we thus argue in a circle, the fertility of all varieties produced under nature will assuredly have to be granted."-(Origin of Species. pp. 236, 256.) 


\section{Distinct genera are fertile inter se.}

"The hybrids from the common and Chinese geese (A. cygnoides) - species which are so different that they are generally ranked in distinct genera-have often bred in this country with either pure parent, and, in one single instance, they have bred inter se. This was effected by Mr. Eyton, who raised two hybrids from the same parents, but from different hatches; and from these two birds he raised no less than eight hybrids (grandchildren of the pure geese) from one nest. In India, however, these cross-bred geese must be far more fertile; for I am assured by two eminently capable judgesnamely, Mr. Blyth and Captain Hutton-that whole flocks of these crossed geese are kept in various parts of the country; and as they are kept for profit, where neither pure parent-species exists, they must certainly be highly or perfectly fertile."-(Origin of Species. p. 240.)

"Dean Herbert's experiments are most instructive in this respect, since they show that in a considerable number of large genera, hybrids are perfectly fertile, and not unfrequently more fertile than the parents, while in many cases they produce quite fertile offspring; and he concludes 'that the sterility or fertility of the offspring does not depend upon original diversity of stock; and that, if two species are to be united in a scientific arrangement on account of a fertile issue, the botanist must give up his specific distinctions generally, and entrench himself within genera.' He showed that many very distinct species of crimum, hippeastrum, gladiolus, pelargonium, calceolaria, and many other genera were quite fertile when crossed, and often produced offspring which could be propagated indefinitely, and have thus formed valuable garden flowers; while other species, more alike externally, either could not be crossed at all, or produced offspring which were sterile; and he thence concludes 'that the fertility of the hybrid or mixed offspring depends more upon the constitutional than the closer botanical affinities of the parents.'" -(Wallace. Fortnightly Reviere. vol.xl., N.S., p. 3II.)

\section{Distinct families are fertile inter se.}

"The mere fact that not only animals of distinct genera, but even those classed in distinct families-as the pheasant and black grouse-sometimes produce hybrid offspring in a state of nature, is itself an argument against there being any constant infertility between the most closely allied species, since if that were the case we should expect the infertility to increase steadily with remoteness of descent till, when we came to family distinctions, absolute sterility should be invariable."-(Wallace. Fortnightly Review. vol. xl., N.S., p. 3II.) 
We have now to consider the most important part of this question,- Are the offspring of hybrids continuously fertile?

" 'A hybrid plant,' says M. Naudin, 'is an individual in which are found blended, in an artificial union, two natures which are mutually opposed, and are continually striving to disengage themselves from one another." "- (Apud P. Flourens. Examen du Livre de M. Darain. p. 97.)

This assertion is a generalisation, based upon a certain amount of actual experience. It cannot be reasonably doubted that, when a hybrid race has been produced, it has often ceased to exist either through reversion to one of the parent forms or through inability to continuous fertility on the part of the race. And there need be no wonder that it is so! For we know that when members of the same species are submitted to new conditions, the effect is very varied on the constitution, especially with reference to the reproductive organs. But the question which we have now to consider is not whether the offspring of some hybrids are sometimes infertile or not continuously fertile, but whether the offspring of some hybrids are continuously fertile. The following evidence goes to show that the hybrid offspring of some species maintain at once their hybridity and their fertility.

"A most attractive group of birds has just been placed by Professor Flower in the great hall of the Natural History Museum, at South Kensington. The case is intended to illustrate the hybridisation of species in a state of nature, and the species selected are the hooded and carrion crows (Corvus comix and C. corone) and the European and Asiatic goldfinches (Carduelis elegans and C.orientalis). The series of these birds has been presented to the Museum by Mr. Henry Seebohm, who procured the specimens himself during his travels in Siberia. The case of the crows is one of the few instances known of actual wild hybridisation, though many more are suspected, especially among the game birds. It is certain, however, that wherever the colonies of hooded crows meet the carrion crows 
throughout the Palæartic region, the two species interbreed freely, and the result is shown in the young, the gray saddle-back of the hooded crow exhibiting a considerable admixture of black, owing to the strain of $C$. corone in the parentage. The case of the goldfinches is not quite so completely proved, but is apparently a parallel instance of hybridisation."-(Nature. vol. xx: $x$., p. 15.)

"The hare (Lepus timidus) is assuredly of a distinct species from the rabbit (Lepus cuniculus). So distinct are these species, that any classification which should range them as one, would violate every accepted principle. The hare is solitary, the rabbit gregarious; the hare lives on the surface of the earth, the rabbit burrows under the surface; the hare makes her home among the bushes, the rabbit makes a sort of nest for her young in her burrow-keeping them there till they are weaned; the hare has reddish-brown flesh, the rabbit white flesh; while the odour exhaled by each and the flavour of each are unmistakably different. The hare has many anatomical characters differing from those of the rabbit-such as greater length and strength of the hind legs, larger body, shorter intestine, thicker skin, firmer hair, and different colour. The hare breeds only twice or thrice a year, and at each litter has only two or four; the rabbit will breed eight times a year, and each time has four, six, seven, and even eight young ones. Finally, the two are violent foes; the rabbits always destroy the hares, and all sportsmen are aware that if the rabbits be suffered to multiply on an estate, there will be small chance of hares. Nevertheless, between species so distinct as these, a new hybrid race has been reared by M. Rouy [sic], of Angoulême, who each year sends to market upwards of a thousand of his Leporides, as he calls them. His object was primarily commercial, not scientific. His experiments, extending from 1847 to the present time (I860), have not only been of great commercial value-introducing a new and valuable breed-but have excited the attention of scientific men, who are now availing themselves of his skill and experience to help them in the solution of minor problems. It is enough to note here that these hybrids of the hare and the rabbit are fertile, not only with either hares or rabbits, but with each other. Thirteen generations have already been enumerated, and the last remains so vigorous that no cessation whatever is to be anticipated. In presence of this case (and others, though less striking, might be named) there is but one alternative; either we must declare that rabbits and hares form one and the same species-which is absurd-or we must admit that new types may be formed by the union of two existing types. . . If the doctrine of Fixity of Species acknowledges the touchstone of hybridity, the fate of the doctrine is settled for ever."-(George Henry Lewes. Studies in Animal Life. pp. r6I-3.) 
" . . The hare-rabbit (Lepus Darwinii), the bastard of our indigenous hare and rabbit . . . many generations of which have been bred in France, since 1850, for gastronomic purposes. I myself possess such hybrids, the products of pure in-breeding,that is, both parents of which are themselves hybrids by a harefather and a rabbit-mother. I possess them through the kindness of Professor Conrad, who has repeatedly made these experiments in breeding on his estate. The half-blood hybrid thus bred, which I name in honour of Darwin, appears to propagate itself through many generations by pure in-breeding, just as well as any genuine species. Although, on the whole, it is more like its mother (rabbit), still in the formation of the ears and of the hind legs it possesses distinct qualities of its father (hare). Its flesh has an excellent taste, rather resembling that of a hare, though the colour is more like that of a rabbit."-(Haeckel. The History of Creation. vol. i., 3rd edition, pp. $147-8$.)

"M. Roux, of Angoulême, finds that he can cross hares and rabbits to any extent, and has thus, by breeding Leporides, established a new and lucrative department in agriculture. For a full account of these experiments, the reader may consult Brown Sequard's Journal de la Physiologie, vol. ii., pp. 374-383."(Chambers Encyclopaedia. First edition. Art: Hybrids.)

After such emphatic evidence, it is startling to find that these apparently well authenticated facts have been called in question by MM. Blanchard and Flourens.

"More than a century ago, an Italian experimentalist, Amoretti, announced the reproduction of offspring from the male rabbit and the female hare. One remained very incredulous. Numerous attempts to unite the male rabbit and the female hare, and the male hare and the female rabbit, made by persons very familiar with the habits of these animals, had not succeeded. Some years ago, however, it was shown that the union of the male hare and of the female rabbit was not only possible, but fertile. The product, to which the name of Leporides has been given, and which presented a mixture of the characteristics of father and mother, with some predominance of those of the rabbit, would preserve the power of reproduction. In the second generation, the characteristic marks of the hare would be already much effaced; in the third generation, one would look in vain for a trace of them-the Leporides would no longer be distinguishable from ordinary rabbits. The zoologists have had little opportunity of studying the Leporides. It is therefore with caution that we cite the facts recorded by observers. In every statement of the case these facts are of considerable importance in the 
question which we are considering, for it is now certain that no one has succeeded, in spite of great efforts, in creating a persistent type, intermediate between the hare and the rabbit."-(Blanchard. La Vie des Êtres Animés. I888, p. 23I.)

"Nothing of what has been said of the pretended half-breeds of the hare and the rabbit has been proved."-(Flourens. p. rog.)

A similar difference of opinion is found in connection with the hybrid offspring of the dog and jackal.

"Experiments, carefully conducted in the Zoological Garden of the Agricultural Institute of the University of Halle, since the year I $88 \mathrm{I}$, have proved that hybrid's between the jackal and the clomestic dog are capable of reproduction, not merely with individuals of pure blood, but among themselves."-(Scientific News. Feb. I7, I888, p. 157. )

But this, again, is denied by M. Flourens, who bases his statement on actual experiment, conducted by himself. He asserts that the hybrid of the jackal and of the dog was as much a jackal as a dog; but that when the hybrids bred with one another, there was less and less of the jackal until, in the fourth generation, the offspring altogether resembled dogs.**

It is quite conceivable that different experiments, possibly conducted under different conditions, may have different issues. But this discrepancy does not affect the argument, because we are quite prepared to find that species often resist modification, and we are not contending that all hybrid offspring are continuously fertile inter se, but that some are; and if the phenomenon only occurred now and then, it would afford a means of producing the transmutation of species apart from Natural Selection.

Another illustration of occasional birth variation is to be found in those cases in which an animal is born which differs from its parents sufficiently to constitute it a new

* Examen du Livre de M. Darvin. pp. IIO-III. 
variety or even a new species, and which is endowed with the power of impressing its likeness upon its offspring. We may designate this phenomenon as the prepotency of the great variant. The ancon ram, the japanned or blackshouldered peacock, and the Mauchamp merino lamb have appeared suddenly and have manifested this remarkable characteristic.

"Towards the end of the last century, Seth Wight possessed a small farm on the banks of the Charles River, in the town of Dover and the state of Massachusetts, about sixteen miles from Boston, and kept a small flock composed of fifteen ewes and one ram. In the year 179I, one of the ewes produced a lamb of singular appearance. Hence proceeded a strongly marked variety in this species of animals, before unknown in the world. The chief characteristics of this breed are the length of the back, the shortness of the legs, and more especially the crookedness of the forelegs, which causes them to appear like elbows and to turn their feet inward while walking. It is also distinguished by the greater looseness of the articulations and the diminished size of the bones, and the comparatively flabby condition of the sub-scapularic muscles. To this variety, the name of the otter breed was given, probably from a real or imaginary resemblance to that animal in the shortness of the legs and the length of the back. Dr. Shattuck, who dissected a specimen, gave the breed the name of Ancon (Greek=elbow), on account of the elbow-like projection of the crooked forelegs. When this variety first appeared, it seems to have been at once obvious that it would be well, if possible, to have a breed of such animals. They could neither run nor jump like other sheep. Hence the breed of ancons was expected to be a valuable acquisition on account of their being less able than others to get over fences. In New England, beyond which they have rarely migrated, there are few commons, no hedges, no shepherds, and no dogs whose business it was to watch flocks. The small freehold estates were enclosed with fences of wood and stone, frequently too low to prevent active sheep from breaking out of pasture into grounds under cultivation. Hopes were entertained that this evil would be remedied by the ancon breed of sheep. Hence, by the advice of some of his neighbours, Seth Wight killed his former ram and kept the young one for breeding. In the first season, one or two lambs were yeaned in his likeness; in the fol. lowing years a number more. The singularity of form seems to be confined in the blood. When both parents are of the otter or ancon breed, the descendants inherit their peculiar appearance and proportions of form. I have learned of but one questionable case of 
a contrary nature. When the parents are one ancon and one common form, the offspring is wholly one or the other without blending -this even extends to twins. The ancon breed arrives somewhat later at maturity than the common breed. The ancons have been observed to keep together, separating themselves from the rest of the flock when put into enclosures with other sheep."-(Colonel David Humphreys, F.R.S. Phil. Trans. of the Royal Society at London, for the year I813. part i., art xi.: On a New Variety in the Breeds of Sheep, in a letter to Sir Joseph Banks.)

In the case of the japanned peacock, the prepotent power seems to be still greater.

"There is one strange fact with respect to the peacock, namely, the occasional appearance in England of the 'japanned' or 'blackshouldered' kind. This form has lately been named, on the high authority of Mr. Sclater, as a distinct species, viz., Pavo nigripennis. . . . Sir R. Heron states that this breed suddenly appeared, within his memory, in Lord Brownlow's large stock of pied, white, and common peacocks. The same thing occurred in Sir J. Trevelyan's flock, composed entirely of the common kind, and in Mr. Thornton's stock of common and pied peacocks." . . . These japanned birds, though appearing suddenly in flocks of the common kind, propagate their kind quite truly. "It is remarkable that in the flocks of Sir J. Trevelyan and Mr. Thornton, the black-shouldered kind, though a smaller and weaker bird, increased to the extinction of the previously existing breed."-(The Variation. vol. i., pp. 290-I.)

"A merino ram lamb (was produced) on the Mauchamp farm, in I 828 , which was remarkable for its long, smooth, straight and silky wool. By the year 1833 , M. Graux had raised rams enough to serve his whole flock, and after a few more years he was able to sell stock of his new breed."-(The Variation. vol. i., p. roo.)

But if it had not been for the experience gained by the domestication of animals, we might not have been bold enough to have conjectured that such a change as this could have taken place. We should not have believed that the ancon ram had appeared as it did if we had not had actual testimony on the subject.

"If the Mauchamp and ancon breeds had originated a century or two ago, we should have had no record of their birth ; and many a naturalist would no doubt have insisted-especially in the case 
of the Mauchamp race-that they had each descended from, or been crossed with, some unknown aboriginal form."-(The Variation. vol.i., p. IOI.)

But having this experience of the sudden appearance and prepotent influence of the ancon sheep, it seems reasonable to suppose that a similar modification, which occurs in connection with the domestic dog, may have arisen in the same way.

"Some of the peculiarities characteristic of the several breeds of the dog have probably arisen suddenly; . . . for instance, the shape of the legs and body in the turnspit of Europe and India." -(The Variation. vol.i., p. 38.)

The question now arises, whether we may not carry the conjecture a step further. Inasmuch as we know that the ancon ram arose suddenly under domestication, and therefore infer that the turnspit dog may have done so too, shall we not also be justified in surmising that a similar emergence of a new variety may have occurred in nature, and might we not thus account for the fact that we have ancon jaguars in Paraguay and ancon pariah dogs in India?*

But here we are at once met with a demurrer. It is said that "we have no evidence of the appearance, or at least, of the continued procreation, under nature, of abrupt modifications of structure." $\dagger$

But in reply it may be said that we have experience, in the case of wild animals, of what looks very much like "the sudden appearance and continued procreation of abrupt modifications." Witness the cases of the onehorned stag and the spike-horned buck.

"From Hofacker's account it appears that a one-horned stag was seen in I78 $\mathrm{I}$ in a forest in Germany; in 1788 two ; and afterwards, from year to year, many were observed with only one horn on the right side of the head."-(The Variation. vol. ii., p. I2.)

* Thie Variation. vol. i., p. I7. +Ibid. vol. ii., p. 414. 
"A writer, in an excellent American journal, says that he has hunted for the last twenty-one years in the Adirondacks, where the Cervnes virginianus abounds. About fourteen years ago, he first heard of spike-horn bucks. These became from year to year more common. About five years ago he shot one, and afterwards another, and now they are frequently killed. 'The spike-horn differs greatly' from the common antler of the $C$. virginianus. It consists of a single spike, more slender than the antler, and scarcely half so long, projecting forward from the brow and terminating in a very sharp point." "-(Descent of Man. and ed., ph. 5II-2.)

In face of these facts, it is difficult to understand the assertion that "we have no evidence of the appearance, or at least of the procreation, under nature, of abrupt modifications of structure." In face of such facts one cannot understand that there can be much validity in the "various general reasons" which "could be assigned against such a belief ;" * for it must be hard work to persuade us not to believe in what is known actually to have occurred. It is said that "without separation a single monstrous variation would almost certainly be soon obliterated by crossing." $\dagger$

"According to our experience, abrupt and strongly marked variations occur in our domesticated productions, singly and at rather long intervals of time. If such occurred under nature, they would be liable, as formerly explained, to be lost by accidental causes of destruction and by subsequent intercrossing; and so it is known to be under domestication, unless abrupt variations of this kind are specially preserved and separated by the care of man."-'Origin of Species. p. 202.)

This argument utterly ignores the lesson taught by the ancon ram, viz. : that in some cases the principle of prepotency is amply sufficient to prevent the regression to mediocrity. But the fact of the appearance and the procreation of the great variant in nature being admitted, it is attempted to explain the phenomenon on different grounds

* The Variation. vol. ii., p. 4I4. + Ibid. 
than those derived from the analogy of domestic animals. In the first place, it is said that

"The spike-horn is a more effective weapon than the common antler. With this advantage, the spike-horn bucks are gaining upon the common bucks, and may in time entirely supersede them in the Adirondacks. Undoubtedly the first spike-horn buck was merely an accidental freak of nature. But his spike-horns gave him an advantage, and enabled him to propagate his peculiarity. His descendants, having a like advantage, have propagated the peculiarity in a constantly increasing ratio, till they are slowly crowding the antlered deer from the region they inhabit."-(The American Naturalist. Dec., I869, p. 552.-Apud Descent of Man. and ed., p. 513.)

Now if we admit this to be the true explanation, so far as the fact that the spike-horn is a more effective weapon of offence and defence than the antler,-if we admit that the spike-horned buck would win for himself as many does as he chose to contend for, yet what would this victory avail, if the spike-horn were only "an accidental freak of nature" with no prepotent power to reproduce itself? But are we quite certain that a spike-horned buck would necessarily gain the victory over the antlered buck? Often appearances, and what seem to be natural inferences from appearances, prove quite misleading.

"The slightly curved horns of the Oryx lencoryx are directed backwards, and are of such length that their points reach beyond the middle of the back, over which they extend in almost parallel lines. Thus they seem singularly ill-fitted for fighting; but Mr. Bartlett informs me that when two of these animals prepare for battle, they kneel down, with their heads between their forelegs, and in this attitude the horns stand nearly parallel and close to the ground, with the points directed forwards and a little upwards. The combatants then gradually approach each other, and each endeavours to get the upturned points under the body of the other; if one succeeds in doing this, he suddenly springs up, throwing up his head at the same time, and can thus wound or perhaps even transfix his antagonist. Both animals always kneel down, so as to guard as far as possible against this manœuvre. It has been recorded that one of these antelopes has used his horns with effect even against a lion."-(Descent of Man. 2nd ed., p.509.) 
On the same principle of arguing from appearance, M. Bailly came to the conclusion that antlers were more injurious than useful. But Mr. McNeill, of Colonsay, speaking from personal observation, says that,-

"The brow antlers, from inclining downwards, are a great protection to the forehead, and their points are likewise used in attack.' Sir Philip Egerton also informs me, both as to red deer and fallow deer, that 'in fighting, they suddenly dash together, and getting their horns fixed against each other's bodies, a desperate struggle ensues. When one is at last forced to yield and turn round, the victor endeavours to plunge his brow antlers into his defeated foe." (Descent of Man. and ed., pp.510-1I.)

It is, however, urged by Mr. Darwin that the animal suddenly endowed with a new implement of offence and defence would gain advantage from the fact of the novelty.

"A new mode of attack with new weapons might be a great advantage, as shown by the case of the Ovis cycloceros, who thus conquered a domestic ram famous for its fighting power."(Descent of Man. and ed., p.513.)

But whatever be the truth, on this point, of the relative efficacy of the spike-horn and the antler as weapons of offence and defence-which could only be decided by observing contests taking place in nature-our present argument is not at all affected by the result. For, if we may be allowed once more to walk by the light shed upon the subject by the experience connected with domestication, it is not at all necessary that the spike-horn should be able to gain a victory over the antlered deer in order to impress its own likeness on posterity. In proof of this we have only to cite the case of the japanned peacock, which, though a smaller and weaker bird, always beaten in battle, increased to the extinction of the previously existing breed.

Again, it is said that the spike-horn "gives a considerable advantage to its possessor over the common buck" 
in the struggle for existence, "enabling him to run more swiftly through the thick woods and underbrush. Every hunter knows that does and yearling bucks run much more rapidly than the large bucks when armed with their cumbrous antlers."* The implication here is that the race establishes itself through the advantage of the spikehorned over the antlered deer in the struggle for existence. The only argument in confirmation of this was that the does and the yearling bucks ran more quickly through the woods. But is not this because their stature is less and because they can stoop more readily and run underneath the boughs? The older and therefore taller bucks appear to find their antlers of considerable use according to the following evidence:-

"At a recent meeting of the Wellington Philosophical Society, Mr. J. W. Fortescue spoke of the rapid increase of deer that have been acclimated in the New Zealand mountains. Having had special facilities for observing these creatures, he proceeded to state some interesting facts as to their habits. At the close of his address, Sir James Hector asked Mr. Fortescue, as an expert on the subject, whether the chief use of the antlers was not so much for fighting as for facilitating the progress of the stag through dense woods. He had considerable experience with the wapiti, in North America, and found that, by throwing up the head, thereby placing the horns along the back, the animals were enabled to go forward with great rapidity and follow the hinds. He asked this, as it had been stated at a previous meeting of the Society, that the antlers tended to entangle the deer. Mr. Fortescue said that Sir James Hector was quite correct in stating that the antlers assisted the stags in penetrating dense forests. Mr. Higginson also bore out this statement from his experience in India."-(Scientific Nerws. Oct.12, I888, p.388.)

It follows from what has been said, that there is no valid reason for doubting that the same effect, the appearance, and the continued procreation of an abrupt modification of structure, has arisen from the same cause in nature 
as that which has produced it in connection with domestication, viz.: the principle of prepotency. As this is amply sufficient to account for the facts there is no need to suppose that any other principle has been at work. But if this is so, a new variety has suddenly appeared, and a process of transforming one species into another has been discovered in nature, which may reasonably be supposed to have been one of the methods by which the transmutation of species has been brought about.

It would seem that this prepotent power is often exhibited for many generations in succession, even when the variation is not so great as to constitute a new species or variety.

"It would appear that in certain families some one ancestor, and after him others in the same family, must have had great power in transmitting their likeness through the male line, for we cannot otherwise understand how the same features should so often be transmitted after marriages with various females, as has been the case with the Austrian Emperors, and as, according to Niebuhr, formerly occurred in certain Roman families with their mental qualities."-(The Variation. vol. ii., p. 65.)

In accordance with this principle, Shakespeare represents the Duchess of York speaking to her husband of their son, and saying :-

" $\mathrm{He}$ is as like thee as a man may be, Not like to me, or any of my kin."

$$
\text { -(Richard II. Act v., sc. 2.) }
$$

A third kind of occasional birth variation, if indeed it can be called occasional, which differs essentially from variations inevitably associated with sexual reproduction, is to be found in the case where the same cause has produced the same effect upon offspring before birth.

It was the opinion of $\mathrm{Mr}$. Darwin that outward conditions and habits of life may act upon an organism in two 
ways. They may either modify the body of the individual or the sexual elements.

"Some variations are induced by the direct action of the surrounding conditions on the whole organisation, or on certain parts alone, and other variations are induced indirectly through the reproductive system being affected in the same manner as is so common with organic beings when removed from their natural conditions. The causes which induce variability act on the mature organism, on the embryo, and, as we have good reason to believe, on both sexual elements before impregnation has been effected." - (The Variation. vol. ii., p. 270.)

Mr. Darwin argues from the fact that changed conditions produce sterility; that it is therefore probable that changed conditions will modify offspring.

"Slight changes in the conditions of life have a remarkable power in causing a greater or less degree of sterility. Hence it seems not improbable that beings generated through a system so easily affected should themselves be affected. . . . On the whole, it is probable that any cause affecting the organs of reproduction would likewise affect their product-that is, the offspring thus generated."-(The Variation. vol. ii., p. 268.)

Mr. Darwin also contends that, if such cause acted at all, it would influence all subjected to its influence in the same definite manner.

"The following case, which has been carefully examined and communicated to me by Dr. William Ogle, is highly instructive. Two girls, born as twins, and in all respects extremely alike, had their little fingers on both hands crooked; and in both children the second bicuspid tooth in the upper jaw, of the second dentition, was misplaced; for these teeth, instead of standing in a line with the others, grew from the roof of the mouth behind the first bicuspids. Neither the parents nor any other member of the family had exhibited any similar peculiarity. Now, as both these children were affected in exactly the same manner by both deviations of structure, the idea of accident is at once excluded; and we are compelled to admit that there must have existed some precise and sufficient cause which, if it had occurred a hundred times, would have affected a hundred children."-(The Variation. vol. ii., p. 253.) 
And clearly such a contention is a perfectly logical one. For the object of selection is to secure the marriage of similar variants; but if all vary in the same way, it is obvious that the most promiscuous marriage will suffice to reproduce the variations common to both parents. What Mr. Darwin says of the direct action of changed conditions must, according to the logic of the theory, be true also of the effect produced through the sexual elements.

"There can be little doubt that the tendency to vary in the same manner has often been so strong that all the individuals of the same species have been similarly modified without the aid of any form of selection."-(Origin of Species. p. 72.)

"When any deviation in structure or constitution is common to both parents, this is often transmitted in an augmented degree to the offspring."-(Origin of Species. p. 237.)

Some years back, Mr. Francis Galton published in the Contemporary Review,* an article entitled "A Theory of Heredity," which has often been credited with anticipating the theory of Dr. Weismann, and is, I believe, generally regarded as favourable to the doctrine of Natural Selection. In this Essay, he designates "the sum total of the contents of the newly fertilised ovum," by the term "stirp" (stirpes $=\mathrm{a}$ root). He asserts that the stirp contains a much greater number of germs than achieve development in the body of the individual. These residual germs retain their vitality, and contribute to form the stirp of the descendants. As fertility resides somewhere, it must have been vested in the non-developed residue of the stirp, or rather in its progeny and representatives (whatever, or however numerous, they may be) at the time when the individual has reached adult life. Mr. Galton 
asserts that when the germinal matter (of the residuum of the stirp) is everywhere affected by the same conditions, it would be everywhere affected in the same way; that, where the sexual elements are thus modified, they produce corresponding modifications in the offspring; and last, but not least in importance, that the modification in the parents' organisms and sexual elements takes place at the same time; and sometimes the sexual elements are modified when the body is not. Here, then, we have a modification taking place before birth in all the individuals subjected to a given influence-and a modification which can be inherited by offspring. Whether the modifications of the body can be inherited or not, is a small matter, if the sexual elements are similarly modified and reproduce these modifications in offspring. These similar variations will be reproduced and fixed in the race without the intervention of the principle of selection.

Very similar to the theory of Mr. Galton is Dr. Weismann's doctrine of the "Continuity of the Germ Plasm," at which the author has laboured now for many years, during which the theory has undergone considerable modification. The germ plasm is the name given to the contents of the germ cells. In sexual reproduction, the germ cells are supposed to produce the cells which go to build up the body of the offspring, and therefore called somatic (body) cells. In doing this, it is possible that all the contents of the germ cells should be used up in producing the body cells, and that then the body cells should produce the germ cells de novo. Or it is possible that only a portion of the contents of the germ cells should be used up, and that what remains should form the germ cells of future generations. The first of these conceivable methods Dr. Weismann designates as the cyclical development of the germ plasm; the latter he 
denotes as the continuity of the germ plasm; and he chooses the latter alternative as the basis of his theory.

This theory is supposed to afford a great support to the doctrine of Pure Darwinism; and it does this by assuming that the only modification which this continuous germ plasm undergoes is due to sexual reproduction through the union of the sexual elements of two individuals. Dr. Weismann says :-

"I regard this combination as the cause of hereditary individual characters, and I believe that the production of such characters is the true significance of amphigonic (sexual) reproduction. The object of this process is to create those individual differences which form the material out of which Natural Selection produces new species."-(Essays upon Heredity. Ist ed., vol.i., p. 272.)

Mr. Osborn regards Dr. Weismann's theory as supporting the theory of Pure Darwinism. He says :-

"This (theory of the continuity of the germ plasm) does not seem to be necessarily antagonistic to the Lamarckian idea, for we can conceive that the germ plasm is continuous and still influenced in definite ways by the body which contains it. Yet Weismann holds that this is not the case; that no special or local life-changes in the body can in any way reach or influence the germ cells in such a manner as to be inherited. This view throws the whole burden of evolution upon the Natural Selection or survival of those individuals which possess, by blending or otherwise, that germ plasm which represents the bodily constitution and structure best fitted to environment."-(Henry Fairfield Osborn. Evolution and Heredity. Apud Biological Lectures, delivered at Wood's Holl, I890. p. 139.)

Mr. Romanes takes the same view as to the significancy of the theory of the continuity of the germ plasm.

"Now it is evident that, according to this theory, Natural Selection is constituted the one and only cause of organic evolution; and for this reason, the followers of Weismann are in the habit of calling his doctrine 'Pure Darwinism,' inasmuch as, without invoking any aid from the Lamarckian principles above described, it constitutes the Darwinian principle of Natural Selection the sole, and not merely as he said the 'main,' means of modification."-(Contemporary Revieu. vol. lvi., p.248.) 
But in spite of these strong assertions, we may doubt whether the doctrine of the continuity of the germ plasm, as expounded by Dr. Weismann, does give that support to Natural Selection which it is asserted to have done. And this for two reasons. First, because the teachings of Weismann himself on the subject of the immutability of the germ plasm are not consistent; and, secondly, because it would be extremely difficult to prove that the germ plasm underwent modification only in connection with sexual reproduction.

The teachings of Dr. Weismann are not self-consistent; for in one place he tells us that the stability of species is an argument for the absolute unchangeableness of the germ plasm. But the germ plasm cannot be absolutely unchangeable and at the same time modified by every act of sexual reproduction. Nor does the stability of species necessarily imply that the germ plasm is altogether unmodified; for stability of species permits, as we have pointed out, a very considerable amount of modification in individuals, and it is the result, not of the total absence of variety, but rather of the fact that no kind of selection has been applied.

On the other hand, Dr. Weismann has admitted, in certain passages, that the germ plasm may have been modified by external circumstances.

"It seems to me the possibility is not to be rejected, that influences continued for a long time, that is, for generations, such as temperature, kind of nourishment, etc., which may affect the germ-cells as well as any other part of the organism, may produce a change in the constitution of the germ-plasm. But such influences would not then produce individual variations, but would necessarily modify in the same way all the individuals of a species living in a certain district. It is possible, though it cannot be proved, that many climatic varieties have arisen in this manner. Possibly other phenomena of variation must be referred to a variation in the structure of the germ-plasm produced directly by external influences." -(Apud Eimer. Organic Evolution. p. 174.) 
If we refer to "Weismannism up to date," as Mr. Romanes so happily indicates the latest teaching of this great savant, we shall find that he has arrived now at a definite conclusion.

"Many climatic varieties of plants may also be due wholly or in part to the simultaneous variation of corresponding determinants in some part of the soma and in the germ plasm of the reproductive cells, and these variations must necessarily be hereditary." -(The Germ Plasm. p. 406.)

Speaking of amphimixis, he says :-

"It is not the primary cause of hereditary variation. By its means those specific variations which already exist in a species may continually be blended in a fresh manner, but it is incapable of giving rise to new variations even though it often appears to do so. . . . The cause of hereditary variation must lie deeper than this. It must be due to the direct effect of external influences on the biophors and determinants."-( The Germ Plasm. pp. 4I4-I5.)

Now the effect of this modification of the theory is enormous; for whereas the denial of any change of the continuous germ plasm, due to the effect of changed conditions, emphasised the importance of sexual reproduction as the sole means of modification, and variations thus produced could only be fixed in a race living in a state of nature by the principle of Natural Selection, the admission that external influences produce a direct effect upon the germ plasm and are the sole source of new variations establishes the influence of the principle of the action of external conditions, so as to render Natural Selection no longer necessary. The effect of all this is to make the theory of the continuity of the germ plasm the ally of Lamarckism rather than of Darwinism.

And this result is not affected by some of the modifications of the theory. The essential point is that the 
germ plasm should be modified by the action of external circumstances; that the germ plasm of all the individuals subjected to the same outward conditions should be modified in the same way; these similar variants will intermarry apart from selection. Let this essential change take place, and it matters little for our argument under what especial conditions and limitations it takes place. It is asserted that sexual reproduction is necessary to develop this influence. We cannot see why this should be necessary any more than it is necessary to mix the contents of two wine vats of the same vineyard, in order to bring out the characteristic aroma of this particular growth. But grant that "amphimixis" is necessary; that does not vitiate but develop the change that has already taken place. The preparatory modification has taken place in all and produces its undoubted result after sexual reproduction. (How could it produce any result on offspring before?) And it is obvious that the germ plasm of all being transformed in the same way, there is no need, no room for the selection of some which have been modified in a special way. Nor is this principle affected by the assertion as to the time when this modification of the germ plasm takes place to sufficiently modify the organism itself. If it be asserted that the result is only visible after several generations, this is only in accordance with the fact that some species do not vary so readily as others.

It would require a volume to deal properly with the theory of Dr. Weismann, regarding it as a statement of some of the most difficult phenomena of nature. I have endeavoured to look at it simply from the point of view of the theory of Natural Selection; and I trust that nothing has been omitted which is essential to the argument, although [ have avoided as much as possible the 
technical language in which the theory is stated by its author.

Before leaving the theory of Dr. Weismann, it may be well to indicate a certain ambiguity in the use of the word "acquired." It is generally used to indicate variations acquired by the body cells of an organism; and unless I am mistaken it is tacitly assumed that no acquired modification whatever can be inherited, and that therefore the transmutation of species in nature is due to the Natural Selection of variations necessarily associated with reproduction. But surely if external conditions can modify the sexual elements, these modifications have been acquired by the sexual elements; and, as we have seen, the necessity for Natural Selection at once disappears, and something very like a Lamarckian principle is at once established. 


\title{
CHAPTER VI.
}

\author{
PURE DARWINISM (continued). \\ (b) MORE METHOdS OF SELECTION THAN ONE.
}

"Il y a fagots et fagots."-Molière.

THERE are, to say the least, three conceivable ways in which similar variations may be isolated for breeding purposes in the world of nature, apart from Natural Selection. Physical separation, which is so effectual in artificial selection, might also operate in nature. Similar variants might segregate themselves with results similar to those of artificial selection; similar variants might be physiologically differentiated so that either their period of sexual maturity differed from that of the rest of the race, or they might be fertile inter se and infertile with the rest of the race. And I see no reason whatever why these three principles should not prove as efficient in nature as the principle of Natural Selection is supposed to be, on the hypothesis that the tacit assumptions of that theory are to be relied on. Let us consider, for a moment, what these assumptions are. Those who believe that Natural Selection is the sole cause of the transmutation of species, argue on the ground of the necessity of "selecting"- that is, of isolating for breeding purposes-those similar favourable variations which arise in connection with variations necessarily associated with sexual reproduction. They assert that the agent of 
this selection is found in the struggle for existence arising from the tendency of all organisms to increase in a geometrical ratio.

But when this assertion is made, it is tacitly assumed that sexual reproduction will necessarily cause the output of variations which are unmodified by any other influence; that these variations will afford the necessary material for selection; and that Natural Selection-selection by life and death-is the only isolation for breeding purposes possible in nature. But if the first two assumptions are taken for granted, it does not necessarily follow that Natural Selection is the sole agent in nature for isolating similar variations. And, first, it may be observed that, on the principles of Natural Selection, isolation by life and death cannot be the only possible means of isolating similar variants for breeding purposes; for in artificial selection this is generally effected by physical separation; and hence we may presume that there may be two or more methods of isolation in nature. The next point to be observed is that it is the fact of isolation which is important, and that the same result may be attained by many different methods. As Mr. Romanes says :-

"All that the causation of the case requires is that there should be exclusive breeding between the similarly modified individuals. Whether this exclusive breeding is secured by killing off all other individuals, or by fencing them all out of a field, is plainly immaterial." -(Contemporary Review. vo!. liii., p. 846.)

The same remarks will apply with equal force to social segregation and to physiological differentiation.

This is true as to the immediate result of the isolation of similar variants, but it is not immaterial what methods are suggested; there may be methods practicable to art which would be impossible in nature; methods appearing like a splendid vision in the realm of theory and yet not 
manifested in the sober realm of fact. Moreover, among methods possible in nature, those which are the easiest and the cheapest will probably prove the most efficient in the long run. But however this may be, it can be shown that, taking the processes of Natural Selection for granted, there are at the least three methods of isolating similar variants, the emergence and successful operation of which in nature cannot be prevented by Natural Selection.

But all these methods of isolating for breeding purposes, similar birth variations, have one insuperable difficulty attaching to them. They all go on the assumption that the variations necessarily associated with reproduction can be produced pure and simple and altogether unaffected by the external conditions. In the next chapter we shall show that this is impossible. If that were possible, I contend that it would be just as easy to isolate favourable birth variations by physical isolation, by social segregation or by physiological differentiation, as by life and death. As it is not possible, such contention is only an argumentum ad hominem which it is useless to pursue, because it is based upon assumptions which do not correspond with the facts of nature. It may not be unprofitable, however, if we endeavour to show how difficult it is to suppose that physical isolation, social segregation and physiological differentiation can act as the agents of selection with respect to purely sexual variations; and, on the other hand, how powerful their action may be, as transforming influences, if we allow for the direct action of outward conditions.

In seeking for possible methods of "selection" in nature, the first thing which strikes us is to ask whether there is in nature anything analogous to that physical separation by which artificial selection is, for the most part, effected. 
In type-producing selection, the circumstances which surround all the animals experimented upon are made as uniform as possible; the variations from which selection is made are, for the most part, those variations which are inevitably associated with sexual reproduction ; and similar variants are prevented from interbreeding with individuals unlike themselves by a physical barrier. This process is continued for several generations until the object which the fancier has set before himself has been attained. Now let us see how far it is possible that this method should obtain in nature. It seems to be probable, if we allow the tacit assumptions which the doctrine of Natural Selection takes for granted. If variations can occur in nature which are solely the result of sexual reproduction, if external conditions produce no direct effect upon organisms, if necessary birth variations are the sole material for selection to act on, then it might appear probable that species should be transmuted, whether the necessary isolation for breeding purposes be effected by an impassable barrier or by the survival of the similar favourable variations and the destruction of the rest. But in order that species should be transmuted in nature by physical separation, we must make further assumptions. Similar variations must first arise in at least a few individuals of a given group; these must be isolated by a physical barrier, so that they breed only with one another. Moreover, in the next generation similar favourable variations must again arise, apart from the direct or indirect effect of circumstances, and these in their turn must be separated. But is it likely that this will take place? It is difficult to understand how such similar variants should be collected together and then isolated by river or mountain, or some natural barrier, in each generation, unless indeed they separated themselves, and then no bar- 
rier whatever would be needed. The only condition under which such a phenomenon is possible would be in connection with migration from one district to another. But in this case we must suppose that the advanced guard always consists of those whose similar variations will be favourable to the transmutation of species, and one does not see exactly why this should be so. Again, the separating barrier must be sufficient to secure isolation for breeding purposes; but if so, it is probable that the circumstances of the new habitat will be different, and it is difficult to believe that these different conditions will not produce some direct effect upon the organism. How are we, in such cases, to tell exactly which modifications are due to sexual reproduction, pure and simple, and which to the effect of external conditions? Dr. Weismann recognises this difficulty, when he says:-

"In single cases it may be difficult, or for the present impossible, to decide whether we have before us a climatic form or a local form arising from other causes."-(Studies in the Theory of Descent. vol.i., p. 46.)

As an illustration of this difficulty, we may refer to Dr. E. Ray Lankester's explanation of the occurrence of blind animals in caves and in the deep sea. He says :-

"But this instance is really fully explained by the theory of Natural Selection acting on congenital fortuitous variations. Many animals are thus born with distorted or defective eyes whose parents have not had their eyes submitted to any peculiar conditions. Supposing a number of some species of Arthropod, or Fish, to be swept into a cavern, or to be carried from less to greater depths in the sea,--those individuals with perfect eyes would follow the glimmer of light and eventually escape to the outer air or the shallower depths, leaving behind those with imperfect eyes to breed in the dark place. A natural selection would thus be effected. In every succeeding generation this would be the case, and even those with weak but still seeing eyes would in the course of time escape, until only a pure race of eyeless or blind animals would be left in the cavern or deep sea."-(Encyclopaedia Britannica. vol. xxiv., p. 8rg.) 
Now, in the first place, it should be observed that this instance is really not a case of Natural Selection-i.e., of selection by life and death-but selection by separation, which is a very different thing, for selection in nature is not necessarily Natural Selection. In the second place, the explanation assumes that the individuals composing a species can always be divided into two classes, one containing those which can see perfectly and the other containing those which can see so imperfectly that they will not move in the direction of a glimmer of light. That is a large assumption to start with. Then, in order that this difference should lead to the "selection" which is supposed to take place, it is necessary that something like a catastrophe should happen, sweeping a group of animals away from their accustomed habitat. In these circumstances, it is reasonable to believe that all would desire to return to their accustomed sphere and to retrace their steps, and those with imperfect vision must be almost blind to begin with, if a glimmer of light was not visible to them. There are other organs of sense besides that of sight, and on the hypothesis that some individuals were carried not only into deep sea but also into the depths of the sea, they would surely seek to mount to the surface if indeed the sudden change did not prove fatal to them altogether. But we will assume that the individuals with imperfect sight do remain in the new habitat and have offspring. In that case, according to the principles of Pure Darwinism, which Dr. Ray Lankester adopts, the offspring would not necessarily inherit the imperfect vision, but only a tendency in that direction; and it is reasonable to suppose that ere that tendency were developed the offspring would rise to seek the light. Such are the difficulties which beset this explanation, if we regard it as a selection in nature which is not Natural Selection. If this 
change had been brought about by Natural Selection, the process would have been quite different. The animals would have changed their habitat, and found themselves in a realm of darkness. Then the presence of an organ which was useless would be prejudicial; and those which could see least would flourish most, until the blindness which was so advantageous as to make the difference between life and death would be fixed in the race. It is surely evident that neither of these explanations is, on the face of it, so probable as the explanation of M.r. Darwin, who believed that the unused organ tends to become atrophied, and that such tendency is inherited. But what I am now concerned to show is that Dr. Ray Lankester's explanation is a process of separation which is not Natural Selection, and that the process which he describes appears to be the most improbable.

But all these difficulties disappear if it is not necessary for us to exclude the occasional influence of changed conditions. If variation takes place before isolation, isolation will prevent the variants from interbreeding with the rest of the species. If certain individuals of a species are isolated before variation begins, and the new conditions modify all the individuals brought under the influence, the isolation will protect them from intermixture with others which are not thus modified. In that case, we say with respect to such a barrier what Shakespeare says of our sea-girt island :-

". . . . . . this scepter'd isle, This fortress, built by nature for herself Against infection, . . .

. . . . . . this little world;

This precious stone set in the silver sea, Which serves it in the office of a wall, Or as a moat defensive to a house."

-(Richard II. Act ii., sc. I.) 
It may be well to notice here a theory by which it is supposed that the physical isolation of unchanged variants may afford an opportunity for the action of the Natural Selection of variations strictly due to sexual reproduction. We may suppose, for the sake of argument, that the conditions were similar to those which obtained before isolation took place. In that case, it is assumed that a new variety will arise, because the offspring will represent the average endowments of the individuals thus isolated. But if that were so, varieties would be always arising, inasmuch as all animals are practically isolated within a narrow range, apart from physical barriers. In this case, the inhabitants of a special locality doubtless intermarry within a very narrow limit among an infinitesimally small fraction of the whole. And yet this arrangement does not affect the general stability of a species, apart from other influences.

The same remarks apply to another cause of isolation. There is an old proverb to the effect that "birds of a feather flock together," and the truth of this familiar aphorism is to be found in the fact that variants which resemble one another generally segregate themselves from the rest of the species.

"The editor of the Joumal of Horticulture, E'c., says, that he can keep bantams with the larger breeds without much danger of their crossing, but not with the smaller breeds, such as games, Hamburgs, \&c. . . . . It has been observed in a district stocked with heavy Lincolnshire and light Norfolk sheep, that both kinds, though bred together, when turned out, 'in a short time separate to a sheep'; the Lincolnshires drawing off to the rich soil, and the Norfolks to their own dry light soil; and, as long as there is plenty of grass, 'the two breeds keep themselves as distinct as rooks and pigeons.' . . . . With respect to fallow-deer, which live in a semi-domesticated condition, Mr. Bennett states that the dark and pale coloured herds, which have long been kept together in the Forest of Dean, in High Meadow Woods, and in the New Forest, have never been known to mingle." (The Variation. vol. ii., pp. IOI-3.) 
With regard to the isolation of segregation which is altogether an act of the animals themselves, and which is exhibited in domesticated and also in semi-domesticated animals, there seems no reason that the same tendency should not be shown by races in a state of nature. And such seems to be the fact.

"In Paraguay the horses have much freedom, and an excellent observer believes that the native horses of the same colour and size prefer associating with each other, and that the horses which have been imported from Entre Rios and Banda Oriental into Paraguay likewise prefer associating together. In Circassia six sub-races of the horse are known, and have received distinct names; and a native proprietor of rank asserts that horses of three of these races, whilst living a free life, almost always refuse to mingle and cross, and will even attack each other." -(The Variation. vol. ii., p. IOz.)

Professor Eimer testifies to the existence of the same phenomenon.

"I have shown, in a very carefully studied example, in the wall lizard, that varieties differing to any important degree fight with one another when they live together as if there was profound antipathy between them ; that therefore they do not sexually mingle, while the similar individuals breed together, and so establish their characters more firmly."-(Organic Evolution. p. 42-note I.)

But it might be said that these are all cases of well defined and long established variants. We may, therefore, point to the fact that the ancon sheep, a variety which arose suddenly, have been observed to keep together, "separating themselves from the rest of the flock when put into enclosures with other sheep." * But in none of these cases, in which social segregation comes into play, can it be confidently asserted that the variations are those necessarily associated with sexual reproduction.

We have next to consider the possibility of similar variants being isolated for breeding purposes by what I

* The Variation. vol i., p. 100. 
have ventured to call physiological differentiation. When the period of maturity is different in the variants to what it is in the normal type, they will be isolated for all practical purposes, so far as breeding is concerned.

"Suppose the variation in the reproductive system is such that the season of flowering or of pairing becomes either advanced or retarded . . This farticular variation being communicated by inheritance to their progeny, there would soon arise on the same area, or, if we like, on closely contiguous areas, two varieties of the same species, each perfectly fertile within its own limits, while absolutely sterile with one another. That is to say, there has arisen between these two varieties a barrier to intercrossing which is quite as effectual as a thousand miles of ocean; the only difference is that the barrier, instead of being geographical, is physiological." (Romanes. Journal of the Limnean Society-Zoology. vol. xix., pp. 352-3.)

"With plants a difference in the period of flowering serves to keep varieties distinct, as with the various kinds of maize and wheat ; thus Colonel Le Couteur remarks - 'the Talavera wheat, from flowering much earlier than any other kind, is sure to continue pure.' In different parts of the Falkland Islands the cattle are breaking up into herds of different colours; and those on the higher ground, which are generally white, usually breed, as I am informed by Admiral Sullivan, three months earlier than those on the lowlands; and this would manifestly tend to keep the herds from blending." (The Variation. vol. ii., pp. IOI-2.)

"Mr. Thomas Meehan has described before the Academy of Natural Sciences of Philadelphia a case of sudden change of characters in some branches of a 'smoke-house' apple tree, which bore clusters of flowers at the ends of young shoots, flowering six weeks after the ordinary blooms from spurs, and yet maturing fruit at the same time as the old spurs. This fruit, however, was very unlike the 'smoke-house' fruit, the fruit stems being long and slender and the fruit flattened. The change was so great that a botanist would have no hesitation in describing the form as a new species; and there appeared no reason why the law which produced this modification might not simultaneously act on all the trees in a district." (Nature. vol. xvi., p. 288.)

But here again we have to ask how has this variation arisen? Has it arisen as the pure result of sexual reproduction?-or has it been caused by physical conditions? 
If it had been produced in connection with sexual reproduction even then it is obviously not a variation necessarily associated with it; and what is not necessarily associated with sexual reproduction is caused, according to the argument of Mr. Darwin, by some definite cause producing a definite resuit. Mr. Romanes distinctly says, what indeed is most probable, that this phenomenon is caused by the influence of various external conditions.

"In every case where a change of food, temperature, humidity, altitude, or of any of the other many and complex conditions which go to constitute environment-whether the change be due to migration of the species, or to alterations going on in an area occupied by a stationary species-in every case where such a change either promotes or retards the season of propagation, there we have the kind of variation which is required for physiological selection. And it is needless to give detailed instances of its occurrence where this is due to so well-known and frequently-observed a cause."-( Joumal of the Limnean Society-Zoology. vol. xix., p. 356.)

The Rev. J. T. Gulick speaks to the same effect.

"Seasonal segregation is produced whenever the season for reproduction in any section of the species is such that it cannot interbreed with other sections of the species. It needs no argument to show that if, in a species of plant that regularly flowers in the Spring, there arises a variety that regularly flowers in the Autumn, it will be prevented from interbreeding with the typical form. The question of chief interest is, under what circumstances are varieties of this kind likely to arise? Is a casual sport of this kind likely to transmit to subsequent generations a permanently changed constitution? If not, how is the new constitution acquired? One obvious answer is that it may arise under some special influence of the environment upon members of the species that are geographically or locally segregated from the rest of the species."-(Journal of the Limean Society-Zoology. vol. xx., p. 229.)

But if we grant that the period of sexual maturity differs in different species by virtue of external conditions, it is quite probable that these conditions will produce other modifications also; so that the members of a species which 


\section{4}

can only breed with one another will be modified in the same way, and so will constitute in a very short time an incipient species.

Another case of physiological differentiation is to be found in those cases (if there be such) in which a group of individuals vary from the rest of the species, and are also infertile with those from whom they differ, while they are perfectly fertile inter se.

Mr. Thomas Belt says :-

"The varieties that arise can seldom be separated from the parent form and from other varieties until they vary also in the elements of reproduction. 'Thousands of varieties probably revert to the parent type, but if, at last, one is produced that breeds only with its own form, we can easily see how a new series might be segregated." -(The Naturalist in Nicaragua. p. 207.)

\section{Mr. Romanes says :-}

"If the variation be such that the reproductive system, while showing some degree of sterility with the parent form, continues to be fertile within the limits of the varietal form, in this case the variation would neither be swamped by intercrossing nor would it die out on account of sterility. On the contrary, the variation would be perpetuated with more certainty than could a variation of any other kind. For, in virtue of increased sterility with the parent form, the variation would not be exposed to extinction by intercrossing; while, in virtue of continued fertility within the varietal form, the variation would perpetuate itself by heredity, just as in the case of variations generally when not re-absorbed by intercrossing."-Uoumal of the Limean Society-Zoology. vol. xix., p. 352$)$.

That this is not a mere idle supposition is seen from the fact that, according to Gärtner,-

"The yellow and white varieties (of Verbascum), when crossed, produce less seed than the similarly coloured varieties of the same species; and . . . that the blue and red varieties of the pimpernel are absolutely sterile together, while each is perfectly fertile within itself." - (Apud Romanes. Joumal of the Limnean SocietyZoology. vol. xix., p.359.) 
This correlation between similar variations and infertility with other members of the species not so modified might arise in three ways: the two phenomena might occur simultaneously; or the variation might arise first and then the infertility with reference to the rest of the species; or infertility might appear first and then variations might ensue. If partial infertility, with the rest of the species, appeared first, then what would happen? There would be no suppression of the sexual passion, and those variants would be as ready to unite as the others would be. They would interbreed with the average of the race, but they would have no offspring, or only a few ; and their peculiarity would soon disappear through the inability to reproduce itself. If, on the other hand, the similar variation in structure appeared first, the isolating cause-viz., infertility with the rest-would be absent; the variants would intermarry with the rest of the species, and in the absence of prepotent power the variations would be swallowed up in the race. Hence it seems to me quite clear that in order that this principle should be effective the structural variation and the infertility with the rest of the species should arise simultaneously in the same organism, and moreover that the infertility should be complete from the first. If there was only a slight degree of infertility this would not prevent intercrossing; and this slight variation might easily disappear as so many others do by the principle of regression to the average of the race. But what cause can we regard as efficient to produce at once a change of structure and absolute infertility with the rest of the species? Assuredly such a modification could not arise from the mere union of two normal individuals. We must find its cause in some external influence brought to bear upon the parturient system in many individuals. Mr. Darwin argues that the 
same causes which led to sterility may lead to other modifications of structure; and surely it is admissible to believe that the reverse may also take place, and that similar variants may possess fertility inter se and infertility with the rest of the species. But if we grant, for the sake of argument, that this correlation is possible, so far as the variation due to sexual reproduction is concerned, there is no conceivable reason why such correlation should occur except in the most casual way. Mr. Catchpole assumes that this correlation may arise in only two individuals, and that these individuals will marry one another.* But if the accident of birth is the only cause of this correlation, these two individuals may be living far apart and may never meet. In this case they have a potential power of becoming the ancestors of a new species; but it will avail nothing in the actual life. If they do unite, it would probably be on account of their similar variation which led them to segregate themselves, in which case their infertility with others would not be of any use. Many similar variants, all of whom were only fertile inter se, would not avail if they occurred at random, unless they could be brought together by segregation or some other means. If they were not, the variants would die out either because they did not find partners or because they intermarried with those with whom they would be infertile.

But if the infertility of variants with the rest of the species be due to some definite cause, acting on a given number of individuals, this will probably arise from the fact that, living together in the same locality, they are subject to the same modifying influences. And inasmuch as they are already living together by the hypothesis, they will intermarry with one another; and then their 
infertility with the rest of the species will serve as a protection against indiscriminate interbreeding should opportunity occur for that, through the invasion of some of the normal forms; or through their encountering such on the outskirts of the locality in which they live.

Mr. Meldona proposes to himself the question, "Can physiological selection work independently of Natural Selection?" and he decides that it cannot.

"Let us suppose, for the sake of argument, that among the individuals of a species there arise certain varieties which are fertile inter se, but sterile with the parent form. There would thus arise a new race which could not be swamped by intercrossing with the predominant form, and the one species would practically be resolved into two - the parent form being still in the ascendency as regards numbers. But the competition is always most severe between the most closely related forms, and unless the new form (arising by inter-racial amixia) possessed some distinct advantage over the old one, it would as surely be exterminated by the overwhelming majority of the parent type, as it would be by intercrossing in the absence of amixia. Physiological selection thus appears to me to be as subordinate to natural selection as sexual selection, correlated variability, the law of homology, or any other of the Darwinian factors. The expression used by Mr. Romanes for his new factor-the 'Segregation of the Fit'-seems to imply fitness for something, presumably for the conditions of life, and if the survival of the 'fit' race is determined by Natural Selection, then I venture to think that Natural Selection must still be regarded as the theory of the origin of species and as something more than a theory of the origin of adaptations."-(Nature. vo?. xxxiv., pp.384-5.)

This argument is based upon a belief in the intenser struggle for existence between closely allied forms and upon the idea of utility as the condition of survival in the case of such struggle. But in some cases, at any rate, closely allied species do not compete with one another in an internecine strife. Sometimes they live together harmoniously. And if we look to local or climatic variations, we shall find that in some cases, at any rate, the 
modification is one that takes place apart altogether from the usefulness of the transmutation.

It follows, from what has been said, that if the tacit assumptions which underlie the theory of Pure Darwinism be accepted as true, there are other modes of isolating similar variants besides that of Natural Selection. But as these assumptions are not true, this argumentum ad hominem is, in effect, a mere war of words, when we are brought face to face with the facts of nature. It is difficult to understand how variations which are necessarily associated with reproduction should be isolated by the methods which we have mentioned. It is easy to see how useful these modes of isolation may be in assisting the effect of the direct action of changed conditions. This discussion will not be fruitless, if it leads to the conviction that physical separation, social segregation, and physiological differentiation, under certain circumstances, are efficient agents for isolating similar variants, and that they produce in nature a selection which is not Natural Selection, and which Natural Selection cannot control. 


\begin{abstract}
CHAPTER VII.
MIXED DARWINISM.

THE TRANSFORMING AND THE SELECTING INFLUENCE OF CHANGED CONDITIONS.

"Tempora mutantur nos et mutamur in illis."

"In unison at times, And then apart again, And both in one have brought us hither."

-Palgrave. The Reign of Law.
\end{abstract}

By the phrase, mixed Darwinism, we must understand the affirmation that there are many possible methods by which the transmutation of species can be brought about. We have already shown that if there is a transmutation of species by Natural Selection, there is nothing inconsistent with that fact in supposing that there may be other methods also. For if there are variations necessarily associated with reproduction which require selection, there may be variations occasionally associated with reproduction which do not require the principle of selection. If the principle of selection be necessary, there may be other modes of selection in nature besides that accomplished by life and death. And in point of fact, we find that such phenomena do exist, and, so far, the belief in mixed Darwinism is perfectly reasonable, supposing that there is such a thing as Natural Selection at all.

But it is not of these matters that we think chiefly when we speak of mixed Darwinism. That phrase more 
especially refers to the belief that changed conditions produce modifications in organic structures by two different processes, which may be severally described as a transforming and selecting influence. Before the date of the publication of The Origin of Species, the majority of those who thought upon the subject at all believed in the fixity of species; but there were a few who asserted the doctrine of the transmutation of species, and who supposed that this transmutation was mainly brought about through the direct and indirect action of changed conditions and habits upon a responsive organism, by what we have called transforming influences. Now, when Mr. Darwin put forth his theory of Natural Selection, he did not deny the reality of this transformation acting apart from selection. On the contrary, he affirmed it most emphatically. But of course he contrived to find a place for his new theory of Natural Selection; and he contended that these two principles might act apart from one another or in co-operation with one another. In other words, he taught that a transmutation of species might be effected by transforming influences alone, by selecting influences alone; or by the co-operation of both these influences.

In opposition to this view, we venture to contend that it is impossible that the selecting influence of Natural Selection should co-operate with the transforming influence which is due to the direct and indirect action of changed conditions upon a responsive organism. The reason for making this assertion lies in the fact that you cannot play the same game under two entirely different sets of rules; you cannot play the same game of football under Rugby rules and under Association rules; you cannot in the same game play short whist and long whist; you cannot frame a single problem in chess which shall 
be solved by checkmating the opponent in ten and in twenty moves; you cannot play a game which is at once almost altogether a matter of skill and at the same time almost altogether a game of chance. But if this is so, surely it is equally true to affirm that the transmutation of species cannot be brought about by the co-operation of two processes which are as different from one another as the different games which have been mentioned.

The transmutation of species by Natural Selection is, by general confession, a slow process; the transmutation by transforming influence is often a very short one. Transmutation of species by Natural Selection is a game of chance, in which all modification in the right direction is determined by a happy accident; transmutation by transforming influence is due to the definite action of the laws of variation. Transmutation by Natural Selection is effected by the selection of a few favourable variations which arise in connection with the variations necessarily associated with sexual reproduction; transmutation by transforming influence does not require any kind of selection whatever. These salient points, among others which might be mentioned, sufficiently indicate the difference of the two methods under consideration, and this difference prevents them from being brought into co-operation in connection with the same group of a given species.

Natural Selection, therefore, cannot co-operate with the transforming influence of changed conditions and habits. But might not the two processes be carried on apart? It might be said,-- "We fully admit that the same group of individuals cannot be submitted to two distinctly different processes; but the two methods might be adopted in connection with two different groups of individuals, just as you might conceive two or even many methods of manufacturing a given article out of two or more 
distinct quantities of raw material." But this apparently reasonable proposition and this apparently apposite illustration do not apply to the case in point. For in order that this should take place, we must not only have two sets of individuals, but we must surround these individuals with two different worlds; in the one case there must be a world in which changed conditions do not affect the organisms, so that all change is left to the variations necessarily associated with sexual reproduction; and, on the other hand, there must be a world in which changed conditions do affect the organism. But it is very difficult to understand where we should find a sphere in which the change of external conditions would not produce an effect upon one group and would produce an effect upon another. The whole process of Natural Selection begins with a change of external conditions to which it is necessary that the organism should adapt itself; but this very change inaugurates a process of transformation which acts, sooner or later, (if it acts at all) on all the individuals submitted to its influence.

No process of Natural Selection can take place in the world of nature, as we know it, without the interference of transforming influence. The attempt to contemplate these two processes as acting apart is an act of abstraction, but there is no corresponding phenomenon in the actual world. The difficulty is as great, and for the same reason, as that which beset the scheme of Professor Tyndall when, many years ago, he proposed a scientific test of the efficacy of prayer. He suggested that the inmates of one ward in a given hospital should undergo the best medical treatment, but that no one should pray for their recovery; and that the recovery of the inmates of another ward should be made the subject of earnest prayer, but that they were not to enjoy the advantages of medical treatment. 
For many reasons, such a test could not be applied; and if it could have been, its verdict would not be reliable. There is one difficulty which applies to our present subject. You might fill a ward with patients, and take care that no public service of religion took place within its four walls; you might be very careful to do the best you possibly could for them so far as medical treatment was concerned, but you could not prevent the most effectual of all prayers being made in their behalf. Who could prevent husband or wife, parent or child, from desiring the recovery of the one who was perhaps the best beloved of all? Even the physicians and nurses might care more for the personal element, for the welfare of their patients or for their own credit, than for the attempt to solve a theological problem by a scientific process, which might well seem blasphemous to the faithful and absurd to the intelligent unbeliever. And as the recovery of the patient involves physical and spiritual elements which cannot be kept apart from one another, so also it is equally certain that changed conditions cannot prepare the way for the action of Natural Selection without, at the same time, giving entrance to transforming influences also.

If we admit, for the sake of argument, that these two processes could be carried on apart, it is impossible that the process of selection by life and death could compete with the transforming influence. We will suppose that we have two groups of the same species which have migrated into a new country and have settled in different localities, identically the same as to all outward conditions. It is necessary that if these groups are to survive, they must be adapted to their new conditions; and hence, those which are the soonest adapted will become the heirs of the whole district; while those which have failed to make equal progress will be exterminated. In this case 
it is obvious that the power which is more direct in its action, more diffused in its influence, more pronounced in its effects, and more economical in its mode of action, will be the successful competitor. The transforming influence of changed conditions produces a definite effect upon the organism, this definite effect is seen in all the individuals subjected to its influence; and, this effect being produced upon both parents, the transmutation is effected in a comparatively short time. Contrast with this the process of Natural Selection, as explained in theoretical expositions. The waiting for favourable variations to turn up at all, the assurance that when they do turn up they will occur only in a very few, and that probably the favourable variation will only be very slight; the selection of these few slightly favourable variants by the death of the rest; the output of fertility to supply new materials for selection with similar uncertain results,this protracted and doubtful process could not possibly compete with the more direct action of transforming influences.

But if we return to our proposition that the two methods of transmutation by transformation and by Natural Selection cannot co-operate or co-exist, we may further appeal to actual experience, and ask ourselves, -Which of these two processes is actually in evidence in the world of nature? Does the actual transmutation exhibit traces of a transforming or of a selective influence? Advocates of the theory of Natural Selection assert that the parental forms remain without any modification whatever; or that such variations, when they occur, are small in amount; or that, whether large or small in amount, they are not inherited by offspring.

Mr. Le Conte says that in Natural Selection "the form and structure are supposed to remain unchanged during 
the individual life"; but that there are "slight variations in different directions (divergent) in the offspring from the same parents"; in opposition to other methods in which the change is during the individual life.*

Dr. Ray Lankester asserts that "Change of structure acquired during life-as stated by Lamarck-is also a fact, though very limited." $\dagger$

When we remember the fact of the stability of species, and its consequent immobility under certain conditions, it is quite possible that instances might be adduced to show that sometimes little or no change takes place during the lifetime of the individual upon the organism of the individual. In these cases we have no evidence of any transmutation at all, either by Natural Selection or by any other method. But, on the contrary, there are cases in which a rapid change does take place.

It is generally, easy to decide from what district the common oyster has been brought, each district having its distinctive form of shell. The shell of the Mediterranean oyster is especially distinguished by the prominent divergent rays. Now it is reasonable to conjecture that external conditions produce these modifications of form. The hypothesis is one which it is not difficult to test, and which has been actually tested.

"With respect to the common oyster, Mr. Buckland informs me that he can generally distinguish the shells from different districts. Young oysters brought from Wales and laid down in beds where 'natives' were indigenous, in the short space of two months begin to assume the 'native' character. M. Costa has recorded a much more remarkable case of the same nature, viz., that young shells taken from the shores of England and placed in the Mediterranean at once altered their manner of growth and formed prominent diverging rays like those on the shells of the proper Mediterranean oyster."-(The Variation. vol. ii., p. 280.)

* Evolution and its Relation to Religious Thought. p. 74. + Nature, vol. xxxix., p. 428 . 
"Hunter long ago observed that the muscular coat of the stomach of a gull (Larus tridactylus) which had been fed for a year chiefly on grain, was thickened; and, according to Dr. Edmondston, a similar change periodically occurs in the Shetland Islands in the stomach of the Larus argentatus, which in the spring frequents the corn-fields and feeds on the seed. The same careful observer has noticed a great change in the stomach of a raven which had been long fed on vegetable food. In the case of an owl (Strix grallaria) similarly treated, Menetries states that the form of the stomach was changed, the inner coat became leathery, and the liver increased in size. Whether these modifications in the digestive organs would in the course of generations become inherited is not known."-(The Variation. vol. ii., p. 302.)

"Professor Bailey observes:-'Squashes often show remarkable differences when grown upon different soils, and these differences can sometimes be perpetuated for a time by seeds. The writer has produced from the same parent squashes so dissimilar, through the simple agency of a change of soil, in one season, that they might readily be taken for distinct varieties." --(Natural Science. vol. i., p. 176.$)$

"A number of pupæe were brought, in I870, to Switzerland from Texas of a species of Saturnia, widely different from European species. In May, I87I, the moths developed out of the cocoons (which had spent the winter in Switzerland) and resembled entirely the Texan species. Their young were fed on leaves of Juglans regia (the Texan form feeding on Juglnns nigra), and they changed into moths so different, not only in colour, but also in form, from their parents, that they were reckoned by entomologists as a distinct species."-(Beddard. Animal Coloration. pp.5I-2.)

"Mr. Ramsey Cox writes as follows:--We captured, in the New Forest, a number of half-grown larvæ of the Peacock butterfly, which were carefully fed for a few days (and then, through oversight, were) 'left several days without food. . . . Very few died. . . . Nearly all the imagos were, of course, rather small; they varied much in the intensity of their colouring, and two specimens are very singularly marked. In one, the yellow costal spot is only represented by a very small white mark. There is scarcely any yellow in the ocellus, a large part of which is filled up with black; the usual chocolate patch in it is also black. The chocolate ground colour is also darker than usual. In the hind wing the ocellus contains only two small round violet spots." -( Ibid. p. 50.)

There can be no doubt, then, that in some cases the organism of some individuals undergoes more or less 
modification. It should, further, be observed that the modification inaugurated in this way is continued, so that in a few generations there has taken place a change which, in some cases, amounts to a transmutation of species.

"Mr. Winwood Reade, in speaking of the different animals and plants introduced into West Africa, speaks of a marked change in all :- 'The horse rapidly deteriorates, and in some places cannot be kept alive at all. The sheep change in other respects than their wool. The very dogs which we should expect to bear the change as well as their masters, alter under the baleful climate.' 'In process of time,' writes Bosman, 'our dogs alter strangely here: their ears grow long and stiff, like those of foxes, to which colour they also incline, so that in three or four years they degenerate into very ugly creatures; and in three or four broods their barking turns into a howl.' As to plants, Mr. Reade says, 'it is only on the borders of malarious Africa-that is to say, in Angola and Senegambia-that most foreign plants and vegetables can be made to live; and these, as Mr. Gabriel, of Loanda, informed me, completely changed their nature when planted in the African soil.'"-(Andrew Murray. The Geographical Distribution of Mammals. p. 8.)

"The effects of the climate of Europe on the American varieties (of maize) is highly remarkable. Metzger obtained seed from various parts of America, and cultivated several kinds in Germany. I will give an abstract of the changes observed in one case, namely, with a tall kind (Breit-komiger mays, Zea altissima) brought from the warmer parts of America. During the first year the plants were twelve feet high, and few seeds were perfected; the lower seeds in the ear kept true to their proper form, but the upper seeds became slightly changed. In the second generation the plants were from nine to ten feet in height, and ripened their seed better; the depression on the outer side of the seed had almost disappeared, and the original beautiful white colour had become duskier. Some of the seeds had even become yellow, and in their now rounded form they approached common European maize. In the third generation nearly all resemblance to the original and very distinct American parentform was lost. In the sixth generation this maize perfectly resembled a European variety, described as the second sub-variety of the fifth race. When Metzer published his book this variety was still cultivated near Heidelberg, and could be distinguished from the common kind only by a somewhat more vigorous growth. Analogous results were obtained by the cultivation of another American race, the 'white- 


\section{8}

tooth corn,' in which the tooth nearly disappeared even in the second generation. A third race, the 'chicken-corn,' did not undergo so great a change, but the seeds became less polished and pellucid."(The Variation. vol. i., p. 322.)

"The modern experiments of Van Mons and of de Vilmorin have instructed us as to the number of generations and of years necessary to raise certain fruit trees, \&c., from the wild state to that of cultivated trees fit for food. Three generations, according to Vilmorin, suffice for the carrot; three generations, which comprise fifteen years, suffice, according to Van Mons, for stone fruit trees-peaches, apr1cots, plums, cherries."-(Prosper Lucas. Traité Philosophique et Physiologique de l'Hérédité Naturelle. vol. ii., p. 472.)

"Wiseman assures us on good authority that in the United States those slaves who for three generations have lived in domestic service, have the nose less depressed (déprimé), the lips less protruding, and the part of the head covered by the hair longer in each generation, while the slaves which work in the fields lose scarcely any of their original conformation."-(Prosper Lucas. Ibid. vol. ii., p. 464.)

\section{Humboldt remarks that-}

"White men born in the torrid zone walk barefoot with impunity in the same apartment where a European, recently landed, is exposed to the attacks of the Pulex penetrans. This insect, the too well-known chigoe, must therefore be able to distinguish what the most delicate chemical analysis fails to distinguish, viz., a difference between the blood or tissues of a European and those of a white man born in the country. But the discernment of the chigoe is not so surprising as it at first appears, for, according to Liebig, the blood of men with different complexions, though inhabiting the same country, emits a different odour."-(The Variation. vol. ii., pp. 275-6.)

"Some of our countrymen engaged, about the year 1825 , in conducting one of the principal mining associations in Mexico, that of Real del Monte, carried out with them some English greyhounds of the best breed, to hunt the hares which abound in that country. The great platform which is here the scene of sport is at an elevation of about 9,00o feet above the level of the sea, and the mercury in the barometer stands habitually at the height of about 19 inches. It was found that the greyhounds could not support the fatigues of a long chase in this attenuated atmosphere, and before they could come up with their prey, they lay down gasping for breath; but these same animals have produced whelps which have grown up, and are not in the least degree incommoded by the want of density in the air, 
but run down the hares with as much ease as the fleetest of their race in this country."-(Sir Charles Lyell. Principles of Geology. IIth ed., vol. ii., p. 297.-Apud Carpenter. Mental Physiology. p. 338.)

The problem which we have now to solve is whether the processes just described resemble a transforming or a selecting influence. And the first question which we have to ask is whether Natural Selection could possibly produce so rapid a transmutation as this? Mr. Darwin, in his cautious way, admits that Natural Selection is a slow process generally.

"That Natural Selection generally acts with extreme slowness, I fully admit. . . . I do believe that Natural Selection will generally act very slowly, only at long intervals of time and only on a few of the inhabitants of the same region. . . . Slow though the process of Natural Selection may be, . . . I can see no limit to the amount of change . . . which may have been effected, in the long course of time, through nature's power of selection-that is, by the survival of the fittest."-(Origin of Species. pp. 84-85.)

But I venture to say that what Mr. Darwin asserts will generally take place, must necessarily take place. The doubtful number of favourable variations which is supposed to be put forth in each generation, to cite no other point, compels us to believe that Natural Selection cannot take place in a generation or two; and hence, the results just enumerated must have been produced by transforming, as distinguished from selecting, influence. Whether acquired modifications can be inherited or not, a transmutation has taken place which has not been brought about by Natural Selection.

We may apply another test to the modifications of organisms. According to the theory of Natural Selection, the variations from which choice is made are variations necessarily associated with reproduction, which are not in one definite direction, and which are more or less different in all the offspring. As we have already pointed 
out, it is necessary that these should be the only variations, if Natural Selection, in the strict sense of that term, is to come into action. Now, where transformation is at work, these individual variations will still occur, as the necessary accompaniments of sexual reproduction; but in addition to these, changed conditions sometimes produce definite results on all the offspring; and, as we have seen, these definite results sometimes appear in the individuals first subjected to changed conditions, and soon become fixed in the race. Wherever this process takes place, it is a transforming, not a selecting influence. Therefore, whatever cause produces definite results, tends to exclude the principle of Natural Selection. This, Mr. Darwin himself admits.

"It should not, however, be overlooked that certain rather strongly marked variations, which no one would rank as mere individual differences, frequently recur, owing to a similar organisation being similarly acted on-of which fact numerous instances could be given with our domestic productions. In such cases, if the varying individual did not actually transmit to its offspring its new-acquired character, it would undoubtedly transmit to them, as long as the existing conditions remained the same, a still stronger tendency to vary in the same manner. There can be little doubt that the tendency to vary in the same manner has often been so strong that all the individuals of the same species have been similarly modified without the aid of any form of selection." -(Origin of Species. $p .72$. )

"The direct and definite action of changed conditions, in contradistinction to the accumulation of indefinite variations, seems to me so important that I will give a large additional body of miscellaneous facts."-(The Variation. vol. ii., p. 277.)

Thus, similar changes of outward conditions, acting on similar organisms, produce similar results on all the individuals subjected to their influence in such a way that there is no necessity to introduce the principle of Natural Selection. It is sometimes contended that in this transmutation the nature of the organism is more important than the nature of the conditions. 
"Organic beings, when subjected during several generations to any change whatever in their conditions, tend to vary; the kind of variation which ensues depending in a far higher degree on the nature or constitution of the being than on the nature of the changed conditions."-(The Variation. vol. ii., p. 250.)

\section{Hence,-}

"The nature of the conditions is of subordinate importance in comparison with the nature of the organism in determining each particular form of variation; perhaps of not more importance than the nature of the spark, by which the mass of combustible matter is ignited, has in determining the nature of the flames."-(Origin of Species. p. 8.)

"If the mere presence of these incident forces produces so ready a response in animals and plants, it must be that there are, in their case, conditions disposing and enabling them so to respond, according to the old maxim, "Quicquid recipitur, recipitur ad modum recipientis'; as the same rays of light which bleach a piece of silk, blacken nitrate of silver."-(Mivart. The Genesis of Species. p. 166. )

In the same way, Professor Lloyd Morgan contends that the crystal exhibits an inherent tendency to a particular type of crystallisation, and argues that, in the organic world, inherent tendency and influence of environment come into play.

How this inherent tendency first came into being, is another matter, but it is not improbable that the response of the organism has been gradually acquired. But if we regard some existing species as already endowed with this inherent tendency, it is obvious, on the face of it, that it will produce definite effects on all the individuals concerned, and that the principle of selection will be required less than ever.

As an illustration of the action of transforming, as opposed to selecting, influence in nature, we may take the case of organic coloration. This is supposed to be the stronghold of Natural Selection. I have endeavoured 
to argue against that idea; and now it seems to me that I can find no better illustration of the direct and definite action of transforming influence, pure and simple.

One striking case of the adaptation of the colour of animals to their surroundings is to be found in the fact that insects resting on the green leaves of the spring and summer change with the changing leaves of autumn.

"When the first larvæ on the elm are seen,

The crawling insects, like the leaves, are green;

Ere chill October shakes the latest down,

They, like the foliage, change their tints to brown."

-(O. W. Holmes.)

Now, I presume that if this were due to Natural Selection, the process of change would be somewhat in this wise. Some individuals would be born with a certain tendency slightly to change from green to brown, as the summer was passing away; that these would be less conspicuous than those which remained green, and that in consequence of this they would survive, while their unchanged comrades would be destroyed. But there is another explanation which can be established by observation and experiment, which dispenses with the need, and excludes the possibility, of Natural Selection.

"Green chlorophyll remains unchanged in the tissues of leaf-eating insects, and, being discernible through the transparent integument, produces the same colour as that of the food plant."-(Wallace. Tropical Nature. p. I70.)

"The green colour of the blood of most larvæ is adventitious in origin, having been derived from the chlorophyll of the leaves; it is, however, much modified in constitution by the time it reaches the blood. The green colouring matter passes from the blood into the cells of the surface of the body in many caterpillars, but is redissolved in the blood of the chrysalis. It is then made use of, in certain species, to tinge the eggs; and after this, is absorbed in to the body of the young larvæ, which afterwards hatch from them, protecting them with a green colour, before they have had time to 
acquire fresh chlorophyll from the leaves. The passage of an adventitious colouring matter on into a second generation is a very remarkable phenomenon."-(Poulton. The Colour of Animals. pp. 79-80.)

In this case, the green leaf causes the concealment which the caterpillar enjoys at once, just as the colour of the chemist's bottle would be altered by the alteration of its contents. But that is not all. It colours the eggs which the caterpillar will lay when it becomes a perfect insect. Nor is that all; for the young caterpillar of the next generation is hatched green,--it is protected from the hour of its emergence from the egg ere it has gained the protection of the leaves on which it feeds. Of course, all the organisms undergo this change. How can this case be cited as a most favourable illustration of the action of Natural Selection?

But sometimes, in a most marvellous manner, the green caterpillar changes its tints pari passu with the changing colour of the autumnal leaf. In order to understand how this transmutation has been brought about, we must remember that the leaves of different plants contain, in various proportions, a principle known as tannin; and botanists tell us that the autumnal tints of leaves are due to the changes which tannin undergoes on exposure to light and air. These tints are the most splendid in the case of trees and shrubs rich in tannin. In such species a leaf or a part of a leaf accidentally screened from light retains its green summer colour, whilst those around have turned into a rich yellow, red or brown. Now, it has been discovered that certain insects also contain this principle of tannin. In the year i 8 Io, M. Penaut, a pharmaceutical chemist of Bourges, found in the body of corn-weevils gallic acid, a compound kindred to tannin. M. Villon, who has been engaged for a long time in searching for 
tannin formed in the organism of an animal, has obtained I 5 lbs. of tannin from $500 \mathrm{lbs}$. of weevils, which he proved to be such not merely by analysis, but by its action upon animal skins and metallic salts, especially those of iron. About the same time, Mr. J. W. Slater, whilst engaged in studying the generation of colouring matters in the bodies of insects, was struck by the fact that a very large proportion of insects, especially beetles which prey on wood, bark, roots, \&c., display colours closely resembling those yielded by tannin and its modifications in contact with animal matter. He, therefore, took the wing-cases of some cockchafers, and having freed them from fatty matters, he steeped them in solutions of iron, chrome, and copper. The changes of colour produced were exactly those which would happen if a slip of tanned leather or other matter, impregnated with tannin, were similarly treated.

From these facts there seems to be but one legitimate inference. The cause of simultaneous change of colour is the tannin of the leaves: which changes the colour of the leaves when they are exposed to light; which is taken into the system of the leaf-eating insects and acts in the same way in their bodies as in the leaves. The insects that eat the tannin-leaves are changed; the insects which are carnivorous do not show these results, for the obvious reason that they have not eaten the leaves.*

The explanation of the colours of desert animals is to be found in the fact that dryness bleaches.

"The colour of the wings of the beautiful Indian Noon-moth (Actics selene) is very susceptible to dryness and moisture. The normal colour is a delicate pale green; pieces of the wing of a specimen, chloroformed for the purpose of this experiment, became very soon straw-coloured in dry air of a temperature of a little under

* Scientific Neres. vol. i., newu series, p. zo. 
$60^{\circ}$ centigrade; when the same fragments were floated in a saucer containing cold water they rapidly recovered their green colour, which was even intensified." -(Beddard. Animal Coloration. p. 6o.)

"Mr. W. W. Smith has remarked that the prolonged drought recently experienced in New Zealand produced pale-coloured varieties ; and that the Lepidoptera of that country are generally paler on the plains than on the hills. 'The higher we ascend the Alps,' he remarks, 'the more humidity we meet with, and the greater the darkening of the Lepidoptera, until we reach the summit, when they become perfectly black." "-(Beddard. Ibid. p. 6r.)

"It is at least possible that the tawny colours of desert animals, which have so often been brought forward as an instance of adaptation to the hues of their environment, may be due to a similar cause." - (Beddard. p. 6o.)

This possibility becomes a very strong probability when we remember that dryness is the especial characteristic of desert regions.

Exposure to, or protection from light, and change of temperature, are also powerful transforming agents.

"As a general rule those insects whose pupae are exposed are brighter in colour than those insects whose pupae are concealed, either in the ground or in a dense cocoon. Contrast, for instance, the bright colours of the Vanessidae - the 'Red Admiral,' the Peacock, and others-whose chrysalids are naked and freely suspended with the dull colours of most Satyrids which undergo their tranformation in the ground. Similarly the Tiger-moths and the Crimson Underwings contrast with the Cossidae and Agrotidae and most other Noctuae; and among the Geometers the bright yellow Swallowtailmoth, Urapteryx sambucaria, Angerona prunaria, \&c., may be compared with the sombrely-coloured species of the genera Boarmia and Biston."-(Beddard. pp. 62-3.)

"Dorfmeister learns from his experiments that temperature exercises the greatest influence on the colour and marking of butterflies, when it acts upon them during the change into the pupa, or shortly afterwards. In many, a rise of temperature produces a lighter, more brilliant, ground colour; a fall, a darker or less brilliant-for example, Vanessa Io, Utricae. In Euprepia caja the red-yellow ground colour of the posterior wings is changed by a rise of temperature into vermilion red; by a fall, into ochre-yellow."-(Eimer. Organic Evolution. p. T3r.) 
The necessity for the continuance of the same external conditions, which have modified an organism, is well seen from the following consideration:- "Not rarely a long period of dry or moist weather exercises a considerable influence on the size of the following generation. Immediately after a continuous dry summer butterflies are always smaller than after a moderately moist season. The second generation of Argynnis selene, which takes flight in the height of summer, is always smaller than the first generation." Seasons, however, vary, and no permanent change takes place. But if butterflies pass into a climate like Australia, which is permanently dry, "the diminution which occurs remains permanent in all subsequent generations in their new habitat, and the deteriorated condition of the species is established for ever."**

Change of food also produces the most marked results.

"The Tiger-moth (Chelonia caja), whose caterpillar is the familiar Woolly-bear, is almost the classical instance of the effects of food upon colour. It appears to be in any case a most variable species. The pages of The Entomologist, and other journals devoted to entomology, contain numerous records of varieties, some of which have been traced tc food, while others have not a known history. The orange-red of the hind wings may be replaced by yellow, and the proportions of brown and white in the fore wings are subject to immense fluctuation. Eimer (Organic Evolution. p. 150) quotes from Koch a number of colour changes which accompany, and are probably caused by a change of diet. Thus, if fed upon lettuce, the white ground of the fore wings predominates over the brown; the precise contrary is produced by feeding the larvae upon the leaves of the deadly nightshade; in moths bred from larrae which have been fed upon the leaves of this plant, the white becomes almost obliterated, while the bluish marks upon the hind wings fuse together and displace the orange-yellow ground colour. Koch concludes the account of his observations with the following remarks: 'Must not similar processes occur equally, and even on a larger scale, in the natural life of the countless forms of the class in question? When a great number of individuals perish through an occasional scarcity

* Eimer. Organic Evolution. t. 152. 
of their proper food plant, must not, nevertheless, considerable numbers survive by contenting themselves with other allied food materials, and so give rise to varieties whose origin we do not dream of, and which therefore we are led to regard as new species?'"(Beddard. Animal Coloration. pp.52-3.)

"Nocturnal species which live exclusively on conifers, have dull colours, usually grey, as, for example, our fine Hawk-moth, or the Pine Spinner, and several foreign species. This is so invariably true, that Koch was able to conclude from the colours of certain species from Sydney and Baltimore that the caterpillars lived upon coniferous plants, and when he suggested that they should be sought on such plants, his conclusion was found to be correct."-(Eimer. Organic Evolution. p. I50.)

"Mr. Goss found that the larva of one of our Fritillaries (Melitoea artemis) when fed upon honeysuckle, which is not the usual foodplant of the caterpillar, became very dark-coloured imagos. One of the Thorn-moths (Ennomos angularia) shows variations in colour according as to whether the larva has been fed upon oak, hawthorn, lime, or lilac."-(Beddard. Ibid. p. 49.)

\section{Structure also affects the colours of organisms.}

"Mr. Tylor has called attention to an important principle which underlies the various patterns or ornamental markings of animals, viz., that diversified coloration follows the chief lines of structure and changes at points, such as the joints, where function changes. $\mathrm{He}$ says:- 'In butterflies the spots and bands usually have reference to the form of the wing and the arrangement of the nervures, and there is much evidence to show that the primitive markings are always spots in the cells, or between the nervures, or at the junction of nervures, the extension and coalescence of these spots forming borders, bands, or blotches, which have become modified in infinitely varied ways." (Wallace. Darwinism. pp. 288-9.)

The organisms of certain caterpillars seem to be modified in colour through the photographic power of reflected light, which assumes the tint of the substance from which it is reflected, as in the case of the child holding the yellow flower of the buttercup to the cheek of his companion.

Some caterpillars of the small cabbage butterfly (Pontia rapae) were confined by Mr. J. W. Wood in boxes lined 
with different tints, just before their change into the chrysalis condition. In black boxes they assumed a very dark colour; in white boxes they became nearly white. He also showed that a similar change took place in nature, the chrysalis placed against a white wall being nearly white, that against a red brick wall being reddish, and that against a pitched paling being nearly black.

The caterpillar of an African butterfly feeds on the orange tree and a forest tree which has a lighter green leaf, and its colour corresponds with that of the leaves upon which it feeds. Mrs. Barber has discovered that it has the property of acquiring more or less accurately the colour of any natural object that it may be in contact with. A number of the caterpillars were placed in a case with a glass cover, one side of the case being formed of the red brick wall, the other side of yellowish wood. They were fed on orange leaves, and a branch of the bottle-brush tree was also placed in the case. When fully fed, some attached themselves to the orange twigs, others to the bottle-brush branch, and these all changed to green pupae and each corresponded in tint to the leaves around it, the one being a dark, the other a pale faded green. Another attached itself to the wood, and the pupa became of the same yellowish colour; while one fixed itself just where the wood and the brick joined, and became one side red the other side yellow.*

Change of organic colour may also be due to chemical action.

"Many of the complex substances which exist in animals and plants are subject to changes of colour under the influence of light, heat, and chemical change, and we know that chemical changes are continually occurring during the physiological processes of development and growth."-(Tropical Nature. p. I86.)

* Wallace. Tropical Nature. pp. $167-9$. 
Writing upon this subject, Prince Kropotkin says :-

"It becomes less and less probable to admit that the animal colours are the result of a selection of accidental variations only. . . The food of the organism, and especially the amount of salt in it, the dryness or moisture of the air, the amount of sunshine, and so on, undoubtedly exercise a direct effect on the colour of the skin, on the fur, and on the very intimate anatomical structure of the animal. The direct modifying action of environment is very great, and no theory can claim to be scientific unless it takes it into consideration to its full amount."--(Nineteenth Century. vol. xxxiz., p. 689.)

But what does this mean, except that the first condition under which Natural Selection can take place is altogether wanting? And this also is what Prince Kropotkin admits, for he says:-

"Coloration responds to function; and there is a law in the distribution of colours and the development of the markings, while there ought to be none under the hypothesis of selected accidental variation."-(Kropotkin. Nineteenth Century. vol. xxxizi., p. 684.)

And yet he hesitates to reject the theory on that account, for he says :-

"As to the relative parts which must be attributed in the origin of each separate variation to Natural Selection on the one side and to the direct action of environment on the other side, it would simply be unscientific to trench upon such questions in a broadcast way so long as we are only making our first steps in discriminating the action of the latter agency. The first steps already indicate how complicated such questions are, especially in those cases where Natural Selection must act in an indirect way-not as a mere selection of already modelled forms, but as a selection of forms best capable to respond to the requirements of new conditions--in which case the intimate organisation of the living being comes in the first place."- $(p .68 q$.

Now in reply to this argument, I would venture to say that, in denying that these changes of colour are accidental, Prince Kropotkin removes what is absolutely essential to the theory of Natural Selection. For if the favourable 
variations are not accidental, this shows that they have not occurred among variations inevitably associated with sexual reproduction. If the change is due to the sensitive response of the organism, acted upon by external conditions, these are not the variations from which Natural Selection professes to select. With respect to the relative part which Natural Selection plays in comparison with the direct action of the environment, it is obvious, to say the least, that the more there is done by external condition, the less will be left to do by Natural Selection. How selection can act on forms best capable of responding to the requirements of new conditions-if that means a mere potency, and not an actually achieved change, more or less - appears to me utterly inconceivable.

A third test is based upon the utility of the variation. Mr. Darwin declares that transforming influences produce useless variations and cannot produce useful variations in face of changed conditions. On the other hand, he contends that Natural Selection cannot produce useless variations, but that all useful variations are the result of its action. But, at the same time, he warns us that it is not always easy to say how much is due to Natural Selection, or how much to transforming influence.

Mr. Darwin frequently insists on the fact that transforming influences produce unuseful variations.

"No doubt the definite action of changed conditions and the various causes of modifications, lately specified, have all produced an effect-probably a great effect-independently of any advantage."(Origin of Species. p. I60.)

"In many other cases modifications are probably the direct result of the laws of variation or of growth, independently of any good having been thus gained."-(Origin of Species. pp. 165-6.)

"As these variations seem of no special use to the plants, they cannot have been influenced by Natural Selection."-(Origin of Species. p. I74.) 
And indeed we find it very difficult to understand the utility of some of the modifications which take place. What advantage can it be, for example, to the insects of a particular district to be coloured blue? And yet,-

"In a forest of Southern Brazil, Dr. Seitz found a perfectly circumscribed region in which the insects were almost entirely blue; a few miles away from this locality the insects were red, yellow-any colour but blue; but in the particular locality blue was so characteristic a tint that, out of twenty butterflies, ten were entirely blue, and the remaining ten partially blue. Nor was blue found to be confined to the Lepidoptera--the flies and hemiptera were also largely blue."-(Beddard. Animal Coloration. p. 46.)

We cannot exactly see what advantage could accrue to a tree from the adoption of a fastigate or pyramidal growth, and yet the hotter parts of India modify some trees in this way.

"Dr. Falconer informs me that he has seen the English Ribston pippin apple, a Himalayan oak, Primus and Pyrus, all assume in the hotter parts of India a fastigate or pyramidal habit ; and this fact is the more interesting, as a Chinese tropical species of Pyrus naturally has this habit of growth."--(The Variation. vol. ii., p. 277.)

But it would be an immense mistake to infer that, because transforming influences are not limited by the principle of utility and can therefore put forth unuseful variations, all the variations which occur through that agency alone are not useful.

We have seen that transforming influences go on in association with the output of individual differences. Now it is quite clear that the absence of identity which distinguishes one individual from another is useful, as those will readily admit who have had to live with twins between whom it was impossible to distinguish. We cannot doubt that it is well that the shepherd should be able to distinguish each individual sheep which he tends, and that the 
ewe should be able to recognise her lambs from all the rest of the flock. It would be a disastrous thing for us if there were no distinctive marks of individuality-if we could say of one another what the dramatist makes the mad Octavian say of his faithful friend Roque :-

"Roque :

"Oct. :

Signor! do you not remember my countenance?"

No. Providence has slubbered it in haste,

'Tis one of her unmeaning compositions

She manufactures when she makes a gross :

She'll form a million such-and all alike-

Then send them forth, ashamed of her own work,

And set no mark upon them. Get thee gone!"-(Colman.)

We know that the contrary is the fact and that

"The Almighty Maker has throughout

Discriminated each from each, by strokes

And touches of $\mathrm{His}$ hand, with so much art

Diversified, that two were never found

Twins at all points."

Mr. Darwin contends that the transforming influence of changed conditions do not produce useful results.

"If, for instance, a plant had to be modified so as to become fitted to inhabit a humid instead of an arid station, we have no reason to believe that variations of the right kind would occur more frequently if the parent-plant inhabited a station a little more humid than usual. Whether the station was unusually dry or humid, variations adapting the plant in a slight degree for directly opposite habits of life would occasionally arise, as we have reason to believe from what we know in other cases."-(The Variation. vol. ii., pp. 290-I.)

This dictum is, however, contradicted in some cases by the palpable effects of transforming influence. When the cat loses its fur, and the sheep loses its wool, in hot countries, the usefulness of the change must be obvious to all. When, under new conditions, or animated by new 
impulses, the animal adopts a new line of action, the law by which the use of a limb strengthens that limb, and the purposive movement tends to become automatic, must be of very great value, as those will admit who have learned to appreciate the difference of facility between performing an accustomed action and one which has never been attempted before.

There can be no doubt that there is a correlation between the outward conditions of deserts and the vegetable organisms which flourish more or less in such localities. In an arid district, overrun with cattle and rodents, spinescent leaves would act as a protection from attack, and would repeat the warning of the thistle-Noli me tangere. And it is equally clear that any formation of growth which tended to enable the plant to resist heat and long drought, would be undoubtedly useful. Where plants remain essentially unchanged in such conditions, it is because they have become annuals, and flourish during the rainy season when the problem of resisting the combined effects of heat and drought does not arise. In some cases a remarkable provision is made to preserve the race. Bulbs of species of Allium store water within the inner scales, whilst the outermost series become woody in texture as a protection against the hot sand in which they lie, the temperature of which sometimes rises to $130^{\circ} \mathrm{Fah}$. There are plants in which certain buds swell into tubercles, capable of enduring the dry season, while the rest of the plant perishes. Where desert plants remain unmodified in the structure of the leaf, it is because they have secured an abundant supply of water. The long roots of certain plants reach a supply of water which would be otherwise unattainable. The Colocinth has an enormous length of root. It stands singly, it has large herbaceous leaves, it is without any means of preventing an excess of transpiration, for a cut shoot 
fades within five minutes, and yet it flourishes unshadowed through the whole summer. Long roots are also useful in enabling the plants to resist the extreme changes of temperature.

In other cases in which a plant survives through the whole year, it is adapted to its conditions by modifications which enable it to resist heat and drought, either by economising such moisture as they acquire or by storing it for subsequent use; and sometimes the same modification produces both these results. With respect to the first point many illustrations might be given. The mechanical tissues are hardened, and very hard wood resists heat because it encloses but little aqueous juices, so that there is little to evaporate. The leaves of desert plants are small, thereby lessening the surface of the transpiring organs; or else they are suppressed almost or altogether. Sometimes the inrolled margins of leaves make them assume the form of a closed cylinder, and thus they present less surface. The thickness of the cuticle tends powerfully to prevent the loss of water. Many plants are protected against a too energetic transpiration by the existence outside the cuticle of a thick layer of a sort of varnish, without doubt of a resinous nature. The cuticle is sometimes "ornamented with parallel and straight or undulating striæ, or they may be more or less reticulated." The effect of this modification is to temper the strong glare of the sunlight. So, at least, it may be inferred from the fact that a sheet of sensitive paper is not darkened to the same extent under sheets of glass with striated and reticulated surfaces as under a clear sheet of glass of the same thickness when fully exposed and for the same time to sunlight.

Some desert plants secrete strong-scented ethereal oils; and, since Dr. Tyndall has shown how minute quantities of such oils diffused through the air are capable of arrest- 
ing radiant heat, it has been suggested that this is one of the many resources to which desert plants appeal in order to reduce the ill effects of the heated atmosphere which surrounds them. Sometimes desert plants effect a storage of water; this is the case with succulent leaves. The increased substance of the leaf is accompanied by a greater development of palisade-tissue, with diminished intercellular passages. Certain mineral salts are secreted by some plants. Later on, after the rainy season is over, these excessively hygrometric salts absorb dew, which is thus transmitted to the plant, and this enables it to retain its bright green character all through the hot season. Some desert plants have leaves of intense hairiness. This feature of desert plants is an invaluable means of lessening the heat, by forming a non-conducting surface. It is also a means of absorbing dew during the summer when no rain falls. Sometimes the same hairs answer first one purpose and then another; they are "bladdery and filled with water." These latter may finally collapse, dry up, and form a glassy sheet.

There can be no reasonable doubt that these modifications are useful to the plants. It may be asked,- - How have they been acquired? The spinescent leaves which protect the plant, the long root which finds its way to the water and supplies the plant with an inexhaustible supply, the buds which endure when the rest of the plant is destroyed, the woody texture which protects the water stored in the scales of the bulb, the hardened wood, the small leaf, the enfolded leaf, the thickness of the cuticle, the coat of varnish, the striated surfaces, the ethereal oils, the succulent leaves, the palisade-tissue, the mineral salts, the "hairiness" of the leaf,-all are believed to result from the direct action of the outward conditions upon a responsive organism. These modifications are made "by 
the circumstances for the circumstances." That is, in effect, the contention of Rev. George Henslow.*

The evidence in support of the assertion that spines are the direct outcome of the environment, rests upon the well-known fact that there are many instances of plants losing their spines altogether when grown under different circumstances. M. Lothelier found that, by growing Berberis vulgaris in a moist atmosphere, it bore no spinescent leaves; but in a perfectly arid atmosphere, it bore spines only. Intensity of light also favoured their production. The elongation of the root is caused by the direct effect of the water which lies within its reach, or, in other words, "the well-known responsive power of the apices to moisture." Thus if, for example, the tip of the root of a seedling turnip gets into a field drain-pipe, it may grow to a length of some yards, of course never producing a turnip. The hardening of the mechanical tissues generally, which so often results in special spiny processes, is brought about by drought and other conditions of the environment. That the reduction of leaf surface is the result of drought is proved in several ways. The same plant will produce much larger leaves in March or April when a good supply of water is at hand, but minute leaves in June when the supply is deficient. If the same plant is grown in the Nile Valley, it ceases to produce the smaller summer foliage, and resembles the ordinary herbaceous leaves of temperate climates. Salvia lanigera, growing in the Delta, has flat leaves eight inches in length; but when in the desert they are only about twoand-a-half inches long with the margins enrolled. The thickness of the cuticle is greater under sunlight than when grown in the shade. The production of wax on the

* The Journal of the Linnean Society-Botany. vol. xxx., pp. 218.263 . 
surface of leaves is dependent ultimately upon the increased amount of light (and heat?) which appears to deoxidise chlorophyll and to leave wax as one of its products. The striated surfaces are associated with cells which are convex towards the exterior, and M. Vesque explains the correlation by supposing that the striated surfaces tend to lessen the effect of the sun's rays which would otherwise be intensified by the form of the cells, which would act as lenses. In this case the utility of the correlation is obvious, and, if we may argue from the analogy presented by other cases, it may be regarded as the result of the action of the environment, and, probably of correlated variation also.

The secretion of ethereal oil is the consequence of intense heat. Thus, Grisebach observes that Arabia is on this account distinguished by its aromatic and resinous plants, of which several are equally indigenous in the steppes of the East. Succulent leaves are the result of the direct action of salt. The presence of salts has been proved by M. Lesage to be the immediate cause of succulency in maritime plants of temperate climates, and he succeeded in making plants succulent which are not so ordinarily. M. Battandier cultivated Sedum Clusianum, and the leaves at once began to assume a flatter character. He also observes that Sedum rubens and Sedum Magnoli have flat leaves in a wet season, but cylindrical leaves in a dry one. The common maritime Samphire of temperate climates, when cultivated in a garden, became luxuriant and bore flat and smooth leaves.

The production of hair occurs when normal development is arrested. This explanation will satisfactorily explain the existence of the hairiness of plants in the deserts; for drought, aided by the barrenness of the soil, tends to arrest the development of parenchymatous tissues. These

AA 
facts will suffice to shew that transforming influences, apart from Natural Selection, are fully able to produce favourable variations.

Organic colouring is the indication of specific differences; and it is the reasonable opinion of some writers that specific variations are highly useful to the groups which they serve to indicate.

"Easy recognition is important to all animals, and especially to those which are gregarious and whose safety largely depends upon their keeping together. . . . I was struck by the remarkable fact that a large number of antelopes, which are usually protectively coloured with sandy or earth-coloured tints, are nevertheless rendered conspicuous by large white patches, usually behind or on the flanks, and often accompanied by peculiar white marks on the face, but always different in each species. . . . It seems to me probable that these markings have been acquired for the purpose of enabling any strayed member of the herd to recognise his fellows, and to be recognised by them. . . . Most of these animals depend for safety on keeping together, when they can defend themselves against most beasts of prey; and as each kind will not usually allow animals of another species to join them, it becomes doubly important that every species should have a distinctive marking, especially with desert animals, which are obliged to roam far in search of food and water, and still more when there are many allied species of the same general form inhabiting the same country."-(Fortnightly Review. vol. xl., pp. 305-6.)

"Mr. J. E. Todd, discussing the subject of 'Directive Coloration in Animals,' in the American Naturalist, defines directive coloration as that which is in any way useful to a species, by assisting in mutual recognition between individuals, or by indicating one to another their attitude of body, and probable movements. Of this he gives a number of instances."-(Scientific Neres. vol. i., p. 516.)

It is highly probable that these specific differences of colour are due to the direct action of definite causes, and do not arise from Natural Selection. Mr. Henslow contends that this is the case in the somewhat analogous instance of "the peculiar and special displays of bright tints distributed in spots and streaks in certain and definite places only, in flowers. These have been called 
'guides' and 'path-finders,' as they invariably lead to the nectaries."

"If the theory be true, which I am endeavouring to maintain throughout this book, all these effects are simply the direct results of the insects themselves. The guides are always exactly where the irritation would be set up; and I take them to be one result of a more localised flow of nutriment to the positions in question."(The Structure of Flowers. p. I78.)

Those causes of modification which can co-operate with transforming influences are also useful. A structure of co-ordinated parts is obviously useful, and the correlated variation which assists in transforming one co-ordinated structure into another is obviously useful. For although this may sometimes act in a way which does not seem of any use, yet, taken on the whole, it must be of immense value; for a large increase in the growth of the horns would be an unbearable burden if correlation of growth did not come to the aid of the animal so modified. In bi-lateral organisms, correlation of growth gives a balance and equipoise, the absence of which would be most disastrous. And if we are permitted to regard coordination of structure as the result of this principle, its value and utility can be doubted by no one.

It is quite conceivable that other changes associated with reproduction may also prove useful. Take, as an illustration, the case of the ancon ram. Here you have a considerable divergence from the normal structure, effected at one birth, and which was useful from the point of view of domestication, because the animal with short legs could not jump so well as the others, and consequently could be kept in bounds by lower, and therefore less expensive, fences. It is quite conceivable that, in some cases at any rate, a similar use might be found for an organism suddenly developed in nature. By such a modification, the 
variants might be compelled to alter their habits to some extent, and thus not to compete so severely with those retaining the normal form from which they were derived.

There may be great use sometimes in the principle of reversion. It is quite possible that animals may suddenly find themselves in some condition of life unfamiliar to themselves and to their immediate forefathers, but identical with conditions to which a still more remote ancestry was subjected. If then, in consequence of their descent, their bodies should be found to possess a special facility of adaptation, or if some long latent instinct were revived, the result might be of a very beneficial character.

Nor must we omit from this enumeration the fact that many of these influences are not only reproduced, but enhanced in the process of reproduction. They are almost sure to be reproduced by the action of heredity, when the modifying circumstances which affect all the individuals of a species, or most of them, remain the same. But they are reproduced with an added power. The habit becomes an instinct, a second nature; the adapted organism is made more fit for its work by transmission through one generation to another.

But if the changes due to transforming influences are sometimes useful, this disposes of the contention that all useful variations are due to Natural Selection. Yet the inexorable logic of the theory still asserts that the useless variation cannot be produced by Natural Selection. So far then as changed conditions produce transforming effects which are not useful and useful at every stage, to that extent the action of Natural Selection is limited. Opportunities of transmutation, open to transforming influences, are closed against Natural Selection.

There is another case, to which further reference will be made hereafter, in which transforming influences may, 
and actually have, produced an organ piece-meal, which is of no use until all the parts are fully developed and set to work together to perform a particular functiona case in which Natural Selection could not have aided in the transmutation; because parts of the imperfectly formed structure were of no use until they were developed into one co-ordinated organ.

Mr. Darwin contends that when we have to deal with useful variations, it is not always possible to say how much is due to Natural Selection and how much to transforming influence.

"When a variation is of the slightest use to any being, we cannot tell how much to attribute to the accumulative action of Natural Selection, and how much to the definite action of the conditions of life. Thus, it is well known to furriers that animals of the same species have thicker and better fur the further north they live; but who can tell how much of this difference may be due to the warmestclad individuals having been favoured and preserved during many generations, and how much to the action of the severe climate? For it would appear that climate has some direct action on the hair of our domestic quadrupeds." -(Origin of Species. p. 107.)

"We may easily err in attributing importance to characters, and in believing that they have been developed through Natural Selection. We must by no means overlook the effects of the definite action of changed conditions of life,- of so-called spontaneous variations, which seem to depend in a quite subordinate degree on the nature of the conditions,-- of the tendency to reversion to long-lost characters,of the complex laws of growth, such as of correlation, compensation, of the pressure of one part on another, \&c.,-and, finally, of sexual selection, by which characters of use to one sex are often gained, and then transmitted more or less perfectly to the other sex, though of no use to this sex. But structures thus indirectly gained, although at first of no advantage to a species, may subsequently have been taken advantage of by its modified descendants, under new conditions of life and newly acquired habits." -(Origin of Species. pp. 157-8.)

Without referring to the argument urged at the commencement of this chapter, that the selection of Natural Selection cannot co-operate with transforming influences, we may cite three cases to test the truth of this assertion. 
It may be noted that there are some useful variations, which are produced by transforming influences in such a way as to exclude the action of Natural Selection.

If variations which are not useful have arisen from other causes than the action of Natural Selection, and change of conditions has rendered them of possible utility, it does not follow that Natural Selection will come into play. They may have arisen first, apart from utility, and they may then have been utilised by the intelligence of animals. Browning, in his Pippa Passes, states a case which may be taken as illustrative of this principle:-

"Have you not seen me range our coppice yonder In search of a distorted ash ?-I find The wry spoilt branch a natural perfect bow."

But it is only those useful variations, the utility of which has led to their selection at every stage of development, which have been produced by Natural Selection.

Mr. Darwin says that, "when a variation is of the slightest use to any being," we cannot tell how much is due to transforming and how much to selecting influences. But we must remember that Natural Selection acts by life and death. A useful variation, to be useful from the point of view of Natural Selection, must make a difference of life and death, and we can hardly believe that "a variation of the slightest use" can have been produced by Natural Selection. The illustration which he gives as to his doubt on this matter does not seem to be particularly well chosen. He does not know whether the better fur is produced by transforming or selecting influences, and he adds that climate has some direct influence on the hair of our domestic quadrupeds. But the facts of the case are hardly such as to justify this statement.

No better illustration of organic sensitiveness to external conditions could be found than the following account, 
in which Captain Owen has recorded his most instructive experience in connection with the cats of Mombas.

"We often remarked that the cats, instead of fur, were covered with a coat of short and stiff hair, but always considered them to be a different species from those in England, and never had an idea that the mere change from the ship to the shore would effect so extraordinary an alteration. A cat which we had brought from Algoa Bay, and which had retained the same appearance as at first, was landed at Mombas during one of our visits. Upon our return, a period of only eight weeks, it had undergone a complete metamorphosis, having parted with its sandy-coloured fur, and gained in return a coat of beautiful short white hair."-(Narrative of Voyages to explore the shores of Africa, Arabia, and Madagascar. vol. ii., p. 180.$)$

Speaking of this story, Mr. Darwin says :-

"All the cats in Mombas are covered with a short stiff hair instead of fur. It is natural to suppose that this is due to the climate, and we are able in this case almost to demonstrate that it is so." - (The Variation. vol. i., p. 46.)

Several accounts have been published of the change which sheep imported from Europe undergo in the West Indies.

"Dr. Nicholson, of Antigua, informs me that after the third generation, the wool disappears from the whole body, except over the loins, and the animal then appears like a goat with a dirty doormat on its back."-(The Variation. vol. i., p. 98.)

"Climate definitely influences the hairy covering of animals; in the West Indies a great change is produced in the fleece of sheep in about three generations. Dr. Falconer states that the Thibet mastiff and goat, when brought down from the Himalaya to Kashmir, lose their fine wool. At Angora not only goats, but shepherd-dogs and cats, have fine fleecy hair, and Mr. Ainsworth attributes the thickness of the fleece to the severe winters, and its silky lustre to the hot summers. Burnes states positively that the Karakool sheep lose their peculiar black curled fleeces when removed into any other country." (The Variation. vol. ii., p. 278.)

I have thus endeavoured to show that Natural Selection and transforming influence cannot co-operate nor co-exist in the world of nature, as it is known to us; and in the 
instances which have been adduced, we have applied tests to show that the transmutation which takes place is by transforming influence, and not by Natural Selection. The effect of this argument can only be weakened in two ways, either by showing that changed conditions do not produce the effects attributed to them in the cases just cited; or by a change of front, by understanding Natural Selection in some other sense than that which the strict definition of the theory indicates.

We have already seen that the argument based upon the assumption that the modifications of "the body" cannot be inherited is rendered invalid by the admission that the sexual elements may be modified, and that these modifications can be inherited. Sometimes the transforming influences of changed conditions have been depreciated in order that the power of Natural Selection may be unduly appreciated. I am not aware that any writer has done this in a formal manner, and with full consciousness of what he was doing; but by collating some passages from the works of Mr. Darwin, we shall be able to see how, no doubt unconsciously, this process of depreciating the transforming influence of changed conditions has taken place. Mr. Darwin asserts the efficacy of the principle as a law of nature, elsewhere he qualifies this statement; then he appeals to our ignorance, or to the all-pervading mystery which is associated with the subject; then he declares that it is not easy to discover how far a given effect is due to Natural Selection, and how far it is due to transforming influence; then the efficacy of the principle of transforming influence is denied; and finally, Natural Selection is substituted for the discarded principle of transformation. We have now to consider what grounds there are for making these assertions, and how far the conclusions arrived at can be justified. 
It is argued that in some cases transmutation does not take place at all, or only after many generations.

"We have good grounds for believing that the influence of changed conditions accumulates, so that no effect is produced on a species until it has been exposed during several generations to continued cultivation or domestication."-( The Variation. vol. ii., p. 26I.)

"It is certainly a remarkable fact that changed conditions should at first produce, so far as we can see, absolutely no effect, but that they should subsequently cause the character of all species to vary." -(The Variation. vol. ii., p. 263.)

It is difficult to understand how Mr. Darwin can make such assertions, apparently as universal law, in face of the facts which have been adduced. But if this were true of all organisms, it would not affect our present argument in the least; inasmuch as it shows that neither transforming influence nor Natural Selection has been at work at all. The point which is vital, is whether the change which takes place, takes place in connection with all submitted to a given influence. If it does, then there may be-and probably is-transmutation without any kind of selection. In the next place, it is asserted that in many cases we are too ignorant to arrive at any satisfactory opinion on the subject.

"No doubt each slight variation must have its efficient cause; but it is as hopeless an attempt to discover the cause of each as to say why a chill or a poison affects one man differently from another. Even with modifications resulting from the definite action of the conditions of life, when all, or nearly all, the individuals which have been similarly exposed are similarly affected, we can rarely see the precise relation between cause and effect." - (The Variation. vol. ii., p. 292.)

"Such considerations as these incline me to lay less weight on the direct action of the surrounding conditions, than on a tendency to vary, due to causes of which we are quite ignorant."-(Origin of Species. p. 107.) 
It may be well to bear in mind how ignorant we are. Only by such a consciousness can we be stimulated to extend the horizon of our knowledge. But if this fact is used to depreciate our knowledge of acknowledged facts, it is a line of argument which is to be strongly deprecated. Mr. Wallace says :-

"This argument, from our ignorance, is a very bad one, when we consider how recently whole groups of specific differences, formerly looked upon as useless, have been brought under the law of utility.' --(Fortnightly Review. vol. xl., new series, p. 303.)

\section{Mr. Romanes says :-}

"Be it observed, I am not objecting to Mr. Mivart's scepticism touching the scientific cogency of the hypothesis which he is criticising. As a man of science, he is within his legitimate province, so long as he is pointing out what he regards as the weaknesses and shortcomings of Mr. Darwin's attempts at explaining certain phenomena of organic nature. My objection to Mr. Mivart's method is that it runs counter to the fundamental instincts of science, by assuming that of these particular phenomena no scientific explanation is possible. Mr. Darwin may have utterly failed in all his attempts at explaining these phenomena; but, at any rate, in seeking to explain them he was working as a man of science; or in the belief of science that all nature is one whole, without any part ruled off as necessarily inaccessible to rational inquiry. But by seeking to merge in the final mystery of things certain observable facts of natural history, Mr. Mivart is abdicating his functions as a man of science, and going back to the mysticism of a former age. Step by step this mystical interpretation of natural phenomena has had to yield before the scientific interpretation."-(Fortnightly Review. vol. xxxviii., new series, p. q2.)

The scientific.man approaches a problem, then, with the faith that an explanation is possible, if he had only the true key to the solution.

Mr. Greg argues forcibly against any depreciation of the action of physical law, on the ground that its effects are obscured by new conditions, the significance of which has not been properly understood. 
"When astronomers found the calculable influence of the law of gravitation on the motion of the planets disturbed, and pro tanto counteracted by some unexplained and undiscovered agency, they at once confidently inferred the existence of an unknown body at an unguessed distance, but in a specified direction. They believed in Neptune long before they found him. Why should we not do in physiology what they did in physics?"-(W. R. Greg. Enigmas of Life. p. 60.)

Mr. Wallace speaks to the same effect.

"When the geologist explains how the contour of a country has been formed by rain and ice, it is not said that he has explained nothing, unless he goes on to show exactly how rain and snow are formed, or even goes further back to the cause of gravitation, which is really what gives them all their power to do any work; and when the physicist explains how thunder and lightning are produced by a reference to the electric spark and its accompanying sound, he is not told that the explanation is valueless till he has discovered the nature and cause of electricity itself."-(Wallace. Nineteenth Century. vol. vii., p. ro5.)

Mr. Darwin asserts that certain variations could not have been caused by the direct action of the conditions of life. Let us take one of the cases he cites, viz., the modified skull of the Niata ox.

"This breed bears the same relation to other breeds, as bull or pug dogs do to other dogs; or as improved pigs do to common pigs. The common codfish presents a similar monstrosity, called by the fisherman the bulldog cod. Almost a similar conformation characterises the extinct and gigantic Sivatherium of India."-(The Variation. vol. i., pp. 89-gr.)

It may be well to compare the assertion of Mr. Darwin, that the Niata cattle could not have been caused by the direct action of the conditions of life, with what he says of the domesticated pig, which resembles the Niata cattle in the characteristic formation of its skull.

He quotes, apparently with approval, the argument of Nathusius, that the shape of the skull is largely due to plentiful food in an early period of life, and to a change of 
habit, the result of domestication, and to the principle of correlated variation.

"It is scarcely possible to read Nathusius's excellent Vorstudien and doubt that, with the highly improved races of the pig, abundant food has produced a conspicuous effect on the general form of the body, on the breadth of the head and face, and even on the teeth. Nathusius rests much on the case of a purely bred Berkshire pig, which when two months old became diseased in its digestive organs, and was preserved for observation until nineteen months old; at this age it had lost several characteristic features of the breed, and had acquired a long, narrow head, of large size relatively to its small body, and elongated legs."-(The Variation. vol. ii., p. 279.)

"He (Nathusius) lays much stress on the fact that all wild and semi-domesticated pigs, in ploughing up the ground with their muzzles, have, whilst young, to exert the powerful muscles fixed in the hinder part of the head. In highly cultivated races this habit is no longer followed, and consequently the back of the skull becomes modified in shape, entailing other changes in other parts."-(The Variation. vol.i., p. 72.$)$

"Nathusius has shown that, with the improved races of the pig, the shortened legs and snout, the form of the articular condyles of the occiput and the position of the jaws, with the upper canine teeth projecting in a most anomalous way in front of the lower canine, may be attributed to these parts not having been fully exercised. For the highly cultivated races do not travel much in search of food, nor root up the ground with their ringed muzzles. These modifications of structure, which are all strictly inherited, characterise several improved breeds, so that they cannot have been derived from any single domestic or wild stock."-(The Variation. vol. ii., p. 299.)

"We shall, in a future chapter, also see that the skull and limbs are apparently in some manner correlated, so that any change in the one tends to affect the other."-(The Variation. vol. $i ., p .73$.)

We have now to ask what part artificial selection has played in the production of this phenomenon.

In the first place it is maintained by Mr. Darwin that the curly tail of the highly-bred pig cannot have been made the subject of selection; so that in this organ we have an illustration of a modification not due to the principle of selection. It seems to me that we may apply the same 
argument to the formation of the head, and there is some justification for this inference in the following fact :-

"Nathusius has remarked (and the observation is an interesting one) that the peculiar form of the skull and body in the most highly cultivated races is not characteristic of any one race, but is common to all when improved up to the same standard. Thus the largebodied, long-eared English breeds with a convex back, and the smallbodied, short-eared Chinese breeds with a concave back, when bred to the same state of perfection, nearly resemble each other in the form of the head and body. . . . With most domestic animals . the result of selection has been divergence of character, here it has been convergence."-(The Variation. vol.i., p. 73.)

Speaking of feral pigs, i.e., of pigs which have been domesticated, but have subsequently been allowed to run wild, Mr. Darwin says :-

"The young, as we have just seen, reacquire their longitudinal stripes, and the boars invariably reassume their tusks. They revert also in the general shape of their bodies, and in the length of their legs and muzzles, to the state of the wild animal. From these several facts we see that with pigs, when feral, there is a strong tendency to revert to the wild type; but that this tendency is largely governed by the nature of the climate, amount of exercise, and other causes of change to which they have been subjected."-(The Variation. vol. i., pp. $77-78$.

The Niata cattle could not have been developed apart from changed conditions. They could scarcely have been developed by Natural Selection; for it is not easy to understand how such a conformation could have been largely profitable. In all probability the phenomenon is due to the abundance of food arising from a luxuriant pasturage. So long as this condition underwent no change, the modification would not be injurious; but if from any cause they could only secure a short pasture, the change would be fatal.

"When the pasture is tolerably long these cattle feed, as well as common cattle, with their tongue and palate; but during the great droughts, when so many animals perish on the pampas, the Niata breed lies under a great disadvantage, and would, if not attended to, 
become extinct; for the common cattle, like horses, are able just to keep alive by browsing on the twigs of trees, and on reeds, with their lips. This the Niatas cannot so well do, as their lips do not join, and hence they are found to perish before the common cattle."-(The Variation. vol. i., pp. go-I.)

It seems to me, then, that, on the whole, the Niata cattle do not afford a good illustration of the principle that changed conditions and their coadjutors could not have produced this conformation. The assertion that it is not always easy to say how far transforming influence and how far Natural Selection have co-operated to produce a given transmutation, has already been answered by the contention that the co-operation of the two processes is an impossible one.

Having thus depreciated the transforming effects of changed conditions, Mr. Darwin proceeds to attribute the transmutation of species to Natural Selection only, and he takes for the special sphere of its operation the case of a confined and isolated area.

"In a confined or isolated area, if not very large, the organic and inorganic conditions of life will generally be almost uniform; so that Natural Selection will tend to modify all the varying individuals of the same species in the same way."-(Origin of Species. $p .8$ S.) )

This illustration is an unfortunate one, because $\mathrm{Mr}$. Darwin, on the very next page, gives a very good reason to show that such conditions would not be favourable to the action of Natural Selection.

"If, however, an isolated area be very small, . . . the total number of the inhabitants will be small, and this will retard the production of new species through Natural Selection by decreasing the chances of favourable variations arising."-(Origin of Species. p. 82.)

And therefore in this connection he admits the possibility of transformation apart from Natural Selection.

"In separated districts long continued exposure to different conditions of life may produce new races without the aid of selection." -(The Variation. vol. ii., p. I76.) 
But this is not all. For when Mr. Darwin acknowledges that he has not paid sufficient attention to the influence of changed conditions, what does he add?-

"In my opinion the greatest error which I have committed has been not allowing sufficient weight to the direct action of the environment-i.e., food, climate, \&c.-independently of Natural Selection. Modifications thus caused, which are neither of advantage nor disadvantage to the modified organism, would be especially favoured, as I can now see, chiefly through your observations, by isolation in a small area, where only a few individuals lived under nearly uniform conditions."-(Life and Letters. vol. iii., p. I59.)

And yet his opinion upon this subject seems to be far from fixed, for elsewhere he says :-

"In North America, in going from north to south, or from east to west, it is clear that the changed conditions of life have modified the organisms in the different regions, so that they now form distinct races, or even species. It is further clear that in isolated districts, however small, the inhabitants almost always get slightly modified, and how far this is due to the nature of the slightly different conditions to which they are exposed, and how far to mere interbreeding in the manner explained by Weismann, I can form no opinion."-(Life and Letters. vol. iii., p. I6I.)

But interbreeding is equivalent to panmixia, and panmixia is equivalent to the absence of Natural Selection. What, then, is the opinion of Mr. Darwin on this subject? I. That in a limited area Natural Selection will act, or will tend to act, through the uniformity of the conditions. 2. That Natural Selection will tend not to act through the small output of variation which there necessarily must be in a small area. 3. That transforming influence-not selection-will act in a limited area, of which the case of the Saturnia is held to be a proof. 4. He does not know whether to attribute the transmutation to transforming influence or to interbreeding, i.e., the absence of Natural Selection.

The phenomena which we have been considering seem to accord with the idea of a transforming influence; they 
do not afford the conditions necessary for the application of Natural Selection. It might, however, be said that in other cases Natural Selection can be seen in full action. If that is so, it is curious that neither by observation nor experiment has Natural Selection pure and simple been proved to have any place in nature. No one has taken a group of animals and placed them in new circumstances and noted the different stages of the theoretical process as they are depicted in the glowing rhetoric of theory; and till that has been done, no one can boast that the truth of Natural Selection has been demonstrated. But a process which is not Natural Selection has taken placea process with which it is impossible that Natural Selection, if it were a law of nature, could compete.

In considering the question of the inherited effect of habit, and the transforming influence of changed habits, it may first of all be observed that some writers, who controvert that principle, admit that a considerable effect is produced upon the individual organism submitted to such influence. This Mr. Ball admits on the very threshold of his enquiry, although he argues against the inheritance of such effects.

"It is obvious that we can produce important changes in the individual. We can, for example, improve his muscles by athletics and his brain by education. The use of organs enlarges and strengthens them; the disuse of parts or faculties weakens them. And so great is the power of habit that it is proverbially spoken of as 'second nature.' It is thus certain that we can modify the individual. We can strengthen (or weaken) his body; we can improve (or deteriorate) his intellect, his habits, his morals."(William Platt Ball. Are the Effects of Use and Disuse Inherited? p. 2.)

Again, it will be admitted by all that, as the organism of the individual responds to the influence of habit, so in the case of a species the adoption of new habits does lead, 
somehow or other, ultimately to a modification of structures similar to that undergone by individuals. It is assumed that this will take place when imaginary cases are suggested to illustrate the way in which the transmutation of species might be brought about by Natural Selection.

We see actual illustrations of this principle in the different kinds of domesticated dogs, among which different habits of life are coexistent with different modifications of structure. In the case of the trotting horse of America, already referred to, there is a correlation, however caused, between the mode of progression and the modifications of structure which result therefrom.

There are two points of difference between changed conditions and changed habits in modifying species, to which it may be well to draw attention. In the first place, the change of outward conditions acts upon an organism which is more or less passive, if responsive; whereas in the case of habits the organism is the active coadjutor. This is altogether to the advantage of habit, considered as a transforming influence. But there is another respect in which habit is sometimes, though not always, at a comparative disadvantage. It does not follow, at least so far as our experience is concerned, that persons who have the same habits necessarily intermarry. The accomplished musician does not always marry the accomplished musician; the athletic youth does not necessarily marry an athletic maiden; the poet does not generally marry a poet (the Brownings afford a splendid exception to the rule), nor a philosopher a philosopher. Hence the special aptitude of the one is qualified by the normal incapacity of the other, and the offspring cannot be expected to repróduce in all cases the attributes of the more gifted parent. But in some cases both parents follow the same calling and $\mathrm{BB}$ 
practice the same habits. I think that we may venture to say that this will often happen in the case of the acrobat. Not only will the young children begin to mimic the actions of their parents, and play at being clowns and tumblers, after the manner of all children, but they will soon begin to be subjected to that severe discipline, at a very early age, which is necessary for supreme excellence in their calling. Assuming that this is so, what is the result? Fortunately I am able to give a concrete instance by way of reply:-

"Hosono Kojiro (a Japanese acrobat) was thirty-two years of age, and was the eleventh descendant of a celebrated athlete who adopted the vocation of rope-dancing, balancing and vaulting, in the period when the mighty Taiko, or Hideyoshi, ruled Japan. He showed me the cherished book of his pedigree, and proudly asserted that only two others of his calling in all the Empire could point to so extended a line of acrobatic ancestry. He believed that a large portion of his skill had been transmitted from his progenitors, and I have no reason to doubt that the superiority of Japanese gymnasts to all others is, in fact, a matter of inheritance, since there are few among them whose professional lineage cannot be traced back at least a century. His offspring were born, as he had been, and his father before him, with physical peculiarities which made them in a measure exempt from rigorous training, and enabled them to enter upon their public career even in infancy without hardship or risk of injury. One of his sons, a sturdy youth of eleven, had been attached to a travelling band before the end of his third year. Another . . . had tumbled about the stage in the shape of a compact ball of flesh while yet incapable of walking steadily, or expressing in articulate speech his delight at his own precocious prowess. A third, still a baby at his mother's breast, was held up before me in evidence of the extraordinary flexibility and suppleness which the house of Hosono claimed as its birthright. The arms and legs of this atom of humanity were twisted and braided, and his whole body was rolled tightly together until he was twisted into a living hard knot, without causing him perceptible discomfort, or provoking the least murmur of dissatisfaction."-(E. H. House, formerly Professor of English Literature in the Royal College at Tokio. Manchester Weekly Times-Supplement. Feb. Sth, I890.)

In the above argument, I have assumed that the acrobat marries an acrobat; but if this is not the case, it will be 
all the better for my argument, for the result will show that exceptional ability on the part of one parent, combined with training from earliest infancy of the offspring, will produce most wonderful results. But it may be very much questioned whether, in nature, this marriage of skilled and unskilled ever takes place. The struggle for existence compels all of them to meet their fate by attaining a common excellence in various arts. When the two sexes practically occupy different spheres, and perform different actions, this is a case of those secondary sexual elements, which afford one of the most striking and marvellous illustrations of correlation; but mysterious as this fact is, there is nothing in it, so far as I can see, to militate against the idea of the transforming influence of changed habits. On the contrary, if we suppose, as seems reasonable, that this difference in the modes of life, is itself an adaptation to new conditions, it shows how new habits arise and are inherited in the different sexes of the same species. This argument seems to justify the doctrine for which we are contending; a transforming influence takes place independently of Natural Selection, which is not Natural Selection. It produces marked results which, in combination with other transforming influences-such as changed conditions, correlated variation, etc.,-will amply suffice for the transmutation of species.

Pure Darwinism, which relies on the selection of favourable birth variations, denies that any acquired character can be inherited; and it may be well to consider the arguments by which this theory is supported.

Dr. Weismann contends that no character can be acquired for which there is not an inborn disposition. He asserts that every character acquired by an individual has two elements,- the predisposition of the organism or of one of its parts which causes it to respond in a certain 
way to a given stimulus; and secondly, the development of this predisposition, which may or may not take place, according to circumstance. But-

"Only one of the causes which produce any acquired character can be transmitted-the one which was present before the character itself appeared, viz., the predisposition. . . . It is quite immaterial to the following generation whether such predisposition comes into operation or not."-(Essays upon Heredity. vol. i., Ist ed., p. I7I.)

"It also follows that those other characters which have been acquired by the influence of special external conditions during the lifetime of the parent cannot be transmitted at all."-(Ibid. p. 267.)

No increment due to the realisation of the predisposition can be inherited; consequently each generation has an identical starting-point :-

"The hypothesis of the continuity of the germ plasm gives an identical starting point to each successive generation, and thus explains how it is that an identical product arises from all of them." -(Ibid. p. I68.)

Now, with respect to this theory, we may remark that, if it were true, it would afford a most interesting explanation of the strictest fixity of species. We could then understand why there should be no modification of structure or increase of capacity in the race; since whatever might be acquired by one generation would be lost in the act of transmission to the next. But this theory is used by the advocate of organic evolution, and it is incumbent upon him to explain the facts of nature in accordance with his theory. There is a transmutation of species, there is an increased facility of operation, as in the case of instincts which have been developed in the race; and yet it is asserted that the offspring inherit the same predisposition from age to age. This theory of "predisposition" is no less fatal to the logical demands of the theory of Natural Selection. If each successive generation has an 
identical starting-point, because all have the same predisposition, they must be all alike, and there is no difference on which Natural Selection can act. If, through the force of circumstances, some predispositions are developed and others are not; and if, in consequence, the individuals whose predispositions are developed survive, and those whose predispositions are undeveloped-supposing such difference is possible to members of the same species existing under very similar outward conditions-even then the increment of power could not be inherited, and there would be no development of capacity in the race.

Still the theory might be true, though it acted in opposition to evolution and to Natural Selection. But we may venture to ask whether the different assumptions contained in this theory can be established. It is difficult to understand how, on this hypothesis, the predisposition first arose. We may take two cases, the predisposition to the long-established habit of a race which may be regarded as their second nature, and the newly-adopted custom of life which has arisen in connection with new conditions of life -the "use which almost can change the stamp of nature." The doctrine of organic evolution surely assumes that there must have been a time when the structure and the habits of a particular species have first come into existence. The logic of the theory requires that a habit must have arisen at a particular point. Before that time, therefore, there can have been no predisposition. In the case of new adaptations of old organs there is no predisposition till the new habit has been formed. If, as evolutionists believe, there was a time when the ancestors of the water-ouzel adopted an aquatic life, there could have been no predisposition on the part of the organism to respond to the touch of water until after that habit had been acquired. The theory errs, therefore, on the threshold of the enquiry 
by making predisposition the ultimate fact, the startingpoint.

It is difficult to believe that the predisposition is equal in all cases. And indeed we need not dwell upon this point, for Dr. Weismann himself admits that the predisposition may vary :-

"I freely admit that the predisposition to an Exercierknochen varies, and that a strongly-marked predisposition may be transmitted from father to son in the form of bony tissue with a more susceptible constitution."-(Essays upon Heredity. vol. i., Ist ed., p. I7o.)

The assertion that the predisposition can only be developed by exercise is true in some cases, but surely not in all. The instantaneous response of the water-ouzel to the stimulus presented by the touch of water, and the perfect dive which instantly follows, is surely an illustration of the predisposition which passes at one leap to perfect action.

The assertion that no effect of exercise can be inherited seems to be contradicted by experience. The greyhounds, which could easily breathe the rarer air, although their parents could not, are a case in point, and something more. We may learn the same lesson from the case quoted by Mr. Darwin :-

"Every one knows that hard work thickens the epidermis on the hands; and when we hear that with infants, long before their birth, the epidermis is thicker on the palms and soles of the feet than on any other part of the body, as was observed with admiration by Albinus, we are naturally inclined to attribute this to the inherited effects of long-continued use or pressure."-(The Variation. vol. ii., p. 297.)

But if this is so, it is a bold assertion to declare that it does not matter to the next generation whether the predisposition has been developed or not in ancestors. 
It only remains to say that this theory is based upon the unchangeableness of the germ plasm, which is continuous from generation to generation. But if external conditions and habits can modify the germ plasm, as Dr. Weismann admits, the last support of the theory gives way.

We have now to consider the problem from the point of view of Mixed Darwinism, as taught by Mr. Darwin himself. The same depreciatory treatment which he used in connection with the transforming effect of changed conditions, he has also applied to the transforming effect of changed habits. No one could have expressed the principle of the inherited effect of habit more tersely and more absolutely than Mr. Darwin himself. "Nature, by making habit omnipotent and its effects hereditary, has fitted the Fuegian for the climate and productions of his country."* "Changed habits produce an inherited effect." $\dagger$

"I may take this opportunity of remarking that my critics frequently assume that I attribute all changes of corporeal structure and mental power exclusively to the Natural Selection of such variations as are often called spontaneous; whereas, even in the first edition of the Origin of Species, I distinctly stated that great weight must be attributed to the inherited effects of use and clisuse, with respect both to the body and mind "-(Descent of Man. and ed., Preface, p. v.)

And yet, in many passages, Mr. Darwin has depreciated the principle of the inherited effect of habit. He contends that "long-continued training, as with the greyhound in coursing hares, must have produced some direct effect on their structure and instincts." $\ddagger$ Again, he says "there is reason to believe that the lessened use of various organs

* Voyages of the Adventure and Beagle. vol. iii., p. 237. I839.-Apud The Deadlock in Darwinism. Universal Review. vol. vi., $p .532$.

+ Origin of Species. p. 8 .

$\ddagger$ The Variation. vol. $i, p .38$. 
has affected the corresponding parts in the offspring. But there is no good evidence that this ever follows in the course of a single generation."*

But it may be very much questioned whether Mr. Darwin would be justified in making such assertions a universal law of nature.

"Many years ago there was a very fine male of the Capra megaceros in the gardens of the Zoological Society. To restrain this animal from jumping over the fence of the enclosure in which he was confined, a long and heavy chain was attached to a collar round his neck. He was constantly in the habit of taking this chain up by his horns and moving it from one side to another over his back. In doing this he threw his head very much back, his horns being placed in a line with the back. The habit had become quite chronic with him, and was very tiresome to look at. I was very much astonished to observe that his offspring inherited the habit; and although it was not necessary to attach a chain to their necks, I have often seen a young male throwing his horns over his back and shifting from side to side an imaginary chain. The action was exactly the same as that of his ancestor."-(J. Jenner-Weir. Nature. vol. xxixix., p. 486.)

"A.B. is moderately myopic and very astigmatic in the left eye; extremely myopic in the right. As the left eye gave such bad images for near objects, he was compelled in childhood to mask it, and acquired the habit of leaning his head on his left arm for writing, so as to blind that eye; or of resting the left temple and eye on the hand, with the elbow on the table. At the age of fifteen the eyes were equalised by the use of suitable spectacles, and he soon lost the habit completely and permanently. He is now the father of two children-a boy and a girl-whose vision (tested repeatedly and fully) is emmetropic in both eyes, so that they have not inherited the congenital optical defect of their father. All the same, they both have inherited his early-acquired habit, and need constant watchfulness to prevent their hiding the left eye, when writing, by resting the head on the left forearm or hand. Imitation is here quite out of the question."-(Marcus M. Hartog. Nature. vol. xxxix. p. 46r.)

He appeals to our ignorance as to the process by which habits modify organisms, just as he does in connection with the effect of changed conditions. 
"It is notorious, and we shall immediately adduce proofs, that increased use or action strengthens muscles, glands, senseorgans, \&c.; and that disuse, on the other hand, weakens them. I have not met with any clear explanation of this fact in works on physiology."-(The Variation. vol. ii., p. 295.)

He denies that in some cases the principle of inherited effect of habit comes into action, and we may note here three reasons which are given for this view. He contends that mere habit may have done nothing towards the acclimatisation of the fruit trees of North America, because a multitude of seedlings are annually raised in that country, and none of them would succeed unless born with a fitting constitution.* That, in short, is to say that the direct effect of climate may have nothing to do with the acclimatisation, because Natural Selection may secure the survival of those which happened to be born with stronger constitutions. But it is not a question of what may be, but what actually is.

Again, Mr. Darwin argues :-

"Under free nature we have no standard of comparison by which to judge of the effects of long-continued use or disuse, for we know not the parent forms."-(Origin of Species. p. I08.)

But in some cases we do undoubtedly know the parent forms. We know the year in which man has introduced certain animals into certain countries; we know what they were when he took them there; we know what they are now ; and, in some cases, we know how greatly they have been changed when they have been permitted to run wild.

It is also argued that habits change while structures remain unmodified. That may take place sometimes, but it certainly does not take place universally. We have to account for the fixity of species as well as the transmu- 
tation of species; and the different effects of use and disuse enable us to see reasons for so different results. But the unchanged organism of one species cannot destroy the evidence of the changed organism of another species.

The effect of this depreciation of the inherited effects of habit is to make room for the theory of Natural Selection. Thus, it is argued that the very considerable effects of use and disuse "have often been largely combined with, and sometimes overmastered by, the Natural Selection of innate variations." * In the case of the hoofs of quadrupeds, "who will pretend to determine how far Natural Selection may be aided in the formation of structures of such obvious importance to the animal ?" $\dagger$ "The very fact that use implies usefulness, renders it almost impossible to eliminate the action of selection in a state of nature." + In the third place, it is contended that, in artificial selection, the improved structures and endowments are due to the principle of selection, almost or altogether. I fail utterly to see how the inherited effects of habit can be overmastered by the Natural Selection of innate variations. If by "innate" is meant what is the nature of the race, as opposed to the recent acquirements of the individual, it is possible that the former may prevail; but it will be preserved by Natural Selection only on the understanding that it is more advantageous than the habit which it displaces. But this habit is presumably the result of an attempt to adapt the organism to conditions, and such a variation must, under the circumstances, be more favourable than any others. If by "innate" you understand the variations inevitably associated with reproduction, is it likely that such a variation will overmaster the useful

* Origin of Species. p. II4.

$\dagger$ The Variation. vol. ii., p. 297.

+Wallace. Darwinism. p. 440 . 
variation? The argument based upon the hypothesis that whatever is useful has been produced by Natural Selection, has already been considered. We will give one more illustration of the way in which Natural Selection is supposed to intervene.

"When the accustomed food of some animal becomes scarce or totally fails, the creature can only exist by emigrating or by becoming adapted to a new kind of food-a food perhaps less nourishing and less digestible. Natural Selection will now act upon the stomach and intestines, and all individual variations favourable to the new state of things will be taken advantage of to modify the race into harmony with the conditions. In many cases, however, it is probable that this cannot be done; the internal organs may not vary quick enough, and then the animal will decrease in numbers, and finally become extinct."-(George St. Clair. Darwinism and Design. $p p$. 73-74.)

But several well-known instances can be adduced to show that some animals will choose to vary their food rather than perish with hunger, and that such variations produce a marked result on the organism.

"Hunter long ago observed that the muscular coat of the stomach of a gull (Larus tridactylus), which had been fed for a year chiefly on grain, was thickened; and, according to Dr. Edmondston, a similar change periodically occurs in the Shetland Islands in the stomach of the Larus argentatus, which in the spring frequents the cornfields and feeds on the seed. The same careful observer has noticed a great change in the stomach of a raven which had been long fed on vegetable food. In the case of an owl (Strix grallaria) similarly treated, Menetries states that the form of the stomach was changed, the inner coat became leathery, and the liver increased in size."(The Variation. vol. ii., p. 302.)

In considering the argument drawn from artificial selection, it may be well to note a remarkable statement made by Mr. Fiske:-

"That agency is neither more or less than selection, taking advantage of that slight but universal variation in organisms implied by the fact that no two individuals in any species are exactly alike. . . . It is in this and no other way that our breeds of race-horses have been 
produced. . . . Now Mr. Darwin's great achievement has been to show that a similar process of selection is going on in the organic world."-(Fiske. Cosmic Philosophy. vol. ii., pp. q-10.)

\section{Mr. Romanes says :-}

"Here (in artificial selection) just as in Natural Selection, the materials on which the selective action operates are 'such new forms as may be born into the world." -(Contemporary Review. vol. liii., p. 845.)

In the following passage $\mathrm{Mr}$. Wallace seems to attribute too little influence to other causes of modification apart from artificial selection :-

"It is a very common, but mistaken idea, that this improvement is due to crossing and feeding in the case of animals, and to improved cultivation in the case of plants. Crossing is occasionally used in order to obtain a combination of qualities found in two distinct breeds, and also because it is found to increase the constitutional vigour; but every breed possessing any exceptional quality is the result of the selection of variations occurring year after year, and accumulated in the manner just described. Purity of breed, with repeated selection of the best varieties of that breed, is the foundation of all improvement in our domestic animals and cultivated plants." (Darzinism. p.85.)

But it is obvious that, in training, the animal is exercised, and that the selection is made with reference to excellence thus exhibited.

"The English race-horse and greyhound could not have been improved up to their present high standard of excellence, without constant training."-(The Variation. vol. ii., p. 234.)

"Man can improve the breed of his game cocks by the selection of those birds which are victorious in the cockpit."-(Descent of Man. and ed., p. 2II.)

The arguments by which it is attempted to substitute Natural Selection for the inherited effect of use and disuse, have now been considered. I do not think that the case which they seek to establish is a strong one. And I see no reason for relinquishing the argument with which I 


\section{5}

began-that, inasmuch as the race ultimately exhibits similar modifications to those which appear in the individual first subjected to the influences of a new habit, this has been brought about by a transforming rather than a selective influence in nature.

We have attempted to reply to those arguments which seek to unduly appreciate Natural Selection at the cost of transforming influences. It only remains to consider briefly the way in which the strict and logical significance of Natural Selection is lowered in order to reconcile it to the facts of nature.

In the first place, it is not unusual to find any selection which takes place in nature designated by the term "Natural Selection." We have an illustration of this mode of speech in Dr. Ray Lankester's explanation of the production of blind animals inhabiting dark caves. He rejects the Lamarckian explanation, and then proceeds to prove that the change is brought about by a process which he designates as "a Natural Selection."

It is not quite easy to say whether Dr. Ray Lankester wishes his readers to understand that "a Natural Selection" means an individual case of the general principle of Natural Selection; or whether he means a particular species or variety of a generic term of Natural Selection; or whether by "a Natural Selection" he simply means a selection which takes place in nature. If he means that any selection in nature is Natural Selection, that is not correct; for similar variants may be isolated for breeding purposes by other influences than that of life and death. If he means that there are many kinds of Natural Selection, that would only be to adopt several definitions of one term-a process not very conducive to clear reasoning. If he means to assert that this is an individual instance of Natural Selection, that assertion is not true; for Natural 
Selection works by life and death, and in this case the isolation for breeding purposes takes place in consequence of the animals peaceably separating from one another. To say that this is an instance of Natural Selection is very much like saying that a pacific agreement to divide a given region between two forces is a species of internecine strife. I do not think that the explanation would bear investigation on the principles of Pure Darwinism; but if we grant that the process was that described by Dr. Lankester, it would be a selection in nature which was emphatically not Natural Selection.

Another way of modifying the meaning of the phrase, is to treat Natural Selection as though it secured the survival of the fittest, quite irrespective of the way in which the variations were produced, and even as securing the survival of the best of those variants, which had been produced by transforming influences. But in this case the transmutation might take place apart from any principle of selection, and an unnecessary amount of risk to the survival of the race would result from the introduction of selection by life and death. Such modifications of the meaning of the phrase either testify to the existence of spheres in nature, in which the principle of Natural Selection properly so called does not exist, or must be understood to mean that the Natural Selection of the world of nature is not the Natural Selection which is expounded so eloquently and so definitely in the descriptions of the theory.

"Natural Selection," says Dr. Weismann, "does not deal with qualitative but quantitative changes in the individual, and the latter are always present."* If this means that Natural Selection does not produce

* Essays. vol. i., rst ed., p. Iоr. 
any modification which alters the quality of an organism, it is an admission that distinctive qualities are the product of some other influence. And surely all quality cannot be resolved into quantity without removing all the distinctive meaning attached to those terms. It is surely legitimate, for example, to treat the perfume of flowers as a quality of the plant. The flowers which emit no scent and the flowers which load the air with perfume have surely distinctive qualities. But if so, the perfume of flowers cannot have been produced by Natural Selection but by an independent transforming influence. Or are we to understand that all modifications of structures are mere matters of quantity? Such a definition seems to me to overlook Mr. Herbert Spencer's distinction between growth and development. Growth is a mere increase of size; development is an increase in the complexity of the structure. It seems to me that we should be perfectly justified in calling the former a quantitative and the latter a qualitative modification. But if we accept this definition, then the dictum of Dr. Weismann would deny to Natural Selection the power of producing that development without which progressive modification of structure would be impossible. Or does he mean to say that Natural Selection only acts through selecting quantitative excellence, as, for example, the flowers which emit the sweetest or the most penetrating perfume? But if so, some other influence, not Natural Selection, must have produced the perfume.

In the preceding section of this work it has been shown that if we were acquainted with no special reasons for doubting that Natural Selection was a law of nature, there would still be good reason to believe that it had taken no part in the modification of species. The stability of species and the extinction of species take place apart from Natural Selection; while they present especial diffi- 
culties to the theory of Natural Selection. The correlated variation of a structure of co-ordinated parts is the result of any cause which may modify one of the parts; it is in no way the special ally of Natural Selection; and Natural Selection, acting alone, cannot produce similar results. If we grant the assertion that only birth variations can be inherited, we find that some birth variations do not require the principle of selection to assist them in bringing about the transmutation of species; while, in other cases, there is a selection in nature which is not Natural Selection. The transforming influence of changed conditions and the selective influence of Natural Selection, in the proper sense of that term, cannot co-operate and cannot co-exist in the world of nature as it stands revealed to human experience and experiment. We have arrived at the conclusion that the transmutation of species is brought about by a process which is not Natural Selection. We have shown that the arguments which have been used to depreciate transforming influences and to unduly appreciate Natural Selection, are invalid. We have seen that the meaning of Natural Selection has been modified in order to meet the difficulties which beset the logical and consistent statement of the theory. We have shown that if the process of Natural Selection could go on contemporaneously with the process of transformation, it could not compete with that cheaper and more expeditious method. But a law of nature which is excluded from many spheres of organic change, which cannot compete with other processes,-which, in a word, never comes into action, may surely be dismissed as a fanciful creation of the human imagination rather than welcomed as the palpable and dominant principle in the world of reality. It is at best an article of scientific faith; it is not a demonstrated law of nature. 


\section{BOOK II I.}

Organic Evolution by Means of NATURAL SELECTION :-

WHAT PROOF HAS BEEN OFFERED? 



\title{
CHAPTER I.
}

\section{ORGANIC EVOLUTION NOT IDENTICAL WITH NATURAL}

\author{
SELECTION.
}

"Happy is he, who lives to understand

Not human nature only, but explores

All natures-to the end that he may find

The law that governs each; and where begins

The union, the partition where, that makes

Kind and degree among all visible beings:

The constitutions, powers and faculties

Which they inherit;

. . . . . that do assign

To every class its station and its office

Through all the mighty commonwealth of things,

Up from the creeping plant to sovereign man."

-WORDSWORTH.

ACCORDING to the doctrine of Organic Evolution, all living organisms have become what they now are by a process of growth or increase in size; and by a process of development or increase in complexity of structure. The argument in favour of Natural Selection as the chief or sole law which has dominated this process may be conducted on three distinct lines. We may bring forward arguments to show that the process of Organic Evolution has taken place, and we may then treat these arguments as proofs that Natural Selection has dominated this process, but without adding any special evidence to show that Natural Selection has been the cause of the phenomenon; or we may adduce evidence to show that 
Natural Selection has produced the transmutation of species, and we may then infer that the law which now produces the transmutation of species has been the efficient cause of Organic Evolution; or we may contend that the arguments for the process of Organic Evolution as a fact of nature would also, on further consideration, suggest proofs that Natural Selection has been the determining principle in that process.

In the present chapter we shall consider the first of these modes of establishing the theory of Natural Selection, which in effect treats Organic Evolution as identical with Natural Selection, and which therefore uses the arguments for Organic Evolution as though they were equally strong arguments for Natural Selection.

Against this view of the subject we have the emphatic warning of Mr. Herbert Spencer, who tells us that-

"the mass of readers . . . identify Mr. Darwin's great contribution to the theory of Organic Evolution with the theory of Organic Evolution itself and even with the theory of evolution at large."(Nineteenth Century. vol. xix., p. 584.)

And certainly it is not the general reader only who falls into this mistake, or at any rate who uses language which leads to confusion on this point.

Professor Oscar Schmidt, in The Doctrine of Descent and Darwinism, speaks to similar effect :-

"The acute author of the book entitled The Unconscious from the Standpoint of Physiology and the Theory of Descent has rerently observed that the truth of the doctrine of descent is independent of the bearings and adequacy of the Darwinian theory. 'This circumstance,' he says, 'is misunderstood by the majority of Darwin's opponents; when they adduce arguments for the inadequacy of Natural Selection in the struggle for life, they usually fancy they have adduced just as many arguments against the reliability of the theory of descent. But the two have no direct connection with one another; for it might be possible that Darwin's theory of Natural Selection was absolutely false and unserviceable, and the doctrine 
of derivation true notwithstanding; that only the causal medium of the derivation of one species from another was different from that stated by Darwin.'" -

\section{Mr. E. D. Cope says :-}

"There are two totally distinct propositions involved in this question, which are confounded by the general public, and not unfrequently by students and writers on it. These are, first, the evidence, which seems to prove that this evolution has taken place; secondly, the evidence as to the nature of the laws of its progress. A want of constant distinction between these views of the case has greatly obscured it, and injured the evidence on one side or the other." -(The Origin of the Fittest. p. 2.)

\section{Mr. Romanes is no less emphatic upon this point.}

"Therefore the argument, while undoubtedly a very forcible one in favour of the fact of evolution, appears to me scarcely consistent with the theory of Natural Selection."-(Journal of the Linnean Society-Zoology. vol. xix., p. 39I.)

"Of course this fact speaks in favour of evolution, but where the question is as to method, I confess that the theory of Natural Selection appears to me wholly irrelevant."-(Journal of the Limean Society-Zoology. vol.xix., p. 393.)

"Darwin and Wallace failed to agree upon certain points of doctrine, which, although of comparatively small importance in relation to any question of evolution considered as a fact, were, and still continue to be, of the highest possible importance in relation to the question of evolution considered as a method--i.e., in relation to the causes or factors which have been concerned in the process." (Contemporary Review. vol. lvi., p. 245.)

Hence if Natural Selection or any other method were proved to be not so efficient as was supposed, or to be utterly powerless, the theory of evolution would not necessarily be overthrown.

"The change would merely amount to a general agreement among evolutionists, that hitherto they had been mistaken with regard to one of the previously suggested factors of organic evolution, which had now been proved not to have been one of the factors."-(Romanes. Contemporary Reviewe. vol. liii., p. 85I.) 
The identification of Organic Evolution with Natural Selection can only be justified on one condition, viz., that there are only two possible explanations of the production of the organic world; the belief in the special creation of each species and its unchangeable fixity; or the belief in Organic Evolution by means of Natural Selection alone. That is what Dr. Aveling asserts:-

"In the words of the great author of that work I would remind all that in the hypothesis of Natural Selection we have only an hypothesis; there is at present on the main question only one other hypothesis before us-that of the numberless species on the earth having each and all originated from distinct acts of creation. It is the bounden duty of all whose minds are not in bondage to choose of the two theories the one that is in accordance with, links together, and makes comprehensible, the larger number of facts." - The Student's Darwin. p. 263.)

Dr. Weismann asserts that Natural Selection "is the only conceivable natural explanation of organisms regarded as adaptations to conditions."* Those who believe that Natural Selection, in the strictest sense of that word, is the only cause of Organic Evolution, are perhaps justified in using this language. But even in that case it would add to the logical clearness of the discussion if the arguments for the process were kept apart from the arguments for the law which dominates that process-as Mr. Wallace does in the following passage:-

"What Mr. Darwin did was to prove, by an overwhelming array of evidence and a connected chain of irresistible argument, that, just as all horses and all asses have each descended from a few common ancestors, so have all asses, horses, quaggas, and zebras descended from a much more remote common ancestral form; and that the same thing has occurred with every group of allied species. This is the 'origin of species, by descent with modification,' or, in other words, by evolution; while, 'Natural Selection' was the term applied

* The Contemporary Review. vol. lxiv., p. 328 . 
to the set of natural causes which formed the motice power and guiding principle by which the change from one species to another was brought about."-(Nineteenth Century. vol. vii., pp. 93-4.)

Moreover, the assertion that there is only one physical method of bringing about the phenomenon of Organic Evolution, assumes that all other theories of the subject have been proved to be false. If such a definition is made the starting point, it is obvious that all discussion is impossible. But however that may be, it is obvious that the believer in Mixed Darwinism should be careful in his use of terms; making a distinction between the idea of Organic Evolution in the abstract and Organic Evolution regarded as the result of different methods, of selective agency alone, of transforming agency alone, or of a combination of both.

The process of Organic Evolution, considered in the abstract and apart from the laws by which it is brought about, may be defined as a theory of descent with modification. In other words, it asserts the principle of heredity by virtue of which like produces like-the principle of variation by virtue of which modifications of structure take place; and it implies that these variations may also be inherited. Pure Darwinism defines Organic Evolution as a theory of descent, with modification, by means of Natural Selection. Specific likeness is accompanied with individual differences, and the favourable variations among them survive through the action of Natural Selection. The theory of transformation asserts that Organic Evolution is brought about by descent with modification-the modifications being due to the laws of variation generally, and especially to the law whereby an organism is adapted by the circumstances to the circumstances; and these modifications are inherited, apart from the principle of selection. Mixed Darwinism asserts that there is in nature a selection 
of favourable birth variations; and also a selection of the best of those variations which have been brought about by transforming influences; and also a modification due to transforming, apart from selective influences.

Yet, in spite of these considerations, the most prominent writers on the subject have used the arguments for Organic Evolution as arguments for Natural Selection. In dealing with this remarkable fact, it is important to realise at the outset that the evidences for Organic Evolution as a process are the common property of all believers in that doctrine. A very remarkable illustration of this assertion may be given. As I write this, it is now (October, I 894) just fifty years ago since Mr. Robert Chambers published his work, Vestiges of the Natural History of Creation. In I88I an article by Mr. Romanes appeared in The Fortnightly Review, ${ }^{*}$ subsequently reprinted under the title of "The Scientific Evidences of Organic Evolution"; and it is interesting to observe what a close resemblance there is between these two writers, one of whom had never heard of the theory of Natural Selection, while the other was to the day of his lamented death one of its principal and most gifted exponents.

Mr. Romanes, under the heading of "The Argument from Classification," points out that classification has been based upon organic affinities, and then proceeds to say :-

"Now in such a classification it is found impossible to place all the species in a linear series, according to the grade of their organization. ( $p .17$.$) Our system of classification may be likened to a tree, in which$ a short trunk may be taken to represent the lowest organisms. This short trunk soon separates into two large trunks, one of which represents the vegetable and the other the animal kingdom. Each of these trunks then gives off large branches, and these give off smaller but more numerous branches which ramify again. (p.I8.) This treelike system is as clear an expression as anything could be of the fact

* vol. xx.x., new series, pp. 739-758. 
that all species are bound together by the ties of genetic relationship. If all species were separately created, it is almost incredible that we should everywhere observe this progressive shading off of characters common to larger groups."-( pp. 23-4.)

But this argument had been anticipated by Mr. Chambers. After speaking of the obvious gradation amongst the families of both the vegetable and animal kingdoms, he confines himself to the animal kingdom, and says :-

"It is to be observed that the gradation is much less simple and direct than is generally supposed. It certainly does not proceed on all parts of its course at least, upon one line. . . . It even appears that there are intimations of more than two lines at various parts of the animal scale. (Fourth edition. $p p$. 195.) These facts clearly show how all the various organic forms of our world are bound up in one-how a fundamental unity pervades and embraces them all. . . . . After what we have seen, the idea of a separate exertion for each must appear totally inadmissible." - $(\not .20 I-2$.

In "The Argument from Morphology or Structure," Mr. Romanes points to the evidence which there is of adaptive modification of structure in cases where the need for such adaptation is apparent, ${ }^{*}$ and instances the various modifications of the arm in mammals. $\dagger$

"Why should the vertebral skeleton, for instance, be tortured into every conceivable variety of modification in order to make it serviceable for as great a variety of functions; while another structure, such as the eye, is made in different sub-kingdoms on fundamentally different plans, notwithstanding that it has throughout to perform the same function?"- $(\not .3 I$.

Mr. Chambers calls attention to the "unity of structure," which "becomes the more remarkable when we observe that the organs, while preserving a resemblance, are often put to different uses." And he goes on to observe that analogous purposes are served in different animals by organs essentially different. $\ddagger$

$$
\text { *p. 26. } \quad+p p \cdot 29-30 . \quad+p p \cdot 196-7 .
$$


Speaking of the existence of rudimentary structures and the inference to be drawn from that fact, Mr. Romanes says :-

"The theory of special creation can only maintain that these rudiments are formed for the sake of adhering to an ideal type." He deprecates such an idea; and further contends that if this principle were acted on we should expect it to be consistently carried out. "This reasonable expectation, however, is far from being realised." - (pp. 39-4I.)

Mr. Chambers, speaking of the total inadmissibility of the idea of a separate creation for each, goes on to say that-

"the single fact of abortive or rudimentary organs condemns it; for these on such a supposition could be regarded in no other light than as blemishes or blunders, irreconcilable with the idea of Almighty perfection." - $(p .202$.

In "The Argument from Geographical Distribution," Mr. Romanes says :-

"We should expect on this theory that the organic types living on any given geographical area should be found to resemble or to differ from organic types living elsewhere, according as the area is connected or disconnected with other geographical areas. And this we find to be the case, as abindant evidence proves." $-(p .49$.

\section{Mr. Chambers says :-}

"Thus various portions of the earth are separated in such a way as to preclude anything like a general communication of the seeds of their respective plants towards each other. Hence arises an interesting question-Are the plants of the various isolated regions which enjoy a parity of climate and other conditions, identical or the reverse? The answer is-that in such regions the vegetation bears a general resemblance, but the species are nearly all different, and there is even, in a considerable measure, a diversity of families." - ( $p .279$.

"When we come to the zoology, we find precisely similar results, excepting that man (with, perhaps, some of the less conspicuous forms of being) is universal, and that several tribes, as the bear and dog, appear to have passed by the land connexion from the arctic regions of the eastern to those of the western hemisphere. 'With these 
exceptions,' says Dr. Pritchard, 'and without any others, as far as zoolngical researches have yet gone, it may be asserted that no individual species are common to distant regions. In parallel climates, analogous species replace each other; sometimes, but not frequently, the same genus is found in two separate continents; but the species which are natives of one region are not identical with corresponding races indigenous in the opposite hemisphere." (pp. 280-I.)

In stating "The Argument from Geology," Mr. Romanes contends that there is " no instance of a highly organised form occurring low down in the geological series." On the contrary,-

"gradual advance from the general to the special, from the low to the high, from the few and simple to the many and the complex, has been the law of organic nature. . . This is precisely the law to which the process of descent with adaptive modification would of necessity give rise." - $(\not p .46-7$.

Mr. Chambers had spoken to similar effect. He speaks of the progress of the development of both plants and animals upon the globe from simpler to higher forms of organisation, and then continues-

"That there is thus a progress of some kind the most superficial glance at the geological history is sufficient to convince us. Indeed, the doctrine of the gradation of animal forms has received a remarkable support from the discoveries of this science, as several types formerly wanting to a completion of the series have been found in a fossil state."-( $p .151$.

\section{Mr. Romanes says :-}

"There is no physiological reason why animals and plants of the different characters observed should inhabit different continents, islands, seas, and so forth . . . and that it is not the suitability of organisms to the areas which they inhabit, which has determined their creation upon those areas, is conclusively proved by the effects of the artificial transportation of species by men." - $(\not .60$.

\section{Mr. Chambers says :-}

"It does not appear that the diversity between the similar regions of Africa, Asia and America, is occasioned in all instances by any disqualification of these countries to support precisely the same 


\section{0}

genera or species. The ox, horse, goat, etc., of the elder continent have thriven and extended themselves in the new, and many of the indigenous tribes of America would, no doubt, flourish in corresponding climates in Europe, Asia and Africa." - $(p .282$.

Mr. Romanes, when stating "The Argument from Embryology," says :-

"If the theory of descent by inheritance is true, the life history of the individual ought to constitute a sort of condensed epitome of the whole history of its descent. But taking this anticipation for granted, as it is fully realised by the facts of embryology, it follows that the science of embryology affords perhaps the strongest of all the strong arguments, in favour of evolution. . . . The higher animals almost invariably pass through the same embryological stages as the lower ones, up to the time when the higher animal begins to assume its higher characters. Thus, for instance, to take the case of the highest animal, man, his development begins from a speck of living matter similar to that from which the development of a plant begins. And, when his animality becomes established, he exhibits the fundamental anatomical qualities which characterise such lowly animals as the jelly fish. Next he is marked off as a vertebrate, but it cannot be said whether he is to be a fish, a snake, a bird or a beast. Later on it is evident that he is to be a mammal; but not till still later can it be said to which order of mammals he belongs." - $(p p .63-5$.

\section{Mr. Chambers says :-}

"Embryotic development is now a science. Its primary positions are-(I) that the embryos of all animals are not distinguishably different from each other; and (2) that those of all animals pass through a series of phases of development, each of which is a type or analogue of the permanent configuration of tribes inferior to it in the scale ( $p .203)$. Speaking roundly, it is undoubted that all animals pass in embryo through phases resembling the general as well as the particular characters of those of lower grade (p.203). Nor is man himself exempt from this law"--(p. 205).

In dealing with arguments drawn from certain general considerations, Mr. Romanes adduces instinct and the supposed evolution of the human conscience and intelligence from animal sympathy and intelligence.

Mr. Chambers adduces the mental constitution of animals as a proof of evolution. He shows a gradation of 
development in the brains of different animals; he shows how the human embryo has in succession the brain of different classes of animals, which succession also corresponds to the succession of brain through the geological ages. He shows that the difference between mind in the lower animals and in man is "a difference in degree only; it is not a specific difference."

Mr. Romanes argues against the objection "which says, Evolution, if true, can only be proved so by an actual observation of the process, and as no one pretends to have witnessed the transmutation of species, it follows that Evolution has not been proved."* On this point, Mr. Chambers uses an illustration essentially the same as that employed by Mr. Herbert Spencer, who says :-

"If we imagine mankind to be contemplated by some creature as short-lived as an ephemeron, but possessing intelligence like our own -if we imagine such a being studying men and women, during his few hours of life, and speculating as to the mode in which they came into existence; it is manifest, that, reasoning in the usual way, he would suppose each man and woman to have been separately created. No appreciable changes of structure occurring in any of them during the few hours over which his observations extended, this being would probably infer that no changes of structure were taking place, or had taken place; and that from the outset, each man and woman had possessed all the characters then visible-had been originally formed with them. This would naturally be the first impression."-(Principles of Biology. vol.i., pp.337-8.)

\section{Mr. Chambers speaks very much to the same effect.}

"Suppose that an ephemeron, hovering over a pool for its one April day of life, were capable of observing the fry of the frog in the water below. In its aged afternoon, having seen no change upon them for such a long time, it would be little qualified to conceive that the external branchix of these creatures were to decay, and be replaced by internal lungs, that feet were to be developed, the tail erased, and the animal then to become a denizen of the land. Precisely such may be our difficulty in conceiving that any of the species 


\section{2}

which people our earth is capable of advancing by generation to a higher type of being."- $-(\not .215$.

Dealing with objections raised on the ground of sentiment, Mr. Romanes says:-

"It is thought that the conception of man being a lineal descendant of the monkey is a conception which is degrading to the dignity of the former animal. Now this obstacle being a matter of feeling or sentiment, as such I am not able to meet it. . . . But although I cannot affect your sentiments in this matter, I may be permitted to point out that, as they are only sentiments they are quite worthless as arguments or guides to truth." $-(\not p .83-4$.

\section{Mr. Chambers says :-}

"But the idea that any of the lower animals have been concerned in any way with the origin of man-is not this degrading? Degrading is a term expressive of a notion of the human mind, and the human mind is liable to prejudices which prevent its notions from being invariably correct." $-(p .24 I$.

It is obvious, from the comparison of these two writers, that the scientific evidences of Organic Evolution are the common property of all believers in Organic Evolution, and that they are stating the simple truth who affirm that Organic Evolution and Natural Selection are not synonymous terms, and that the arguments for the former are not necessarily arguments for the latter. This distinction has been overlooked by those who have no doubt inadvertently used the more general terms to indicate the more special theory of Natural Selection.

Mr. Balfour speaks of Mr. Darwin's theory in the following terms :-

"It has long been recognised, that the embryos and larvæ of the higher forms of each group pass, in the course of their development, through a series of stages in which they more or less completely resemble the lower forms of the group. This remarkable phenomenon receives its explanation on Mr. Darwin's theory of descent. There 
are, according to this theory, two guiding, and in a certain sense antagonistic, principles which have rendered possible the present order of the organic world. These are known as the laws of heredity and variation. The first of these laws assert that the characters of an organism at all stages of its existence are reproduced in its descendants at corresponding stages. The second of these laws asserts that offspring never exactly resemble their parents. By the common action of these two principles, continuous variation from a parent type becomes a possibility, since every acquired variation has a tendency to be inherited."-(Comparative Embryology. vol. i., pp. 2-3.)

All this is simply a description of Organic Evolution, and makes no reference to what is distinctively Darwinian, or, in other words, to Natural Selection.

This identification, real or apparent, of Organic Evolution and Natural Selection may arise from the desire to use the shortest possible description; or from a belief that Natural Selection is the sole method of Organic Evolution; or from the fact that writers who deal with details overlook the importance of a strictly correct nomenclature in the statement of theories. But whatever the explanation may be, the fact of such identification is obvious from the passages already quoted. But we have further to remark that this treatment of the subject has sometimes taken place in the case of those who have been most careful to emphasise the distinction between Organic Evolution and Natural Selection.

Mr. Fiske distinguishes between the power to marshal "the arguments from classification, embryology, morphology, and distribution, and thus fairly to establish the fact that there has been a derivation of higher forms from lower" and the power to discern the modus operandi of the change; in other words, he distinguishes between evolution in general, and one mode of evolution irı particular. And yet Mr. Fiske ignores this distinction, and makes an assertion which is apt to mislead, when he 
speaks of the proof of Natural Selection as synonymous with that of Organic Evolution.

"Professor Huxley may well say that the history of the descent of the horse from a five-toed mammal supplies all that was required to complete the proof of the Darquinian Theory."-(Darwinism and other Essays. ph. 3o-I.)

Whereas it is obvious that this case of the horse is only a particular illustration of the argument from geology in favour of Organic Evolution in general. Moreover, Mr. Huxley is not so inaccurate and loose in his language as Mr. Fiske makes him out to be, for he says :-

"Thanks to these important researches, it has become evident that, so far as our present knowledge extends, the history of the horse type is exactly and precisely that which could have been predicted from a knowledge of the principles of evolution."-(American Addresses. p. 8g.)

We have seen that Mr. Romanes has emphasised this distinction most emphatically, and yet he seems to have sometimes lost sight of it completely in the Essay already referred to. Its republication was due to the fact that "the late Mr. Darwin thought well of the epitome of his doctrine which the lecture presented." It professed to come to the aid of those who had not time to read scientific works, and who were consequently more or less ignorant on the subject.

"Under these circumstances, I have thought it desirable to supply a short digest of The Origin of Species, which any man, of however busy a life or of however indolent a disposition, may find both time and energy to follow." - (p. 2.)

In the first place, it should be noted that the title of this essay gives an admirable statement of its contents, for Mr. Romanes only reproduces from The Origin of Species the arguments used by Mr. Darwin in behalf of the process of Organic Evolution. It is true that Mr. Romanes 
defines what Natural Selection is; and assuming that Natural Selection is a sufficient explanation of all the phenomena, he invokes the law of parsimony, and declares that it is unnecessary to seek for any other cause. He asserts that the choice lies between Natural Selection and sudden creation, thereby ignoring the fact that, according to Mixed Darwinism, Organic Evolution may result from transforming influences only, from Natural Selection only, or from a combination of both. In a digest of The Origin of Species we should have expected to find some arguments urged for Natural Selection as the method by which Organic Evolution has been brought about. It is interesting to note how Mr. Romanes meets this just expectation. In the first form in which this essay appeared Mr. Romanes says :-

"But now it may properly be asked what is your evidence in favour of Natural Selection? Well, the evidence in favour of Natural Selection as a cause is simply the evidence in favour of Organic Evolution as an effect." - - $p$. 742.)

This is omitted in the republished essay, but in the latter he says :-

"If once the fact of Organic Evolution were established, no one would dispute that much of the adaptation was probably effected by Natural Selection. How much we cannot say-probably never shall be able to say; for even Mr. Darwin himself does not doubt that other causes besides that of Natural Selection have assisted in the modifying of specific types. For the sake of simplicity, however, I shall not go into the subject, but shall always speak of Natural Selection as the only cause of Organic Evolution. Let us then weigh the evidence in favour of Organic Evolution." - (pp. I3-14.)

There is here no statement of the arguments in favour of the distinctive teachings of $\mathrm{Mr}$. Darwin. But while the theory is explained, the objections to it are either ignored or treated as the mere results of ignorance. It is assumed without proof that Natural Selection is the method whereby the process of Organic Evolution has been DD , 
brought about. Mr. Darwin does not know how much Natural Selection has to do with the matter, and therefore, to avoid discussion on such a trivial point, it is assumed that Natural Selection has done all; and on this ground the arguments for Organic Evolution are treated as the arguments for Natural Selection.

But though Mr. Romanes' Essay must be regarded as an inadequate exposition of The Origin of Species, the order in which the argument is stated in the latter work does, after all, suggest the idea that the arguments for Organic Evolution are arguments in favour of Natural Selection. The latter doctrine is expounded, and then the arguments for Organic Evolution are treated as confirmatory evidence. And it is thus very easy for Mr. Darwin to find many considerations which tend to confirm his theory, which are not by any manner of means the peculiar property of that theory. And this view is confirmed by the fact that what he does implicitly in The Origin of Species, he states explicitly in The Variation of Aninals and Plants under Domestication.

"The principle of Natural Selection may be looked at as a mere hypothesis, but rendered in some degree probable by what we positively know of the variability of organic beings in a state of nature-by what we positively know of the struggle for existence, and the consequent, almost inevitable preservation of favourable variations, and from the analogical formation of domestic races. Now this hypothesis may be tested-and this seems to me the only fair and legitimate manner of considering the whole question-by trying whether it explains several large and independent classes of facts, such as the geological succession of organic beings, their distribution in past and present times, and their mutual affinities and homologies. If the principle of Natural Selection does explain these and other large bodies of facts, it ought to be received."-(The Variation. vol.i., p. q.)

The theory of Natural Selection is thus tested and proved by the arguments which go to prove that the process of organic evolution has taken place. This seems 


\section{7}

to me to be putting the cart before the horse. Let us try to make this clear by an illustration. Let us suppose that men had ceased to paint pictures, and that they contented themselves with reproducing existing paintings by the process of chromo-lithography. Let us further suppose that a controversy arose as to the authenticity of a painting supposed to be from the hand of an ancient master. The logical process would surely be first to prove that the work was hand-painted, and then to give reasons for believing that it was from some particular hand. But what should we say if the expert were to give some reasons of little weight for the belief that it was the work of a particular artist, and were then to test that assertion by proofs that it was not a chromo-lithograph, but that it had been hand-painted?

In the same spirit Mr. Darwin treats the difficulties accompanying the arguments for Organic Evolution as though they were the difficulties especially belonging to the theory of Natural Selection.

"In considering the theory of Natural Selection he will assuredly meet with weighty difficulties, but these difficulties relate chiefly to subjects-such as the degree of perfection of the geological record, the means of distribution, the possibility of transitions in organs, \&c. -on which we are confessedly ignorant; nor do we know how ignorant we are. If we are much more ignorant than is generally supposed, most of these difficulties wholly disappear."-(The Variation. wol. i., p. I3.)

Here the chief difficulties in accepting the fact of Organic Evolution are regarded as the chief difficulties to the particular method of Organic Evolution. This treatment of the subject creates the impression of extreme candour; and it may even seem to the eager opponent that Mr. Darwin is giving himself and his cause away. But in recognising these difficulties he is only doing what all believers in Organic Evolution ought to do, quite apart 
from the theory of Natural Selection. Such treatment has the effect of withdrawing attention from the difficulties which beset the theory of Natural Selection, or of leading us to suppose that they are insignificant in comparison with the difficulties associated with Organic Evolution in general.

This treatment of the question might be justified on the condition that there were difficulties associated with Organic Evolution which could only be solved on the hypothesis of Natural Selection. This is the ground assumed by Mr. Darwin :-

"I shall discuss the difficulties which are opposed to the theory. These difficulties may be classed under the following heads: The apparent impossibility in some cases of a very simple organ graduating by small steps into a highly perfect organ ; the marvellous facts of instinct; the whole question of hybridity ; and, lastly, the absence at the present time, and in our geological formations, of innumerable links connecting all allied species. Although some of these difficulties are of great weight, we shall see that many of them are explicable on the theory of Natural Selection, and are otherwise inexplicable."(The Variation. vol. i.,p. 8.)

But we must remember that, so far as the fact of Organic Erolution is concerned, there is only one rival hypothesis, that of special creation. The argument for the fact of Organic Evolution deals with the existing organic world as a result of one out of two possible methods of production. If the result is not such as might be expected from Organic Evolution, the fact of Organic Evolution is not proved. The phenomenon has not taken place, so far as we can see; but surely that negation cannot be affected by any hypothesis as to how evolution might have been brought about.

There seems to be the very greatest difference among experts as to the relative worth of the arguments for Organic Evolution as a result, and Natural Selection as the 
method by which that result has been brought about. Mr. Huxley believes that Organic Evolution has been proved, while at the same time he hesitates to accept any of the theories which explain the method by which the process has been brought about. He says :-

"An inductive hypothesis is said to be demonstrated when the facts are shown to be in entire accordance with it. If that is not scientific proof, there are no merely inductive conclusions which can be said to be proved, and the cloctrine of evolution, at the present time, rests upon exactly as secure a foundation as the Copernican theory of the motions of the heavenly bodies did at the time of its promulgation. Its logical basis is precisely of the same characterthe coincidence of the observed facts with theoretical requirements." -(American Addresses. p. go.)

"On the evidence of palæontology, the evolution of many existing forms of animal life from their predecessors is no longer an hypothesis, but an historical fact ; it is only the nature of the physiological factors to which that evolution is due, which is still open to discussion."-(Encyclopaedia Britannica.)

And again he says :-

"I can testify from personal experience that it is possible to have a complete faith in the general doctrine of evolution and yet to hesitate in accepting the nebular, or the uniformitarian, or the Darwinian theory in all their integrity and fulness."-(Proceedings of the Royal Institute. vol. $\%$, p. 279.)

Mr. Wallace, on the other hand, seems to think that Organic Evolution, even by Natural Selection, is not so certainly a fact as the transmutation of species by Natural Selection.

"The point here insisted upon is, that the origin of all organisms, living and extinct, by 'descent with modification,' is not necessarily the same thing, and is not included in 'the origin of species by means of Natural Selection.' The latter we not only know has occurred, but we can follow the process, step by step, by means of known facts and known laws; the former, we are almost equally certain, has occurred, but we cannot trace its steps, and there may have been facts and laws involved of which we have no certain knowledge." (Nineteenth Century. vol. wii., p. 95.) 
I cannot believe that the identification of the arguments for Organic Evolution with those for Natural Selection has been consciously adopted by $\mathrm{Mr}$. Darwin and some of his followers in the spirit of the special pleader. How, then, can we account for this singular intellectual phenomenon? If we seek for an explanation of this confusion, it is to be found, first of all, in the fact that the battle of Natural Selection was waged against the traditional view of the fixity of species.

We can hardly realise at the present day how strong the belief in the fixity of species once was. And yet we need not wonder that the belief in the fixity of species was a generally accepted doctrine. For, in the first place, it was taught in the Bible, and piety has always accepted the teaching of the Bible on scientific points, as long as it has been possible to do so. In the second place, the theory of the instantaneous creation of species and their continuance in an unchanged state until the present day, was implied in the stately poetry of Milton's Paradise Lost, which aided the popular imagination in realising the Biblical picture. This influence has been doubtless enhanced by the co-operation of the musician. The thrilling strains and the descriptive music of Haydn enforced the poet's picture. The poet's description-

"the tender grass whose verdure clad Her universal face with pleasant green,"

finds its echo in the musician's exquisite air, "With verdure clad."

But in addition to this, the general public were given to understand that all the authorities of the scientific world were on the side of this doctrine. In other words, those who had observed the organic world declared that it confirmed the teaching of Divine Revelation. This 
general concensus of the opinion of experts must have had great influence over the world at large. The appeal to such authority could not be in vain. Even in quite recent times, a similar plea has been put forth. Dr. Bree says :-

"Now these are the deliberately expressed opinions of men who have devoted their lives to the study of these questions. No one will, I think, be bold enough to say the conclusions arrived at by such men as Owen or Agassiz are to be treated with indifference."(Species not Transmatable. pp. 44-5.)

In the next place, there was, doubtless, a sentimental feeling, which would induce people to accept the dogma which had so much authority on its side. Nature is dear to us because of its unchangeableness. This feeling is beautifully expressed by George Eliot in the following passages :-

"We could never have loved the earth so well if we had had no childhood in it; if it were not the earth where the same flowers come up again every spring, that we used to gather with our tiny fingers as we sat lisping to ourselves on the grass-the same hips and haws on the autumn hedgerows - the same red-breasts that we used to call God's birds, because they did no harm to the precious crops. What novelty is worth that sweet monotony where everything is known, and loved because it is known?"-(The Mill on the Floss. p. 33.)

"Sitting on the banks in this way, Silas began to look for the once familiar herbs again; and as the leaves with their unchanged outline and markings lay on his palm, there was a sense of crowding remembrances from which he turned away timidly, taking refuge in Eppie's little world that lay lightly on his enfeebled spirit."-(Silas Marner. p. III.)

Richard Jefferies gives utterance to the same sentiment.

"I do not want change; I want the same old and loved things, the same wild flowers, the same trees and soft ash green; the turtledoves, the blackbirds, the coloured yellow-hammer, sing, sing, singing so long as there is light to cast a shadow on the dial, for such is the measure of his song; and I want them in the same place."-(The Gentleman's Magazine. vo?. colxiaii., p. gr.) 
We must further remember that $\mathrm{Mr}$. Darwin accepted Lamarckian principles as part of his teaching, and held them not inconsistent with the action of Natural Selection; so that his chief foe was the traditional view which had so much sentiment and authority on its side. This fact seems to me to have largely affected the way in which the arguments for Natural Selection have been presented. The facts of the case justified-perhaps almost demanded, the argumentum ad hominem addressed to the advocates of the traditional view, and containing theological objections to their theologically supported doctrine of nature. This fact also accounts for and justifies the mode of attack. The absolute fixity of species was the orthodox doctrine. The idea of its sanctity-I venture to use even so strong a word as that-is expressed in the word hybrid, which signifies that the offspring of individuals of different species is the shame of its parents and an outrage upon nature-a transgression of a demarcation laid down at the creation of the world.

The doctrines of the special creation and fixity of species must first be overcome. Then, as Buffon said long ago, the doctrine of Organic Evolution would prevail.

"If the point were once gained, that among animals and vegetables there had been, I do not say several species, but even a single one, which had been produced in the course of direct descent from another species; if, for example, it could be once shown that the ass was but a degeneration from the horse, then there is no farther limit to be set to the power of nature, and we should not be wrong in supposing that with sufficient time she could have evolved all other organised forms from one primordial type."-(Universal Review. vol. vii., p. 77.)

Hence, as it seems to me, it happened that the first and chief stress of the argument consisted in proving that species were not absolutely fixed; and that the agent employed by nature to secure the transmutation and even the origin of species was Natural Selection. And on the 
other hand, the advocates of the traditional view had no thought of altering their standpoint. They stuck to their authorised version of the world's history, and could substitute no other. If they yielded, of course they would have to yield to their opponents. The result was a great advantage to the advocates of Natural Selection. So far as their opponents were concerned, the theory sufficed to prove that the transmutation of species was a fact in nature; and the easily learned formula of Natural Selection, embodying as it seemed the most obvious facts, gave to this teaching a power which no other, at that time, could have wielded.

But while this victory was being won, the triumphant theory was itself undergoing modification. The more absolute and, as it seems to me, the more logical theory of Pure Darwinism, was taking the place of Mixed Darwinism. This conviction was steadily growing, in consequence of the depreciatory language used by Mr. Darwin with respect to transforming influences; of the introduction by Dr. Weismann of his theory of the germ plasm; of the growing tendency of Mr. Wallace to the more exclusive doctrine; and of the powerful advocacy of writers like Dr. Ray Lankester. Pure Darwinism thus became the accepted view of the majority of the advocates of Natural Selection; and hence the identification of the arguments for the process of Organic Evolution, and for the one only law which was supposed to have brought about that process, seemed perfectly fair.

For these reasons, the arguments for the process of Organic Evolution have been treated as identical with the arguments for the particular law or method of Natural Selection. But while the historical development of the doctrine of Natural Selection has more or less justified this treatment of the subject, we must remember that for 


\section{4}

the clear and logical conception of the subject it is necessary for us to bear in mind that Natural Selection is not necessarily identical with Organic Evolution, and that the arguments for the latter are not necessarily proofs of the former. 


\section{CHAPTER II.}

ORGANIC EVOLUTION NOT PROVED BY NATURAL

SELECTION.

"It is possible to have a complete faith in the general doctrine of evolution, and yet to hesitate in accepting the Darwinian theory."

-HUXLEY.

IT was shown in the preceding chapter that the arguments for Organic Evolution were the common property of all those who believe in Organic Evolution; that they could be, and actually had been, urged by one who never heard of Natural Selection, no less than by those who are the convinced believers in that theory. Hence we infer that evidence to show that a certain process has taken place is not necessarily evidence as to the particular law of nature by which that process has been dominated. We have now to consider how far the doctrine of Organic Evolution has been confirmed by the theory of Natural Selection.

$\mathrm{Mr}$. Romanes contends that "the evidences which he (Mr. Darwin) adduced in favour of Natural Selection as a method have constituted some of the strongest reasons which scientific men have felt for accepting evolution as a fact." * But in the context he makes admissions which tend to weaken this assertion. He says: "I have made the evidences of evolution as a fact to stand independently on their own feet-feet which, in my opinion, are amply strong enough to bear any weight of adverse criticism that

* Darain and After Daruin. p. 252. 
can be placed upon them." He fully admits that "the evidence in favour of this fact has gone on steadily growing, quite independently of the assistance which was thus so largely lent to it by the distinctively Darwinian theory of its method." He feels that "we must have some reasonable assurance that a fact is a fact before we endeavour to explain it." But if we are perfectly convinced that Organic Evolution is a fact, I fail to see how any argument as to the law which dominated the process can strengthen a conviction which is already strong enough "to stand upon its own feet" in face of the most adverse criticism.

It is true, historically, that it was this theoretical explanation of the method which first set him (Darwin) seriously to enquire into the evidences of evolution as a fact; but it is scarcely true to say that "the evidence of evolution as a fact has from the first been largely derived from testing Darwin's theory concerning its method"; for, as we have already shown, the arguments for Organic Evolution were stated by Mr. Robert Chambers fifteen years before the appearance of The Origin of Species, and, therefore Mr. Fiske is not justified in saying that Mr. Darwin "was the first to marshal the arguments from classification, embryology, morphology, and distribution, and thus fairly to establish the fact that there has been a derivation of higher forms from lower."

It is true that the battle for Organic Evolution was fought and won by those who held Darwinian opinions. The special Darwinian hypothesis may have aided in this conflict without being on that account necessarily true. I am inclined to think that the simplicity of the theory, and the possibility of stating it in language which could be 
easily understood, and the adoption of its salient principles as household words, have largely contributed to the acceptance and popularity of the doctrine.

And this brings me to the consideration of another point. Is the ready acceptance of a theory a proof of its truth? Mr. Wallace declares that "in less than eight years The Origin of Species has produced conviction in the minds of a majority of the most eminent living men of science."* And he goes on to say that "new facts, new problems, new difficulties, as they arise, are accepted, solved, or removed by this theory." But, in the same chapter, he himself shows that it is possible that a false theory may meet with a speedy acceptance, though it may not be able to stand the test of time; and he gives as an illustration the Circular and Quinarian System of classification propounded by MacLeay and developed by Swainson. Yet it quite died out in a few short years. In cases which are not susceptible of mathematical proof, it is quite possible that a false theory may be accepted as soon as propounded. It would not be too much to say that a false theory which takes a superficial view and offers an easy explanation, may triumph over the complicated statement of a congeries of scientific truths.

But while a false theory may enjoy a temporary triumph more or less protracted, it does not follow by any manner of means that a true theory will be at once accepted, even when it is susceptible of mathematical proof. Mr. Fiske says :-

"Newton's law of gravitation, though proved by the strictest mathematical proof, received from many eminent men but a slow and grudging acquiescence. Even Leibnitz, who, as a mathematician hardly inferior to Newton himself, might have been expected to be convinced on simple inspection of the theory, was prevented from

\footnotetext{
* Contributions. pp. 46-7.
} 
accepting it by the theological objection that it appeared to substitute the action of a physical force for the direct action of the Deity. In France, where ideas not of French origin are very apt to be but slowly apprehended, the opposition to the Newtonian theory was not silenced till I759, when Clairaut and Lalande, by calculating the retardation of Halley's comet, furnished such crucial proof as could not possibly be overcome. At this time Newton had been thirty-two years in his grave; seventy-two years had elapsed since the publication of the Principia, and ninety-four since the hypothesis was first definitely conceived."-(Darwinism and other Essays. pp. $I$-2.)

Mr. Wallace asserts that new facts fit in satisfactorily with the theory of Natural Selection, but since he wrote his Contributions to the Theory of Natural Selection, there have not been wanting experts who contend that certain facts call hardly be reconciled with the theory of Natural Selection; and it is not too much to say that a reaction against Pure Darwinism, if not against Natural Selection, has already set in.

Mr. Wallace pleads in favour of the doctrine of Natural Selection "the evidence of necessity." He meets the objection, that we have no direct evidence for the action of this selecting power in nature, thus :-

"But it seems to me we have better evidence than even direct observation would be, because it is more universal-namely, the evidence of necessity. It must be so."-(Contributions. p. 309.)

The assertion that Natural Selection is a necessary truth is so far true that, if we grant its premises, the result which it predicts must necessarily take place. But the reliability of the result depends upon the correctness of the statement of the case. If you assume that the fecundity of the organic world, and the limited area for the accommodation of living forms, must lead to a struggle for existence; that this struggle for existence must exercise a selective influence in all essential respects analogous to the selection practised by the cattlebreeder and the pigeon-fancier-if you assume that this 
Natural Selection will lead inevitably to the survival of the fittest, and that this survival of the fittest will necessarily lead to the transmutation of species, and has led to the evolution of all organic forms-then it might be said that Organic Evolution by means of Natural Selection is a necessary truth. It has been our endeavour to show in the First Book of this work that the assumptions of the theory do not correspond with the facts of the world in which we live; that the fertility of nature does not tend in all cases to produce a struggle for existence which is selective; that the struggle for existence is so modified in nature that it is not in many cases selective in the sense required; that where selection takes place it does not necessarily produce a transmutation of species; and $\mathrm{Mr}$. Wallace himself admits, in a passage just quoted, that if the transmutation of species were brought about by the action of Natural Selection, we must not therefore infer that the same cause, acting in precisely the same way, has been the cause of Organic Evolution. Natural Selection can only be a necessary truth in so far as it is the logical outcome of certain assumptions. But if those assumptions are not true, Natural Selection cannot be a necessary law of nature.

Another argument used by Mr. Wallace is based on what is known as the law of parsimony.

"As the survival of the fittest must inevitably weed out those whose colours are prejudicial, and preserve those whose colours are a safeguard, we require no other mode of accounting for the protective tints of arctic and desert animals.-(Contributions. p. 125.)

\section{Professor Rolleston says of this law :-}

"It was known in the days of the schoolmen as the Razor of Occam, and in later days it has been styled the Law of Parsimony or Economy. . . I know that this Regula (of Newton's) has great influence on the minds of many biologists, and I believe that its influence is 
by no means always for good. . . . Our business is to ask, not what men have laid down, but how nature operates. Can a phaenomenon have more than one cause, or can it not?"-(Scientific Papers and Addresses. vol. ii., p. 72I.)

"Because one agency is proved to be a vera causa, it is not thereby proved that no other can by any possibility be competent simultaneously to produce the same effect, whatever the schoolmen, with the law of parsimony ringing in their ears, may have said to the contrary."-(Ibid. p. 859.)

He then proceeds to state certain cases in which a law of parsimony has a place in nature, but he contends that this law in no case excludes the possibility of a plurality of causes :-

"Many other instances of the law of parsimony might be given; but I know not of any which cannot be reduced under one or other of these three heads; I know of none, that is, which can be in any way held to negative the tenability of a law of plurality of causes."(p. 723.)

If there is any sphere of nature in which a plurality of causes is at work, it is surely in the colour and coloration of animals. Heat and cold, summer and winter, light and darkness, plenty and famine; the kind no less than the amount of food; physical, chemical, and organic conditions, the inward organisation and the outward condition indicated by that significant and much-embracing term "climate"-all of these affect the colours of animals; and not unfrequently it happens that the same colour is produced by two distinct causes. Such being the case with respect to colour generally, it should not surprise us to find that protective colouring is also due to many causes as before explained. Assuming that Natural Selection is one of the causes of this phenomenon, it cannot be denied that it sometimes occurs apart from Natural Selection-as, for example, when the colour of the food-plant is seen through the skin; when the colour of the food-plant affects the blood, 
so that the insect lays a green egg which hatches into a green grub. In other cases it is reasonable to suppose that changed conditions have produced a direct effect, though it may not be possible to prove that this is so. Take, for example, the case of the eland :-

"A curious point in the always singular freaks of the geographical distribution of animals is to be found in connection with the eland. The eland of the Cape Colony, Orange Free State, Transvaal, Namaqualand, and Demaraland, in the old days, and the eland of the Kalahari, at the present time, were and are always entirely devoid of markings, the body-colouring varying from a dun or fawn in the younger beasts to a bluish buff in the old animals. In Mashunaland and Portuguese South-eastern Africa and beyond the Zambesi-in all parts of Africa where elands are to be found-they are met with, bearing invariably a number of white stripings across the body--very similar to the markings of the koodoo-and are marked also with a black patch on the outer side of the fore-arm, and a dark list running down the spine. These characteristic stripings are entirely wanting in the eland of South-western Africa, which from the rapid narrowing of its habitat and its constant persecution, is, as I have pointed out, likely not long hence to vanish altogether. That the absence of stripings has accompanied a more desert and waterless, more temperate and less tropical habitat, is a plain fact enough. And that the stripings appear in all elands throughout the more tropical parts of Africa is also perfectly apparent. To explain the variation is a much more difficult matter. Possibly heat and moisture have something to do with it. This, however, is a difficult and a thorny subject, and even Darwin himself was oftentimes puzzled to account for the capricious nature of the markings and stripings of animals."(H. A. Bryden. Chambers' Journal. vol. xi., 5 th series, p. 674.The Vanishing Eland.)

No doubt the markings are capricious from the point of view of Natural Selection, but if we knew all the effects of external conditions and of internal organisation, we should see that every mark had its obvious cause.

What are we to understand Mr. Wallace to mean when he tells us that having found, as he believes, that protective colouring can be produced by Natural Selection, we may rest content and need seek no other cause for the phenomenon? Remembering that this is a case in which the EE 
principle of a plurality of causes is evidently at work, are we to be content with the assertion which is only a fraction of the truth, if it be a truth at all, that protective colouring is the result of Natural Selection? Ought we not to wish to know the truth, the whole truth? We cannot suppose that Mr. Wallace wished to arrest further enquiry in the interests of the theory which he espoused. Such a treatment of the subject would only be justified if nature was known to work always on the principle of "one effect, one cause."

There is one other consideration to be borne in mind, namely, that the supposed law of parsimony, in asserting that a given cause is sufficient, by itself, to explain a given result without reference to other causes, always assumes that this cause is a true cause. I have given reasons for my belief that Natural Selection is not the true cause of protective colouring. If this is so, the application of the law of parsimony to this case would lead not merely to the inculcation of a half truth, but to the preservation of error. In no aspect of this subject can the argument be regarded as worthy of the true scientific spirit.

There is but one proof which is worth anything with respect to a scientific theory of physical nature, and this is a rigid comparison of its assumptions with the actual phenomena. In the earlier part of this work I gave reasons for believing that the theory of Natural Selection would not bear this test. It is unnecessary to go over this ground again, except to say this: that if Natural Selection is not proved to be active now in the transmutation of species, it deprives us of all right to assume that it has been active through untold eras in bringing about the process of Organic Evolution.

And now we come to what seems to me the most astounding argument which was ever urged in defence of 
a theory. Dr. Weismann asserts that we cannot imagine the process of Natural Selection:-

"I must say that, in respect of warrant to assume the process of Natural Selection, it does not seem to matter much whether we can easily, or with difficulty, or only with great difficulty, imagine it; and for this reason, that I do not believe that we are in any case able to conceive in detail the actual morphological metamorphoses concerned."-(The Contemporary Review. rol. laiv., p. 320.)

He asserts that we cannot demonstrate the truth of Natural Selection :-

"Just as in this instance, so is it in every individual case of Natural Selection. We cannot demonstrate any of them, and there is no use attempting to make them seem unanswerable." - (p. 323.)

"It is true the results of artificial selection are in favour of the occurrence of Natural Selection, but, as Herbert Spencer justly observes, the two processes, though they may be analogous, are certainly not identical. The struggle for existence plays the part of breeder in the case of Natural Selection; and how this factor works we are unable to determine in any single case. Who would say of any little variation in the form of any existing species that it is sufficient to give its possessor the victory in the struggle for existence, and so may become the starting-point of an advantageous metamorphosis of the part? Even in the simplest of cases that is impossible ; no one, for instance, could decide how much the colour of a green insect must vary so as to originate a process of selection dependent perhaps on adaptation to a new and somewhat differently coloured fodder-plant. We cannot estimate what Romanes has recently very well called the 'selection value' of variations, which Lloyd Morgan had previously spoken of as the 'elimination value'; we can only say generally with Darwin that selection works by the accumulation of very slight variations, and conclude from this that these' 'slight variations' must possess selection value. To determine accurately the degree of this selection value in individual cases is, however, as yet, impossible."-( $p$. 324.)

"As soon as an attempt is made to think out in detail the process of selection by which perhaps the little bristles or the small baskets of the worker-bees have arisen, it is seen that all and every one of the data are wanting. Moreover, in my opinion, we cannot hope that we shall ever possess them, either in these cases or in any yet simpler process of Natural Selection. Not only would it be necessary to form an estimate of the smallest variations so as to know 
whether and how often among 1,000, 100,000, or millions of individuals there is a variation which gives verdict over life and death, but much more that we can never determine is required; for instance, the number of individuals of a species living at one time, the degree of their mingling with one another in their own domain, and the percentage occurrence of the variation in question-all which, I am convinced, cannot be ascertained; and so we shall never be able to establish by observation the progress of Natural Selection. What is it, then, that nevertheless makes us believe in this prog'ress as actual, and leads us to ascribe such extraordinary importance to it? Nothing but the power of logic; we must assume Natural Selection to be the princıple of explanation of the metamorphoses, because all other apparent principles of explanation fail us, and it is inconceivable that there could be yet another capable of explaining the adaptations of organisms reithout assuming the help of a principle of design. In other words, it is the only conceivable natural explanation of organisms regarded as adaptations to conditions."-(The Contemporary Review. vol.xliv., pp.327-8.)

It is a startling thing to find it asserted that, in a certain case to which it is applied, the theory of Natural Selection cannot be imagined, either with regard to the selective process or the morphological results. That cannot mean that it could not be painted by the imagination if it were left unrestrained, for who shall put a limit to the creations of the fancy? It must mean that we cannot imagine it, because we have no grounds for believing in its possibility-because we know too much to be deluded, or because we know too little to have confidence in an attempt to depict what we still believe a reality.

On the other hand, it is asserted that the statement that certain phenomena are the results of Natural Selection cannot be proved from actual observation. What cannot be proved by observation is simply a matter of personal faith, it cannot be regarded as a demonstrated law of nature. I venture to say that the secrets of nature have only been revealed to those who have had imagination to conceive a theory, and who have rigorously tested that theory by observation and experiment. But here we have 
a theory which cannot be imagined and which cannot be proved by observation. Such a theory must be inconsistent with itself and contrary to nature. And this is precisely what we have attempted to show that Natural Selection is.

But these considerations do not seem to affect the loyalty of Dr. Weismann to the Darwinian hypothesis. And here it is curious to talic note of the one point on which he seems to be quite confident. He admits that we have no means of ascertaining how much variation will determine the selection of variants, and then continues thus :-

"We can only say generally that selection works by the accumulation of very slight variations, and conclucle from this that these slight variations must possess selection value."

This seems to me to be a good specimen of the process known as arguing in a circle. But apart from that consideration, it may be well to call to mind what $\mathrm{Mr}$. Darwin says upon this subject. Mr. Darwin uses some very strong language, the purport of which is to maintain that the validity of his theory of Natural Selection depends upon the assumption that the variations which occur in nature are slight in quantity.

"Natural Selection, if it be a true principle, will banish the belief in any great and sudden modification of structure."

"Why should not nature take a sudden leap from structure to structure? On the theory of Natural Selection we can clearly understand why she should not; for Natural Selection acts only by taking advantage of slight successive variations; she can never take a great and sudden leap, but must advance by short and sure, though slow, steps."-(Origin of Species. p. 156.)

"On the theory of Natural Selection we can clearly understand the full meaning of that old canon in natural history, Nature non focit saltum." -(Origin of Species. p. 166. .)

We must not suppose that Mr. Darwin meant simply to deny the possibility of a leap so great as to constitute 
a transition from one species to another. He meant to assert that the variations in nature were small in amount, and that the theory of Natural Selection demanded that it should be so. Mr. Darwin says :-

"Natural Selection acts only by the preservation and accumulation of small inherited modifications."-(Origin of Species. p. 75.)

"This preservation during the battle of life, of varieties which possess any advantages in structure, constitution, or instinct, I have called Natural Selection."--(The Viriation. vol. i., p. 6.)

"The more I work, the more I feel convinced, that it is by the accumulation of such extremely slight variations (as a beak $\frac{1}{100}$ of an inch longer than usual) that new species arise."-(Edinburgh Review. vol. clxvii., p. 432.)

"Natural Selection is daily and hourly scrutinising throughout the world the slightest variations, rejecting those that are bad, preserving and adding up all that are good."-(Origin of Species. p. 65.)

The assertion that variations must be slight is confirmed by actual observation :-

"As with birds the individuals of the same species, inhabiting the same country, vary extremely little, I have particularly attended to them; and the rule certainly seems to hold good in this class." (Origin of Species. p. I20.)

If I am right in my interpretation of these passages, Mr. Darwin makes the truth of his theory dependent upon the fact, that Natural Selection never takes a sudden leap; the variations are always slight, and in confirmation of this fact he cites the case of birds, which are said to vary little.

None the less, the truth of the general dictum, Natura non facit saltum, does not pass unchallenged by some of the highest authorities. In his review of Professor Kölliker's criticism, Professor Huxley says :-

"We greatly suspect that she (i.e., Nature) does make considerable jumps in the way of variation now and then, and that these saltations give rise to some of the gaps which appear to exist in the series of known forms."-(Lay Sermons. p. 312.) 


\section{Professor Parker says :-}

"To a certain extent the old adage, Nihil per saltum ("Nothing by leaps and starts'), is true in nature, but it is not universally true. Hence no well-informed naturalist is an absolute uniformitarian." Contemporary Revieze. vol. xlvii., p. 843.)

"Yet changes of this kind, almost insensible, though very potent factors in evolution, are certainly not all that have taken placesome parts must have modified themselves suddenly."-(Ibid. p. 853.)

"I feel the greatest difficulty in accounting for the establishment of a new breed in a state of freedom by slight selective influences, unless there have been one or more abrupt changes of type, leading step by step to the new form."-(Galton. Nature. vol. xxxizi., p. 297.)

If anyone supposes that the authority of Mr. Darwin is greater than that of the authors quoted, we can meet that difficulty by pointing out that Mr. Darwin himself speaks of the dictum, Natura non facit saltum, as-

"that old and somewhat exaggerated canon in natural history."(Origin of Species. p. 156.)

In some cases Mr. Darwin admits that there is a considerable gradation in the amount of variations :-

"Under the term of 'variations' it must never be forgotten that mere individual differences are included."-(Origin of Species. p. 64.)

"Monstrosities graduate so insensibly into mere variations that it is impossible to separate them."-(The Variation. vol. ii., p. 254.)

The slight degree of variation which obtained among the birds which Mr. Darwin noticed, does not seem to correspond with the investigations of other naturalists :-

"A correspondent states that he has seen a variety of the goldfinch marked by strong distinguishing characters-considerably larger size, more graceful form, and much richer and more lustrous plumagewhich bird-catchers say occurs frequently as a progeny of the ordinary bird. The distinctions of this animal are greater than those held in many instances as specific; there seems no room to doubt in such an instance that pairs so peculiar might, in fresh ground of their own, give rise to a race which naturalists would call a separate species."-(Vestiges of the Natural History of Creation. Izth cd., p. 227-note.) 
Mr. Wallace, speaking of the variations in the birds of the United States as described by Mr. J. A. Allen, says :-

"These variations are by no means small in amount, or requiring very accurate measurements for their detection, since they often reach one-seventh, one-sixth, or sometimes even one-fourth of the entire average dimensions."-(Nineteenth Century. vol. vii., p. 99.)

Thus we have a theory which cannot be imagined, which cannot be seen at work; which requires a condition of its action which does not occur in nature: and then we are coolly asked to accept this theory "because all other principles of explanation fail us."

Now, it was the object of the Second Book to prove that other causes of the transmutation of species exist and are in full operation apart from Natural Selection, and that they tend to exclude the action of Natural Selection, supposing that to be a possible law of nature. We do not feel called upon to relinquish these explanations in favour of a theory which cannot be imagined and cannot be demonstrated, and which demands a condition of things which has no place in the natural world.

But assuming that all other explanations fail us, why should we therefore be driven to accept a theory unimaginable and without proof? By what principle of election are we to favour one more than the others? If all of them are unsatisfactory, why are we to accept any one? If none of them will bear the ordinary tests which are applied to scientific theories, is not that a proof that the secret has not yet been revealed? Should not that fact be accepted as an intimation that the true solution is to be found elsewhere? We who believe that Organic Evolution has been proved, are not bound to have any theory as to the laws by which that process has been dominated.

But we are told that we must accept this theory of Natural Selection, or else accept the principle of design, 
which, in the opinion of the writer, is a reductio ad absurdum. This, as it seems to me, is the language of despair, utterly unworthy of a great scientific writer. For by design it is evident that he means miraculous interposition in the order of nature. We must invoke a deus ex machina because forsooth we have not yet discovered the laws which regulate the order and the progress of nature.

We have seen that it is the opinion of Mr. Wallace that though the transmutation of species by Natural Selection is a fact, it does not necessarily follow that Organic Evolution has been brought about by the same process in identically the same way. I do not feel the force of this assertion. I should suppose that if Natural Selection were the law of organic change now, it would be a legitimate inference to suppose that it always had been. But if Organic Evolution is a fact, corresponding to all the phenomena of nature with which we are acquainted, I fail to see how it can be strengthened by the theory of Natural Selection, if the objections which have been brought against it are valid. Natural Selection may be accepted so far as it is identified with Organic Evolution, but Organic Evolution can receive no support from the theory of Natural Selection. 
CHAPTER III.

ORGANIC EVOLUTION NOT AIDED BY NATURAL

SELECTION.

"A spoke in the wheel."

When I assert that Organic Evolution has not been aided by Natural Selection, I mean that the attempt to imagine the process of Organic Evolution has not been assisted by the explanations of certain phenomena offered by the advocates of the theory of Natural Selection; and that in some respects Natural Selection has deprived us of what used to be considered as proofs of Organic Evolution. In order to understand this, it may be well to remember that the arguments in favour of Organic Evolution may be resolved into three classes: I. Those which go to show that a process of gradual modification must have taken place; 2. Those which show that one species or type of organic life has been developed into a higher one, structurally and functionally; 3. Those which tend to show that an organ or an organism once structurally perfect and functionally active, has been degraded into one less structurally perfect and less functionally active.

Now, in stating the argument for Organic Evolution as against fixity of species, apart from Natural Selection, these arguments do not at all clash. An especially strong argument for the transmutation of species as against the fixity of species is found in the modification of structure, to which reference is made under the argument from morphology, or the science of form. The argument from 
embryology gives an equally emphatic proof that all living organisms have been gradually developed. There are, so far as I can see, only three conceivable ways in which the fertilised ovum can have become an organic being. A perfect microscopic organism may have been formed as the first magical process of reproduction, and it may simply have grown-i.e., increased in dimensions until the time of birth; or there may have been a gradual formation of an organism, the outlines being laid down from the first and filled in gradually as the process of development went on, or that might be which actually is, and which perhaps would have seemed least probable from a priori considerations - the fecundated ovum might assume the forms of various living beings, passing from the simpler to the more complex. The first two of these processes would have been perfectly in harmony with a belicf in the fixity of species, for the homunculus formed at the first, and the organism gradually developed into an ultimate complexity on lines laid down from the first, would simply have told us how a given species had power to reproduce its own likeness from generation to generation. But from the demonstrated facts of embryology there is but one reasonable inference, and that is that the development of the individual organism reproduces the evolution of the race to which it belongs, from the lowest to the highest types of organism. This inference would be unassailable, even if it stood alone and there were no confirmatory argument; but the geological succession of animals and plants tends to establish the same principle-namely, an advance from the simpler to the more complex form, and the tree-like form into which the true classification resolves itself is in accordance with the argument from embryology and palxontological sequence. Any argument adduced for the progressive development of a lower into a higher 
specics, such as could be cstablished by observation by experiment and from reasonable inference, would tend to confirm, if that were needed, a belief for which there was already the most abundant evidence. The argument from morphology, which is really based on the degradation of an organ or an organism, looked at either from a structural or from a functional point of view, could only go to show that all change was not necessarily progressive change according to a particular conception of progress; but it would have no power to alter the established belief that the process of progressive Organic Evolution must have taken place, and if it were not always possible to give actual illustrations of this process, the believer in Organic Evolution would come to the conclusion that the limitation of his knowledge, and not the weakness of his arguments, was to blame. He would still be bound to believe in the progressive development of organs and of organisms, and there would be nothing inconsistent with his belief in the fact that perfect organs could be further modified and even degraded. Consequently, in his view, some imperfect organs would be on the upward grade, albeit others could be proved to be on the downward grade. Many imperfect organs would still remain as illustrations of that gradual progressive evolution which, he has good reason to believe, must have taken place.

Mais nous avons changé tout cela. The theory of Natural Selection has largely modified the view of imperfect organs just referred to. There is a passage in Mr. Wallace's writings which brings out this point in a very distinct manner. In 1855 he wrote an Essay, in which he explained the significancy of imperfect organs from the point of view of a belief in Organic Evolution :-

"To every thoughtful naturalist the question must arise: What are rudimentary organs for? What have they to do with the great 
laws of creation? Do they not teach us something of the system of nature? If each species has bèen created independently and without any necessary relations with pre-existing species, what do these rudiments, these apparent imperfections, mean? There must be a cause for them; they must be the necessary results of some great natural law. Now, if, as it has been endeavoured to be shown, the great law which has regulated the peopling of the earth with animal and vegetable life is, that every change shall be gradual; that no new creature shall be formed widely differing from anything before existing; that in this, as in everything else in nature, there shall be gradation and harmony-then these rudimentary organs are necessary, and are an essential part of the system of nature. Ere the higher vertebrata were formed, for instance, many steps were required, and many organs had to undergo modifications from the rudimental condition in which only they had as yet existed. . . . Limbs first concealed beneath the skin and then weakly protruding from it were the necessary gradations before others should be formed fully adapted for locomotion."-(Contributions. pp. 23, 24.)

In republishing this Essay in $\mathrm{I} 870$, he adds a note, in which he asserts that this view is no longer tenable, because it is inconsistent with the principles of Natural Selection. He says :-

"The theory of Natural Selection has now taught us that these are not the steps by which limbs have been formed, and that most rudimentary organs have been produced by abortion owing to disease (?disuse), as explained by Mr. Darwin."-(Contributions. p.24-note.)

\section{Mr. Lydekker speaks to the same effect:-}

"With the advent of the doctrine of evolution, and the more careful investigations into the structure of animals which had by that time taken place, a total change of view as to the real nature and import of these so-called rudimental structures at once ensued. Thus it was soon found (not by conjecture, but from actual circumstantial evidence) that in place of being the beginnings of structures which eventually became functional, these rudiments were really the remnants of structures which had once been functional, but had now become useless. This change of view necessitates, therefore, that the term 'rudiment' in zoology must at least very generally be used in precisely the opposite sense to the one in which it is employed in ordinary parlance."-(Phases of Animal Life, Past and Present. t. 237.) 
Mr. Darwin says :-

"In order to understand the existence of rudimentary organs, we have only to suppose that a former progenitor possessed the parts in question in a perfect state, and that under changed habits of life they became greatly reduced."-(Descent of Man. and ed., p. 25.)

"Owen considers the simple filamentary limbs of the lepidosiren as the beginnings of organs which attain full functional development in higher vertebrates; but, according to the view lately advocated by Dr. Guinther, they are probably remnants consisting of the persistent axis of a fin with the lateral rays or branches aborted."-(Origin of Species. p.399.)

"The wing of the penguin is of high service, acting as a fin. It may therefore represent the nascent state of the wing. Not that I believe this to be the case. It is more probably a reduced organ modified for a new function."-(Origin of Species. p. 398.)

It should be observed that the advocate of Natural Selection does not deny that there have been, in the history of the world, imperfect organs progressing towards perfection; but he asserts that the imperfect organs with which we are actually acquainted are not progressive but retrogressive forms. All who accept Organic Evolution must necessarily believe in progressive development as the demonstrated truth of science. But if this is so, it might be asked, How does the advocate of Natural Selection come to question the progressive character of the imperfect organs now existing? Why does he deny that some of these (or all of these?) are progressive forms? What is the reason which perhaps unconsciously leads him to put this spoke in the wheel of Organic Evolution? The answer seems to be quite a simple one. He has to prove that Organic Evolution has taken place through the action of Natural Selection, and he looks with suspicion upon all processes which cannot be so explained. In doing this he limits the action of Organic Evolution by the logical requirement of the theory of Natural Selection, which is 
always and everywhere itself controlled by the principle of utility.

Two consequences follow from this treatment of the problem: I. The advocate of Natural Selection seizes upon the fact of degeneration because he can explain, or thinks that he can explain, that phenomenon on the principles of his theory; 2 . While he does not deny the possibility of the existence of progressive organs, he limits the action of progressive Organic Evolution by insisting that at every stage each step of progress shall be useful in a very emphatic sense, while he allows that it is not always easy to prove that this is so.

The discussion as to the true significancy of imperfect organs has been much obscured by the curious confusion which has arisen in connection with the terms which are employed. The facts already referred to suggest that an organ or organism may exist in one or other of the following conditions:--In the first place it must have begun in some very small modification, that went on progressing until a condition of tolerable perfection was attained, the organ being structurally and functionally perfect. Having attained perfection, it is possible that it should become degenerate, either in structure or in function, until at last it disappeared altogether. But not only might an organ or an organism exist in any stage of progress or of retrogression, it might also be moving or it might be arrested in this progress or retrogression. Now I venture to say that the resources of the English language suffice to provide us with a clear and distinct nomenclature on this subject. What better word could possibly be found to express the first beginnings of the process of development than the word "nascent"? for as the birth is the beginning of the career of the man, so the first modification is the beginning of the development of an organism. 
The word is used in chemistry to indicate the condition of an element in the state of passing or having just passed from one combination to another. The earlier stages of the process might well be expressed by the word "rudiment." In the glossary to The Origin of Species "rudimentary" is rightly defined as "very imperfectly developed." The Latin word rudimentum comes from rudis, which means unvrought, untilled, unformed, unused, rough, new, and, figuratively, rude, unpolished, uncultivated. Hence rudimentum means a first attempt-rudimenta adolescentice ponere means to pass one's novitiate. Hence "rudiments" means the elements of a subject.

"Hor.: I must begin with rudiments of art:

To teach you gamut. . . ."

"Bicnn.: Why, I am past my gamut long ago." -(Taming of the Shrew. Act iii., sc. I.)

In the glossary to The Origin of Species it is asserted that "an organ is said to be 'aborted' when its development has been arrested at a very early stage." * Now this is in accordance with the meaning of abortion-which signifies, in the first place, premature birth, and, in the second place, the immature form which accompanies such a birth. Hence Richard III. says of himself, according to Shakespeare-

"I, that am curtail'd of this fair proportion, Cheated of feature by dissembling nature, Deform'd, unfinish'd, sent before my time Into this breathing world, scarce half made up, And that so lamely and unfashionable, That dogs bark at me, as I halt by them."

-(King Richard III. Act i., sc. I.)

The later stages on the way to perfection, subsequent to those which could be rightly called rudimentary, might be 
described as progressive. On the other hand, an organ undergoing degeneration might be regarded as a degraded organ, a remnant or a relic of a past perfection and efficiency; or as an atrophied organ referring to the process of wasting away, of which its modification is an illustration. If such a nomenclature could have been adopted, we should always have known exactly what a writer meant, supposing that he was careful in the use of his terms.

We have already seen, that Mr. Lydekker says that the change of view introduced by the theory of Natural Selection has given to the word "rudiment" a meaning in scientific discussion the very opposite of that which obtains in common parlance. Innumerable instances might be quoted to show the truth of this assertion :-

"Rudimentary organs may be compared with the letters in a word, still retained in the spelling, but become useless in the pronunciation, but which serve as a clue to its derivation."-(Origin of Species. p. 402.)

"It appears probable that disuse has been the main agent in rendering organs rudimentary. It would at first lead by slow steps to the more and more complete reduction of a part, until at last it became rudimentary, as in the case of the eyes of animals inhabiting dark caverns."-(Origin of Species. p. 400.)

The term "rudimentary" is also used to signify what is functionally useless, though constitutionally perfect.

"An animal may possess various parts in a perfect state, and yet they may in one sense be rudimentary, for they are useless."-(Origin of Species. p. 397.)

. . "the remarkable rudimentary organs--eyes that see not, wings that are never used in flying, muscles that do not contract."(Haeckel. Essays. p. 280.)

Once more the same organ is treated as rudimentary from one point of view and non-rudimentary from another. $\mathrm{FF}$ 
"An organ may become rudimentary for its proper purpose and be used for a distinct one."-(Origin of Species. p. 398.)

"An organ serving for two purposes may become rudimentary or utterly aborted for one, even the more important, purpose, and remain perfectly efficient for the other."-(Origin of Species. p. 398.)

The term "rudimentary" is identified with "aborted" and "atrophied." "Rudimentary organs may be utterly aborted."* Mr. Wallace speaks of the "atrophied or rudimentary remains of more important characters." $\dagger$ Mr. Conn speaks of "aborted" and "atrophied" as synonymous. $\neq$ In fact all the terms used to represent imperfect organs are used to describe relics, with the exception of the word "nascent," which now occupies the place once legitimately held by the word "rudimentary." This use of speech is a very remarkable fact. It is within the power of scientific men to put a new meaning into the most familiar words. It may be questioned whether it is a wise thing to do. But whatever has become of the word "rudiment," the progressive organ remains a necessary condition in that process of Organic Evolution which we know must have taken place, and consequently a necessary fact of nature.

The argument from morphology, as employed by the advocates of Natural Selection, is based upon the idea of "type." Each modification is measured, so far as its form is concerned, by a typically perfect structure. What, then, do we mean by type? In the first place, it is possible that this typically perfect form might be an abstract idea in the mind of man. There might conceivably be no perfect type in actual existence; just as the type of any species is an abstract idea, to which no single individual

* Origin of Spccies. p. 399.

† The Fortuightly Review. New scries. vol. xl., f. 306.

+ Evolution of To-day. p. So. 
of that species exactly corresponds, inasmuch as it represents the specific likeness without the individual peculiarity. But such a conception in the mind of man would have no effect on the operations of nature. In the second place, it is possible that the Creator, in making all the different species of vertebrates, might have created them with reference to a type which $\mathrm{He}$ had in His own mind, the actual realisation of which took place in some cases; the idea of which, in other cases, exercised a restraining influence over creative action, so that the greatest skill was required to adapt organs to their functions; and the influence of which is sometimes seen in the existence of a reduced and useless part, retained for the sake of symmetry. We may dismiss this view from our consideration in the present connection, for it has been rejected with ridicule by the advocates of Natural Selection.

But this argument of the Darwinian is the argument of all advocates of Organic Evolution. It is an argumentum ad hominem addressed to a particular kind of theist. It says in effect,--If you believe in the fixity of species, if you believe that all animals were produced in the course of a week of creative energy, if you believe that God had a type or pattern in His mind-then you must believe that He imposed upon Himself conditions which it is not likely that He would impose. Whatever its worth may be, it is an argument against the miraculous creation of species and their subsequent fixity. But this argument has nothing whatever to say against the possibility of God's foreknowledge of all that was to take place as the result of evolutionary processes. The scientific man and the scientific theist are agreed that their business is in the first place to discover what the actual phenomena of nature are; physical science goes no further, and leaves 
to the philosopher or the theologian to hold any faith he may formulate concerning the Divine Being, on the condition that these theories shall not contradict the discovered facts of nature. As a matter of fact, typical structures have been evolved. The significancy of that phenomenon, from a divine point of view, is the theologian's business; the discovery of the processes by which these types have been produced is the business of the scientific man. In this connection, it is to be observed that the Darwinian theory only accolints for the modification of the structurally perfect organ, and says nothing of its evolution. Conformity to type is accounted for by inheritance from a common ancestry, while the modifications of type are due to the necessary adaptation to changed conditions. This is, in effect, the view suggested by Professor Sir W. H. Flower, and apparently adopted by Mr. Darwin :-

"We may call this conformity to type without getting much nearer to an explanation of the phenomenon; but is it not powerfully suggestive of true relationship, of inheritance from a common ancestor?"-(Origin of Species. p.382.)

Let us take as an illustration of this argument the case of the five-fingered hand and the organs which seem to be modifications of the type which it presents. There can be little doubt that in many of these cases the relation between these different kinds of "hands" is to be explained by descent from a common ancestor. The watertortoise and the frog have five-fingered hands, and as we are assured that birds are descended from reptiles, and mammals from amphibia, we have here the explanation of all those modifications of the five-fingered manus which occur in the ranks of organic life above the reptilia. It is possible that eren this assertion may require some 
modification. But if we assume, for the salse of argument, that the structurally perfect five-fingered hand of a reptile was the ancestral source of all modifications of that type in and above the reptilia, it would still follow that the fivefingered hand must of itself have been evolved; that there must have been stages of progression towards that form as well as subsequent modifications of it, and that these progressive stages cannot in any proper sense be regarded as modifications of an ancestral type which had not yet come into existence.

Before referring to the stages of the evolution of the "hand," it may be well to observe that there is no reason whatever for regarding the perfect five-fingered form as the starting-point; though looked at from the point of view of that particular kind of structure, it may be called the culminating point. How, then, did the five-fingered hand come into existence? The phenomenon, known as polydactylism-literally, the tendency to have many fingers, but often manifesting itself in the possession of six fingers-seems to carry us a step further back. Dr. Marigold, that prince of cheap-jacks, seems to have had an inkling of the truth, when, speaking of a weddingring, he says :-

"It's smaller than any finger in my set of ten. Why ten? Because when my parents made over my property to me, I tell you true there was twelve sheets, twelve towels, twelve table cloths, twelve knives, twelve forks, twelve table spoons, and twelve tea spoons, but my set of fingers was two short of a dozen and could never since be matched."

If he had said, "My remote ancestor who preceded my progenitor with the five fingers, had six fingers, one of which he failed to hand over to his successor," he would have put into general terms what Mr. Romanes expresses more definitely when he supposes that a manus equivalent 
to that possessed by the extinct aquatic reptile, Baptanodon discus, may have been developed into the perfect typical five-fingered manus of the water-tortoise, Chelydra serpentina.

"The left hind limb of Baptanodon discus has six rows of little symmetrical bones springing from a leg-like origin. But the whole structure resembles the fin of a fish about as nearly as it does the leg of a mammal. For not only are there six rows of bones instead of five suggestive of the numerous rays which characterise the fin of a fish, but the structure as a whole, having been covered over with blubber and skin, was throughout flexible and unjointed-thus in function, even more than in structure, resembling a fin. . . . Such then is the most generalised as it is the most ancient type of vertebrate limb above the class of fishes. Obviously it is a type suited only to aquatic life. Consequently, when aquatic vertebrata began to become terrestrial the type would have needed modification in order to serve for terrestrial locomotion. In particular it would have needed to gain in consolidation and in firmness, which means that it would have needed also to become jointed. Accordingly, we find that this archaic type gave place in land reptiles to the exigencies of these requirements." In the right forefoot of the water-tortoise "as compared with the homologous limb of its purely aquatic predecessor, there is to be noticed the disappearance of one of the six rows of small bones, a confluence of some of the remainder in the other five rows, a duplication of the arm-bone into a radius and ulna, in order to admit of jointed rotation of the hand, and a general disposition of the small bones below these arm-bones which clearly foreshadows the joint of the wrist. Indeed, in the fore-foot of the Chelydra a child could trace all the principal homologies of the mammalian counterpart growing, like the next stage in a dissolving view, out of the primitive paddle of Baptanodon, namely, first the radius and ulna, next the carpals, then the meta-carpals, and, lastly, the three phalanges in each of the five digits. Such a type of foot meets the requirements of slow reptilian locomotion over swampy ground. But for anything like rapid locomotion over hard and uneven ground greater modifications would be needed. Such modifications, however, need not be other in kind. It is enough that they should continue in the same line of advance, so as to reach a higher degree of firmness combined with better joints."-(Darwin and After Darwin. pp. I79-I82.)

According to the views expressed in the preceding passage, there are three typical forms-the fin of the fish, the paddle of the Baptanodon discus, and the manus of 
the Chelydra serpentina or water-tortoise; and these three types appear successively in the process of Organic Evolution.

Now, in the first place, it follows from this view of the case, that the fin of the fish cannot be regarded as a modification of the five-fingered hand. It is sometimes implied, though perhaps not explicitly stated, that it is. The attempt so frequently made to identify the bones of the fish fin with corresponding bones in the mammalian "manus," might be understood to imply that the fin was a modified hand. But as it is undoubtedly true that "all anatomists are agreed that the limbs of the higher vertebrata are derived from those of fishes,"* it is quite clear that the fin of the fish cannot be a degraded hand, although, in one case, the fin of the fish does assume the form of a five-fingered hand. $\dagger$

There is another matter which should be observed in this connection. The "hand" of the water-tortoise is perfect from a structural point of view; but it is what it is, according to Mr. Romanes, because it is the form best adapted to the function which the organ has to perform. The same may doubtless be said of the paddle of Baptanodon. If you say these are typical, in that they are the least specialised forms, that does not necessarily imply that these forms were the terminus ad quem of one stage of evolution and the terminus a quo of a new departure. I see no reason why a paddle like that of the Baptanodon in its progress to becoming the reptilian manus may not have been modified on its own lines in different instances without necessarily first becoming that least specialised form which is the structurally perfect type.

* Balfour. Comparative Embryology. vol. ii., p. 621 .

† Natural Science. vol. i., p. 3I, fig. 3 . 
A writer in Nature seems to regard this view as affording the best explanation of some difficulties connected with the evolution of the bird from the reptile.

"From the ontological standpoint, it will be conceded that that which has dominated the whole bird form is the wing, and embryology shows that this is merely the modified fore-paddle of a low gillbreathing amphibian-a nailless fore-paw. But the nails or claws do appear, yet in the wing they are out of place, and this reptilian stage is only transient. If the bird is, indeed, the child of the reptile, it must forget its father's house ; it must proceed beyond its progenitor. . . But if we are willing to see the bird's wing grow, not out of a perfect and typical cheiropterygium, but out of an ichthyopterygium in an unsettled state, ready for transformation into the higher type of limb, then the difficulty is solved. It was a fish paddle ; it was not to become a fore-foot; it did change into the framework of a bird's wing; in that respect it is a perfect thing; as a paw it is an abortion. But an organism moves together in all its parts, if it moves at all; and thus we see that, in correlation to the profoundly modified fore-limb, every other part of this feathered creature has suffered changes."-(Nature. vol. xliii., pp. 486-7.)

It seems to me that the adaptations which take place in fish and reptiles tend to confirm this view. In the case of some fish the pectoral fins assist in the progressive motion, but rather by directing its course than by acting as powerful propellers. The chief function of the paired fins is to maintain the balance of the fish in the water. When the pectoral on one side, or the pectoral and ventral on the other, are removed, the fish loses its balance and falls on the side opposite; when both pectorals are removed, the fish's head sinks; on removal of the dorsal and anal fins, the motion of the fish assumes a zig-zag course; deprived of all fins, it floats like a dead fish, with the belly upwards, the back being the heavier part of the body. In the rays, locomotion is almost entirely effected and regulated by the broad and expanded pectoral fins acting with the undulating motion of their margins. In some gobioids the pectoral fins are perfect organs for walking. In the flying- 
fish the pectorals act as a parachute. In the gobies the ventral fins are transformed into an adhesive disk.**

The same adaptation to circumstances which is found in connection with the fin of the fish, is also to be found in the manus of the reptile. The paddle of the water-tortoise is an organ of propulsion through the water; the manus of the land reptile is the organ of progression on land; the manus of the pterodactyle is the organ of flight through the air

But if such changes can take place within the limits of these classes, and if, as Mr. Romanes supposes, the paddle of some aquatic reptile has been changed into the manus of an animal which walks upon the land, why should not the demand for a stronger limb produce a somewhat similar development in an animal which still remained totally aquatic in its habits? For example, it is taken as a matter of course that the ancestor of the whale was a terrestrial quadruped (I presume a mammal). But is it absolutely certain that this has been so? Mr. Romanes describes the order of the change which takes place, "first the radius and ulna, next the carpals, then the meta-carpals, and, lastly, the three phalanges of the five digits." Now, if this was the order of change, the paddle of the Baptanodon became the five-fingered manus of the reptile. We have to note that it is in the last stage referred to that the whale exhibits what is abnormal from the point of view of the five-fingered manus; the phalanges are generally more numerous than in the three-jointed finger, which is the typical form.

That it was possible for the paddle of an aquatic animal to undergo considerable modification in the direction of a five-fingered hand, may be seen from the paddle of the 
Plesiosaurus, ${ }^{*}$ which, it is conjectured, must have been almost, if not altogether, confined to the water. We see in the paddle of this extinct reptile an illustration of a possible transition from the paddle of the Baptanodon to the paddle of the whale.

Of course it is possible to regard these organs as modifications of the five-fingered hand; as Mr. Darwin seems to do when he says :-

"In the paddles of the gigantic extinct sea-lizards the general pattern seems thus to have become partially obscured. -(Origin of Species. pp.383-4.)

But it seems to me far more reasonable to suppose that such an organ is derived from a form like that of the Baptanodon.

Now the result of what I have said is this: it tends to free the process of Organic Evolution from the limitations which are impressed upon it by the idea of "typical" structures, and to give "ample room and verge enough" for modification to act in every stage of evolution, and we claim the right to assume that such modified structures are progressive rather than retrogressive forms.

The idea of a typical form from which other forms have become degenerate, has led to the belief that vertebrate animals now devoid of limbs are the descendants of ancestors which had limbs of the usual character. Professor Haeckel says :-

"If we admit that all the vertebrate animals mentioned above are derived from one common ancestor, possessing two seeing eyes and two well developed pairs of legs, the different stages of suppression and degeneration of these organs are easily accounted for in such of the descendants as could no longer use them."-(The History of Creation. vol. i., p. I7.)

* Nicholson. Manual of Zoology'. p.540, fig. 592. 
"In most of the vertebrate animals we find two pairs of limbs on the body, a pair of fore-legs and a pair of hind-legs. Very often, however, one or other pair is imperfect; it is seldom that both are, as in the case of serpents and some varieties of eel-like fish. But some serpents, viz., the giant serpents (Boa, Python), have still in the hinder portion of the body some useless little bones, which are the remains of lost hind-legs." - Ibid. p. I4.)

And yet, if the great principle of Organic Evolution may be followed as our leading light, it is manifest that there must have been a process of development from the simple to the more complex, from the animal having a backbone without limbs to an animal possessed of both backbone and limbs, or, in other words, from an animal with an axial skeleton only to an animal with an axial and an appendicular skeleton combined. Clearly the appendage must have followed in order of time the evolution of the organ to which it was appended. We are able to adduce phenomena which confirm this view. We have already seen that the fins, and more especially the pectoral fins, of fish have been modified in various ways. We may now go a step further back, and take note of the fact that these fins are themselves the outcome of a more generalised structure. From the researches of the late Professor Balfour, it appears that the paired limbs arise as differentiations of continuous lateral folds or projections from the surface of the body, and the unpaired fins arise as differentiated projections from the dorsal and ventral surfaces. The paired and the unpaired are of similar origin and nature. The paired limbs are thus in all probability essentially peripheral structures, which have become more or less closely connected with the axial skeleton. Their proximal parts uniting and growing inwards have often become directly connected with parts of the axial skeleton. Thus the limb-girdles seem to have arisen mainly as ingrowths from the basal cartilages of the limbs, and therefore 
the whole appendicular skeleton belongs to a different skeletal category from that of the head and spinal column.

It would seem to follow from this that there must have been a time when the ancestral vertebrate had no limbs. But if this is so, we may further ask whether the axial skeleton has not itself been cvolved from still simpler elcments. We can scarcely entertain any doubt on this subject, if we compare the lancelet with some normal form of vertcbrate; for this creature possesses a skeleton of the most primitive form. The vertebral column is represented by a simple chordd dorsalis or notochord only, which extends from one extremity of the fish to the other, and, so far from being expanded into a cranial cavity, is pointed at the anterior end as well as at the posterior. There is no trace of vertebral segments or ribs. A serics of short cartilaginous rods above the spine represent apophyses. Elements representing limbs are entirely absent.

If, then, there has been a gradual evolution of the normal vertebrate skeleton, dating from a structure similar to that of the lancelet, and if, in every stage of the evolution of limbs, in fishes, in reptiles, and in mammalia, these organs have been adapted as organs of progression to cnable their possessor to swim in the water, to walk on the land, or to fly in the air, is it not possible that the axial skeleton may also have been modified to adapt its possessor to various conditions of cxternal life without necessitating the development of limbs at all, or only in most rudimentary stages-taking the word "rudimentary" in its proper and legitimate sense? If we may argue from analogy, we shall be driven to believe that there is the strongest probability that this is what has actually taken place. Is it not more probable that the axial skeleton of the eel and of the snake have been developed into organs adapted to all the needs of those animals than 
that they should have put off the usual normal limbs of the vertebrate animal, which, once evolved, must have been too useful to have been dispensed with? That the axial skeleton of the eel and of the serpent is adapted to the needs of those animals, must be clear to all who study the motions of those animals. Witness what Sir Richard Owen says, with respect to the motions of the serpent :-

"Serpents are too commonly looked down upon, as animals degraded from a higher type; but their whole organisation, and especially their bony structure, demonstrate that their parts are as exquisitely adjusted to the form of their whole and to their habits and sphere of life as is the organisation of any animal which we call superior to them. It is true that the serpent has no limbs, yet it can outclimb the monkey, outswim the fish, outleap the jerboa, and suddenly loosing the close coils of its crouching spiral it can spring into the air and seize the bird upon the wing. All these creatures have been observed to fall its prey. The serpent has neither hands nor talons, yet it can outwrestle the athlete, and crush the tiger in the embrace of its ponderous overlapping folds. Instead of licking up its food as it glides along, the serpent uplifts its crushed prey and presents it grasped in the death coil, as in a hand, to its slimy gaping mouth."-(On the Anatomy of the Vertebrates. vol. i., p. 26r.)

In such a case it is plain that there has been no need for the development of limbs, and hence they have not been evolved; and in the absence of any useful end to be answered, such development could not have taken place through Natural Selection. But if so, the limbs of eels and serpents have not disappeared through a process of degeneration and atrophy, but they have never been developed, because another plan has been adopted whereby the backbone; or the backbone, the ribs and the scutes, as of the serpent; have become perfectly adapted to meet the requirements of the conditions of life.

The idea of type, which is so often made use of, only signifies an ancestral form, of which descendants present a larger or smaller degree of modification. It is obvious 
that the type must first appear before it can become modified. All forms which came into the world before the appearance of the type may represent a type in the process of being developed; they cannot represent a type in the condition of becoming rudimentary. Organic life must first reach a certain stage of progress, before it can be degraded from it. And hence we come to the conclusion that it cannot be a true interpretation of nature to regard all imperfect organs as rudiments and relics of a structurally perfect type, as some seem inclined to do. If this argument has any force, the restriction put upon the problem by the Darwinian use of "types" must be withdrawn, and we are left at liberty to attempt the realisation of the process by which that gradual development came about which Organic Evolution presupposes and demands.

It would appear, therefore, that while the existence of degeneration cannot be denied, it is quite possible that the application of this principle may be carried too far. Professor Milnes Marshall says :-

"There is at present a tendency to invoke degeneration rather freely as a talisman to extricate us from morphological difficulties; and an inclination to accept such suggestions, at any rate provisionally, without requiring satisfactory evidence in their support.

"Degeneration, of which there is direct embryological evidence, stands on a very different footing from suspected degeneration, for which no direct evidence is forthcoming; and in the latter case the burden of proof undoubtedly rests with those who assume its existence.

"The alleged instances among the lower vertebrates must be regarded particularly closely, because in their case the suggestion of degeneration is admittedly put forward as a means of escape from difficulties arising through theoretical views concerning the relation between vertebrates and invertebrates.

"Amphioxus itself, so far as I can see, shows in its development no sign of degeneration, except possibly with regard to the anterior gut diverticula, whose ultimate fate is not altogether clear. With regard to the earlier stages of development-concerning which, thanks to the patient investigations of Kowalevsky and Hatschek, our knowledge is precise-there is no animal known to us in which the 
sequence of events is simpler or more straightforward. Its various organs and systems are formed in what is recognised as a primitive manner; and the development of each is a steady upward progress towards the adult condition. Food yolk, the great cause of distortion in development, is almost absent, and there is not the slightest indication of the former possession of a larger quantity. Concerning the later stages, our knowlege is incomplete, but so much as has been ascertained gives no support to the suggestion of general degeneration."-(Nature. wol. xlii., p. 475.)

We have next to consider the phenomenon presented by the survival of degencrate organs which are neither structurally perfect nor functionally useful. Mr. Romanes ridicules "the vacillating policy of rudiments" adopted by those who assert that they have been retained for the salie of symmetry by the design of the Creator; but it may be questioned whether the survival of the useless can be more satiafactorily explained by the theory either of Mixed or of Pure Darwinism.

In the first place, we must bear in mind the various causes which, according to Mr: Darwin and some of his followers, conspire to bring about the extinction of degencrate organs. It is confidently asserted that disuse leads to the degeneration of organs.

"It appears probable that disuse has been the main agent in rendering organs rudimentary. It would at first lead by slow steps to the more and more complete reduction of a part, until at last it became rudimentary, as in the case of the eyes of animals inhabiting dark caverns."-(Origin of Species. ph. 400-I.)

"The term 'disuse' does not relate merely to the lessened action of muscles, but includes a diminished flow of blood to a part or organ, from being subjected to fewer alternations of pressure, or from becoming in any way less habitually active."-(Descent of Man. and cd., p. I2.)

Degeneration is often the result of the principle of economy.

"The process of reduction is probably often aided through the two principles of compensation and economy of growth."-(Descent of Man. and ed., p. I2.) 
Mr. W. P. Ball argues that this principle has been very largely influential.

"The great principle of economy is continually at work shaping organisms, as sculptors shape statues by removing the superfluous parts; and a mere glance at the forms of animals in general will show that it is well nigh as dominant and universal a principle as is that of the positive development of useful parts."-(Are the Effects of Use and Disuse Inherited? p. 5I.)

It will of course be said that Mr. Ball supposes this economy of growth to be brought about by the action of Natural Selection. But to this it may be replied that the principle of economy of growth may act, and in all probability does act, independently of Natural Selection. For a given organism can only digest a given quantity of food; and the supply will go to that organ which by its action is using up the most material, and will not go to that organ which is doing no work.

In order to account for the complete suppression of a part, the hypothesis of pangenesis is involed.

"The final and complete suppression of a part, already useless and much reduced in size, in which case neither compensation nor economy can come into play, is perhaps intelligible by the aid of the hypothesis of pangenesis."-(Descent of Man. 2nd ed., p. I2.)

"A few words must be added on the complete abortion or suppression of organs. When a part becomes diminished by disuse, prolonged during many generations, the principle of economy of growth, as previously explained, will tend to reduce it still further, but this will not account for the complete, or almost complete obliteration of, for instance, a minute papilla of cellular tissue representing a pistil, or of a microscopically minute nodule of bone representing a tooth. In certain cases of suppression not yet completed, in which a rudiment occasionally reappears through reversion, diffused gemmules, derived from this part, must, according to our view, still exist ; hence we must suppose that the cells, in union with which the rudiment was formerly developed in these cases, fail in their affinity for such gemmules. But in the cases of complete and final abortion, the gemmules themselves no doubt have perished; nor is this in any way improbable, for though a vast number of active and longdormant gemmules are diffused and nourished in each living 
creature, yet there must be some limit to their number; and it appears natural that gemmules derived from an enfeebled and useless rudiment would be more liable to perish than those derived from other parts which are still in full functional activity."-(The Variation. vol. ii., pp. 397-8.)

Mr. Wallace, in the following passage, seems to recognise the co-operation of various causes to produce abortion.

"On a review of the various examples that have been given by Mr. Darwin and others, of organs that have been reduced or aborted, there seems too much diversity in the results for all to be due to so direct and uniform a cause as the individual effects of disuse accumulated by heredity. For if that were the only or chief efficient cause, and a cause capable of producing a decided effect during the comparatively short period of the existence of animals in a state of domestication, we should expect to find that, in wild species, all unused parts or organs had been reduced to the smallest rudiments, or had wholly disappeared. Instead of this, we find various grades of reduction indicating the probable result of several distinct causes, sometimes acting separately, sometimes in combination, such as those we have already pointed out."-(Darwinism. pp. 4I6-17.)

It is obvious, then, that, according to the teaching of the most eminent exponents of Darwinism, there are forces at work in nature tending to produce degeneration of organs, altogether apart from Natural Selection. But of course it is maintained that Natural Selection has exercised a great influence also. This conviction is based upon the severe struggle for existence, in consequence of which an animal cannot afford to support an organ functionally useless, or even to nourish a rudiment, however small.

"Natural Selection is continually trying to economise every part of the organisation. If, under changed conditions of life, a structure, before useful, becomes less useful, its diminution will be favoured, for it will profit the individual not to have its nutriment wasted in building up an useless structure. . . .

"The saving of a large and complex structure when rendered superfluous, would be a decided advantage to each successive individual of the species; for in the struggle for life to which every individual is exposed, each would have a better chance of supporting GG 
itself by less nutriment being wasted. Thus, as I believe, Natural Selection will tend in the long run to reduce any fart of the organisation as soon as it becomes, through changed habits, superfluous."-(Origin of Species. pp. II7-I8.)

. . "the natural selection of those individuals which were least encumbered by a superfluous part."-(Descent of Man. 2nd ed., p.'25.)

Professor Weismann speaks still more emphatically :-

The complete disappearance of a rudimentary organ can only take place by the operation of Natural Selection: this principle will lead to its elimination, inasmuch as the disappearing structure takes the place and the nutriment of other useful and important organs. Hence the process of Natural Selection tends to entirely remove the former. The predisposition towards a weaker development of the organ is thus advantageous, and there is every reason for the belief that the advantages would continue to be gained, and that therefore the processes of Natural Selection would remain in operation, until the germ had entirely lost all tendency towards the development of the organ in question."-(Essays upon Heredity. vol. i., p. 88.)

Now I venture to think that this statement represents what the theory of Natural Selection requires. For if we feel sure that any variation in the least degree injurious would be rigidly destroyed; and if the growth of a mere relic be injurious, in that it consumes some of the nourishment which would otherwise feed the effective organs which do an important work, then by the logic of the theory Natural Selection ought to eliminate what as a matter of fact is not eliminated. The logic of the theory demands that the useless should be altogether eliminated -if not as speedily, yet as absolutely as in the case of the heroes in Princess $I d d$.

"Arac: This tight-fitting cuirass

Is but a useless mass;

It's made of steel

And weighs a deal.

A man is but an ass

Who fights in a cuirass;

So off goes that cuirass!" 
We may here remark that there is a most important difference between the elimination of the degenerate organ, when effected by various other causes, and when produced by Natural Selection. Experience shows us that disuse is sometimes accompanied by degeneration and sometimes not; that compensation and economy are sometimes active and sometimes not. Pangenesis may or may not be a true theory. The most ardent believer in these forces could only venture to assert that they are sometimes active. They may be efficient causes. And consequently we ought not to be surprised if we find in nature degenerate organs in every stage of reduction. But the case is quite different with Natural Selection, which asserts that the struggle for existence will not permit an animal to indulge in the luxury of possessing an organ, or the remnant of an organ, which is of no use. And Dr. Weismann is loyal to the logic of the theory when he contends that the final elimination of an organ will be produced by Natural Selection; and yet clearly this elimination does not always take place. How, then, are we to account for this disappointment of a just expectation? No answer, so far as I know, has been given to this question. The problem certainly is not solved by Mr. Darwin when, in opposition to all that he says elsewhere, he contends that degenerate organs being useless, will not be influenced by Natural Selection at all.

"Variations, neither useful nor injurious, would not be affected by Natural Selection, and would be left either a fluctuating element or would ultimately become fixed, owing to the nature of the organism and the nature of the conditions."-(Origin of Species. p. 63.)

"Rudimentary organs, from being useless, are not regulated by Natural Selection."--(Origin of Species. D. 13r.)

"Rudimentary parts, as it is generally admitted, are apt to be highly variable. . . Their variability seems to result from their 
uselessness, and consequently from Natural Selection having had no power to check deviations in their structure."-(Origin of Species. p. III.)

In the face of the failure of Natural Selection and other reputed laws of nature to eliminate the degenerate organ, it is curious to find that Dr. Weismann introduces another cause, and declares that under its influence a remnant of an organ will disappear altogether.

"Organs which have ceased to be useful become rudimentary and ultimately disappear, owing to the principle of panmixia alone."(Essays upon Heredity. vol. ii., p. 76.)

I have already dwelt upon this subject. It will therefore suffice if I now point out the results at which we have arrived. The argument from imperfect organs is doubtless satisfactory to the advocates of Darwinism because they feel strongly that it is easy to prove that Natural Selection is at work in this department. Many of them contend that there are other causes largely at work, while Natural Selection is bound to exercise a great influence; and yet the anticipated result does not appear. To get over this difficulty, Mr. Darwin supplements the assertion that Natural Selection will tend to degrade the useless organ, with the contention that Natural Selection does not affect the useless organ. Pure Darwinism, as represented by Dr. Weismann, qualifies the principle that useless organs will be ultimately eliminated by Natural Selection, with the dictum that useless organs will be eliminated by panmixia alone. So that Natural Selection and the absence of Natural Selection produce the same elimination. But do these conflicting statements account for the fact that, in spite of all this talk, the useless remnant is in many cases not eliminated after all? It seems that "the vacillating policy of rudiments" may invade the sphere of scientific as well as of theistic faith. 
The treatment of imperfect organs which we have been considering arises from the limitation which Natural Selection places upon the evolution of progressive organs and organisms-a limitation which is the peculiar feature of that theory. According to this view, every stage of progress must have been of vital importance to the race: it must have determined the issue between life and death of the individuals composing a species.

"Nascent organs, though not fully developed, are of high service to their possessors, and are capable of further development." (Descent of Man. and ed., p. I2.)

"As Natural Selection acts by life and death-by the survival of the fittest and by the destruction of the less well-fitted individualsI have sometimes felt great difficulty in understanding the origin or formation of parts of little importance."-(Origin of Species. p. I56.)

Speaking of cases where slight (because initial and afterwards finely graduated) improvements are concerned, Mr. Romanes says :-

"Unless, at every stage of their progress, they were matters of life and death, they could not have been produced by the unaided influence of Natural Selection."-(Contemporary Review. vol. Ivi., p. 254.)

This dimitation has a two-fold significancy. Those who believe that no evolution can take place except in connection with Natural Selection, are bound to maintain that each step of progress, however slight, must be a matter of life and death. Those who believe that Natural Selection only co-operates with other laws of nature, in an intermittent fashion, suppose that for this evolution of the progressive organ the interposition of Natural Selection is not required at every stage.

"It is surely conceivable that, in many cases where slight (because initial and afterwards finely graduated) improvements are concerned, such improvements need not have been, in every stage of their progress, matters of life and death to the organisms presenting them. 
- . Now, it is just in such cases that the supplementary or Lamarckian principles are supposed by Darwinists to come in ; for, to the operation of these principles, it is not necessary that at each stage of the process every slight improvement should be a matter of life and death to the organisms presenting it. To me, it appears that we have here a consideration of the highest importance."(Romanes. Contemporary Revieru. vol. lvi., pp. 254-255.)

In contradiction to the assertion that the Natural Selection of useful variations is always, or at intervals, necessary to the evolution of nascent organs, Mr. Darwin assumes that organs may be fully developed, though useless, without the aid of Natural Selection, and afterwards preserved by Natural Selection or through being utilised by their fortunate possessors.

"We may easily err in attributing importance to characters and in believing that they have been developed through Natural Selection. We must by no means overlook the effects of the definite action of changed conditions of life-of so-called spontaneous variations which seem to depend in a quite subordinate degree on the nature of the conditions; of the tendency to reversion to long-lost characters; of the complex laws of growth, such as of correlation, of compensation, of the pressure of one part on another. . . . But structures thus indirectly gained, although at first of no advantage to a species, may subsequently have been taken advantage of by its modified descendants under new conditions of life and newly acquired habits." --(Origin of Species. pp. 157-8.)

But these qualifications are not easy to understand. Why should the action of Natural Selection be intermittent, so that slight modifications should be a matter of life and death at one time, and further slight modifications on the same line of progressive change be of no use at another time? If moreover an organ can be developed without Natural Selection-as Mr. Darwin seems to teach in the passage just quoted-why invoke the aid of Natural Selection to supplement the process? It must be confessed that Natural Selection comes rather late upon the scene, to say the least. More- 
over if the organ has been developed without Natural Selection, and then taken advantage of by the modified descendants, animal intelligence intervenes and not Natural Selection. Such an explanation can only have one meaning. It refers to cases in which the nascent organ can be developed without Natural Selection. But if this is so, why do the advocates of Natural Selection maintain that the improvements in the nascent organ must be of the highest use to their happy possessors? The only way of harmonising the two statements is to suppose that it is their intention to affirm that nascent organs are generally developed by Natural Selection, and that on some rare occasions they are developed without its aid. If this is what we are to understand, we may remark that some writers do not by any means regard this evolution of nascent organs without Natural Selection as an exceptional phenomenon in nature.

Mr. Joseph John Murphy, in a letter to Nature, says :-

"If all perfectionment is due to the two causes of exercise through habit and Natural Selection among variations, it is obvious that no improvement can be effected which is not immediately useful. I believe that the animal kingdom, and in all probability the vegetable kingdom also, are full of organs which cannot have been evolved by anything like a Darwinian process, because their immature states cannot have been in functional activity. . . . Müller, in his Facts for Darwin, says of the transition from the Zoea to Mysis form, in the metamorphoses of a species of Peneus or prawn, that "the long abdomen, which just before was laboriously dragged along as a useless burden, now, with its powerful muscles, jerks the animal through the water in a series of lively jumps.' The Nauplius, which is the form in which this Peneus leaves the egg, has no abdomen; this is acquired when the Nauplius develops into a Zoea, and consists of segments which appear between the body and the tail of the Nauplius. Müller's account seems to show that this abdomen is developed before it is useful to the animal, and for the purpose of becoming useful further on in its development. . . Another instance of the same kind is that of those Ascidian larvæ, which are the probable origin of the vertebrata. Of what use can the dorsal groove and the notochord be to those minute and lowly organised 
animals themselves? They appear capable of interpretation only as the preparation for a vertebral column and a spinal cord to be afterwards evolved. . . . But the strongest instance of the kind which I know of, except that of the brain of man, is the existence of pneumatic bones 'that is to say, bones hollowed out for lightness, like those of flying birds) among Dinosaurians (see Professor Cope's paper on Megadactylus probyzclus, as reported in Nature. vol. i., p. 347). The resemblances of the skeleton appear to prove that birds must be descended from Dinosaurians. No Dinosaurian had the power of flight, yet here is a character useful only to flying animals, and interpretable only as a preparation for a power of flight to be afterwards evolved."-(Nature. vol. xixviiii., pp. 4II-IZ.)

In order to show that Natural Selection has had no part in the evolution of a nascent organ, it would be necessary to prove that at no transitional stage of the development has the organ been of any use to the animal in which it is developed. Have we any such instance of a tendency to develope in definite lines, so that when the evolution is complete, and only then, it is capable of performing a useful function? Of course it would be natural for the theologian to interpret such a phenomenon as an indication of "purpose"; and looking at the matter from this point of view, Mr. Romanes speaks in no uncertain manner:-

"To deal with the important question before us (the highlyspecialised and long-elaborated structures) therefore, we must fasten attention exclusively upon incipient variations, or variations as they occur de novo in first generations. Now I request any teleologist to produce evidence that such incipient variations ever exhibit any particular tendency to occur in definite lines-still less in lines suggestive of any ultimate 'purpose.' And I make this request because it clearly rests with the teleologist to furnish some such justification of his belief, that the causative influence of Natural Selection is supplemented (either wholly or partly) by some causative influence of another and ulterior kind, which is supposed to furnish variations only in definite, not to say 'prophetic' lines. Yet I make this request, well knowing that it cannot be complied with. For, notwithstanding the opinions expressed by Asa Gray, Nägeli, and the others, no one has hitherto been able to point to any instance of incipient variations thus tending to occur only in definite lines; while, on the other hand, the success of breeders and horticulturalists furnishes overwhelming proof that variations occur in such a number 
of directions (even within the limits of a single species) that they may practically be regarded as 'omniferous.' The Duke of Argyll, therefore, is dialectically in the wrong, when he challenges Darwinists to prove that initial variations are indeterminate. The burden of proof lies with him to show that they are determinate. For the Darwinist can point to the results of 'artificial selection' unquestionably to demonstrate that, in our domesticated plants and animals, variation is so far omniferous as to lend itself to all the morphological changes in divergent lines which have been produced by the continuous, or cumulative, selection of the horticulturalist and the breeder. Why, then, are we to suppose that, in the case of wild species, the principles of variation are different? If they are so, it remains with anti-Darwinians to prove the fact."-(Contemporary Revierw. vol. liii., p. 850.)

But it would seem as if the advance of scientific investigation had provided the opponent of Natural Selection with the very instance which $\mathrm{Mr}$. Romanes challenged him to find. And it is to be noted that it is Mr. Romanes himself who, with a fine generosity and loyalty to truth, states the case even more strongly than the Duke of Argyll had done. The particular case is the evolution of the electric organ in certain fish, of which Mr. Romanes says :-

"Electric organs are known to occur in several widely different kinds of fish; wherever these organs do occur, they perform the function of electric batteries, in storing and discharging electricity in the form of more or less powerful shocks. Here, then, we have a function which is of obvious use to the fish for purposes both of offence and defence. . . . In the particular case of the skate, . . although its structure is throughout as complex and perfect as that of the electric organ in Gymmotus or Torpedo, its smaller size does not admit of its generating a sufficient amount of electricity to yield a discharge that can be felt by the hand." Nevertheless, there is a discharge; but "such weak discharges as the skate is able to deliver must be wholly imperceptible alike to prey and to enemies. Yet for the delivery of such discharges there is provided an organ of such high peculiarity and huge complexity that, regarded as a piece of living mechanism, it deserves to rank as at once the most extremely specialised and the most highly elaborated structure in the whole animal kingdom. . . . Therefore it appears impossible to suggest how this astonishing structure-much more astonishing, in my opinion, than the human eye or the human hand-can ever have 
been begun or afterwards developed by means of Natural Selection. For if it be not even yet of any conceivable use to its possessor, clearly thus far survival of the fittest can have had nothing to do with its formation. On the other hand, seeing that electric organs when of larger size, as in the Gymnotus and Torpedo, are of obvious use to their possessors . . . the organ in the skate seems to be on its way towards becoming such an organ as we meet with in these other animals. . . Professor Ewart's investigations go to indicate that the organ is here not in a state of degeneration but of evolution. For instance, in Raia radiata it does not begin to be formed out of the muscular tissue until some time after the animal has left the egg-capsule and assumed all the normal proportions (though not yet the size) of the adult creature. . . . Moreover, it does not attain its full development (i.e., not merely growth, but transforming of muscular fibres into electrical elements) till the fish attains maturity. . . . If, for the sake of saving an hypothesis, we assume that the organ, as it now stands, must be of some use to the existing skate, we should still have to face the question :Of what conceivable use can those initial stages of its formation have been when first the muscle-elements began to be changed as the very different electrical-elements, and when therefore they became useless as muscles while not yet capable of performing even so much of the electrical function as they now perform? Lastly, in the formation of this structure, there has been needed an altogether unparalleled expenditure of the most physiologically expensive of all materialsnamely, nervous tissue. . . We are forced to conclude that Natural Selection ought strongly to have opposed the evolution of such organs."-(Darwin and After Darwin. pp.365-372.)

Mr. Romanes admits that the difficulty presented by this case is of a magnitude and importance altogether unequalled by that of any other case. "If there were any other cases of the like kind to be met with in nature, I should myself at once allow that the theory of Natural Selection would have to be discarded."* But as there are not, Mr. Romanes thinks that probably some explanation will be offered to account for this in accordance with Darwinian principles, as in the case of the conspicuous colouring of caterpillars.

But, as we have seen, there are other cases, in which experts have supposed that there was evolution without

$$
\text { * } p \cdot 373 \text {. }
$$


Natural Selection. In this case it is proved to be so. In these circumstances we surely ought to explain other cases by this, rather than to attempt to explain this so as to harmonise it with the theory which it contradicts throughout.

We have already endeavoured to show that the conspicuous colours of certain caterpillars are not capable of being brought under the law of Natural Selection; how much less, then, so clear a demonstration of the falsity of the principles of Natural Selection! As Mr. Romanes himself says, "It almost seems to have been specially designed for the discomfiture of Darwinians." And there I will venture to leave the matter, until some method is found to reconcile this phenomenon with the theory of Natural Selection; but I confess that it requires more faith than I possess to believe that such explanation will ever be forthcoming.

In the preceding chapters, I have endeavoured to show that the arguments for the process of Organic Evolution are not to be accepted as arguments for Natural Selection as a law of nature dominating that process; that the proofs, or assumed proofs, for the transmutation of species by means of Natural Selection do not confirm our conviction of the truth of Organic Evolution; and that in the treatment of imperfect organs the theory of Natural Selection hinders us in the attempt to realise the process of Organic Evolution, while it proves itself an untenable theory by demanding that, on its principles, nascent organs must be always useful to its possessor, and that the "rudimentary," or, in other words, the degenerate and useless, organs ought to be eliminated; while, as a matter of fact, they are not. 


\section{CHAPTER IV.}

NATURAL SELECTION NOT MANIFESTED IN ORGANIC EVOLUTION.

(a) GEOGRAPHICAL DISTRIBUTION.

"I see my way, as birds their trackless way. I shall arrive. What time, what circuit first, I ask not; but, unless God send His hail Or blinding fircballs, slect or stifling snow, In some time-His good time-I shall arrive."

-BROWNING.

I PROPOSE in this and the two following chapters to consider whether, in the process of Organic Evolution which the arguments of its supporters tend to establish, there is any manifestation of the action of Natural Selection. It seems to me that those who believe that the transmutation of species has been brought about by Natural Selection might reasonably anticipate that this would be the case. On the other hand, those who believe that other laws have led to the transmutation of species in such a manner that Natural Selection cannot come into play-supposing such a law to exist-and, still more, those who believe that there is no selective power in nature to produce such transformation, will not expect to find its influence manifest in the evolution of organic structures. But, putting aside all preconceived opinions; we will now proceed to investigate the arguments for Organic Evolution, in order to see if we can discover any traces of the action of Natural Selection. 
The first argument which I propose to consider is that drawn from the geographical distribution of animals and plants, and from the relation which sometimes exists between the past and the present inhabitants of any given locality. From these phenomena it is inferred that existing species "came into existence where they now occur by way of genetic descent, with perpetual migration and correlative modification," and that "every species has come into existence coincident both in space and time with a pre-existing and closely-allied species." In short, the argument is an argument to show that the transmutation of species has taken place in the past even as it is now taking place in the present.

The change of conditions which requires a readjustment of the organism to adapt itself may arise either through the transference of a species to other spheres, or through the change of conditions. which may occur in the same locality from time to time. In connection with the former problem, we have especially to consider the circumstances under which the distribution has taken place, whether of conscious emigrants or of the passive victims of certain means of dispersal. We have now to consider how far this geographical distribution has been favourable to the transmutation of species by means of Natural Selection.

Assuming that a species started from a given locality, it would naturally spread in those directions where there was an opening, and move on those lines in which there was an unbroken and continuous connection. The principal method of distribution would therefore be by a process of emigration whenever a favourable outlet could be found. The argument for Organic Evolution, drawn from geographical distribution, is based upon the fact that along such lines of unbroken communication we find a series of allied species adapted to their different conditions. There 
would be no necessity for such an arrangement on the hypothesis of fixity of species; but it is just what we should expect to find on the hypothesis of the transmutation of species. Now, in this connection we venture to assert that there is no trace of the action of Natural Selection, but that, on the contrary, the principles of Natural Selection present great difficulties when we associate them with geographical distribution and the consequent transmutation of species.

The cause of emigration is to be found in increase of numbers. Mr. Wallace says :-

"Animals multiply so rapidly that we may consider them as continually trying to extend their range."-(Gengraphical Distribution of Animals and Plants. vol.i., p. 7.)

But this assumption, that animals will always be trying to extend their range and that they will be forced to do so by continually increasing numbers, which make a given area a congested district so far as that species is concerned, is not in accordance with the fact that, under ordinary occasions, the population of any species over a given area is uniform from generation to generation because the destruction is equal to the output of life.

Nor does it seem to be generally true that animals manifest a universal readiness to migrate and to settle elsewhere.

"The more permanent varieties are generally found, so far as I can discover, inhabiting distinct stations, such as high land or low land, dry or moist districts. Moreover in the case of animals which wander much about and cross freely, their varieties seem to be generally confined to distinct regions."-(Origin of Species. p. I6q.)

"Most animals and plants keep to their proper homes and do not needlessly wander about. We see this even with migratory birds, which almost always return to the same spot."--(Origin of Species. p. 72.) 
But we will assume, for the sake of argument, that a species does increase in numbers in consequence of the tendency to increase in a geometrical ratio, and that some members of the species are compelled to emigrate. By no manner of means does it follow in that case that they will find an unoccupied sphere ready for their reception. On the contrary, Mr. Darwin assures us that-

"under nature the individuals of the same species . . . are rigorously kept to their proper places by a host of competing animals and plants."-(The Variation. vol. ii., p. 254.)

The consequence of this state of things is apt to be fatal to the pioneers of an emigrant species.

"Each species on the confines of its range, where it exists in lessened numbers, will, during fluctuations in the number of its enemies, or of its prey, or in the nature of the seasons, be extremely liable to utter extermination."-(Origin of Species. pp. 135-6.)

If there has been a tendency to increase in a geometrical ratio within the range of a given species, there may be the same tendency in the other species which inhabit the contiguous territory, and the emigrants might then afford the needed food for the growing numbers of the carnivora; or there would be no room for more ruminants where ruminants already abounded. Nor would they be any better off if the contiguous sphere were already occupied by a stationary population due to an already existing competition. Clearly, if the circumstances were the same which now exist, according to Darwinian writers, emigration would be beset with difficulty.

But let us suppose that the conditions were differentlet us grant that the species were not hindered in their desire to spread, and that the contiguous region was not fully occupied. Then, if the locality were precisely 
similar to the one that a species had left, there would be no advantage in modification of structure, and none could be brought about by Natural Selection. If the locality were favourable to the species, its members would increase, but in the absence of their normal enemies they would not suffer from one of the greatest disabilities in the struggle for existence, and the element of selection by death would be wanting. If, on the other hand, the conditions were unfavourable, they would not at first have their normal fertility, and the output of life would not be forthcoming. Thus, in all cases, one or other of the conditions of Natural Selection would be wanting, and consequently any modification which might be necessary could not be brought about by Natural Selection.

We have already considered the case in which the immigrant species masters or drives out a native population; and we have seen that the phenomenon could not have been brought about by Natural Selection.

What has just been said will apply to those cases in which settlement in a new locality takes place under the most favourable conditions to the emigrant. But the difficulties are much increased when we consider those "means of dispersal," on which apparently much reliance is placed. We have to consider the danger accompanying the transit; the probability that the animal or plant will not be able to find a footing in the new sphere, and the difficulties which will accompany its adaptation to new conditions, if it should be fortunate enough to pass successfully through these initial difficulties.

It is said of mammals that they might be dispersed by being accidentally carried out to sea, and in this way succeed in reaching islands many miles distant. In the arctic regions icebergs originate in glaciers, which descend into the sea, and often bear masses of gravel, earth, and 
even some vegetation on their surfaces, and extensive level ice-fields break away and float southwards. Again, uprooted trees and rafts of driftwood are often floated down great rivers and carried out to sea. Such rafts or islands are sometimes seen floating a hundred milesmonkeys, tiger-cats, and squirrels have been seen upon some of them. Even small and weak birds are often carried accidentally across great widths of ocean by violent gales. Migrants flying along the eastern coast of the United States are blown out to sea to the Bermudas. Hurricanes and whirlwinds often gather up considerable quantities of water, and with it fishes of small size. Eggs of fish are carried by aquatic birds; aquatic birds feed on these eggs and sometimes they are not destroyed, but pass through the body unimpaired.

Now, with regard to these "means of dispersal," the first thing that strikes us is the precarious nature of the process of migration. Mammals may be carried out to sea, but it does not at all necessarily follow that their raft will ever reach land, and if they get washed off their raft, or the raft itself breaks up, they will become food for fishes. Masses may break off from the end of the glacier which hangs over the sea, and the iceberg thus formed may carry seeds and plants and perhaps some animals upon it, but this fact will not avail unless the floating iceberg come in contact with solid land. The bird which has just filled its crop, and the bird of prey which has made a meal off a bird which has just filled its crop, with seeds, may convey these seeds to a considerable distance; but it will avail nothing if the birds are not killed after a short time, and on land where these seeds will grow. When we consider the risks which must necessarily accompany such voyages, it is allowable to believe that only a few favoured individuals will reach a new habitat.

$\mathrm{HH}$ 
We have next to consider what chance there is that organisms thus carried into a distant sphere will be able to establish themselves therein. In the case of seeds thus wafted to a new sphere-will they germinate and establish themselves? Clearly we must not anticipate this result as a matter of course. Mr. Wallace adduces certain facts which may warn us against any very great confidence on this point. He says :-

"Of the many hundreds of hardy plants which produce seed freely in our gardens, very few ever run wild, and hardly any have become common. . . A. de Candolle states that several botanists of Paris, Geneva, and especially of Montpellier, have sown the seeds of many hundreds of species of hardy exotic plants, in what appeared to be the most favourable situations, but that in hardly a single case has any one of them become naturalised. Even a plant like the potato, so widely cultivated, so hardy and so well adapted to spread by means of its many-eyed tubers, has not established itself, in a wild state, in any part of Europe. It would be thought that Australian plants would easily run wild in New Zealand. But Sir Joseph Hooker informs us that the late Mr. Bidwell habitually scattered Australian seeds during his extensive travels in New Zealand, yet only two or three Australian plants appear to have established themselves in that country, and these only in cultivated or newly moved soil."-(Darwinism. pp. 15-16.)

\section{Mr. Darwin says :-}

"Almost every year one or two land-birds are blown across the whole Atlantic Ocean, from North America to the western shores of Ireland and England, but seeds could be transported by these rare wanderers only by one means-namely, by dirt adhering to their feet or beaks, which is in itself a rare accident. Even in this case, how small would be the chance of a seed falling on favourable soil and coming to maturity! But it would be a great error to argue that because a well-stocked island, like Great Britain, has not, as far as is known (and it would be very difficult to prove this), received within the last few centuries, through occasional means of transport, immigrants from Europe or any other continent-that a poorly-stocked island, though standing more remote from the main land, would not receive colonists by similar means. Out of a hundred kinds of seeds or animals transported to an island, even if far less well-stocked than Britain, perhaps not more than one would be so well fitted to its new 
home as to become naturalised. But this is no valid argument against what would be effected by occasional means of transport, during the long lapse of geological time, whilst the island was being: upheaved, and before it had become fully stocked with inhabitants. On almost bare land, with few or no destructive insects or birds living there, nearly every seed which chanced to arrive, if fitted for the climate, would germinate and survive."-(Origin of Species. pp. 329-30.)

In this passage Mr. Darwin asserts that there is but little chance of a seed falling on favourable soil and coming to maturity. He implies that, if such a seed or animal drift to a well-stocked island like Great Britain, it might find the space preoccupied. Even if the island were not so well-stocked as Great Britain, perhaps not more than one out of a hundred would become naturalised. But in an uninhabited island, on almost bare ground, every seed might germinate and survive, "if fitted for the climate." On this point Mr. J. Ball adduces some striking evidence to show that even on almost bare land the result is not what Mr. Darwin anticipates.

"Northern Patagonia and a portion of the Argentine region have been raised from the sea during the most recent geological period. The only quarters from which the flora could be recruited were the range of the Andes to the west and the sub-tropical zone of South America to the north. Everything goes to prove that the forms of plants are far more slowly modified than those of animals-or, at least, of the higher vertebrate orders. The new settlers are unable quickly to adapt themselves to the new conditions of life, and, as a result, we find that the indigenous flora of the region in question is both numerically poor in species, and that these have been unable fully to occupy the ground."-(Notes of a Naturalist in South America. pp. 164-8.)

In rocky islets just emerging from the sea, there would have to be insects before insect-eating birds could colonise them; and other animals before the carnivora could settle there.

The foregoing facts have been cited to show that if geographical distribution has taken place by certain 
"means of dispersal," enormous difficulties have accompanied the process. I am far from denying that such means may have proved successful, so far that the wafted seed may have germinated and even produced seed. What we have now to consider is the part which Natural Selection plays in the process of adaptation by which the new immigrant adapts itself to its new conditions. The process which would have to take place is thus described by Mr. Wallace :-

"The change may affect a great many (of the species) injuriously to such an extent as to require some change in their structure or habits to enable them to get on as well as before. Now 'variation' and the struggle for existence come into play. All the weaker and less perfectly organised individuals die out, and while those which vary in such a way as to bring them into more harmony with their new conditions constantly survive. If the change of conditions has been considerable, then, after a few centuries, or perhaps in a few generations, one or more nere species will be almost sure to be formed."-(Island Life. p. 56.)

All the objections which have been urged against adaptation by Natural Selection when some members of a species emigrate into a contiguous sphere or along a line of unbroken communication, would beset the organisms wafted to a considerable distance. But in one or two respects the difficulties would be enhanced considerably. In the first place, the members of a given species thus carried to a distant sphere would be very few. Obviously an individual animal, unless it were a pregnant female, could not found a colony. At the most only a very few would be deported in this fashion, and these few would probably be enfeebled by their compulsory voyage; and from this cause, or from the mere change of climate, might not be so fertile as to provide that output of life which Natural Selection requires. 
Mr. Darwin says :-

"It would appear that any change in the habits of life, whatever these habits may be, if great enough, tends to affect in an inexplicable manner the powers of reproduction." Again he says: "Those animals which usually breed freely under confinement, rarely breed, I was assured, in the Zoological Gardens within a year or two after their first importation."-(The Variation. vol. ii., pp. 159-60.)

It is a large assumption, then, on the part of Mr. Wallace when he assumes that, all other conditions being favourable, immigrants will exhibit at once the greatest possible fertility.

"All animals are capable of multiplying so rapidly, that if a single pair were placed in a continent with abundance of food and no enemies, they might fully stock it in a very short time. Thus a bird which produces ten pairs of young during its life-time (and this is far below the fertility of some birds) will, if we take its life at five years increase to a hundred millions in about forty years-a number sufficient to stock a large country."-(The Geographical Distribution of Animals. vol.i., p. IO.)

As a matter of fact, we know that immigrants into new localities exhibit for a time at least a limited fertility. For example,-

"The fecundity of geese introduced upon the table-land of Bogota, according to Dr. Roulin, was much altered in the first season. They laid only a few eggs, the eggs were small in number-a fourth, at the most, were hatched; and more than half of the young goslings died in the first month, but from generation to generation the fecundity tended to return."--(P. Lucas. "Hérédité Naturelle. vol. ii., pp. $478-9$.)

In the case of a single pair, this limited fertility might well be fatal to any attempt at colonisation.

There is one other special difficulty to be noted. Animals and plants, eggs or seeds carried to great distances would find themselves, in many cases, in conditions which varied considerably from those to which they were accustomed. Supposing that they were able to survive all the difficulties of transit and of establishing themselves, they would have 
to undergo the process of acclimatisation. This is often very far from easy when man takes all the care he can to guard the exotics which he imports. It would, of course, be still more difficult in the case of the organism left to fight its own battle unaided. One special point may be mentioned here. The protection which an animal or plant possesses in one locality is apt to disappear very shortly when it is removed to a different sphere. The desert plant loses its spines,-

"The hemlock is said not to yield conicine in Scotland. The root of the Aconitum napellus becomes innocuous in frigid climates. The medicinal properties of the Digitalis are easily affected by culture. The rhubarb flourishes in England, but does not produce the medicinal substance which makes the plant so valuable in Chinese Tartary. In the South of France the Pistacia lentiscus yields no mastic. Hemp fails to produce in England that resinous matter which is so largely used in India as an intoxicating drug." -(The Variation. vol. ii., pp. 274-5.)

The argument for Organic Evolution deduced from the geographical distribution of animals and plants, implies that species undergo modification to adapt them to the new conditions into which they are thrown by their voluntary and involuntary emigration. It is an argument for the transmutation, as opposed to the fixity, of species. The process is a perfectly intelligible one. The district overcrowded by the individuals of a given species sends forth its emigrants, who find a modus vivendi in the new sphere. Change of structure ensues, sometimes useful and sometimes unuseful. The process may have its difficulties, which are fatal to individuals but it is successful so far as the race of emigrants are concerned. The species survives in a modified form, because, on the whole, the struggle for existence does not press too heavily upon it. But if you assert that this transmutation has taken place by means of Natural Selection, and you introduce all the conditions 
which the logic of that theory demands, you make transmutation of species by geographical distribution impossible. But the theory which renders an acknowledged fact impossible ought surely to be discarded.

\section{(b) GEOLOGICAL CHANGES.}

"O heaven! that one might read the book of fate, And see the revolution of the times Make mountains level, and the continent (Weary of solid firmness) melt itself Into the sea! and other times to see The beachy girdle of the ocean Too wide for Neptune's hips."

-King Henry IV. Part 2. Act iii., sc. I.

The present habitat of the existing fauna and flora of the earth is due either to geographical distribution, or to a continuity of life in the same region during periods of geological transformation. Of such physical changes we have ample proofs in the strata of the earth's crust. Mountains bear traces of the fact that they have emerged from the sea. Tracts now covered with the sea were once dry land. The coal beneath our feet is an evidence that a tropical heat was once present in places which are now in the temperate zone, and evidence is not wanting of a vigorous vegetation in regions which are now arctic. And besides these great transformations of the outward scenes, there were also more gradual ones which introduced conditions so novel, that it was necessary that races of animals should be modified, if they were to continue to remain in the same locality.

Much that has been said against the transmutation of species by means of Natural Selection, in the last 
section, would apply also in the present case. But I propose to show that, in connection with these geological changes, we have the strongest evidence in favour of their direct action upon the responsive organism in such a manner as to preclude the action of Natural Selection.

One change which is now going on, and which in all probability has been going on more or less through the geological ages, is the encroachment of the sea upon some coasts and its retirement from other shores. When the sea encroaches on the land, fresh water pools and streams would first become brackish and ultimately salt. And with the retirement of the sea, the result would be reversed. Now we have a remarkable illustration of the direct influence of such changes to affect certain organisms.

It may be premised that there are two distinct species of a salt water crustacean known as Artemia Milhousenii and Artemia salina. These are the most unlike of all the species of Artemia which are to be found in Europe. They live respectively in salt and in brackish water. Moreover there is a fresh water crustacean known as Branchipus stagnalis, remarkably like Artemia salina, and yet with dissimilarities also-which belongs even to a different genus to Artemia salina.

Here, then, we have three distinct species which vary from one another in proportion to the amount of salt contained in the water in which they live. Yet it might have been esteemed a daring hypothesis to have conjectured that the modification of the organism was produced by the quantity of the salt in the water. But that there is this correlation between the different organisms and the different conditions, and that the amount of salt determines the nature of the organism, is now a universally acknowledged fact in consequence of the observations and experiments made by the Russian naturalist, 
Schmankewitsch. In I87I, a dam which divided two lakes gave way, so that the water from the higher, which was brackish, flowed into the lower, whose water was salt. With the brackish water there passed into the lower lake numerous individuals of Artemia salina, and there they soon settled and propagated. After the dam was repaired, the saltness of the lower lake gradually increased until, in 1874 , it had reached its original condition. During this period the Artemia salina which had migrated had gradually become transformed into Artemia Milhausenii, the stages of transformation being actually observed one after another. Not content with this observation, Schmankewitsch made the matter the subject of direct experiment. $\mathrm{He}-$

"showed that it was possible to raise a brood of Artemia Mithausenii from Artemia salina, which lived in salt water of $4^{\circ}$ Beaumé, by gradually raising the percentage of salt to $25^{\circ} \mathrm{B}$. . . He also conducted the converse experiment with perfect success, for he brought Artemia Milhausenii back to Artemia salina by breeding successive generations in salt water which he made weaker and weaker."-(Semper. The Natural Conditions of Fxistence as they Affect Animal Life. pp. 556-7.)

We can hardly resist the conclusion at which Semper arrives when he expresses his belief that the amount of salt is the cause of the transmutation; and that this is one of the cases in which nature exhibits a transforming, as distinguished from a selective, influence.

"These discoveries are certainly of the greatest interest, for they afford a proof we can scarcely doubt, that a change in the amount of silt contained in the water can produce a regularly recurring and very conspicuous modification of the specific and even of the generic characters of certain animals." - (Ibid. p. I58.)

The encroachment of the sea would, in course of time, bring inland plants into contact with sea breezes and the sea itself. How readily the organism of some plants 
responds to such a change of conditions may be seen from the experiments of M. Le Sage. It is usual to attribute the fleshy character of the leaves of several maritime plants to their growth by the seaside where salt can reach them; and that salt is the cause of fleshiness is believed from a large number of coincidences, coupled with the fact that the same plants are not always fleshy when growing inland. This hypothesis was confirmed by experiment. M. Le Sage succeeded in producing the characteristic fleshiness of maritime plants in inland plants by watering them with salt water; and the alteration of the tissues was carried on in the second generation from the point gained in the first.*

Another change, of which we have evidence at the present time, and which doubtless has taken place during the geological ages, is the gradual drying up of lakes.

"At the north end of Lake Nyasa, old natives will point to a ridge of sand ten or more feet in height above the present level of the lake, and tell you that they remember the water being at that point; while there is undisputed evidence from observations to show that the present average level of the lake is several feet below what it was ten or twelve years ago. Lake Shirwa, which may be looked upon as neither more nor less than a vast flat basin, has receded on the western shore at least a mile, within the memory of lads under twenty-five years of age."-(The Geographical Joumal. vol. i., p. 247.)

The effect of such a change of external condition may be seen from certain observations and experiments made by Karl Semper, who accidentally observed that the common pond-snail (Lymnaea stagnalis) was so remarkably sensitive to the effects of the volume of the water, that in the space of six days the difference in the length of those living in different volumes of water could be easily and

* Henslow. Natural Science. vol. i., p. 176. 
accurately determined. In order to demonstrate that this change was really due to the volume of water, he instituted a series of experiments, in which he took care that all the other conditions of healthy existence should be the same. In all his experiments the only difference was the volume of water, with this result:-The smaller the volume of water which fell to the share of each animal, the shorter its shell remained.

"The first of the shells formed in Ioo cubic centimetres of water attained a length of only six millimetres; the second, in 250 cubic centimetres, was nine millimetres long; the third, in 600 cubic centimetres, was twelve millimetres; finally, the fourth grew to eighteen millimetres in 2,000 cubic centimetres of water. . . These animals, with such immense differences in length, were all the offspring of one mass of eggs simultaneously transferred, and had all reached the same age of sixty-five days." - $(p .162$.

Dr. Henry de Varigny admits the fact, although he offers a different explanation to that which Semper suggests.* The fact is all that my present argument requires.

But the growth of the pond-snail also depends upon temperature. The pond-snail cannot grow if the temperature is below $12^{\circ}$ centigrade. Hence an unusually cold season would prevent the natural growth of the animal.

It should next be observed that this animal grows for at least a half of its life.

"This mollusc," says Semper, "grows at a very moderate rate; individuals brought up even under favourable circumstances, take about three months to develope a shell twenty-four millimetres long, and they do not attain their full size under two years, although the whole life of the individual can scarcely exceed three or four years at the utmost."-(Animal Life. p. Io8.)

And not only is there ample opportunity for the low temperature to take effect in dwarfing a particular genera-

* Experimental Evolution. pp.79-80. 
tion, but it is also quite clear that this dwarfed condition will be inherited.

"Assuming that a young Lymnaca were placed in a lake or stream, of which the temperature constantly exceeds the minimum at which the snail can begin to grow, during only two months of the year, while it never perhaps reaches the high optimum $25^{\circ}$, the mollusc will be unable to attain its due proportions during the first year, or to grow to its full size even during the second, and thus a dwarfed form will inevitably arise. This dwarfed form will still be able to reproduce and multiply itself; for the maturation of germinal matter-the ovum and sperm-takes place during the winter and early spring, at a time when the low temperature of the water hinders all growth, and the optimum of warmth for the sexual processes is much lower than that for growth. Thus a permanently diminutive race might arise if the conditions of temperature above described remained constant for several successive years in the lake or stream where the young molluscs or the eggs have been deposited. Hence it has been supposed, and in many cases no doubt with justice, that the dwarfed races of animals which are found on high mountains or in the polar regions-where they must meet with the conditions of temperature just describedhave originated directly from the low temperature hindering their growth. This assumption, as is quite evident, perfectly accords with my experiments on Lymnaea."-(Semper. Animal Life. pp. 108-9.)

It is obvious that any cause which retarded the growth of the Lymnaea, until the period of sexual maturity, would produce a similar result. In this, as in previous instances, we have examples of the direct action of changed conditions, apart from the principle of selection. 
CHAPTER V.

NATURAL SELECTION NOT MANIFESTED IN ORGANIC EVOLUTION (contimued).

(c) EMBRYOLOGY.

"Une échelle des êtres."-BONNET.

TIIE strongest argument in favour of Organic Evolution, and the one which supplies the key to all the others, is the science of Embryology, which deals with the evolution of the individual. The successive stages through which the organism passes from the fecundated ovum to the mature structure display an increasing complexity. This development of the individual organism is regarded as the "abstract and brief chronicle" of the evolution of the race. The ontogeny or the history of the development of the individual organism, is taken as a proof of the phylogeny or the history of the development of the tribe or race from which the individual has been derived. It is true that there are certain limitations to this principle, but these limitations do not in any way militate against the general inference in favour of Organic Evolution; they simply modify our views as to the precise details of the development which has taken place. Assuming that the development of the individual is a reproduction of the evolution of the race, and that each individual "climbs up its own ancestral tree," we have now to ask whether we can find any trace of the action of Natural Selection in the process 
of individual development which would entitle us to infer that it has also been a factor in the evolution of the race.

If all animals were born in a perfect form, except so far as growth and the development of the sexual elements were concerned, we might have some difficulty in drawing any inference on the subject; for it might be contended that the development which took place before birth occurred independently of external conditions, and was the result of heredity; and that it was therefore impossible to investigate the causes which brought about these changes in the first instance. Even if this were so, we might glean some hints upon the subject. In some instances, the young while yet unborn are fully equipped for an aquatic life, although destined when born for a terrestrial one. The Alpine salamander is born in the fully developed condition without gills. In the uterus, it is provided with very long gill-filaments.* And the inference from this fact is, that the ancestors of the animal were gill-breathers before they became lung-breathers.

But sometimes the process is very much curtailed, and it might be dangerous to draw our inferences too freely. But fortunately for our present enquiry, many animals are not born with the perfect forms which they subsequently acquire, and we are thus enabled to make these imperfect or larval forms the subject of observation and experiment; and the result of this investigation favours the idea that nature has exercised a transforming, as opposed to a selective, influence. It is interesting, at this point, to observe that the difference in the stage of development at the time of birth is determined by circumstances.

"The ringed snake lays eggs which require three weeks' time to develope. But when it is kept in captivity, and no sand is strewn in 
the cage, it does not lay its eggs, but retains them until the young ones are developed. The difference between animals producing living offspring and those laying eggs is here effaced simply by the change of the ground upon which the animal lives."-(Haeckel. The History of Creation. 3rd ed., rol. i., p. 240.)

"Allen Thomson informs me that the Crested Newt (Triton cristatus) is in rare instances viviparous."-(Balfour. A Treatise on Comparative Embryology. vol. ii., p. I42-note.)

In the next place, we may observe the phenomenon which Kollman calls Neotenia-or the lengthening for an indefinite time of the period during which larval amphibians remain gill-breathers.

"When tadpoles were placed, by Dr. Milne Edwards, in a perforated box, sunk in the Seine, . . . they grew to a great size in their original form, but they did not pass through the usual metamorphose which brings them to their mature state as frogs." - (Chambers. Vestiges. 4th ed., p. 238.)

The explanation of this fact is not, as the author of Vestiges seems to think, "light being the only condition thus abstracted," but rather that the tadpoles were kept from rising to the surface and coming into contact with the air. This inference is confirmed by what takes place sometimes in connection with the proteus.

"The proteus is furnished with branchiae as well as with lungs, and Schreibers found that when the animal was compelled to live in deep water, the branchiae were developed to thrice their ordinary size and the lungs were partially atrophied. When, on the other hand, the animal was compelled to live in shallow water, the lungs became larger and more vascular, whilst the branchiae disappeared in a more or less complete degree."--(The Variation. Ist ed., vol. ii., p. 297.)

Another cause of the arrested development of larval forms would seem to be a deficiency of food. Dr. Henry de Varigny says :-

"I have myself kept toads in the tadpole state for over two years, merely by feeding them very scantily. They were born in the spring of 1889 , and remained all the time in an aquarium in the laboratory, 
having water enough at their disposal, being always sufficiently provided with aquatic plants, and enjoying heat enough. It can by no means be said that their evolution was arrested by the cold of winter, as often happens in mountain ponds, when the cold of autumn sets in before the tadpoles have achieved their development, so that they become frogs or toads only in the course of the following year. In the case of my tadpoles, it seemed that the completion of development was due to my imprudently feeding them, in the spring of I89I, on the very substantial flesh of their congeners, and in the course of some three weeks at most the limbs were evolved, the long tail disappeared gradually, the very colour and appearance of the skin underwent considerable changes, and my superannuated tadpoles became toads at last."-(Experimental Evolution. p. III.)

Now these two experiments seem to me to be sufficient to enable us to explain the rationale of this arrested development. They indicate two conditions, without which larval evolution is impossible. In the first place a sufficient quantity of food is necessary in order to stimulate the organism to proceed to the next stage of an inherited process of development. Only on this hypothesis can we explain the two-fold fact that, with insufficient food, the process of development was arrested; and that through the agency of the most stimulating food the process was resumed, so that abundant nourishment led to the absorption of the tail. But there is yet another condition, without which such evolution is clearly impossible, and that is, that in those creatures which are born in a larval state, the circumstances surrounding them should be such as to render the next stage of their development possible. Cut off the tadpole from the air of the atmosphere, and it will not develope into an air-breathing amphibian; and if it did it must necessarily perish. Here, then, in the case of the tadpole of the frog, we have a demonstration of the conditions under which the animal which breathed the air of the water by means of gills must have been converted into the animal which breathed the air of the atmosphere by means of lungs. But here again we are brought face 
to face with the old dilemma. Do these circumstances produce a change in the organism by their direct transforming influence, or are they the results of Natural Selection? The case of the proteus just quoted goes to show that there is a direct response. The organ which is being used for a time is enlarged, while the organ which is being unused grows smaller through inaction.

But if circumstance and outward condition act in this way in the case of animals who are provided with both lungs and gills, why should they not exercise a similar direct influence over the merest rudiment of a lung and the fully-developed gill? Assuming the necessity for breathing the air, why should not the rudimental lung increase in proportion as the fully-developed gill decreases?

But it does not seem to me to be equally easy to picture this transmutation taking place by means of Natural Selection. So long as there is an ample supply of air in the water which the fish inhabits, there is no reason to doubt that he would remain as he was. This hypothesis is confirmed by the experiment made on larval amphibians whose development was retarded by the oxygenation of the water in which they lived.

Whatever the cause of the want of supply of air in the water, there is only one other possible way of supplying the demand, and that is to seek to secure a supply from the air of the atmosphere. Now, if the same necessity affected a group of a given species, and they all sought, at the same time, the same solution of the difficulty, they would all be subject to the transforming influence which is so powerful in the case of the proteus.

In order that the evolution of the lungs should be brought about by Natural Selection, three things are necessary: the elementary organ must vary in each individual by reason of the variations inevitably associated 
with sexual reproduction; some of these must be more adapted to the needs of the animals than others. Those best adapted must be preserved, while the rest are destroyed. Let us grant the first two conditions to be true to nature. What chance is there that the requisite selection will be made? Those which were most fitted to breathe the air of the atmosphere would either rise to do so as frequently, more frequently, or less frequently than those who were less endowed. If all rose to the surface to breathe the atmosphere as frequently, all would be equally exposed to danger, but the fish-eating enemy would make no choice, he would seize any individual which happened to come in his way. If the better endowed individuals rose more frequently, the danger would be greater than in the case of the less endowed. If the better endowed rose less frequently, not needing to come up to the surface so often, and thus enjoyed greater security, the others, by using their lungs more frequently, would soon obliterate the difference brought about by the slight advantage of birth variation.

For the reasons just assigned, I believe that the change of the tadpole into the frog was originally brought about, in the far-off ancestral history of the race, by the transforming influence of outward circumstances, and not by Natural Selection. And this explanation avails to solve another problem. There are certain animals which were once regarded as belonging to entirely distinct species, such, for example, as the axolotl and the amblystoma. Certainly they differ from one another in a very marked degree. And yet observation and experiment have proved that the axolotl under certain conditions can be transformed into the amblystoma.

"In I 867 some axolotls were observed to emerge from the water in the Jardin des Plantes at Paris, to cast their skins, and to become 
transformed into a gill-less newt, long known as an American genus, and named Amblystoma. . . . By careful experimentation, a lady naturalist, Fraïlein von Chauvin, showed that by gradually inuring the axolotl first to a life among damp moss and then to an existence entirely removed from the water, it could be made to assume the amblystoma form, with its black skin and yellow spots. . . . It is obvious that this treatment must be applied very gradually and in such a manner as not to overtax the vital energy of the amphibian." -(Dr. Andrew Wilson. Chapters on Evolution. pp. 242-3.)

Two explanations of this phenomenon are possible. It may be said that the axolotl represents the larval stage of the amblystoma-one branch of the amblystoma race never having got beyond that stage of evolution; or it may be said that the axolotl is the degenerate form of the amblystoma. Now, if the case of the frog may be regarded as analogous, it seems probable that the axolotl is a larval form of the amblystoma. No one, I suppose, doubts that the frog is descended from ancestors which once lived as fishes, and as newts before they became frogs, and which handed down their distinctive characteristics from generation to generation. But if the frog had been born a frog, and if nothing had been known concerning the history of the race until a tadpole had been for the first time seen to be metamorphosed into a frog, it might then have been an open question whether the frog were a larval or a degenerate form.

Certain reasons are, however, assigned for the belief that the axolotl is actually a retrogressive form of amblystoma. Dr. Weismann maintains that the case in question is one not of sudden advance in a species, but of reversion to a lower stage.

"I believe that the axolotls which now inhabit the Mexican lakes were amblystomas at a former geological (or, better, zoological) epoch, but that owing to changes in their conditions of life, they have reverted to the earlier permanently-gilled stage."-(Apud Wilson. p. 248.) 
One of the most interesting facts which lend support to this view of the backward development of the axolotl is the discovery that the axolotl has a rudimentary intermaxillary gland furnishing a glutinous secretion, and which serves to aid the capture of insect-prey. Now, as this gland exists in a perfect shape in all land amphibians, but is absent in gill-possessing forms, its presence in the gilled axolotls would seem to indicate that these animals retain the gland as a legacy from the higher or amblystoma stage, from which they are believed by Dr. Weismann to be descended and retrograded.*

So far as my present argument is concerned, it is unnecessary that we should determine which is the correct view with respect to the actual and existing axolotl. If it be a progressive stage, it represents a stage in the evolution of the race awaiting further development. If it be a retrogressive form, we are either deprived of any evidence whatever of the progressive evolution of the race, or we must accept the axolotl conditions as more or less representing a half-way house past which the amblystoma race must have travelled-back to which the amblystoma has reverted, with some characteristics inherited from its amblystoma parents. For the purposes of the present argument, either of the above suppositions may be entertained. What we are specially concerned to know is whether we can find any trace whatever of the action of Natural Selection in this connection.

Dr. Wilson, who believes that the axolotl is a larval form, refers the change to transforming influence. The case of the axolotl, he says, illustrates powerfully the effects of a change of surroundings in metamorphosing a species. A succession of dry seasons, operating in the 
past, has most likely been the active origin of the amblystoma race from the axolotl stock. Presumably the axolotl as the gill-bearing form is the primitive stock, the amblystomas being a derived race, but nevertheless representing a true species, of which the axolotl may be regarded as the larval form. The shrivelling of the gills, seen in the experiments on the axolotl, was probably due to a mechanical cause - that of dryness of the surroundings.

Dr. Weismann, who believes that the axolotl is a degencrate form, declares that the transformation of the axolotl into the amblystoma was not brought about by Natural Selection.

"If their gills by this means become shrivelled up or completely disappear, even this is not adaptation in the Darwinian sense, but the effect of directly-acting external influences and chiefly of diminished use."-(Studies in the Theory of Descent. p. 59I.)

Mr. W. Mattieu Williams, speaking of the transformation of the Mexican axolotl into an amblystoma, says:-

"Here is a case of very rapid modification, in which the animal, without the aid of hereditary variation, without any destruction of the unfit and survival of the fittest, has at once adapted itself to varying external conditions-a case apparently supporting the old-fashioned development theories of the predecessors of Darwin."-(Gentleman's Magazine. vol. cclxii., p. Ioo.)

(d) PALFONTOLOGY.

"Bones bear witness." -Comedy of Errors. Act iv., sc. 4 .

It is the opinion of some writers that palæontology does not afford any conclusive evidence of the action of Natural Selection.

"While the general testimony of palæontology is overwhelmingly in favour of the view that some general law of evolution has operated 
in the production of the varied forms of life, there is no direct palieontological evidence which would certainly establish any particular theory as to the precise modus operandi. With regard more particularly to the theory of the origin of species by means of Natural Selection, the evidence of palæentology cannot be said to be conclusive."-(Nicholson and Lydekker. A Mamual of Palcontology. 3rd ed., vol. i., p. 104.)

It is only right to observe that this declaration is made mainly on the ground of the absence of closely graduated transitional forms between allied morphological forms. This phenomenon is-

"in part explained by the known imperfection of the geological record, but this does not appear to offer an adequate solution of the difficulty. The theory of the origin of species by means of Natural Selection, as elaborated by the master-mind of Darwin, constitutes nevertheless an invaluable, indeed an indispensable, guide in all branches of palæontological research."-( $\not$. I05.)

What is really valuable in this statement is that we have no direct palæontological evidence of the particular modus operandi by which the process of Organic Evolution has been brought about. I should be sorry to adopt the argument against Natural Selection drawn from the imperfection of the geological record, seeing how fatal such objection would be to the belief in Organic Evolution, no less than in Natural Selection; and remembering how many missing links have already been found. And surely it is a remarkable assertion that Natural Selection, whose direct action cannot be perceived in palæontology, should be regarded as an indispensable guide in palæontological research. It is not a belief in Natural Selection, but in Organic Evolution, which affords the necessary guidance.

If palæontology affords, as most writers assume, a very strong, if not the strongest, argument in favour of Organic Evolution, and yet does not give any proof as to the particular law or conditions under which the evolution has taken place, it only remains for us to interpret the past by 
our experience of the present. And this indeed is one of the axioms of geological science. Naturally those who believe that Organic Evolution can only be brought about to-day by Natural Selection, will assume that it was so from the first, as now. But those who believe that there has been an Organic Evolution without Natural Selection in the present, and that Natural Selection is impossible now, will search for evidence to show the operation of other laws, and haply to find actual evidence that Natural Selection could not act, then, any more than at the present time. And this is what I shall now attempt to establish.

We have an illustration of Mr. Darwin's use of this inference from known facts in the case of the ancon ram and the turnspit dog. We know that the variety of the ancon ram arose suddenly, and was endowed with the power of impressing its own likeness upon its offspring We know that the same phenomenon has been repeated in the case of the japanned peacock and the Mauchamp ram. No one could have guessed what was the origin of the ancon and other breeds, had it not been a matter of experience; but from this experience Mr. Darwin infers, that "some of the peculiarities of the several breeds of the dog have probably arisen suddenly-for instance, the shape of the legs and body in the turnspit of Europe." That the ancon variation may have appeared in nature, and has so appeared, is obvious from the fact that there are ancon jaguars in Paraguay and ancon pariah dogs in India. Mr. Darwin, on the ground of these facts, infers that the turnspit dogs depicted on the tombs of Egypt in remote historical times, may have arisen in a similar manner.

We have seen the immense difference which exists between the improved pigs and the common pigs, and still more the wild boar. A similar difference obtains 
between bull and pug-dogs. These changes, as seen in the pigs, are due to changed conditions and habits of life, to abundance of food, to the cessation of those activities on which the wild pig depends for its preservationperhaps the phenomenon is enhanced by the principle of correlated growth and other influences. We have instances of similar modifications which take place in nature, as for example, the bull-dog codfish and the "monstrous breed" of cattle known as niatas or natas. If we argue from the case of the improved pig, we may infer that an abundant source of food in the shape of luxuriant pasturage was the cause of this transformation in nature, as it is one of the conditions of such change in art. But if this is so, we can go a step further, for in the Sivatheriun giganteum of the Pliocene Sivalik Hills of North-eastern India we have an animal with a similar configuration of facial bones.

In one case, at any rate, we have evidence which goes to show that the change could not be brought about by Natural Selection. One of the strongest arguments in favour of Organic Evolution is based upon the evolution of the horse, as revealed in successive strata of the earth's surface. The change from a five-fingered to a one-fingered manus is generally selected for special observation. I am not quite sure that it would be possible to show that the change, made gradually, would have been a matter of life and death to the differently endowed individuals; but unless we can prove this, or give good reasons for supposing that this has been so, we have no right to attribute the change to Natural Selection. It may, however, be observed that concurrently with this modification of the manus, there has been a development of the teeth. On this latter point, Mr. Henry Fairfild Osborn says :-

"The teeth . . . furnish not only the most intricate correlations and readjustments, but the complete history of the addition of a 


\section{3}

number of entirely new elements - the rise of useful structures from their minute embryonic, apparently useless, condition, the most vulnerable point in the pure selection theory. . . . Upon the probability that the mammalian teeth were developed from the reptilian type, Cope predicted, in $\mathrm{I} 87 \mathrm{I}$, that the first accessory cusps would be found on the anterior and posterior slopes of a single cone -i.e., at the points of interference of an isognathous (equal-jawed) series in closing the jaws. Much later I showed that precisely this condition is filled (? fulfilled) in the unique molars of the Upper Triassic Dromotherium. These, with the main cusp, form the three elements of the tritubercular crown. Passing by several well-known stages, we reach one in which the heel of the lower molars intersects, and, by wearing, produces depressions in the transverse ridges of the upper molars. At these points are developed the intermediate tubercles, which play so important a role in the history of the ungulate molars. So, without a doubt, every one of the five main component cusps superadded to the original cones, is first prophesied by a point of extreme wear, replaced by a minute tubercle, and grows into a cusp. The most worn teeth-i.e., the first true molars, are those in which these processes take place most rapidly. We compare hundreds of specimens of related species: everywhere we find the same variations at the same stages, differing only in size, never in position. We extend the comparison to a widely separate phylum and find the same pattern in a similar process of evolution. . . Whatever may be true of spontaneous variations in other parts of the organism, these new cusps arise in the perfectly definite lines of growth. Now, upon the hypothesis that the modifications induced in the organism by use and disuse have no directive influence upon variations, all these instances of sequence must be considered coincidences. If there is no other causal relationship, what other meaning can this sequence have? . . Granting the possibility that the struggle for existence is so intense that a minute new cusp will be selected if it happens to arise at the right point, where are the non-selected new elements, the experimental failures of nature? We do not find them. Palæontology has indeed nothing to say upon individual selection, but chapters upon unsuccessful species and genera. Here is a practical confirmation of many of the most forcible theoretical objections which have been urged against the selection theory."-(Nature. vol. xli., pp. 227-228.)

Here, then, in connection with the palæontological evidence for the evolution of the horse, we have evidence to show, in the opinion of an expert, that it could not have been brought about by Natural Selection. 


\section{CHAPTER VI.}

\section{NATURAL SELECTION NOT MANIFESTED IN ORGANIC EVOLUTION (continued).}

\section{(e) CLASSIFICATION.}

"The King of Babylon stood at the parting of the way, at the head of the two ways, to use divination."-EZEKIEL. $x i x$, 21 .

THE natural classification of organic beings turns out to be an arrangement according to their genetic relationships, and the result of this classification is seen in a tree-like ramification, having several points of divergence. This fact is accepted as a strong argument in favour of the process of Organic Evolution. If we had been privileged to be spectators of what took place when different groups of similar individuals bade farewell to one another at the parting of the way, we might then have divined the laws by which these initial modifications were effected. That the scientific imagination will be able to achieve this some day, I am fully confident; but the hour has not yet come, and we must move now, if we move at all, in the region of conjecture. This chapter is added, "for the sake of symmetry," to complete the logical statement of my argument, and yet deals with subjects on which our knowledge is still "elementary," in the ordinary sense of that word.

It is obvious that all existing organisms may be classified so as to exhibit these tree-like ramifications; and if the inference of the advocates of Organic Evolution is to be relied on, there must have been a point at which some inorganic elements became endowed with what we call 
life, while other such elements remained inorganic; there must have been a point at which some vegetables became animals, while other vegetables remained vegetable; or perhaps there were some common forms, neither animal nor vegetable, which at certain points became distinctively vegetable on the one hand, or distinctively animal on the other. There must have been a point at which some invertebrates began to be vertebrates, while other invertebrates remained invertebrate. There must have been a point at which, following one line of descent, some fish became reptiles, some reptiles amphibians, some amphibians mammals; and when, following another line of descent, some reptiles became birds. And if all this took place under the reign of law, there must have been mechanical, chemical, vital laws by which Organic Evolution has been brought about. But, at present, they are too dimly discerned to enable us to found any strong argument upon them in favour of the theory of transformation, as opposed to the theory of Natural Selection; and, with one notable exception, I believe that no attempt has been made to prove that Natural Selection has been the determining cause of those new departures which produce such different results.

But if the discussion of these topics has not proceeded far enough for the purposes of our present argument, the chasm which once appeared to divide the inorganic from the living, the simple forms from the more complex, the invertebrate from the vertebrate, the fish from the reptile, the reptile from the bird, or the reptile from the amphibian, and the amphibian from the mammalian, has been narrowed very considerably, and the whole process of Organic Evolution, represented by a tree-like classification, becomes no more difficult to conceive than the transmutation of one species into another. 


\section{6}

In order to show that any process of Organic Evolution, by which an advance in the complexity of organisation has been brought about, has been influenced by Natural Selection, one of two methods might be adopted. It might be proved that Natural Selection has been at work in all cases, or in some cases, to produce a transmutation of species; and from thence it might be inferred that the principle, active in the transmutation of species, must have been active in the process of Organic Evolution at large. Or, on the other hand, it might be assumed that the successive stages of development which the theory presupposes are represented by organisms existing at the present day; or, at the least, that such organisms enable us to conjecture what the primordial forms actually were; and then, by observation of, or experiment upon, existing forms, it might be possible for us to conjecture what took place from the very first stages of Organic Evolution up to the present time. Now, both of these arguments have been employed by Mr. Herbert Spencer in his Essay on The Factors of Organic Evolution, in which he endeavours incidentally to show that Natural Selection has played its part in bringing about the first steps of the evolution of organic life out of a primordial protoplasm. I say he incidentally shows this, because the main contention of the Essay is to prove that there are three factors of Organic Evolution, viz.: the inherited effect of use and disuse, Natural Selection, and the "direct action of environing matters and forces." But if this Essay is read from the point of view from which we have now to consider it, it may be regarded as an attempt to show how Natural Selection is manifested in the earliest stages of Organic Evolution.

In the first place, let us take note of the method of argument by which Mr. Spencer endeavours to show that 
Natural Selection must have been at work to produce some of those changes by which the transmutation of species has been effected. It should be remembered that the theory of Mixed Darwinism implies that transmutation of species can take place either with or without Natural Selection; that, in the phraseology of Semper, nature works by transforming influences alone, by means of selective influences alone, or through the co-operation of both these agencies. This being so, the logical mode of procedure would surely be first to show all that can be done by nature through transforming influences before we introduce the principle of Natural Selection. We must be quite sure that we know all the factors of Organic Evolution before we venture to say that because certain results have not been brought about by the transforming influences with which we are acquainted, it must have been brought about by Natural Selection. And even then we must be quite sure that all the logical demands of the theory are capable of being realised in nature. But Mr. Spencer has not followed this method of demonstration. First of all he proves that the inherited effects of use and disuse is a law of nature which amply accounts for certain phenomena, but not for all; and then ignoring his third factor of "the direct action of environing matters and forces," he proceeds to argue as if the choice lay between the inherited effects of use and disuse and Natural Selection, and to infer that what cannot be produced by the one must be produced by the other.

Having thus introduced the principle of Natural Selection, he proceeds to show that there are certain instances of transmutation for which Natural Selection cannot account, and then, without asking whether the inherited effects of use or disuse will account for these phenomena, he proceeds to deduce the necessity for his third factor. 
This is the only proof which he offers for the action of Natural Selection as an agent in the transmutation of species. Now we venture to protest against the method of this argument. The advocate of Mixed Darwinism has no right to assert that certain phenomena which cannot have been brought about by the inherited effects of use or disuse, must have been produced by Natural Selection, until he has proved that they cannot have been produced by the direct action of the medium. He has no right to argue that what cannot be brought about by Natural Selection, must have been brought about by the direct action of the medium, until he has proved that they are not due to the inherited effect of use or disuse. Believing as he does that the direct action of the medium is a very potent influence in Organic Evolution, he scarcely does justice to his convictions, when he regards this factor as coming in to supplement the action of the other two factors. And in point of fact he argues subsequently that the direct action of the medium was the cause of the first modification of primordial living matter.

But we venture to protest not only against the method of this argument, but also against the conclusions arrived at in the consideration of details. Mr. Spencer's first reason for regarding Natural Selection as a factor is that, by it, adjustments, which are not the result of the effect of inherited use, are made comprehensible. His second reason is that Natural Selection alone accounts for the appearance of new parts. His third reason is derived from the changes in the arrangement and attachment of muscles. His fourth reason is based on the phenomenon of mimicry. With respect to the third of these classes of phenomena, he says: "Here again, then, we have a class of structural changes to which Mr. Darwin's hypothesis gives the key, and to which there is no other 
key." And the argument requires that the same should be said of all the four classes of phenomena which he cites.

After all that has been said in the previous sections of this work, it is unnecessary here to consider every instance which has been brought forward by Mr. Spencer. At the same time it may be well to select a few as illustrations of the different steps of his argument.

Among the instances adduced to prove that Natural Selection must have produced certain results, because the inherited effects of use and disuse will not account for them, we find the case of the thorns of the bramble cited. Now, with respect to the origin of thorns, the experience of desert plants may be cited, and it will then be seen that thorns are the result of the direct action of the dry and arid air of the desert.

Mr. Spencer further says :-

"Plants which are rendered uneatable by the thick woolly coatings of their leaves, cannot have had these coatings produced by any process of reaction against the action of enemies; for there is no imaginable reason why, if one part of a plant is eaten, the rest should thereafter begin to develope the hairs on its surface." $-\left(\not p^{3}.\right)$

But if we consider that the leaves of plants are directly influenced by the conditions of life to which they are subjected, an imaginable reason is at once found without being compelled to call in the action of Natural Selection.

Again Mr. Spencer asks :-

"Or how can those seeds which contain essential oils, rendering them unpalatable to birds, have been made to secrete such essential oils by these actions of birds which they restrain?"-( $\not$. 3.)

But the reply at once suggests itself, that the production of essential oils is the result of the action of certain conditions of life, and so the necessity for the introduction of Natural Selection is again removed. 


\section{0}

Mr. Spencer says that the introduction of new organs could not be explained by the principle of the inherited effects of use and disuse, and he therefore infers that this phenomenon must have been brought about by Natural Selection. But, as we have already shown, the evolution of the electric organ in certain fishes cannot be explained on the principles of Natural Selection. On the contrary, it is readily admitted that it offers the greatest difficulty to the acceptance of the theory.

Mr. Spencer argues that :-

"the relations of tendons to bones and to one another, are not always the same. Variations in their modes of connection may occasionally prove advantageous, and may thus become established. Here again, then, we have a class of structural changes to which Mr. Darwin's hypothesis gives us the key, and to which there is no other key."(p. 8.)

I am in ignorance of the precise nature of the facts from which $\mathrm{Mr}$. Spencer draws this very important inference. But we may remark that the case, as put by Mr. Spencer, is altogether hypothetical. He does not prove that some of these variations must be useful; he simply asserts that they may be useful. But they must be useful - they must secure the survival of those who possess these modifications, while the others, not so modified, are destroyed-if they are to be referred to a class of structural changes to which Mr. Darwin's hypothesis gives us the key.

And then, what are we to say as to the assertion that there is no other key than that of Natural Selection to explain this phenomenon. What is the phenomenon? "The relations of bones to tendons are not always the same." That, I suppose, means that the tendons are not always attached to exactly the same point. But the fact that such variations are to be found, seems to indicate that 
they are mere individual variations which are perfectly consistent with fixity of species.

In order to prove that Natural Selection was the only key to solve this problem, it would be necessary to show that an existing generation of a species had the tendons attached to the bones in a different way to that in which they had been attached some generations previously. It would be necessary to show that the present attachment had prevailed over the previous one by the survival of the one set of variants and the destruction of the other. It is impossible to prove this, unless we dissected all the individuals of each generation of a group of animals.

"The relations of bones to tendons is not always the same." That must mean that in each generation indiriduals are differently constituted. Does this difference make any difference to the animals? In order to prove this you would have to establish a correlation between the most active or the most powerful limbs and one or other of their different modes of attachment. You must compare their several degrees of capability and strength; and then by dissection ascertain whether difference in the attachment of tendons to bones is the cause.

Again, it may be safely assumed that the mode of attachment normal to a species would be best adapted to the wants of its individuals. Any deviations which were very slight could not be of any advantage or disadvantage; if they were considerable, they might not be advantageous, and could not be preserved by the means of Natural Selection. If a slight modification in the attachment of the tendon were accompanied by a slight modification of the contour of the bone, the phenomenon would be explained by the correlation of growth which changes one co-ordinated structure into another; but in order that the new modification should be preserved by Natural Selection, 
it must preserve those who possess it, while those who do not possess it are destroyed. But we know that slight or even considerable modifications in the co-ordination of structure are perfectly compatible with fixity of species. I hold it, then, to be a very large assumption that, because a new attachment of the tendon to the bone may be advantageous, the existence of such a phenomenon presents a difficulty to which Mr. Darwin's hypothesis gives us the key, and to which there is no other key.

I have already dealt with the problem of mimicry, and need not here repeat the arguments already urged.

Having established the necessity for the action of Natural Selection by ignoring his third factor of Organic Evolution, Mr. Spencer proceeds to limit the action of Natural Selection. It will not account for the diminished jaws of civilised man. It will not account for modifications which involve an elaborate co-ordination of structure. It will not come into action in those cases in which several members of a species may have various kinds of superiority over another. And on the ground of this inability of inherited use and disuse, and of Natural Selection, to produce all the phenomena connected with the transmutation of species, Mr. Spencer proceeds to argue that it is necessary to introduce the principle of the direct action of the medium. But here it may be observed that Mr. Spencer believes that the diminution of the jaw is brought about by use and disuse and the principle of correlation; so that the necessity for a third factor is not established. If Natural Selection will not account for the complicated changes which some co-ordinated structures undergo, the inherited effects of use and disuse and the principle of correlation would give a sufficient explanation, in some cases, at any rate; and so far, again, the need for a third factor is not established. That 
where various kinds of superiority are manifested in a race, Natural Selection will not act-does not lead to the belief in a direct action of the medium, but in the assurance that such a state of things tends to establish a fixity of species, as already proved from considering what would take place in artificial breeding if the breeder were foolish enough to select first the fattest, then the swiftest, and then the strongest, and thus to imitate a process which must often, if not always, take place in nature.

If it could be proved that there were only three factors of Organic Evolution, and that we knew all about them, the method of argument here applied could not be accepted. But if it should turn out that there were other factors, which had been overlooked, Mr. Spencer's argument would be still less tenable; and we may quote the author himself against the idea of finality in this respect :-

"Inattention and reluctant attention lead to the ignoring of facts which really exist in abundance, as is well illustrated in the case of pre-historic implements. Biassed by the current belief that no traces of man were to be found on the earth's surface, save in certain superficial formations of very recent date, geologists and anthropologists not only neglected to seek such traces, but for a long time continued to pooh-pooh those who said they had found them. When M. Boucher de Perthes at length succeeded in drawing the eyes of scientific men to the flint implements discovered by him in the quarternary deposits of the Somme valley, and when geologists and anthropologists had thus been convinced that evidences of human existence were to be found in formations of considerable age, and thereafter began to search for them, they found plenty of them all over the world. Or, again, to take an instance closely germane to the matter, we may recall the fact that the contemptuous attitude towards the hypothesis of Organic Evolution which naturalists in general maintained before the publication of Mr. Darwin's work, prevented them from seeing the multitudinous facts by which it is supported. Similarly, it is very possible that their alienation from the belief that there is a transmission of those changes of structure which are produced by changes of action, makes naturalists slight 
the evidence which supports that belief, and refuse to occupy themselves in seeking further evidence." $-(p .25$.

On the same principle it is possible that other factors may have been overlooked by Mr. Spencer, because he has taken for granted that there are only three, or that these three are sufficient to produce all the phenomena of Organic Evolution.

The result of what has been said is that the contention of Mr. Spencer does not justify him in assuming that Natural Selection must necessarily have had a part in the transmutation of species, while at the same time he argues most conclusively that in some cases Natural Selection could not possibly be the cause of transmutation.

Before I leave Mr. Spencer's proof of the necessity for the introduction of Natural Selection, it may be well to consider his definition of the phrase "the fittest." There are some who regard Natural Selection and the survival of the fittest as synonymous terms, and having proved to their own satisfaction that Natural Selection is a law of nature, it follows that there must be a survival of the fittest. But the truth is that Natural Selection is the reputed cause, and the survival of the fittest is the reputed effect; and on that account the two phrases ought to be kept perfectly distinct from one another. And yet Mr. Spencer affirms that-

"though Mr. Darwin approved of this expression, and occasionally employed it, he did not adopt it for general use; contending, very truly, that the expression 'Natural Selection' is in some cases more convenient." - $(p .4 I-$ note. $)$

It is difficult to understand the propriety of not using the two phrases; and one is bound to suspect the convenience which leads a reasoner to use the term which indicates the cause for the term which indicates the effect. 
I have already drawn attention to this point and also the admission of Mr. Spencer, that-

"organisms which live thereby prove themselves fit to live in so far as they have been tried; while organisms which die thereby prove themselves in some respects unfitted for living." -(The Principles of Biology. vol.i., p. 445.)

But in this Essay Mr. Spencer gives us a further definition of "the fittest":-

"If a key fits a lock, or a glove a hand, the relation of the things to one another is presentable to the perceptions. No approach to fitness of this kind is made by an organism which continues to live under certain conditions. Neither the organic structures themselves, nor their individual movements, nor those combined movements of certain among them which constitute conduct, are related in any analogous way to the things and actions in the environment. Evidently the word 'fittest,' as thus used, is a figure of speech, suggesting the fact that, amid surrounding actions, an organism characterised by the word has either a greater ability than others of its kind to maintain the equilibrium of its vital activities, or else has so much greater a power of multiplication, that though not longer lived than they, it continues to live in posterity more persistently. And indeed, as we here see, the word 'fittest' has to cover cases in which there may be less ability than usual to survive individually, but in which the defect is more than made good by higher degrees of fertility." $(p .42$.

I will pass over the assertion that there is not a lockand-key fitness between organisms and their environment, although it has always appeared to me that it was the contention of the advocates of Natural Selection that some such fitness does exist, and has been brought about very often, if not always, by the aid of Natural Selection. But the assertion that the phrase "the fittest" may indicate either the individuals which are best adapted or the individuals which are most prolific, seems to me to be a most remarkable statement.

To indicate by the same phrase the individuals of a species which are the best adapted to their environment, and the individuals which participate in the great fertility 
which characterises all the members of a species, must lead to much confusion of thought. If prolificness can secure the survival of a species, in spite of the absence of all adaptation of structure to new environment, the necessity for Natural Selection is excluded. But prolificness is an essential element in the action of Natural Selection. Thus the very condition which is necessary for the introduction of Natural Selection dispenses with the necessity for its interposition.

We now proceed to consider Mr. Spencer's proof that Natural Selection has co-operated in the evolution of the earliest forms of life. At the outset of this enquiry, it will be well to bear in mind that we are moving in a sphere of conjecture more or less. Mr. Spencer thus concludes his Essay :-

"Of course, this sketch of the relations among the factors must be taken as in large measure a speculation. We are now too far removed from the beginnings of life to obtain data for anything more than tentative conclusions respecting its earliest stages, especially in the absence of any clue to the mode in which multiplication-first agamogenetic and then gamogenetic-was initiated."-( $\not .74$.

In the second place, we must remember that the simplest forms of life may not represent in all cases the actual ancestry of the higher organisms. They have existed almost from the beginning of the appearance of life upon the earth, and they may have undergone considerable modifications. Still, it would be a mistake to allow too much force to this difficulty. We have instances of the simplest forms of living matter still existing either in a permanent or a transitional form ; and, on the principle of Organic Evolution, we are bound to believe that development must have taken place in some way or other from the simplest form to the less simple, from the less complex to the more complex. 
It is the opinion of Mr. Spencer that " the direct action of the medium was the primordial factor of Organic Evolution,"* and that "the differentiating action of the medium never ceased to be a co-operator in the development of these first animals and plants." $\dagger$ The first step in the evolution of an undifferentiated homogenous speck of living matter must have been the differentiation of the outside from the inside. The cause must have been the different exposure of its parts to incident forces of its medium or environment. This argument is supported in a note by reference to the experiments of Messrs. Downes and Blunt with relation to the destruction of bacteria by sunlight and free oxygen. Mr. Spencer infers that if sunlight and free oxygen destroy these minutest portions of protoplasm, in the case of larger portions they will work an effect on the surface, instead of the whole mass. "The larger mass will be made inert only on its outside; and indeed the like will happen with the minutest mass if the light or the oxygen is very small in quantity. Hence, there will result an envelope of changed matter, enclosing and protecting the unchanged protoplasm-there will result a rudimentary cell-wall." +

The passage of the amoba into an encysted state is also supposed to have been originally due to the direct action of the medium.

"The contained protoplasm of a vegetal cell . . may be regarded as an imprisoned amœba; and when we pass from it to a free amœba, which is one of the simplest types of first animals, or protozoa, we naturally meet with kindred phenomena. . . While its plastic or semi-fluid sarcode goes on protruding, . . . there is but an indistinct differentiation of outer from inner . . . ; but when it eventually becomes quiescent, the surface becomes differentiated from the contents; the passing into an encysted state, doubtless

$$
\text { * p. } 72 . \quad+p \cdot 73 . \quad+p \cdot 76 .
$$


in large measure due to inherited proclivity, being furthered, and having probably been once initiated, by the action of the medium." (p. 52.)

It seems to me that Mr. Spencer might have spoken more definitely on this point. For so long as an amoeba continued to be supported by the protrusion of its body so as to enclose its food, and at certain periods to reproduce itself by the process of fission, these acquired proclivities, and no others, would be inherited; and if the action of the medium led, under certain conditions, to the adoption of an encysted condition, it is easy to understand how such a tendency would also become inherited. Inherited proclivities would simply reproduce the modifications originally initiated by the environment.

We have now to consider the arguments which $\mathrm{Mr}$. Spencer employs to prove that Natural Selection has also played an important part in the earliest stages of Organic Evolution. In the first place, he contends that different environments would produce different results in the differentiation of the outside from the inside, and that this would give an opportunity. for the action of Natural Selection.

"Acting alone, the primordial factor must have initiated the primary differentiation in all units of protoplasm alike. I say alike, but I must forthwith qualify the word. For since surrounding influences, physical and chemical, could not be absolutely the same in all places, especially when the first rudiments of living things had spread over a considerable area, there necessarily arose small contrasts between the degrees and kinds of superficial differentiation effected. As soon as these became decided, Natural Selection came into play; for inevitably the unlikenesses produced among the units had effects on their lives; there was survival of some among the modified forms rather than others."--( $\not p .72-3$.)

Now, it should be observed that the variations upon which Natural Selection is here supposed to act are not the variations inevitably associated with reproduction, but 
they are variations due to the direct action of the environment, by virtue of which a similar effect is produced upon all the similar organisms subjected to its influence. But Mr. Spencer elsewhere in this Essay maintains that this is not Natural Selection. He lays down the proposition that Natural Selection could only act "after numbers of spontaneous variations had occurred, as the hypothesis implies."* Where similar causes produce similar effects, there is no need for Natural Selection. Certain external conditions would produce the same modifications on all individuals subjected to their influence. If elsewhere other circumstances modified other individuals, in another manner, there would not necessarily be any rivalry between the two groups of variants, if each group kept to its own environment.

Mr. Spencer argues that elaborately constructed covering's must have been produced by Natural Selection.

"Among protophytes, it needs but to think of the multitudinous varieties of diatoms and desmids, with their elaborately-constructed coverings, . . to see that most of their distinctive characters are due to inherited constitutions which have been slowly moulded by survizul of the fittest to this or that mode of life. To disentangle such parts of their developmental changes as are due to the action of the medium, is therefore hardly possible." - $(p .50$.

It should be observed that Mr. Spencer makes no attempt here to discern how the medium may have acted directly on the organism. He assumes that Natural Selection has been at work, and that the problem is complex; that we 'cannot tell how much the direct action of the medium has accomplished, nor of course how much Natural Selection has achieved. What we should have liked to have seen would have been some development examined with a view to prove that it could not have

$$
* \text { p. } 67 .
$$


been produced by the direct action of the environment, and therefore must have been produced by Natural Selection; or at least to indicate how it might have been accomplished by Natural Selection.

In reference to the development of the amoba, Mr. Spencer says :-

"The limiting membrane becomes in higher infusoria definite and often complex, showing that the selection of favourable variations has had largely to do with its formation." -

But why should the believer in Mixed Darwinism affirm that definite and complex structures must have been produced by Natural Selection, and take that for granted without attempting to discuss the direct action of the environment?

We have next to consider the process of invagination, by which the gastrula stage of development is attained. Mr. Spencer gives the following illustration of the process :-

"Take a small indiarubber ball, not of the inflated kind, nor of the solid kind, but of the kind about an inch or so in diameter, with a small hole, through which, under pressure, the air escapes. Suppose that, instead of consisting of indiarubber, its wall consists of small cells, made polyhedral in form by mutual pressure, and united together. This will represent the blastoderm. Now with the finger thrust in one side of the ball until it touches the other, so making a cup. This action will stand for the process of invagination." $-(p .64$.

"If we go back to the first stage in which Protozoa, having by repeated fissions formed a cluster, then arranged themselves into a hollow sphere, as do the protophytes forming a volvox (Mr. Spencer argues that), originally alike all over its surface, the hollow sphere of ciliated units thus formed would, if not quite spherical, assume a constant attitude when moving through the water; and hence one part of the spheroid would more frequently than the rest come in contact with nutritive matters to be taken in. A division of labour resulting from such a variation being advantageous, and tending, therefore, to increase in descendants, would end in a differentiation like that shown in the gemmules of various low types of 
Metazoa, which, ovate in shape, are ciliated over one part of the surface only. There would arise a form in which the cilium-bearing units effected locomotion and aeration; while on the others, assuming an amœba-like character, devolved the function of absorbing food-a primordial specialisation variously indicated by evidence. Just noting that an ancestral origin of this kind is implied by the fact, that in low types of Metazoa a hollow sphere of cells is the form first assumed by the unfolding embryo, I draw attention to the point here of chief interest-namely, that the primary differentiation of this hollow sphere is in such case determined by a difference in the converse of its parts with the medium and its contents; and that the subsequent invagination arises by a continuance of this differential converse." $-(\not .68$.

"Out of that part of the external layer which remains permanently external, are developed all the structures which carry on intercourse with the medium and its contents, active and passive." $--(p .65$.

"Commencing at the stage in which 'gastrula' has been produced by the permanent introversion of one portion of the surface of the hollow sphere, it will suffice if we consider what must thereafter have happened. That which continued to be the outer surface was the part which from time to time touched quiescent masses and occasionally received the collisions consequent on its own motions or the motions of other things. It was the part to receive the soundvibrations occasionally propagated through the water; the part to be affected more strongly than any other by those variations in the amounts of light caused by the passing of small bodies close to it, and the part which met those diffused molecules constituting odours. That is to say, from the beginning the surface was the part on which there fell the various influences pervading the environment, the part by which there was received those impressions from the environment serving for the guidance of actions, and the part which had to bear the mechanical reactions consequent upon such actions. Necessarily, therefore, the surface was the part in which were initiated the various instrumentalities for carrying on intercourse with the environment. To suppose otherwise is to suppose that such instrumentalities arose internally where they could neither be operated on by surrounding agencies, nor operate on them-where the differentiating forces did not come into play, and the differentiated structures had nothing to do ; and it is to suppose that meanwhile the parts directly exposed to the differentiating forces remained unchanged. Clearly, then, organisation could not but begin on the surface, and having thus begun, its subsequent course could not but be determined by its superficial origin. And hence these remarkable facts, showing us that individual evolution is accomplished by successive infoldings and ingrowings." (p. 6q.) 
Mr. Spencer points out the extreme difficulty of supposing that this process could have been initiated by Natural Selection :-

"The process is not one to have been anticipated as a result of Natural Selection. After numbers of spontaneous variations had occurred, as the hypothesis implies, in useless ways, the variation which primarily initiated a nervous centre might reasonably have been expected to occur in some internal part where it would be fitly located. Its initiation in a dangerous place, and subsequent migration to a safe place, would be incomprehensible. Not so if we bear in mind the cardinal truth above set forth, that the structures for holding converse with the medium and its contents arise in that completely superficial part which is directly affected by the medium and its contents; and if we draw the inference that the external actions themselves initiate the structures, these once commenced and furthered by Natural Selection, where favourable to life, would form the first term of a series ending in developed sense organs and a developed nervous system." $--(p .67$.$) .$

\section{Elsewhere he says :-}

"Doubtless Natural Selection soon came into action, as, for example, in the removal of the rudimentary nervous centres from the surface; since an individual in which they were a little more deeply seated would be less likely to be incapacitated by injury of them. And so in multitudinous other ways. But nevertheless, as we here see, Natural Selection could operate only under subjection. It could do no more than take advantage of those structural changes which the medium and its contents initiated."--(pp.69-70.)

We have now to consider how far Mr. Spencer is justified in supposing that there was a point in which Natural Selection interposed. Let it be observed that, in his opinion, the process was not initiated by Natural Selection; that the action of the medium continued throughout the whole process of development; and that "Natural Selection could only act under subjection. It could do no more than take advantage of those structural changes which the medium and its contents initiated."

Now, in the first place, let us once more remember that Mr. Spencer maintains that the hypothesis of Natural 
Selection supposes the emergence of spontaneous variations-i.e., of variations necessarily connected with sexual reproduction. The variations due to the action and reaction of a similar organism and a similar medium would be the same in all cases, and the principle of selection would not be required; and if there were selection, it would not be the selection presupposed by the hypothesis of Natural Selection.

Again, Mr. Spencer seems to suppose that the differentiation of the hollow sphere of the volvox, by which some cells performed the function of aeration, and others of assimilating nutriment, was not brought about by Natural Selection, but by the fact that only certain cells had the opportunity of seizing food. He says indeed that the variations being favourable would be inherited. But they would be inherited, favourable or not. And being a necessary result of the conditions supposed, they would occur in all, and the principle of selection would not be required.

Now, it would appear from the account of Mr. Balfour, to whom Mr. Spencer refers us, that

"it is probable that in simple ancestral organisms the whole body was sensitive to light, but that with the appearance of pigment-cells in certain parts of the body, the sensitiveness to light became localised to the areas where the pigment-cells were present. Since, however, it was necessary that stimuli received by such organs should be communicated to other parts of the body, some of the epidermic cells in the neighbourhood of the pigment-spots, which were at first only sensitive in the same manner as other cells of the epidermis, became gradually differentiated into special nerve cells. . . As to the details of this differentiation, embryology does not as yet throw any great light; but from the study of comparative anatomy, there are grounds for thinking that it was somewhat as follows:-Cells placed on the surface sent protoplasmic processes of a nervous nature inwards, which came into connection with nervous processes from similar cells placed in other parts of the body. The cells with such processes then became removed from the surface, forming a deeper layer of the epidermis below the sensitive cells of the organ 
of vision. With the latter cells they remained connected by protoplasmic filaments, and thus they came to form a thickening of the epidermis underneath the organ of vision, the cells of which received their stimuli from those of the organ of vision and transmitted the stimuli so received to other parts of the body. . . . Such a thickening would obviously be the rudiment of a central nervous system. - . It is easy to see by what steps it might become larger and more important, and might gradually travel inwards, remaining connected with the sense organ at the surface by protoplasmic filaments which would then constitute nerves. The rudimentary eye would at first merely consist of cells sensitive to light, and of ganglioncells connected with them; while at a later period optical structures, constituting a lens capable of throwing an image of external objects upon it, would be developed, and so convert the whole structure into a true organ of vision."-(A Treatise on Comparative Embryology. vol. ii., pp. 40T-402.)

"All the (auditory) organs have their origin in specialised portions of the epidermis. Some of the cells of a special region become provided at their free extremities with peculiar hairs known as auditory hairs; while in other cells concretions known as otoliths are formed, which appear often to be sufficiently free to be acted upon by vibrations of the surrounding medium, and to be so placed as to be able, in their turn, to transmit their vibrations to the cells with auditory hairs."-(Ibid. p.5T2.)

"It seems quite possible that many of the epithelial cells of the epidermis and walls of the alimentary tract were originally provided with processes the protoplasm of which, like that of the Protozoc, carried on the functions of nerves and muscles at the same time, and that these processes united amongst themselves into a network. . . . By a subsequent differentiation some of the cells forming this network may have become specially contractile, the epithelial parts of the cells ceasing to have a nervous function, and other cells may have lost their contractility and become solely nervous."--(Ibid. p. 405.)

Natural Selection does not account for the fact that certain cells became more sensitive to light than the rest of the surface cells: all that its supporters can say is that if this difference arose in some, and if it was very advantageous to its possessors, they would survive and the rest would perish. And the same is true of the pigment cell, the otolith, and the differentiation into nerve and muscle. On the other hand, it seems to me that if 
Mr. Spencer had asked himself whether the direct action of the environment, combined with the inherited effect of function and other transforming causes, could have brought about the differentiations just referred to, he would not have needed to go to Natural Selection for an explanation.

It is evidently the opinion of Mr. Balfour that the formation of pigment cells, in certain parts of the surface, is the immediate cause of the special susceptibility of those parts to light. And if we argued from analogy, we might assume that the otoliths played a similar part in creating a special local susceptibility to sound. In these cases the organism and the environment act upon one another without the aid of Natural Selection. Again, it is the opinion of Mr. Balfour that the primordial filaments of protoplasm performed the double function of muscles and nerves; but that in course of time some portions only performed the function of nerves and lost their contractility, while other portions performed the function of contractility and lost their nervous power. But if this is so, we have here an illustration of the differentiating effects of inherited use and disuse; and again there is no need for the introduction of Natural Selection.

Mr. Spencer maintains that Natural Selection would lead to the removal of the sensitive organ from the surface to the inside. But the surface of an organism must always remain the means of communication with the external world. What took place was not the removal of a highly sensitive organ from the outside to the inside, but the gradual concentration of a certain susceptibility to a particular portion of the surface; the communication of the influence to the interior of the organism by the means of nerves; and the interposition between the environment and the sensitive nerves of a more and more perfect organ of sight. But behind this organ and in 
communication with the environment is still the sensitive nerve which responds to the stimulus of light,--far more sensitive probably than the undifferentiated primordial protoplasm.

In dealing with the phenomenon of fission, Mr. Spencer affirms that we are utterly in the dark respecting the causes which set up that process everywhere occurring among the minutest forms of life; but he goes on to say that "when established, it furthered the spread of those which were most favourably differentiated by the medium."*

But, in the first place, it may be asked whether we are altogether in the dark as to the causes which led to the fission of an amoboid substance.

Mr. J. Arthur Thompson says :-

"When the limit of growth is reached, the cell divides. The necessity for this division has been partly explained by Spencer and Leuckart. If you take a round lump of dough, weighing an ounce, another of two ounces, a third of four ounces, you obviously have three masses successively doubled, but in doubling the mass you have not doubled the surface. The mass increases as the cube, the surface only as the square, of the radius. Suppose these lumps alive, the second has twice as much living matter as the first, but not twice the surface. Yet it is through the surface that the living matter is fed, aerated and purified. The unit will therefore get into physiological difficulties as it grows bigger, because its increase of surface does not keep pace with its increase of mass. Its waste tends to exceed its repair, its expenditure gains on its income. What are the alternatives? It may go on growing and die (but this is not likely), it may cease growing at the fit limit, it may greatly increase its surface by outflowing processes (which thus may be regarded as life-saving), or it may divide. The last is the usual course. When the unit has grown as large as it can conveniently grow, it divides; in other words, it reproduces at the limit of growth, when processes of waste are gaining on those of construction. By dividing, the mass is lessened, the surface increased, the life continued."-(The Study of Animal Life. t. IS2.) 
The only way in which such fission could offer an opportunity for the action of Natural Selection, in the strict sense of that term, would be by the production of those variations which are inevitably associated with reproduction. But it may be very much doubted whether such variation can occur in connection with fission. Professor Haeckel, after describing how a protamoba or a protogenes, having attained a certain size, contracts in the middle of the globule and finally falls in two pieces, says that this-

"process of propagation is nothing but a growth of the organism beyond its own individual limit of size."-(The History of Creation. thed., vol. i., p. 192.)

"Now, when we examine this simplest form of propagation, this self-division, it surely cannot be considered wonderful that the products of the division of the original organism should possess the same qualities as the parental individual. For they are parts or halves of the parental organism, and the matter or substance in both halves is the same, and as both the young individuals have received an equal amount and the same quality of matter from the parent individual, one can but consider it natural that the vital phenomena, the physiological qualities, should be the same in both children. In fact, in regard to their form and substance, as well as to their vital phenomena, the two produced cells can in no respect be distinguished from one another or from the mother cell. They have inherited from her the same nature."-(Ibid. pp. x95-6.)

"An amœba simply divides into two amœbæ, each exactly like itself."-(Parker. Elementary Biology. p. I9.)

Now, if this fission is the universal mode of propagation among a certain kind of organisms which were all alike, inasmuch as they are the products of the same conditions of being, it is difficult to see how such a phenomenon could have "furthered the spread of those which were most favourably differentiated by the medium." What evidence is there of such variety of differentiation? If it could be shown that certain individuals grew faster and underwent fission more rapidly by virtue of some differentiation, then $\mathrm{KK}$ 


\section{8}

they would probably prevail at the expense of those which did not proceed as quickly. If there is no evidence of this, there is evidently no variety of structure on which Natural Selection can act.

But it might be said that what is not true in the case of fission is true in connection with the phenomenon of conjugation. Mr. Spencer argues that,-

"along with that remarkable process which, beginning in minute forms with what is called conjugation, developed into sexual generation, there came into play causes of frequent and marked fortuitous variations. The mixtures of constitutional proclivities, made more or less unlike by unlikenesses of physical conditions, inevitably led to occasional concurrences of forces producing deviations of structure. These were, of course, mostly suppressed, but sometimes increased by survival of the fittest."-( $p$. 73.)

In reply to this argument, we must ask once more what we really mean by "fortuitous" variations. All scientific people, I suppose, would denounce the idea that these variations arise by chance, accepting that word in the ordinary unphilosophical sense of the word. If we say that these variations arise from causes of which we are ignorant, that cannot help any physical or biological theory. The scientific man may be compelled to tolerate such ignorance as exists for the present, but he denies that there is any point beyond which research cannot be successful. He believes that there is a physical cause for every phenomenon which can be proved to exist. By him every problem is regarded as capable of solution, if still unsolved. We may apply this principle to two kinds of variation: the modifications due to all the conceivable influences which act on organisms, directly or indirectly; and the variations which are the inevitable result of sexual reproduction, the results of which cannot be foreseen by man, but the causes of which would perhaps be clear if we could see the process which takes 
place, and the results of which are fortuitous only in the sense that some of them may happen to coincide with the needs of the animal in its attempt to adapt itself to changed conditions. Mr. Spencer refers his fortuitous variations to "the mixtures of constitutional proclivities," but it is probable that constitutional proclivities have arisen by the direct action of outward conditions. And inasmuch as these proclivities are said to be made more and more unlike by unlikeness of physical conditions, it would seem probable that the cause which augmented the differences, was also the cause which originated them. But if this is so, the variations are not the variations on which Natural Selection is supposed to act. Moreover, if there are two sources of variation, the direct influence of the medium acting on similar organisms in a similar manner, and the Natural Selection of "fortuitous" variation, the former will be the most potent factor. Organisms are adapted by the circumstances to the circumstances, and Natural Selection is not required.

It may be questioned whether, in the simplest cases of conjugation, or the union of the contents of two unicellular organisms, there is necessarily any development of those variations which are necessarily associated with the sexual reproduction of higher animals. It was at one time supposed that the simplest forms of life reproduced themselves by fission only; and that the race, like Mr. Besant's Ten Years' Tenant, was immortal, barring accidents. But it has been shown that such fission can only go on for a certain time, and that conjugation is necessary after a given period to restore the vigour of the race.

"In November, I885, Maupas isolated an Infusorian (Stylonichia), and observed its generations till March, 1886. By that time there had been two hundred and fifteen generations produced by ordinary division, but since these lowly organisms do not conjugate with near 
relatives, conjugation had not occurred. The result, corroborated in other cases, was striking. The whole family became exhausted, small and senile; they ceased to divide or even to feed; their nuclei underwent a strange degeneration; they began to die. But individuals, removed before the process had gone too far, were observed to conjugate with unrelated forms, and to live on. The inference was obvious. Conjugation in these Infusorians is of little moment to any two individuals; during long periods it need never occur, but it is essential to the continued life of the species. 'It is a necessary condition of their eternal youth." "-(J. Arthur Thomson. The Study of Animal Life. p. 214.)

It is quite clear that conjugation in this case is necessary simply for the renewal of vital energy; and if, in spite of such conjugation, the species remain unmodified, there is no reason for assuming that Natural Selection has interposed in any way.

In other cases of conjugation, there may be an output of individual differences; but such differences are always occurring in connection with species which remain unmodified; and it is a large assumption to take for granted that Natural Selection has been at work simply because one of its conditions has occurred; especially when that condition is one inevitable in connection with sexual reproduction.

Mr. Spencer, in pursuing his argument, proceeds to point out the conditions under which Natural Selection becomes a predominating factor.

"When, along with the growing multiplication in forms of life, conflict and competition became continually more active, fortuitous variations of structure, of no account in the converse with the medium, became of much account in the struggle with enemies and competitors, and Natural Selection of such variations became the predominant factor. Especially throughout the plant world its action appears to have been immensely the most important, and throughout that large part of the animal world characterised by relative inactivity, the survival of individuals that had varied in favourable ways must all along have been the chief cause of the divergence of species and the occasional production of higher ones." --(pp. 73-4.) 
Whatever force there may be in this argument, it is scarcely consistent with the principles laid down by $\mathrm{Mr}$. Spencer; for, if we assume that the race is so adapted to external conditions that further change is not required with reference to them, it does not follow that the struggle with enemies will naturally afford a special opportunity for the action of Natural Selection. For Mr. Spencer lays down two different definitions of the survival of the fittest, according to one of which a species survives by virtue of its enormous fertility. Now we have already pointed out that a great output of life is a necessary condition of the action of Natural Selection, and that if a great output of life is sufficient to secure the survival of a species without any modification, then one of the conditions necessary for the action of Natural Selection prevents it from coming on the scene. But let us, for the sake of argument, assume that a great output of life may act in two ways,- - either by leading up to Natural Selection or by dispensing with its action. In which case is the output of life most likely to act to the exclusion of Natural Selection? A great output of life, accompanied with a corresponding output of "fortuitous" variations, would affect nothing in adapting a species to a new locality apart from Natural Selection. But a great output of life would preserve the species from extinction through the attack of enemies. Where there is a fixed balance between species living in the same locality, there is a correlation between the output of life and the destruction to which a species is liable.

Nor is it true to say that a great output of life will lead to the transmutation of species by Natural Selection in consequence of the competition between individuals of the same species, for the normal population of a district is correlated to the number of enemies; while an excep- 
tional output of life attracts enemies from afar, or in some way acts prejudicially to the species to such an extent as to threaten it with extinction. With Mr. Spencer's dual definition of "the fittest," I do not think that conflict with enemies or competition between individuals of the same species would present a favourable opportunity for the action of Natural Selection.

The assumption that certain organisms are more or less passive to external influence might seem to be more favourable to Natural Selection than to the principle of the inherited effect of use and disuse; but organisms might be, and often are, equally passive whether submitted to transforming or selective influences.

Mr. Spencer proceeds to argue that gradually, with increased activity and increased complexity of life, the inheritance of modifications of structure caused by modifications of function would come into play and become an important factor.

"And I think there is reason to conclude that in the case of the highest of creatures, civilised men, among whom the kinds of variation which affect survival are too multitudinous to permit easy selection of any one, and among whom survival of the fittest is greatly interfered with, it has become the chief factor; such aid as survival of the fittest gives being usually limited to the preservation of those in whom the totality of the faculties has been most favourably moulded by functional changes." - $(p .74$.

If it be granted that increased activity leads to the increased modifications of structure caused by modifications of functions, it does not hence follow that the direct action of the medium will not still continue to exist. Indeed, Mr. Spencer over and over again asserts that it does continue throughout all stages. But if this were not so, it would not at all follow, as Mr. Spencer contends, that "such aid as survival of the fittest gives" would be "usually limited to the preservation of those in whom the 
totality of the faculties has been most favourably moulded by functional changes." For, as we have already shown, the application of different tests of fitness in the animal world would not produce Admirable Crichtons, but would tend to bring about a fixity of species rather than a transmutation of species possessing more highly developed organisms; and Mr. Spencer argues most conclusively to the same effect. It is true that civilised man has not yet adopted the merciless policy of permitting the survival of the fittest only, nor even of securing the elimination of the worst. But civilised life involves a subdivision of labour, and the consequent special culture of special faculties and aptitudes. If there is competition, it is among those who follow the same callings and develope the same faculties. Such a state of things does not promote the cultivation of the totality of the faculties. Success in life generally attends those who are the most accomplished specialists. 


\section{CHAPTER VII.}

ORGANIC EVOLUTION WITHOUT NATURAL SELECTION.

"The playbill, which is said to have announced the tragedy of Hamlet, the character of the Prince of Denmark being left out."

-ThE TALisMaN.

To those who believe that Natural Selection has been demonstrated to be a great law of nature beyond the shadow of a doubt, and who affirm that only those who are incapacitated by ignorance, misled by superficial knowledge, or blinded by theological prejudice, can hold the contrary opinion, it will seem an absurd thing to talk of the possibility of Organic Evolution without Natural Selection. It will seem as nonsensical as it is to talk of a representation of the play of Hamlet, the character of Hamlet being left out. And yet it is conceivable, to say the least, that a play might be designated by the name of a person who never appears upon the scene at all. That is actually the case in a dramatic representation known as Walker, London, of whom we hear nothing till the very last, when we discover that it is, or is pretended to be, the telegraphic address of the barber who has been posing as a world-renowned traveller. Nor does it seem to me inconceivable that a play of Hamlet Prince of Denmark might have been written, in which Hamlet should not appear ; in which we might hear of his return home, of his interview with the ghost, of his immediate retirement from 
the scene, either going back to Wittenberg or joining the forces of Fortinbras, and from the distance frustrating with his vacillating policy the action of the friends who were entrusted with the duty of discovering the guilt of the king and avenging the death of Hamlet's father. Nay, we might go even further than this. A play might be written, in which the whole plot turned upon the probable appearance of some quite supposititious character, and the dénouement of the play might consist in emancipation from a stupendous delusion.

Something very much like this must one day take place in the scientific world, if the opinions expressed in previous pages should ever prevail; and if arguments, better than I have been able to urge, should be adduced.

This audacious assumption suggests a difficulty at the outset. "How is it possible," it might be asked, "that such an error could have prevailed? Is it probable that the greatest scientific thinkers have been labouring under a delusion?" There are many reasons, it seems to me, to render such a phenomenon possible. First of all we must remember that there was a time when the controversy lay between Fixity of Species and Organic Evolution by means of Natural Selection. Hence arguments for the fact of Organic Evolution and arguments for the process of Natural Selection, were treated as identical; nay, the arguments for Organic Evolution were quoted in confirmation of the hypothesis of Natural Selection. In this way Natural Selection and Organic Evolution became almost convertible terms.

The second reason why this theory prevailed, arose from the fact that it offered an explanation which was easily intelligible, which could be expressed in epigrammatic phrases, which seized on the popular imagination, which became familiar in our mouths as household words; the 
logic of which was irresistible, assuming the premises to be true. It left untouched some of the greatest difficulties associated with Organic Evolution-the origin of life, the laws of variation, the mysteries of reproduction. It explained all by assuming that the variations necessarily associated with reproduction were the source of heritable variations-that selection in nature acted in the same fashion, for the most part, as selection in art; and that similar results might be looked for-nay, still greater, inasmuch as the works of nature are greater than the works of man.

The third reason for the success of this theory lies in the fact that it was promulgated by men who were not mere theorists, but careful observers of the actual world of nature. But experience warns us that scientific observers of the calibre of Darwin and of Wallace, who have done good work as careful observers of nature, have sometimes promulgated scientific theories which have not been sustained.

Another reason is found in the elasticity of the terms employed and the indefiniteness of the definitions which are often given. It prevailed moreover because the effect of its promulgation was to depreciate the influence of other factors of Organic Evolution. But I venture to go a step further back, and to say that the theory of Natural Selection has prevailed because scant justice has been done to the arguments for Organic Evolution, which were used before the date of the publication of The Origin of Species.

It is candidly admitted by believers in Natural Selection that, if it should be proved that Natural Selection was not after all a law of nature, it would not affect the arguments for Organic Evolution; it would only imply that some factors, other than Natural Selection, had 
brought about that phenomenon. In point of fact, the arguments for the fact of Organic Evolution are perfectly independent of any particular method by which it was brought about. Now, it so happens that Mr. Robert Chambers, in his Vestiges of the Natural History of Creation, stated these arguments in language almost identical with those employed by Mr. Romanes in his Evidences of Organic Evolution-a work which professed to give a synopsis of Darwinism, but in which no proofs of Natural Selection are adduced. These arguments themselves, being identical in idea and very similar in phraseology, were as valid in I844 as they were in I882. If they were not accepted in I844, the fault is not in the arguments, but in the receptivity of the minds to which they were addressed. And yet the book was read with interest by many cultured people. Why, then, were these arguments for Organic Evolution not accepted? The reason, we are told, was because no adequate explanation was offered as to the processes by which this Organic Evolution had come about. The reason seems to me to have been because the doctrine of the fixity of species died hard; because it was still accepted by the overwhelming majority of scientific men; because they overlooked the arguments for Organic Evolution, or judged them only by arguments adduced for certain factors of Organic Evolution. Meanwhile, the theory of Natural Selection came upon the scene and triumphed, for the reasons already assigned. But in all this, a great injustice was done to those who promulgated the arguments for Organic Evolution as a fact of the natural world; for if those arguments are logically sound, they ought to have been accepted, even if the actual factors could not be discovered. I know that the Eiffel Tower at Blackpool has been gradually produced, and that it did not come down from heaven 
ready-made. I have seen it in every stage, from the laying of its foundations to its completion. It might have been that I had only seen it on Sundays, when no one was at work. But surely no one would contend that I was bound not to believe that it was really gradually built up, unless I saw men actually engaged in the work, and knew the various firms whose men have co-operated in producing the structure. On the same principle, the world ought to have accepted the arguments for Organic Evolution without demanding, as a preliminary condition, that it should know all the factors which had co-operated to bring about that result.

In the next place, it should be observed that, on the assumption that this theory is false, it has yet done a good work in promoting the ultimate discovery of the truth. It may seem a cynical thing to say this, but it is no less true on that account. I believe that the arguments for Organic Evolution as a process were quite conclusive before the publication of the Origin of Species; but I believe that they would never have been accepted in their abstract form. It was not enough to show that the process had taken place; it was necessary to show how, and by the action of what laws, it had taken place. Natural Selection met that demand with a theory which everybody could understand, or thought they could understand. And by this means Organic Evolution came to be accepted.

But the temporary acceptance of a false theory is not without its drawbacks. If only it could be regarded as a tentative hypothesis, all might then be well. It would give the observer of nature something to look for, and whatever the result to the theory, observation would be quickened and enlarged. But too soon, alas! the tentative theory comes to be regarded as a law of nature, 
and the phenomena of nature come to be looked at simply from the point of view which the theory has taken up.

"It is to be regretted that at the present time so many naturalists accept the theory of Natural Selection as an exclusive explanation of the evolution of existing species. They unconsciously blind themselves to the existence of any other agent in the work of evolution. To them there can be, nor is, no other. No greater error could be made; and it is my firm conviction that, as time goes on, the theory of Natural Selection will gradually lose much of its present presumed universality. What is becoming more evident every day is that existing species do not owe near so much to Natural Selection for their evolution as extreme Darwinians would have us believe." (Charles Dixon. Nature. vol. xxxiii., p. I28.)

But if the proofs for the fact of Organic Evolution are valid, and if Natural Selection has no place in nature, we are bound to believe in the existence of other laws and conditions by which it has been brought about. And this belief is justified by the facts of the case.

In the first place, there is a selection in nature, even if there is no Natural Selection. Similar variants, which arise in connection with the variations necessarily associated with sexual reproduction, may be isolated for breeding purposes by other agencies than that of life and death. Such similar variants may separate themselves from the other members of a species, and breed with one another; and, in point of fact, they actually do this. Similar variants may only be fertile inter se, or their period of sexual maturity may differ from that of the rest of the race; and this also we find to be actually the case.

The effect of changed conditions and habits, by virtue of which similar causes produce similar results on all the members of a species subjected to their influence, whether it act upon sexual elements or upon "the body" of a group of individuals, will be to produce a transmutation of 
species apart from Natural Selection and all the limitations which that theory presupposes.

The appearance of an individual with a considerable divergence from the normal type, and the power of that individual to impress its special likeness on its descendants, is another source of necessary transmutation. The principle of correlation of growth, which is necessary for the conversion of one co-ordinated structure into another, has also to be taken account of. And finally, we have to remember that it is quite certain that some of the factors must sometimes work together, and the result of their common action will be proportionately great.

It may well be that there are other factors of Organic Evolution yet to be discovered. It may be that living matter may have a tendency to develope in a certain way in consequence of its particular composition. I mean that it may be possible that there should be a connection between certain organic combinations and the forms which they produce, just as there is a tendency in certain chemical compounds to crystallise in a special manner.

But whether this last contention can be sustained or not, it suffices for my present purpose to affirm that the arguments for Organic Evolution in their abstract form are independent of any arguments in favour of a particular law through which this evolution has taken place; that so far as they are cogent (and their cogency is generally admitted), we are compelled to believe that there must be efficient agencies to bring about this result; and that we are already in possession of many facts which tend to confirm that belief. When investigation shall have been carried still further, I believe that new facts will be discovered tending in the same direction. The process may be a long one. Favourite theories, supported by the majority of scientific investigators, will not be relinquished at once. But the 
claims of Natural Selection as a predominant factor are already being questioned; the influence of other factors of evolution is being more and more recognised. If this process goes on, it must end in the ultimate relinquishment of the distinctively Darwinian theory, and in the acknowledgment of those principles of development whose existence can be proved-by observation and experiment, and by fair inference from these-to exercise that transforming influence to which we are indebted for the transmutation of species and the evolution of organic structures. I do not expect to live to see that day. I have little expectation that what I have written will have any influence in bringing about this change of opinion. But none the less am I possessed with the firm conviction that Organic Evolution, apart from Natural Selection, will be universally recognised as a scientific truth long before the twentieth century shall have run its course. So, as I believe, Time will perform its office, which is "to eat errors by opinion bred"; and reveal its glory, which is "to unmask falsehood and bring truth to light." 



\section{INDEX OF SUBJECTS AND OF NAMES.}

Abortion : $v$. Rudimentary Organs. Aconitum napellus, imported : variation in, 534.

Acraeida: protective elasticity of, I66-7.

Agrionida: protective colouration of, I73.

ALLEN, GRANT : on colouration of arctic fauna, I89-90; on survival of fittest amongst wasps, 272-3.

AlLEN, J. A.: on variations in birds, 488.

Allium: its storage of water, 4I3.

AlTum, DR. B. : on sudden great increases and subsequent possible great destruction of mice, 53.

Amblystoma: $v$. Axolotl.

AMERICAN NATURALIST (quoted by Darwin): on spikehorned buck, 36r.

Amaba: instinct in, 237 ; propagation by fission, 577 ; Herbert Spencer on, 567,570 .

Amphimixis : 370-I.

Ancon Dogs, Jaguar, Ram : $v$. Dogs, Jaguar, Ram.

Animals "made for use of man": I 24-30.

Antelopes : Survival of Fittest among, 63; utility of specific variations in, 4I8- $\%$ also Deer.

Ant-lion, larva of : instinct in, 234.

Ants : instinct and character in, 258 ; queens and workers produced from same or different kind of eggs, 268.

Aphides : potential rate of increase, 46 ; protective secretion of, 166.

ARGYLL, DUKE OF : on protective colouration of birds, 185 ; on instinct in water-ouzel, $22 \mathrm{I}-3$; on special creation, $52 \mathrm{I}$.

ARNOLD, MatTheW : Empedocles on Etna quoted, 4, 8.
Arrested Development : 543-9.

Artemia : variation in, 536-7.

Artificial Selection: analogy of Natural Selection to, I 30-56. "Methodical" and "Unconscious" (Darwin), I 36-7.

Asses, Imported : rapid multiplication of, 52.

Athleticism, Hereditary : 434-5.

Aveling, DR. EDWARD : on sensitive faculties of sun-dew, 286-7; on the hypothesis of Natural Selection, 454.

Axolotl : transmutation of, into Amblystoma, 546-7.

Baboons: co-operation amongst, 93.

BAILEY, Prof.: on the influence of external conditions on squashes, 396.

BAKER, SiR S. W. : on struggle for existence, $22-3$; on indiscriminate destruction of life in nature, 62 ; on parental devotion of cow, 82 ; on co-operation amongst birds of prey, 92.

Balancement, Law of : 335-6.

BALFOUR, F.M.: on the Darwinian theory, 462-3; on limbs of higher vertebrata, 503 ; on sensitiveness of cells, 573-4, 575 .

BALL, J.: on geographical distribution, $53 \mathrm{I}$.

BALL, W. P. : on the effects of use and disuse, 432 ; on law of economy, 5 I 2.

Baptanodon discus : an illustration of conformity to type, 502, 503, 506.

BARBER, MRS. : on influence of environment on colouration of caterpillar, 408.

BASTIAN, DR. H. C. : on animal instincts, 286. 
BATES, H. W. : on animal colouration, 160 ; on mimicry in relation to Natural Selection, I78, I94-5; on protective habits of shrimps and prawns, I84-5; on unprotectiveness of nauseous taste amongst insects, 2 I 8.

BATESON, WilliaM : on protective method of concealment amongst crabs, I7r-2 ; on mimicry amongst flies, 202.

Bears, Polar: colouration of, I 89-93. BECKER, A. : on sudden disappearance of sousliks, 53 .

BEDDARD, F. E. : on scientific observation, I 82 ; on colouration of snow-bunting, i 88 , of arctic foxes, I9I, of bears, I9I-2 ; on accidental colouration with a varied environment, 205 ; on colouration of puff-adder, 205-6; on correlation between conspicuous colouration and nauseous taste amongst insects, 207-8 ; on warning colouration, 208 ; on nauseous skin of caterpillar not protective, 2 I 4 ; on caterpillars being pinched before eaten by birds, 2 I 5 ; on non-universality of nauseous taste in heliconius beskii, 219 ; on skinpigments the cause of nauseous taste, 220 ; on influence of external conditions on saturnia, 396 ; on cause of colouration in animals, 404-5; on non-useful variation in insects, $4 \mathrm{I} \mathrm{I}$.

Beech : extermination of, by birch, I IO, 105.

Bees: great increase in imported, in New Zealand, 5 I ; intelligence in, 242-3.

Beetles : co-operation amongst, 87 ; unprotectiveness of nauseous taste amongst, 2 I 8.

BELT, ThOMAS: on variation, 4 ; on bird-life in tropics, 22 ; on indiscriminative slaughter of wari by jaguars, 62 ; on protective secretion of some insects, I66; on protective colouration and sagacity of locust, I73-4; on protective mimicry of movements by insects, I75; on mimetic colouration of spiders, 176 ;
BeLt, Thomas-(continued). on mimicry, I95; on co-operation amongst birds, 200 ; on correlation between conspicuous colouration and nauseous taste, 207 ; on physiological barriers to breeding amongst variants, 384 . BENNETT, A. W.: on mimicry in relation to Natural Selection, r77-8; on probability of survival of a favourable variant, 201.

Berberis, Spines of : 416.

Bifurcation of Species : 324-6.

"Bird-droppings" : I 74-5.

Birds : dangers to life of eggs and young, 6I ; sociability amongst, 88-9; as destroyers of insects, 164-5; protective colouration of, I 73, I 85 ; co-operation amongst, 200 ; loss of nest-building instinct in, 262 ; faculties of very young birds, 267 ; hybridisation of, 353-4; variations in, 487-8; evolution of, from reptile, 504 .

Bisache : habits of, 253-5.

Bison : co-operation amongst, 94 .

BLANCHARD, ÉMILE : on hybrisation of hares and rabbits, 355-6.

Blind Animals : evolution of, $377-9$, 445-6.

BoIsDUVAL, J. A. : on resemblance amongst butterflies, I6I.

BONNET : on instinct, 225-6.

BREE, DR. C. R. : on special creation, $47 \mathrm{I}$.

Breeding: Physiological barriers to, $382-4$.

PRONN, H. G. : on distinct species never different from each other in single characters but in many parts, 342 .

Browning, Robt.: Pippa Passes quoted, 422.

BRYANT, CAPT. (quoted by Darwin): on sexual selection in seals, 39-40.

BRYDEN, H. A. : on the eland as illustration of Law of Parsimony, $48 \mathrm{I}$.

BÜCHNER, Prof. LUdwig : on instinct in butterflies, etc., 264 ; in birds, 265 .

Buck, Spike-horned: an instance of abrupt structural modification, 359-6o, 36I-v. also Deer. 
BUCKLAND, FRANK : on influence of external conditions on oysters, 395.

Buffon, G. L. L., COMTE DE: on origin of species, 472 .

Butterfies : protective colouration of, I73, I76-7; mimetic structure and colouration of, 195; false mimicry amongst, r 196-7 ; ineffectiveness of protective nauseous taste amongst, 2r8-9; instinct in, 263-4- $\%$. also Heliconidre, Insects, Moths.

Cabbage- : protective colouration of, I 74, 193-4; influence of environment on colouration of caterpillar of, 407-8.

Peacock-: influence of external conditions on, 396.

Cabbage : compensation of growth in, 336 .

CALDERWOOd, Prof. HenRy : on instinct in lower animals, 235.

CANDOLle, AlFRED DE (quoted by Wallace): on usual abortiveness of attempts to naturalize plants, III ; on geographical distribution of plants, 530; (quoted by Darwin) on winged seeds never found in fruits which do not open, 342.

Capra negaceros: inherited effects of habit in, 440 .

Carleton, Will : Farm Ballads quoted, 36.

Carp and Gold-fish : compared, 296.

CARpenter, Dr. W. B.: on instinct in caterpillars, 232 , in dogs, 243 ; on amœba, 237-8.

CARRINGTON, J. F. : on protective colouration of cabbage butterfly, I74.

Carrot : influence of external conditions on, 398.

CARUS, DR. (quoted by Kirby): on sensitive life existent without nerves, 238.

CATCHPOLE, MR.: on hybridisation, 386.

Caterpillars : protective method of conccalment of, $\mathrm{I} 72$; protective colouration, etc., I 76, I 85-6; protective nauseous taste of, 212-3;

\section{Caterpillars-(continued).}

hairy covering not always protective, 2 I 4 ; pinched by birds before being eaten, 215 ; instinct in, 232 ; use of chlorophyll by, 403-4, of tannin, 404-5; influence of environment on colour of, 408 ; conspicuous colouration of, not due to Natural Selection, 522-3 - $\%$ also Cabbage-butterfly, Tiger moth.

Cats : absence of instinct in, $23 \mathrm{r}$; instinct in, 23I ; instinct and character in, 259.

- of Mombas : influence of environment on, 423.

Cattle : Black Cattle (Columbus') in America, 5 $\mathrm{I}-2$; independence of character checked by struggle for existence, 70; Mr. Romanes' pictures of, as the outcome of Artificial Selection, I 5 I-2.

- Niata: variations in, 427-30.

Cattle-breeding : objects to be aimed at, 142.

Cells : sensitiveness of, $573-6$; fission of, 576-7 ; conjugation, 578, 57980.

Centipede : instinct in, 236 ; too low to possess instinct, 235 .

Chameleon : experiment of, on bee in absence of ordinary food, 2 I 4.

Chambers, Dr. Robt. : on unity of organic nature, $456,457,587$; on argument for organic evolution from rudimentary structures, 458 ; from geographical distribution, 458-9, 459-6o; from geology, 459; from embryology, 460; from mental constitution, $460-\mathrm{r}$; on special creation, 46r-2; on sentimental objections to doctrine of descent of man, 462 ; on variation in goldfish, 487 ; on arrested development of tadpoles, 543 .

CHAMBERS' ENCYCLOPAE$D I A$ : on indiscriminate voracity of pike, 62 ; on capture of prey by lions, 63 ; on instinct in larva of ant-lion, 234 ; on incubating instinct in pythons, 265 ; on hybridisation of hares and rabbits, 355 . 
CHAMBERS' JOURNAL : on parental love in nature, $80-I$.

Chance : definition of, by Dr. Johnson, 27; by Cournot, 29; by Janet, 29 ; Shakespeare on, 6o, 65. in Darwinian and evolutionary hypotheses : 30-2 ; Graham on, 26; Huxley on, 26-7, 29-30, 70-I ; Pfaffe Kneipp on, 27; Darwin on, 27-9, 60; Wallace on, 6o, 65-v. also Life, Destruction of : Accidental.

Changed Conditions: $v$. Environment.

Chelydra serpentina: an illustration of conformity to type, 502, 503 .

Chemical Action: a cause of change of organic colour, 408-10.

Chickens: instinct in, 227-8-v. also Fowls.

Chicken-corn : influence of external conditions on, 398.

Chlorophyll : use of, by caterpillars, 402-3.

CICERO : on theory of the world created by God for benefit of man, 127.

CLARK, EDWARD (quoted by Wallace): on pampas of S. America, I I I - 2 .

Classification : as evidence for Natural Selection, 554-83.

Climate: influence of, on organic structure, 397-9.

Coccida: protective secretion of, I66.

Cod-fish : potential rate of increase, $46,56$.

Colocinth : length of root of, 4I3-4.

Columbus' cattle, etc., imported into America : 5 I-2.

Colouration: skin-pigments the cause of nauseous taste, 21920.

20. Defensive : I 59-82 ; colours which conceal, I82-94; Mimetic Colouration, I94-203, 26 ; Warning Colours, I94-220; inutility of some organic colouration, 204-5.

Compassion in Animals: $v$. Cooperation, Animal.

Compensation of Growth, Law of : $335-6$.
Competition : $v$. Struggle for Existence.

Conformity to Type : 500-10.

Conjugation : 578, 579-80.

CONN, H. W. : on rudimentary organs, 498.

Co-operation: among wild-cattle, $84-5$; pelicans, 85,95 ; cranes, 86 ; crabs, 86-7,87; beetles, 87 ; eagles, 9O-I ; vultures, 9I ; baboons, 93 ; hawks, 93-4; bisons, 94 ; wild swine, 94; mares, 94-5; rats, 95 ; snails, 95 ; weasels, 95 ; mammals, 99-IO2 ; plants, I I 4-7 ; birds, 200 ; in animal world, I23; defeats "elimination of the worst," 93v. also Parental Devotion; Sociability; Animal ; Struggle for Existence.

COPE, E. D.: on Survival of Fittest, I 4 ; on mimetic colouration, 26 ; on extinction of species, 316 ; on non-identity of organic evolution and Natural Selection, 453.

CORNHILL MAGAZINE: on co-operation in a Malagasy forest, I $14-5$, II6; on competition in same, II6-7; on birds as destroyers of insects, I64-5.

CosTA (quoted by Darwin): on influence of external conditions of oyster, 395.

COTTON (of Christ Church, Oxon.): his bees, in New Zealand, $5 \mathrm{I}$.

COURNOT : his definition of chance, 29.

Cow : parental devotion of, 82 .

COX, RAMSAY : on influence of external conditions on peacockbutterfly, 396.

Crabs : co-operation amongst, 86-7, 87 ; protective method of concealment of, I 7 I-2.

Cranes: co-operation amongst, 86.

CROLL, DR. J.: his definition of Natural Selection, 44.

Crossing : $\%$. Hybridisation.

Crows : hybridisation of, 353-4.

Cunningham, J. T. : on insect workers and soldiers produced from same kind of egg, 269.

CUVIER: on his discovery of extinct types, 3 I 4 . 
Danaide: protective elasticity of, I66-7 ; acquisition of protective nauseous secretions by, 2 I 7 .

DARWIN, CHARLES : on variation, 4-5, 6, Io, I9, I 46 ; on law of correlated variation, $334,338-40$, $34 \mathrm{I}, 343-7$; of instincts, $279-8 \mathrm{o}$, 284; of Niata ox, 427; of imported plants, 534 ; on unuseful variations, 306, 4IO, 4II; on useful variations, 42I, 422; on causes of variability, $365-6$; on natural "Preservation," I 5 ; on Struggle for Existence, I 7-9, 43, 76, 96, 97 ; on Survival of Fittest, 23, I45; amongst gulls, 443; amongst owls, 443; amongst scarlet-runners, 33-4, I39-40; on chance, 27-9, 60 ; on evolution of human eye, 33; on Sexual Selection, 36, $37-8,38-9$; on romantic love in animals, 38-9; on rate of increase of man and elephants, 46 ; on destruction of life as a check to natural rate of increase, 47,57 ; his relation to Malthus, 50 ; on increase in imported plants, 52 ; on rarity of species, 57 ; on accidental destruction of life, 62 ; on indiscriminate destruction of life in seedlings, 66; on the element of time in variation, $72-3$; on animal sociability, 88 ; on co-operation amongst baboons, 93; amongst hawks, 93 ; on Natural Selection, I04-5, I 38 , I 46, I58; principle of Natural Selection, 466, 485-6; difficulties connected with Natural Selection, 467, 468; slow action of Natural Selection, 399 ; on analogy between Natural and Artificial Selection, I3I ; on "Methodical" and on "Unconscious" Selection, I $36-8$; on Artificial Selection, I39, I 53 ; in relation to sheep-breeding, I39; on power of Forelle-pear to resist cold, I 45 ; on protective colouration among dragon-flies, 173 ; on influence of environment, I67, 395-6, 400-I, 43I ; on cats, dogs and sheep, 423 ; on feral pigs, 429; on proteus,
DARWIN, ChARLES--(continued).

543 ; on influence of climate on organic structure, 397-8; on influence of environment not producing useful results, 4 I 2 ; on change of environment in relation to sexual reproduction, 533 ; on inutility of some organic colouration, 204-5; on skin-pigments the cause of nauseous taste, 220 ; on instinct, $22 \mathrm{I}, 228$; $278-9,279$; on barking instinct in dogs, 256; on instincts in ants, 269-70; on neuter insects, 267-8; on sterile insects, 27I ; on vegetable sensitiveness, 286 ; comparison of gold-fish and carp, 296 ; Transmutation of Species : nature of conditions subordinate to nature of organism, 310 ; in a confined area due to Natural Selection alone, 430 ; influence of changed conditions on, not always rapid, 425-6, 430; on form and habits of water-ouzel, 3 I 2 ; on extinction of species, 3I6; of horse, 318; on the petrel, 323-4; on co-existence of two variants in same district, 326 ; on law of compensation of growth 335-6; on law of homology, 337 ; on evolution of elk from stag, $343,345-6$; on hybridisation, $350-2$; on recent evolution of ancon and merino ram, 358-9; of breeds of dogs, 359 ; on Ancon, Jaguar and Pariah-dog, 359; on abrupt structural modifications, 359-64; on antlers and spike-horns, 362-3; on human physical heredity, 364 ; on isolation in breeding, 380-I ; on physiological barriers to breeding amongst variants, $3 \delta_{2}$; on shape of skull in pig, 427-8; on inherited effects of use and disuse, $438,439-40,44 \mathrm{I}, 442$; on disuse as agent in formation of rudimentary organs, 5II; his acceptance of Lamarckian principles, 472 ; on 'nithil per saltum,' 487 ; on rudimentary organs, 494 , 496, 497-8; on conformity of type, 500 ; on degeneration a result of 
DARWIN, CHARLES--(contimued). law of economy, 5I I, 5I3-4; on organic suppression, 5I $2-3$; on degenerate organs not influenced by Natural Selection, 515-6; on importance of nascent organs, $5 \mathrm{I7}$; on fully-developed useless organs, 5 I8; on geographical distribution, 526-7, 530-I.

DARWIN, PROF. GEORGE H. : on variation, I I-I2.

Darwinism: Pure, 349-88; Mixed, 389-448.

Death : $v$. Life, Destruction of.

Deer: parental devotion of, 83 ; isolation in breeding, 380-v. also Antelope, Buck, Stag.

Degeneration, Organic : 506-I2.

DESCARTES, RENE : on theory of creation of world by God for benefit of man, 127 .

Desert Animals : colouration of, I93-4; cause of colouration of, 404-5.

by, $4 \mathrm{I} 4$.

DEWITZ: on queens and workers of ants produced from different kinds of eggs, 268.

Digitalis, Imported : variation in, 534.

DORFMEISTER (quoted by Eimer): on influence of temperature on colouration and markings of butterflies, 405, 406.

Disuse : $\%$. Use and Disuse.

DIXON, CHARLES: on the exaggerated importance of theory of Natural Selection, 589.

Dogs : Mr. Romanes' pictures of, as the outcome of Artificial Selection, I 5 I-2 ; instinct in, 243 ; barking, 255-6; pointing, 257 ; compensation of growth in, 336 ; hybridisation of, 356 ; recent evolution of some breeds, 359; influence of external conditions on, 397, 423- $\%$ also Greyhounds.

—. Ancon : 359.

Domestication : its facts illustrate the action of Natural Selection and of Sexual Selection, I48-50 - $\%$ also Artificial Selection.
Dragon-flies : protective colouration of, 173 .

DrumMond, Prof. Henry: on "bird-droppings," I 74-5; on defensive colouration of puff-adder, 205.

Drosera: v. Sun-dew.

Ducklings: aquatic instincts in, and their loss, 259-6I ; maternal education of, $26 \mathrm{I}$.

Ducks : incubating instinct of, 265.

DUNCAN, DR. : on instinct in butterflies, 263.

DUVAL: on improved varieties of pears arising under natural conditions, I4I.

Eagle, Golden : dangers to its life, 6 I.

Economy, Law of: v. Parsimony, Law of.

Edmonston, DR. (quoted by Darwin): on influence of external conditions on larus argentatus and raven, 396.

EIMER, Prof. G. H. TH. : on the work of a scientist, I 59; on isolation in breeding of lizards, $38 \mathrm{I}$; on cause of colouration in butterflies, 405, 406, 407 .

EISIG, DR. : on pigments in skin the cause of nauseous taste, 2 I9.

Eland: an illustration of Law of Parsimony, 48I.

Elephant : rate of increase, 46.

"ELIOT, GEORGE": quotation from Romola, $2 \mathrm{I}$; from Middlemarch, 75 ; from Mill on the Floss, 47 I; from Silas Marner, $47 \mathrm{I}$.

Elk: evolution of, from stag, 343, 345-6.

Embryology: as evidence for Natural Selection, 54 I-9.

Emperor-moth : sexual aroma of female, 37.

ENCYCLOPADIA BRITAN$N I C A$ : on instinct, 123 ; on maternal education of ducklings, 26I ; on ventral fins of gobies, 505 .

Environment : direct action of, independently of Natural Selection, I67-70 ; effect of, on colouration, I 89 ; accidental colouration with 
Environment-(continued).

a varied environment, 205 ; adaptation of creolla sheep to, 282-3 ; influence of changed conditions on transmutation of species, 389-448; this influence not always rapidly effective, $425-6$; in relation to adaptation of new species to, 532-3; influence of, on thomisus onustus, I68; on fruit-trees, 398 ; on hair, 4I7 ; mastiff and goat, 423 ; on birthgiving in snakes, $542-3$; on arrested development of tadpoles, 543 ; on structural development of proteus, 543 .

Ermine : protective colouration of 187.

Evolution : definitions of, 1.6 ; five tests for, 6-7.

Organic: not identical with Natural Selection, 45I-74; not proved by Natural Selection, 475-90; not aided by Natural Selection, 490-523; without Natural Selection, 584-9I-v. also Natural Selection.

External Conditions: $v$. Environment.

Eye, Human : evolution of, 33.

FAlCONER, DR. (quoted by Darwin): on non-useful variation, 4II; on influence of environment on mastiff and goat, 423 .

Falcons : influence of, on development of grouse, 63-4.

Finch, H. F. : on Haeckel's cellular psychology, 238.

Fish, Electric : evolution of, 204, $52 \mathrm{I}-2$.

FISKE, Prof. JOHN : on potential rate of increase of cod-fish, 46, 56 ; of plants, 49; on Survival of Fittest amongst antelopes, 63 ; on animal colouration, I70; on relation of Natural Selection to stability of species, 298 ; on bifurcation of a species, $324-6$; on law of correlated variation, 340 ; on Artificial Selection, 443-4; on evolution, $463-4$; on Darwin as a pioneer, 476 ; on tardy acceptance of Newton's law, 477-8.
Flies: mimicry amongst, 202.

Flourens, Prof. M. J. P.: on hybridisation, 350,353 ; of hares and rabbits, 356 ; of dogs and jackals, 356 .

FI.OWER, SIR WM. H. : on conformity of type, 500 .

Flying-fish : pectoral fins of, 504-5.

Food, Change of : an influence on colouration of insects and pupæ, 405-8.

Fore-arm and Hand : evolution of, 505.

FORTNIGHTLY REVIEW: on utility of specific variations, 4 I8.

Fowls : isolation in breeding, 380 - $\%$ also Chickens.

Fox : intelligence in, 247.

- Arctic: protective colouration of, I87, I9I.

Frogs : sex ratio of, Io8; mimetic colouration of, 176 ; protective nauseous taste of, 207.

Fruit-trees: influence of external conditions on, 398-v. also Plants.

GALTON, FRANCIS : on regression to mediocrity, 5-6; on Sexual Selection, 36 ; on tendency of Struggle for Existence to check independence of character, 70; on parental devotion of cow, 82 ; on co-operation amongst wild cattle, $84-5$; on heredity, 366-7.

GAMMIE, Mr. (quoted by Dyer): on Survival of Fittest amongst ipecacuanha plants, I I 3 .

GÄRTNER (quoted by Romanes): on impossibility of hybridisation of varieties of verbascum, 384 ; of pimpernel, 384 .

Gastrula: Mr. Herbert Spencer on, 570-2.

Geese : incubating instinct in, 265 ; hybridisation of, 352 ; diminished fecundity of imported, 533.

Geographical Distribution: as evidence for Natural Selection, 52435.

GEOGRAPHICAL JOURNAL: on gradual drying-up of lakes, 538. 
Geological Changes: as evidence for Natural Selection, 535-40.

Geometrical Ratio: $v$. Increase.

Germ-plasm : $\nu$. Weismann.

Gilbey, Walter : on beauty as an object in horse-breeding, I 34.

Globigerina: stability of the species, 294-5.

Goats : influence of environment on, 423 .

Gobies : ventral fins of, 505 .

Gobioids : pectoral fins of, 504 .

GoETHE, J. W. $\nu_{0}$ : on theory of creation of world by God for benefit of man, I27-8; on Law of Compensation of Growth, 335 .

Gold-finch : acquisition by, of wren's notes, 267 ; variation in, 487.

Gold-fish : compared with carp, 296, 299.

Goldsmith, Oliver: The Deserted Village quoted, Iog.

Gosse, PP. Hy. : on influence of change of food on colouration of insects, 407.

GRAHAM, W.: on chance in the Darwinian and evolutionary hypothesis, 26.

GRAPHIC : on discriminative destruction of life of the "most fit" nuts by squirrels, 67 .

GREG, W. R. : on the scope of scientific interpretation of nature, 427.

Greyhounds : influence of external conditions on, 398-9; effect of exercise hereditary in, 438 .

GRISEBACH, DR. A. : on secretion of ethereal oil by plants, 4I 7 .

Gromia: $v$. Jelly-fish.

Grouse : great fecundity of, always followed by disease, 53-4; on Struggle for Existence amongst, in presence of falcons 63-4.

- North American: Sexual Selection amongst, 69; tunnelburrowing instinct in, 246-8.

Guanacoes : an apparently meaningless habit of, 253.

"Guides" in Flowers : 418-9.

Guillemot : an instance of two variants co-existing in same district, 326.
Gulick, Rev. J. T. : on physiological barriers to breeding amongst variants, 383 .

Gull : influence of external conditions on, 396 ; Survival of Fittest amongst, 443.

Gymnotus : electric organ of, 522 .

H., J. M. : on mimetic action of thrush, I76.

HAECKEL, PROF. E. : his cellular psychology, 238 ; on evolution of sucking amongst young marsupials, 239-40; on hare-rabbit, 355 ; on organic degeneration, 506-7 ; on influence of environment on birth-giving in snakes, 542-3; on fission in amœba, 577 .

Hair: influence of environment on production of, $4 \mathrm{I} 7$.

Hare : protective colouration, etc., of, I83-4; compared with rabbit, 354 ; hybridisation of, 354,355 .

Alpine: protective colouration and habits of, $187, \mathrm{I} 88$.

American : colouration of, not very protective, I87-8.

HARTOG, MARCUS H.: on inherited effect of habit in man, 440 .

Hawk-moth : colouration of, not protective, 207 ; influence of change of food on colouration of, 407.

Hawks : co-operation amongst, 93-4. HECKEL, E. (of Marseilles): on direct action of environment on thomisus onustus, I68.

Heliconider : acquisition by, of protective nauseous taste, 217 ; ineffectiveness of same, 218-9; only a few individuals possess nauseous taste, 2 I 9 .

Hemlock, Imported : variation of, 534 .

Hemp, Imported : variation of, 534 . HensLow, Rev. GEORGE : on Survival of Fittest amongst plants, $6 \mathrm{I}$; on useful modifications of structure, 416 ; on "path finders" in flowers, 4I 8-9.

Heredity, Physical : in man, 364 Galton on, 366-7 ; Weismann on, 367-72 ; Osborn on, 368 Romanes on, 368 . 
Hogs, imported by Columbus into America, 52.

Holmes, DR. Oliver W. : on variation, 3-4; on influence of external conditions on colouration of insects, 402 .

Homology, Law of : 336-7.

Homoptera : protective secretion of, I66.

HOOKER, Sir JOSEPH (quoted by Wallace): on usual abortiveness of attempts to naturalise plants, II I on geographical distribution of plants, 530 .

Horse-breeding : types to be aimed at in, I 43-4.

Horses: isolation in breeding, $38 \mathrm{I}$; influence of external conditions on, 397; an illustration of organic evolution, 552-v, also Mares.

Race, English : evolution of, 335 .

Teeth of : an illustration of organic evolution, 552-3.

- Trotting, American : 335, 433.

Wild : rough games of, Ioo; extinction of, in South America, 3 I 8.

Horse-fly, English, in New Zealand: destruction of, by native fly, I05.

House, Prof. E. H. : on hereditary athleticism, 434.

HUBER, PIERRE : on animal instinct, 228, 278.

HUDSON, W. H. : on destruction following a great "wave of life" among imparted animals, etc., $53,54,297$; on parental devotion in deer, 83 ; on co-operation and strife for mastery amongst mammals, 99-IO2; on difference between flocks of birds and herds of cattle, 99 ; on persecution of wounded individual by herd, IOO-I ; on rescuing instinct, IOI-2; on protective effluvium of skunk, 2 IO, 2I I-2 ; example of instinct in mice and absence of instinct in all cats but one, 231 ; on habits of bisache, 253 , 254 .
Humboldt, Alex. $v$. (quoted by Darwin): on influence of external conditions on man, 398.

Hutchinson, Rev. H. N.: on Cuvier's discovery of extinct types, 3 I 4.

HuXley, Prof. Thos. H. : on variation, IO, 35; on chance in Natural Selection, 26-7, 29-30, $7 \mathrm{O}-\mathrm{I}$; on rate of increase of plants, 47 ; on stability of species, 294-5; on the principles of evolution, 464 ; on the facts of organic evolution, 468 ; on "nihil per saltum," 486.

Hybridisation : $350-2$; on continuous fertility of offspring, 353-6.

Increase : in Geometrical Ratio, 4359 ; destruction a check to, 47 ; in imported animals and plants, $5 \mathrm{I}-4$.

Incubating Instinct : 264-7.

Insects : indiscriminative destruction of life of, 63 ; accidental death amongst, I62-7; expanse of wing in, I65; protective secretion in, 166 ; protective elasticity in, I66-7; correlation between conspicuous colouration and nauseous taste of, 207-8; tannin in, 404 ; cause of colouration of, 405 , 406-8; non-useful variation in, 4I I. Neuter : 267-76.

Walking-stick : protective colouration, etc., of, i 76 .

Instinct, Animal: I23-30, 220-30 ; instinctive comprehension by insect-eaters, etc., of correlation between conspicuous colouration and nauseous taste in insects, etc., 208-I 2 ; instinct and intelligence act apart, 230-2 ; evolution of instincts precedes intelligence, 232-4I ; instincts developed by Natural Selection, 24I-5I ; intelligent animals unobservant of actions not intelligently performed yet inherited, 25I-63; loss of, 259-63; instincts developed apart from intelligence, 263-7 ; instincts acquired by individuals not inherited, 267-89; variation of, $279-85$. 
Invagination : 570-2.

Ipecacuanha Plants: Survival of Fittest amongst, I I 3 .

Isolation for breeding purposes : 373-5, 379-8 I.

Ivy Linaria : action of peduncle of, 287-8.

Jackal : hybridisation of, 356.

Jackdaws: nest-building instinct of, 262.

Jaguars, Ancon : in Paraguay, 359.

JANET, PAUL: his definition of chance, 29; on theory of creation of world by God for benefit of man, 128.

JEFFERIES, RICHARD : article in Gentleman's Magazine quoted, $47 \mathrm{I}$.

Jelly-fish : instinct in, 235 ; too low to possess instinct, 235 .

JENNER-WEIR, J. L. : on inherited effects of habit in capra negaceros, 440.

JESSE, EDWARD : on nest-building instinct in jackdaws, 262.

JoHnS, Rev. B. G. : on mimetic colouration of white spider, 193-4.

JOURNAL OF LINNEAN SOCIFT $Y$ : on hybridisation of verbascum, $35 \mathrm{I}$.

Kangaroo: parental devotion in, $8 \mathrm{I}-2$.

Kingsley, Can. Charles: on effects of drainage of Whittlesea Mere, 3I 5-6.

KIRBY, REV. WilliAM : on animal instinct, 126, 230.

KIRBY and SPENCE: on mimicry amongst insects, $16 \mathrm{I}$; on intelligence amongst bees, 242-3; on habits of termites, 273.

KNEIPP, PFAFFE : on chance in the Darwinian and evolutionary hypotheses, 27.

KOCH, HERR (quoted by Beddard): on influence of change of food on colouration of insects, 406-7.

KOLLMAN : on neotenia, 543.

KöLREUTER (quoted by Darwin): on hybridisation, $35 \mathrm{I}$.
Kropotkin, Prince: on Survival of Fittest, 54-5; on want of evidence for Struggle for Existence, 77-80; on co-operation amongst pelicans, 85 ; cranes, 86 ; crabs, 86-7 ; beetles, 87 ; eagles, 90-I ; on sociability amongst birds, 88-9; ruminants, 89 ; on cooperation defeats "elimination of the worst," 93; on animal compassion, 95 ; on competition, 97,98 ; on co-existence of black rat and brown rat, I I 4 on animal colouration and direct action of environment, 168-9, 409; human and natural action compared, 289 .

Lamb, Merino: an illustration of prepotency of the great variant, 357, 358-9-v. also Ram.

LANESSAN, J. L. DE: on Struggle for Existence amongst plants, 67-8, 96; on co-operation amongst plants, I I 5-6.

LANKESTER, PROF. E. RAY : on Pure Darwinism, I9; on evolution of blind animals, 377-9, 445-6; on change of structure, 395 .

"Lapsing" of Intelligence : 24I, 245-6.

Larus argentatus: influence of external conditions on, 396 ; Survival of Fittest amongst, 443 .

LECONTE, Prof. J. : on divergent variation, I I ; on change of structure, 394-5.

Leopard-moth: conspicuous colouration not protective, 207-8.

LESAGE, M. : on presence of salt the cause of succulency in maritime plants, $4 \mathrm{I} 7$; on variation of maritime plants, 538 .

LEWES, GEO. HENRY : on "lapsing" of the intelligence, 24I ; on origin of instinct, $243-4$; on hybridisation of hares and rabbits, 354 .

Life, Destruction of : how far discriminative and how far accidental, 59-7 I ; great destruction of young, 6I ; non-selective destruction, 61 ; indiscriminative destruction, 62-7 I, I 53; accidental, 62-74; amongst insects, I62-3. 
Lions : indiscriminative capture of prey, 63; symmetrical disease in, 337.

Lizard: Isolation in breeding, 38I v. also Chameleon. of, 506 .

Locust : protective colouration and sagacity of, $173-4$.

LONG, JAMES : on beauty as an object in horse-breeding, 134 .

LONGFELLOW, HENRY W.: On cooperation amongst vultures, 9I.

LONSDALE (quoted by Darwin): co-operation amongst snails, 95.

LOTHELIER : on spines of berberis, 4 I 6.

Love, Romantic, Human : "Ouida" on, 38 ; Shakespeare on, 38 .

Animal : Darwin on, 38-9.

LUBBOCK, SIR JOHN : on experiments as tests of instinct, 232 ; on neuter insects, 269 ; on queens and workers of ants produced from same kind of egg, 268 ; on instinct amongst sand-wasps, 277-8.

LUCAS, PROSPER : on diminished fecundity of imported geese, 533 .

LUPTON, MR.: on evolution of American trotters and English race-horses, 335 .

LYDEKKER, RICHARD : on rudimentary organs, 493, 497-v.also Nicholson and Lydekker.

Lyell, Sir Charles: on influence of external conditions on English greyhound, 398-9.

Lymncea stagnalis: $v$. Snail, Pond-.

MacDonald, DR. Geo.: Wilfred Cumbermede quoted (on the chicken), 266.

MaCkay, 1)r. Charles: Freedom and Lawe quoted, 30.

MALThUS, T. R.: on rate of increase of man, 50.

Man : rate of increase, 46-50; theory of creation of world for benefit of, I24-30 ; instinctive intelligent action in, 243; influence of external conditions on, 398 ; inherited effects of habit in, 440 .
Mares : co-operation amongst, 94-5 -v. also Horses.

"Marigold, Dr." : quoted, 50r.

Marshall, Prof. Mulnes: his comparison of action of Natural Selection to process of purchase of an umbrella, I47-8; on degeneration, 5 IO-I.

Marsupials : evolution of sucking of young, 239-40.

M?ARTINEAU, DR. JAMES : on relation between science and theology, I36; on probability of survival of a favourable variant, $20 \mathrm{I}$; on animal instinct, 228-9; on meaning of evolution, 3IO, 3I I.

MAW, GEORGE : on co-operation amongst mares, 94-5.

Menault, C. (quoted by Büchner): on animal intelligence, 226.

MEtzGer (quoted by Darwin): on influence of external conditions on vegetable structure, 397-8.

MELDOLA, PROF. R. : on variation, 35 ; on stability and transmutation of species, 304 ; on physiological selection and Natural Selection, 387.

MENETRIES (quoted by Darwin): on influence of external conditions on owl, 396.

"Methodical" Selection : I36-8.

Mice : sudden great increase and subsequent possible great destruction of, 53, 54; instinct in, 231.

Migration : 526-9.

MILNE-EDWARDS, H. : on variation, 4.

Mimicry: in relation to Natural Selection, I77-82 ; "true" and "false," I 95-9; between equallyprotected insects, I97-v. also Colouration, Mimetic.

Mivart, St. GeOrge : on variation, II ; on instinct and the theory of evolution, 220-I ; in transmutation of species nature of conditions subordinate to nature of the organism, 3 Io; on influence of external conditions on organic structure, $40 \mathrm{I}$; on limits of scientific interpretation of nature, 426 . 
Monstrosities : artificial production of, I 50.

Montaigne, M. E. DE : on theory of creation of world by God for benefit of man, I28.

Morant, MAJOR GEORGE F.: on Struggle for Existence amongst grouse in presence of falcons, $63-4$.

MORGan, PROF. C. Lloyd: on instinct in chickens, 228 ; on influence of external conditions on organic structure, $40 \mathrm{I}$.

MORGAN, T. H. : on co-operation amongst pelicans, 95 .

MORRIS, REV. F. O.: on co-operation amongst hawks, 93-4.

Moths : protective resemblance to "bird-droppings", I75-v. also Butterflies, Emperor-moth, Hawk-moth, Insects, Leopardmoth, Noon-moth, Tiger-moth.

MÜlLER, Dr. FRITZ (quoted by Darwin): on transition stages of prawn, 5 I9; (quoted by Wallace) on mimicry between equally-protected insects, 197.

MURPHY, JOSEPH JOHN : on Darwinism, 277-8.

MURRAY, ANDREW : on influence of external conditions on organic structure, 397.

NANSEN, DR. F. : on competitive methods among sealers, 90 ; on animal faculties and Natural Selection, 249.

Nascent Organs : 517-20.

NATHUSiUs, HERMANN $v$ : on shape of skull of pig, 427-30.

Natural "Preservation": sometimes used synonymously with "Selection," 1 5-6; Darwin on, 15. Natural Selection: Transmutation of Species by means of, I-290; can it compete with other methods? 293-448; what proof is offered of its effects on organic evolution? 45 I-59I.

definitions of, $2-7,44$; its influence on Transmutation of Species, 2, 19, 103-5; differences of definition, 8-24, 20 ; perhaps more than one theory, 23 ; difficulties inherent in theory, 25-4I ;
Natural Selection-(continued). its causative influence, 34-5; theory compared with reality, 42-IO2; need for assuming the keenest competition under, 76IOI ; largely modified by cooperation, IO2 ; analogy with Artificial Selection, I 30-55; summary of pro's and con's, I 55-6; its action compared with process of purchase of an umbrella (Marshall), I47-8; illustrated by facts of domestication, I48-50 ; accidental death as an illustration of, $163-7$; in relation to theory of instinct, 220-90, 276-8; to stability of species, 297-9; results of cessation of, 30I-I3, $43 \mathrm{I}$; in relation to extinction of species, 320-8; to correlated variation, $343-8$; to Physiological Selection, 387 ; to changed conditions, 389-448; slow action of, 399 ; not identical with Organic Evolution, 45I-74; no proof of Organic Evolution, 475-90; no aid to Organic Evolution, 490523 ; not manifested in Organic Evolution, 524-83; [(a) geographical distribution, 524-35; (b) geological changes, 535-40; (c) embryology, 54 I-9; (d) palæontology, 549-53; (e) classification, 554-83]; not necessary for Organic Evolution, 584-9I; in relation to theology, $42 \mathrm{O}-\mathrm{I}$; to adaptation of new species to environment, 532 .

146, I 58 ; Orwin, I04-5, I 38 , Poulton, I58; Spencer on the expression, 564; Wallace on, I 05.

Naturalization : of Plants : attempts at, usually abortive, I I I.

NATURE : on direct action of environment on thomisus onustus, I68; on protective colouration of birds, I73; on intelligence in starlings, 245 ; on change of instinctive action of toad, $28 \mathrm{I}$; on hybridisation of birds, 354 ; on physiological barriers to breeding amongst variants, 382 ; on evolution of birds from reptiles, 504 . 
NAUDIN (quoted by Flourens) : on hybridisation, 353 .

"Negative Selection" : 308.

Neotenia : 543.

Nest-building: modification in art of, $28 \mathrm{I}-2$.

Neuter Insects : 267-76.

NEwTON, SiR ISAAC : tardy acceptance of his law of gravitation, 477-8.

NICHOLS, ARTHUR: on intellig ence in retriever, $24 \mathrm{I}-2$.

NICHOLSON, DR. (of Antigua ; quoted by Darwin): on influence of environment on sheep, 423.

NICHOLSON, DR. H. A., and LYDEKKER, R. : on palæontology as evidence for Natural Selection, 549-50.

Noon-moth : cause of colouration of, 404-5.

Nuts : discriminative destruction of the "most fit," 67.

Oryxleucoryx : ineffectiveness of spike-horns of, $36 \mathrm{I}$.

OsBorn, H. F. : on Natural Selection, I 58 ; on heredity, 368 ; on horse's teeth as illustration of Organic Evolution, 552-3.

Ostriches : incubating instinct in, 265.

Oswell, W. Cotton : modification in art of nest-building, $28 \mathrm{I}-2$.

"OUIDA" : Branch of Lilac quoted (on romantic love), 38 .

OWEN, CAPT. : on influence of environment on cats, 423 .

OWEN, SIR RICHARD : on change of species, 309-IO ; on organic structure of serpents, 509 .

Owls : influence of external conditions on, 396 ; Survival of Fittest amongst, 443 .

$\mathrm{Ox}$, Niata: variations in, 427-30.

Oysters : influence of external conditions on, 395 .

PAGET, SiR JAMES: on symmetrical disease, 337 .

Palæontology: as evidence for Natural Selection, 549-53.

PAley, ARChIbAlD W.: on animal instinct, I26, 222.
Pangenesis, Theory of : 5 12-3.

Panmixia : $306-9$; in relation to transmutation of species, $43 \mathrm{I}$.

Parasites: destructive effect on insects' eggs, 164 .

Parental Devotion: in animals, 80-4; in baboons, 93; hawks, 93-4; bisons, 94 ; wild swine, 94 ; mares, 94-5.

PARKER, THEODORE : on theory of creation of world by God for benefit of man, I28.

PARKER, PROF. W. K. : on "nihil per saltum," 487 ; on propagation of amœba, 577.

Parsimony, Law of : $479-82$; degeneration a result of, $5 \mathrm{II}$.

"Path-finders" in flowers : 418-9.

PAUL, ST. : on relation of animals to man, I24-5.

Peacock, Japanned : an illustration of permanency of prepotency of the great variant, 357,358 .

Pears : improved varieties arising under natural conditions, I4I.

Forelle : power of resisting cold not necessarily dependent on general vigour, I 45 .

Pelicans: co-operation amongst, 85 .

PENAUT: on tannin in corn-weasels, 403 .

Petrels: the most nunierous bird in the world yet lays but one egg, 323-4.

Phillips, Clive : on mimetic colouration of polar bear, $192-3$.

Physiological Selection : in relation to Natural Selection, 387.

Pigeon-breeding: man's process an analogue of nature's process of evolution, I3I ; type-production in, $134-5$.

Pigeons: Mr. Romanes' pictures of, as outcome of Artificial Selection, I 5 I-2.

Pigs : imported into New Zealand, 52 ; shape of skull in, 427-30v. also Wari.

__ Feral : influence of external conditions, 429 .

Pigments, Skin : the cause of nauseous taste, $219-20$.

Pike : indiscriminative voracity of, 62. 
PIKE, ARNOLD: on mimetic colouration of polar bear, 192.

Pimpernel : impossibility of hybridisation of varieties of, 384 .

Plants: sensitiveness, "intelligence," etc., in, 285-9; extinction of species amongst, 319; an illustration of law of correlated variation, 338 ; influence of external conditions on, 397-8; their thorns and hairs in relation to Natural Selection, 559; nauseous taste in relation to Natural Selection, 559.

Plesiosaurus : paddle of, 505-6.

Polyandry: a method of exterminating rabbits, $4 \mathrm{I}$.

Polygamy : among seals, 39-40.

Population, Stationary : 55-7.

Poulton, E. B. : on Natural Selection, I58; on animal colouration, I6o; on protective method of concealment among crabs, I 7 I-2; among caterpillars, I72, I75 ; on "bird-droppings," I75; on destruction of life very rarely actually witnessed by man, I 8 I ; on protective colouration, etc., of hare, I 83 ; of American hare, I87-8; of caterpillar, I85-6; on "winter white," I 87 ; on colouration of lemming, I89; of arctic fauna, 189 ; on correlation between conspicuous colouration and nauseous taste, 206-7, 208, 209 ; on protective character of nauseous smell and taste, 216 ; on chameleon's experiment on bee in absence of ordinary food, 2 I 4 ; on chlorophyll, 402-3.

Prawns: protective habits of, $184-5$; transition stages of, $5 \mathrm{I} 9$.

PRIOR, MATTHEW : on instinct, 226.

PRINCESS IDA: quoted, 5 I 4.

Protective Mimicry of Movements by insects, I75.

Proteus : influence of environment on structural development of, 543,545 .

Protophytes: Survival of Fittest among, 569.

Protoplasm : $v$. Amœba.

Puff-adders : colouration of, 205-6. Pythons : incubating instinct in, 265.
Quails: indiscriminative destruction of life in, 69.

QUARTERLY REVIEW: on co-operation amongst rats, 95 .

Rabbits : loss of burrowing instinct in, 26I ; compared with hare, 354 ; hybridisation of, 354 , 355.

Race Conflict : I03-I9.

Raia radiata : evolution of electric organ of, 522 .

Ram, Ancon : $v$. Sheep, Ancon.

Rats : co-operation amongst, 95 ; cannibalism of, under certain circumstances, I08; extinction of species of, in Jamaica, 3 I 7.

Raven : influence of external conditions on, 396.

READE, WINWOOD : on influence of external conditions, 397.

Regression to Mediocrity : 5-6, 298, 299.

REID, THOMAS : on animal instinct, 230.

Retriever-dog : intelligence in, 24I-2.

Rhubarb, Imported : variation of, 534.

Robin : colouration of, 206.

Roget, Dr. P. M.: on animal instinct, $\mathrm{I} 26$.

Rolleston, Prof. GeORge : on anatomy of divers, $312-3$; on Law of Parsimony, 479-80.

Romanes, GEORGE J.: on definitions of Natural Selection, 8-9; on variation, IO, I I ; on causative influence of Natural Selection, 34-43 ; on Struggle for Existence, 76 ; his three main arguments for Natural Selection, I03-4, I I9-30, I 30-56, I38, I 57 ; on argument from classification, 456-7; from morphology, 457; from geographical distribution, 458, 459 ; from geology, 459; from embryology, 460 ; on principle of Natural Selection, 464-6; on evidences for Natural Selection, 475-6; on $\mathrm{Na-}$ tural Selection in relation to teleology, 520-I ; on Encyclopadia Britannica's article on instinct, I23-4; on instinct, I29-30, $22 \mathrm{I}$, 
Romanes, Geo. J.-(continued). 228, 229, 25 I, 276-8; of jelly-fish, 235 ; in land-shell, 236 ; grouse, 246-8; dogs, 256 ; loss of instinct, 259 ; nest-building, 262 ; incubating, 264-5; non-intelligent, $256-7$; instinctive intelligent action in man, 243; on analogy between Natural and Artificial Selection, I 30- I, I35-6, I 40- I, I 50-6 ; on Artificial Selection, I 39, I 53, 444 ; on exclusive breeding, I 40 ; his pictures of different kinds of dogs, etc., as outcome of Artificial Selection, I $5 \mathrm{I}-2$; on defensive colouration, I 59-60, 204 ; some animals too low in zoological scale for intelligence, 233, 234, 235 ; on evolution of sucking among young marsupials, 240 ; on "lapse" of intelligence, 285 ; on results of cessation of Natural Selection, 30I-2, 302-3, 305 ; on heredity, 368 ; on exclusive breeding, 374; on physiological barriers to breeding amongst variants, $382,383,384$; on scope of scientific interpretation of nature, 426 ; on non-identity of Organic Evolution and Natural Selection, 453 ; on special creation, 458 ; on sentimental objections to doctrine of Descent of Man, 462 ; on conformity to type, 5OI-2; on evolution of forearm and hand, 505 ; on nascent organs, 517, 517-8; on electric organs of fish, $52 \mathrm{I}-2$.

RosS, SIR J.: experiment of, on colouration of lemming, i 89 .

Roux, M. : his hybridisation of hares and rabbits, 354, 355-6.

Rudimentary Organs : $492-8$; evolution of, 5 I I-23.

Ruminants : sociability amongst, 89 .

RUSKIN, JOHN : on maternal devotion, $8 \mathrm{I}$.

St. Clair, Rev. G. : on analogy between Natural and Artificial Selection, I3I, I 55 ; on Survival of Fittest, 443.

ST. JOHN, CHARLES : anecdote of hare, 184.
St. Pierre, Bernardin de: on self-destructive instinct in fleas for benefit of man, I27; on melon and pumpkin, I 27.

Salvia lanigera: influence of environment on, 4I 6.

Samphire: influence of environment on, 4I7.

Sand-wasps : instinct in, 277-8.

Satumia : direct action of environment on, 167 ; influence of external conditions on, 396.

Scarabcus : sexual habits of, 275.

Scarlet-runners: Survival of Fittest amongst, 33-4, 139-40.

SCHMANKEWITSCH : on variation in artemia, 537.

SCHMIDT, PROF. OSCAR : on Struggle for Existence, 76, 77, IO2 ; on non-identity of Organic Evolution and Natural Selection, 452-3.

SCIENCE POUR TOUS: on extinction of species of rats in Jamaica, 317.

Scientific Interpretation of Nature : scope of, 426.

SCIENTIFIC NEWS: on hybridisation of dogs and jackals, 356 ; on effectiveness of antlers of stag, 363 ; on cause of change of colouration due to colouring matter absorbed, 404 ; on "Directive Colouration" in animals, 4 I 8.

SCUDDER, S. H. : on great destruction of life among insects, I62-3.

Seals: Sexual Selection in, 39-40; intelligence in, $249,250$.

Sea-slugs : skin-pigments of, the cause of their nauseous taste, 220.

SEdillot : on Law of Compensation of Growth, 336.

Sedum: influence of environment on, 4I 7 .

Seeds, Winged : never found in fruits which do not open, 342.

SEITZ, DR. (quoted by Beddard) : on non-universality of nauseous taste in heliconius beskii, 219; on non-useful variation in insects, 4II. 
Selaginella convoluta: migratory action of, 288.

Selenia illunaria: protective colouration of, I75.

SEMPER, KARL: on protective colouration amongst butterflies, I 73; on colouration of white weasel, I88; of arctic foxes, I9I ; on variation in artemia, 537 ; on sensitiveness of pond-snail, 53840.

Serpents : $\%$ Snakes.

Sexual Selection : its hostility to Natural Selection, 36-40; difficulty in its acceptance, 37-4I ; illustrated by facts of domestication, I 48-50.

\section{Carleton on, 36 ;}

Darwin on, $36,37-8,38-9,39-40$, 68-9; Galton on, 36.

SHAKESPEARE, WILLIAM : quotation from As You Like It, 99; from Henry $I V$. (on instinct), 258 ; from Macheth (on parental devotion of wren), 8I ; from Merchant of Venice (on marriage), 40 ; (on chance), 65,66; from Midsummer Night's Dream (on love), 38 ; from Pericles (on appearances), 208 ; from Richard II. (on physical heredity), 364 ; (on isolation), 379 ; from Richard III. (on abortion), 496 ; from Taming of the Shrew (on rudiments), 496 ; from $A$ Winter's Tale (on chance), 6o ; (on nature and art), I3I-2.

Sheep : isolation in breeding, 380 ; influence of external conditions on, 397,423 .

Ancon Ram : an illustration of Law of Correlated Variation, $334,357-60,55 \mathrm{I}$; isolation in breeding, $38 \mathrm{I}$.

Creolla : adaptation to environment of, 282-3.

Sheep-breeding: Artificial Selection in, I39.

Shrimps: protective habits of, I 84-5.

Sivatherium giganteum: an illustration of Organic Evolution, 552.

Skate : inutility of electric organ of, $52 \mathrm{I}-2$.

Skunk: warning colouration and effuvium of, 209-I 2.
Slater, J. W. : his researches on tannin in animals, 404 .

Smell, Nauseous : protective character of, 21 5-20.

Snails : co-operation amongst, 95 ; too low to possess instinct, 235 ; instinct in, 236. 538-40.

Snakes : organic structure of, 509 ; influence of environment on birth-giving in, 542-3.

Snow-bunting : colouration of, I 88.

Sociability, Animal : 88 ; amongst birds, 88-9; ruminants, 89.

Somerville, William : The Chase quoted, I 83, I84, 239.

Sousliks: sudden disappearance of, 53 .

Spalding, Douglas A. : on animal instinct, 230.

Sparrows : imported into New Zealand, $5 \mathrm{I}$; intelligence in, 250.

Special Creation : 470-4.

Species : rarity of, 57 ; stability of, 293-9; extinction of, 314-28 ; transmutation of- $v$. Transmutation of Species.

SPENCE, William : on instinct in insects, 234.

SPENCER, HERBERT : his definition of evolution, I ; on meaning of evolution, 3I I ; on Survival of Fittest, I 4, 23, 565 ; amongst protophytes, 569; amongst men, 582 ; on instinctive action in man, 243 ; on relation of Natural Selection to stability of species, 298 ; on results of cessation of Natural Selection, 30I ; on extinction of species, 316 ; on distinction between growth and development, 447 ; on Special Creation, 46r; on non-identity of Organic Evolution and Natural Selection, 452 ; on Natural Selection in relation to Organic Evolution, 55683; passim (thorns and hairs of plants, 559; nauseous taste in plants, 559; relations of tendons and bones, 560-2 ; use and disuse, 562-3; other factors, 563-4; 
Spencer, Herbert-(continued). on the expression "Natural Selection," 564; earliest stages of life, 566-8; action of Natural Selection in Organic Evolution, 568-70 ; amœba, 567, 570 ; invagination and gastrula, 570-2 ; volvox, 570-2, 573; sensitiveness of cells, $573^{-6}$; fission of cells, 576 ; conjugation, 578, 579 ; "fortuitous" variations, 578-9).

SPENCER, LORD : on aims of cattlebreeder, I 42.

Spider: mimetic colouration of, I76; of white spider, 194.

Sport: a cause of extinction of species, 320.

Squashes: influence of external conditions on, 396.

Squirrels: discriminative destruction of the "most fit" nut by, 67.

Stability of Species : 395.

Stag : as ancestor of elk, 343, 345-6 v. also Deer.

- One-horned : an instance of abrupt structural modification, 359.

Stanley, Dean A. P.: on St. Paul's view of relation of animals to man, I24.

Stanley, H. M. : on animal intelligence, 238.

Stansbury, CAPT. (quoted by Morgan): on co-operation amongst pelicans, 95 .

Star-fish : instinct in, 235-6 ; too low to possess instinct, 235 .

Starlings : intelligence amongst, 245.

Stebbing, T. R. D. : on parental devotion in wolves, 83-4.

STEWART, DUGALD : on general heorems of particular applications, I 57.

Stiebeling, Dr. (quoted by Büchner): on absence of aquatic instincts in ducklings, 260.

"Stirp": 366-7.

Stoats : colouration of, I87.

StockToN, MR.: on "negative selection," 308 .
Structure : a cause of colouration of animals, 407.

"Struggle for Existence" : amongst grouse in presence of falcons, 63-4; amongst birds of prey, 89; amongst plants, I6-7 ; does not bring about even the elimination of the least fit, 66 ; sometimes leads to destruction of fittest, 67 ; its tendency to check independence of character, 70 ; due to absence of co-operation, 77 ; includes inter-dependence of individuals, 98 ; in relation to stability of species, 296-7.

Sir S. W. Baker on, 22-3; Darwin on, I7-9, 43, 76, 96, 97 ; Kropotkin on, 77-80; de Lanessan on, amongst plants, 67-8, 96 ; Romanes on, 76, 122-3; Oscar Schmidt on, 76,77 , I02 ; Wallace on, I7, I8, 43, 44, 77 .

STUART, Villiers : on the scarabreus, 275.

Stylonichia: conjugation in, 47980.

Suckling : evolution of instinct of, in young marsupials, 239-40.

Sun-dew: sensitive faculties of, 286-7.

Survival of the Fittest : amongst plants, 6I ; antelopes, 63 ; scarletrunners, 33-4, I 39-40; pears, I 4 I ; arctic fauna, I90; protophytes, 569 ; men, 582.

Cope on, 14 ; Darwin on, 23, 33-4, I 45 ; Fiske on, 63 ; Henslow on, 6I ; Kropotkin on, 54-5 ; St. Clair on, 443 ; Herbert Spencer on, I 4, 565, 569, 582 ; Wallace on, I 4-5, I 8-9, 43, 67, 74, I90, 479-v. also Degeneration, Natural Selection.

Sweet.briar, Imported: in Australia, $5 \mathrm{I}$.

SwINBURNE, A. C.: The Sisters quoted, 75 .

Swine, Wild : co-operation amongst, 94.

SYME, David : on vegetable "intelligence," 286 ; on movement of vegetable life, 287 .

Symmetry : $v$. Variation, Correlated. 
Tadpoles : arrested development due to environment, 543; due to limitation of food, 543-4.

Tannin: use of, by caterpillars, 403-4; in animals, 403-4.

Taste, Nauseous : its relation to conspicuous colouration, 204, 20620 ; protective nature of, 2 I 5-20.

TAYLOR, DR. J. E. : on vegetable "instinct," 286.

Teeth : $v$. Horses.

TEgetmeier, W. B. : on artificial production of monstrosities, I 50.

Teleological Argument ; in relation to Natural Selection, 520-I-v. also Special Creation.

Temperature : an influence on colouration and markings of butterflies, 405 .

Tendons and Bones : variations of relations of, an evidence for Natural Selection, 560-2.

TENNYSON, LORD : The Northern Farmer quoted, 70.

Terebratula : stability of the species, 294.

Termites: habits of, opposed to theory of Natural Selection, 273.

Theology : in relation to Natural Selection, I30 ; to science, I36.

Thistle, Scotch : imported into Australia, $5 \mathrm{I}$.

Thomisus onustus : direct action of environment on, I68.

THOMPSON, J. ARTHUR: on cooperation amongst bisons, 94 ; amongst wild swine, 94 ; on fission of cells, 576 ; on conjugation of stylonichia, 580 .

Thrush : protective colouration of, I73; mimetic action of, 176 .

Tiger-moth : conspicuous colouration of, not protective, 207.

Caterpillar of : effects of food on its colouration, 406.

Time: much shorter required by Artificial than by Natural Selec. tion, I 52-3.

Toad : change of instinctive action of, $28 \mathrm{I}-\%$. also Tadpoles.

TODD, J. E. : on "directive" colouration in animals, $4 \mathrm{I} 8$.

Torpedo (fish): electric organ of, 522.
Tortoise, Water: $v$. Chelydra serpentina.

Transmutation of Species : by means of Natural Selection, I290, 329-32, 389-448, 430-I, 55683; argument for, 103-I8; against, I I8-9; much shorter time required for, by Artificial than by Natural Selection, I 52-3; rival methods of, 293 ; in relation to Extinction of Species, 322-3.

TRIMEN, R. : on protective elasticity amongst insects, I66-7.

Turtle : sea-ward instinct in, 264.

TYLOR, MR. (quoted by Wallace); on structure a cause of colouration of animals, 407 .

Umbrella : process of purchase of compared with action of Natural Selection (Marshall), I47-8.

"Unconscious" Selection, I36-8.

UNIVERSAL REVIEW: on origin of species, 472 .

Use and Disuse : inherited effects of, $432,438-40$; disuse an agent in formation of rudimentary organs, 5 I ; in relation to Natural Selection, 562-3.

VAN MONS, M. (quoted by Lucas): on influence of external conditions on vegetable structure, 398.

Variation : probability of survival, $20 \mathrm{I}$; causes of, 365 ; sometimes associated with sexual reproduction, 349-72 ; Matthew Arnold on, 4 ; Belt on, 4 ; Chas. Darwin on, 4-5, I0, 13-4, I9, 146; George $\mathrm{H}$. Darwin on, II-2; O. W. Holmes on, $3-4$; Huxley on, Io, 35 ; Leconte on, I I ; Meldola on, 35; Milne Edwards on, 4; Mivart on, II ; Romanes on, IO, I I W Wallace on, 3, IO, IO-I, I2-3, I 46.

Correlated : 334-48.

Specific : usefulness of, 4I 8. Unuseful: produced by changed conditions, 4 IO-I, 422.

VARIGNY, HENRY DE : on sensitiveness of pond-snail, 539 ; on arrested development of toads, 543-4. 
Vegetable Organisms : $\nu$. Plants.

Verbascum : hybridisation of, $35 \mathrm{I}$, 384.

VILLON : researches of, on tannin in animals, $403 \cdot 4$.

VILMORIN, M. (quoted by Lucas) : on influence of external conditions on vegetable structure, 398.

VOGT and SPECHT : on colouration and habits of Alpine hare, I88; on habitat of Polar bear, I92, I93.

Volvox : evolution of, 570-2, 573 .

W. J. : on great fecundity of grouse always followed by disease, 53-4.

WALLACE, AlFRED RUSSEL : on variation, 3 , IO, IO-I, I2-3, I46 ; element of time in variation, $73-4$ on Survival of Fittest, I4-5, 43, $67,190,475 ;$ on change in external conditions, 16 ; on influence of environment on colouration of butterfly, 408 ; on Natural Selection in relation to adaptation of new species to environment, $32 \mathrm{I}$, 532, 533; usual abortiveness of attempts to naturalise plants, I I I ; on English watercress in New Zealand, 107, 108, 105; on Struggle for Existence, I7, I 8-9, $43,44,77$; on rate of increase in geometrical progress, 47-8; on increase among imported animals, etc., $5 \mathrm{I}-2$; on stationary population, 55; on accidental death in nature, 65 ; on chance, 60,65 ; on Natural Selection, IO5, I44, 454-5; on man's intelligence arresting effect of, on his frame, I70 ; on "necessity" of, 478 ; on race-conflict, IO6-12 ; on different species flourishing together, II 4 ; on mutual protection of tropical trees, II5; on protective colouration in animals, 160 ; in insects, $165-6$; in caterpillars, 176; in Arctic fox, Ermine and Arctic hare, 187 ; on mimetic colouration of caterpillar, I76; of butterflies, 195 ; on his reasons for adopting theory of warning colours, 203 ; on chlorophyll, 402 ; on structure a cause
WALlace, Alf. R.-(continued). of colouration, 407 ; on influence of chemical action on change of colouration, 408; on protective nauseous taste, 220 ; in caterpillars, 212-3; in heliconias, 218 ; on mode of development of protective nauseous taste, 217 ; on mimicry in relation to Natural Selection, I78-9; on the laws of mimicry, 194, I99; on mimicry amongst insects, I62 ; amongst flies, 202 ; false mimicry amongst butterflies, I96; on expanse of wing amongst insects, 165; on immunity of a favourable variant from destruction, 200 ; on faculties of very young birds, 267; on results of cessation of Natural Selection, 302 ; on water-ouzel, 3 I2 ; on extinction of species, 319-20 ; reasons for, 323 ; on hybridisation, 352 ; on the scope of scientific interpretation of nature, 426, 427; on Artificial Selection, $444 ;$ on the facts of Organic Evolution, 468; on The Origin of Species, 477 ; on rudimentary organs, $492-3,498$; on organic suppression, 513; on geographical distribution, 526, 530.

Wari : on indiscriminative slaughter of, by jaguars- $v$. also Pigs.

Wasps : Survival of Fittest amongst, 272-3.

Watercress, English : destruction of, by New Zealand willows, I07, IO8, 105.

Water-ouzel : instinct in, 222-3; form and habits of, 3I2.

Weasels : co-operation amongst, 95.

I88.

WEIR, J. JENNER : on accidental death amongst insects, 163 .

WeISMANN, DR. A. : on great destruction of the young, 6I ; on indiscriminative destruction of life of insects, 63 ; on Struggle for Existence amongst birds of prey, 89; on accidental death amongst insects, $\mathrm{I}_{3}$; on neuter insects, 
WeIsmann, DR. A.-(continued). $27 \mathrm{I}$; on panmixia, 305-8; doctrine of continuity of germ-plasm, $367-8,369-72$; on isolation, 377 ; on acquired characters, 435-6, 438,439 ; on Natural Selection, $446-7,454,483-5$; on disappearance of rudimentary organs due to Natural Selection, 5I4, 5I 5 ; due to panmixia, 5I6; on axolotl a retrogressive form of amblystoma, 547-8, 549 .

WestwoOD, PROF. J. O.: on mimetic structure and colouration of butterflies, I 95 .

Whale : evolution of paddle of, 506.

Williams, W. MAtTiEU : on transmutation of axolotl into amblystoma, 549 .

WILSON, DR. ANDREW : on transmutation of axolotl into amblystoma, 546-7, 548-9.
Winter White : as a result of Natural Selection, I86-93.

WISEMAN, MR. (quoted by Lucas): on influence of external conditions on negroes in America, 398.

Wolves : parental devotion in, 83-4.

WOOD, J. C.: on co-operation amongst weasels, 95 .

WOOD, J. W. : researches of, on influence of environment on colour of caterpillars of cabbagebutterfly, 407-8.

WOOD, THEODORE : on potential rate of increase of aphis, 46 .

WORDSWORTH, WILLIAM : The Excursion quoted, 59, 230.

YUNG, ÉmILE : researches of, on sex-ratio amongst frogs, Io8. 


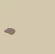




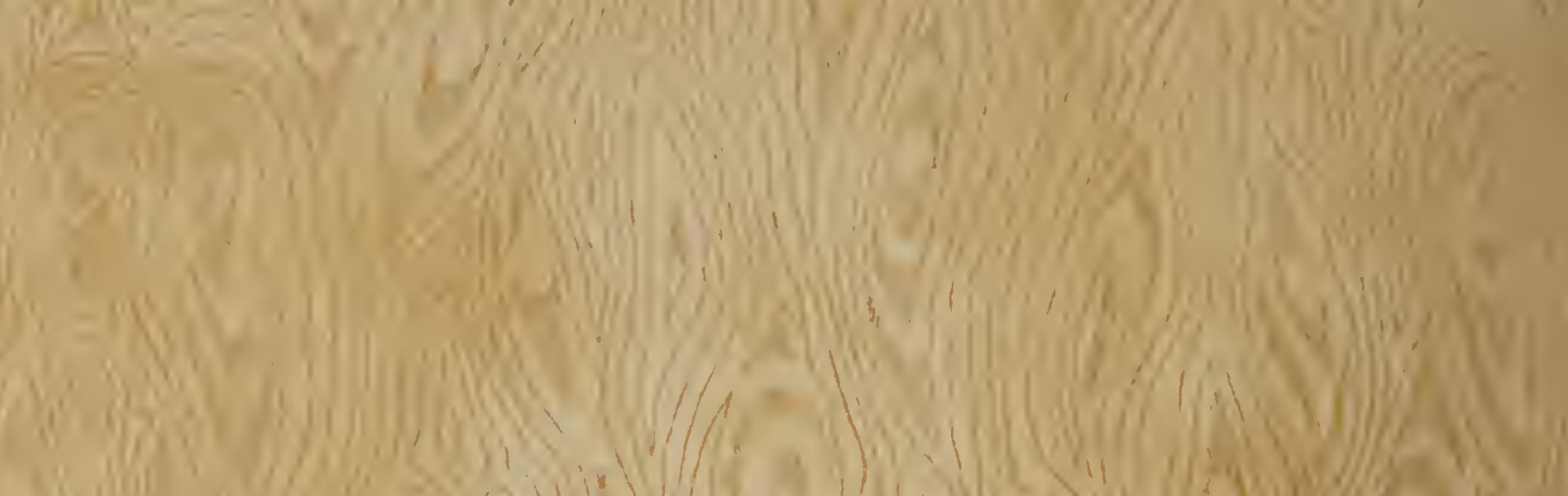

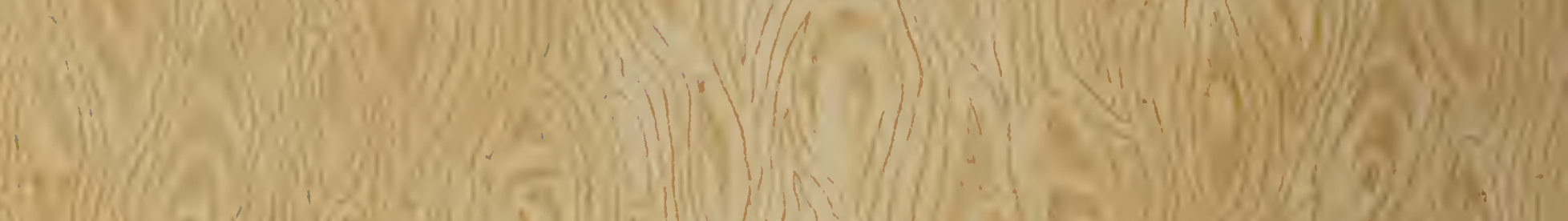
(3) a

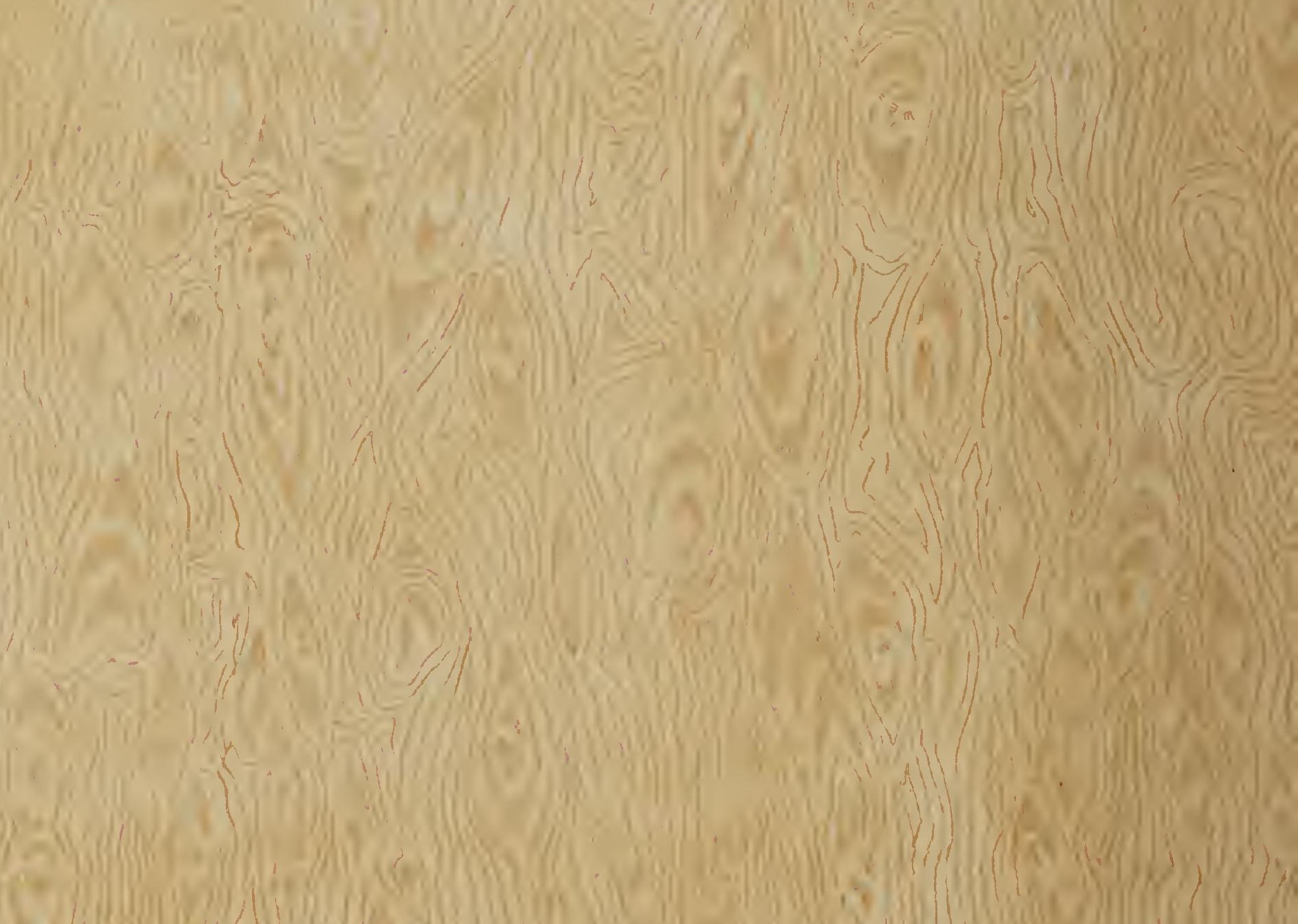
(3) (2) (6) Ef( H.j. 
ary (3) (3) (3) (3) (2) awly movers

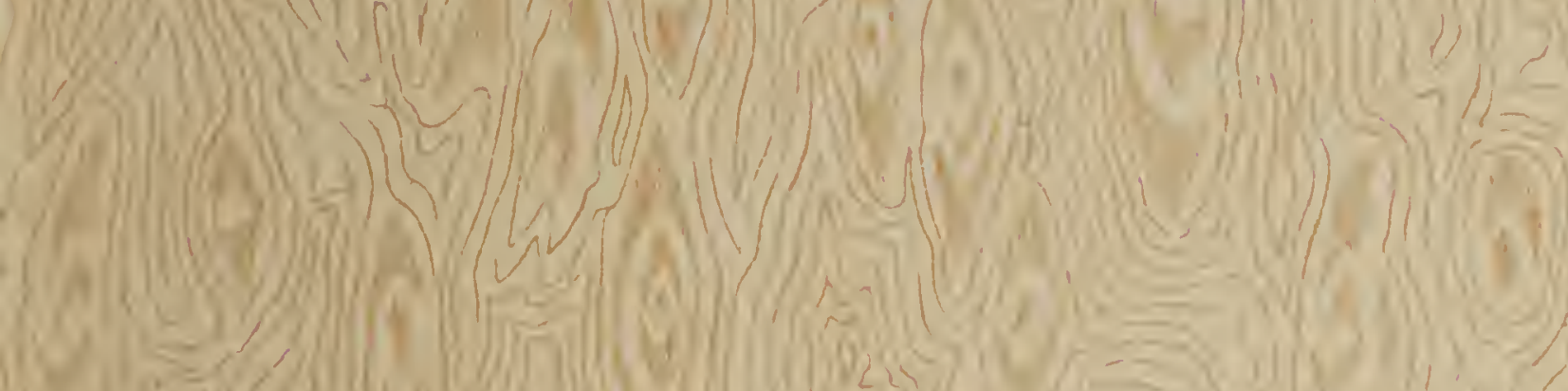
(3) - 
